Cagnolati, Beatriz Emilce

La producción discursiva en la traducción de textos pragmáticos francés/castellano: Estudio traductológico a través de los enunciados elípticos con anomalías

\author{
Tesis presentada para la obtención del grado de \\ Doctor en Letras \\ Director: Sánchez, Ida Sonia. \\ Co-director: Gentile, Ana María.
}

Este documento está disponible para su consulta y descarga en Memoria Académica, el repositorio institucional de la Facultad de Humanidades y Ciencias de la Educación de la Universidad Nacional de La Plata, que procura la reunión, el registro, la difusión y la preservación de la producción científico-académica édita e inédita de los miembros de su comunidad académica. Para más información, visite el sitio

www.memoria.fahce.unlp.edu.ar

Esta iniciativa está a cargo de BIBHUMA, la Biblioteca de la Facultad, que lleva adelante las tareas de gestión y coordinación para la concreción de los objetivos planteados. Para más información, visite el sitio www.bibhuma.fahce.unlp.edu.ar

\section{Cita sugerida}

Cagnolati, B. E. (2010) La producción discursiva en la traducción de textos pragmáticos francés/castellano: Estudio traductológico a través de los enunciados elípticos con anomalías [En línea]. Tesis doctoral. Universidad Nacional de La Plata. Facultad de Humanidades y Ciencias de la Educación. Disponible en: http:// www.fuentesmemoria.fahce.unlp.edu.ar/tesis/te.359/te.359.pdf

Licenciamiento

Esta obra está bajo una licencia Atribución-No comercial-Sin obras derivadas 2.5 Argentina de Creative Commons.

Para ver una copia breve de esta licencia, visite http://creativecommons.org/licenses/by-nc-nd/2.5/ar/.

Para ver la licencia completa en código legal, visite http://creativecommons.org/licenses/by-nc-nd/2.5/ar/legalcode. 


\section{FACULTAD DE HUMANIDADES \\ Y CIENCIAS DE LA EDUCACIÓN}

\section{UNIVERSIDAD NACIONAL DE LA PLATA}

Tesis de doctorado

La producción discursiva en la traducción de textos pragmáticos francés/castellano: estudio traductológico a través de los enunciados elípticos con anomalías.

Tesista: Prof. Beatriz Emilce Cagnolati

Directora: Dra. Ida Sonia Sánchez (UNT)

Codirectora: Dra. Ana María Gentile (UNLP)

La Plata, febrero 2010 


\section{AGRADECIMIENTOS}

El diseño y desarrollo de un proyecto de estudio se nutren de una cantidad de elementos que van más allá de la profundización de un problema, el armado de una biibliografía o el tesón del investigador. Un papel fundamental corresponde al entorno profesional y humano que nos va acompañando en las sucesivas etapas de nuestro emprendimiento.

En mi caso, el primer paso fue una lejana conversación con José Luis De Diego, que constituyó una suerte de estímulo y anclaje en la realidad de lo que significa elaborar una tesis de doctorado.

Vinieron luego intercambios con Jeanne Dancette, traductóloga de la Universidad de Montreal que me sugirió el nombre de Ida Sonia Sánchez de la Universidad de Tucumán para dirigir esta tesis, consejo que siempre agradeceré porque encontré en ella no solamente el perfil académico que yo necesitaba, sino también y especialmente una persona de gran comprensión, dispuesta a escuchar y debatir opiniones, que me alentó en cada etapa de este largo recorrido. Gracias Sonia.

Sin embargo, el hecho de que la directora no perteneciera a mi universidad requería la figura de un codirector: encontré en Luisa Granato a una investigadora dispuesta a acompañarme en los pasos iniciales del proyecto, con quien compartí diálogos valiosísimos que me guiaron para resolver cuestiones epistemológicas, a través de preguntas directas que me ayudaron a desarmar y rearmar mis propuestas. Gracias Luisa.

La Traductología es un campo con desarrollo discreto en el país en general y en nuestra facultad en particular, sin embargo mientras avanzaba en mi proyecto, Ana María Gentile, integrante del grupo de investigación en esta disciplina que inauguramos en 1994 y con quien sigo compartiendo interrogantes y certezas traductológicos, obtuvo su doctorado en una rama relacionada con la traducción especializada: fue ella quien aceptó tomar la posta en la codirección con gran compromiso y dedicación. Gracias Ana. 
María Luisa Fernández, integrante del equipo de investigación me brindó su tiempo y conocimiento en consultas específicas relacionadas con la Gramática Española. Gracias María Luisa.

María Inés Urrutia, colaboradora incondicional ha estado presente toda vez que he necesitado resolver cuestiones relacionadas con la representación estadística. Gracias María Inés.

También agradezco a Andrea Cucatto su disposición a responder interrogantes lingüísticos, a Telma Piacente por haberme hecho conocer interesantes estudios de Psicología Cognitiva y a José Alberto Mainetti por guiarme en la búsqueda de fuentes de la Bioética.

Agradezco a los alumnos de la cátedra Traducción Científico-Técnica en Francés del último año de estudio de la carrera de Traductor Público de la Facultad de Humanidades y Ciencias de la Educación de la Universidad Nacional de La Plata, y de la carrera de Traductor científico y literario del Instituto de Educación Superior en Lenguas Vivas "Juan Ramón Fernández" de la Ciudad Autónoma de Buenos Aires, por su buena disposición y entusiasmo en realizar las tareas solicitadas.

Además de mis compañeras ya nombradas, deseo recordar a quienes también integran el equipo de investigación desde hace mucho tiempo: Amalia Forte Mármol, María Inés Perroud, Fabiana Vieguer, Nelba Lema, Jovanka Vukovic y Marina Menéndez. La mayor parte de las personas mencionadas no son solamente colegas sino que entran en la esfera de mis afectos. Ellas aportaron buenos consejos y cierta dosis de humor con el único propósito de estimular la continuidad de este trabajo: pienso especialmente en Alicia Alliaud que demostró toda su confianza en la realización de esta tesis. Gracias Alicia.

A lo largo de mi vida he contado con el acompañamiento de mi familia en las decisiones que he ido tomando, especialmente de Emma y Danilo, ya ausentes. Durante el proceso de esta tesis, el núcleo familiar que me ha sostenido íntimamente lleva los nombres de Christian, Laura y José Ignacio.

A este entorno profesional y humano le dedico mi trabajo. 


\section{ÍNDICE}

$\begin{array}{ll}\text { AGRADECIMIENTOS } & \mathbf{3}\end{array}$

$\begin{array}{ll}\text { INDICE } & \mathbf{5}\end{array}$

$\begin{array}{ll}\text { ÍNDICE DE FIGURAS Y TABLAS } & 11\end{array}$

$\begin{array}{ll}\text { SIGLAS Y SÍMBOLOS } & 13\end{array}$

$\begin{array}{ll}\text { PRÓLOGO } & 15\end{array}$

$\begin{array}{ll}\text { INTRODUCCIÓN } & 19\end{array}$

CAPÍTULO I: MARCO TEÓRICO Y ANTECEDENTES

Primera parte: Marco teórico $\quad 29$

1.1. La necesidad de un marco multidisciplinario 29

$\begin{array}{ll}\text { 1.1.1. Aporte interpretativo-cognitivo } & 31\end{array}$

1.1.2. La traducción como actividad integradora 32

1.1.2.1 La evaluación por niveles 33

1.1.3. El modelo tripartito de Eugenio Coseriu 35

1.1.4. Los Estudios Descriptivos de Traducción (EDT) 35

1.1.5. El contraste interlingüístico 37

1.1.6. La interferencia ¿Por qué las anomalías sintáctico- 39 discursivas?

Segunda parte: Antecedentes $\quad 42$

1.2. Reflexión traductológica e interdependencia teoría-práctica 42

1.2.1. Reformulación de Amparo Hurtado Albir 43

1.2.1.1. Las seis variables 43

1.2.2. Los cinco enfoques teóricos 44

1.2.3. La relación teoría y práctica como constante traductológica 45

1.2.3.1. Desde lo lingüístico 46

1.2.3.2. Desde lo lingüístico-cultural 47

1.2.3.3. Desde lo lingüístico-cognitivo 48

1.2.3.3.1. El proceso de traducción escrita de textos 48 pragmáticos (Jean Delisle)

1.2.3.4. Desde el funcionalismo 50

1.2.3.5. Desde enfoques comparatistas y prescriptivos 51

1.2.3.5.1. Procedimientos vinculados con la sintaxis 51

1.2.3.6. Desde enfoques comparatistas descriptivos, no prescriptivos 53

1.2.4. Investigación traductológica francés/castellano relacionada con el 53 problema del presente trabajo en universidades argentinas

1.2.5. A modo de conclusión 


\section{CAPÍTULO II: PRODUCCIÓN DISCURSIVA}

2.1. En torno al concepto de producción 59

2.2. Criterios de clasificación de la producción discursiva 61

2.2.1. Tipos de producción 62

2.3. Tipos de traducciones según Daniel Gouadec 64

2.4. La producción discursiva en traducción absoluta de textos pragmáticos 66

2.4.1. Planificación 66

2.4.2. Toma de decisiones 67

2.5. Memoria 68

2.5.1. Memoria y esquemas internos 69

2.5.2. Memoria y sintaxis 70

2.5.3. Memoria y producción discursiva en traducción de textos 70 pragmáticos

$\begin{array}{ll}\text { 2.5.3.1. Esquemas globales } & 70\end{array}$

2.5.3.2. Expresión lingüístico-discursiva 71

2.6. Comprensión y producción discursiva en traducción 72

2.6.1. Fases de la traducción según la Teoría Interpretativa de la Traducción 72 (TIT)

2.6.1.1. Primera fase o comprensión 72

2.6.1. 2. Segunda fase o desverbalización 73

2.6.1. 3. Tercera fase o reformulación 74

2.6.2. La traducción escrita como proceso según Jean Delisle 75

2.6.2.1. Un abordaje metódico de producción discursiva en traducción $\quad 76$

2.6.2.1.1. Las convenciones de redacción 76

2.6.2.1.2. La exégesis léxica $\quad 76$

2.6.2.1.3. Interpretación de la carga estilística 77

2.6.2.1.4. La coherencia textual 77

2.6.3. Comprensión centrípeta y comprensión centrífuga 78

2.6.4. La metáfora del escritorio: una aproximación cognitiva 79

2.6.5. Las normas: una aproximación sociocultural 80

2.6.5.1. Norma inicial: adecuación y aceptabilidad 81

2.6.5.2. Normas preliminares $\quad 81$

2.6.5.3. Normas operacionales $\quad 82$

2.6.5.3.1. Normas operacionales matriciales 82

2.6.5.3.2. Normas operacionales lingüistico-textuales 82

2.6.6. El tercer código 83

2.6.7. La competencia traductora 83

2.7.¿Cómo estudiar una traducción? 84

2.7.1. Estudios orientados al producto 84

2.7.2. Estudios orientados al proceso 85

2.7.3. Estudios orientados a la función $\quad 85$

2.7.4. Estudios comparativos 86

2.7.5. Estudios empíricos orientados al producto, al proceso y a la función $\quad 86$

2.7.5.1. Propuestas provisorias o borradores de traducción 86

$\begin{array}{ll}\text { 2.7.5.2. Test de cloze } & 87\end{array}$

2.7.5.3. Entrevista de explicitación 88

2.7.5.4. Protocolo verbal 88

2.7.6. Reflexiones finales sobre los estudios empíricos 89

2.8. Mecanismos en la producción discursiva de una traducción 90

2.9. Conclusión 92 


\section{CAPÍTULO III: INTERFERENCIA}

3.1. Interferencia: una noción sin límites precisos 97

3.1.1. Interferencia y transferencia 103

3.1.2. Interferencia y normas 104

3.1.3. Error 105

3.2. Clasificación de las interferencias 106

3.2.1. Clasificación tradicional 106

3.2.1.1. Interferencia fonética 106

3.2.1.2. Interferencia gramatical 107

3.2.1.3. Interferencia léxica 107

3.2.2. Clasificación contextual 108

3.2.2.1. Interferencia discursiva 108

3.2.2.2. Interferencia pragmática 108

3.3. Interferencia en traducción 109

3.3.1. Interferencias según la metáfora del escritorio 112

3.3.2. Bilingüismo en traducción 113

3.3.3. Transferencia positiva, transferencia negativa, transferencia del 115 discurso

3.4. Conclusiones

\section{CAPÍTULO IV: ELIPSIS}

4.1. Medios de cohesión y elipsis 119

4.2. Concepto de elipsis 120

4.2.1. Elipsis gramatical 121

4.2.2. Elipsis contextual 122

4.3. Elementos y condiciones fundamentales de la elipsis 122

4.3.1. Recuperabilidad 123

$\begin{array}{ll}\text { 4.3.2. Criterios paralelísticos } & 123\end{array}$

4.3.3. Mecanismos endofóricos: anáfora y catáfora 123

4.4. Elipsis nominal 124

$\begin{array}{ll}\text { 4.4.1. Concepto de argumento } & 124\end{array}$

4.4.1.1. Elipsis del argumento externo o sujeto (mecanismo máximo) 125

4.4.1.2. Elipsis de los argumentos internos (mecanismo máximo) 126

4.4.1.3. Elipsis de los núcleos de los SSNN (mecanismo parcial) 127

$\begin{array}{ll}\text { 4.4.2. Elipsis nominal y cambio de género } & 128\end{array}$

$\begin{array}{ll}\text { 4.4.3. Elipsis nominal y cambio de número } & 128\end{array}$

$\begin{array}{ll}\text { 4.4.4. Presencia de determinantes y complementos } & 129\end{array}$

4.5. Elipsis verbal: vaciado, hueco y resto 129

4.5.1. Características del vaciado 130

4.5.2. Reducción del sintagma verbal coordinado 130

4.5.3. Reducción del sintagma verbal coordinado y vaciado 130

4.5.4. Partícula u operador de polaridad 131

4.5.4.1. Elisión del sintagma verbal con partícula de polaridad 132

4.5.4.2. Elisión del sintagma verbal con partícula de polaridad y vaciado 132

4.5.5. Anáfora de complemento nulo 132

4.5.6. Truncamiento 133

4.6. Importancia del fenómeno de la elipsis para la traducción 133 


\section{CAPÍTULO V: METODOLOGÍA}

5.1. Introducción 135

5.2. Criterios metodológicos que han guiado nuestro estudio 136

5.3. Criterio para circunscribir el alcance del tema 138

5.4. Criterios evolutivos de análisis 139

5.4.1. Criterio de abordaje 139

5.4.2. Análisis según series de categorías abiertas y cerradas 141

5.4.3. Análisis según ausencias y presencias 142

5.4.4. Criterios definitivos de análisis 143

5.5. Casuística: criterios evolutivos de su constitución 148

5.5.1. Corpus textual 148

5.5.1.1. Condiciones del corpus 148

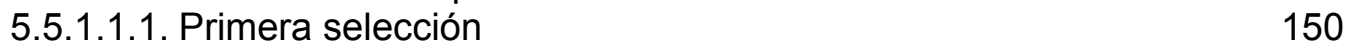

5.5.1.1.2. Segunda selección 153

5.5.2. Criterios evolutivos en la determinación de los sujetos y de la 153 experiencia

5.6. Conceptos operativos 154

5.6.1. Mecanismo, proceso, y operación 154

5.6.2. Discurso y texto 159

5.6.3. Ambigüedad 160

5.6.4. Anomalía 160

5.6.5. Binomio textual 161

5.6.6. Elevación de la frecuencia de uso de recursos o elementos 162

5.6.7. Entropía 162

5.6.8. Oración y enunciado 163

5.6.9. Enunciado elíptico 163

5.6.10. Producción discursiva, reexpresión, reformulación 164

5.6.11. Producción palimpséstica 164

\section{CAPÍTULO VI: ANÁLISIS}

6.1. Organización del capítulo 165

6.2. Primera parte: Binomios textuales 167

6.2.1. Binomios textuales de la fuente www.genethique.org o Gènéthique 167

6.2.2. Binomios textuales de las fuentes El racismo de gen/ Au bazar du 172 vivant

6.3. Segunda parte: Características y análisis de Gènéthique 177

6.3.1. Características de la fuente digitalizada 177

6.3.2. Análisis de los binomios textuales 179

6.4. Tercera parte: Características y análisis de El racismo del gen, 231 traducción de Au bazar du vivant

6.4.1. Características de las fuentes 231

6.4.2. Análisis de los binomios textuales 233

\section{CAPÍTULO VII: RESULTADOS E INTERPRETACIÓN}

7.1. Determinación de las anomalías para su estudio 281

7.1.1. Las elipsis con anomalías 284

7.1.1.1. Extensión de las elipsis nominlaes 286

7.1.1.2. Funciones de las elipsis nominales máximas 288

7.1.1.3. Funciones de las elipsis nominales parciales 290 
7.1.1.4. Tipos de anomalías de las elipsis $\quad 291$

7.1.2. Recuperabilidad en las elipsis nominales $\quad 294$

7.1.3. Recuperabilidad en las elipsis verbales $\quad 297$

7.2. Mecanismos en la producción de elipsis con anomalías 398

7.3. Visibilidad de la interferencia negativa 302

7.4. Repercusión de la interferencia negativa 305

CAPÍTULO VIII: CONCLUSIONES

8.1. Introducción 311

8.2. Marco de la interferencia 312

8.2.1. Enunciados elípticos anómalos 313

8.2.2. Influencia del discurso de partida sobre el de llegada 315

8.2.2.1. Anomalías sintácticas $\quad 315$

8.2.2.2. Anomalías discursivas $\quad 315$

8.2.3. Influencia del sistema de la lengua materna 316

$\begin{array}{ll}\text { 8.2.3.1. Anomalías sintácticas } & 316\end{array}$

$\begin{array}{ll}\text { 8.2.3.2. Anomalías discursivas } & 317\end{array}$

8.3. Enunciados anómalos e interferencia bidireccional 318

8.4. Mecanismos observables 320

8.5. Repercusión de los enunciados elípticos anómalos 321

8.6. Perspectivas 323

$\begin{array}{ll}\text { BIBLIOGRAFÍA GENERAL } & 327\end{array}$

$\begin{array}{ll}\text { BIBLIOGRAFÍA DEL CORPUS TEXTUAL } & 341\end{array}$

$\begin{array}{ll}\text { ANEXOS } & 343\end{array}$ 


\section{ÍNDICE DE FIGURAS Y TABLAS}

FIGURA 1. El modelo de la doble hélice (Dancette) 22

FIGURA 2. Cuadrado traductivo (Larose) 33

FIGURA 3. Los estudios sobre la traducción (Holmes, 1972) 43

FIGURA 4. Tipos de producción discursiva 63

FIGURA 5. $\quad$ Contraste español/francés 100

FIGURA 6. Distribución de los operadores de polaridad en la elisión del SV 131

FIGURA 7. Instrumento de análisis $\quad 144$

FIGURA 8. Relación entre anomalías sintácticas encontradas $\quad 281$

FIGURA 9. $\quad$ Relación entre ausencias y elipsis 282

FIGURA 10. Distribución de las elipsis con anomalías 285

FIGURA 11. Distribución de las elipsis nominales 287

FIGURA 12. Funciones de las elipsis nominales máximas 289

FIGURA 13. Funciones de las elipsis nominales parciales 290

FIGURA 14. Elipsis con anomalías sintácticas y discursivas 292

FIGURA 15A. Elipsis nominal con anomalías discursivas y recuperabilidad 295

FIGURA 15B. Elipsis nominal con anomalías sintácticas y recuperabilidad 299

FIGURA 16. Mecanismos observables en relación con la elipsis 303

FIGURA 17. Visibilidad de la interferencia 303

FIGURA 18. Repercusión de la interferencia $\quad 307$

TABLA 1. Distribución de las elipsis con anomalías 284

TABLA 2. Distribución de las elipsis nominales 286

TABLA 3. $\quad$ Funciones de las elipsis nominales máximas 388

TABLA 4. Funciones de las elipsis nominales parciales 290

TABLA 5. Elipsis con anomalías sintácticas y discursivas 291

TABLA 6. Elipsis nominal y recuperabilidad oracional o transfrástica 294

TABLA 7. Elipsis verbal y recuperabilidad oracional o transfrástica 297

TABLA 8. Mecanismos observables en relación con la elipsis 298

TABLA 9. Visibilidad de la interferencia 302

TABLA 10. Repercusión de la interferencia 305 


\section{SIGLAS Y SIMBOLOS}

EDT: Estudios Descriptivos de Traducción.

OD: objeto directo.

Ol: objeto indirecto.

SA : sintagma adjetivo.

SN: sintagma nominal.

SP: sintagma preposicional.

SV: sintagma verbal.

TIT: Teoría Interpretativa de la Traducción.

TO: texto original.

TT: texto traducido.

GDLE: Gramática Descriptiva de la Lengua Española.

DRAE: Diccionario de la Real Academia Española.

ESIT: Escuela Superior de Intérpretes y Traductores de París.

PACTE: programa de adquisición de competencia traductora de traducción escrita.

L1: lengua materna.

L2: lengua extranjera.

$>$ : indicador del sentido de la traducción, siendo el ángulo la forma original y el vértice la forma traducida.

$\rightarrow:$ sentido TT $\rightarrow$ TO o TO $\rightarrow$ TT

*: agramaticalidad.

?: grado de agramaticalidad. 


\title{
PRÓLOGO
}

Esta tesis se inscribe dentro de la Traductología, campo de estudio sobre el cual se ha debatido largamente, comparándolo con el de los Estudios de Traducción, de la Translémica o de los Estudios descriptivos. Rosa Rabadán (1991) ${ }^{1}$ establece las diferencias entre ellos, pero a su vez señala la existencia de confusión terminológica por tratarse de una disciplina en desarrollo.

En nuestro caso, nos hemos decidido por la denominación Traductología puesto que la consideramos económica y motivada etimológicamente, más allá de los usos particulares que se le hayan atribuido. Por otra parte, esta denominación presenta una fuerte inserción en la investigación argentina y su frecuencia de uso es elevada en la bibliografía de procedencia francesa. Al respecto, citamos a Amparo Hurtado Albir (1996: 151): ${ }^{2}$

\begin{abstract}
"Actualmente, coexisten varios términos para denominar a la disciplina encargada de analizar la Traducción: en francés, «Traductologie » y "Théorie de la traduction»; en el mundo anglófono, "Translation Theory», "Science of Translation», «Translation Studies», «Traductology», «Translatology»; en alemán, «Übersetzungstheorie», «Übersetzungswissenschaft», «Translationswissenschaft»; en español, «Teoría de la traducción», "Traductología», "Translémica», «Translatología», «Estudios sobre la traducción», «Estudios de la traducción», «Lingüística aplicada a la traducción»... Nosotros preferimos utilizar el término «Traductología» o «Estudios sobre la traducción», ya que pensamos que engloba mejor los estudios teóricos, descriptivos y aplicados de nuestra disciplina; "Traductología» además posee la ventaja de ser una única palabra."
\end{abstract}

La Traductología, cuya naturaleza es interdisciplinaria, plantea, en consecuencia, el estudio de los procesos implicados en el complejo fenómeno de la traducción y también de los productos discursivos en la lengua hacia la cual se

\footnotetext{
${ }^{1}$ Remitimos a las siguientes páginas: 28, 29, 106, 291, 299 y 300.
} 
traduce o el estudio contrastivo de textos desde el punto de vista semánticocognitivo y pragmático-discursivo.

El enfoque y desarrollo de esta tesis descriptiva estarán marcados inevitablemente por nuestra actividad, en la que podemos identificar dos núcleos: por un lado profesional, que comprende la traducción propiamente dicha y la formación de traductores, y por el otro especulativo, a través de la reflexión e investigación sobre temas traductológicos.

El primer núcleo que hemos denominado profesional es el que se vincula con el ejercicio de la profesión liberal de Traductor Público, a través de la cual se pulsan las urgencias de quienes solicitan el servicio de traducción, lo que acarrea un ritmo de trabajo exigente que impide detenerse en la especulación sobre los mecanismos que ponemos en juego para llegar a la mejor expresión, al término más preciso, proceso que Christine Durieux (1987: 42) define como:

« (...) succession permanente de prises de décisions (...) fondées sur la dynamique du discours, sur le contexte général, sur la situation, sur les connaissances préalablement acquises par le traducteur, c'est à dire son bagage cognitif. »

(...) sucesión permanente de toma de decisiones (...) fundadas sobre la dinámica del discurso, el contexto general, la situación, los conocimientos previamente adquiridos por el traductor, es decir su bagaje cognitivo. ${ }^{3}$

También en el núcleo profesional, ubicamos la formación de traductores en la cátedra de Traducción científico-técnica en Francés del último año de estudio de la carrera de Traductor Público Nacional de la Facultad de Humanidades y Ciencias de la Educación de la Universidad Nacional de La Plata, y de la carrera de Traductor científico y literario del Instituto de Educación Superior en Lenguas Vivas "Juan Ramón Fernández" de la Ciudad Autónoma de Buenos Aires. En los dos ámbitos y dentro de los objetivos que hemos propuesto, intentamos estimular a los alumnos para que tomen conciencia de la necesidad de llegar a una traducción que sea

\footnotetext{
${ }^{3}$ Todas las traducciones de la presente tesis son de la autora (BEC).
} 
producto del razonamiento lógico, pero simultáneamente eficiente en los tiempos de ejecución. Si bien es cierto que dejar descansar la traducción es uno de los mejores consejos para alejarse del original y producir con mayor libertad, ganando en personalidad y evitando el mimetismo servil, no es menos cierto que las exigencias impuestas por el mercado laboral son cada vez mayores -manejo de herramientas informáticas, acortamiento de los plazos de entrega-, lo que tiene como correlato la menor posibilidad de contemplar críticamente nuestro producto.

Por su parte, el núcleo especulativo ha contribuido a ir plasmando la problemática de esta investigación. En tal sentido, desde 1994, en el seno de la Facultad de Humanidades y Ciencias de la Educación de la UNLP, hemos llevado a cabo varios proyectos ${ }^{4}$ inscriptos en la línea traductológica.

En resumen, las perspectivas señaladas se han ido complementando unas con otras y nos han guiado a circunscribir el tema general de la presente tesis, la producción discursiva en traducción o reexpresión de traducciones de discursos especializados francés/español, tema que abordaremos desde las anomalías sintáctico-discursivas de construcción o de presencia de la elipsis en el corpus textual que hemos elegido.

${ }^{4}[\rightarrow$ Capítulo I, Marco teórico y Antecedentes. 1.2.4.]. 



\section{INTRODUCCIÓN}

« La plupart des théoriciens et praticiens de la traduction énoncent la 'primauté du sens sur la forme' et la nécessité, pour le traducteur, de bien comprendre le message qu'il traduit. Ils reconnaissent souvent la difficulté (voire l'impossibilité) de tout comprendre et donc le caractère incomplet de la restitution du sens. Cependant, faisant fi de l'objection théorique découlant de l'impossibilité de tout comprendre, les traducteurs traduisent et les professeurs de traduction forment des traducteurs ». ${ }^{1}$

Jeanne Dancette (1995:22).

En el Prólogo hemos presentado el término Traductología que tiene como objeto central el estudio de la traducción, concepto polisémico que puede abordarse según la acepción más elemental y difundida, es decir, la expresión en una lengua dada de enunciados que han sido previamente expresados en otra lengua, lo que intuitiva e ingenuamente llevaría a pensar que cada una de las palabras utilizadas en esta primera lengua encontrará su expresión equivalente ${ }^{2}$ en la lengua hacia la cual

\footnotetext{
${ }^{1}$ La mayor parte de los teóricos de la traducción y de quienes la practican sostienen la 'primacía del sentido sobre la forma' y la necesidad de que el traductor comprenda bien el mensaje que traduce. Frecuentemente, admiten la dificultad (e incluso la imposibilidad) de comprender todo y en consecuencia, el carácter incompleto de la restitución del sentido. Sin embargo, desatendiendo la objeción teórica que deriva de la imposibilidad de comprenderlo todo, los traductores traducen y los profesores de traducción forman traductores.

2 El concepto de equivalencia ha sido largamente debatido y varía según la escuela que se aborde. Conceptos vinculados con ella son los de equivalencia dinámica, correspondencia, equifunción. La Escuela Interpretativa de París, en su evolución ha fijado una diferencia entre correspondencia y equivalencia, siendo la primera la que se refiere a los vocablos cuya significación no varía fuera y dentro del contexto, mientras que equivalencia comprende a los textos o segmentos de texto que presentan identidad de sentido pero no de forma. La equivalencia requiere comprensión, desverbalización, toma de distancia de la lengua original y búsqueda de formas idiomáticas en la lengua hacia la que se traduce (Lederer, 2003: 19, 20).

Traduciendo a Jeanne Dancette (1995: 80), la equivalencia es el segmento de texto de lengua término que el traductor elige para restituir un segmento correspondiente de la lengua origen.

Por su parte, Katharina Reiss define a la equivalencia como "la relación entre un texto final y un texto de partida que pueden cumplir la misma función comunicativa en sus respectivas culturas. $[\rightarrow$ Reiss, Katharina y Vermeer, Hans (1996: 124). Christiane Nord prefiere hablar de textos equifuncionales en lugar de equivalentes, reservando el concepto de equivalencia a la esfera de los términos. Seminario "Didáctica de la Traducción" (2004), dictado por la Dra. Christiane Nord. UNCórdoba. Guía del Seminario, Unidad I, p. 4.
} 
se traduce. Sin embargo, sabemos que, aunque la traducción se materializa en la lengua, no es una operación exclusivamente lingüística sino que requiere el desarrollo de competencias de comprensión y de expresión, de movilización de conocimientos previos, es decir, un trabajo que va desde la comprensión de un texto escrito en una lengua y cultura de partida hacia la producción de un texto en una lengua y cultura de llegada.

Frecuentemente, al leer traducciones publicadas, experimentamos la necesidad de hacerlo repetidas veces en algunos de sus enunciados de modo de lograr ajustar la expresión con el contenido que se desea transmitir. En el mismo sentido y siguiendo la metáfora del palimpsesto, ciertas traducciones suelen conservar la presencia de una escritura previa, que pareciera ajena a quien traduce.

Tales observaciones indicarían que en la producción discursiva, la reexpresión o la reformulación se han producido anomalías ${ }^{3}$ en algún campo (fónico, morfológico, sintáctico, léxico) del sistema de la lengua o que se han seleccionado formas lingüísticas que cumplen con las normas del sistema pero se alejan de la norma de uso cuyo carácter es sociocultural. ${ }^{4}$

Antes de dar inicio a esta investigación, nos hemos planteado internamente varios interrogantes que están relacionados con las observaciones anteriores: ¿existen indicios que pongan en evidencia que un texto es producto de una traducción?; en caso de identificarlos, ¿es válido que los consideremos retrospectivamente como huellas de la toma de decisiones de un traductor?; si comparamos un texto traducido con el texto original, ¿la interferencia ha actuado para desestabilizar el sistema y las normas de la lengua de llegada?

Aplicando la metáfora que da título a la obra de Virgilio Moya (2004), dentro de la selva de la traducción podemos identificar los procesos presentes en la actividad de traducir, que para la mayor parte de las teorías traductológicas dan lugar a las fases de comprensión, transferencia y reexpresión o producción

No nos proponemos profundizar el debate sino utilizar el concepto de equivalencia en los taxtos pragmáticos como la forma que ha elegido el traductor para producir en la lengua-cultura de llegada la información contenida en los enunciados de la lengua-cultura de partida.

${ }^{3}[\rightarrow$ Capítulo V, Metodología. 5.6.].

${ }^{4}$ Seguimos la terminología de Eugenio Coseriu (1989: 70-85). 
discursiva, o bien a las fases de comprensión, desverbalización y reformulación, según lo que sostiene la Teoría Interpretativa de la Traducción (TIT), escuela francesa de gran influencia en la formación de traductores en Argentina. Por tratarse de procesos mentales, no son compartimientos estancos sino que interactúan entre sí, estableciéndose puentes entre comprensión y producción de equivalencias (Dancette, 1995: 204), en los que la memoria como mecanismo básico que permite la comprensión (Lederer, 2005) y el razonamiento analógico que se activa para la búsqueda de la reexpresión ajustada (Delisle, 1984: 78), juegan un papel de privilegio.

Un principio que sostiene la literatura traductológica es que al elaborar una traducción sólo puede traducirse lo que se comprende; sin embargo, como dice el epígrafe, los traductores siguen traduciendo y los profesores formando traductores, aun cuando sea imposible determinar el grado de comprensión a que se llega antes de la reexpresión (Dancette, 1995: 23).

Daniel Gile (1986: 367, 368) considera que el traductor que traduce textos pragmáticos ${ }^{5}$ de distintas áreas del conocimiento, es decir polivalente, logra una compréhension flottante, en castellano comprensión flotante, como umbral para traducir, que es el resultado de un exhaustivo proceso de análisis lingüístico del texto de partida, acompañado de un buen conocimiento de las lenguas que interactúan y de la adquisición de conocimientos extralingüísticos. Esta noción está emparentada con la de seuil de confort, en castellano umbral de confort, que Gile (1990) ubica por encima de los criterios funcionales de una traducción y que se manifiesta en el traductor que siente no haber comprendido todo, aun cuando su producción discursiva haya respetado esos criterios funcionales. De ello se desprende que la actividad central del traductor polivalente es el análisis del texto por traducir; sin embargo, su comprensión no es análoga a la de un profesional del área específica del conocimiento de pertenencia del texto que aquél traduce.

\footnotetext{
5Jean Delisle (1984: 22), con criterio amplio, designa textos pragmáticos a aquéllos que brindan información sin búsqueda estética. [ $\rightarrow$ Capítulo I, Marco teórico y Antecedentes. 1.2.3.3.1.]. Sobre la base de la tipología de Sophie Moirand, Ida Sonia Sánchez (2000: 127-128) refiere a los textos profesionales, cuyo triple análisis formal, pragmático y argumentativo contribuirá a que el traductor construya la representación necesaria y previa a la producción discursiva; por otra parte, la autora destaca que la información es un invariante de la producción discursiva en traducción.
} 
Jeanne Dancette explica los complejos procesos de vaivén entre comprensión y producción a través del modelo de la doble hélice, constituido por dos curvas helicoidales, de las cuales una representa el movimiento que describiría la comprensión y la otra curva el movimiento de la producción. Si bien estas curvas no se cortan nunca, en algunos momentos de su movimiento helicoidal las dos comparten la misma superficie, durante los cuales pueden construirse puentes que conecten la comprensión y la producción de equivalencias, hasta llegar a un punto en que el traductor juzga satisfactoria la relación alcanzada entre la comprensión y la producción de equivalencias. Es decir que las sucesivas verbalizaciones que realiza el traductor indican una estrecha relación entre ambas, observando que en ese continuo, la reexpresión o producción de equivalencias toma apoyo tanto en la investigación documental y terminológica como también en la reconstrucción discursiva, que es la que ordena, dentro de la lengua-cultura de llegada, el sentido que ya se ha construido en el texto de partida.

Reproducimos a continuación el modelo de la doble hélice:

FIGURA 1. El modelo de la doble hélice (Dancette, 1995: 204) $\begin{array}{lll}\text { Comp. } 1 & \text { Comp. } 2 \quad \text { Comp. } 3\end{array}$

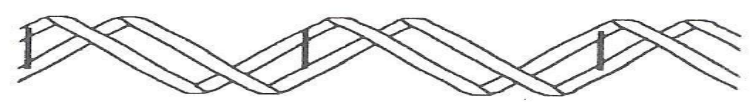
Eq. 1
Eq. 2
Eq. 3

Como decíamos, entre los procesos señalados se establece un movimiento de ida y vuelta permanente cuyo estudio es complejo; en especial, la reexpresión es la fase $-y$ el resultado- que sintetiza y hace visibles los procesos psicolingüísticos y cognitivos previos, pese a lo cual no se la ha estudiado en profundidad como su emergente. Así lo admiten otros traductólogos reconocidos que no dudan en considerar que es la refase menos trabajada; al respecto, Marianne Lederer, exponente de la Teoría Interpretativa de la Traducción (TIT) formula: 
«Enfin nous avons montré plus haut l'importance des avancées de notre théorie pour le volet de la réexpression (voir correspondances / équivalences et le principe de la synecdoque). II est vrai que beaucoup reste à faire sur ce plan. Nous sommes conscients que nous n'avons encore tout exploité et que bien des pistes sont encore à explorer. C'est à quoi nous nous employons.» (2005: 126).

Por último, hemos demostrado anteriormente la importancia de los avances de nuestra teoría en lo que concierne a la reexpresión (véanse correspondencias/equivalencias y el principio de sinécdoque). Sin embargo queda mucho por hacer en este plano. Somos conscientes de que no hemos investigado todo y de que todavía hay muchas pistas por explorar: nos estamos dedicando a ello.

Gideon Toury, máximo representante de los Estudios Descriptivos de Traducción (EDT), expresa que en esta corriente la investigación sobre el alumbramiento de una traducción (2004: 244, 245) es aún marginal y son pocos los datos disponibles, puesto que los estudios retrospectivos plantean dificultades metodológicas.

Por su parte, Mona Baker (1998: 480-485) ha realizado estudios en base a corpora comparables sobre el discurso de traducción y sus características propias como forma única de comunicación, a través de los cuales ha corroborado el concepto de tercer código instaurado por William Frawley, alejándose de la noción de translationese que reviste connotaciones peyorativas en relación con la aparición de formas de la lengua original sobre la lengua meta que se apartan de la norma.

Las consideraciones anteriores y los resultados de investigaciones que hemos realizado en el ámbito universitario ${ }^{6}$ nos han guiado a formular la siguiente hipótesis general:

Los productos discursivos resultantes de la traducción absoluta ${ }^{7}$ de textos pragmáticos francés/castellano, presentan transferencias sintáctico-discursivas gobernadas por el universal de interferencia.

${ }^{6}[\rightarrow$ Capítulo I, Marco Teórico y Antecedentes. 1.2.4.]. 
Esta hipótesis a la luz de la lectura de traducciones publicadas, de correcciones de la cátedra y de las conclusiones de trabajos de investigación, ${ }^{8}$ nos ha orientado a seguir circunscribiendo nuestro problema de estudio que radica en la presencia de elementos ajenos a la lengua-cultura de llegada o poco familiares dentro del texto traducido; es decir, hemos detectado que el texto traducido puede mostrar que se ha recurrido a formas lingüísticas que no pertenecen o que no son familiares a la lengua-cultura de llegada para la resolución de algunos problemas del discurso de partida.

Esta hipótesis general implica las siguientes hipótesis específicas:

La producción discursiva resultante de la traducción de textos pragmáticos francés/castellano, exhibe enunciados elípticos anómalos gobernados por el universal de interferencia.

En los productos discursivos resultantes de la traducción de textos pragmáticos francés/castellano, se visualizan enunciados elípticos anómalos gobernados por el universal de interferencia, según una influencia del discurso de partida sobre el de llegada.

En los productos discursivos resultantes de la traducción de textos pragmáticos francés/castellano, se visualizan enunciados elípticos anómalos gobernados por el

\footnotetext{
${ }^{7}$ Según la clasificación de Daniel Gouadec (1989: 21- 30), la función de transferir informaciones en forma integral, genera los siguientes tipos de traducción: grabada (oral), automática (escrita) y, traducción absoluta (« traduction enregistrée », « traduction automatique », « traduction absolue »). $[\rightarrow$ Capítulo II, Producción discursiva. 2.3.].

Ida Sonia Sánchez (1994: 102) proporciona resultados cuantitativos elevados en cuanto a la frecuencia de elipsis en los textos traducidos al castellano, con respecto a los originales franceses (1994: 102).
} 
universal de interferencia, según una influencia del sistema de la lengua materna del traductor.

En el inicio de esta Introducción, hemos comenzado a delimitar el concepto de traducción y a su vez, nos hemos planteado interrogantes traductológicos orientados a la producción como resultado y como proceso. Con esta problemática, trataremos el concepto de producción en una única lengua-cultura y el de producción discursiva en traducción, es decir desde una lengua-cultura a otra, dentro del cual se verá a la memoria como mecanismo básico [ $\rightarrow$ Capítulo II, Producción discursiva].

En las hipótesis enunciamos que la interferencia está en la raíz de nuestro problema y la estudiaremos en la Adquisición de Lenguas Extranjeras, que es el camino de ingreso al campo de la Lingüística, y en la Traductología como uno de sus universales que implican la activación de mecanismos automáticos $[\rightarrow$ Capítulo III, Interferencia].

Al comienzo de esta Introducción, decíamos que en algunas traducciones se perciben huellas de otro texto que frecuentemente dificultan el ajuste entre la expresión y el contenido por transmitir. En este camino, fuimos identificando emergentes sintáctico-discursivos en nuestro corpus de textos traducidos $[\rightarrow$ Capítulo V, Metodología] que entorpecen la lectura fluida, ya sea porque acarrean ambigüedades o porque desdibujan el sentido. Esa identificación fue compleja porque, como sabemos, dentro del entramado que supone la palabra texto, es muy difícil apartar un único aspecto de la producción discursiva por cuanto las redes de dependencias que se establecen dentro de la construcción textual son multidireccionales y no sólo sintagmáticas.

De todos modos, llegamos a establecer que en el nivel morfosintáctico, los dos fenómenos que con más frecuencia dificultan la lectura de nuestro corpus son: en primer lugar, los enunciados elípticos que implican anomalías sintácticodiscursivas y en segundo lugar, la excesiva presencia de demostrativos. Es decir que se trata de fenómenos que juegan, por un lado, con ausencias o vacíos y por el otro, con presencias o aparición de categorías lingüísticas específicas. 
Creemos que ambos problemas son interesantes para ser tratados por separado como aporte a la Traductología: el primero implica tanto el estudio de las anomalías de construcción de las elipsis y/o de funcionalidad en corpora textuales traducidos como el análisis contrastivo o translémico que describa la visibilidad de la interferencia en la traducción. En cambio, el segundo fenómeno, que trata de la ocurrencia de determinantes, implicaría un estudio contrastivo de su uso y frecuencia en corpora de textos paralelos ${ }^{9}$ variado francés/castellano, es decir en producciones originales que no estén mediadas por la traducción, de allí que no será investigado en el presente trabajo [ $\rightarrow$ Capítulo V, Metodología. 5.4.3.].

Estas apreciaciones y el hecho de que no traducimos categorías lingüísticas sino textos, nos decidieron a estudiar en nuestro corpus, a la luz de criterios de recuperabilidad [ $\rightarrow$ Capítulo IV, Elipsis] los enunciados con vacíos y en particular los enunciados elípticos que presentan anomalías estructurales en el terreno de la lengua y funcionales, en el del discurso [ $\rightarrow$ Capítulo $V$, Metodología. 5.3.].

El Capítulo VI está destinado al análisis y lo hemos dividido en tres partes: la primera reúne los cuarenta (40) enunciados provenientes de los textos traducidos al castellano y de los textos originales en francés que constituyen nuestro corpus; la segunda comprende el análisis de los enunciados elípticos con anomalías de la fuente textual gènéthique.org y la tercera parte se ocupa de los binomios textuales de las obras Au bazar du vivant/El racismo del gen. El contenido de este capítulo responde a los criterios enunciados en el Capítulo $V$ que muestra la Metodología sintetizada en el cuadro Figura 7, Instrumento de Análisis.

El corpus textual ha sido constituido con una recopilación de originales y traducciones absolutas de textos pragmáticos, lo que supone la inexistencia de manipulación de la información del original para modificar la función de la traducción, es decir, son traducciones instrumento y equifuncionales, según la terminología de Christiane Nord. Los autores que produjeron los originales son de lengua materna

\footnotetext{
${ }^{9}$ En la terminología de Christiane Nord (2003: 28-29), los textos paralelos deben cumplir, como mínimo, las siguientes condiciones: haberse producido en dos culturas diferentes y pertenecer al mismo género o tipo textual. Es importante que sean análogas las situaciones comunicativas en las que se usan ambos textos.
} 
francesa y quienes realizaron la traducción tienen el castellano como lengua materna. Hemos elegido textos del área de la Bioética por su alto grado de interdisciplinariedad, puesto que el desarrollo de cualquier tema bioético específico contiene valoraciones fácticas, conceptuales y normativas que se manifiestan desde la síntesis de las posturas que ha tenido esta disciplina, según perspectivas biológicas, filosóficas, jurídicas, espirituales, entre otras (Mainetti, 2001: 8). De allí que las argumentaciones conceptuales generalmente se vean pobladas de términos de las disciplinas mencionadas que adquieren una nueva dimensión en la tour de Babel du langage bioéthique, en castellano torre de Babel del lenguaje bioético, (Byk, 2000: 21), y plasmadas lingüísticamente a través de una sintaxis compleja, propia de las ciencias sociales, que debe encontrar su producción discursiva o reexpresión.

Esta tesis pretende estudiar la producción discursiva desde la lectura y análisis de productos traducidos publicados que ponen de manifiesto anomalías que se vincularían con el universal de interferencia (Toury, 2004), ${ }^{10}$ en especial con la presencia de enunciados elípticos cuya construcción fuera del sistema u ocurrencia en el discurso dificultan una lectura fluida de ciertos enunciados de los textos de llegada; tales enunciados se analizan individualmente en un primer momento y luego comparativamente con el correspondiente texto original, de modo de interpretar los mecanismos que han dado lugar a esas producciones en relación con la interferencia como universal.

En resumen, hemos realizado este estudio partiendo de las anomalías palpables de un único fenómeno lingüístico-discursivo, con la esperanza de que, a través de él, podamos contribuir a explicar cómo producimos en traducción, más allá de la elipsis.

\footnotetext{
${ }^{10}$ La fecha de publicación corresponde a la traducción al castellano.
} 



\section{CAPÍTULO I}

\section{MARCO TEÓRICO Y ANTECEDENTES}

"Si la traducción es una actividad múltiple y compleja, la multidisciplinariedad se impone como marco de análisis". Amparo Hurtado Albir (2004: 171).

El presente capítulo se organiza en dos partes, siendo la primera la presentación de un marco teórico multidisciplinario que encuentra su explicación, por un lado, en la esencia misma de la Traductología, y por el otro en los conceptos que han dado cuerpo a las hipótesis de partida [ $\rightarrow$ Introducción].

En la segunda parte, citamos los antecedentes relacionados con la reflexión traductológica en general y con la interdependencia teoría-práctica, en las que se identifica que el proceso de traducción está atravesado en todas las fases por la interferencia. Como sabemos, una de las fases es la producción discursiva en traducción, también denominada reexpresión, restitución o reformulación. ${ }^{1}$

\section{Primera parte: Marco teórico}

\subsection{La necesidad de un marco multidisciplinario}

Nuestro problema general es la producción discursiva en traducción que hemos estudiado desde las anomalías sintáctico-discursivas ${ }^{2}$ de enunciados elípticos, con el objetivo de llegar a la identificación de mecanismos discursivos que expliquen las producciones de nuestro corpus textual.

\footnotetext{
${ }^{1}$ La noción reformulación es utilizada por varios traductólogos como la fase de producción discursiva en traducción. En otro orden de cosas, en el discurso científico-técnico, la reformulación es un recurso omnipresente cuando se retoma una información total o parcialmente para adaptarla a una nueva situación o a nuevos destinatarios, por ejemplo, la reformulación icónica a través de gráficos o cuadros. Pétroff, André (1984: 53-66).

${ }^{2}$ La definición de los conceptos operativos, entre ellos el de anomalía sintáctica y discursiva, se encuentran en el capítulo V, Metodología. 5.6.
} 
Esta investigación se ubica dentro de la Traductología cuya matriz es considerada multidisciplinaria por algunos traductólogos (Hurtado Albir, 2004: 137) e interdisciplinaria por otros (Ladmiral, 2005: 160) y, dentro de ella, nuestro problema se relaciona con el par de lenguas francés/castellano.

Nos hemos apoyado sobre la Gramática Descriptiva de la Lengua Española y el Análisis del Discurso para reconocer las anomalías de las elipsis según criterios estructurales y discursivos en lengua meta, lo cual implica la aplicación de las teorías de la anáfora y de la cohesión-coherencia, por un lado, y sobre las Ciencias Cognitivas, desde la teoría de la interferencia para intentar reconocer, a través de las anomalías detectadas en la producción de enunciados elípticos, los mecanismos discursivos puestos en juego en el último eslabón del proceso de traducción que es la producción. Por tratarse de un estudio sobre una producción discursiva en textos traducidos, que se cotejarán con los textos fuente, hemos recurrido al Análisis Contrastivo entre las lenguas puestas en juego.

Cuando nos referimos a la Traductología, lo hacemos desde la perspectiva moderna de una teorización que se ha ido gestando en las dos últimas décadas del siglo XX, que apunta a describir, quizás explicar y predecir problemas de traducción, comportamientos de quien traduce, con lo cual se ha ido desplazando el eje prescriptivo que regía en la primera etapa de la disciplina traductológica.

En línea con la multiplicidad y complejidad que señala el epígrafe, Jea-René Ladmiral (2005: 160) enuncia:

"Cela dit, cette dernière [la traductologie] se situe en aval d'une interdisciplinarité qui, de proche en proche, tend à mettre en contribution la quasi-totalité des 'lettres et sciences humaines', à quoi on pourra ajouter maintenant les sciences cognitives...Plus spécifiquement, je mets quant à moi en avant ce que j'appelle le triangle interdisciplinaire de la traductologie que constitue la synergie des trois disciplines suivantes: linguistique, philosophie et psychologie, lesquelles sont très directement mises en jeu par les problèmes de traduction, en sorte qu'elles interfèrent au sein de la traductologie telle que je la définis. » 
Por lo tanto, esta última, [la traductología] es la consecuencia de una interdisciplinariedad que tiende a reunir, cada vez más, a casi la totalidad de las "letras y ciencias humanas", pudiendo agregar ahora también las ciencias cognitivas...Más específicamente, en lo que a mí respecta, destaco lo que denomino el triángulo interdisciplinario de la traductología que constituye la sinergia de las tres disciplinas siguientes: lingüística, filosofía y psicología, las cuales están directamente implicadas por los problemas de traducción, de modo que interfieren dentro de la traductología tal como la defino."

Dicho esto, a continuación enunciamos las posturas teóricas que hemos considerado para realizar nuestro estudio.

\subsubsection{Aporte interpretativo-cognitivo}

Hacia finales de los años sesenta, la Traductología comienza a interesarse por el conocimiento del proceso mental del traductor, desde análisis cognitivos o psicolingüísticos, según la expresión de Amparo Hurtado Albir (2004: 314). La Escuela Interpretativa de París inaugura el enfoque interpretativo-cognitivo en el campo de la Traductología que cuenta entre los investigadores allí formados a Jean Delisle (1984). Fue este autor quien analizó el proceso de traducción escrita, llegando a una propuesta de deconstrucción del proceso de traducción (Démontage du processus de traduction), en el que reconoce tres etapas: comprensión, reformulación y análisis justificativo, que a su vez, comprenden subetapas. Este enfoque interpretativo-cognitivo que persigue una aplicación didáctica, considera que por medio de la comprensión se llega al sentido desverbalizado que debe ser anterior a la reformulación, por lo tanto, se requieren competencias de comprensión o interpretativas que activen estrategias exegéticas para llegar a lo que quiso decir el autor, ${ }^{3}$ y competencias de reexpresión para revestir con las palabras adecuadas el concepto desnudo de los signos lingüísticos:

"Cette démarche de l'esprit est sans doute celle qui est encore la plus mal connue, la plus mystérieuse et la plus complexe à analyser. Les idées isolées par l'exégèse déclenchent un processus analogique dans le cerveau du traducteur.» (...) «La reformulation n'est pas un acte banal d'étiquetage mais fondamentalement un acte d'intelligence.» (1984: 77).

\footnotetext{
${ }^{3}$ " (...) le traducteur cherche à s'approcher à ce 'vouloir dire' » (Cagnolati, 2001: 33). En castellano: el traductor trata de aproximarse a ese querer decir.
} 
Sin ninguna duda, este camino intelectual sigue siendo el menos conocido, el más misterioso y el más complejo de analizar. Las ideas aisladas por la exégesis activan un proceso analógico en el cerebro del traductor. (...) La reformulación no es un acto banal de etiquetado sino fundamentalmente un acto de inteligencia.

Nuestro trabajo analiza la traducción escrita $[\rightarrow$ Capítulo $V$, Metodología], de allí que resulte de interés la propuesta de este autor que desarrollamos en la segunda parte del presente capítulo, porque como ya hemos señalado, la Teoría Interpretativa de la Traducción ha centrado su estudio en el proceso de traducción, siendo la producción discursiva o reexpresión, una de sus etapas. Es decir que nuestro problema forma parte de uno de sus intereses, más allá de que esta postura teórica no incluya la comparación entre texto original y texto traducido (TO $\rightarrow$ TT) o viceversa (TT $\rightarrow$ TO) como estrategia de estudio del proceso de traducción.

\subsubsection{La traducción como actividad integradora}

Durante los años '80 y hasta su fallecimiento en 1997, Robert Larose desarrolló en la Universidad de Montreal, un exhaustivo estudio tanto teórico como aplicado del producto traducido, integrando aportes de la lingüística textual y la gramática contrastiva. Larose concibe el texto traducido desde una óptica ensembliste, es decir integradora, pero a su vez como lugar de tensión dialéctica entre cuatro elementos: el tenor informativo y el componente material, por un lado, el objetivo de enunciación inicial y el trasfondo sociocultural de los destinatarios, por el otro.

A continuación reproducimos su esquema traducido, en el que se identifican los cuatro elementos nombrados que influyen sobre los cuatro elementos constitutivos del texto: superestructura (esquemática) y macroestructura (semántica) que se realizan a través de la forma de la expresión microestructural y la forma del contenido microestructural. Esta combinación de a 4 elementos justifica el nombre de la siguiente figura: 
FIGURA 2. Cuadrado traductivo (Larose, 1989: 223)

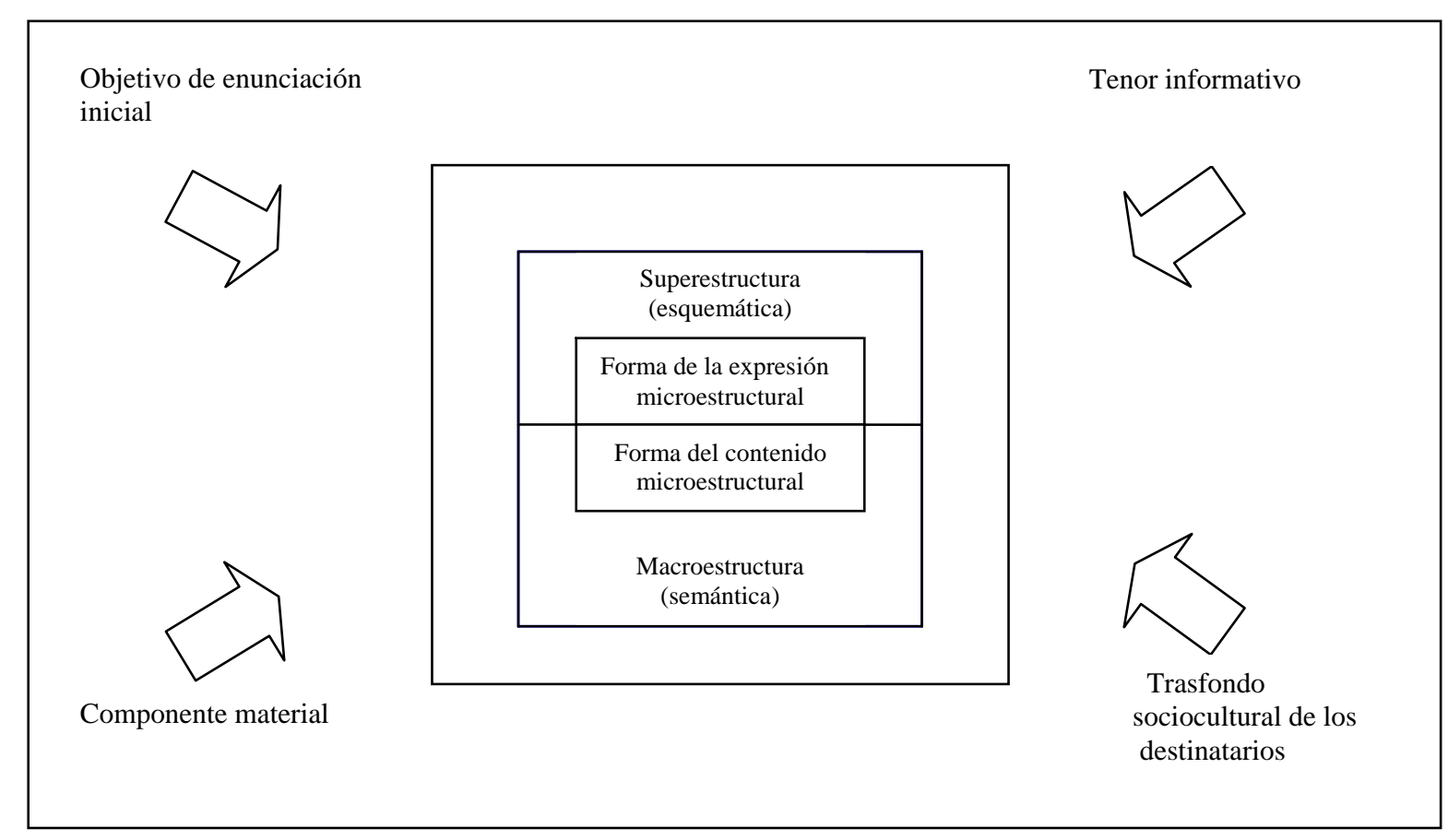

\subsubsection{La evaluación por niveles}

Con análogo criterio integrador, Larose propone una evaluación de traducciones que toma en cuenta las condiciones de enunciación que van orientando los niveles textuales inferiores en los que se materializa la producción discursiva. EI autor considera indispensable un análisis en detalle del texto original que permita aislar porciones delimitables para una evaluación de la microestructura o segmentos textuales aislados, todo ello sin perder de vista que la microestructura integra la macroestructura y la superestrucutura, por lo que el grado de repercusión de un error estará marcado por los niveles que éste afecte.

Sus instrumentos de evaluación analizan la microestructura según la forma de la expresión y la forma del contenido, terminología de reminiscencia hjelmsleviana, dentro de las cuales establece los niveles fonografémico, morfológico, lexicológico y sintáctico. 
En su obra Théories contemporaines de la traduction, luego de interpretar las distintas corrientes que se han ocupado del fenómeno de la traducción, estudia la evaluación textológica de las traducciones y afirma (Larose, 1989: 222) que las traducciones deben evaluarse por niveles: nivel microestructural, nivel textual superestructura y macroestructura-, nivel peritextual o condiciones de enunciación, nivel de condiciones previas que involucran al conocimiento de las lenguas $y$ culturas de trabajo, del tema y de las técnicas de traducción. En este estudio descriptivo, Larose propone grillas según la forma de la expresión y del contenido, y dentro de ellas los niveles de análisis fonológico, grafémico, morfológico, lexicológico y sintáctico, puesto que coincide con autores como Katharina Reiss, Karl Bühler y Robert De Beaugrande, en que:

"Pour que l'évaluation d'une traduction puisse porter sur des portions de texte délimitables, tout texte à traduire doit être analysé en détail. » (Larose, 1989: 256)

"Para que la evaluación de una traducción pueda realizarse en porciones delimitables de texto, el texto por traducir debe analizarse detalladamente."

Los análisis del autor han sido de suma importancia para considerar la incidencia de las anomalías sintáctico-discursivas que tratamos en nuestro trabajo. Por otra parte, han constituido uno de los ejes de trabajos de investigación previos a esta tesis, que mencionamos en la segunda parte del presente capítulo.

Por último, cabe destacar que nuestra investigación no estudia la superestructura puesto que el corpus textual que hemos elegido está integrado por textos traducidos integralmente en los que los problemas no se hallan en las diferencias esquemáticas, sino en aspectos micro y macroestructurales. 


\subsubsection{El modelo tripartito de Eugenio Coseriu}

La idea de que traducimos para comunicar nos lleva a tomar al traductor como el mediador que interpreta el mensaje original según coordenadas lingüísticas y extralingüísticas y lo reexpresa intentando reproducirlas en función del destinatario. Desde esta perspectiva, resulta apropiado el modelo tripartito de Eugenio Coseriu que considera sistema, norma y habla. El lingüista aplica su modelo al campo fónico, morfológico, sintáctico y léxico (1989: 70-71). En particular, en el campo sintáctico, Coseriu se aleja de la postura de varios lingüistas como Saussure, Bühler, Brøndal, según los cuales la sintaxis pertenece más al habla que a la lengua. Según Coseriu, la distinción entre sistema y norma aparece como:

“los tipos generales o 'regulares' de construcción y las fórmulas fijas de las que habla Saussure: mientras que aquéllos pertenecen al sistema, éstas representan realizaciones tradicionales de esquemas contenidos en el sistema mismo, es decir que son hechos de norma." (1989: 83-84).

Dicho de otro modo, el sistema es el marco lingüístico general, la norma representa el uso preferido que es de orden pragmático-semántico y el habla es la toma de decisión cuyo carácter es individual.

Este modelo lingüístico es eficiente en traducción puesto que identifica los tres andariveles que tensionan la producción discursiva, reexpresión o reformulación, a la vez que reconoce el factor social a través del concepto de norma, visión que ha sido tomada por los Estudios Descriptivos de Traducción.

\subsubsection{Los Estudios Descriptivos de Traducción (EDT)}

Como decíamos, el modelo de Eugenio Coseriu ha tenido influencia en la consolidación de los Estudios Descriptivos de Traducción (EDT), cuyo máximo representante es Gideon Toury, a partir de su tesis doctoral Las normas de traducción y la traducción de la literatura al hebreo 1930-1945. 
Los EDT son de matriz empírica y su objetivo es constituir una herramienta para que el investigador analice y describa datos, dejando la explicación y/o la predicción al terreno de la teoría de la traducción o Estudios de Traducción.

En el marco de los EDT, se comienza por ubicar los textos traducidos dentro del sistema meta al que pertenecen y se los compara con sus originales desde segmentos en los que se aíslan pares de problema y solución, mediante los cuales se detectan regularidades que podrán indicar si el texto traducido responde a la adecuación en el polo original o a la aceptabilidad en el polo meta (Toury, 2004: 26$27,98) .{ }^{4}$ Inscripta en esta línea investigativa, Rosa Rabadán (1991: 46) analiza la equivalencia translémica considerando que debe de haber algún parámetro más allá de la dicotomía competencia y actuación ${ }^{5}$ introducida por la gramática generativa, que explique por qué se prefieren algunas opciones del potencial del sistema en lugar de otras, de allí que su estudio comparativo excluye los errores de traducción (Rabadán, 1991: 231).

Los EDT dan cuenta de la existencia de fenómenos palpables, observables, siendo una de sus características la versatilidad, puesto que, dentro de una epistemología propia que concibe a la traducción como un fenómeno lingüístico y especialmente cultural, permiten abordar problemas diversos, entre ellos el proceso de traducción.

Este marco de referencia ha sido de interés en nuestra investigación puesto que habilita la comparación entre textos traducidos y textos originales como metodología para abordar problemáticas diversas, en nuestro caso la producción discursiva en traducción, desde las anomalías en la formulación de elipsis y los problemas que pueden surgir adjuntos a dicho fenómeno.

\footnotetext{
${ }^{4}$ Estas nociones comparten algunas de las características con los conceptos cibliste (hacia la lenguacultura meta o receptora) y sourcier (hacia la lengua-cultura original) acuñados por Ladmiral.

5 "Competencia 'competence'. Lo que el hablante de una lengua sabe implícitamente." "Actuación 'performance'. Lo que el hablante de una lengua dice y oye (...) La actuación provee los datos para la investigación de la competencia." (Chomsky, N. 1970: 221, 222).
} 


\subsubsection{El contraste interlingüístico}

En un plano exclusivamente interlingüístico, todo contraste supone una etapa previa de análisis en cada una de las lenguas que desean confrontarse, lo que conlleva la decisión de elegir un enfoque descriptivo.

Al respecto, Nelson Cartagena (1992) de la Universidad de Heidelberg, considera que los métodos de descripción interlingüística van desde los tradicionales, estructuralistas, funcionales, generativo-transformacionales, pragmáticos y lingüístico-textuales hasta el contrastive mix, es decir, la aplicación de diversos enfoques, puesto que ninguno tomado aisladamente puede dar cuenta de una visión completa de dos lenguas.

En sentido amplio, Hugo Alloa y Silvia M. de Torres (2001: 17) inscriben su obra dentro de un marco teórico multidisciplinario, con enfoques lingüísticopragmáticos, cognitivos y comunicativos.

Por su parte, Dominique Maingueneau, en la presentación de Syntaxe du Français (1994) y Ángela Di Tullio en su Manual de gramática del español (1997) coinciden en que el análisis formal de los sistemas que estudian, entre otros el sistema de determinantes o de pronombres, debe ser completado con el uso y con su inserción en el discurso. Dicho en palabras de Jean-Michel Adam (1999: 32):

"Une linguistique de la langue ne va pas sans une linguistique du discours qui la complète. »

Una lingüística de la lengua no es viable sin una lingüística del discurso que la complete.

En Éléments d'une linguistique textuelle (1990: 150), Adam sostiene la misma línea de pensamiento : 
En el marco de una pragmática textual, pienso que si bien el análisis morfosintáctico no es inútil, al menos es insuficiente.

En nuestra opinión, la Traductología, por su naturaleza interdisciplinaria, tiene mucho que aportar a los estudios contrastivos, puesto que su objeto de estudio, la traducción, supone en primer lugar, el contacto de dos sistemas lingüísticos con especificidades conceptuales y morfosintácticas propias, por lo que se evidenciarán transformaciones en la lengua-cultura de llegada, con la finalidad de recrear las condiciones de la información por transmitir desde la lengua-cultura de partida. Al respecto y sin entrar en el debate traductológico sobre lo que se entiende por equivalencia, adherimos a lo que enuncia Nelson Cartagena en el artículo ya mencionado:

"dos o más textos son equivalentes para la traducción si pese a sus diferencias de estructuras superficiales, muestran el mismo valor referencial, pragmático y textual. A menudo se usa tal criterio de invariación como tertium del análisis contrastivo en el ámbito del discurso". ${ }^{6}$

Como ya hemos señalado en este capítulo [ $\rightarrow 1.1$.$] , el análisis gramatical y$ discursivo de los enunciados elípticos en lengua materna sigue, principalmente, la Gramática Descriptiva de la Lengua Española (GDLE), obra que desarrolla temas gramaticales clásicos y nuevos, tratados por especialistas en cada una de los tópicos. En sus tres tomos de poco más de 5000 páginas y centrándose en la caracterización de problemas empíricos y no en la validación de constructos teóricos, la GDLE pretende:

\footnotetext{
"exponer y razonar el comportamiento de las estructuras gramaticales, las pautas que regulan su estructura interna y las relaciones morfológicas, sintácticas semánticas y discursivas que se dan en todos los ámbitos que abarca el análisis" (2000: XXI).
}

\footnotetext{
${ }^{6}$ No consignamos la página porque no aparece en el texto digitalizado que hemos consultado el 20/02/06.
} 
Por otra parte, y fundamentalmente, la GDLE refleja un cambio de perspectiva que se manifiesta a partir de los años '90, en cuanto a una tendencia hacia el diálogo entre investigadores provenientes de distintos marcos teóricos, que redunda en el acercamiento de sus posturas o en el interés por conocer y aprovechar estudios y logros de otros investigadores, sin que ello signifique eclecticismo (2000: XXVIII).

Con una visión también integradora proveniente de diversas investigaciones sobre la elipsis en francés, ha sido de mucha utilidad el libro Ellipse et effacement. Du schème de phrase aux règles discursives, de la Universidad de Saint-Étienne.

\subsubsection{La interferencia ¿Por qué las anomalías sintáctico-discursivas?}

Nuestra hipótesis general plantea la presencia de anomalías sintácticodiscursivas en las traducciones de textos pragmáticos francés/castellano que se explicarían según el universal de interferencia. Ahora bien, ¿incide la cercanía o la lejanía del origen del par de lenguas con las que se trabaja, en nuestro caso francés/castellano? Aparentemente, no hay unidad de criterio al respecto:

"On sait que les langues de familles proches ne se prêtent que trop aux dangers d'interférences, le calque lexical et syntaxique représentant un moindre effort pour la réexpression. » (Lederer, 2003:17).

Se sabe que las lenguas de familias cercanas están muy expuestas a los riesgos de las interferencias, ya que el calco léxico y sintáctico, representan un menor esfuerzo para la reexpresión.

Gideon Toury (2004: 346), lo expresa así:

\footnotetext{
"Baste con decir que, creencias populares aparte, la distancia entre lenguas, tradiciones textuales y/o culturas completas no parecen tener influencia automática en el grado de interferencia. La semejanza puede muy bien tener sus implicaciones para la proporción de transferencia 'negativa' y/o 'positiva', pero como desde el punto de vista psicolingüístico, hay un único procedimiento que dé lugar a ambos tipos de transferencia, la interferencia como tal siempre estará presente. Lo que sí puede ocurrir es que se vea con mayor o menor facilidad."
} 
En Carsten Sinner (2004: 73), hemos encontrado un punto de vista original sobre interferencia al afirmar que frecuentemente la influencia de una lengua sobre la otra da como resultado una elevación de la frecuencia de uso de ciertos elementos, sin que se pueda considerar como infracción a la norma $[\rightarrow$ Capítulo III. 3.1.3.].

Cuando Marianne Lederer explica la fase de reexpresión (2003: 20) afirma que todos los textos traducidos, tanto generales como técnicos, presentan una coexistencia de equivalencias que dan sentido al texto y de correspondencias, caracterizadas por su exactitud. Esta comprobación se opone a la idea generalizada de que los textos técnicos se traducen únicamente mediante correspondencias.

"La théorie interprétative a mis en évidence une des caractéristiques les plus récurrentes de tous les textes traduits: la coexistence constante d'équivalences qui donnent leur sens au texte et de correspondances dont l'exactitude contribue elle aussi au sens. Cette coexistence se retrouve dans les textes généraux mais aussi dans tous les textes techniques qui, quoiqu'on en dise, ne se traduisent pas uniquement à coup de correspondances. »

La teoría interpretativa ha puesto en evidencia una de las características más recurrentes de todos los textos traducidos: la coexistencia constante de equivalencias que dan su sentido al texto y de correspondencias cuya exactitud también contribuye a dar sentido. Esta coexistencia se encuentra en los textos generales pero también en los textos técnicos que, diga lo que se diga, no se traducen únicamente con correspondencias.

Para la Teoría Interpretativa de la Traducción (TIT), la correspondencia es el vocablo cuya significación es invariable, dentro o fuera del discurso, mientras que la equivalencia es la porción de producción de textos traducidos que refleja identidad de sentido respecto del texto original, expresada según formas idiomáticas de la lengua de llegada [ $\rightarrow$ Introducción. Nota 1]. En la formulación de equivalencias, la sintaxis juega un papel fundamental.

En los procesos comprensivo y productivo, el sujeto fija la atención en las unidades centrales de contenido mientras que automatiza las periféricas (De Beaugrande, 1987, citado por Silvestri, 2000: 181), de modo tal que la demanda de esfuerzo en la recuperación de las palabras de contenido es importante y es 
automática en las palabras funcionales. El estudio del proceso de reformulación intralingüística en público no experto indica que hay una mayor tendencia a producir errores léxicos (Silvestri, 2000: 180).

Sobre la base de lo expresado anteriormente -de sencilla comprobación en la revisión de traducciones y en la propia experiencia de producción de traducciones especializadas- resulta natural que el traductor concentre su atención en la resolución de problemas terminológicos o léxicos, dejando la expresión sintáctica relegada a un segundo plano puesto que ésta forma parte de las competencias de expresión que surgen automáticamente. La creencia generalizada es que la traducción especializada plantea únicamente problemas de índole terminológica en la rama del conocimiento que se esté tratando.

Sin embargo, en 1980, Valentín García Yebra de la Universidad Complutense de Madrid, publica Teoría y práctica de la traducción, con la finalidad de hacer un aporte didáctico al Instituto Universitario de Lenguas Modernas y Traductores. En la obra mencionada, expone sus ideas acerca de la traducción, que se basan en las lecturas de Georges Mounin, J.-P. Vinay y J. Darbelnet, Eugene Nida y Charles Taber, entre otras y en su experiencia como traductor. Al abordar la interferencia lingüística y especialmente los galicismos, García Yebra (1997: 385) comenta ejemplos diversos de obras traducidas del francés y concluye diciendo:

"De las interferencias relacionadas en el § 45.2. y 3., sólo cinco son galicismos léxicos; uno es de carácter morfológico, y veintitrés, de naturaleza sintáctica."

En coincidencia con la tendencia de los resultados proporcionados por este autor, más adelante en este capítulo, mencionaremos algunas investigaciones que demuestran que en producción se ha encontrado descuido en el nivel morfosintáctico [ $\rightarrow$ Capítulo I, Antecedentes. 1.2.4.].

Es irrefutable que un traductor formado conoce los sistemas lingüísticos que se ponen en juego, sin embargo, es necesario un esfuerzo permanente durante el 
proceso de producción para disminuir, en la medida de lo posible, las transferencias negativas [ $\rightarrow$ Capítulo III, Interferencia. 3.3.1.].

\section{Segunda parte: Antecedentes}

\subsection{Reflexión traductológica e interdependencia teoría-práctica}

Los trabajos sobre la evolución de las corrientes traductológicas sostienen que a partir de la segunda mitad del siglo $X X$, nace un interés particular por desarrollar el estudio de la traducción, que hasta ese momento había tomado la forma de comparación filológica. Tal teorización comienza a desarrollarse al finalizar la Segunda Guerra Mundial, cuando surge una fuerte demanda de traductores por parte de los organismos internacionales, y ante la dificultad de dar respuesta a esa demanda por la escasez de traductores formados institucionalmente; esa circunstancia incentiva la investigación sobre la naturaleza de la actividad traductora.

La información siguiente parte del período de posguerra, dentro de la esfera de la Traductología y se relaciona con el problema de nuestra investigación.

Con la finalidad de organizar los trabajos vinculados a la reflexión en traducción, James Holmes (1972) expuso su mapa durante el Tercer Congreso Internacional de Lingüística Aplicada en la ciudad de Copenhague, que cita Hurtado Albir (2004: 138) y considerado clásico dentro de la literatura traductológica:

\footnotetext{
${ }^{7}$ Para una explicación detallada de la propuesta de Holmes, véanse: Toury, Gideon (2004. 45 y ss.) y Hurtado Albir, Amparo (2004: 138 y ss.).
} 
FIGURA 3. Los estudios sobre la traducción (Holmes, 1972)

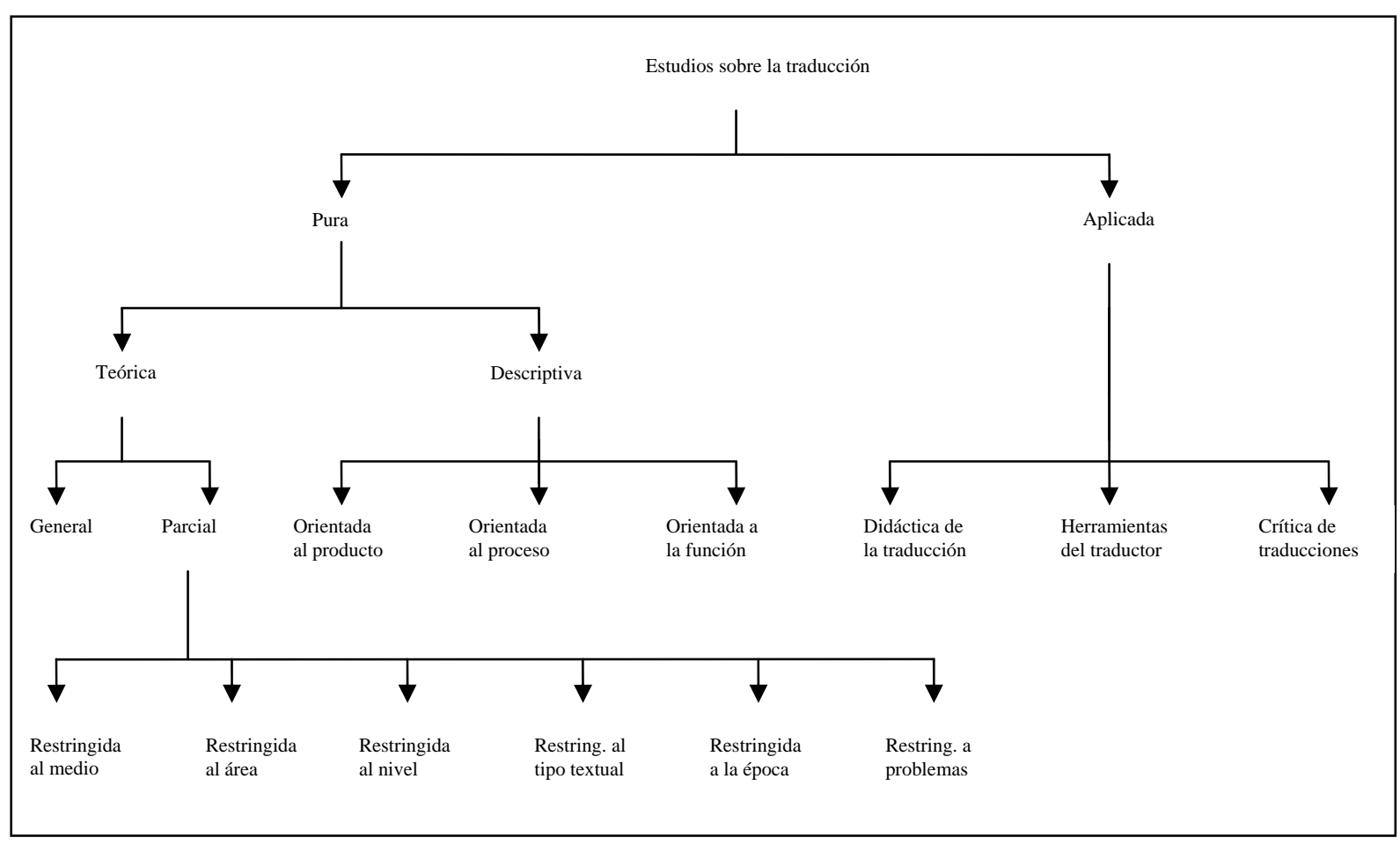

\subsubsection{Reformulación de Amparo Hurtado Albir}

Amparo Hurtado Albir (2004: 140-146) discute y reformula el esquema de Holmes proponiendo un esquema de tres ramas imbricadas: los estudios descriptivos, ubicados en el centro, son la base de la disciplina, ya que proporcionan los datos empíricos para los estudios aplicados y para los teóricos. Insiste en la imbricación de las tres ramas, ya introducida por Holmes, que debe entenderse como trasvase de datos y principios, y no como aplicaciones mecánicas de una rama a otra; así los estudios aplicados no han de ser considerados como meras aplicaciones mecánicas de los estudios teóricos y descriptivos, sino manteniendo, como señalaba Holmes, una relación dialéctica.

\subsubsection{Las seis variables}

Hurtado Albir propone seis variables que pueden aparecer en los estudios teóricos, descriptivos o aplicados, es decir en las tres ramas del esquema de Holmes: 
1) Traducción como proceso y/o producto.

2) La noción que se analiza: equivalencia, invariable, unidad de traducción, método, estrategia, técnica, problema, error.

3) El problema concreto estudiado: lingüístico, textual, extralingüístico, pragmático, entre otros.

4) La variedad de traducción analizada, terreno de los estudios descriptivos, por excelencia: modalidad, tipo textual y clase.

5) Las lenguas y culturas implicadas en el análisis.

6) La dimensión histórica, es decir si se trata de un análisis en diacronía o en sincronía.

Todas las ramas introducen variables de las lenguas y culturas implicadas en el análisis, como así también históricas, por ejemplo la historia de una variedad de traducción o la historia de la didáctica de la traducción. Las imbricaciones van, pues, en todas las direcciones.

\subsubsection{Los cinco enfoques teóricos}

Dentro de las teorías modernas de la traducción, Hurtado Albir (2004: 130) propone cinco enfoques que no deben verse como compartimientos estancos sino como prioridad de estudio de un elemento sobre otro.

1) Los enfoques lingüísticos propiamente dichos, dentro de los cuales se observan los centrados en la descripción y comparación de lenguas y que, con el aporte de John Catford (1965), preanuncian los estudios textuales. Siguen modelos de lingüística comparada tradicional, a partir de unidades aisladas como el léxico o elementos morfológicos y sintácticos (Valentín García Yebra); de estilísticas comparadas, con el aporte de los procedimientos de traducción de J.-P. Vinay y J. Darbelnet; de descripciones semánticas (Mildred Larson) y de semióticas (Alexander Ljudskanov). 
2) Los enfoques textuales surgen en los años '70 y ven en la traducción una operación no centrada en el plano de la lengua, como es el caso de los trabajos de Danica Seleskovitch, Eugene Coseriu, René Ladmiral, Katharina Reiss.

Se trabajan los aspectos intratextuales de análisis como los mecanismos de coherencia y cohesión textual, el funcionamiento de los tipos textuales, en Mona Baker, Mercedes Tricás Preckler, Ida Sonia Sánchez, y los aspectos extratextuales, en Robert Larose, Basil Hatim y lan Mason, Katharina Reiss y Hans J. Vermeer, Christiane Nord.

\section{3) Los enfoques cognitivos}

Su objetivo es el análisis de los procesos mentales del traductor, dentro de los cuales ubicamos a la Teoría de la Traducción (TIT) y a los estudios de Jeanne Dancette, entre otros.

4) Los enfoques comunicativos y socioculturales que estudian particularmente los aspectos extratextuales que inciden en la traducción, como es el caso de la traducción bíblica de Eugene Nida y Charles Taber; la teoría del skopos y funcionalista de Katharina Reiss, Hans J. Vermeer y Christiane Nord; la teoría polisistémica de Gideon Toury $^{8}$ y su aplicación en Europa con la llamada Manipulation School, uno de cuyos exponentes es Rosa Rabadán, en España, desde su óptica de la equivalencia translémica.

5) Enfoques filosófico-hermenéuticos de la traducción llevados a cabo por autores como George Steiner o Hans-Georg Gadamer.

\subsubsection{La relación teoría y práctica como constante traductológica}

A continuación, pasarmos revista a esta relación desde distintos enfoques: lingüístico, lingüñistico-cultural, lingüístico-cognitivo, funcionalismo, comparatistas prescritivos y comparatistas descriptivos.

\footnotetext{
${ }^{8}$ Toury (2004: 64 -65) marca la evolución operada hasta los años 60 y a partir de entonces. Relata que en el primer período, los estudios se dirigían al polo origen; en cambio, con el surgimiento de la teoría del escopo, comienza a privilegiarse el polo meta, aunque estas reflexiones se hallaban dentro de la traductología alemana. Hispanistas de origen alemán han comenzado a divulgar en castellano los avances de las escuelas alemanas (entre otros, Christiane Nord, Universidad de Magdeburgo; Gerd Wotjak, Universidad de Leipzig).
} 


\subsubsection{Desde lo lingüístico}

En la clasificación propuesta por Amparo Hurtado Albir, vemos que en primer lugar aparecen los enfoques lingüísticos, no solamente por una cuestión cronológica, sino también por una cuestión lógica, ya que si bien la traducción excede un planteo estrictamente lingüístico, no es menos cierto que su modo de materializarse es a través de recursos lingüísticos.

Así las cosas y sin la intención de abarcar todas las categorías que señala Holmes, hay unanimidad en las obras que refieren a los avances exclusivamente teóricos en traducción, cuando afirman que Roman Jakobson fue uno de los pocos lingüistas que demostraron preocupación por estudiar el fenómeno de traducción en sus Ensayos de Lingüística General. Por su parte, John Rupert Firth va a tener una influencia decisiva sobre el traductólogo John Catford y tanto él como diversos teóricos de la traducción, Georges Mounin, John Catford, Eugene Nida, Charles Taber, Maurice Pergnier, entre otros, vinculan esta actividad fuertemente con la Lingüística.

En los años '60, Georges Mounin en Les problèmes de la traduction estima que, con respecto a la relación entre sintaxis y traducción (1963: 251-270), la primera brinda los argumentos más sólidos en contra de la posibilidad de traducir (Wihelm von Humboldt, Benjamin Lee Whorf) ya sea desde la heterogeneidad de las visiones del mundo como desde la impenetrabilidad recíproca de las sintaxis de las lenguas. Georges Mounin plantea que una teoría de la traducción no puede ignorar las dificultades que han sido puestas en evidencia por la lingüística contemporánea; sin embargo, a pesar de todo, la traducción se la practica desde siempre. En síntesis, Mounin concluye que los elementos de sintaxis general aportan muy poco a la traducción como cosecha de universales (1963: 259) y considera que la respuesta verdaderamente teórica proviene del concepto bloomfieldiano de situación, como el único invariante al que se refiere el mensaje en lengua-fuente y el mensaje en lengua-término. Cuando se mira la inconmensurabilidad de las estructuras sintácticas, reflejo de una inconmensurabilidad de las visiones del mundo o de las organizaciones de experiencias, desde la perspectiva de la situación común expresada por dos mensajes en dos lenguas diferentes, ello se transforma en 
postulado o en hipótesis que merece especial observación. Es decir que es indispensable que haya identidad de la situación no lingüística, para poder traducir, superando así las heterogeneidades de las sintaxis de dos mensajes.

Por su parte, John Catford (1965), con su obra A Linguistic Theory of Translation, se inspira en M.A.K. Halliday y J.R. Firth, y establece tipos de traducción, entre los cuales se encuentra la traducción del nivel sintagmático ya sea como traducción integral y traducción parcial, siendo ésta la que conserva segmentos de la lengua de partida, por razones de intraducibilidad o de conservación de rasgos exóticos. ${ }^{9}$ La traductología ha acordado que la full translation o traducción integral, no existe puesto que el lenguaje es sólo un aspecto de la comunicación total (Larose, 1989: 107).

\subsubsection{Desde lo lingüístico-cultural}

También el lingüista y traductor estadounidense Eugene Nida, pionero de la traductología contemporánea, percibe que la traducción excede los marcos estrictamente lingüísticos, ya que no basta con el manejo de las lenguas, y avanza en dirección de un enfoque sociolingüístico poniendo énfasis en la necesidad de conocer los hechos culturales y antropológicos que atraviesan los textos por traducir; es él quien acuña el término equivalencia dinámica en su obra Toward a Science of Translation (1964) que se refiere al cambio de forma de un texto con la finalidad de que provoque el mismo efecto que el texto original. En 1969, publica junto con Charles Taber Theory and Practice of Translation, inspirado en la traducción de la Biblia, en el que los autores logran unir los principios teóricos con la aplicación. ${ }^{10}$

Se destaca entonces el surgimiento de una preocupación por combinar la reflexión teórica con su aplicación, criterio moderno de la Traductología al que adherimos para hacer referencia a otros hitos que conforman el mapa traductológico en relación con los elementos a tener en cuenta a la hora de producir discursivamente.

\footnotetext{
${ }^{9}$ Véase Larose, Robert (1989: 105 y ss).

${ }^{10}$ Véase Delisle, Jean (1984 : 55 y ss.)
} 


\subsubsection{Desde lo lingüístico-cognitivo}

En la relación dialéctica teoría y aplicación, y dentro de los estudios orientados al proceso de traducción con vistas a la formación de intérpretes, nace en 1957 la Escuela Superior de Intérpretes y Traductores de París (ESIT), impulsada por Danica Seleskovitch y por su sucesora Marianne Lederer. En una segunda etapa, la escuela extendió su actividad a la formación de traductores de textos pragmáticos y en una última etapa a la traducción de textos literarios, bajo la influencia de Fortunato Israël, traductor literario que llegó a ocupar la dirección de la ESIT. Esta escuela propone captar el querer decir del autor, a través del sentido desverbalizado, con la finalidad de que la reexpresión se libere de las formas del texto original, una vez que se han conjugado los conocimientos lingüísticos y extralingüísticos, a los que se llega por la propia experiencia y por la documentación consultada.

Por su parte, como señalamos en la Introducción, Jeanne Dancette en Parcours de traduction (1995) centra su estudio en el proceso de comprensión en traducción en el par de lenguas francés/inglés, desde una interacción entre lo lingüístico y lo cognitivo (1995: 191). Para el análisis de la traducción en su relación con la comprensión, la autora llevó adelante una experiencia con 20 estudiantes universitarios de traducción que consó de cuatro pruebas: prueba de comprensión de un texto, traducción de un fragmento de ese texto, pruebas de competencia lingüística y prueba de conocimientos temáticos (1995: 111). El análisis de las producciones fue realizado semánticamente oración por oración, aplicando el modelo sentido↔texto del lingüista ruso Igor Mel'čuk, investigador de la Universidad de Montreal [ $\rightarrow$ Introducción y Capítulo II, Producción discursiva. 2.6.3.].

\subsubsection{El proceso de traducción escrita de textos pragmáticos (Jean Delisle)}

\section{Los textos pragmáticos}

Jean Delisle jugó un papel fundamental mediante el diseño de un método de enseñanza de traducción de textos pragmáticos, basado sobre la teoría interpretativa, a partir de su tesis doctoral publicada en 1984 bajo el título Analyse du discours comme méthode de traduction, parte de la cual ya hemos comentado. 
La designación textos pragmáticos ${ }^{11}$ acuñada por este autor surge de una búsqueda de un criterio amplio, simple y cómodo que incluya a los textos cuyo objetivo esencial es transmitir una información sin búsqueda estética dominante. Esta clasificación comprende a los textos conocidos bajo las denominaciones de textos especializados, textos científicos, textos técnicos, textos en lengua de especialidad, entre otras, y también a los textos en francés general, quedando excluidos los textos literarios (Delisle, 1984: 22).

En ella, el autor desarma el proceso de traducción, lo que da como resultado la individualización de tres grandes operaciones: comprensión, reformulación y análisis justificativo, dentro de las cuales, la que corresponde directamente a la producción es la segunda etapa o reformulación.

La postura interpretativa pone especial énfasis en independizarse de los signos lingüísticos puesto que la traducción consiste en decir de otra manera un concepto desverbalizado, al que se llega por diversos caminos, de los cuales sólo algunos son lingüísticos; de allí que los autores plantean ejercicios similares a los de toma de notas en interpretación consecutiva, es decir, prácticas que tiendan a discernir y delimitar las nociones clave de cada texto por traducir (Delisle y Bastin, 1997: 170). De ello se desprende que el apego al signo no garantiza fidelidad, sino que, por el contrario, refleja servilismo a las palabras.

Nuestro interés radica en la segunda etapa, la reformulación de un mensaje (restitución, reexpresión), que supone la previa extracción de su sentido entendido como la síntesis no verbal del proceso de comprensión, que se construye a partir de las significaciones de las palabras, en contexto, asociadas a los complementos cognoscitivos (Delisle y Bastin, 1997: 265).

\section{Los cuatro estadios de manejo del lenguaje}

Delisle identifica cuatro estadios de manejo del lenguaje, necesarios tanto para la reformulación como también para la comprensión: convenciones de escritura; exégesis léxica; interpretación de la carga estilística y organicidad textual [ $\rightarrow$ Capítulo II, Producción discursiva]. El primer estadio, las convenciones de escritura, remite al

\footnotetext{
${ }^{11}$ En la Introducción, ya hemos adelantado la noción de textos pragmáticos.
} 
conocimiento, en las dos lenguas de trabajo, de reglas de gramática, ortografía, cortesía, empleo de mayúsculas y minúsculas, nombres geográficos e históricos, puntuación, entre otras, todas de raíz interlingüística, es decir que en este nivel, el método contrastivo es de suma utilidad.

Sin embargo, el enfoque interpretativo no se hace cargo de la enseñanza sistemática de la lengua puesto que establece una diferencia entre curso de lengua extranjera y curso de traducción.

Como ya señalamos, la TIT desalienta los trabajos contrastivos entre original y traducción, como práctica a la traducción puesto que considera que debe trabajarse sobre estrategias que agilicen el proceso de construcción de sentido.

\subsubsection{Desde el funcionalismo}

Otra visión teórico-práctica está dada por el funcionalismo. A partir de los años '70, en la Universidad de Heidelberg, se destacan Katharina Reiss y Hans Vermeer (1996: 5, 120), quienes formulan la teoría del escopo, del griego skopos, en castellano propósito, centrando su atención en la finalidad de la traducción. La teoría del escopo tiene como meta superar las barreras culturales y comunicativas del texto de partida, privilegiando la función que debe cumplir la traducción, según el público al que está destinada.

En la misma línea, pero con trabajos aplicados a la formación de traductores, ubicamos a Christiane Nord, especialista de Didáctica de la traducción en la Universidad de Magdeburgo, a partir de los años '80. Nord diseña el modelo circular del proceso traslativo de la traducción en el que identifica distintos momentos: interpretación del encargo de traducción, análisis del texto de base, estrategia traductora, producción del texto meta. Cabe señalar que el proceso descripto se refiere a los pasos que sigue el traductor en la elaboración de una traducción, pero no plantea, deliberadamente, los procesos cognitivos que se ponen en juego. Al considerar la evaluación de traducciones, Nord parte de la base de que el error será tanto mayor cuanto mayor sea su efecto en la funcionalidad del texto meta; de este modo, la esfera de lo lingüístico será un solo aspecto que no reviste importancia en las primeras etapas de la progresión didáctica, mientras que el esfuerzo se 
focalizará en el cumplimiento de la función pragmática en la cultura meta, a través de las pautas estipuladas en el encargo de traducción.

\subsubsection{Desde enfoques comparatistas y prescriptivos}

Una década antes del nacimiento de la Escuela Superior de Intérpretes y Traductores de París (ESIT), se publica en Canadá una obra clásica teórico-práctica que se ubica en las antípodas de la perspectiva interpretativa: Stylistique comparée du français et de l'anglais de Jean-Paul Vinay y Jean Darbelnet (1958). Si bien los autores no se habían propuesto la redacción de una obra didáctica, llegaron a formular siete procedimientos de traducción que han sido aplicados y siguen siéndolo, en la formación de traductores, a pesar de las críticas formuladas por sus detractores, que giran en torno a los dos puntos siguientes: la obra se centra en la comparación de dos sistemas lingüísticos y no en la actividad traductora que se da solamente en discursos concretos; la obra no prevé que pueda haber más de una expresión correspondiente a cada unidad de traducción. Los autores establecen una división entre traducción directa y oblicua y dentro de esa división formulan los siete procedimientos, siendo procedimientos directos el préstamo (1), el calco (2), la traducción literal (3) y procedimientos oblicuos la transposición (4), la modulación (5), la equivalencia (6) y la adaptación (7).

\subsection{Procedimientos vinculados con la sintaxis}

A continuación, citamos los procedimientos que se vinculan con la sintaxis.

Dentro de los directos, el calco (2) es el procedimiento que traduce literalmente los elementos que componen el sintagma de la lengua extranjera, obteniendo un calco de expresión, que respeta la estructuras sintácticas de la lengua de llegada e introduce una nueva expresión, o bien un calco de estructura que introduce en la lengua de llegada una construcción nueva. La traducción literal (3) es el procedimiento que utiliza el traductor cuando se ocupa únicamente de resolver las servidumbres lingüísticas al realizar el pasaje de la lengua de partida a la de llegada, en su búsqueda de un texto correcto e idiomático. Vinay y Darbelnet destacan que hay abundantes ejemplos de este tipo en las traducciones de lenguas de la misma familia y especialmente de la misma cultura. 
En cuanto a los procedimientos oblicuos, todos implican transformaciones a nivel sintáctico: la transposición (4) consiste en reemplazar una parte del discurso por otra, sin cambiar el sentido del mensaje, lo que puede dar lugar a transposiciones obligatorias y facultativas; la modulación (5) es una variación en el mensaje que se justifica cuando la traducción literal o la transpuesta llegan a un enunciado gramaticalmente correcto pero que se aparta del espíritu de la lengua de llegada. La equivalencia (6) utiliza recursos estilísticos y estructurales diferentes; las equivalencias son generalmente de naturaleza sintagmática e involucran a la totalidad del mensaje, caso de las fórmulas fijas como los idiotismos, proverbios, refranes, entre otros. El último procedimiento, la adaptación (7) se aplica cuando en la lengua de llegada hay un vacío de la situación a la que se refiere el mensaje (Vinay y Darbelnet, 1958: 46-55).

Desde una perspectiva saussuriana, la segunda parte de Stylistique comparée du français et de l'anglais, bajo el título L'agencement, ordenamiento o distribución, es presentada por los autores como la actualización del léxico y se refiere a las diferencias que ponen en juego las lenguas estudiadas, al momento de construir enunciados. Con la terminología de Geroges Galichet especies o clases de palabras y categorías gramaticales asociadas a cada especie, se intenta formular tendencias que se ponen en práctica en la producción en una u otra lengua, de manera análoga al estudio clásico de estilística de Charles Bally (1951).

Otra visión opuesta a la Escuela Superior de Intérpretes y Traductores de París (ESIT) es la obra del autor inglés Peter Newmark (1987) A Textbook of Translation, traducida al español como Manual de Traducción, en 1992. En ella el autor determina los tipos de traducción según el diagrama en $\mathrm{V}^{12}$ y prescribe una serie de procedimientos sin jerarquizarlos. Revaloriza la traducción literal, si es que con ella se consigue la equivalencia referencial y pragmática con el original. La posición de Newmark surge como reacción a las teorías que toman el texto como

\footnotetext{
${ }^{12}$ Véase Newmark, Peter (1992: 69 y ss)

Énfasis en la LO

Traducción palabra por palabra

Traducción literal

Traducción fiel

Traducción semántica
}

Énfasis en la LT Adaptación Traducción libre

Traducción idiomática Traducción comunicativa 
única unidad de traducción y rechazan la traducción literal como procedimiento válido.

\subsubsection{Desde enfoques comparatistas descriptivos, no prescriptivos}

Una perspectiva íntimamente ligada con el concepto de producción en traducción según normas y centrada en la necesidad de relacionar teoría y práctica de la traducción, es la de los Estudios Descriptivos de Traducción (EDT), que surge en la Universidad de Tel-Aviv, en directa relación con la teoría del polisistema de Even-Zohar. Su máximo exponente, Gideon Toury ha escrito varias obras, entre las cuales Los estudios descriptivos de traducción y más allá. Metodología de la investigación en estudios de traducción, presenta una Introducción a la versión española, en donde leemos (2004: 19):

"Los EDT son el puente entre la teoría y la práctica, el necesario punto de partida hacia los estudios aplicados (o extensiones aplicadas), así como un viaducto de ida y vuelta entre la práctica real existente y la que los traductores producirán en el futuro."

Esta teoría considera imprescindibles los estudios comparados entre original y traducción para conocer los problemas y las soluciones, que en la realidad no se dan entre textos completos sino entre segmentos textuales y elementos lingüísticos de menor escala o niveles inferiores. (2004: 121). Por lo tanto, sólo las producciones en relación con el original, que se materializan en parejas de segmentos que reemplazan + segmentos reemplazados, demostrarán que solución y problema se determinan mutuamente (2004: 121).

\subsubsection{Investigación traductológica francés/castellano relacionada con el problema del presente trabajo en universidades argentinas}

En Argentina, dentro de los trabajos comparados, Ida Sonia Sánchez de la Universidad Nacional de Tucumán, con su tesis doctoral radicada en la Universidad de Montreal Etude de la cohésion textuelle dans la traduction de quatre textes 
philosophiques du français à l'espagnol (1994), ha desarrollado una investigación en el par de lenguas francés/español sobre la transferencia de medios cohesivos de textos en francés lengua original a traducciones al español. Para el análisis, la autora tomó como unidad de segmentación la secuencia verbal máxima (SVM) en francés y en español, es decir los segmentos compuestos por una proposición independiente, una proposición matriz con sus subordinadas o un enunciado (1994: 88). El análisis consistió en dos etapas, la primera sobre la cohesión gramatical y léxica y la segunda sobre la transferencia de los medios cohesivos entre los textos originales en francés y los traducidos al castellano. Es decir que se trata de un análisis del producto, pero retrospectivo puesto que afina el acercamiento al estudio del proceso traductor de la cohesión.

En la Universidad Nacional de La Plata, la investigación aplicada que se relaciona con la traducción especializada se inicia en 1994. A continuación, comentamos los proyectos de investigación según las temáticas, pero sin seguir un orden cronológico:

Textos especializados: comprensión y traducción por profesionales del área científico-técnica y por traductores, ${ }^{13}$ cuyo marco teórico es la Teoría Interpretativa de la Traducción. Se elaboraron diversos instrumentos con la finalidad de estudiar la comprensión y la traducción y se trabajó con 6 grupos de 10 integrantes cada uno. Tres grupos de profesionales: ingenieros hidráulicos, psicólogos y médicos traumatólogos. Tres grupos de traductores, cada uno de los cuales realizó las tareas de comprensión y traducción de una de las áreas. En esta investigación se estudia la competencia traductora de profesionales de las especializadas con conocimiento de francés y de traductores profesionales polivalentes.

Descripción de discursos científico-técnicos en español y francés: aporte a la comprensión y a la reexpresión. ${ }^{14}$ El estudio descriptivo (1998-2000) realizado en un corpus de 12 textos paralelos en francés (6) y castellano (6), es decir, textos

\footnotetext{
${ }^{13}$ Integrantes: Profesoras Alicia Alliaud, Beatriz Cagnolati, Ana María Gentile, María Inés Urrutia. Dirección: Dra. María Luisa Freyre (1994-1996).

${ }^{14}$ Integrantes: Profesoras Alicia Alliaud, Amalia Forte Mármol, María Inés Urrutia. Codirección:

Profesoras Beatriz Cagnolati, Ana María Gentile. Dirección: Dr. Miguel Ángel Montezanti (1998-2000).
} 
originales en ambas lenguas, sobre las especialidades Didáctica de las Matemáticas y Psicología, se orientó hacia un análisis textual, enunciativo y semiológico.

El análisis textual tomó las nociones de Teun van Dijk (1983), superestructura y macroestructura textuales, entendidas como estructuras globales de naturaleza abstracta obtenidas por reducción de las estructuras textuales locales, es decir de las palabras y de las frases del texto o microestructura. El estudio de la enunciación estuvo orientado por las lecturas de la escuela francesa de análisis del discurso y en especial por el análisis que Sophie Moirand (1992) realiza de los discursos especializados, a partir de tres entradas. Simultáneamente, se abordó la semiología del discurso científico-técnico siguiendo a André Pétroff (1984), cuyo análisis se basa en los conceptos desarrollados por Barthes, en cuanto a la identificación de las unidades núcleo, unidades catálisis y unidades estructurantes a través de indicios lógicos, de redundancia y de estructuración, respectivamente. En una etapa diferenciada, se efectuaron relevamientos de los recursos lingüísticos elegidos para la expresión, es decir que apuntan sólo al aspecto formal, según las lecturas de observación de Claude Bédard (1986).

Traducción científico-técnica francés-español: criterios de evaluación, ${ }^{15}$ cuyo marco teórico está dado fundamentalmente por el modelo de evaluación de traducciones por niveles de Robert Larose (1989) [ $\rightarrow$ Capítulo I, Marco teórico y Antecedentes. 1.1.2.1.]. Larose explica que la confrontación del texto original y su traducción permite inferir el conjunto de similitudes y divergencias en todos los niveles de análisis, lo que implica un constante vaivén entre la microestructura, lo textual y lo peritextual, resultando entonces que la gravedad de un error dependerá finalmente de su grado de compromiso con las dimensiones que trascienden a la microestructura.

El análisis realizado por el equipo de investigación se centró en el nivel de la microestructura y su repercusión en niveles superiores. ${ }^{16}$ Con la grilla elaborada, se

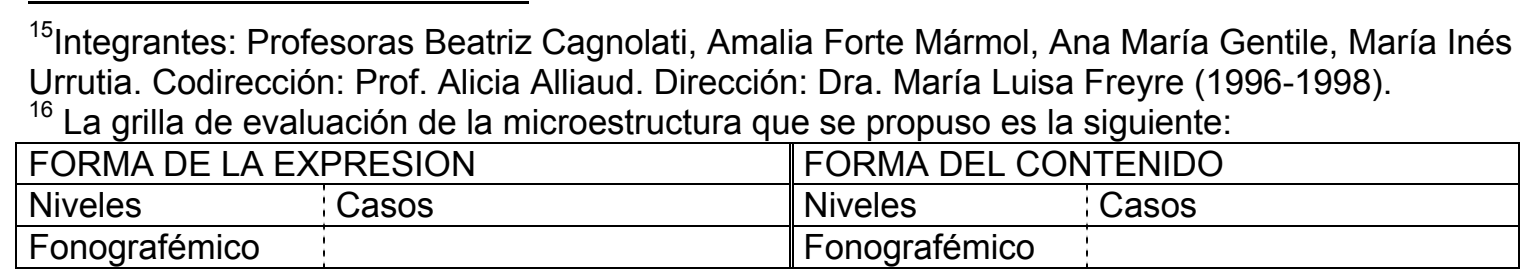


propuso un análisis basado en el espíritu crítico, la rápida detección de los desaciertos individuales, la discusión lingüística y documental argumentada, todo lo cual demuestra que la evaluación en traducción es más el resultado de la competencia que de la intuición.

Esta investigación se completó en una segunda etapa con Análisis $y$ cuantificación del error en la evaluación de traducciones especializadas. ${ }^{17}$ Ambas investigaciones indican que, desde lo cuantitativo, la mayor parte de los errores en la traducción del discurso de la Bioética, dentro de la traducción científica, se ubican en el nivel morfosintáctico, ya sea en la forma de la expresión, como en la forma del contenido, con la particularidad de que en la primera el mensaje pasa con alguna dificultad en el manejo de la lengua de llegada, mientras que en la segunda la distorsión sintagmática es tal que acarrea conflictos en el contenido que se pretende transmitir. $^{18}$

\begin{tabular}{|l|l|l|l|}
\hline Morfosintáctico & & Morfosintáctico & \\
\hline Lexicológico & Terminológico & \\
\hline
\end{tabular}

${ }^{17}$ Integrantes: Profesoras Amalia Forte Mármol, María Inés Perroud, Fabiana Inés Vieguer. Codirección: Prof. Alicia Alliaud y Ana María Gentile. Dirección: Prof. Beatriz Cagnolati (2001-2005).

${ }^{18}$ Se dio a traducir el texto de Chritian Byk (2000: 21-22). "La bioéthique: langage médiateur ou langage médiatique?, en: La Bioéthique: un langage pour mieux se comprendre?, ESKA, París. Debido a la diversidad de resultados, tomamos como primer criterio de análisis la observación de los niveles en donde todas las intervinientes cometieron errores, a saber, Fonografémico (FE) y Morfosintáctico (MSE) dentro de la FORMA DE LA EXPRESIÓN, como así también el nivel Morfosintáctico (MSC), dentro de la FORMA DEL CONTENIDO.

Esta primera observación permite indicar que la mayor complejidad se halla dentro del encadenamiento de las palabras y de las relaciones que establecen entre sí. A fin de conocer cómo las intervinientes percibieron la dificultad del texto original (TO) y de observar si ello coincidía o no con nuestra posición, se elaboró el Cuestionario de dificultades del texto traducido (TT), de reducido número de preguntas precisas pero abarcadoras, que partían de apreciaciones generales y llegaban a consideraciones particulares. La consigna general fue explicitar y justificar ampliamente cada punto de vista, con libertad de elección de la lengua de trabajo (francés o español).

Con respecto a la pregunta que apuntaba a señalar las dificultades y a explicar cómo fueron resueltas, decidimos indicar algunos procedimientos (razonamiento en voz alta, aplicación de conocimientos léxico-gramaticales, asociaciones entre ambas lenguas, u otras estrategias personales) de modo de evitar dispersión en las respuestas; simultáneamente precisamos que si optaban por señalar estrategias personales, éstas debían ser explicadas. Las respuestas que se obtuvieron fueron valiosas puesto que a partir de ellas se pudo observar la metodología de trabajo de las intervinientes.

En cuanto al léxico, coincidieron en que hubo poca hermeticidad terminológica, dado que se sentían familiarizadas por trabajos previos con textos de la especialidad. Manifestaron, en cambio, que la dificultad léxica se centró en la búsqueda de correspondientes de ciertas palabras de uso general.

Con respecto a la sintaxis, la mayoría de las participantes resaltó su complejidad (sujeto de la proposición subordinada demasiado extenso en relación con el predicado, lo que obstaculiza una comprensión inmediata, resuelto en algunos casos mediante reordenamiento sintagmático; inicio de párrafo con voz pasiva que complejiza el desarrollo de la frase, resuelto mediante voz activa con las modificaciones necesarias). 


\title{
1.2.5. A modo de conclusión
}

\author{
En la dialéctica teoría-práctica, creemos que la producción discursiva en \\ traducción está atravesada por el concepto de interferencia en traducción, lo cual \\ nos previene sobre la aparición de anomalías sintáctico-discursivas tanto en \\ traducciones de estudiantes avanzados como en traducciones publicadas, cuyo \\ grado de repercusión estará relacionado con el nivel afectado, desde el \\ microestructural hasta el peritextual, y con la posibilidad de que en los casos que se \\ analizan, tales anomalías tengan consecuencias pragmáticas y culturales. ${ }^{19,20}$
}

También se indagó sobre un aspecto que suele parecer menor: la puntuación. En general, consideraron que la misma acarreó ciertos inconvenientes y señalaron que efectuaron cambios en el momento de traducir. Algunas de las intervinientes corrigieron incluso la puntuación del TO, con la finalidad de lograr mejor comprensión, aunque tal recurso no siempre dio buen resultado.

${ }_{19}$ El proyecto Análisis y cuantificación del error en la evaluación de traducciones especializadas, presenta el texto de Neumología (Marguet, C. et alii « Les détresses respiratoires dans les services d'accueil et d'urgences pédiatriques. Épidémiologie et critères d'évaluation », en: Arch. Pédiatr.2000:7 Suppl. 1 : 4-9 @ 2000 Éditions scientifiques et médicales Elsevier SAS, pp 5s-6s.), se siguió la misma metodología de análisis de la explicada en la nota anterior, pero con resultados muy diferentes. Las intervinientes coincidieron en señalar que si bien el texto ofrece serias dificultades de orden terminológico, el mayor grado de complejidad lo encontraron en la imposibilidad de acceder a una comprensión total de lo expresado, si sólo se limitaban a la búsqueda de información documental (enciclopedias, bancos de datos terminológicos, textos digitalizados, etc.); es decir la densidad de conocimientos previos para acceder al texto es tal que en el momento de tomar decisiones para traducir, sintieron inseguridad ante la diversidad de posibilidades aportadas por la documentación a que se hace referencia, lo cual indicó la necesaria consulta al especialista del área de conocimiento científico; de allí que hubo que establecer criterios de aceptabilidad de las formas léxicas en particular en los productos lexicográficos. Siguiendo lo establecido por traductólogos y terminólogos, la consulta a fuentes de documentación va más allá de los diccionarios, llegando incluso a la propuesta personal del traductor según la dinámica de la traducción. De este modo, en el plano de la expresión pudimos comprobar que existen formas preferidas a partir de la búsqueda en línea de fuentes confiables, es decir organismos reconocidos por la comunidad de especialistas y preferentemente académicas. A modo de ejemplo, la sigla DEP (Débit expiratoire de pointe) puede restituirse como FEM (Flujo espiratorio máximo) o FEP (Flujo espiratorio pico), sin embargo la primera (FEM) presenta mayor frecuencia (179 sitios) que la segunda (74 sitios).

20 "Decir que la lengua es un sistema semiótico equivale a decir que, siendo a la vez físico, biológico y social, se caracteriza por una cuarta dimensión: 'el significado'. Además, es un sistema semiótico de segundo orden, porque la proyección de un contenido en una expresión va mediatizada por la gramática, o sea que el sentido resulta ser construido. El término 'constructo' sirve para hacer referencia a ese fenómeno. Es preferible al término 'construcción', dada la doble ambigüedad de este: (a) construcción como proceso o como resultado, (b) objeto de estudio en sintaxis. Nicole Delbecque (1996: 98, nota 5). 



\section{CAPÍTULO II}

\section{PRODUCCIÓN DISCURSIVA}

"La cuestión que plantea el análisis de la lengua, a propósito de un hecho cualquiera de discurso, es siempre éste: ¿según qué reglas ha sido construido tal enunciado y, por consiguiente, según qué reglas podrían construirse otros enunciados semejantes? La descripción de los acontecimientos del discurso plantea otra cuestión muy distinta: ¿cómo es que ha aparecido tal enunciado y ningún otro en su lugar?"

Michel Foucault (2002: 44).

\subsection{En torno al concepto de producción discursiva}

Hemos señalado [ $\rightarrow$ Introducción] que las investigaciones sobre la producción discursiva en traducción tienen un grado de desarrollo discreto en comparación con la profusión de estudios que existen sobre la comprensión, ${ }^{1}$ proceso que sería anterior a la producción. Con respecto a los procesos de comprensión en traducción, Jeanne Dancette (1995: 108) señala la dificultad metodológica para llegar a su verificación, puesto que se trata de procesos que no pueden observarse directamente, sino a través de indicios textuales, ya sea presencias, ausencias o variaciones, que suponemos que son la manifestación de la comprensión o de la nocomprensión.

Por su parte, los estudios generales del lenguaje presentan una situación análoga a la de la Traductología, en cuanto al desarrollo de los estudios referentes a los procesos de comprensión y de producción. Adriana Silvestri (2002) ${ }^{2}$ sostiene que de las tres fases del tratamiento de un texto escrito -entrada o input, memorización y

\footnotetext{
${ }^{1}$ Véase Dancette, Jeanne (1995), cap. 2.

${ }^{2}$ Silvestri, Adriana (2000). Su estudio sobre adquisición discursivo-cognitiva se refiere a producción a partir de fuente o reformulación, intralingüística, en estudiantes de la escuela secundaria, es decir, sujetos no expertos.
} 
salida o output- la psicolingüística cognitiva se ha abocado al estudio de los procesos de comprensión-memorización, mientras que la fase de salida ha sido estudiada como verificación y evaluación de las dos primeras.

Danièle Dubois y Annik Weil-Barais (1999: 278, 279) explican que la diferencia de los avances en el tratamiento de estos temas, se debe a un hecho puramente metodológico, puesto que es muy difícil medir la intención o el contenido de lo que la persona desea expresar. En cambio, en la comprensión, si bien la medición también es compleja, al menos el investigador puede determinar variables independientes como entrada o input, de cuyo procesamiento se esperan ciertos efectos.

Estas dos autoras identifican al menos dos componentes específicos de la producción: la planificación y la toma de decisiones.

La planificación se realiza en los diferentes niveles del lenguaje (discurso, enunciado, sintagma, entonación, etc.) y requiere tener en cuenta, entre otras consideraciones, los objetivos de la comunicación, las características del interlocutor, qué se quiere decir, en qué orden se presentarán las informaciones.

En relación con la planificación que se haya realizado y según el género discursivo que se esté construyendo, el enunciador tomará las decisiones específicas de naturaleza léxica, sintáctica y pragmática.

La elección léxica es función del nivel de lengua que se ha decidido utilizar, del campo semántico en el que se inscribe la comunicación, del uso de lo implícito y explícito, entre otros factores. La elección sintáctica puede vincularse con la voluntad de priorizar una información respecto de otra y la elección pragmática toma en cuenta, entre otros elementos, los actos de habla, las modalidades del discurso que éstos adoptan, la articulación de los elementos del discurso cuyos efectos inciden en la cohesión y la coherencia. 
Estudios cognitivos sobre producción mediada por el lenguaje indican que este proceso depende del grado de experiencia del escritor ${ }^{3,4}$ que pone en juego el conocimiento lingüístico manifestado al activar la memoria de largo plazo, además de elementos de orden sociocultural, cognitivo, emocional. El aporte de los conceptos de memoria de largo plazo y de memoria de trabajo, que definimos más adelante, es esencial en la génesis del discurso, pues el enunciador apela a un ya dicho a un discurso previo sin cuerpo, semisilencioso, que al manifestarse lingüísticamente, se transforma en un enunciado único (Foucault, 2002: 40, 44).

A continuación, proponemos una clasificación de los tipos de producción con la finalidad de discriminar los que se vinculan con la traducción.

\subsection{Criterios de clasificación de la producción discursiva}

Para la siguiente clasificación de producción discursiva, tomamos los siguientes criterios: transmisión oral / escrita; expresión libre / desde fuente (total o parcial) y código lingüístico utilizado.

Dentro del primer criterio, Dubois y Weil-Barais (1999: 280) señalan que los estudios sobre producción escrita son más recientes que los de producción oral.

En cuanto al segundo criterio, expresión libre/desde fuente, éste establece si el enunciador produce sin necesidad de respetar el contenido de un ya dicho o, si, por el contrario, reformula el contenido de una fuente, de modo que en la fase de salida, la producción conserve su macroestructura o la totalidad de la fuente, lo que implica su comprensión.

El tercer criterio puede leerse desde dos aproximaciones: en el caso de la producción libre, el enunciador se expresa intralingüísticamente si utiliza su propio código o lengua materna, en cambio producirá interligüísticamente, si recurre a un segundo código lingüístico; es el caso de los escritores, pero también de los

\footnotetext{
${ }^{3}$ Linda Flower y John Hayes sostienen que la composición difiere entre escritores expertos y novatos. Por esa misma razón, Carl Bereiter y Marlene Scardamalia, consideran que no puede haber un único modelo de producción. Véase Marinkovich, Juana (2002: 51-52).

${ }^{4}$ En la nota 8, Amparo Hurtado Albir establece una relación entre el saber experto y la automaticidad.
} 
científicos que publican directamente en una segunda lengua. ${ }^{5} \mathrm{Si}$ nos referimos a la producción desde fuente, ésta será intralingüística si lo comprendido se expresa en el mismo código de la fuente e interlingüística si se recurre a un código lingüístico distinto al de la fuente.

El cruce de los tres criterios da lugar a las combinaciones que detallamos a continuación.

\subsubsection{Tipos de producción}

-producción oral libre intralingüística;

-producción oral desde fuente intralingüística;

-producción oral libre interlingüística;

-producción oral desde fuente e interlingüística, que en el ámbito de la Traductología se denomina interpretación;

-producción escrita libre intralingüística;

-producción escrita desde fuente intralingüística;

-producción escrita libre interlingüística;

-producción escrita desde fuente e interlingüística, que en el ámbito de la Traductología constituye una de las fases del proceso de traducción y que en esta investigación denominamos producción discursiva en traducción. ${ }^{6}$

A modo de ordenamiento de las categorías anteriores, proponemos el siguiente gráfico:

\footnotetext{
${ }^{5}$ A modo de ejemplo, el novelista y dramaturgo irlandés Samuel Beckett ha escrito la mayor parte de sus obras en francés. O bien el médico y neurocientífico argentino Iván Izquierdo que ha escrito en portugués varias obras, entre las cuales $A$ arte de esquecer, traducida luego al castellano bajo el título El arte de olvidar.

${ }^{6}$ En sentido análogo al de producción discursiva en traducción, son familiares en la literatura traductológica las designaciones reformulación, reexpresión. [ $\rightarrow$ Capítulo V, Metodología. 5.6.10.]
} 
FIGURA 4. Tipos de producción discursiva

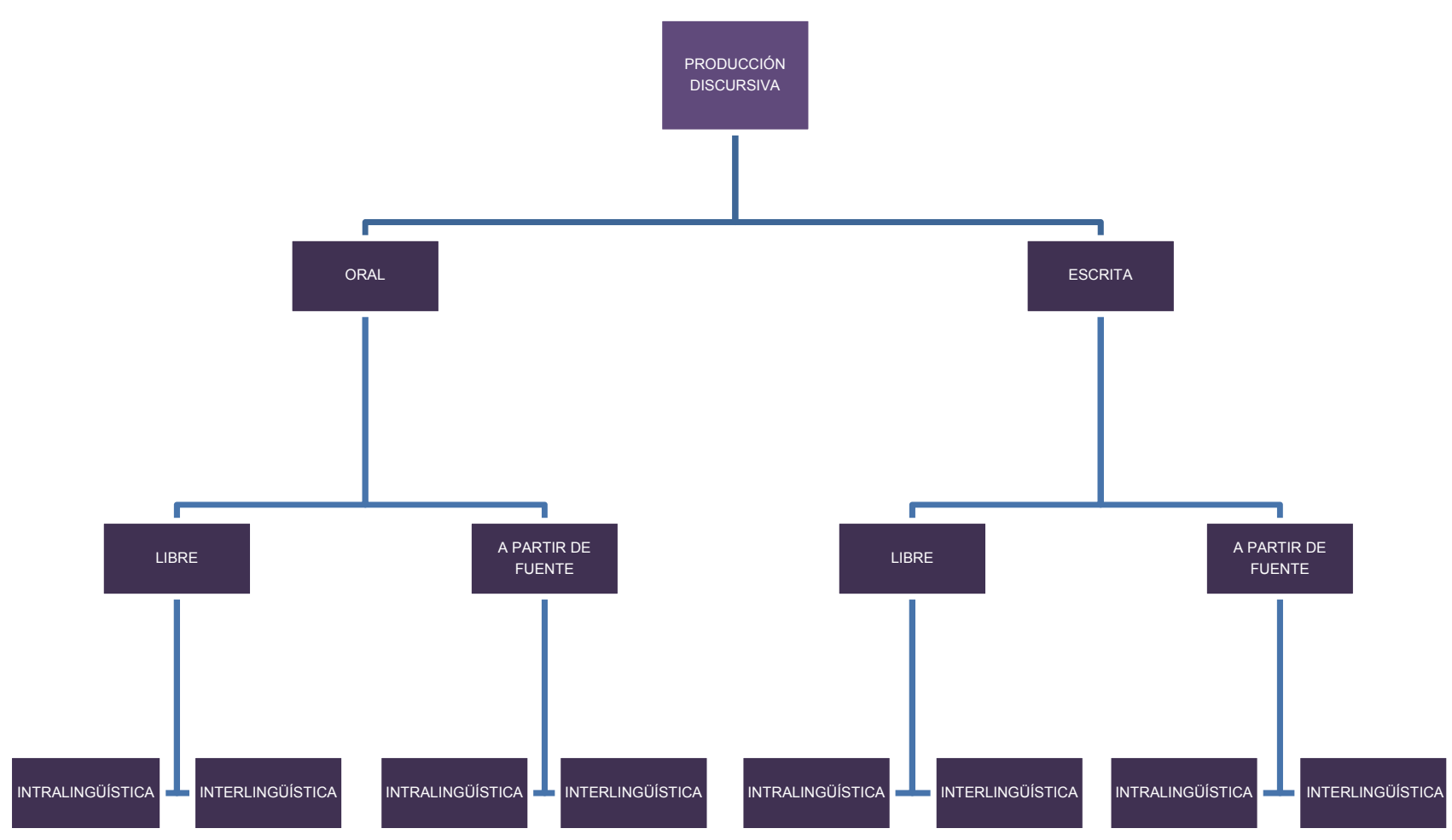

Dentro de la rama correspondiente a la producción discursiva escrita a partir de fuente, diferenciamos la intralingüística de la interlingüística.

Nuestro estudio traductológico se ubica en la producción discursiva escrita a partir de fuente y en su relación con el resultado que es interlingüístico e intercultural.

Las traducciones resultantes de la producción discursiva pueden ser de distintos tipos, como distinguimos a continuación. 


\subsection{Tipos de traducciones según Daniel Gouadec ${ }^{7}$}

Daniel Gouadec (1989: 21-30) ha propuesto una tipología de traducciones, basada en la función que se le atribuye al producto final. El autor identifica seis funciones, a saber:

Función 1: informar sobre los contenidos de un documento, mediante la traducción descriptiva aportada por las palabras clave del texto original, en francés traduction signalétique;

Función 2: informar con precisión sobre los contenidos del documento y sobre su ubicación, a través de la traducción analítica, en francés traduction analytique;

Función 3: transmitir solamente las informaciones cuya manifestación es la traducción selectiva mediante discriminación de datos, en francés traduction sélective par tri des données;

Función 4: transferir informaciones simplificadas, utilizando la traducción abreviada lineal sin discriminación de datos y la traducción sintética, en francés traduction abrégée linéaire, traduction synthétique;

Función 5: transferir informaciones en forma integral, mediante la traducción grabada oral, traduction enregistrée, la traducción automática escrita, traduction automatique y, en especial la traducción absoluta, traduction absolue;

Función 6: adaptar la traducción de cada sección del documento según condiciones específicas, mediante la traducción con geometría variable, en francés traduction à géométrie variable.

Dentro de la función 5 , nos detendremos en la definición del término traducción automática ${ }^{8}$ dada por Gouadec, especialmente en la segunda acepción:

\footnotetext{
7 Existen distintas tipologías de traducciones, según el criterio clasificatorio que se considere. A modo de ejemplo, desde el enfoque lingüístico, John Catford toma la traducción en distintos planos: sintagmático, niveles del lenguaje y subdivisiones del lenguaje y dentro de cada uno establece tipos: traducción integral versus full translation y traducción parcial o partial translation, traducción total o total translation versus traducción restrictiva o restrictive translation y traducción literal versus traducción libre. Amparo Hurtado Albir trata en detalle la clasificación de las traducciones, en la primera parte de su libro (2004: 43-95) según diversos criterios y establece específicamente los Tipos de traducción (58: 68) según las características de los textos por traducir, dividiéndolos en especializados, no especializados.
} 
«Par traduction automatique, nous entendons ' traduction effectuée intégralement par un ou plusieurs automates'. Le terme recouvre la production des machines à traduire et la production immédiate, spontanée, non préparée, des traducteurs agissant, en l'occurrence, en 'automates'. Sous l'une ou l'autre de ces variantes, la traduction ' automatique ' est utilisable lorsqu'il s'agit de communiquer des informations de manière accélérée la réduction des délais de traduction résultant d'une réduction des contraintes de 'finition ' à l'écrit. » (Gouadec, 1989: 27).

Entendemos por traducción automática a la "traducción efectuada integralmente por uno o varios autómatas". El término cubre tanto la producción de las máquinas de traducción como la producción inmediata, espontánea, no preparada, de los traductores que, en ese caso, actúan como "autómatas". En cualquiera de sus variantes, la traducción "automática" se utiliza cuando las informaciones deben comunicarse de manera acelerada y la reducción de los plazos de traducción son el resultado de la reducción de las exigencias de "terminación" de la redacción final.

El primer concepto, que no abordaremos en esta investigación, vincula la traducción automática con el uso de equipos y programas informáticos cuyos avances van de la mano del desarrollo de las industrias de la lengua.

En cambio, el segundo concepto metafórico de traducción automática involucra al traductor que actúa según una variable de tiempo reducida, produciendo en versión escrita con bajo control redaccional, lo que puede ser considerado como una variante de la traducción grabada oral.

Nuestro análisis toma como insumo textos traducidos, pragmáticos, que corresponden a la función 5 , es decir que transmiten de manera integral datos, informaciones, contenidos y formas del documento original. La traducción absoluta ${ }^{9}$ implica que se respeten las características y normas del documento fuente, pero atendiendo a las exigencias que se relacionan con eventuales adaptaciones

\footnotetext{
${ }^{8}$ Amparo Hurtado Albir relaciona el adjetivo automático con el saber experto (2004: 284, 380, 381), basándose en los estudios de Dreyfus y Dreyfus (1986) y Chesterman (1997). La adquisición de un conocimiento pasa por las etapas de novato, aprendiz avanzado, apto, perito y experto. Se llega a esta última categoría cuando en la acción realizada la conciencia se manifiesta en una reflexión crítica acerca de las propias intuiciones, siendo el conocimiento experto automático o arracional. En el proceso para llegar a él se pasa del reconocimiento atomístico al holístico, de lo consciente a lo inconsciente, de las decisiones analíticas a las intuitivas, de la reflexión calculadora a la reflexión crítica, de lo objetivo a la implicación. Marianne Lederer (2003) utiliza traducción automática en un sentido análogo al asignado por Gouadec.

9 La designación traducción absoluta de Gouadec no está relacionada con la full translation de Catford, puesto que los criterios clasificatorios son diferentes.
} 
culturales del documento final, con la lógica propia del campo del saber dentro del que se inscribe el texto fuente, con la calidad lingüística, la coherencia terminológica y las condiciones impuestas por quien solicita la traducción (Gouadec, 1989: 28).

\subsection{La producción discursiva en traducción absoluta de textos pragmáticos}

De manera análoga a la producción discursiva intralingüística, la producción discursiva de traducciones (interligüístico-cultural), comprende planificación y toma de decisiones.

\subsubsection{Planificación}

La planificación en traducción encuentra explicaciones detalladas en el concepto encargo de traducción de Christiane Nord, funcionalista, dentro de su enfoque didáctico y circular del proceso de traducción; el encargo de traducción informa, implícita o explícitamente, sobre una serie de características (intención comunicativa del solicitante de la traducción, perfil del destinatario, tiempo y lugar de recepción del texto traducido, soporte o medio, ocasión en la que se utilizará el texto traducido) que determinan la función que cumplirá el texto traducido en la cultura meta. El traductor debe interpretar el encargo de traducción pues éste es la herramienta que lo guiará en la toma de decisiones durante las fases del proceso traslativo.

Desde una visión ligada al panorama profesional del traductor, Daniel Gouadec (1989: 60-62) explica el concepto cahier des charges, en castellano pliego de condiciones, como la enumeración y descripción pormenorizada de las obligaciones entre el solicitante y el traductor para planificar una traducción, que van desde la entrega del texto a traducir y el tipo de traducción, hasta los plazos de entrega del texto traducido y la remuneración, pasando por la modalidad de tratamiento de la terminología, la revisión y el control de calidad.

Ambas nociones, encargo de traducción y pliego de condiciones definen la planificación porque dan cuenta de las características fundamentales de la traducción, entre las cuales citamos la finalidad y la función de la traducción, la 
identificación del público, el soporte de presentación, el género discursivo, los plazos de entrega, la revisión y la calidad de la traducción, entre otras.

\subsubsection{Toma de decisiones}

Christine Durieux (1987: 42) define la traducción como una permanente sucesión de toma de decisiones, en base a la dinámica del discurso, el contexto general, la situación y los conocimientos previos del traductor o bagaje cognitivo.

Análogamente a la producción discursiva intralingüística a partir de fuente, la traducción absoluta implica decisiones léxicas, sintácticas y pragmáticas.

Sin embargo, existen al menos dos especificidades propias en esta última: por un lado, las decisiones que toma el traductor de una traducción absoluta sin cambio de género están guiadas por el principio no dejar nada sin traducir (Toury, 2004: 124, 137), que de ahora en adelante denominaremos traducir toda la información, es decir la búsqueda de equivalencias; por el otro, ellas estarán condicionadas por lo acordado en el encargo de traducción o pliego de condiciones.

El concepto de equivalencia, debatido y polisémico, atraviesa toda la literatura traductológica, ${ }^{10}$ pero no nos proponemos discutirlo aquí sino más bien utilizarlo operativamente como la forma acertada que ha elegido el traductor para producir en la lengua-cultura de llegada los enunciados que se han expresado en la lengua-cultura de partida. ${ }^{11}$

En definitiva, la toma de decisiones léxicas, sintácticas y pragmáticas está doblemente condicionada: por la búsqueda de equivalencias para la totalidad de las informaciones contenidas en la fuente o texto original y por la interpretación del encargo de traducción o la aplicación del pliego de condiciones.

\footnotetext{
${ }^{10}$ Sin pretender historiar su evolución, solamente recordamos algunos hitos. En primer lugar, el cambio epistemológico en la concepción equivalencista a partir de Eugène Nida, con la introducción del concepto de equivalencia dinámica; en segundo lugar, el cuestionamiento etimológico del término equivalencia y la propuesta de equifuncionalidad (Chrisitane Nord) y por último, el rol de las normas socio-históricas al analizar la equivalencia translémica (Rosa Rabadán, 1991).

${ }^{11}$ Jeanne Dancette $(1995: 59,80,81,191)$ subraya que la equivalencia tiene longitud variable, en línea con su concepto de unidad de traducción, que no responde a criterios externos de delimitación sino que proviene de la manera como el traductor procesa las palabras y los grupos de palabras. Por otra parte, el hecho de que muchas veces no existen palabras o expresiones que cubran exactamente la misma noción en las dos lenguas puestas en juego en la traducción, incide en el resultado respecto del sentido.
} 


\subsection{Memoria}

De manera análoga a la producción discursiva general, la experiencia del traductor que va desarrollando reconocimiento holístico y reflexión crítica (Hurtado Albir, 2004) gravita en el proceso de la producción discursiva en traducción en los que la memoria ocupa un lugar central.

Si bien la memoria es un único mecanismo, por razones de análisis se la ha dividido en memoria de corto plazo (MCP) y memoria de largo plazo (MLP). La MCP es un mecanismo de recepción de información y un sistema de control activo que coordina y organiza flujos de información generados por los estímulos y por el propio sistema cognitivo. Esta función es responsable de la adquisición de nueva información. Por su parte, la MLP también llamada memoria semántica, realiza la recuperación de la información en diferentes niveles de procesamiento.

Desde la perspectiva de un pensamiento complejo la MLP es fundamental. Distinguimos tres tipos de MLP: la memoria semántica, que contiene el conocimiento general sin ubicación en el espacio y en el tiempo, es como una gran enciclopedia en nuestra mente; la memoria episódica que contiene recuerdos específicos organizados en orden temporal, esto es información sobre lo que uno ha hecho la última semana o sobre el recuerdo de un viaje de placer personal; la memoria procesual, que contiene el conocimiento sobre cómo hacer las cosas, por ejemplo andar en bicicleta, tocar el piano o resolver silogismos lógicos. ${ }^{12}$

Un concepto relacionado con la MCP y la MLP es la memoria de trabajo cuya función es controlar que se mantenga la permanencia y la coherencia tanto de los objetivos perseguidos como de las estrategias puestas en juego (Tiberghien 1997: $60)$.

En Traductología, las corrientes cognitivas son las que estudian el rol de la memoria en la producción discursiva en traducción. Por ejemplo, para la Teoría Interpretativa de la Traducción la memoria como mecanismo básico que permite la

\footnotetext{
12 Sonia Sánchez (2005). Curso Traductología y Cognición; Maestría en Traductología en la Universidad de Córdoba.
} 
comprensión es una preocupación fundamental que ha sido estudiada a partir de los aportes de Jacques Barbizet, especialista en neurología y memoria que explica su funcionamiento a través de la coexistencia de una actividad no verbal, otra verbal o del lenguaje (langagière) y de la noción de metacircuitos; su modelo presenta lo que posteriores cognitivistas tratarán de hacer mediante modelos informáticos. Se distinguen la memoria inmediata o formal -que en el adulto permite conservar entre 7 y 8 palabras durante 2 o 3 segundos- y la memoria cognitiva que contiene el conjunto de los conocimientos del sujeto; dentro de ella, se identifica una memoria cognitiva de mediano plazo que retiene las unidades de sentido desverbalizadas como componentes del contexto cognitivo y una memoria cognitiva de largo plazo que retiene el conjunto de los conocimientos adquiridos por el sujeto. [ $\rightarrow$ Capítulo II, Producción discursiva. 2.6.1.2., 2.6.4.].

\subsubsection{Memoria y esquemas internos}

Los primeros estudios experimentales sobre la memoria de Alfred Binet y Victor Henri (1895) partieron del análisis de casos clínicos de distorsiones de la memoria que, indirectamente, aportaron datos para conocer su funcionamiento. Serge Nicolas (1993: 422) enumera algunos de esos resultados sobre la relación entre la memoria y los textos, que a continuación reformulamos y traducimos: la memoria de los textos es superior a la de las palabras aisladas; la información estructural de superficie se pierde más rápido que el significado de las palabras, es decir que la forma de las palabras es evanescente frente a su significado, de allí que, al recordar textos, naturalmente se recurre a sinónimos; el recuerdo es selectivo puesto que se activan mejor las unidades que juegan un papel esencial, por lo tanto el recuerdo es considerado como un proceso de abstracción; el conocimiento del mundo interactúa con el proceso de recuerdo, lo que permite afirmar que el sujeto que recuerda un texto intenta hacer una reconstrucción que sea coherente y familiar.

Además, la memoria juega un papel central en la activación automática de recuperación de los esquemas internos o estructuras planificadas, conocidos como frame, script, scénario, marco, entre otros, aunque las consecuencias para la comprensión de textos puedan ser tanto positivas como negativas: positivas porque 
la activación del esquema puede ayudar a memorizar un texto e inferir informaciones no explícitas en él; negativas, porque las inferencias pueden no ser las esperadas, lo que produce confusión en el recuerdo y en la comprensión.

\subsubsection{Memoria y sintaxis}

Dubois y Weil-Barais (1999: 281) refieren que en la planificación de la producción oral la programación sintáctica no estaría sujeta a estados de conciencia, sino que sería automática, ${ }^{13}$ es decir que la memoria recuperaría automáticamente los esquemas internos ligados a la competencia lingüístico-discursiva.

Ahora bien, si se considera la variable tiempo en la producción escrita y en la producción oral, en principio, es mayor en la primera, lo que traerá consecuencias ligadas, en parte, al hecho de que el enunciador tiene la posibilidad de reflexionar y tomar decisiones sobre reordenamientos fundamentados en su competencia lingüístico-discursiva, es decir que habría un descenso del grado de decisiones automáticas o no sujetas a estados conscientes.

\subsubsection{Memoria y producción discursiva en traducción de textos pragmáticos}

Una vez comprendido el texto original y realizadas las búsquedas documentales y terminológicas que correspondan, los dos elementos fundamentales sobre los que trabaja el traductor al realizar su producción son el material lingüístico y el molde formal, términos utilizados por Rosa Rabadán al establecer los componentes principales que forman parte de cualquier texto (1991: 196).

\subsubsection{Esquemas globales}

En líneas generales, y aplicando a la producción discursiva de textos pragmáticos lo que señalamos en producción de textos en general, al realizar su planificación nos planteamos: elegir las informaciones que desean transmitirse; elegir un género textual según el público al que van dirigidas las informaciones y la intención del autor; disponer las informaciones según la superestructura del género

${ }^{13}$ Estudios sobre la distribución de las pausas en el discurso espontáneo llevados a cabo por Frieda Goldman-Eisler concluyen, en cambio, que la programación del contenido semántico incide en la duración de las pausas. 
textual elegido; seleccionar las ocurrencias lingüístico-discursivas que correspondan al género textual.

La producción discursiva en traducción supone que el traductor se ubique como mediador entre el autor y el destinatario directo, por lo tanto, no es él quien elige el género textual ni tampoco las informaciones por transmitir, a menos que el contrato de traducción especifique fehacientemente cambios de género o un tipo de traducción especial [ $\rightarrow$ Capítulo II, Producción discursiva. 2.3.].

En el caso de traducciones absolutas sin cambio de género textual, el traductor tendrá que recuperar los esquemas globales en la lengua-cultura de llegada en relación con las características superestructurales propias del género del texto original y, de su comparación, establecer las diferencias puesto que ellas aportan datos indispensables para la construcción del discurso en lengua meta.

Es decir que al planificar la producción, en primer lugar habrá que considerar si ambas lenguas-cultura comparten los esquemas textuales, o si por el contrario, existen diferencias que habrá que respetar para que la traducción gane aceptabilidad en el polo meta, en términos de Gideon Toury.

\subsubsection{Expresión lingüístico-discursiva}

En cuanto a la expresión lingüístico-discursiva, como ya hemos señalado, el hecho de que en una traducción aparezcan formas lingüísticas y estructuras no frecuentes en la lengua-cultura meta puede estar vinculado a que el tratamiento de la información del texto original no haya sido holístico sino de abajo a arriba, lo que supone una producción paso a paso, desde los niveles bajos o microestructurales, que no ha llegado a activar las formas lingüístico-discursivas normales de la lengua-cultura de llegada con el consiguiente descenso en la aceptabilidad (Toury, 2004: 269). ${ }^{14}$

Como hemos anunciado en la Introducción, nuestro análisis está orientado a la expresión lingüístico-discursiva.

$\overline{{ }^{14}[\rightarrow \text { Capítulo II, Producción discursiva. 2.8.] }}$ 


\subsection{Comprensión y producción discursiva en traducción}

«...en production, le traducteur doit trouver des termes et une phraséologie adaptés et les assembler pour construire un texte, alors qu'en compréhension, il doit interpréter les choix de l'auteur » (Gile, 2005: 172).

...en producción, el traductor debe encontrar los términos y la fraseología adaptados y ensamblarlos para construir un texto, mientras que en comprensión, el traductor debe interpretar las elecciones del autor.

La comprensión de un texto en lengua original y su reexpresión en lengua meta son las dos fases del proceso de traducción en las que el traductor desarrolla actividades analíticas y analógicas recurriendo a sus conocimientos individuales, a su capacidad de búsqueda terminológica y documental, con la finalidad de decidir al punto que, como ya dijimos, Christine Durieux define a la traducción en términos de toma de decisiones.

Los enfoques teóricos que se han propuesto el estudio de la traducción, presentan algunos rasgos comunes de tratamiento y otros diferenciados, en especial en la metodología utilizada.

\subsubsection{Fases de la traducción según la Teoría Interpretativa de la Traducción (TIT)}

La Teoría Interpretativa de la Traducción (TIT) ha sido pionera en intentar una explicación cognitiva de la traducción, tomando como objeto de estudio el proceso de interpretación consecutiva y simultánea, que hemos clasificado como producción oral desde fuente e interlingüística [ $\rightarrow$ Figura 4. Tipos de producción discursiva]. Dánica Seleskovitch y Marianne Lederer, a partir de los años '60, identifican tres fases: comprensión, desverbalización y reformulación.

\subsubsection{Primera fase o comprensión}

En la primera fase o comprensión el intérprete de conferencia va apropiándose del sentido desverbalizado, que se desprende de los enunciados en situación de interlocución, es decir del producto de la fusión de las significaciones lingüísticas de las palabras y de las oraciones que lo componen con los elementos extralingüísticos o complementos cognitivos pertinentes. La comprensión, como 
proceso interpretativo de captación del sentido, comprende cinco aspectos esenciales: la importancia de los conocimientos extralingüísticos, el carácter interpretativo de todo proceso de comprensión, la especificidad de la fase de comprensión en el proceso traductor, el rol de lo implícito, de lo explícito ${ }^{15}$ y en especial el rol de la memoria, como hemos visto más arriba. Es importante también la diferencia entre comprensión de un destinatario o receptor normal y de un intérprete o traductor, que debe lograr la totalidad del sentido del querer decir del emisor del texto original (Hurtado Albir, 2004: 323). ${ }^{16}$

\subsubsection{Segunda fase o desverbalización}

Como sustento de la desverbalización, la Teoría Interpretativa de la Traducción toma los estudios de la psicolingüista Tatiana Slama-Cazacu que sostienen que las palabras pierden importancia en relación con el sentido del discurso, como así también los enfoques de Jean Piaget, para quien el pensamiento precede al lenguaje (Lederer, 2005: 102), y de Bernard Pottier, que afirma que quien traduce recorre un universo conceptual no-verbal (niveau noémique), dentro del cual identifica dos partes: la primera parte del trayecto en L1 semasiológica y la segunda en L2, onomasiológica (Lederer, 2005: 105). El concepto desverbalización ha sido criticado por los lingüistas, psicólogos y filósofos que consideran que el pensamiento está unido a la lengua y observamos que Lederer propone la designación disociación de idiomas, como sintagma terminológico de aceptación generalizada (Lederer, 2005: 133), que quizás reemplazaría al primero.

La Teoría Interpretativa de la Traducción, cuya primera designación fue École du sens, en castellano Escuela del sentido, sobre la base de los aportes ya comentados de Jacques Barbizet, explica que el sentido es el recuerdo cognitivo, que estaría constituido por una organización neuronal (metacircuitos). Los estudios de Marianne Lederer sobre presencia mnésica, exposición mnésica, remanencia

\footnotetext{
${ }^{15}$ Dentro de lo implícito y lo explícito, la autora se refiere al efecto de sinécdoque, como característica de las lenguas pero también del discurso; es en el discurso elíptico, en donde se establecen movimientos de expansión y condensación, de compromiso entre lo explícito y lo implícito (Hurtado Albir, 2005: 163-188).

${ }^{16}$ Entendemos que la función del traductor es interpretar desde su propia individualidad lo que dice el texto de partida para volcarlo en otra lengua-cultura, según ciertas condiciones que fluctúan y que dan lugar a los tipos de traducción. [ $\rightarrow$ Capítulo I, Marco Teórico y Antecedentes. 1.1.1.].
} 
mnésica demuestran que el sentido es dinámico pues se construye de modo no lineal durante el discurso gracias a la comprensión. Es decir que en la terminología de esta teoría, cognitivo se opone a verbal y hace referencia a la huella mnésica presente en la memoria después de la desverbalización o la disociación entre la forma lingüística y el sentido (Hurtado Albir, 2004: 326).

\subsubsection{Tercera fase o reformulación}

De lo dicho se desprende que los cambios de paradigma que introduce la Teoría Interpretativa de la Traducción respecto de la tercera fase radican en que la reformulación o reexpresión es producto de una idea o sentido y no de una forma lingüística, y supone un movimiento no lineal de ese nivel no verbal (fase de desverbalización) hacia la verbalización en la lengua meta. ${ }^{17} \mathrm{Al}$ igual que en la fase de comprensión, en la reexpresión se moviliza todo el aparato cognitivo en el que participan los saberes lingüístico y extralingüísitco. El concepto de expresión de lo preverbal a lo verbal, parte de un modelo en el que el pensamiento humano es una actividad espontánea del cerebro e independiente de la lengua, y se lo vincula estrechamente con las estrategias de la comunicación unilingüe (Ladmiral, 2005: 69, Hurtado Albir, 2005: 174).

En la Introducción señalamos que esta teoría reconoce que la tercera fase o reformulación no ha sido aún demasiado desarrollada y propone la puesta en juego de tres elementos a la hora de reformular: correspondencia, equivalencia y sinécdoque (Lederer, 2003: 20), según los últimos acuerdos terminológicos, pues lo que hasta 1986 se denominaba equivalencia de la lengua y equivalencia textual, a partir de entonces pasó a denominarse correspondencia en el plano de la lengua y equivalencia en plano del discurso. El tercer término, sinécdoque, proviene de la retórica y remite a la idea de que las lenguas hacen explícita una parte de los referentes que designan y, como se sabe, no siempre hay coincidencia entre ellos. ${ }^{18}$

\footnotetext{
${ }^{17}$ La Teoría Interpretativa de la Traducción (TIT) sostiene que la traducción debe hacerse solamente hacia la lengua materna.

${ }^{18}$ A título ilustrativo, el castellano variante argentina utiliza Despacio. Hombres trabajando en la señalización vial; el francés Ralentir. Travaux, lo que indica que cada lengua ha verbalizado facetas distintas.
} 
Dentro del enfoque interpretativo, es insoslayable el aporte de Jean Delisle en lo que se refiere a traducción escrita.

\subsubsection{La traducción escrita como proceso según Jean Delisle}

Como adelantamos en el Capítulo I, el aporte de Jean Delisle (1984) a la Teoría Interpretattiva de la Traducción se ha plasmado en la descripción del proceso cognitivo de traducción escrita mediante un modelo de deconstrucción, en el que el autor reconoce tres etapas y subetapas:

A) Comprensión realizada intra y extralingüísticamente, sin establecer comparaciones interlingüísticas: 1. Descodificación de los signos dentro del sistema de la lengua u operación que se propone identificar el contenido conceptual de las palabras recurriendo a un análisis léxico-gramatical, para establecer lo que los signos significan en el código, como el paso previo para llegar a la aprehensión o captación del sentido; 2 . Captación ${ }^{19}$ del sentido que consiste en precisar el entorno conceptual de un enunciado con el aporte del contexto referencial en el que está inmerso. Como dfijimos, esta operación parte de la significación de los signos lingüísticos en el sistema de la lengua pero para lograr el sentido es necesario descubrir lo que esos signos designan dentro del mensaje; 3. Interpretación del título, intentando descubrir las intenciones del autor.

B) Reformulación o reexpresión, posterior a la comprensión, que consiste en reverbalizar los conceptos con significantes tomados de otra lengua. La finalidad de llegar a equivalencias no emana de la memorización de repertorios, sino que surge de la activación de mecanismos cerebrales no lingüísticos (Delisle, 1984: 78), a saber: 1. Razonamiento analógico, asociaciones sucesivas de ideas y deducciones lógicas o inferencias, mediante lo cual el traductor busca el sentido de un enunciado en situación de comunicación y su reexpresión en otra lengua; es decir que la competencia de un traductor está estrechamente ligada a su habilidad deductiva y asociativa; 2. Reverbalización o exploración analógica de los recursos de la lengua de llegada con la finalidad de descubrir signos lingüísticos capaces de expresar los conceptos que ha construido el traductor.

19 La saisie du sens ha sido traducido al castellano como aprehensión del sentido (Delisle y Bastin, 1997: 80) y captación de sentido (Hurtado Albir, 2004 : 331). 
C) Análisis justificativo o etapa durante la cual se verifica la exactitud de las soluciones adoptadas, para asegurar que hay equivalencia con el enunciado inicial.

\subsubsection{Un abordaje metódico de producción discursiva en traducción}

Con una finalidad pedagógica, Delisle propone un abordaje metódico de iniciación a la traducción respecto del manejo del lenguaje, conocido como Les paliers du maniement du langage (Planos del manejo del lenguaje) que son: las convenciones de redacción, la exégesis léxica, la interpretación de la carga estilística y la organicidad textual.

\subsection{Las convenciones de redacción}

El primer nivel de las convenciones de redacción incluye las exigencias de presentación formal y la aplicación de las reglas de gramática. El enfoque interpretativo no toma en cuenta la enseñanza sistemática de la gramática puesto que establece una diferencia entre curso de lengua extranjera y curso de traducción. Parte de la hipótesis de que el estudiante de traducción conoce las reglas de funcionamiento de las lenguas de partida y de llegada; por lo tanto cualquier falencia en ese sentido tendrá que ser cubierta por el propio estudiante, por ejemplo, a través de las divergencias entre las lenguas de trabajo, es decir, del método contrastivo. De todos modos, las verdaderas dificultades de traducción no se hallan en este plano.

\subsection{La exégesis léxica}

El segundo nivel se refiere al diálogo hermenéutico que es conveniente establecer para interpretar las palabras dentro del discurso por traducir y comprende una clasificación según el grado de dificultad para llegar a la designación adecuada. Se distinguen tres grados: los vocablos monosémicos, los vocablos que reactivan alguna de las formas consignadas en los sistemas lingüísticos y por último, los que requieren un esfuerzo de recreación contextual puesto que el sentido evocado no es usual y necesita entonces de un análisis más allá de la significación puramente lingüística. 


\subsection{Interpretación de la carga estilística}

El tercer nivel plantea cómo interpretar la carga estilística, a través del estudio de los siguientes elementos siempre presentes en un texto: el autor, el tema tratado, el vector, es decir el género textual y los recursos lingüísticos utilizados y por último, los destinatarios.

\subsection{La coherencia textual ${ }^{20}$}

El cuarto nivel de coherencia textual corresponde al armado del edificio textual y se vincula con la interdependencia jerarquizada de todos los elementos de un texto. A diferencia de lo idiomático que se estudia desde un punto de vista normativo, la coherencia supone una perspectiva de conjunto y no de correspondencia entre gramáticas. Las transformaciones para lograr tal coherencia pueden ser la redistribución de elementos de información, la concentración de varios significados en pocos significantes, la implicitación y la explicitación de elementos de información. En este nivel se consignan apreciaciones ligadas a una gramática textual, a una semiótica discursiva y/o a estrategias de distribución de la información, que corresponden a una organización textual basada sobre el impulso de producción del discurso.

Es un abordaje metódico de iniciación a la traducción en el que se aprecia un crescendo en la complejidad desde el primero al cuarto nivel, en el cual todo se entremezcla y se confunde durante la construcción del discurso.

En síntesis, la actividad de traducción comprende una doble interpretación cuyo eje es el sentido y esa actividad comprende dos aproximaciones: semasiológica y onomasiológica. La primera, semasiológica, en movimiento continuo de ida y vuelta entre el texto origen, la lengua de partida y la construcción del concepto desnudo de palabras; la segunda, onomasiológica, en la lengua de llegada, en movimiento continuo entre el concepto desnudo de palabras y la

\footnotetext{
${ }^{20}$ La organicité textuelle ha sido traducido al castellano como coherencia textual (Delisle y Bastin, 1997: 133).
} 
construcción del texto traducido. ${ }^{21}$ La producción discursiva en traducción coincidiría entonces con la producción discursiva unilingüe.

Esta teoría considera que toda traducción es una mezcla de reexpresión coherente de contenidos textuales y de transcodificación de alguno de sus elementos, según la metáfora de la brioche aux raisins utilizada por Seleskovitch (Hurtado Albir, 2005: 163-188). ${ }^{22}$

Como ya señalamos, esta construcción teórica es refractaria al trabajo comparativo entre original y traducción porque su objetivo es separar el contraste interlingüístico del proceso de interpretación propiamente dicho. De allí que ya en los años '70 sostenía que los estudios lingüísticos sobre lenguas vecinas y lejanas, disociación entre lenguas, interferencias, no constituyen el objetivo del enfoque interpretativo, pues el acto de traducir es de carácter discursivo y contextual, y la unidad de traducción es la unidad de sentido cuya construcción es dinámica (Lederer, 2005: 100).

Nuestro estudio, que toma binomios textuales de comparación entre texto original y texto traducido, no coincide metodológicamente con esta teoría, pero sí encuentra en ella explicaciones sobre la producción discursiva en traducción.

\subsubsection{Comprensión centrípeta y comprensión centrífuga}

Jeanne Dancette (1995: 72, 205) ha analizado diversos enfoques empíricos de la comprensión en traducción y ha llegado a la clasificación de comprensión centrípeta o global y comprensión centrífuga o detallada. En la primera el mensaje determina el sentido de las unidades microestructurales mientras que en la segunda, el sentido de las unidades determina el sentido del mensaje. Reuniendo ambas posturas, sostiene que es imprescindible que se realicen vaivenes entre microestructura y macroestructura, como así también entre estructura de superficie y

21 En el mismo sentido se pronuncia Eugenio Coseriu: "La traducción es semasiología y onomasiología implícitas, pero semasiología y onomasiología de los textos, no de las lenguas." (1977: 22).

${ }^{22}$ Con esta metáforta culinaria traducida al castellano como bollo con pasas (Hurtado Albir, 2005: 322) la masa del bollo se asociaría a la reexpresión coherente de contenidos textuales, mientras que las pasas de uva serían los elementos transcodificados, que no varían ya estén dentro o fuera de la masa. 
estructura subyacente, para ir elaborando la comprensión. Su modelo de la doble hélice describe visualmente la interacción entre comprensión y producción en traducción [ $\rightarrow$ Introducción].

El enfoque de Dancette aportará a nuestro estudio su visión interactiva o de vaivén entre comprensión y traducción.

\subsubsection{La metáfora del escritorio: una aproximación cognitiva}

Daniel Gile (2005: 173-177) utiliza la metáfora del escritorio para explicar que tanto la comprensión como la producción se realizan en la memoria de trabajo, que él representa como la superficie de una mesa de trabajo, mientras que grafica a la memoria de largo plazo como anaqueles de una biblioteca.

En comprensión, los documentos de trabajo vienen del exterior, se procesan en la mesa de trabajo activando documentos de los anaqueles, y los nuevos documentos también se van archivando en esos anaqueles. Las informaciones escuchadas o leídas permanecen durante un segundo o menos en el registro sensorial -auditivo o visual, según corresponda- pasan a la memoria de trabajo que utiliza conocimientos lingüísticos y extralingüísticos alojados en la memoria de largo plazo, ciclo que se repetirá una y otra vez.

En producción, la memoria de trabajo recibe de la memoria de largo plazo las informaciones lingüísticas y extralingüísticas necesarias para enunciar, transmite las instrucciones a los órganos de la palabra oral o escrita y controla las operaciones de esos órganos. Las instrucciones o ideas vienen del exterior y el enunciador ${ }^{23}$ recurre a los anaqueles para activar conocimientos lingüísticos y extralingüísticos, vuelve a su mesa de trabajo para continuar procesando y, una vez concluida su producción, la envía al destinatario. Según la frecuencia de uso de los documentos, el enunciador dejará más cerca de la mesa de trabajo los que necesite permanentemente, y la distancia marcará la disponibilidad o el grado de activación.

\footnotetext{
${ }^{23}$ Tomamos el término enunciador en su acepción de sujeto productor efectivo del enunciado. Charaudeau, Patrick y Maingueneau, Dominique (2005: 215).
} 
En resumen, la memoria de trabajo o mesa de trabajo se presenta como interfaz entre la memoria de largo plazo o anaqueles en los que se archivan contenidos lingüísticos y extralingüísticos que serán consultados por la mesa de trabajo, activándolos, seleccionando los pertinentes para el enunciador que pone en juego mecanismos de control. Este concepto podría explicar, por la negativa, algunas anomalías encontradas en nuestro análisis de producción.

\subsubsection{Las normas: una aproximación sociocultural}

La traducción es una actividad en la que participan, al menos, dos lenguas y dos culturas construidas según normas, de allí que pueda estudiársela desde una perspectiva sociocultural, como es la que sostienen los Estudios Descriptivos de Traducción (EDT). Desde esta perspectiva, una traducción toma determinada posición y función en una cultura dada puesto que los traductores trabajan fundamentalmente en interés de la cultura para la que traducen, relación que es estudiada por la teoría del polisistema. En consecuencia, el polo meta está habilitado para determinar qué características del texto original se conservarán y reexpresarán con material en la lengua meta. Es decir, la posición y función sistémica de una traducción determinan su configuración lingüístico-textual superficial y rigen las estrategias que se activan en la producción discursiva. La perspectiva semiótica que adoptan los EDT hace que las funciones estén situadas jerárquicamente por encima de las estrategias del traductor y de la configuración lingüístico-textual (Toury, 2004: 49-50).

Los EDT constituyen una disciplina cuya esencia son los hechos observables o reconstruibles de la realidad; a partir de esta premisa empírica, la gama de estudios es amplia: la traducción como producto, los procesos de traducción, las unidades infratextuales, las relaciones intertextuales, el comportamiento traductor y las estrategias para solucionar problemas de traducción.

Los EDT, desde su enfoque empírico y su premisa de que la traducción es una operación gobernada por normas, plantean encaminar el estudio de los procesos de traducción reales, a través de la comparación de binomios textuales, en los distintos estadios de elaboración o borradores de las traducciones. De este 
modo, se puede rastrear el proceso de toma de decisiones hasta la versión final, evitando el estudio retrospectivo a partir de entrevistas o cuestionarios a los traductores que reconstruyan, después de la traducción, las soluciones que ellos han ido dando durante la elaboración de la traducción, puesto que esos datos provienen del recuerdo y, por lo tanto, no siempre son confiables. Según el marco metodológico de los EDT, la comparación textual podría fortalecer la formulación de hipótesis explicativas, si se llegara a una suerte de regularidades de superficie como prueba directa del comportamiento traductor. La obtención de regularidades posibilitaría la formulación de leyes que es lo que está más allá de los EDT, es decir los Estudios de Traducción, como teoría. Hay que señalar, sin embargo, que el estudio de la génesis de traducciones individuales tiene aún un desarrollado moderado (Toury, 2004: 109, 240-242, 253).

\subsubsection{Norma inicial: adecuación y aceptabilidad}

En traducción se ponen en relación dos polos, origen y meta, y esa distinción establecerá la norma inicial, según la cual las decisiones del traductor podrán adherir a las normas del polo origen, o bien seguir las normas del polo meta. En el primer caso, estamos frente al concepto de adecuación de una traducción respecto al original, mientras que en el segundo, hablamos de la aceptabilidad de la traducción en la cultura de llegada.

El proceso de traducción y, en especial, el de producción, estará regido por esta división básica, a partir de la cual podrán formularse hipótesis explicativas (Toury, 2004:102).

Al mismo tiempo, dos grandes grupos de normas gravitan en las decisiones de traducción: las normas preliminares y las normas operacionales

\subsubsection{Normas preliminares}

Las normas preliminares comprenden consideraciones previas al acto de traducir que están relacionadas con la política de traducción y con la distinción de traducción directa-traducción indirecta. La traducción directa es la que se realiza desde la lengua en que se compuso el texto original; en cambio, se denomina 
traducción indirecta la que va desde una lengua distinta a la utilizada en la formulación del texto original, o lengua intermedia.

\subsubsection{Normas operacionales}

En cuanto a las normas operacionales, son las que guían las decisiones del traductor durante el proceso de traducción y tienen su correlato en las elecciones lingüísticas materializadas en el texto traducido. Son de dos tipos: las normas operacionales matriciales y las normas lingüístico-textuales.

\subsection{Normas operacionales matriciales}

Las normas operacionales matriciales regulan la aparición, omisión, adición de elementos de la lengua meta para sustituir el material presente en el texto original, como también la distribución y la segmentación en el texto de llegada.

\subsection{Normas operacionales lingüístico-textuales}

Las normas operacionales lingüístico-textuales de la lengua meta determinan las elecciones que sustituyen el material lingüístico-textual del texto original. Dentro de las normas operacionales lingüístico-textuales se diferencian las generales o de aplicación a todas las traducciones y las particulares que atañen a un género textual en particular o a un modo de traducción.

De todas maneras, una de las especificidades de las traducciones es que en ellas aparecen formas lingüísticas y estructuras que rara vez o nunca se encuentran en los textos originales de la lengua meta y ese hecho puede vincularse con la modalidad de tratamiento del texto original en sentido bottom-up, en lugar de haberlo considerado holísiticamente. En el primer caso, el análisis y las soluciones se van tomando desde niveles bajos, microestructurales, con las consiguientes interferencias del discurso de partida y la producción va desviándose de las formas normales de la lengua meta (Toury, 2004: 269).

En conclusión, los EDT reúnen intereses diversos desde hechos observables e interesan a nuestro estudio por dos razones: en principio por su reconocimiento de que la génesis de traducciones individuales ha sido poco estudiada y luego 
porque el enfoque sociocultural que considera a la traducción como actividad regida por normas, avanza, a nuestro juicio, en las causas que inciden en que el traductor opere las selecciones según la norma inicial que determina los conceptos de adecuación y aceptabilidad, pero también desde las normas operacionales matriciales y lingüístico-textuales.

\subsubsection{El tercer código}

Mona Baker (1998: 480-485) ha trabajado sobre corpora de textos en lengua original $A$ y corpora de productos traducidos hacia esa misma lengua $A$, con la finalidad de estudiar la existencia de generalidades que avalen o no la noción de tercer código o lengua de traducción introducida por Frawley, como compromiso entre las normas o estructuras de la lengua de partida y las de la lengua de llegada. Estas características permiten estudiar descriptivamente la lengua de traducción, sin que ésta sea considerada de manera peyorativa como translationese o jerga de la traducción, sino como una forma de comunicación única (Baker, 1998), que podría experimentar algún tipo de institucionalización (Toury, 2004: 269).

La naturaleza de nuestro corpus hace inviable la aplicación de este enfoque, si bien nos advierte sobre la aparición de expresiones aceptadas en producción escrita desde fuente, interlingüística o producción discursiva en traducción, que no serían frecuentes en la producción escrita intralingüística libre.

\subsubsection{La competencia traductora}

Amparo Hurtado Albir ve en la traducción un objeto poliédrico que puede ser abordado desde lo lingüístico, textual, cognitivo, comunicativo y sociocultural, filosófico y hermenéutico. A partir de un enfoque cognitivo y pedagógico, de impronta interpretativa, ha desarrollado el programa de adquisición de competencia traductora de traducción escrita (PACTE) en la Universidad Autónoma de Barcelona, como investigación empírico-experimental, a través de la aplicación de diversos instrumentos, entre ellos el Thinking-Aloud Protocol (TAP), o protocolo verbal.

La competencia traductora según el PACTE se caracteriza por ser: un sistema subyacente de conocimientos, habilidades, destrezas y actitudes necesarios para 
traducir; una competencia cualitativamente distinta a la competencia bilingüe; un conocimiento básicamente operativo.

Los componentes de la competencia traductora actúan de manera imbricada y son: la competencia lingüística en las dos lenguas objeto de la actividad de traducción; la competencia extralingüística; la competencia de transferencia; la competencia instrumental y profesional; la competencia psicofisiológica; la competencia estratégica. En el modelo holístico de la competencia traductora, las competencias de transferencia y estratégica son centrales; la primera porque integra a las demás y la estratégica porque afecta a las demás.

Por otra parte, la adquisición de la competencia traductora es entendida por el PACTE como proceso de reconstrucción y desarrollo de las subcompetencias que la conforman y para su análisis ha generado el modelo dinámico de adquisición (Hurtado Albir, 2004: 395, 396, 407).

El enfoque de la competencia traductora se vincularía indirectamente con los resultados a los que llegue nuestro estudio.

\section{7. ¿Cómo estudiar una traducción?}

Como lo consignan las teorías actuales de traducción, ha habido una evolución desde enfoques prescriptivos hacia los descriptivos o no-prescriptivos, que se han ido fortaleciendo, en gran medida, por los avances de estudios descriptivos orientados al producto, al proceso y a la función de la traducción.

\subsubsection{Estudios orientados al producto}

Como ya mencionamos [ $\rightarrow$ Capítulo II, Producción discursiva. 2.6.5.], la norma inicial establece qué polo de la relación origen-meta se priorizará en la producción de una traducción. Al observar un producto traducción con una mirada retrospectiva, como es nuestro caso, es posible identificar la norma inicial -si la hubo- o, en su reemplazo, visualizar si la traducción en general, o alguna de sus secciones, adhieren al concepto de adecuación que acerca el producto al polo original, o bien al concepto de aceptabilidad que se vincula con el polo meta. 


\subsubsection{Estudios orientados al proceso}

Los estudios orientados al proceso generalmente desestiman la versión final pues su objetivo es determinar las fases que conforman ese proceso (Toury, 2004: 285). Se interesan especialmente en los problemas de traducción, que pueden detectarse indirectamente a través de la observación de las estrategias puestas en juego por el traductor para solucionarlos. Al respecto, Hurtado Albir vincula la noción de problema con la de error de traducción puesto que el problema puede detectarse cuando no ha habido una buena resolución, y también con la de estrategia traductora o mecanismos de resolución de problemas (2004: 279-288). Nuestro estudio toma el texto traducido y detecta anomalías morfosintácticas que son analizadas comparativa y retrospectivamente, de allí que se instala en el proceso aun cuando parta de la versión final [ $\rightarrow$ Capítulo II, Producción discursiva. 2.7.4.].

\subsubsection{Estudios orientados a la función}

Los estudios orientados a la función se relacionan con las normas preliminares [ $\rightarrow$ Capítulo II, Producción discursiva. 2.6.5.] que son las consideraciones previas al acto de traducir, es decir las que están relacionadas con la política de traducción o con el encargo de traducción (Nord), según las necesidades y condiciones del solicitante de una traducción. En ambas posturas, la función que cumpla la traducción en la lengua-cultura de llegada condiciona el resto de la traducción. De allí que las actualizaciones en la superficie dependerán de la función semiótica del texto traducido y de la posición que se le asigne dentro de la constelación sistémica o red de relaciones de la que van a formar parte las traducciones, especialmente literarias, basándose en un sistema cultural dado (Toury, 226-227).

El hecho de que nuestro trabajo parta de un corpus textual final, no nos permite contar con datos para llevar un estudio de estas características. 


\subsubsection{Estudios comparativos}

Los estudios que toman como instrumento la comparación entre texto original y texto traducido, en principio, no dan cuenta de las operaciones intelectuales de introspección que activa el traductor para llegar a soluciones provisorias y finales; sin embargo, la descripción de binomios seleccionados según metodologías precisas puede dar lugar a hipótesis explicativas sobre los mecanismos de traducción; en ese sentido, Toury justifica el uso de segmentos emparejados como mecanismo operativo para el análisis retrospectivo, fundamentándolo, entre otros razonamientos, en las conclusiones emanadas de los protocolos verbales que indican que la mayoría de los segmentos del texto original y del texto traducido se delimitan y se emparejan según cada caso concreto (2004: 141, 147).

Nuestro estudio utiliza los segmentos de enunciado o binomios textuales en los términos que lo enuncia Toury, es decir, como mecanismo operativo para analizar retrospectivamente las anomalías en los enunciados elípticos.

\subsubsection{Estudios empíricos orientados al producto, al proceso y a la función}

La resolución de un problema y el problema en sí mismo se determinan mutuamente (Toury, 2004: 121) y la manera de acceder a ellos es indirecta, ya sea a través de tests, entrevistas o de protocolos verbales o de razonamiento en voz alta (TAP).

\subsubsection{Propuestas provisorias o borradores de traducción}

Por regla general, la producción en traducción no es definitiva de primera intención, sino que antes de llegar al producto final el traductor pasa por una o más propuestas provisorias. La lectura de esos borradores puede ayudar a visualizar el proceso de toma de decisiones seguido por el traductor, aunque de modo indirecto puesto que ya están formuladas lingüísticamente, es decir que no se comprueba lo que realmente ocurre en la mente del traductor (Toury, 2004: 244).

Desde el punto de vista metodológico es complejo contar con todas las versiones previas, puesto que el traductor suele corregir o retocar cada vez que lee 
su producción, sin dejar constancia de cada uno de esos pasos, cortando así la cadena de decisiones. En la primera etapa de esta investigación, nos habíamos propuesto trabajar con las sucesivas producciones de alumnos avanzados de traducción, sin embargo, no logramos que conservaran todas las versiones provisorias [ $\rightarrow$ Capítulo $\mathrm{V}$, Metodología. 5.5.2.].

Consideramos que constituye una excelente herramienta para acercarse al camino de las decisiones, aun cuando muchas de ellas estarían justificadas por el estilo individual del traductor. ${ }^{24}$

\subsubsection{Test de cloze}

El test cloze $e^{25}$ utiliza la supresión de palabras dentro de un texto, para que el lector complete los blancos, de modo de que puedan explorarse los procesos de anticipación, inferencia, juicio, resolución de problemas, que se activan en la lectura.

El cloze está fundamentado teóricamente por diversos enfoques: la psicología de la forma o cierre gestáltico; la teoría sistémica que relaciona el concepto de entropía o incertidumbre por la falta de organización de un sistema -opuesto a redundancia- con el buen lector que logra inferir términos elididos; el análisis del discurso que asume el uso de la lengua como un todo integrado y no como un simple ejercicio de completamiento; la psicolingüística o enfoque interactivo de la lectura que plantea el procesamiento de los datos aportados por el texto (proceso de abajo hacia arriba) y la anticipación que realiza el lector (proceso de arriba hacia abajo), es decir la habilidad para obtener información de la lectura gracias al éxito de las predicciones.

Aplicado a textos traducidos, el cloze combinado con otros métodos podría aportar datos sobre cómo procesan las traducciones los receptores y cómo las componen los traductores, con lo cual se podría estudiar la inteligibilidad relativa de

\footnotetext{
${ }^{24}$ Actualmente, en la Universidad de Aconcagua se está llevando a cabo una investigación sobre "La secuencia del proceso traductor en estudiantes de la carrera del traductorado", cuyo informe fue presentado por Mónica Gatti y María del Mar D'Gregorio en las II Jornadas Internacionales de Traductología, organizadas por el Centro de Investigación de la Facultad de Lenguas de la Universidad Nacional de Córdoba, en agosto 2009.

${ }^{25}$ Véase Difabio de Anglat, Hilda (2009: 121-137). [Consultado el 10/01/09].
} 
las traducciones y de los textos originales. Sin embargo, las limitaciones comentadas por Toury (286-289) nos decidieron a no utilizarlo.

\subsubsection{Entrevista de explicitación}

La entrevista de explicitación es uno de los instrumentos de verbalización utilizados por la psicología cognitiva para acceder a las representaciones y a los procesos seguidos por una persona que ha realizado una tarea. A fin de que este tipo de entrevista se acerque a su objetivo, se necesita un interrogatorio guiado activamente para que el entrevistado responda sobre una ocurrencia singular de la acción realizada (Dubois y Weil-Barais, 1999: 284).

En un principio, nuestro corpus integraba producciones de alumnos con quienes habíamos mantenido entrevistas de explicitación, pero, al haber ajustado nuestro problema de estudio posteriormente a su realización, esos resultados no pudieron encontrar aplicación en el estudio actual $[\rightarrow$ Capítulo $V$, Metodología. 5.5.2.].

\subsubsection{Protocolo verbal}

El protocolo verbal es la única aproximación indirecta no retrospectiva (Toury, 2004: 121) y su utilización tiene como objetivo desentrañar las representaciones y las actividades cognitivas puestas en juego durante la ejecución de una tarea cognitiva compleja, especialmente como método de estudio de los procesos en la resolución de problemas. Los protocolos verbales que se desarrollan simultáneamente con la tarea principal que se está ejecutando interfieren con ella e imponen dificultades relacionadas con los mecanismos de memoria.

De todos modos, en la literatura traductológica hay consenso en afirmar que, a pesar de que el TAP tiene limitaciones por ser un método de observación indirecta y porque el traductor está sometido a la doble verbalización de su traducción y de su comportamiento, proporciona datos en relación con los pasos que va dando el traductor para la toma de decisiones (Hurtado Albir, 2004: 193-195). 
No hemos utilizado este instrumento en nuestro estudio porque no se ajusta a las condiciones de elaboración de las traducciones que indicamos a los alumnos, al inicio de esta investigación [ $\rightarrow$ Capítulo V, Metodología. 5.5.2.].

\subsubsection{Reflexiones finales sobre los estudios empíricos}

De lo expuesto, podemos afirmar que tanto en los estudios intralingüísticos como interlingüísticos, la producción es el proceso que menos avances ha demostrado, debido principalmente a razones de tipo metodológico. Danièle Dubois y Annik Weil-Barais (1999: 279, 280) parten de la base de que toda aproximación experimental al proceso de producción está anclada en una teoría de la subjetividad y en una concepción sobre la posibilidad de hacer explícitos los estados mentales, que conducen a dos posturas distintas. Una de ellas sostiene que en el estado de desarrollo actual las investigaciones sólo pueden determinar aspectos periféricos de los procesos de producción que se materializan en mecanismos de emisión de las formas lingüísticas, puesto que los procesos son esencialmente subjetivos e inaccesibles. La postura opuesta afirma que los estados mentales y las actividades cognitivas son verbalizables por lo tanto puede accederse a los procesos de producción.

En cuanto a la primera postura, los estudios psicolingüísticos más avanzados aparecen en el campo de la génesis de la escritura en los niños y muy poco existe en la exploración científica de los procesos psicológicos de producción del lenguaje en general, sin tomar en cuenta los numerosos trabajos específicos sobre casos clínicos.

La segunda postura, más estudiada por la psicología cognitiva, utiliza los protocolos verbales, verbalizaciones, a través de los cuales se accede indirectamente a las representaciones y a las actividades cognitivas que están presentes en las tareas cognitivas complejas, como la resolución de problemas y análisis del trabajo. Estos instrumentos pueden aplicarse simultánea o posteriormente a la actividad que desarrolla el individuo cuya producción se estudia.

Algunas de las dificultades que se encuentran en su aplicación y en la lectura de sus resultados radican en la interferencia con la tarea que los actores realizan y 
verbalizan al mismo tiempo, o con aspectos de memoria, en el caso de instrumentos utilizados luego de realizada la actividad, como es el caso de las entrevistas explicativas. Al respecto, y aludiendo a errores de identificación provenientes de testigos de causas judiciales, Serge Nicolas (1993: 427) afirma que el recuerdo sufre una deformación importante en las informaciones que se brindan a posteriori de un acontecimiento.

\subsection{Mecanismos en la producción discursiva de una traducción}

La producción discursiva en traducción suma a la complejidad propia del proceso de producción intralingüístico la problemática de la producción en la lenguacultura meta, que antes de materializarse lingüísticamente pasará por la interfaz de transferencia.

El proceso heurístico de la traducción da cuenta de una etapa no verbal, cuyos mecanismos cerebrales no lingüísticos son muy difíciles de desentrañar cuando los significantes han desaparecido, antes de iniciar la fase de reverbalización. Como ya dijimos $[\rightarrow$ Capítulo I, Marco teórico y Antecedentes. 1.1., 1.1.1.], esos mecanismos no se reducen a encontrar en un repertorio las palabras que restituyen las nociones sino que se activa un proceso analógico, de asociación de ideas, de modo que, en gran medida, la competencia de un traductor depende de su habilidad deductiva y asociativa.

Por su parte, la propuesta integrativa de Sánchez (2000: 28-29), identifica el proceso de transferencia como cognitivamente más complejo y explica que:

“(...) entre el proceso de comprensión, el proceso de transferencia y el proceso de producción se producen mecanismos discursivos que tienen que ver con la memoria mediata e inmediata."

Hay coincidencia en la literatura traductológica en que los mecanismos cerebrales sólo pueden ser conocidos indirectamente. Se ha podido comprobar que el traductor, frente a un texto en lengua original, procesa la información allí plasmada, desandando el camino recorrido por el autor, mediante procesos 
ascendentes (bottom-up) y descendentes (top-down), cuya metáfora espacial proviene del campo de la inteligencia artificial:

« Cette métaphore pose les données perceptives 'en bas' (bottom), en 'entrée' ou en 'périphérie' du système, alors que le contenu significatif, ou encore la représentation sous forme de 'concepts' est 'en haut' (top), 'centrale' » (WeilBarais, 1999: 242). ${ }^{26}$

Esta metáfora ubica los datos perceptivos 'abajo' (bottom), a la 'entrada' o en la 'periferia' del sistema, mientras que el contenido significativo, o también la representación en forma de 'conceptos' está 'arriba' (top), 'central'

En este proceso global hay una serie de subprocesos desde el momento de ingresar los datos sensoriales que suben (planificación ascendente) al sistema cognitivo para ser interpretados, fase en la que también intervienen las representaciones que el sujeto ya tenía en su memoria y que corresponden al conocimiento de las formas y los significados de las palabras en la lengua-cultura como también el conocimiento de las reglas sintácticas. Los conceptos bajan (planificación descendente) gobernando el subproceso que se va a plasmar sensorialmente en las palabras propiamente dichas. La descripción del proceso de traducción que realiza la Teoría Interpretativa de la Traducción responde a estas características [ $\rightarrow$ Capítulo II, Producción discursiva. 2.6.1.].

El estudio del procesamiento de la información ha puesto en evidencia que en la resolución de problemas cobran importancia las representaciones individuales, las capacidades de planificación de las actividades y los mecanismos de control, que no habían sido considerados previamente. Al respecto, Gideon Toury (2004: 312, 314), afirma que la transferencia es central para activar la capacidad interlingüística,

\footnotetext{
${ }^{26}$ Estos procesos están vinculados con la memoria humana, cuyo primer modelo fue elaborado por Atkinson y Schiffrin (1968), según una concepción informática. Según Serge Nicolas (1999:400), existen dos grandes clases de modelos de memoria: los computo-simbólicos, que se refieren a la metáfora informática clásica y los modelos conexionistas, referidos a la metáfora neuronal; pero a su vez señala que existen otros modelos que difícilmente puedan incluirse de manera exacta en uno de las clases establecidas.
} 
señalando la existencia de mecanismos de control externo, originados en el entorno social, mediante respuestas explícitas u overt, que pueden ser capitalizadas por el traductor para revisar su traducción y mecanismos de control interno, que el traductor va generando por sí mismo mediante respuestas potenciales durante y/o después de la traducción.

\subsection{Conclusión}

Los estudios traductológicos evocados se han acercado al doble juego entre competencias de comprensión, que activan estrategias exegéticas y competencias de reexpresión, a través de las decisiones específicas que ha ido tomando el traductor para seleccionar las palabras que hagan explícitos los conceptos que surgen de la comprensión y según una planificación que gira en torno de elementos que no son la actividad de traducción en sí misma (objetivos, público, soporte, género discursivo, contrato de traducción), pero que son inherentes a ella.

Si se desea observar cómo se ha traducido, se necesitará contrastar el texto traducido con el texto original desde los enunciados menores en donde se materializan las soluciones que el traductor ha ido dando a los problemas planteados a lo largo de la traducción; es decir, no son apriorísticos sino que, por el contrario, se van descubriendo junto con el desarrollo de la traducción. Por esa razón, no existen criterios objetivos que determinen de antemano el grado de dificultad de una traducción: cada texto es un caso particular. ${ }^{27}$

Coincidimos con Toury (2004: 121, 128-131) en que un estudio retrospectivo adquiere relevancia a través de los rasgos del texto original que demuestren la presencia de problemas, a lo que únicamente puede accederse desde la identificación de las soluciones correspondientes en el o los textos traducidos y tales soluciones pueden ser vistas desde un razonamiento negativo o positivo. En el primer caso, se identificarán los fallos o lo que no se logra y los aciertos, o lo que se se consigue, mientras que el razonamiento en términos positivos aborda el estudio

\footnotetext{
${ }^{27}$ Monique Cormier (1990: 173-187), propone una tipología de textos para la enseñanza de la traducción técnica, según criterios de facilidad y dificultad de comprensión por parte del traductor. La propuesta queda sintetizada en que, generalmente los textos más fáciles de comprender son los más difíciles de traducir.
} 
de la traducción desde el punto de vista interno, descubriendo los principios que son relevantes en un corpus.

En nuestro caso, la descripción de las anomalías identificadas en la producción discursiva en traducción, en especial las vinculadas con ausencias o enunciados elípticos, encuentran como insumo para su análisis al modelo tripartito de Eugenio Coseriu, que sintetizamos como: el sistema o aplicación de las reglas gramaticales; la norma, que responde al uso preferido, es decir de orden pragmático-semántico, propio de la problemática traductológica; el habla, de carácter individual, o elección del traductor.

Nuestro estudio parte de la coincidencia o no entre sistema y norma en el nivel sintáctico, sin desconocer que el límite superior de la sintaxis es la oración (Di Tullio, 1997: 17, 43) y que no se traducen oraciones aisladas sino textos, ya que, si se sostuviera lo contrario, caeríamos en la trampa de concluir que la suma de producciones exitosas a nivel microestructural, dará una producción también exitosa a nivel macroestructural.

Al respecto, Robert Larose (1989: 219-222, 256) en su propuesta de evaluación de traducciones según parámetros peritextuales y textuales, explica que los primeros reflejan las condiciones de enunciación, mientras que los segundos implican elementos del propio texto, es decir la forma global de la superestructura (esquemática), ${ }^{28}$ el contenido aportado por la macroestructura, semántica, y la microestructura, o segmentos textuales aislados, es decir la estructura sintagmática de una lengua determinada.

\footnotetext{
${ }^{28}$ Según el enfoque procedural, los esquemas internos que responden a las estructuras globales son esenciales para la toma de decisiones al producir un texto: "El conocimiento de los esquemas globales es sumamente importante tanto para la producción como para la recepción efectivas de textos; profundizar los conocimientos sobre las clases de textos significa hacer más claras y eficaces las actividades comunicativas individuales y sociales." (Ciapuscio, 1994: 132).
} 
Nuestra hipótesis general de partida es que los productos discursivos resultantes de la traducción francés/castellano de textos pragmáticos, presentan anomalías sintáctico-discursivas gobernadas por el universal de interferencia, hipótesis que hemos ido delimitando desde la observación de las correcciones de los trabajos por alumnos del último año de traducción, de la lectura de traducciones publicadas, de la experiencia como traductora y de las conclusiones de algunos trabajos de investigación.

En especial, hemos tenido en cuenta los resultados cuantitativos parciales de Etude de la cohésion textuelle dans la traduction de quatre textes philosophiques du français à l'espagnol (Sánchez, 1994), que analiza descriptivamente cuatro textos filosóficos originales en francés y su traducción al castellano, desde la distribución de los medios cohesivos gramaticales. Los resultados a que hacemos referencia indican que, cuantitativamente, la mayor diferencia está en las ocurrencias de elipsis en los textos originales en francés y las traducciones al castellano (17/162), debido a la riqueza flexiva verbal del sistema español en comparación con la del sistema francés, lo que le permite al primero obviar la presencia del pronombre sujeto antes del verbo.

Todo ello nos ha orientado a circunscribir dentro del proceso de traducción gobernado por el universal de interferencia, la producción de enunciados elípticos. Ahora bien, como hemos sostenido que se traducen textos y no lenguas, la dinámica propia del discurso que se construye en lengua-cultura meta, castellano en nuestro caso, sería la guía de cada una de las elecciones del traductor, en las que a veces habrá coincidencia entre sistema y normas y otras veces no. 
Entendemos que un mecanismo es la dirección inconsciente, automática y regular que activa o sigue desarrollando un proceso o un subproceso [Capítulo $\mathrm{V}$, Metodología. 5.6.]. Los mecanismos son generados por el propio traductor que actúan durante y después de la traducción y por el entorno social que lo hace después. Entendemos en esa aseveración una postura integradora que reconoce en los dos tipos de mecanismos un camino para la formación traductora, en tanto y en cuanto las respuestas internas y externas estén exentas de valoraciones globales, que poco -o nada- aportan al traductor.

En la producción discursiva en traducción, los mecanismos se interrelacionan con los conceptos de memoria, interferencia, procesamiento de la información en sus dos planificaciones ascendente-descendente y con el control de las formas lingüísticas en lengua cultura-meta, según las normas preliminares que se hayan adoptado. Dicho de otro modo, los mecanismos están vinculados con el análisis de la información, la manera de procesar la información del texto original, el conocimiento del mundo, el conocimiento lingüístico de la lengua-cultura origen, el conocimiento lingüístico de la lengua-cultura meta, la decisión -y la capacidad- de deshacerse de los significantes del texto original por medio de la disociación lingüístico-discursiva y el esfuerzo de controlar la producción durante y una vez finalizada la producción.

En especial por ser el discurso un concepto de construcción según condiciones de producción preestablecidas, las exigencias del solicitante de la traducción incidirán en el mecanismo universal de interferencia cuya visibilidad emerge operativamente en un análisis comparativo entre texto traducido y texto original. 


\title{
CAPÍTULO III
}

\section{INTERFERENCIA}

\author{
"La realización simultánea de dos tareas es posible \\ cuando ambas tienen una baja demanda de atención, \\ pero cuando se incrementan las demandas atencionales \\ de una de ellas, se produce un deterioro en la realización de la otra.
} Ello indica claramente que las dos tareas hacen uso de los mismos recursos". Manuel de Vega (1995: 143).

\subsection{Interferencia: una noción sin límites precisos ${ }^{1}$}

El concepto de interferencia nace en la Física ondulatoria y pasa, como préstamo interno a otras ramas del conocimiento, entre las cuales, la Lingüística, durante el IV Congreso Internacional de Lingüistas de Copenhague, en la primera mitad del siglo $X X$.

Dentro de las Ciencias del Lenguaje, la interferencia es un término que refiere a un mecanismo omnipresente en los estudios que implican lenguas en contacto en sentido amplio, es decir, en la relación entre lengua materna y lenguas extranjeras, en el fenómeno de bilingüismo y también en el proceso de traducción (Sánchez, 2005: 159-173). ${ }^{2}$

Sin embargo, no se registra un empleo uniforme, lo que puede llevar a malentendidos e interpretaciones no acertadas, como lo consigna Carsten Sinner (2004: 58). En este sentido, se observan dos cuestiones: por un lado, la inexistencia de un concepto con límites precisos puesto que la interferencia se hace visible

\footnotetext{
${ }^{1}$ Sobre la definición interferencia y de transferencia, véanse los estudios: Sinner, Carsten (2004); Domínguez Vázquez, María José (2001).

${ }^{2}$ Los tres procesos que se realizan en el contacto de lenguas son el préstamo, la transferencia y la interfererencia (Sánchez, 2005).
} 
mediante cambios lingüísticos de cualquier nivel, sea entre dos lenguas o dos registros dentro de una misma lengua, sea como sociolecto o idiolecto; por otro lado, una noción evolutiva que va de la consideración de la interferencia desde una concepción aleatoria o de aparición imprevista hacia una concepción no aleatoria o sistemática que obedece a reglas precisas. Al respecto, Carsten Sinner (2004: 58) recoge los términos de integración como correspondiente de interferencia en el sistema de Uriel Weinreich, e interferencia como el uso de elementos de otra lengua en la producción oral o escrita de un hablante, distinción que ha sido incorporada en la lingüística de contacto europea. Además, Sinner (2004: 73) considera contraproducente determinar como negativa a la interferencia, puesto que ello conlleva connotaciones peyorativas, de allí que en su trabajo sobre las particularidades del castellano hablado en Cataluña propone como interferencia un fenómeno que atañe sólo a las personas bilingües nativas:

"Entendemos, para los objetivos de este trabajo, como interferencia los rasgos o elementos de una lengua $X$ que aparecen cuando un hablante de las dos lenguas $X$ e $Y$ habla la lengua $Y$, que no pueden interpretarse como meros cambios de código (code switching) entre las lenguas $X$ e $Y$ (cf. 2.1.2.3), y que no se integran en citas de una persona bilingüe o de un hablante de lengua $Y$. Dichos rasgos o elementos además constituyen fenómenos individuales que no afectan a los monolingües de la lengua $Y$ y que no se aceptan en las normas de uso ni en la norma prescriptiva de esta lengua. El término convergencia viene a denominar aquellos casos en que las dos lenguas en contacto tienen tendencias evolutivas o estructuras coincidentes (idénticas o muy parecidas), aunque se empleen con una frecuencia mayor o menor en una de ellas."

Para Georges Mounin (2000: 181), el fenómeno de interferencia aparece en:

"Les changements ou les identifications résultant des contacts avec une autre langue, du fait du bilinguisme ou du plurilinguisme des locuteurs »

Los cambios o identificaciones que resultan de los contactos con otra lengua, a causa del bilingüismo o plurilingüismo de los hablantes. 
J.F. Hamers y M. Blanc (1983: 452) definen a la interferencia como fenómeno lingüístico dentro de la Didáctica de la Lengua Segunda y dicen que:

" (il) est utilisé pour décrire tout comportement langagier qui fait appel à des éléments de deux ou plusieurs codes linguistiques. II faut distinguer entre l'interférence qui réfère à l'utilisation inappropriée d'éléments d'une langue dans une autre et l'interdépendance, c'est-à-dire des stratégies langagières qui font une utilisation des ressources de plusieurs langues. »

...se lo utiliza para describir todo comportamiento del lenguaje que recurre a elementos de dos o más códigos lingüísticos. Hay que distinguir entre la interferencia que refiere a la utilización inapropiada de elementos de una lengua en otra y la interdependencia, es decir las estrategias de lenguaje que utilizan recursos de varias lenguas.

Ronald Wardhaugh (1991: 41-49), al estudiar la hipótesis del análisis contrastivo, postula la existencia de dos versiones: una versión fuerte o predictiva proveniente del generativismo que no parte de los hablantes para confirmar o refutar el conjunto de los contrastes de las lenguas que se estudian, y la versión débil o explicativa, a la que él adscribe, que toma los fenómenos de la interferencia lingüística como punto de partida para explicar contrastivamente los sistemas implicados. Entre esos fenómenos, se señalan la traducción imperfecta y las dificultades de aprendizaje.

William Nemser (1991: 51-61) comparte en general la opinión de Wardhaugh respecto de las versiones fuerte y débil de los análisis contrastivos, dudando sobre el poder predictivo de la versión fuerte y considerando que la versión débil es testimonial, puesto que da cuenta del comportamiento del alumno. La interferencia en el análisis contrastivo es dinámica y está comprendida dentro de una visión general del aprendizaje que considera que todo aprendizaje previo afecta al siguiente, ya sea positivamente cuando coinciden sus dominios, o de forma negativa cuando éstos se oponen. En el primer caso estamos frente a la transferencia positiva y en el segundo frente a la transferencia negativa.

Dentro del Análisis Contrastivo, resulta útil la adaptación realizada por María Jesús Santos Maldonado (2002: 56 ) sobre la terminología y los casos de contraste 
español/francés, en base a la jerarquización de estructuras gramaticales inglés/español de D. Larsen-Freeman y M.H. Long, que transcribimos, y que sintetizan algunos de los problemas generados por las transferencias negativas:

FIGURA 5. Contraste español/francés (Santos Maldonado, 2002: 56)

\begin{tabular}{|c|c|c|}
\hline TIPO DE DIFICULTAD & L1:ESPAÑOL/L2:FRANCÉS & EJEMPLO \\
\hline 1-DIVERGENCIA & $x$ & por $<$ \\
\hline 2-PRESENCIA & $\varnothing-x$ & Marca de artículo partitivo \\
\hline 3-AUSENCIA & $x-\varnothing$ & $\begin{array}{l}\text { Pronunciación de la } r \text { final } \\
\text { en los infinitivos de la } \\
\text { primera conjugación }\end{array}$ \\
\hline 4-CONVERGENCIA & $\mathrm{X}$ & $\begin{array}{l}\text { Ser y estar se actualizan } \\
\text { en être. }\end{array}$ \\
\hline 5-EQUIVALENCIA & $x-x$ & $\begin{array}{l}\text { Marca de género y de } \\
\text { número }\end{array}$ \\
\hline
\end{tabular}

María José Domínguez Vázquez (2001: 5) encuentra que la concepción de interferencia de Uriel Weinreich como desviación de las normas implica partir de una visión negativa, puesto que refiere a los problemas lingüísticos que un hablante no puede resolver dentro de las normas de la lengua que éste emplea en una situación determinada [ $\rightarrow$ Capítulo III. Interferencia. 3.1.2.].

En cambio, otros autores ven la interferencia desde una postura positiva como una licencia del hablante de más de una lengua que pone en práctica la alternancia de códigos (Code-Switching).

J.F. Hamers y M. Blanc (1983: 445) definen la alternancia de códigos, también denominada cambio de código o de lengua, alternancia de códigos o alternancia códica, alternancia de lengua de la siguiente manera: 
«-stratégie de communication utilisée par des locuteurs bilingues entre eux; cette stratégie consiste à faire alterner des unités de longueur variable de deux ou plusieurs codes à l'intérieur d'une même interaction verbale. On distingue entre alternance de codes de compétence et alternance de codes d'incompétence.

-alternance de codes de compétence ou code alterné du bilingue : alternance de code utilisé par un bilingue compétent dans les deux langues et employé comme stratégie de communication avec d'autres bilingues; ce code est une expression de la compétence du bilingue à faire appel aux ressources de ses deux codes dans une même interaction.

-alternance de codes d'incompétence: stratégie de communication utilisée par un bilingue dominant et qui consiste à faire alterner les codes en faisant appel à sa langue dominante pour suppléer un manque de compétence dans sa langue plus faible. »

-estrategia de comunicación que utilizan los hablantes bilingües entre sí; esta estrategia consiste en alternar unidades de longitud variable de dos o más códigos dentro de una misma interacción verbal. Se distinguen la alternancia de códigos de competencia y la alternancia de códigos de incompetencia.

-alternancia de códigos de competencia o código alternado del bilingüe: alternancia de código que utiliza un bilingüe competente en ambas lenguas y emplea como estrategia de comunicación con otros bilingües; ese código es una expresión de la competencia del bilingüe de recurrir a sus dos códigos en una misma interacción.

-alternancia de códigos de incompetencia: estrategia de comunicación utilizada por un bilingüe dominante que consiste en alternar los códigos recurriendo a su lengua dominante para suplir una falta de competencia en su lengua más débil.

El concepto emparentado de mezcla, está definido por J.F. Hamers y M. Blanc (1983: 455):

«- mélange de code : stratégie de communication dans laquelle un locuteur mêle des éléments ou règles des deux langues et de ce fait brise les règles de la langue utilisée (voir emprunt, alternance de codes).

-mélange linguistique: énoncés utilisant des éléments ou règles des deux langues, soit en alternance, soit en mélangeant les règles ou les éléments. »

-mezcla de código: estrategia de comunicación en la que un hablante mezcla elementos o reglas de las dos lenguas y al hacerlo rompe las reglas de la lengua utilizada (véase préstamo, alternancia de códigos). 
-mezcla lingüística: enunciados que utilizan elementos o reglas de las dos lenguas, ya sea alternadamente o mezclando las reglas o los elementos.

La descripción que antecede surge de estudios dirigidos a problemas de Adquisición de Lenguas Extranjeras, generalmente dedicados a la interferencia unidireccional, es decir, desde la lengua materna, L1, hacia la lengua extranjera, L2.

Al respecto, en su tesis doctoral, María Jesús Santos Maldonado (2002) identifica tres posiciones respecto al grado de influencia de la lengua materna: en primer lugar la interferencia de la lengua materna como primera causa de los errores que se producen en la adquisición de la lengua extranjera; en segundo lugar una disminución de la importancia de la lengua materna debido a la existencia de una gramática universal que es la que rige las distintas etapas de la adquisición de una segunda lengua; en tercer lugar, la lengua materna es vista como generadora de influencia positiva o negativa.

La misma autora sostiene que las diferencias entre L1 y L2 no presuponen dificultades de aprendizaje, afirmando que generalmente las similitudes de las lenguas en contacto son las que generan más problemas (2002: 152).

Por su parte, Domínguez Vázquez (2001: 11) señala que no ha sido profundamente estudiada la influencia de la lengua extranjera, L2, sobre la lengua materna, $L 1,{ }^{3}$ especialmente cuando el dominio de la lengua extranjera es elevado, lo cual daría cuenta de la bidireccionalidad de la interferencia.

Esta visión ampliada de interferencia lingüística es de suma importancia en nuestro problema traductológico, puesto que abre la posibilidad de tratar la influencia de la lengua extranjera en general y del discurso en lengua original, sea ésta lengua materna o lengua extranjera, sobre la producción discursiva en traducción, sea ésta en lengua materna o extranjera. ${ }^{4}$

\footnotetext{
${ }^{3}$ La autora toma la visión de bidireccionalidad de la interferencia del estudio de Czochralski, J. A. (1971), "Zur spralichen Interferenz", en: Lingusitics, An International Review 67, pp. 5-25. A su vez opina que ese aspecto ha sido bastante olvidado, o en su defecto, obviado.

4 "La interferencia de la LE sobre la LM es abordada por Ana María Gentile (2006) al estudiar el contacto particular que se produce en los cursos de lecto-comprensión de francés en la universidad
} 


\subsubsection{Interferencia y transferencia}

Análogamente al alcance del concepto de interferencia, la investigación sobre contacto de lenguas en sentido amplio acusa imprecisión respecto del de transferencia. Domínguez Vázquez (2001: 8-10) sostiene que los conceptos de interferencia y transferencia (positiva, cero y negativa), surgidos del behaviorismo dan cuenta de que la interferencia es un fenómeno interno e individual del hablante que pone en juego más de una lengua. Como dijimos más arriba, el grado de similitud entre esas lenguas determinará si el aprendizaje de una de ellas se ve facilitado (transferencia positiva) por la otra, si no tiene incidencia (transferencia cero), o si se ve dificultado (transferencia negativa).

En su estudio, Domínguez Vázquez (2001: 10) identifica alcances diversos sobre interferencia y transferencia: interferencia como resultado lingüístico visible y transferencia como el proceso psicológico previo que dará lugar a la interferencia; ${ }^{5}$ Transferenz como proceso y transvase de otra lengua y Transfer su resultado, desestimando la designación de interferencia; interferencia como noción globalizadora que abarca tanto al proceso como al resultado y entendiendo que puede ocurrir entre dos sistemas o dentro de un mismo sistema.

En consonancia con la ausencia de designaciones homogéneas en el campo de la Adquisición de Lenguas Extranjeras, también en Traductología coexisten al menos dos conceptos de interferencia como proceso psicolingüístico ineludible en el paso de una lengua a otra que trataremos más adelante en este capítulo [ $\rightarrow$ 3.3.].

\footnotetext{
cuando 'el aprendiz recurre y se sujeta con mayor fuerza ya no a la LM, sino a la LE que está traduciendo' (p. 14).

Este tema es también objeto de un proyecto en curso en la UNLP, dirigido por esta autora e integrado por las profesoras Amalia Forte Mármol, María Inés Perroud y Fabiana Vieguer. En este caso la bidireccionalidad de la interferencia se estudia a partir de la estrategia de transcodificación que el estudiante realiza a lo largo de su lectura del texto en francés, transcodificación mayor cuanto menores son sus conocimientos temáticos y lingüísticos del texto en lengua extranjera" (Gentile, Mármol, Perroud, 2008: 251, nuestra traducción).

${ }^{5}$ Para fundamentar estos alcances, Domínguez Vázquez se basa en Kellermann, E. (1977). "Towards a characterization of the strategy of transfer, Clyne, M. (1969). Transference and triggering, La Haya second language learning", Interlanguage Studies Bulletin 2.1 y Juhász, J. (1980). "Interferenzlinguistik", en: Althaus, P-H/Henne/Wiegand (edts.): Lexikon der germanistischen Linguistik, Tubinga.
} 


\subsubsection{Interferencia y normas}

El lingüista Uriel Weinreich (1963: 1), primer antecedente que mencionan los estudios sobre el tema de este capítulo, sostiene que los mecanismos de interferencia son los mismos cualquiera sea el grado de lejanía o cercanía estructural de las lenguas en contacto, sin que ello signifique tomar en cuenta la cantidad de los casos de su visibilidad. Afirma que en el habla de las personas bilingües las interferencias surgen de la desviación de las normas de cualquiera de las dos lenguas en contacto que les son familiares:

"Those instances of deviation from the norms of either language which occur in the speech of bilinguals as a result of the familiarity with more than one language, i.e. as a result of language contact, will be referred to as INTERFERENCE phenomena. It is these phenomena of speech, and their impact on the norms of either language exposed to contact, that invite the interest of the linguist. "

Esos casos de la desviación de las normas de cualquier lengua que ocurren en el discurso de bilingües como resultado de la familiaridad con más de una lengua, es decir como resultado del contacto verbal, serán referidos como fenómenos de INTERFERENCIA. Estos fenómenos del discurso, y su impacto en las normas de cualquier lengua expuesta al contacto, son los que interesan al lingüista.

Desde la Lingüística General, en 1962 Eugenio Coseriu formula su modelo tripartito (sistema-norma-habla) en la primera edición de Teoría del Lenguaje y lingüística general ${ }^{6,7}$ y ve en la norma un sistema de realizaciones obligadas, de imposiciones sociales y culturales que varía según la comunidad; es decir que dentro del mismo sistema funcional o lengua, coexisten varias normas, lenguaje familiar, popular, especializado, entre otros, siendo entonces la norma, una limitante más fuerte que el sistema (Coseriu, 1989: 98). De allí que el autor plantea, mediante preguntas retóricas, que las innovaciones poéticas generalmente son violaciones o ampliaciones de la norma permitidas por el sistema (Coseriu, 1989: 63) dentro de un concepto de norma que se vincula con lo objetivamente comprobable en una lengua y no con el concepto corriente de norma que se asocia a los criterios de corrección y

\footnotetext{
${ }^{6}$ Weinreich (1963) y Coseriu (1962) expresan los conceptos de norma en la misma época.

${ }^{7}$ La versión que hemos consultado es de 1989, según figura en la bibliografía.
} 
de valoración subjetiva de lo expresado. En resumen, el concepto coseriano de norma se refiere al cómo se dice, normal/anormal, y no al cómo se debe decir, correcto/incorrecto. (Coseriu, 1989: 90).

\subsubsection{Error}

Indudablemente, los conceptos interferencia y error van de la mano. Al respecto, Carsten Sinner (2004: 73) afirma que desde Uriel Weinreich en adelante, ha prevalecido la idea de que la interferencia es infracción de la norma, por lo tanto se la ha tratado como fuente de error, en especial en los estudios relacionados con la Adquisición de Lenguas Extranjeras. Sin embargo, no siempre la influencia de una lengua conduce a una infracción de la norma en la otra lengua, observando que frecuentemente la influencia tiene como resultado una elevación de la frecuencia de uso de ciertos elementos, sin que ello implique infracción de la norma, enfoque que ha sido muy valioso en nuestro estudio.

Por su parte, Stephen P. Corder (1991: 32) sostiene que el concepto de error abre dos corrientes en el campo de la metodología: la que asigna al método de enseñanza la responsabilidad de los errores de actuación, ${ }^{8}$ por lo tanto si el método fuera perfecto, el que aprende no produciría errores; la segunda postura, que sostiene que siempre habrá errores a pesar de los esfuerzos por evitarlos, parte de la naturaleza imperfecta del mundo (Corder, 1991: 37-38).

Cabe aclarar que aparece inestabilidad de designación entre error y falta, problema que Corder resuelve mediante el criterio de sistematicidad como rasgo diferenciador. Partiendo de la distinción entre los errores de actuación que se caracterizan por ser asistemáticos y los errores de competencia que son sistemáticos, el autor da el nombre de falta a los primeros, es decir al error de actuación, y designará error al segundo, es decir, cuando hay sistematicidad, lo que revela una competencia transitoria del aprendiente. De ello se desprende que, a

\footnotetext{
${ }^{8}$ Remite a la oposición clásica entre competencia y actuación. La competencia es «lo que el hablante de una lengua sabe implícitamente. La competencia del hablante-oyente puede ser expresada, idealmente, por un sistema de reglas que relaciona representaciones fónicas con sus interpretaciones semánticas». La actuación, en inglés 'performance', remite a «lo que el hablante de una lengua dice y oye (i.e. la producción y la percepción de habla). La actuación provee los datos para la investigación de la competencia. (Saussure usa al menos una vez exécution en un sentido análogo)». (Chomsky, 1970: 221-222). Introducción, versión, notas y apéndice de C.P. Otero.
} 
diferencia del error, que es sistemático, la falta no reviste importancia en el proceso de aprendizaje. ${ }^{9}$

Esta discusión sobre el alcance de las definiciones provenientes del campo de la Adquisición de Lenguas Extranjeras, nos ha hecho reflexionar sobre la designación que utilizaríamos en nuestra investigación traductológica y que ha sido el concepto operativo de anomalía [ $\rightarrow$ Capítulo V, Metodología. 5.6.].

\subsection{Clasificación de las interferencias}

La clasificación de las interferencias refleja la evolución de los estudios lingüísticos, en los que identificamos un primer interés orientado a la palabra y extendido hasta la oración, que denominamos tradicional siguiendo los lineamientos de Uriel Weinreich, al que se sumarán los niveles discursivo y pragmático, o clasificación que denominamos contextual, en sentido amplio. Es decir que el hecho de considerar a las lenguas como estructuras y como hechos sociales son las dos ideas que orientan la clasificación.

\subsubsection{Clasificación tradicional}

La clasificación tradicional de Uriel Weinreich (1963: 14-62) postula la existencia de interferencia fonética, gramatical y léxica.

\subsubsection{Interferencia fonética}

La interferencia fonética corresponde a la manera en que el hablante percibe y reproduce sonidos de una lengua segunda según las reglas de la lengua primaria.

\footnotetext{
9 "Los errores de los alumnos, por tanto, nos proporcionan evidencia del sistema de la lengua que están utilizando (es decir, que han aprendido) en un momento específico del curso (y debemos insistir en que están utilizando algún sistema, aunque no sea aún el correcto) y son importantes a tres niveles diferentes. En primer lugar, para el profesor, puesto que le dicen, si emprende un análisis sistemático, cuánto ha progresado el alumno hacia su meta y, consecuentemente, qué es lo que queda por aprender. Segundo, proporciona al investigador evidencia de cómo se adquiere o aprende una lengua, qué estrategias o procedimientos está empleando el alumno en su descubrimiento de dicha lengua. Tercero ( $y$ en un sentido es el aspecto más importante) son indispensables para el propio alumno, puesto que podemos considerar que cometer errores es un mecanismo que éste utiliza para aprender; es un modo de que dispone para probar sus hipótesis acerca de la naturaleza de la lengua que está aprendiendo. Cometer errores es, pues, una estrategia que se emplea tanto por los niños que adquieren su lengua materna como por los individuos que aprenden una lengua segunda" (Corder, 1991: 37, 38).
} 
La interferencia aparece cuando un bilingüe identifica un fonema del sistema secundario reproduciéndolo según las reglas de sistema primario.

\subsubsection{Interferencia gramatical}

La interferencia gramatical es considerada por Weinreich como uno de los temas más debatidos y complejos de la lingüística general. Ella engloba a las realizaciones tanto morfológicas como sintácticas, siendo las interferencias correspondientes a las relaciones gramaticales muy comunes en el bilingüe, especialmente en lo que se refiere al orden sintáctico (1963: 29, 37-38).

La morfología trata de la estructura interna de las palabras, partiendo de la unidad significativa mínima que es el morfema y deteniéndose en la palabra. La sintaxis, en cambio, se ocupa de la combinatoria a partir de la palabra y se detiene en la oración. Por lo tanto, la diferencia fundamental entre morfología y sintaxis reside en el hecho de que la primera tiene en la palabra a su unidad máxima de análisis, mientras que la sintaxis comienza su análisis en la palabra y se detiene en su unidad máxima que es la oración (Di Tullio, 1997: 17, 31).

Con respecto a las unidades mínimas que pueden conformar una palabra se diferencian, por un lado, los formantes morfológicos o morfemas léxicos que tienen significado léxico y que pertenecen a clases abiertas, es decir, sustantivos, adjetivos, adverbios, verbos, y por el otro, los formantes gramaticales, que tienen significado gramatical y que se agrupan en clases cerradas, es decir, preposiciones, conjunciones, afijos en palabras derivadas, formantes compuestos (Di Tullio, 1997: 32).

\subsubsection{Interferencia léxica}

La interferencia léxica de Weinreich tiene un punto de contacto con la interferencia gramatical, especialmente en el aspecto morfológico. En función de la diferencia entre formantes léxicos y gramaticales, ha habido nuevas propuestas que incluyen en la interferencia léxica tanto la palabra como unidad indivisible como a los formantes léxicos; éstos pertenecen a las clases abiertas (sustantivos, adjetivos, adverbios, verbos), y por lo tanto afectan tanto a la forma como al contenido, es 
decir que están habilitados para provocar interferencia semántica. En base a los principios saussurianos según los cuales el signo presenta una estructura que asocia significante y significado, la categoría de la interferencia que describimos reúne también esos dos niveles y su denominación es interferencia léxicosemántica.

\subsubsection{Clasificación contextual}

Como dijimos más arriba, la clasificación contextual engloba los niveles discursivo y pragmático que se explican a continuación.

\subsubsection{Interferencia discursiva}

El término discurso supone una serie de oposiciones clásicas como discurso vs. oración, discurso vs. lengua o discurso vs. enunciado. El límite del análisis gramatical es la oración y, más allá de esa unidad, entramos en el terreno del discurso; al mismo tiempo, los hablantes se comunican mediante enunciados que se alejan de la oración como entidad idealizada. El análisis del discurso ha ido más allá de la oración, intentando comprender cómo se lo construye, cuáles son las manifestaciones formales que dan coherencia a esa organización transoracional, las cuales están vinculadas con reglas relativas a los géneros de discurso, es decir a prácticas sociodiscursivamente reguladas (Charaudeau y Maingueneau, 2005: 179).

De manera operatoria, nos referimos a interferencia discursiva cuando ella excede los límites de la oración y está vinculada con el contexto en sentido restringido o cotexto. Coincidimos con Jörg Seib (2001: 52) en que la interferencia discursiva pertenece a la lengua comprendida como sistema cerrado mientras que la interferencia pragmática toma en cuenta factores extra-discursivos. Sin embargo, hay que señalar que el límite entre interferencia pragmática e interferencia discursiva no siempre es claro puesto que para el análisis de ambos campos se recurre al contexto.

\subsubsection{Interferencia pragmática}

El adjetivo pragmático puede referir a uno de los tres componentes de la lengua -sintáctico, semántico, pragmático- según la tripartición de Charles Morris 
(1938) que indica la relación de los signos con los usuarios. Actualmente, el componente pragmático remite a los procesos de interpretación en contexto (Charaudeau y Maingueneau, 2005: 457), tomando operativamente al contexto desde una noción amplia que reúne tanto el entorno verbal, también denominado cotexto, como la situación de comunicación (Charaudeau y Maingueneau, 2005: 124).

El adjetivo pragmático tiene usos amplios, frecuentemente asociados al adjetivo cultural, lo que indica que entre ambos existen puntos en común, puesto que tanto pragmático como cultural son categorías que se relacionan con la situación de comunicación a través de los usuarios de la lengua que constituyen uno de sus componentes.

En el área de contacto de lenguas, los primeros estudios sobre interferencia pragmática pertenecen al lingüista australiano Michael Clyne, en los años '70. La interferencia pragmática refiere a los calcos de unidades o estructuras del habla o sistema idiomático-normativo, que no pueden explicarse como calcos sintácticos en su relación con el sistema de la lengua pero tampoco encajan en los niveles tradicionales de interferencia como componentes extralingüísticos. Además, es un fenómeno asociado tanto a bilingües como a personas que experimentan situaciones más elaboradas y diferidas de contacto de dos lenguas, como la traducción (Gómez Capuz, 2001, Parte 1).

\subsection{Interferencia en traducción}

El concepto general de interferencia en relación con el Contacto de Lenguas y la Adquisición de Lenguas Extranjeras encuentra puntos en común con la aplicación a la traducción, pero además, la interferencia en traducción muestra características específicas.

Como ya hemos enunciado, el macroproceso de traducción implica como mínimo dos fases que son los procesos de comprensión y la producción discursiva o reexpresión, entre los cuales existe una interfaz que es el proceso de transferencia. Todos ellos están atravesados por el universal o mecanismo por defecto de 
interferencia, que condiciona los mecanismos discursivos relacionados con la memoria (Toury, 2004: 345).

La interferencia estudiada desde la Lingüística en su relación con las lenguas en contacto como efecto natural de situaciones sociales -caso de la inmigración- por un lado, o como efecto de la Adquisición de Lenguas Extranjeras, por otro lado, presenta puntos en común con la interferencia en traducción, ya que esta última supone, en primer lugar, el contacto de dos sistemas lingüísticos con especificidades conceptuales y morfosintácticas propias, haciendo uso de los cuales, el traductor tendrá que resolver problemas de índole tanto lingüístico-textual como cultural o pragmático [ $\rightarrow$ Capítulo I, Marco teórico y Antecedentes. 1.1.5.].

Al respecto, García Yebra (1997: 359) ve en la interferencia lingüística del traductor efectos análogos a los que aparecen en el contacto interlingüístico, por debilidad en el conocimiento o dominio de la lengua propia, mientras que Jean Delisle postula que cuanto mayor es el conocimiento lingüístico de quien traduce, menor será el riesgo de interferencia, de allí que el perfeccionamiento lingüístico es considerado como una actividad individual y progresiva en la que el trabajo contrastivo encuentra su espacio (1997: 46).

La noción de interferencia en el proceso de traducción escrita u oral es citada por la mayor parte de las reflexiones traductológicas provenientes de diferentes corrientes, lingüística, cognitiva o cultural, entre otras, y es entendida, generalmente, como contaminación de la lengua-cultura desde la que se traduce hacia la lenguacultura meta. A título ilustrativo, mencionamos los recurrentes conceptos de préstamo en su forma original o extranjerismos, de préstamo naturalizado a la lengua-cultura de llegada y de calco. El préstamo se refiere al mínimo esfuerzo por parte de la lengua-cultura receptora, porque ella toma directamente la forma extranjera creando sin proponérselo, o bien haciéndolo, una atmósfera de exotismo en la expresión o de color local (Vinay y Darbelnet, 1958: 47); el préstamo naturalizado remite a formas que son tomadas de otras lenguas, pero que se adaptan fonética o morfológicamente a la lengua-cultura de llegada; por último, el calco se produce cuando el sintagma de partida es sometido a una traducción literal, 
cuyo resultado es la conservación de la estructura sintáctica superficial de origen dicha en palabras de la lengua meta. ${ }^{10,11,12}$

En Adquisición de Lenguas Extranjeras, la influencia de la lengua materna es inconsciente o difícilmente controlable, ya sea en el proceso de acercamiento a la nueva lengua, en el proceso de almacenamiento de las unidades lingüísticas y en sus reglas morfosintácticas de combinación, como también en los hábitos de la lengua materna.

En Traductología, la interferencia es considerada como un riesgo especialmente en lenguas de familias cercanas, porque el calco tanto léxico como sintáctico representa menor esfuerzo para la reexpresión (Lederer, 2003: 17), mientras que otros enfoques afirman que la distancia entre lenguas no tendría influencia automática en el grado de interferencia, sino en su visibilidad (Toury, 2004: 346).

En las afirmaciones que preceden, inferimos que, análogamente a lo que señalamos en cuanto a la imprecisión del término interferencia, en las dos posturas anteriores, el acercamiento al término es diferente: Marianne Lederer toma a la interferencia de manera global y no diferenciada para referir al mecanismo y a su manifestación negativa; por su parte, Gideon Toury reserva el término interferencia únicamente para el mecanismo, mientras que su resultado será su grado de visibilidad.

En nuestro estudio, hermos adoptado el enfoque de Toury porque establece claramente la diferencia entre el mecanismo de interferencia presente durante el proceso de traducción y su visibilidad como resultado.

\footnotetext{
${ }^{10}$ Remitimos a Valentín García Yebra (1997: 339-358) para el tratamiento de los términos préstamo y calco.

11 Sobre presencia de préstamos en traducciones de la literatura argenitna del siglo XX, véase Willson, Patricia (2004 : 178-182).

${ }^{12}$ Sobre norma, neología, préstamos y calcos véase Gentile, Ana María (2007: 164-188).
} 


\subsubsection{Interferencias según la metáfora del escritorio}

Recordamos que Daniel Gile (2005) utiliza la metáfora del escritorio para explicar cómo se realizan la comprensión y la producción en traducción, según conceptos cognitivos de memoria, procesos que implican interferencias lingüísticas, que él las define como:

" l'irruption d'éléments d'une langue 'parasite' dans une opération en principe interne à une langue donnée ; il peut s'agir d'éléments lexicaux ou syntaxiques, phonologiques ou pragmatiques, voire d'éléments culturels à un niveau plus abstrait (...)». (2005: 177-180)

la irrupción de elementos de una lengua "parásita" en una operación en principio interna a una lengua dada; puede tratarse de elementos léxicos o sintácticos, fonológicos o pragmáticos y hasta de elementos culturales en un nivel muy abstracto (...).

Dentro de esta metáfora, las interferencias lingüísticas de los bilingües activos serían la consecuencia de una mala selección de los documentos que ha realizado el hablante bilingüe, puesto que los documentos de las dos lenguas están ubicados en los mismos anaqueles, más o menos lejos de la mesa de trabajo, según su frecuencia de uso. En traducción escrita, la mesa de trabajo, o memoria de trabajo, necesita despojarse de las huellas de la lengua original y disminuir así la confusión con los elementos que se activan en la lengua meta (Gile, 2005: 180), para lo cual es necesario poner en práctica un análisis consciente, deliberado y sistemático (2005: 111) y los tests de plausibilidad sistemática (2005: 114). Con el primero, el traductor intenta compensar su déficit informacional crónico, guiándolo en la búsqueda de informaciones complementarias. Con los tests de plausibilidad sistemática el autor plantea que la primera lectura de un enunciado no es más que una hipótesis de sentido que el traductor deberá verificar sistemáticamente mediante dos preguntas: lo que el traductor cree haber comprendido ¿es lógicamente coherente con respecto al resto del texto o hay contradicción entre opiniones o hechos descriptos en el mismo texto?; lo que el traductor cree haber comprendido ¿es compatible con lo que él ya sabía de antemano o el enunciado dice algo que el traductor sospecha que es falso? Las respuestas a estas preguntas serán el 
principio de nuevas lecturas hasta la verificación de que las palabras dicen lo que el traductor había comprendido, y con esa hipótesis de sentido, buscará la redacción que exprese de mejor manera el pensamiento del autor, sin necesidad de preservar su estructura lingüística.

El recorrido que propone Gile se acerca al de desverbalización de la Escuela Interpretativa de la Traducción, como camino para reducir las interferencias.

\subsubsection{Bilingüismo en traducción}

Los trabajos sobre interferencia tratan como fenómeno central al bilingüismo, cuyos alcances y definiciones implican estudios interdisciplinarios, con aportes de la Psicología, la Lingüística, la Sociología, entre otras.

El bilingüismo en sentido general y la traducción comparten al menos el hecho de que ambos son la manifestación del contacto de lenguas, y, por lo tanto, fuente inagotable de interferencia.

Georges Mounin (1963) aborda el problema de la traducción y el bilingüismo en el primer capítulo como un caso especial de contacto de lenguas, en el que identifica un esfuerzo consciente para evitar la interferencia definida negativamente como lo hace Uriel Weinreich, es decir como desviación de la norma lingüística:

« La traduction, bien qu'étant un situation non contestable de contact de langues, en serait décrite comme un cas limite: celui, statistiquement très rare, où la résistance aux conséquences habituelles du bilinguisme est la plus consciente et la plus organisée; le cas où le locuteur bilingue lutte consciemment contre la déviation de la norme linguistique, contre toute interférence -ce qui restreindra considérablement la collecte de faits intéressants de ce genre dans les textes traduits. » (1963: 5)

La traducción, aun siendo una situación incuestionable de contacto de lenguas, se describiría como un caso límite: un caso, estadísticamente muy raro, en que la resistencia a las consecuencias habituales del bilingüismo se hace más consciente y más organizada; el caso en que el hablante bilingüe lucha conscientemente contra la desviación de la norma lingüística, contra toda interferencia -lo cual restringirá considerablemente la recolección de hechos interesantes de ese tipo en los textos traducidos. 
Si bien el conocimiento de dos lenguas es condición necesaria para traducir, no es condición suficiente. Jean Delisle (1984: 34-38, 40) aborda el tema del bilingüismo del traductor, oponiéndolo al bilingüismo oral y completo que está emparentado con el acto verbal espontáneo. Sostiene que el traductor desarrolla su actividad profesional escribiendo a partir de un original, del que tendrá que expresar el sentido y, al igual que Georges Mounin, califica al bilingüismo puesto en juego por el traductor como consciente y organizado, es decir, no espontáneo.

El traductor requiere una comprensión profunda de la lengua desde la que traduce y, como debe mantener intactas dos estructuras lingüísticas en contacto, es central que cuente con aptitud para disociar las dos lenguas que se ponen en juego, lo que contribuirá a desentrañar el sentido de los textos:

« (...) le bilinguisme du traducteur se caractérise par un savoir de compréhension de la langue seconde, une connaissance active des formes écrites de la langue d'arrivée et l'aptitude à dégager le sens d'un texte. "

(...) el bilingüismo del traductor está caracterizado por un saber de comprensión de la lengua segunda, un conocimiento activo de las formas escritas de la lengua de llegada y la aptitud para desentrañar el sentido de un texto.

El enfoque interpretativo de la Teoría Interpretativa de la Traducción, al cual adscribe Delisle, ha sido reticente respecto del aporte de la lingüística a la traducción y se ha desmarcado de esa disciplina; sin restar importancia a los estudios lingüísticos sobre lenguas vecinas y lejanas, esta teoría no los reconoce como su objetivo (Lederer, 2005: 100, tomo 1) y sostiene que el camino para luchar contra las interferencias es la profundización de la segunda fase del proceso de traducción, la desverbalización o disociación de idiomas (Lederer, 2005a: 133, tomo 1), (Lederer, 2005b: 75-84, tomo 3), lo que le permite afirmar que la reformulación o reexpresión, tercera fase del proceso de traducción sea considerada como expresión unilingüe (Israël, 2005: 69, tomo 1). La postura interpretativa pone especial énfasis en independizarse de los signos lingüísticos puesto que la traducción consiste en decir de otra manera un concepto desverbalizado, al que se llega por diversos caminos, de los cuales sólo algunos son lingüísticos; de allí que los autores plantean ejercicios 
similares a los de toma de notas en interpretación consecutiva, es decir, prácticas que tiendan a discernir y delimitar las nociones clave de cada texto por traducir (1997: 170) [ $\rightarrow$ Capítulo II, Producción discursiva. 2.6.1.].

\subsubsection{Transferencia positiva, transferencia negativa, transferencia del discurso}

Como venimos diciendo, los planteos o estudios traductológicos están enmarcados dentro del concepto de interferencia, o dicho al modo de Gideon Toury (2004: 269, 346-349), la interferencia es un universal de la traducción o mecanismo por defecto en el proceso de traducción, cuya presencia varía según que esa traducción se ajuste más o menos a la configuración del texto original, desde los niveles más bajos, en lugar de acercarse holísticamente.

Dentro de la diversidad en torno a los conceptos de interferencia y transferencia, Gideon Toury reconoce la existencia de transferencia positiva y transferencia negativa, conceptos que tienen la misma designación que habíamos visto en la primera parte de este capítulo, vinculados a la Adquisición de Lenguas Extranjeras, pero que en Traductología adquieren un sentido propio.

Por transferencia positiva, Gideon Toury entiende la mayor probabilidad de seleccionar características que existen y se utilizan y por transferencia negativa las desviaciones de prácticas normales y codificadas del sistema meta.

A su vez, considera que la transferencia del discurso está ligada a los procesos mentales básicos, especialmente a los cambios rápidos entre código origen y código meta, que alternan en ambas direcciones constituyendo una estrategia universal durante el proceso de producción. Al intentar traducir en una lengua concreta, por norma la lengua que se utiliza para la producción no se recupera desde el conocimiento del hablante sino que está directamente accesible en la lengua original (Toury, 2004: 317, 345).

El grado de interferencia visible está ligado al modo de acercarse al texto original puesto que el traductor siempre está ante la tensión de producir traducciones que representen a sus fuentes de la forma más ajustada posible e intentando, a su 
vez, que respondan a la lengua-cultura meta y se lean como textos autóctonos (Toury, 2004: 346).

El enfoque de este autor respecto al concepto de interferencia toma en cuenta la raíz psicolíngüística de este fenómeno, que es uno solo, pero cuyas manifestaciones pueden ser negativas o positivas. En el primer caso, la visibilidad es notoria porque está emparentada con las nociones de error, fallo, anomalía. En cambio, si la interferencia tiene como resultado una transferencia positiva, solamente se la visualizará como resultado de la interferencia si se contrastan el texto original con el texto traducido.

A esa raíz psicolingüística, el referente de la Escuela de Tel-Aviv le agrega factores socioculturales y textuales decisivos a la hora de establecer la tolerancia a la interferencia, lo que hará posible manipular la interferencia según los objetivos de la traducción. De esta manera, se podrán reducir las interferencias que molesten, ignorar las que no tengan mayores consecuencias e incluso utilizarlas como estrategia en las esferas de la cultura-meta que necesitan desarrollarse (Toury, 2004: 349).

\subsection{Conclusiones}

En las Ciencias del Lenguaje en general y en la Traductología en especial, hemos detectado diversas aplicaciones de interferencia, en su relación con la transferencia, y en su uso como sintagma terminológico asociado a diversos adjetivos: interferencia unidireccional o bidireccionalidad, interferencia directa o interlingual, interferencia indirecta o intralingual, entre otros.

Dentro de esta profusión, nos hemos centrado en seleccionar los términos con los que podremos operar en nuestro estudio y, dentro del campo de Contacto de lenguas, hemos diferenciado la interferencia en Traductología, por un lado, y la interferencia en Adquisición de Lenguas Extranjeras, por el otro.

En general, hay coincidencia en cuanto a que a mayor semejanza entre lenguas, mayor será la probabilidad de que se produzca visibilidad de interferencias a nivel gramatical. Al respecto, García Yebra (1997: 389) postula que la mayor parte 
de los galicismos o calcos del francés son de naturaleza sintáctica, conclusión que compartimos, tanto desde la comprobación didáctica como especulativa. ${ }^{13}$

Por otra parte, coincidimos con la diferenciación touriana entre interferencia como mecanismo por defecto en el proceso de traducción y su visibilidad según transferencia positiva, transferencia negativa y transferencia del discurso (Toury, 2000: 345).

Del juego de tensiones en el proceso de traducción, las decisiones materializadas lingüísticamente responden a distintos factores: factores psicolingüísticos que intrínsecamente son los mismos en el contacto de las lenguas puestas en juego en la traducción, sin que influya en ellos la mayor o menor semejanza entre esas lenguas, pero pudiendo variar la visibilidad de interferencia; factores de tratamiento del texto original, ya sea como organización de constituyentes de los niveles más bajos o microestruturales, ya sea como un todo global, desviándose de las formas normales de la lengua meta si el tratamiento queda limitado al primer caso; factores individuales, según el grado de formación del traductor, vinculado a los dos puntos anteriores y a los esfuerzos especiales que realiza el traductor para disociar y para conectarse con el polo meta, lo que indica que el comportamiento del traductor no es automático; factores socioculturales que inciden en la aceptación de la interferencia en algún nivel, puesto que las comunidades difieren en cuanto a su resistencia a la interferencia, especialmente del tipo negativo, todo ello vinculado con el prestigio relativo de la lengua-cultura de partida sobre la lengua-cultura de llegada (Toury, 2004: 231, 348).

Ante estas encrucijadas, las posturas teóricas varían: la Teoría Interpretativa de la Traducción responde al problema de la interferencia mediante la desverbalización, con la que intenta disminuir -o hacer desaparecer- las

\footnotetext{
${ }^{13}$ El autor divide a los galicismos en léxicos, morfológicos y sintácticos. García Yebra, Valentín (1997: 389). En las investigaciones que hemos realizado en la Facultad de Humanidades y Ciencias de la Educación UNLP, Traducción científico-técnica francés-español: criterios de evaluación; Análisis y cuantificación del error en la evaluación de traducciones especializadas, observamos que, cuantitativamente, la mayor parte de los errores en la traducción especializada, se ubican en el nivel morfosintáctico [ $\rightarrow$ Capítulo I, Marco Teórico y Antecedentes. 1.2.4.].
} 
interferencias de la producción. Sin tomar en consideración los estudios contrastivos entre texto original y texto traducido, como estrategia para la formación traductora, esta teoría considera que la producción en traducción no tiene por qué diferenciarse de una producción original, si es que voluntariamente se ha transitado por la etapa de desverbalización.

Los Estudios Descriptivos de Traducción avanzan en el sentido de la descripción de binomios como herramienta recomendable para investigar, entre otros fenómenos, la visibilidad de interferencias, según las lenguas-cultura que se pongan en juego en géneros discursivos determinados, cuya organización responde a normas sociales.

Aplicando conceptos coserianos, destacamos que el traductor traduce textos en el marco general de dos sistemas lingüísticos en contacto, según normas de uso preferido de orden pragmático-semántico de la lengua-cultura meta, mediante las decisiones que son individuales pero que dan lugar a una producción de libertad condicionada.

La práctica traductora de textos escritos demuestra el inevitable vaivén entre el texto original y la producción de formas equivalentes, situación que desestabiliza el principio que idealmente equipara la producción de un texto con la de un texto traducido.

Según nuestra hipótesis general de partida y a la luz de la terminología touriana, la transferencia del discurso se hace visible en el texto traducido a través de transferencias positivas y negativas, todos ellos fenómenos de la interferencia que, en la etapa final de la traducción que es la reexpresión, pone al desnudo las fortalezas y debilidades del traductor.

En el caso particular de los productos discursivos resultantes de la traducción francés/castellano de textos pragmáticos, hemos elegido las transferencias negativas sintáctico-discursivas que llegan a involucrar tanto las anomalías dentro del sistema como también los casos de elevación de la frecuencia de uso de ciertos elementos, sin que se pueda hablar de infracción de la norma, en coincidencia con lo que sostiene Carsten Sinner, todo ello aplicado a los enunciados elípticos. 


\section{CAPÍTULO IV}

\section{ELIPSIS}

«Depuis des siècles, le concept d'ellipse est une des pierres

d'achoppement de la réflexion grammaticale. En dépit des problèmes épistémologiques qu'elle induit, l'ellipse a toujours eu le mérite de mettre en avant un problème essentiel à toute réflexion linguistique : celui de la confrontation entre parole, les données, les occurrences, et la langue, le système, le type »

Michèle Bigot (2008a: 17)

\subsection{Medios de cohesión y elipsis}

Al finalizar el capítulo anterior de Interferencia, nos referíamos a la presencia, en el producto traducción, de un uso abusivo de elementos sintáctico-discursivos que desnaturaliza el texto de llegada, sin que podamos decir que haya una infracción de la norma, retomando las palabras de Carsten Sinner. Ingresamos así al fenómeno de la cohesión que ha sido ampliamente estudiado y que remite a los medios que se utilizan en la producción discursiva para enlazar las unidades a través de todo el discurso (Larson, 1989: 511). M.A.K. Halliday y R. Hasan (1976) consideran la cohesión como relación intratextual o endofórica que se pone en evidencia a partir de cinco categorías de medios cohesivos: referencia, substitución, elipsis, conjunción y cohesión léxica. En traducciones francés/castellano, Sonia Sánchez (1994) identifica como medios cohesivos a los pronombres enclíticos en los verbos castellanos, el restablecimiento de "ce » por "lo", 2 el tratamiento de los pronombres « en » e « $y$ » en su traducción al castellano, las formas pronominales sujeto en castellano y la elipsis. En producción discursiva, el francés admite la elipsis de sujeto de manera limitada, en comparación con el castellano:

\footnotetext{
${ }^{1}$ Desde siempre, el concepto de elipsis ha sido uno de los obstáculos en la reflexión gramatical. Pese a los problemas epistemológicos que implica su tratamiento, la elipsis ha conservado el mérito de poner en evidencia un problema esencial en toda reflexión lingüística: la confrontación entre el habla, los datos, las ocurrencias, y la lengua, el sistema, el tipo.

${ }^{2}$ Para destacar y diferenciar los sistemas lingüísticos de pertenencia de los enclíticos citados, hemos utilizado comillas latinas («») y caracteres en cursiva para los franceses y únicamente las comillas inglesas ("') para los castellanos.
} 
" Une conséquence majeure de cette caractéristique de l'espagnol est l'emploi d'une fréquence nettement supérieure au français de l'ellipse du sujet dans les enchaînements d'énoncés en discours (...) » (Sánchez, 1994: 51).

Una consecuencia mayor de esta característica del español es el empleo de una frecuencia netamente superior, en comparación con el francés, de la elipsis de sujeto en los encadenamientos de enunciados discursivos.

\subsection{Concepto de elipsis}

Dentro de la gramática, el concepto elipsis ha sido y sigue siendo discutido, según posturas a favor y en contra de su existencia; las primeras lo consideran un mecanismo regularizador necesario para analizar muchas construcciones de la lengua; en cambio, las posturas que están en contra de la elipsis, la consideran un mecanismo irrestricto que permite operaciones de manipulación al momento de encontrar problemas de análisis.

La gramática generativa identifica al castellano, italiano, rumano y catalán como lenguas que admiten la estructura pro-drop, es decir, que permiten construir oraciones con $\mathrm{SN}$ sujeto elidido pues poseen un rico sistema de desinencias a través del cual se recuperan rasgos de un sujeto pronominal (persona y número), cuando el sujeto no aparece con forma fonética en la oración (Múgica y Solana, 1989: 162, 204).

José María Brucart (2000: 2789) la define como mecanismo limitador de la redundancia léxica de los enunciados:

"La elipsis es, pues, un mecanismo de infraespecificación léxica mediante el cual se evita la realización fónica de alguno de los constituyentes necesarios para interpretar adecuadamente un enunciado. Tal omisión es posible gracias a que el contenido de la unidad elíptica es directamente accesible al oyente a través del contexto discursivo o situacional." 
El concepto de elipsis se ha ido circunscribiendo tanto a través de los estudios generativistas a nivel de la lengua, por un lado, como a través de las investigaciones lingüístico-textuales, por el otro, siendo éstas las que han propuesto inscribirla dentro de la cohesión textual. Muchas veces, la explicación de la noción de elipsis hay que buscarla más allá de la sintaxis oracional, en el encadenamiento pragmático o anafórico-textual de las oraciones. Por lo tanto interesa tanto a la pragmática, en el marco de lo implícito, como a la gramática textual, puesto que forma parte de los recursos cohesivos como elemento endofórico, en oposición a la referencia, de características exofóricas (Bigot, 2008a: 22).

Dado que la noción de anáfora es una constante en cualquier tratamiento de la elipsis, más allá de la teoría del lenguaje que se adopte, citamos la siguiente definición:

« une ellipse est l'anaphore du contenu lexical associé à une catégorie grammaticale identifiée, considérée manquante dans une configuration syntaxique admise canonique par une théorie grammaticale. " (Krazem y Soulet, 2008: 49).

Una elipsis es la anáfora del contenido léxico asociado a una categoría gramatical identificada y considerada faltante en una configuración sintáctica admitida como canónica por una teoría gramatical.

Además, la elipsis no tiene la misma categoría gramatical del elemento que está representando, porque las propiedades relacionales de aquélla no son las mismas que las de la categoría gramatical que la elipsis representa (Krazem y Soulet, 2008: 49).

Con respecto a los tipos de elipsis, según criterios de naturaleza del elemento ausente y de criterios de recuperabilidad, se distinguen la elipsis gramatical y la elipsis contextual.

\subsubsection{Elipsis gramatical}

Históricamente, en el siglo XVI, Francisco Sánchez de las Brozas (El Brocense) fue el primero que trató el fenómeno como recurso gramatical. 
La introducción del concepto de elipsis en la gramática se sustenta en factores léxico-semánticos y/o sintácticos, que generalmente participan en conjunto para justificar la aparición de una categoría elíptica. Los primeros son fundamentales para lograr una correcta interpretación del enunciado al relacionar la categoría elidida con su antecedente. Los segundos, es decir los factores sintácticos, son los que justifican la elipsis pues sin ese elemento regulador, habría construcciones que se apartarían de las reglas estructurales básicas de la sintaxis, de allí que también se la denomine elipsis estructural (Bigot, 2008b: 280).

La elipsis es gramatical cuando los elementos faltantes son gramaticales, como la cópula, y recuperables a partir del contexto oracional (Di Tullio, 1997: 77), a la vez que responden a la tendencia de ciertas estructuras -como la coordinación por ejemplo- a presentar categorías vacías (Brucart, 2000: 2798).

\subsubsection{Elipsis contextual}

Habrá elipsis contextual cuando los enunciados infraoracionales o fragmentos sin autonomía semántica requieran de un contexto discursivo o situación para poder ser interpretados (Di Tullio, 1997: 77; Brucart, 2000: 2796-2798). La elipsis contextual también se la puede denominar elipsis funcional o elipsis discursiva, pues funciona en el uso, sus interpretaciones no están determinadas por reglas gramaticales y es analizada según una gramática del discurso que toma en cuenta el encadenamiento frástico y la situación (Bigot, 2008b: 280, 283).

Este tipo de funcionamiento instalado en lo transfrástico aparece en cualquier discurso pero es utilizado especialmente en el literario como impulso interpretativo, provocando en el lector la necesidad de salir del nivel local de la oración y abrirse a un nivel más global (Wulf, 2008: 275). Un funcionamiento análogo ocurre en el discurso publicitario ligado a lo transfrástico y a lo situacional.

\subsection{Elementos y condiciones fundamentales de la elipsis}

Para que haya elipsis, necesitamos contar con una categoría elidida y con un antecedente que fije el valor léxico que debe atribuirse a esa categoría elíptica. El antecedente está a la izquierda del elemento elíptico en relación anafórica, pero 
también puede encontrarse a la derecha en relación catafórica bajo la designación consecuente ${ }^{3}$ que adoptamos en este trabajo.

En todos los casos, el criterio general es que pueden elidirse únicamente los constituyentes obligatorios, según principios estructurales o léxicos.

\subsubsection{Recuperabilidad}

Este concepto refiere a determinadas condiciones estructurales que permiten al hablante recuperar el elemento elíptico de modo indirecto e intuitivo (Brucart, 2000: 2799).

\subsubsection{Criterios paralelísticos}

En la elipsis de núcleos de sintagmas, se aplican criterios paralelísticos entre los sintagmas que se relacionan entre sí, es decir, el sintagma con núcleo elidido y el sintagma que contiene el antecedente. El paralelismo sintáctico entre los sintagmas involucrados debe ser estricto, lo que implica la presencia de los mismos especificadores, complementos y adjuntos del núcleo que forman parte del hueco de la oración elíptica. Por otra parte, en la oración con núcleo elidido, las unidades que adoptan valores distintos de los correspondientes a la oración con antecedente constituyen el resto (Brucart, 2000: 2807).

\subsubsection{Mecanismos endofóricos: anáfora y catáfora}

La anáfora en los enunciados con núcleo elíptico puede remitir a un antecedente dentro de una misma oración o de otras anteriores. La elipsis funciona anafóricamente y la recuperabilidad la encontrará en el contexto previo.

La catáfora, en cambio, sólo puede remitir a un consecuente que esté dentro de la misma oración, cuya estructura preferencial es predicativa o atributiva. $[\rightarrow$ Capítulo IV, Elipsis. 4.3., 4.4.1.2.].

\footnotetext{
${ }^{3}$ También recibe las designaciones de antecedente o subsecuente (Brucart, 2000: 2859, nota 97).
} 


\subsection{Elipsis nominal}

Como dijimos, la elipsis se realiza sobre elementos obligatorios y, en el caso de la elipsis nominal, estos elementos son los argumentos integrales o mecanismo máximo, y los núcleos de los SSNN o mecanismo parcial [ $\rightarrow$ Capítulo IV, Elipsis. 4.3.].

Es importante diferenciar los argumentos, que son obligatorios, de los adjuntos o complementos circunstanciales, que son opcionales, cuya falta de realización fonética no configura una elipsis.

Semánticamente, sólo la elipsis de un argumento es capaz de establecer una relación de correferencia entre antecedente y categoría elidida (Brucart, 2000: 2806).

\subsubsection{Concepto de argumento}

Múgica y Solana (1989: 201) definen al argumento como:

"término tomado de la Lógica; ocupa una posición en la oración y recibe rol o papel semántico de un predicado."

El predicado determina cuántos y cuáles argumentos son necesarios, sin restringir el concepto de predicado al verbo sino ampliándolo a los adjetivos, sustantivos y preposiciones.

En relación con los verbos, el grado o valencia de un predicado es el número de argumentos seleccionados; Di Tullio (1997: 84) reconoce los cuatro siguientes: el predicado cero-ádico que no necesita argumento como en los verbos impersonales y los verbos cópula, presentes sólo como expediente gramatical que asegura la flexión; el predicado monádico que admite un solo argumento, denominado argumento externo o sujeto correspondiente a los verbos intransitivos propiamente dichos o inergativos; el predicado diádico o de dos argumentos, que son el externo o sujeto y un complemento, es decir, de los verbos cuya diátesis transitiva alcanza el grado de un solo complemento; el predicado triádico o de tres argumentos (externo o 
sujeto y dos complementos) como el caso de los verbos que admiten lo que algunos autores denominan objeto secundario. ${ }^{4}$

\subsubsection{Elipsis del argumento externo o sujeto ${ }^{5}$ (mecanismo máximo)}

Los predicados cero-ádicos no necesitan argumento externo o sujeto (llueve, nieva), de allí que la ausencia de argumento externo no determina elipsis. En las lenguas como el francés o el inglés, el lugar del argumento debe estar ocupado, de allí que recurren a pronombres de tercera persona que acompañan a los verbos cero-ádicos, con la única función de cumplir con un expediente gramatical, sin contenido semántico (il pleut, il neige/ it rains, it snows).

En predicados monádicos, diádicos y triádicos, que necesitan argumento externo, la presencia fonética de argumento sujeto, en español, es fluctuante, mientras que en francés son muy pocas las ocurrencias de inexistencia de sujeto. Esta diferencia de comportamiento lingüístico instituye una divergencia entre los gramáticos: para algunos, la categoría vacía sujeto en lenguas que no lo necesitan por su rica flexión no es considerada elipsis (Di Tullio, 1997: 77), pues la función sujeto queda asegurada por esa flexión verbal. Otros gramáticos, por el contrario, consideran al sujeto necesario estructuralmente y, por lo tanto, su ausencia fonética se entiende como elipsis (Brucart, 2000: 2799). Éste es el enfoque que tomaremos en nuestro estudio, es decir, que consideramos elipsis de sujeto a su ausencia fonética en la expresión de los textos en español.

Uno de los requisitos para identificar una elipsis de argumento externo es que en la misma oración queden fijados sus rasgos gramaticales básicos, es decir, la flexión verbal de persona y el número; en cambio en cuanto al género, existen

\footnotetext{
${ }^{4}$ Alloa, Hugo y Miranda de Torres, Silvia (2001: 180-187) presentan la diátesis transitiva definiendo el objeto secundario como el sintagma preposicional que se construye en castellano y en francés, con verbos transitivos de doble complemento como donner / dar o remettre/ entregar.

5'Dentro de la gramática generativa, y desde Williams 1981, se denomina 'argumento externo' al argumento sujeto agente o experimentante de un verbo transitivo, y 'argumento interno' al argumento objeto o tema, atendiendo a su relación más lejana o más cercana con el verbo para la expresión de la predicación. El argumento interno u objeto está regido semántica y sintácticamente por el verbo y puede ser elidido en determinados contextos sin que ello afecte a la clasificación del verbo".
} 
indicaciones precisas que trataremos más adelante en este capítulo, bajo el título Elipsis nominal y cambio de género.

En cuanto a la distribución textual, el valor léxico de la elipsis debe aparecer en el discurso inmediatamente previo, siempre que no haya ningún otro antecedente más adecuado.

Desde una perspectiva semántica del argumento externo o sujeto, la función agente es más prominente que la función instrumento; sin embargo, en caso de duda, el contexto discursivo y situacional fija el valor léxico de la categoría elíptica.

\subsubsection{Elipsis de los argumentos internos (mecanismo máximo)}

Los predicados que pueden presentar argumentos internos son los diádicos y triádicos. El mecanismo utilizado para representarlos es el uso de pronombres clíticos de acusativo y dativo.

Los pronombres personales de tercera persona del español conservan parcialmente el sistema casual latino, de manera que lo, la, lo derivan de los demostrativos acusativos ILLUM, ILLAM, ILLUD, correspondiendo su uso etimológico al objeto directo; por su parte, el pronombre le deriva del dativo ILLI y su uso etimológico es la función objeto indirecto.

Con respecto al objeto indirecto, el español admite la duplicación con clítico dativo. En cuanto al objeto directo, la duplicación con clítico acusativo es agramatical en español peninsular y gramatical en español rioplatense.

Cuando el uso de los pronombres lo, la, lo, le, no viene determinado por la posición (o función) sintáctica del antecedente, tradicionalmente se lo denomina, loísmo, laísmo, leísmo. La gramática normativa observa que en España el leísmo más frecuente y extendido es el referido a un objeto directo singular masculino y personal (Fernández-Ordóñez, 2000: 1319).

En resumen, el castellano peninsular y el rioplatense difieren pues:

-la duplicación del objeto directo con clítico acusativo es agramatical en español peninsular y gramatical en español rioplatense; 
-el anafórico le es de uso extendido en España para recuperar un SN objeto directo, mientras que en las mismas circunstancias, el rioplatense adscribe a las normas del sistema general del castellano utilizando el clítico lo.

\subsubsection{Elipsis de los núcleos de los SSNN (mecanismo parcial)}

La elipsis parcial opera sobre el núcleo léxico de un sintagma que es obligatorio para generar un SN. El núcleo elíptico (hueco) podrá recuperarse si se cumple la condición de que en el enunciado elíptico parcial (resto) esté realizado el determinante $y$, a veces opcionalmente, el complemento del núcleo elidido. ${ }^{6}$

A diferencia de la elipsis de un argumento que es la única que puede establecer una relación de correferencia entre antecedente y categoría elidida, en la elipsis parcial o de núcleo, por ser de rango menor, la relación de identidad no es de referencia sino de sentido.

Según criterios estructurales y comparativos o paralelísticos, el resto, que es el que asegura la recuperabilidad de la categoría elíptica, no debe reproducir elementos idénticos que rodean al núcleo en la primera ocurrencia [ $\rightarrow$ Capítulo IV, Elipsis. 4.3.2.].

El mecanismo parcial, muy frecuente en las lenguas naturales, afecta al núcleo de los SSNN y se realiza según ciertas condiciones estructurales y léxicas. ${ }^{7}$ Esta elipsis básica puede estar acompañada por otras que afectan a proyecciones del núcleo, siendo el resultado de la elipsis parcial la aparición de un hueco acompañado, como mínimo, por la realización fonética de una de las proyecciones

\footnotetext{
${ }^{6}$ Brucart toma de la terminología anglosajona los conceptos de resto o elemento fonético representante de todo el sintagma y hueco o categoría elíptica, siendo la función del resto asegurar la recuperabilidad de la categoría elíptica.

${ }^{7}$ El determinante artículo definido, en español, puede combinarse con otras categorías distintas al sustantivo: SSAA, SSPP, oraciones de relativos, que forman SSNN con elipsis parcial o sin núcleo nominal, construcciones que no se dan en francés, lengua que recurre a los adjetivos demostrativos. (Ej.: La foto de este hombre es la que apareció en todos los diarios/La photo de cet homme est celle qui a paru dans tous les journaux). En español también podría usarse el demostrativo con sus propiedades deícticas (La foto de este hombre es aquella que apareció en todos los diarios), en cambio en francés el demostrativo pierde tales propiedades al sustituir al artículo (Leonetti, 2000: 818).
} 
del núcleo nominal, lo que da lugar al resto, es decir, el elemento que garantiza la recuperabilidad de la identidad de sentido.

La elipsis parcial puede presentarse dentro de la misma oración, en el discurso previo en donde halle su antecedente endofóricamente o bien en el contexto en el que se produce el enunciado, en el que el antecedente se interprete por ostensión, deícticamente.

La aplicación de criterios paralelísticos estrictos es fundamental para juzgar sobre la gramaticalidad de la realización de una elipsis parcial y asegurar su interpretación: los dos sintagmas, sintagma con antecedente y sintagma con hueco y resto deben contener exactamente los mismos especificadores, complementos y adjuntos del núcleo.

\subsubsection{Elipsis nominal y cambio de género}

El cambio de género implica que se realicen las siguientes observaciones:

-si el cambio de género se establece entre un sustantivo elíptico y su antecedente, el resultado es agramatical, puesto que en el sustantivo el género es una propiedad léxica inherente en los nombres, mientras que en los adjetivos el género es una propiedad derivada de una regla de concordancia con el sustantivo.

-si el cambio de género se establece entre un adjetivo elíptico y su antecedente, el resultado no es agramatical (Brucart, 2000: 2790).

\subsubsection{Elipsis nominal y cambio de número}

Con respecto a la relación entre la elipsis nominal y el cambio de número, es posible realizar elipsis nominal con variación de número del nombre antecedente, puesto que:

"los nombres entran a la derivación sin rasgo de número, el número se obtiene mediante una operación de concordancia. La identidad se obtiene en algún punto de la derivación. Por otro lado, los nombres entran a la derivación con el 
rasgo de género ya especificado y no existe ningún punto en la derivación en donde la identidad se pueda satisfacer." (Depiante y Hankamer, 2005: 3). ${ }^{8}$

\subsubsection{Presencia de determinantes y complementos}

Los requisitos estructurales para la elisión del núcleo del sintagma nominal indican que ella sólo puede realizarse si el determinante de su proyección sintáctica aparece fonéticamente realizado, debido al valor referencial que éste posee.

Si el determinante en cuestión es un artículo determinado fonéticamente átono, es obligatoria la presencia de un complemento preposicional sobre el que aquél pueda apoyarse prosódicamente; la segunda restricción es que únicamente la preposición de podrá encabezar el SP complemento.

En modo contrario, si el determinante del SN con núcleo elíptico no es un artículo definido, el complemento puede ser introducido por cualquier preposición.

\subsection{Elipsis verbal: vaciado, hueco y resto ${ }^{9}$}

El vaciado es un mecanismo de elipsis parcial que afecta al SV muy frecuente en las lenguas naturales.

En las oraciones habrá vaciado si y sólo si se elide el núcleo verbal. Esta elipsis básica puede estar acompañada por otras que afectan a adjuntos y complementos; el resultado del vaciado es la aparición de un hueco que necesariamente debe presentar un complemento o un adjunto, como mínimo, lo que da lugar al resto. Dicho de otro modo, el resto tiene como condición necesaria y suficiente la realización fonética de un complemento o un adjunto del verbo que asegure la recuperabilidad de la entidad elidida.

\footnotetext{
${ }^{8}$ En el artículo citado, los autores refieren a un trabajo previo de Depiante y Masullo (2001) que consigna el concepto reformulado por la cita actual.

${ }^{9}$ Según la denominación de Brucart (2000: 2812) que se inspira en la bibliografía anglosajona.
} 


\subsubsection{Características del vaciado}

En principio, el vaciado puede aparecer con todo tipo de evento ${ }^{10}$ cualquiera que sea el modo en que se realiza la acción y en contextos en los que puedan aplicarse los principios paralelísticos de contraste, como ocurre especialmente con la coordinación copulativa, pero también en otras estructuras sintácticas como la coordinada adversativa, el esquema comparativo explícito e implícito, el esquema hipotético; la yuxtaposición y la relativa especificativa.

Generalmente, el vaciado es un mecanismo que se realiza en el nivel oracional, aunque puede aparecer en contextos discursivos de yuxtaposición de un constituyente infraoracional que remite a un constituyente del enunciado anterior emitido por otro interlocutor. La yuxtaposición paralelística puede subrayar un contraste. $^{11}$

El español posibilita la movilidad de los complementos del predicado, de allí que el vaciado también pueda representar entidades con antecedente no directamente contiguo; sin embargo existen limitaciones y recursos lingüísticos para evitar ambigüedades. Dentro de la aparición de agramaticalidades, se destaca la compleja relación con la negación y con la aparición de operadores de polaridad.

\subsubsection{Reducción del sintagma verbal coordinado}

Mecanismo utilizado en las estructuras coordinadas, en las que la elipsis alcanza al verbo y al sujeto.

\subsubsection{Reducción del sintagma verbal coordinado y vaciado}

El francés y el inglés no exhiben distinciones formales entre sujeto y objeto directo, lo que permite que ciertas oraciones elípticas puedan ser leídas como

\footnotetext{
${ }^{10}$ (...) "Evento engloba (...) acciones (acontecimientos llevados a cabo voluntariamente por un sujeto agente), procesos (acontecimientos desencadenados espontáneamente o causados por una fuerza externa al proceso) y estados (situaciones que se mantienen a lo largo de un periodo)..." Miguel, Elena (2000: 2979), nota 1.

${ }^{11}$ Brucart (2000: 2792), nota 7, en donde el autor refiere al concepto de coordinación escindida de Hudson.
} 
reducción de SV coordinado o como vaciado, con la consiguiente ambigüedad. En castellano este fenómeno puede generarse solamente en oraciones que presentan un SN capaz de ser interpretado como sujeto o como complemento de objeto directo y el problema de ambigüedad resultante se soluciona asignando al hueco la interpretación más simple (Brucart, 2000: 2821).

\subsubsection{Partícula u operador de polaridad ${ }^{12}$}

Adverbio que representa la afirmación o la negación en grado primario sí/no o secundario también/tampoco. Pueden funcionar semánticamente como proformas oracionales, reproduciendo enunciados inmediatamente anteriores y pragmáticamente respondiendo a preguntas o indicando conformidad o disenso, para lo cual habrá que efectuar las modificaciones discursivas necesarias según la información del enunciado anterior. Las partículas también y tampoco reafirman la polaridad de la cláusula antecedente, en cambio sí y no la alteran (Di Tullio, 1997: 288). Su distribución en la elisión del SV es la siguiente:

FIGURA 6. Distribución de los operadores de polaridad en la elisión del SV (Brucart, 2000: 2829)

\begin{tabular}{|l|l|l|}
\hline $\begin{array}{l}\text { Polaridad de la oración } \\
\text { antedecente }\end{array}$ & $\begin{array}{l}\text { Polaridad de la oración } \\
\text { elíptica }\end{array}$ & $\begin{array}{l}\text { Resto en el predicado } \\
\text { elíptico }\end{array}$ \\
\hline Afirmativa & Afirmativa & también \\
\hline Negativa & Afirmativa & Sí \\
\hline Afirmativa & Negativa & No \\
\hline Negativa & Negativa & Tampoco \\
\hline
\end{tabular}

\footnotetext{
${ }^{12}$ Tales partículas pueden tener otras funciones y usos que escapan al tema de la elipsis.
} 


\subsubsection{Elisión del sintagma verbal con partícula de polaridad}

La elisión del sintagma verbal es una construcción paralelística cuyo hueco no incluye a la partícula de polaridad, siendo ésta (también, tampoco, sí, no), el único resto del predicado elidido que asegura la recuperabilidad (Brucart, 2000: 2828).

Se identifican restricciones para la realización de la elisión del SV con partícula de polaridad vinculadas con estructuras de coordinación, esquemas de subordinación -especialmente la condición-, casos de ambigüedad por identidad borrosa y el esquema de la negación correctiva.

En el terreno de la selección léxica, la realización de la elisión del SV con partícula de polaridad está relacionada con el tipo de verbos asertivos que sí la admiten frente a los factivos que no lo hacen.

\subsubsection{Elisión del sintagma verbal con partícula de polaridad y vaciado}

En el mecanismo de elisión del sintagma verbal con partícula de polaridad y en el de vaciado, se observan las siguientes diferencias: 1. el vaciado se establece preferentemente a nivel oracional, mientras que la elisión del SV con partícula de polaridad, es frecuente en enunciados independientes sin antecedente, por lo tanto en contextos oracionales y también discursivos; 2. el vaciado no admite relación catafórica entre hueco y consecuente, mientras que la elisión del SV con partícula de polaridad sí lo admite, si y sólo si se cumplen condiciones muy precisas. ${ }^{13}$

\subsubsection{Anáfora de complemento nulo}

La anáfora de complemento nulo tiene la característica de que el núcleo del predicado está ocupado por un verbo en forma personal que selecciona una oración de infinitivo elíptica, cuyo contenido está presente en el contexto previo. Admiten la anáfora de complemento nulo, los predicados que aceptan la elipsis de un objeto directo oracional en cláusulas subordinadas introducidas por cuando, si, como, donde, porque.

\footnotetext{
${ }^{13}$ Sobre las limitaciones de la catáfora en la elisión en el SV, véase Brucart (2000: 2823) , §43.2.3.1.
} 
Es un fenómeno defectivo porque muchos verbos no admiten esta clase de elipsis, como es el caso de los verbos que suelen permitir que su objeto proposicional sea representado por el clítico lo.

En cambio, entre otros, la admiten los modales deber, poder, querer; los aspectuales acabar de, comenzar a; verbos pronominales que expresan actitud o estado psicológico; verbos que rigen un complemento directo.

Su recuperabilidad es pragmática y se infiere a partir de la situación de enunciación, razón por la cual se la suele estudiar como elipsis contextual en lugar de gramatical.

\subsubsection{Truncamiento}

Existe truncamiento cuando desaparecen los constituyentes de una oración interrogativa indirecta, excepto el sintagma interrogativo que la encabeza.

El análisis estructural del truncamiento es polémico, siendo abordado ya como análisis oracional, ya como no oracional.

\subsection{Importancia del fenómeno de la elipsis para la traducción}

La elipsis, al igual que las categorías vacías y demás signos $\varnothing$, plantean el problema de la representación de la ausencia, que es primordial en la descripción de las estructuras fundamentales de las lenguas (Noailly, 2008: 35) y pueden aplicarse a nivel discursivo criterios generales de la descripción de las lenguas, como por ejemplo el pro-drop (Pitavy, 2008: 101).

Estilísticamente, la elipsis contextual funciona conectando los segmentos del texto, pero a diferencia de los conectores que unen marcando al mismo tiempo la frontera entre los elementos unidos, la elipsis integra.

Como dijimos, los elementos léxico-semánticos aseguran la interpretación correcta del enunciado, mientras que los sintácticos regulan las construcciones para que éstas no se aparten de las reglas básicas de la sintaxis [ $\rightarrow$ Capítulo IV, Elipsis. 4.2.1., 4.2.2.]. 
Es indudable que el buen manejo de los elementos léxico-semánticos y sintácticos garantiza tanto la comprensión del texto original, en nuestro caso expresado en lengua francesa, como la producción en lengua de llegada, en nuestro caso el castellano.

También dijimos que el hablante recupera el elemento elíptico o produce la elipsis de modo indirecto y haciendo uso de la intuición lingüística [ $\rightarrow$ Capítulo IV, Elipsis. 4.3.]. Esta aseveración hace que tome relevancia la actuación del traductor traduciendo hacia su lengua materna, pues en ella éste encuentra, naturalmente, mayor aplomo redaccional. Además, apoyándonos sobre la idea de que la recuperación del elemento elíptico y la producción de la elipsis apelan a la intuición lingüística, podemos afirmar que además de medio cohesivo, la elipsis es un mecanismo, puesto que se produce inconsciente y automáticamente, y permite continuar el proceso de producción [ $\rightarrow$ Capítulo V, Metodología. 5.6.1.].

Sin embargo, el proceso de traducción está atravesado por el universal de interferencia de modo que la producción intuitiva se ve obstaculizada por la forma del texto original; de allí que se requieran criterios analíticos más que automáticos para lograr un producto que responda a las reglas del polo meta.

En nuestro corpus de análisis, tomamos las elipsis nominales y verbales que presentan anomalías tanto a nivel gramatical o estructural como a nivel contextual o discursivo, con la finalidad de identificar la interferencia subyacente.

A continuación, presentamos la metodología que hemos seguido para la realización de este trabajo. 


\section{CAPÍTULO V}

\section{METODOLOGÍA}

"Al contrario de lo que ocurre con las ciencias no empíricas, el fin de las disciplinas empíricas es dar cuenta, de un modo controlado y sistemático, de segmentos concretos del 'mundo real' por tanto, no se puede considerar que una ciencia empírica esté desarrollada y sea (relativamente) autónoma a menos que cuente con una sólida rama descriptiva."

Gideon Toury (2004: 35).

En este capítulo pasaremos revista o remitiremos a los criterios que nos han guiado para tratar nuestro problema de la producción discursiva en la traducción de textos pragmáticos francés/castellano, desde su estudio a través de los enunciados elípticos con anomalías, para constituir y analizar la casuística, e identificar los principales conceptos operativos utilizados a lo largo de este trabajo. ${ }^{1}$

\subsection{Introducción}

En primer lugar, hemos considerado que el tratamiento de nuestro corpus necesitaba de abordajes lingüísticos del sentido en los modelos de traducción, especialmente los modelos conceptuales del sentido, el modelo de tratamiento de la información y las propuestas integrativas, entre ellas la de Larose $[\rightarrow$ Capítulo I, Marco teórico y Antecedentes]. En relación con lo expresado, hemos considerado el

\footnotetext{
${ }^{1}$ Desde el punto de vista grafémico, utilizaremos: las expresiones completas texto original, texto traducido o TO/TT; las comillas latinas («») y los caracteres en cursiva cuando citamos palabras de los textos originales en francés y solamente las comillas inglesas (")" en los constituyentes de los textos traducidos al castellano. Esta selección obedece al uso preferido en cada una de las lenguas de trabajo. En el caso de que los elementos textuales estén entre paréntesis, utilizaremos únicamente la cursiva en las palabras en francés y los caracteres regulares en castellano, separados por la barra de contraste.
} 
papel de la memoria en la activación automática de los textos y en las representaciones de las lenguas de origen y de llegada que el traductor posee, independientemente de las representaciones que cada lengua provee desde su sistema y su correspondiente predicación, para tratar el macroproceso de traducción y el producto traducido [ $\rightarrow$ Capítulo II, Producción discursiva].

Dentro del macroproceso de traducción, la transferencia considerada desde la perspectiva cognitiva es una mirada desde la mente del que traduce y plantea el estudio de las representaciones conceptuales, de las representaciones lingüísticas, de las representaciones morfosintácticas y de todas aquellas imágenes mentales con sentido, que son caras al que transfiere algo desde una lengua a otra. El tratamiento de la información se hace por un trabajo de almacenamiento y de búsqueda de memoria a nivel de la memoria episódica y de la memoria semántica. Este modelo refuerza la hipótesis de que la traducción no es una simple transcodificación sino que sigue el camino del pensamiento, establece relaciones conceptuales y orienta al traductor en la búsqueda de la exactitud en la transferencia $[\rightarrow$ Capítulo II, Producción discursiva]. (Sánchez, 2005b)

\subsection{Criterios metodológicos que han guiado nuestro estudio}

Toda reexpresión implica problemas de traducción ${ }^{2}$ (Hurtado Albir, 2004: 287, 288) cuyas soluciones son exitosas o no; por otra parte, soluciones y problemas se determinan mutuamente y en este juego bi-textual cobra fuerza el uso de segmentos emparejados como mecanismo retrospectivo (Toury, 2004: 122) [ $\rightarrow 5.4 .1$.$] .$

Toury (2004:124) sostiene que al realizar un estudio comparativo entre un texto original y su traducción o viceversa, se debe partir de la base de que:

\footnotetext{
2 EI PACTE propone una clasificación de los Problemas de traducción según las siguientes categorías: lingüística, extralingüística, instrumental y pragmática.

Christiane Nord, en cambio, establece una distinción entre dificultades de traducción (textuales, personales, pragmáticas, técnicas) subjetivas y relacionadas con el traductor y las condiciones de trabajo, por un lado, y problemas de traducción objetivos (pragmáticos PPT, convencionales PCT y lingüísticos PLT) que todo traductor tendrá que resolver, por otro lado. Text Analysis in Translation, Amsterdam, Rodopi.
} 


\begin{abstract}
"1-Toda comparación es parcial, es decir que se comparan ciertos aspectos y no todo;
\end{abstract}

2-Toda comparación es indirecta por naturaleza ya que sólo se puede llevar a cabo utilizando conceptos intermedios que deben estar relacionados con los aspectos que se comparan en ambos textos (tertium comparationis);

3-Los conceptos intermedios deben estar relacionados con la teoría según cuyos principios se lleva a cabo la comparación."

En nuestro estudio, la mirada pedagógica desde la evaluación de traducciones ha gravitado para establecer como carácter parcial de la comparación a las anomalías de producción, ${ }^{3}$ cuya visibilidad se relaciona con la transferencia negativa que forma parte del universal traductológico de interferencia; de esa manera, dejamos de lado criterios subjetivos de evaluación global, traducción buena, traducción mala, intentando comprender y explicar la anomalía. ${ }^{4}$

La traducción de textos pragmáticos se propone, como mínimo, comunicar en una lengua-cultura meta una información proveniente de textos de una lenguacultura original; de allí que sea deseable lograr un texto de lectura fluida, coherente y que comunique el sentido del texto original. En este marco, la anomalía gramatical es un concepto operativo a través del cual podemos estudiar su repercusión en el discurso. En alguna medida, se conjugan los conceptos que, en términos de R. de Beaugrande, remiten a cohesión, como un aspecto de la gramaticalidad y a coherencia como un aspecto de la aceptabilidad, ${ }^{5}$ que toma apoyo en el conocimiento de la situación y en los saberes léxico-enciclopédicos de los sujetos (Charaudeau y Maingueneau, 2005: 88). La relación entre cohesión-coherenciasentido se constituye en nuestro tertium comparationis.

\footnotetext{
${ }^{3}$ Dubois y Weil-Barais (1999: 275). Las autoras refieren a cómo se comunica el ser humano. Al abordar la relación entre sintaxis y comprensión desde un enfoque psicolingüístico, las autoras plantean cuestiones de orden metodológico para un estudio tan complejo afirmando que las situaciones irregulares (anomalías semánticas, errores de grafía, dificultades o patologías de los lectores) actúan como situaciones cuasi experimentales de análisis de los subsistemas, las que permiten reconocer mecanismos de compensación reconocibles dentro de las investigaciones del enfoque modularista.

${ }^{4}$ En formación, hemos comprobado que el alumno exige una evaluación crítica, fundada en criterios claros y válidos, en lugar de hacerlo a través de enunciados me gusta, no me gusta que provocan insatisfacción en los alumnos y la sensación de no ser atendidos.

${ }^{5}$ Este concepto de aceptabilidad tiene puntos en común con el concepto sociotraductológico de aceptabilidad acuñado por Toury y aplicado a la traducción que responde a las normas del polo meta.
} 
Por último, las anomalías emergentes serán analizadas dentro de la interferencia como universal de traducción.

\subsection{Criterio para circunscribir el alcance del tema}

Como venimos diciendo desde la Introducción, la fase de reexpresión o producción discursiva no ha tenido demasiado tratamiento, como lo reconocen, entre otras, las escuelas de París y de Tel-Aviv, que tienen enfoques diferentes para el estudio de la traducción.

Por otra parte, las conclusiones de Valentín García Yebra (1997: 385) y los resultados de investigaciones empíricas sobre evaluación de traducciones especializadas en nuestra universidad, entre otros, indican que la mayor parte de los galicismos y de los errores en traducción son de naturaleza sintáctica, por lo que nos propusimos avanzar en el estudio de la producción discursiva desde un enfoque lingüístico-discursivo.

Ahora bien, por ser ésta una investigación traductológica y no específicamente lingüístico-contrastiva, desechamos partir de un fenómeno lingüístico seleccionado apriorísticamente en el texto original (participe présent, gerundio, por ejemplo), puesto que lo que se traduce son textos y no palabras, por lo tanto no es posible calcular cómo el traductor modificará cada una de esas categorías del texto original en función del sentido que necesita reexpresar en el texto traducido.

En su lugar, partimos de una serie de análisis de binomios textuales tomados de nuestro corpus textual, como lo describe el presente capítulo en el apartado Criterios evolutivos de análisis, que fueron útiles como plataforma de observación de las anomalías sintácticas que obstaculizaban la lectura fluida y a veces coherente, lo que nos permitió ir circunscribiendo nuestro objeto de análisis. Por este camino comprobamos, cuantitativamente, que la opacidad en la transmisión del sentido estaba asociada a enunciados con vacíos [ $\rightarrow$ Capítulo V, Metodología. 5.4.3.].

Una vez focalizados los vacíos, nos abocamos a caracterizarlos y comprobamos que muchos de ellos respondían al concepto de elipsis, según los 
criterios de recuperabilidad, lo cual nos decidió a estudiarlo como hecho lingüísticodiscursivo en castellano y en francés, siguiendo a José María Brucart ${ }^{6}$ y Angela Di Tullio, ${ }^{7}$ para el castellano y la obra colectiva dirigida por Jean-Christophe Pitavy y Michèle Bigot, ${ }^{8}$ para el francés.

La elipsis es un concepto que desde siempre ha problematizado la reflexión gramatical, poniendo en primer plano la confrontación entre sistema y uso de la lengua, siendo para la gramática un mecanismo limitador de la redundancia léxica y para el discurso, un medio de cohesión [ $\rightarrow$ Capítulo IV, Elipsis].

En nuestro estudio según la fluidez y coherencia del corpus elegido, nos hemos propuesto analizar tanto las elipsis que no están construidas según las normas del sistema lingüístico de referencia y sus consecuencias discursivas como las elipsis que si bien están resueltas dentro del sistema lingüístico de referencia, en el discurso complejizan la expresión perturbando la cohesión y por consiguiente la transmisión del sentido.

Resumiendo, hemos intentado acercarnos al complejo tema de la producción discursiva, parcial e indirectamente, a través de las anomalías ${ }^{9}$ en los enunciados elípticos.

\subsection{Criterios evolutivos de análisis}

Como su título lo indica, en esta sección nos referiremos al modo como fue evolucionando el trabajo, es decir las decisiones que hemos ido tomando según las necesidades de nuestro estudio y las circunstancias que se fueron presentando.

\subsubsection{Criterio de abordaje}

Como hemos señalado, los problemas de traducción no son apriorísticos, sino que se van descubriendo y resolviendo a medida que se avanza en la traducción, con una actitud holística, de allí que no se puedan establecer criterios universales que predigan dónde va a haber un problema de traducción. En formación de

\footnotetext{
${ }_{7}^{6}$ Brucart, José María (2000).

${ }^{7}$ Di Tullio, Angela (1997).

${ }^{8}$ Pitavy, Jean-Christophe, Bigot, Michèle y otros (2008).

${ }^{9}[\rightarrow$ Capítulo V, Metodología. 5.6.].
} 
traductores, es fácilmente comprobable que aunque el docente prevea problemas potenciales de traducción en un texto original, puede ocurrir -y ocurre- que algunas soluciones del texto traducido dan cuenta, retrospectivamente, de la existencia de problemas no previstos y de soluciones naturales a ciertos problemas, según una relación bidireccional entre ambos.

Nuestro criterio de abordaje va desde el texto traducido (TT) hacia el texto original (TO), es decir en el sentido $\mathrm{TT} \rightarrow \mathrm{TO},{ }^{10} \mathrm{y}$ hemos realizado las dos primeras lecturas en el siguiente orden: la primera al texto traducido o TT y publicado, intentando considerarlo como producción discursiva de primera mano y la segunda lectura, al texto original o TO, observando en ambos casos el género discursivo, la legibilidad, la fluidez, la dinámica discursiva, la naturalidad en el empleo de términos y de vocablos, dentro de la noción general de equivalencia informativa por el hecho de que se trata de textos pragmáticos.

Coincidimos con Toury (2004: 78, 79) en que, desde un punto de vista cognitivo, lo que se coteja son segmentos del TT con segmentos del TO, más que el texto como unidad, emparejándolos, según una noción de equivalencia que será la norma para esa pareja.

Establecimos como unidad de análisis ${ }^{11}$ cortes en el TT y en el TO mediante un criterio grafémico, es decir, enunciados separados por punto u oración en sentido

\footnotetext{
${ }^{10}$ Gideon Toury (2004: 77 y ss.) afirma que un programa de EDT orientado al polo meta es así porque las observaciones comienzan en el polo meta, desde lo observable en el producto, intentando reconstruir los rasgos no observables, concretamente los procesos mediante los que surgieron.

${ }^{11}$ Compartimos con Jeanne Dancette (1995: 81), la idea de que el concepto de unidad de traducción no es biunívoco puesto que responde a criterios teóricos heterogéneos. La autora retoma el tema del carácter no operatorio de la unidad de traducción en varias oportunidades, que ilustramos con la siguiente cita:

"Les frontières de l'unité de traduction sont variables, élastiques, puisque l'unité est inscrite dans un processus individuel, non normalisé. L'unité de traduction, segment d'énoncé correspondant à un élément global de sens, peut être un seul terme ou même un seul trait morphologique (l'aspect du verbe, par exemple), ou bien une phrase ou une expression entière". Las fronteras de la unidad de traducción son variables, elásticas, puesto que la unidad se inscribe en un proceso individual no normalizado. La unidad de traducción, segmento de enunciado correspondiente a un elemento global de sentido, puede ser un solo término o incluso un único rasgo morfológico (por ejemplo el aspecto del verbo), o bien una oración o una expresión íntegra.

En un sentido análogo, Amparo Hurtado Albir (2004: 170) afirma que no es importante la extensión de la unidad de traducción puesto que su variación es tan amplia que hasta un signo de puntuación puede ser considerado como tal, por lo tanto el rasgo operatorio que caracteriza a la unidad de traducción es el dinamismo, que está vinculado tanto con la modalidad de traducción como con la tipología de textos (textos técnicos, literarios, etc.).
} 
amplio, disponiendo los provenientes del TT en la columna izquierda, y sus correspondientes del TO en la columna derecha, de modo que el orden de tratamiento elegido quede plasmado visualmente. Toury señala el criterio de versatilidad sobre el método elegido para establecer los pares texto meta/texto original (2004: 122), siempre que dentro de los límites de ambos segmentos emparejados aparezca la solución a partir de la cual se detectará el problema.

\subsubsection{Análisis según series de categorías abiertas y cerradas}

La primera selección de enunciados que realizamos fue amplia, reteniendo todos los que obstaculizaban una lectura fluida y coherente para el pasaje de la información (118 casos para Gènéthique y 145 casos para Au bazar du vivant).

La segunda selección dejó de lado los aspectos terminológicos y grafémicos, centrándonos en los segmentos de enunciados con anomalías sintácticas en el TT, lo cual no ha significado desconocer que los textos traducidos presentan tanto designaciones que se alejan de las consagradas como también errores ortográficos. A título de ejemplo, citamos los siguientes:

1-Corpus de Gènéthique: En el texto 43b) La creación de un embrión bisexual / La création d'un embrión bi-sexué: ovarino en lugar de ovárico, renglones 5 y 8. En el texto 46c) El proyecto de investigación sobre los embriones ante la Asamblea Nacional/ Le projet de recherche sur les embryons devant l'Assemblée Nationale: claro consentimiento en lugar de consentimiento informado, renglón 34; proyecto paternal en lugar de proyecto parental, renglones 19 y 25 . En el texto $48 \mathrm{c}$ ) Enmienda Garraud, imposible la protección penal de la mujer embarazada / Amendement Garraud, impossible protection pénale de la femme enceinte: derechos del hombre en lugar de derechos humanos. En el texto 45b) El embrión reprogramado por violentos mecanismos artificiales / L'embryon reprogrammé par des contraintes mécaniques artificielles: cinistros por ministros, renglón 3; plateada

Rosa Rabadán (1991: 199) denomina translema a toda unidad bi-textual, de cualquier tipo o nivel, constituida por un mismo contenido y dos manifestaciones formales pero solidarias, y cuya existencia depende de la relación global de equivalencia subyacente a cada binomio textual TM-TO. 
por planteada, renglón 7. En el texto 47c) La O.N.U. no prohíbe la clonación / Pas d'interdiction du colage humain à l'ONU: astención en lugar de abstención, renglón.

2-Obra El racismo del gen/Au bazar du vivant: « numérique » (TO chapitre 2, page 27 , ligne 25) > "numérica" (TT, capítulo 2, página 24, renglón 23), en lugar de la forma preferida en el ámbito de la Informática que es el adjetivo "digital". Del mismo modo, aparece alguna desviación de contenido, por cambio de término; así, "les techniques de génie génétique » (TO chapitre 2, page 43, ligne 16) > "las técnicas de genetistas renombrados" (TT capítulo 2, página 36, renglón 22), que entendemos como las técnicas de ingeniería genética.

Hechas estas aclaraciones, volvemos a nuestro problema de identificación de segmentos de enunciados con anomalías sintácticas en el TT, con los cuales hicimos los primeros análisis contrastivos según un criterio categorial y funcional; es decir, segmentos microestructurales sin contexto (Larose; 1989: 219-222, 256), que al ser transferidos a otra lengua producen una transcodificación; luego esos mismos segmentos se analizaron funcionando en el discurso construido y traducido.

Para clasificar los problemas de traducción encontrados en esos segmentos, seguimos el criterio clásico de categorías léxicas pertenecientes a series abiertas, es decir, sustantivos, adjetivos, verbos y adverbios terminados en -mente, y a series cerradas: determinantes, pronombres, verbos auxiliares, el resto de los adverbios, preposiciones, conjunciones, según la clasificación de Di Tullio (1997: 136) $[\rightarrow$ Capítulo III, Interferencia. 3.2.1.2.].

Luego de algunos ensayos de análisis, desechamos este criterio de clasificación por no ser económico y porque nos anclaba en explicaciones que no nos permitían generalizar.

\subsubsection{Análisis según ausencias y presencias}

En una etapa posterior, releímos los enunciados de los textos traducidos y cuantificamos los fenómenos más frecuentes. Comprobamos que se trataba, en primer lugar, (67 casos para Gènéthique y 28 casos para Au bazar du vivant) de casos de ausencias o vacíos y en segundo lugar de presencias -a nuestro entender 
excesivas- de determinantes, en especial adjetivos demostrativos y determinantes indefinidos (15 casos de demostrativos y 4 de indefinidos en Gènéthique).

Con los primeros datos, nos abocamos al estudio de los enunciados con vacíos, comprobando que, a la luz de la gramática generativa y de los criterios de recuperabilidad enunciados en el Capítulo IV que trata la elipsis, muchos de ellos (21 casos para Gènéthique y 19 casos par Au bazar du vivant), respondían al concepto de elipsis, lo cual nos decidió a estudiarlo desde las anomalías de construcción y de funcionalidad, como visibilidad del universal de interferencia $[\rightarrow$ Capítulo $V$, Metodología. 5.3.].

Afirmamos también que la presencia excesiva de determinantes debería ser abordada dentro del universal de interferencia, mediante la realización de un estudio contrastivo en textos paralelos ${ }^{12}$ francés-castellano, con la finalidad de comprobar la ocurrencia de los determinantes mencionados que no parecería ser tan frecuente en producciones originales, es decir, no mediadas por la traducción. Como enunciamos en Introducción, este problema no será tratado en el presente estudio.

\subsubsection{Criterios definitivos de análisis}

A partir de las consideraciones precedentes, elaboramos el instrumento que presentamos a continuación seguido de su explicación, que hemos aplicado para llevar adelante el análisis de los enunciados elípticos contenido en el Capítulo VI.

\footnotetext{
${ }^{12}$ En la terminología de Christiane Nord (2003: 28-29), los textos paralelos deben cumplir, como mínimo, las siguientes condiciones: haberse producido en dos culturas diferentes y pertenecer al mismo género o tipo textual. Es importante que sean análogas las situaciones comunicativas en las que se usan ambos textos [ $\rightarrow$ Introducción].
} 
FIGURA 7. Instrumento de análisis

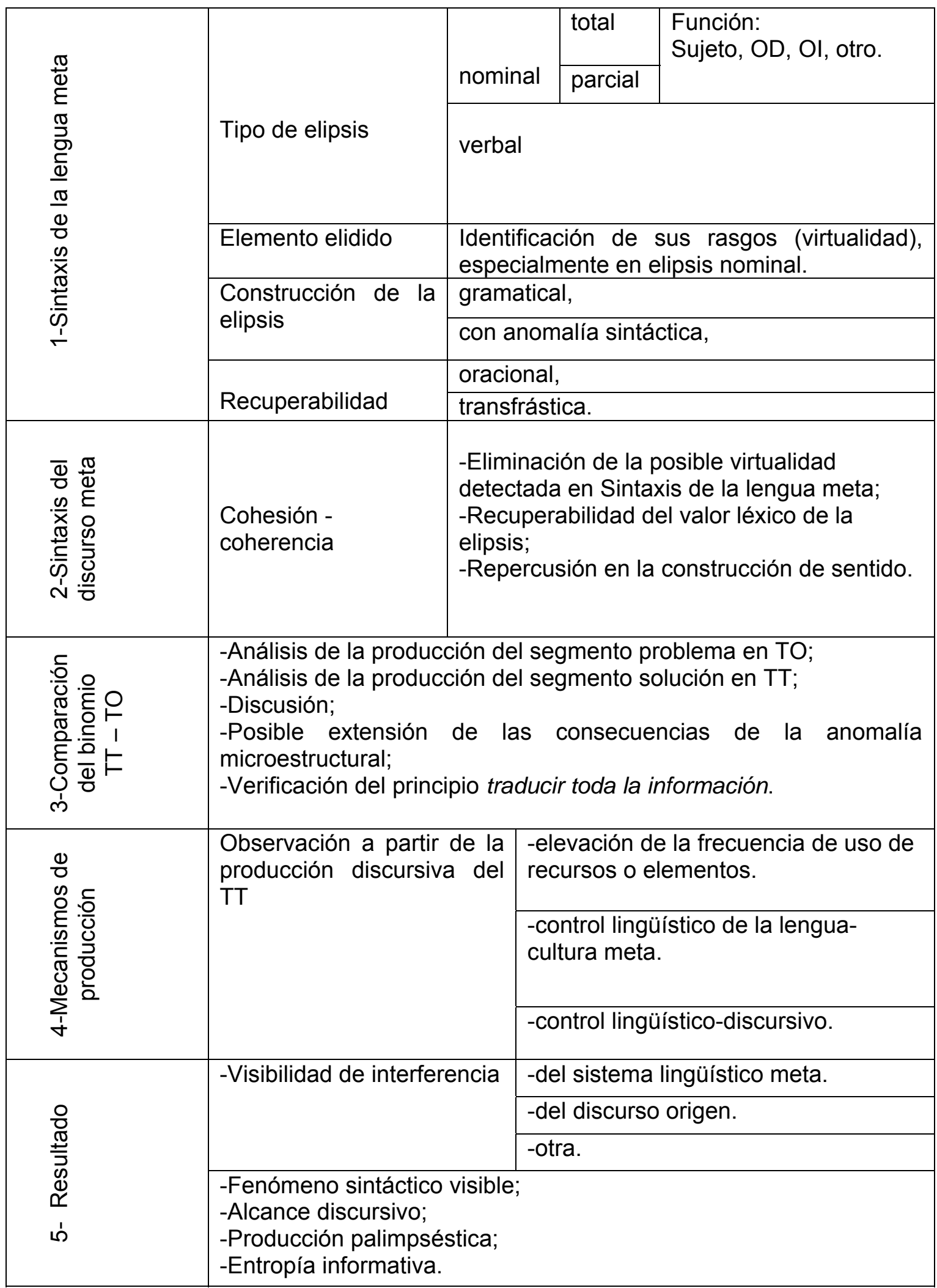


1-Sintaxis de la lengua meta. En este apartado, partimos de la producción del TT en castellano y observamos:

-el tipo de construcción sintáctica (verbal, nominal, modal, predicativa, coordinada, subordinada) en donde está contenida la elipsis;

-el tipo de elipsis, nominal o verbal, que permite contabilizarlas, y subclasificarlas en elipsis totales o parciales. En el caso de las nominales, elipsis de argumento externo o sujeto, elipsis de argumento interno u OD, OI, predicativo, complemento adnominal;

-si en la oración quedan identificados los rasgos del elemento elidido;

-si a partir de los datos estructurales, la construcción es gramatical o tiene una anomalía sintáctica.

2- Sintaxis del discurso meta. La traducción se resuelve en el plano discursivo: inspirándonos en los criterios coserianos, consideramos que en el transcurso de la toma de decisiones que corresponden al habla, el traductor pone en juego conocimientos lingüísticos del sistema y de uso o norma.

En un primer momento, a partir de las virtualidades que pueden aparecer en Sintaxis de la lengua meta, circunscribimos su uso dentro de Sintaxis del discurso meta, visualizado en la producción elegida por el traductor.

En un segundo momento, rastreamos la recuperación del valor léxico de la elipsis y su repercusión en la construcción de sentido que queda materializada en la construcción sintáctica elegida por el traductor. La elipsis es un medio cohesivo muy utilizado $^{13}$ que puede estar resuelta adecuadamente a nivel oracional pero también puede ser motivo de opacidad en la construcción de sentido.

\begin{tabular}{|c|c|}
\hline Cohesión gramatical & Cohesión léxica \\
\hline Pronombre personal & Anáfora presuposicional \\
\hline Pronombre relativo & Reiteración explícita \\
\hline Pronombre demostrativo & Reiteración parcial \\
\hline Pronombre posesivo & Sinonimia \\
\hline
\end{tabular}


3-Comparación del binomio TT-TO: esta comparación se realiza a través del análisis y discusión de la producción del segmento problema en TO y de la producción del segmento solución en TT, en la que se aprecia la posible extensión de las consecuencias de la anomalía microestructural a niveles macro y superestructurales [ $\rightarrow$ Capítulo I, Marco teórico y Antecedentes. 1.1.2.] y la verificación de que no se ha traducido toda la información.

4-Mecanismos de producción:

Adscribimos a la postura cognitiva que sostiene que los procesos son esencialmente subjetivos e inaccesibles y sólo se pueden determinar aspectos periféricos de los procesos de producción que se materializan en mecanismos de emisión de las formas lingüísticas [ $\rightarrow$ Capítulo II, Producción discursiva. Reflexiones finales]. Parcialmente, ellos informan retrospectiva e indirectamente sobre cómo se ha resuelto un problema de traducción [ $\rightarrow$ Capítulo II, Producción discursiva. 2.8.].

Hemos tomado como insumo la información de los puntos anteriores, es decir, Sintaxis de la lengua meta, Sintaxis del discurso meta, Comparación del binomio TTTO y para interpretarla, hemos recurrido únicamente a conceptos operativos fácilmente observables, es decir que no hemos realizado hipótesis acerca de cómo leyó el traductor el TO para llegar a su producción porque no contamos con esos datos. Los conceptos que hemos considerado son los siguientes:

-elevación de la frecuencia de uso de recursos o elementos -en nuestro casola elipsis y su relación con la infracción de la norma. Esta noción de Carsten Sinner $[\rightarrow$ Capítulo III, Interferencia. 3.1.3.] es una de las que explica el descenso de la fluidez en la lectura por efecto de la redundancia de un fenómeno, que, en el caso de la elipsis, está asociado con la ausencia léxica;

\begin{tabular}{|l|l|}
\hline Adjetivo posesivo & Relación parte/todo \\
\hline Pronombre interrogativo & Otras relaciones léxico-semánticas \\
\hline Pronombre indefinido & \\
\hline Adjetivo indefinido & \\
\hline Elipsis & \\
\hline Conjunción & \\
\hline Comparativo & \\
\hline Adverbios & \\
\hline
\end{tabular}


-control lingüístico de la lengua-cultura meta indica en qué medida el traductor ha realizado el esfuerzo por deshacerse de los significantes del TO, dentro de la Sintaxis de la lengua meta. Nos referimos exclusivamente al control -durante y después de la traducción- puesto que descontamos el conocimiento de los sistemas lingüísticos en los que trabaja el traductor [ $\rightarrow$ Capítulo II, Producción discursiva. 2.8.]; [ $\rightarrow$ Capítulo III, Interferencia. 3.3.];

-control lingüístico-discursivo indica en qué medida el traductor ha realizado el esfuerzo por deshacerse de los significantes del TO, dentro de la Sintaxis del discurso meta. Nos referimos al control -durante y después de la traducción- de los elementos sintácticos reveladores de anomalías discursivas, tanto endofóricas como exofóricas, vinculadas con el conocimiento del mundo $[\rightarrow$ Capítulo II, Producción discursiva. 2.8.]; [ $\rightarrow$ Capítulo III, Interferencia. 3.3.].

\section{5-Resultado}

Con los datos aportados por los puntos anteriores, establecemos la visibilidad de interferencia en el TT y sus consecuencias, respondiendo a los siguientes interrogantes: ${ }^{14}$

-¿Qué interferencia gobierna el enunciado traducido? ¿Proviene del sistema lingüístico meta? ¿del discurso origen?

-¿Cuál es el fenómeno sintáctico visible y qué repercusión discursiva tiene?, en donde se recoge la información de los puntos 1, 2 y 3 .

-¿Qué grado de libertad tiene la producción? En la Introducción hemos afirmado la frecuencia con que aparecen enunciados dentro de las traducciones que necesitan ser leídos varias veces para ajustar lo expresado con el contenido que se desea transmitir, en parte porque conservan la presencia de una escritura previa, a la manera de un palimpsesto. A partir de esa idea hemos utilizado metafóricamente

\footnotetext{
${ }^{14}$ Señalamos que el continuo sociotraductológico aceptabilidad-adecuación indica cómo se posiciona el texto en una lengua-cultura meta al comparar varias traducciones de un mismo original como lo hace Rabadán, sin considerar los errores (1991). En cambio nuestro estudio intenta comprender la anomalía, razón por la cual los conceptos de aceptabilidad-adecuación en los enunciados seleccionados no son relevantes [ $\rightarrow$ Capítulo II, Producción discursiva. 2.6.5.].
} 
el término palimpsesto, proponiendo la designación de producción palimpséstica, cuando en el TT emergen huellas de un texto ajeno que obstaculizan la construcción de sentido y que nos hacen consultar el TO.

- ¿Se ha cumplido el precepto traducir toda la información? o hay entropía informativa?

\subsection{Casuística: criterios evolutivos de su constitución}

La primera casuística que planteamos estuvo constituida por un corpus textual y una prueba de traducción:

a-Corpus textual: 20 textos de ciencias sociales -original francés y su traducción al español- de corta extensión (entre 250 y 300 palabras) y publicados. Condición: el francés será la lengua materna de los autores de los originales y el español la lengua materna de los traductores.

b-Sujetos: 10 alumnos avanzados del Traductorado Público Nacional en Francés de la Facultad de Humanidades y Ciencias de la Educación y del Traductorado Científico y Literario de Francés del Instituto de Enseñanza Superior en Lenguas Vivas "Juan Ramón Fernández". Condición: haber cursado el segundo nivel de Traducción Científico-técnica en francés.

\subsubsection{Corpus textual}

Las investigaciones sobre traducción especializada que citamos en la Introducción provenientes de la Facultad de Humanidades y Ciencias de la Educación de La Plata, demuestran que los textos de Bioética plantean cuantitativamente más problemas de traducción vinculados a la reexpresión sintáctica, si se la compara con la reexpresión terminológica o grafémica.

\subsubsection{Condiciones del corpus}

Debido a la naturaleza de nuestro estudio, decidimos constituir un corpus con textos del campo de la Bioética relativamente actuales, con originales redactados por hablantes nativos de francés y por las correspondientes traducciones publicadas 
en soporte papel y electrónico, realizadas por traductores hablantes nativos de castellano.

Mantuvimos entrevistas personales, telefónicas y electrónicas con bioeticistas $^{15}$ para conocer las últimas publicaciones que respondieran a nuestras condiciones y simultáneamente realizamos búsquedas de publicaciones bilingües en soporte papel y electrónico.

El primer escollo fue que las fuentes consultadas remitían a publicaciones bilingües francés/inglés y en menor medida al par de lenguas francés/italiano o combinaciones de italiano con otras lenguas, mientras que la combinación francés/castellano era prácticamente inexistente.

Sin embargo, encontramos que el Fondo de Cultura Económica, editorial que suele traducir textos de origen francés en Ciencias Sociales, contaba en su catálogo con la traducción al castellano realizada en Argentina (2002) de una obra cuyo original en francés tenía fecha de publicación en 2001.

Además, el aporte informático fue fundamental a través de dos sitios: www. portal.unesco.org y www.genethique.org. ${ }^{16} \mathrm{El}$ primero permite acceder a textos normativos y el segundo, además de los normativos, a trabajos de investigación, artículos sobre la evolución de la Bioética y textos no demasiado extensos (Lettres d'information et d'analyse sur l'actualité de la bioéthique / Cartas informativas y de análisis sobre la actualidad bioética) que comentan una diversidad de temas específicos dentro del campo de la Bioética (clonación, eutanasia, aborto, cambio de sexo, etc.) provenientes de fuentes variadas (libros, informes técnicos, fallos judiciales, publicaciones científicas, leyes, diarios, circulares, etc.), por lo tanto son temas que no se agotan en la Genética, sino que se completan con una mirada desde la Ética y el Derecho. En este sitio, sólo una parte de la sección Lettres /

\footnotetext{
${ }^{15}$ Dr. José Alberto Mainetti, creador de la cátedra de Humanidades Médicas de la Facultad de Ciencias Médicas de la UNLP y autor de numerosas obras sobre Bioética; Dr. Eduardo Tinant, director de la Maestría de Bioética de la Facultad de Ciencias Jurídicas y Sociales; Prof. Eneas Riú, a cargo de la cátedra de Bioética de la UCA de Buenos Aires; Dr. Christian Byk, director del Journal international de Bioéthique.

${ }^{16}$ Esta fuente textual será denominada indistintamente por el sitio o por el título Gènéthique.
} 
Cartas tiene su traducción al español; otras secciones como Dossiers o Thèses son accesibles solamente a través del francés o del inglés [ $\rightarrow$ Capítulo VI, Análisis].

\subsection{Primera selección}

La primera selección fue la siguiente:

1-Textos normativos provenientes del portal de la UNESCO:

-Déclaration internationale sur les données génétiques humaines.

-Declaración Internacional sobre los Datos Genéticos Humanos.

-Déclaration universelle sur le génome humain et les droits de l'homme.

-Declaración Universal sobre el Genoma y Derechos Humanos.

La UNESCO proporciona versiones en varios idiomas, generalmente redactadas a partir del inglés, lo cual entra en colisión con las condiciones arriba planteadas, es decir, textos originales en francés.

Para confirmar si los textos seleccionados eran originales en francés, elaboramos un instrumento de consulta que enviamos electrónicamente al organismo mencionado, pero no obtuvimos respuesta. La falta de información nos impidió también determinar si el español era la lengua de origen del grupo de textos de este sitio o si era traducción intermedia, todo lo cual nos decidió a dejar de lado su análisis.

2-Textos de divulgación especializada que responden a las condiciones de producción de original en francés y de traducción al español.

Del mismo modo que lo hicimos con la UNESCO, elaboramos un cuestionario que enviamos en línea al sitio www.genethique.org y recibimos la respuesta inmediatamente que nos informó que los autores de los originales son hablantes nativos de francés y la traducción fue realizada por un especialista de Biología cuya lengua materna es el castellano ibérico. A continuación, transcribimos los títulos 
seleccionados, según su orden cronológico, por lo tanto también los títulos de los textos fuente aparecen en primer lugar. ${ }^{17}$

Julio 2003

La création d'un embryon bi-sexué/ La creación de un embrión bi-sexual

Les chiffres du rapport de la Cour des comptes sur le handicap mental/Las cifras del informe del Tribunal de cuentas sobre la minusvalía psíquica

Agosto 2003

La fin de l'homme - Francis Fukuyama/ El fin del hombre - Francis Fukuyama

Septiembre 2003

« Bébés médicaments » ou l'extension du diagnostic préimplantatoire »/ « Bebés

medicamentos » o la extensión del diagnóstico preimplantatorio

L'embryon reprogrammé par des contraintes mécaniques artificielles/El embrión reprogramado por violentos mecanismos artificiales

Financement européen de la recherche sur l'embryon humain ?/¿Financiación europea de la investigación sobre el embrión humano?

Octubre 2003

Avis du CCNE sur l'obligation d'informer sa famille d'un risque généthique/Opinión del C.C.N.E. sobre la obligación de informar a su familia de un riesgo genético

Affaire Humbert : faut-il légiférer sur l'euthanasie ?/Caso Humbert: ¿Es necesario legislar sobre la eutanasia?

Le projet de recherche sur les embryons devant l'Assemblée Nationale/El proyecto de investigación sobre los embriones ante la Asamblea Nacional

Noviembre 2003

\footnotetext{
17 Señalamos aquí especialmente este ordenamiento cronológico, puesto que en el análisis aparece en primer lugar el texto traducido reflejando la modalidad de trabajo TT $\rightarrow$ TO.
} 
Pas d'interdiction du clonage humain à l'ONU/La ONU no prohíbe la clonación

Diciembre 2003

Amendement Garraud, impossible protection pénale de la femme enceinte/ Enmienda Garraud, imposible la protección penal de la mujer embarazada.

Enero 2004

Résultats prometteurs de la recherche sur les cellules souches adultes/Prometedores resultados sobre la investigación de células madre adultas

Febrero 2004

L'euthanasie au Conseil de l'Europe/La eutanasia en el Consejo de Europa

Marzo 2004

Embryon, mon amour, Jérôme Lejeune à Maryville - Céline Soriac/ Embryon, mon amour, Jérôme Lejeune en Maryville - Céline Soriac

Abril 2004

Naissance d'une souris par parthénogenèse ?/¿Nacimiento de un ratón por partenogénesis?

3-Textos de reflexión: Au bazar du vivant, transcripción de entrevista de autoría de Jacques Testart y Christian Godin (2001) y su traducción realizada por Víctor Goldstein, bajo el título El racismo del gen (2002) y publicada por Fondo de Cultura Económica.

Se acotó la cantidad de palabras sujetas a análisis, entre 250 y 300, para cada uno de los textos y sólo algunos textos serían traducidos por alumnos del último año de formación en traducción.

\subsection{Segunda selección}


La dificultad de encontrar documentos fuente según las condiciones establecidas y el hecho de haber evolucionado en el tema de investigación, nos motivó a rever los criterios de constitución del corpus y nos decidió a conservar la mayor parte de los textos de la primera selección, tomándolos integralmente, es decir, sin límite de palabras. ${ }^{18}$

Este cambio nos permitió avanzar evitando el análisis de textos de lengua original desconocida, como en el caso de los textos de la UNESCO, lo que hubiera puesto en duda el contraste interlingüístico francés/castellano. Además, tomamos unidades textuales -y por lo tanto de sentido- completas y compensamos así cuantitativamente el volumen de palabras previsto originariamente.

\subsubsection{Criterios evolutivos en la determinación de los sujetos y de la experiencia}

Se realizó una experiencia con diez alumnos de segundo nivel de Traducción Científico-técnica en francés del Traductorado Público Nacional en Francés de la Facultad de Humanidades y Ciencias de la Educación y del Traductorado Científico y Literario de Francés del Instituto de Enseñanza Superior en Lenguas Vivas "Juan Ramón Fernández". Consistió en una traducción según las pautas que se enumeran más adelante, material con el cual se realizaron estudios sobre la reexpresión de las versiones de los alumnos y de la versión publicada, que fueron presentados en congresos de nuestra especialidad; ese material nos dio la posibilidad de transitar la primera etapa de nuestra investigación en la que fuimos probando los criterios de análisis. Los fragmentos traducidos en esa experiencia pertenecen a los siguientes textos:

Texto normativo:

Déclaration universelle sur le génome humain et les droits de l'homme.

Texto de divulgación:

«Bébés médicaments » ou l'extension du diagnostic préimplantatoire.

\footnotetext{
${ }^{18}$ La selección definitiva aparece en el Anexo I.
} 
Texto de reflexión:

Chapitre 3: Les métamorphoses de la médecine (pp. 54-56).

Las traducciones fueron realizadas según las siguientes consignas:

-trabajo autónomo fuera del curso, con la finalidad de que los alumnos pudieran acceder a las fuentes de documentación que consultan habitualmente;

-entrega de la traducción por parte de los alumnos en donde se vieran las redacciones provisorias antes de llegar a la definitiva. Para ello, propusimos que utilizaran la herramienta de control de cambios o la copia de cada una de las versiones; la finalidad de este requerimiento era poder contar con datos sobre el proceso de traducción, a partir de los borradores;

-indicación de las fuentes consultadas;

-indicación del tiempo destinado a cada traducción, desde la lectura hasta la entrega definitiva.

Las observaciones de esta experiencia no son generalizables puesto que no todos los alumnos respondieron a las consignas, lo que redujo aún más la muestra. De allí que se la haya abandonado, aunque fue de utilidad, como ya señalamos, en la etapa de inicio de esta investigación.

\subsection{Conceptos operativos}

Enumeramos a continuación los conceptos que hemos querido precisar o simplemente indicar el uso general en la bibliografía traductológica, puesto que se reiterarán a partir del capítulo VI.

\subsubsection{Mecanismo, proceso y operación}

El empleo de estos términos es profuso en la literatura traductológica y creemos que es necesario circunscribir su alcance para el presente trabajo, a través de una búsqueda lexicológica y terminológica en diccionarios generales y especializados como así también en bibliografía traductológica y lingüísticocognitiva. Los resultados son los siguientes: 


\begin{tabular}{|c|c|}
\hline SME & \\
\hline $\begin{array}{l}\text { Moliner, María (1996), } \\
\text { Diccionario de uso del } \\
\text { español, Madrid, } \\
\text { Gredos/Novell, CD-Rom. }\end{array}$ & $\begin{array}{l}\text { 1. Conjunto de piezas que, con movimientos combinados, } \\
\text { realizan una función. Se llaman preferentemente } \\
\text { "mecanismos" y no "máquinas" cuando forman parte de un } \\
\text { objeto que tiene otros elementos importantes no mecánicos, o } \\
\text { constituyen en el objeto de que se trata un elemento } \\
\text { accesorio: 'El mecanismo del reloj. Un mecanismo sencillo } \\
\text { hace que la válvula se cierre cuando el depósito está lleno. } \\
\text { 2. Manera de producirse una actividad, una función o un } \\
\text { fenómeno: 'El mecanismo de la digestión, de un negocio, de la } \\
\text { formación de las rocas'. }\end{array}$ \\
\hline $\begin{array}{l}\text { Real Academia Española } \\
\text { (1992) Diccionario de la } \\
\text { lengua española, Madrid, } \\
\text { Espasa Calpe. }\end{array}$ & $\begin{array}{l}\text { 1. Conjunto de las partes de una máquina en su disposición } \\
\text { adecuada. }\end{array}$ \\
\hline $\begin{array}{l}\text { Robert, Paul (1992), Le } \\
\text { Petit Robert 1, París, } \\
\text { Dictionnaires Le Robert. }\end{array}$ & $\begin{array}{l}\text { 1. Combinaison, agencement de pièces, d'organes, montés en } \\
\text { vue d'un fonctionnement d'ensemble. } \\
\text { Combinación, disposición de piezas, de órganos, cuyo armado } \\
\text { tiene como objetivo un funcionamiento en conjunto. } \\
\text { 2. (Mil. XVIII). Mode de fonctionnement de ce qu'on assimile à } \\
\text { une machine. Mécanismes biologiques, organiques. } \\
\text { (Abstrait) Le mécanisme de la pensée, de la parole. } \\
\text { Modo de funcionamiento de lo que se asimila a una máquina. } \\
\text { Mecanismos biológicos, orgánicos. } \\
\text { (Abstracto) El mecanismo del pensamiento, de la palabra. }\end{array}$ \\
\hline $\begin{array}{l}\text { Béla Székely, L.C. (1958). } \\
\text { Diccionario Enciclopédico } \\
\text { de la Psique. Buenos Aires, } \\
\text { Claridad. }\end{array}$ & $\begin{array}{l}\text { 1. La dirección inconsciente de un proceso mental en que } \\
\text { sentimientos y emociones desempeñan una parte importante. } \\
\text { 2. En sus aplicaciones al comportamiento humano, el término } \\
\text { se refiere a aquellas funciones que en su constancia y } \\
\text { regularidad se asemejan a la manera de trabajar de una } \\
\text { máquina. }\end{array}$ \\
\hline $\begin{array}{l}\text { Warren, Howard C., editor } \\
\text { (1956). Diccionario de } \\
\text { Psicología. Traducción y } \\
\text { revisión al castellano de E. } \\
\text { Imaz, A. Alatorre, L. } \\
\text { Alaminos. Buenos Aires, } \\
\text { FCE }\end{array}$ & $\begin{array}{l}\text { 3. (psicoanál.) Dirección inconsciente de un proceso psíquico } \\
\text { en el que el sentimiento o la emoción desempeñan un papel } \\
\text { importante. }\end{array}$ \\
\hline
\end{tabular}


Dubois, Jean y otros (1983). Diccionario de Lingüística. Traducción al castellano de Inés Ortega y Antonio Domínguez.

Dirección y adaptación de Alicia Yllera. Madrid, Artes Gráficas Ibarra S.A.
En lingüística generativa, la gramática es un mecanismo finito capaz de generar un conjunto infinito de oraciones gramaticales, a las que asocia automáticamente una descripción estructural.

En las definiciones anteriores, aparte del enfoque específico de cada una de las disciplinas, individualizamos la idea de que mecanismo refiere a un conjunto de elementos de índole diversa, entre los cuales encontramos piezas, funciones, reglas, sentimientos, que actúan de manera constante, regular y automática, para desempeñar distintas acciones. Las definiciones van desde aquéllas en las que la función está implícita, como es el caso del Diccionario de la lengua española de la Real Academia Española, hasta conceptos intrínsecamente funcionales, asociados al comportamiento humano, como el Diccionario Enciclopédico de la Psique de Béla Székely.

\begin{tabular}{|l|l|}
\hline \multicolumn{2}{|l|}{ PROCESO/PROCESSUS } \\
\hline $\begin{array}{l}\text { Real Academia Española } \\
\text { (1992) Diccionario de la } \\
\text { lengua española, Madrid, } \\
\text { Espasa Calpe. }\end{array}$ & $\begin{array}{l}\text { 4. Conjunto de las fases sucesivas de un fenómeno natural o } \\
\text { de una operación artificial. }\end{array}$ \\
\hline $\begin{array}{l}\text { Robert, Paul (1992), Le } \\
\text { Petit Robert 1, París, } \\
\text { Dictionnaires Le Robert. }\end{array}$ & $\begin{array}{l}\text { 2. Sc. Ensemble de phénomènes, conçu comme actif et } \\
\text { organisé dans le temps. Processus biologique, physiologique, } \\
\text { pathologique (ou morbide). }\end{array}$ \\
\hline & $\begin{array}{l}\text { Cs. Conjunto de fenómenos, concebido como activo y } \\
\text { organizado en el tiempo. Proceso biológico, fisiológico, } \\
\text { patológico (o mórbido). }\end{array}$ \\
\hline
\end{tabular}

Ambas definiciones agrupan las nociones de conjunto de elementos que actúan de manera dinámica en el tiempo. 


\begin{tabular}{|l|l|}
\hline $\begin{array}{l}\text { Real Academia Española } \\
\text { (1992) Diccionario de la } \\
\text { lengua española, Madrid, } \\
\text { Espasa Calpe. }\end{array}$ & 2. Ejecución de una cosa. \\
\hline $\begin{array}{l}\text { Robert, Paul (1992), Le } \\
\text { Petit Robert 1, París, } \\
\text { Dictionnaires Le Robert. }\end{array}$ & $\begin{array}{l}\text { 2. Acte ou série d'actes (matériels ou intellectuels) supposant } \\
\text { réflexion et combinaison de moyens en vue d'obtenir un } \\
\text { résultat déterminé. }\end{array}$ \\
$\begin{array}{l}\text { Actos o serie de actos (materiales o intelectuales) que } \\
\text { suponen reflexión y combinación de medios con la finalidad de } \\
\text { obtener un resultado determinado. }\end{array}$ \\
\hline
\end{tabular}

La primera definición es menos explícita que la segunda, en la que aparecen datos relacionados con acciones premeditadas para conseguir un objetivo.

Recorriendo la bibliografía, encontramos que Annick Weil-Barais (1999: 569) al hablar de la teoría de la información, recurre a la coocurrencia processus de résolution de problèmes, en castellano proceso de resolución de problemas, con la intención de construir un modelo de funcionamiento que pueda tener un correlato informático. En cambio, al hablar de mécanismes de contrôle, mecanismos de control (1999: 573), los relaciona con la capacidad de planificación de las actividades y las capacidades de control.

Manuel de Vega $(1995: 33,38)$ parecería no establecer netas distinciones entre procesos y mecanismos, que tienen alta frecuencia de uso; en menor medida utiliza el concepto operaciones. A modo de ejemplo, al comparar la psicología cognitiva y la psicología de la inteligencia, establece que la primera se dedica al análisis detallado de los mecanismos y procesos, y en la construcción de modelos unitarios, es decir, válidos para interpretar los principios generales de la inteligencia. Más adelante menciona los mecanismos ontogenéticos de la psicología genética (1995: 40).

En las actas del Segundo Congreso internacional de traducción de la Universidad Autónoma de Barcelona, ${ }^{19}$ se mencionan en los artículos los términos procesos y subprocesos, pero no se encuentra ninguna ocurrencia de mecanismos.

\footnotetext{
${ }^{19}$ www.bib.uab.es/pub/traduccio/Actes2.pdf [Consultado el 10-02-04].
} 
Jeanne Dancette (1995: 192), habla de los mécanismes de complementarité et de supplétion, en castellano mecanismos de complementariedad y de supleción definiéndolos como:

"la faculté, en cas d'incompréhension ou d'incertitude, de recourir à un autre niveau d'analyse pour émettre une hypothèse (supplétion) ou pour la vérifier. »

la facultad, en caso de incomprensión o incertidumbre, de recurrir a otro nivel de análisis para emitir una hipótesis -supleción- o para verificarla.

Más adelante, al tratar los procesos específicos de la actividad de traducción Jeanne Dancette (1995: 207), dice:

"la métaphore de la double hélice permet de mieux saisir la spécificité des opérations de compréhension du traducteur, par opposition aux opérations du simple lecteur. »

la metáfora de la doble hélice permite aprehender mejor la especificidad de las operaciones de comprensión del traductor, en oposición a las operaciones del lector común.

En resumen, podemos decir que hemos encontrado cierto grado de solapamiento e inestabilidad en el uso de estos conceptos, de allí que intentamos definiciones operativas:

Entendemos por mecanismo, la dirección inconsciente, automática, regular que pone en marcha o continúa un proceso o un subproceso.

En cambio, proceso es el conjunto complejo de etapas o fases (no necesariamente sucesivas) que conforman un fenómeno en actividad y que según el grado de complejidad, estará integrado por subprocesos.

Por último, operación está ligada a la manipulación (material o intelectual) que realiza el sujeto con vistas a obtener un resultado. 


\subsubsection{Discurso y texto}

Numerosas definiciones y diferencias entre texto y discurso recoge la literatura lingüística desde la publicación del artículo de Z.S. Harris (1952) Discourse Analysis. ${ }^{20}$ Una distinción esencial es que el discurso se vincula con la actividad de construcción mientras que el texto es producto. En tal sentido, el Diccionario de Análisis del Discurso (2005: 180), define:

"El discurso es concebido como la inclusión de un texto en su contexto (= condiciones de producción y de recepción)"

según la fórmula de Adam (1999: 39):

$$
\begin{aligned}
& « \text { Discours }=\text { Texte } \quad+\quad \text { Conditions de Production } » \\
& « \text { Texte }=\text { Discours }-\quad \text { Conditions de Production. } »
\end{aligned}
$$

Discurso $=$ Texto + Condiciones de Producción .

Texto $=$ Discurso - Condiciones de Producción .

El plano del discurso, cognitivamente es anterior al texto y surge de un impulso psicopragmático, mientras que el plano del texto se superpone al discurso y es su estructuración. Como el plano del discurso se va construyendo tiene mayor espesor; además, necesita una coherencia interna basada en el sentido común y en la lógica, todo lo cual se irá materializando a través de rasgos cohesivos que emergerán en el plano delgado del texto, es decir, el plano que se ve y que acusa su propia gramática. La cohesión del texto es una forma de coherencia y ésta es al texto lo que la gramaticalidad es a la frase. ${ }^{21}$

\footnotetext{
${ }^{20}$ En la bibliografía citamos la versión francesa de 1969.

${ }^{21}$ Sánchez, Ida Sonia. Documento de defensa de la tesis de doctorado (11/01/95).
} 


\subsubsection{Ambigüedad}

El Diccionario de la Real Academia Española (DRAE) define la ambigüedad como calidad de ambiguo y ambiguo, en su primera acepción, como lo que puede entenderse de varios modos o admitir distintas interpretaciones y dar, por consiguiente, motivos a dudas, incertidumbre o confusión. Dícese especialmente del lenguaje.

El Dictionnaire de Linguistique (Dubois y otros, 1994: 31-32) la define como sigue:

« l'ambiguitté est la propriété de certaines phrases qui présentent plusieurs sens. L'ambiguïté peut tenir au lexique, certains morphèmes lexicaux ayant plusieurs sens. Ainsi, la phrase Le secrétaire est dans le bureau a au moins deux sens, car secrétaire est soit une personne, soit un meuble (on parle alors d'ambiguïté lexicale). L'ambiguïté peut tenir au fait que la phrase a une structure syntaxique susceptible de plusieurs interprétations. Ainsi, Le magistrat juge les enfants coupables répond soit à l'interprétation Le magistrat juge que les enfants sont coupables, soit à l'interprétation Le magistrat juge les enfants qui sont coupables (on parle alors d'ambiguïté syntaxique ou d'homonymie de construction). »

La ambigüedad es la propiedad de ciertas oraciones que presentan diversos sentidos. La ambigüedad puede provenir del léxico, debido a que ciertos morfemas léxicos tienen diversos sentidos. Por ejemplo, la oración Le secrétaire est dans le bureau tiene al menos dos sentidos, pues la palabra secrétaire puede ser una persona o un mueble (hablamos entonces de ambigüedad léxica). La ambigüedad puede provenir de una oración cuya estructura sintáctica es ofrece diversas interpretaciones. Por ejemplo, Le magistrat juge les enfants coupables puede interpretarse como que El magistrado juzga que los niños son culpables o que el El magistrado juzga a los niños que son culpables (hablamos entonces de ambigüedad sintáctica o de homonimia de construcción).

Nuestro trabajo está vinculado con las estructuras sintácticas que dentro del discurso pueden llevar a más de una interpretación.

\subsubsection{Anomalía}

EI DRAE define la anomalía como la irregularidad o discrepancia de una regla.

Desde la gramática, Di Tullio (1997: 17) diferencia la noción de gramaticalidad que permite deslindar construcciones bien formadas, tanto morfológicas como sintácticas, de la noción de secuencia anómala, que implica la contravención de alguna regla del sistema y no de normas de orden prescriptivo. 
Christian Godin (2001: 66), ${ }^{22}$ al tratar el tema de la pulsión eugenésica, define la anomalía como el simple desvío respecto de la norma y lo diferencia de anormalidad que es supresión de la norma.

Adriana Silvestri (2000: 168) toma la anomalía como sinónimo de error discursivo-textual, entre otros las apelaciones alejadas del género, el recurso de perseveración u ocurrencia reiterada de un elemento léxico o sintáctico, la dificultad en el manejo de elementos de cohesión.

Dubois y Weil-Barais (1999: 275) toman las anomalías semánticas, al igual que a los errores de grafía y a las dificultades o patologías de los lectores como situaciones irregulares.

Para este trabajo, el concepto operativo de anomalía abarca, por un lado, las elipsis construidas sin observar las reglas del sistema lingüístico de referencia, que hemos denominado anomalías sintácticas o gramaticales, y por el otro, las elipsis resueltas dentro del sistema lingüístico de referencia, pero que así y todo inciden negativamente en la cohesión, en la construcción del sentido y por consiguiente en el pasaje de la información, que hemos denominado anomalías discursivas. Ambas pueden visualizarse desde el universal de interferencia.

\subsubsection{Binomio textual}

Toury justifica el uso de segmentos emparejados como mecanismo operativo para el análisis retrospectivo y a la vez destaca la dificultad para delimitarlos (2004: $122,141,142,147)$.

Rabadán compara diversas traducciones de un mismo texto original y llama binomio textual a cada TM-TO, tomado como unidad bi-textual al translema, según criterios de equivalencia (1991: 199).

En este trabajo, los segmentos que hemos aislado para su estudio son enunciados elípticos con anomalías, en los que subyace una relación entre el TT y el TO, lo que justifica la designación de binomios textuales.

\footnotetext{
${ }^{22}$ Véase Testart, Jacques y Godin, Christian (2001).
} 


\subsubsection{Elevación de la frecuencia de uso de recursos o elementos}

La elevación de la frecuencia de uso de recursos o elementos, que entendemos como análogo al recurso de perseveración u ocurrencia reiterada de un elemento léxico o sintáctico, y su relación con la infracción de la norma es un concepto clave en nuestro estudio porque explica el descenso de la fluidez en la lectura por efecto de la redundancia de un fenómeno, que, en el caso de la elipsis, está asociado con la ausencia léxica [ $\rightarrow$ Capítulo III, Interferencia. 3.1.3.].

\subsubsection{Entropía}

EI DRAE define entropía en la Termodinámica como término que indica medida de la parte no utilizable de la energía contenida en un sistema y, en la Informática, como la medida de la incertidumbre existente ante un conjunto de mensajes, del cual va recibirse uno solo.

El Dictionnaire de Linguistique (Dubois y otros, 1994: 182) la define como sigue:

« Le terme d'entropie, emprunté à la théorie de la communication, représente le degré d'incertitude où l'on est de l'apparition de chaque signal. Ainsi, pour un nombre donné de réponses possibles, l'entropie est maximale lorsque toutes les réponses ont la même fréquence; elle est faible lorsque deux réponses ont une haute fréquence d'apparition, les autres étant très peu fréquentes. L'entropie augmente donc avec l'incertitude du récepteur sur la réponse qui va lui être donnée. »

El término entropía, tomado de la teoría de la comunicación, representa el grado de incertidumbre que se tiene de la aparición de cada señal. De allí que, para una cantidad dada de respuestas posibles, la entropía es máxima cuando todas las respuestas tienen la misma frecuencia; es baja cuando dos respuestas tienen alta frecuencia de aparición mientras que las demás son poco frecuentes. La entropía aumenta con la incertidumbre del receptor sobre la respuesta que se le dará.

En Traductología, Ladmiral (1994: 224) utiliza entropie en su teorema fundamental, oponiéndolo a incrémentalisation, mientras que Antoine Berman prefiere défectivité, noción que engloba todas las formas posibles de fallos que pueden encontrarse en una traducción (1995). 
En este trabajo hemos tomado el concepto entropía desde la incertidumbre o de la pérdida informativa.

\subsubsection{Oración y enunciado}

Existen diversas definiciones según criterios semánticos, fonéticos, sintácticos, comunicativos, entre otros. Advertimos la coexistencia de dos términos emparentados oración/enunciado, a tal punto que Georges Mounin (2000: 262) observa que muchos usos lingüísticos los toman como sinónimos. Sin embargo, establece una distinción que surge de la oposición entre ambos y llega a convenir que las oraciones son unidades de lengua y los enunciados unidades o ejemplos de habla, es decir, el enunciado es lo que aparece en el material no analizado.

Por su parte, Patrick Charaudeau y Dominique Mainguenenau (2005: 213) advierten que la palabra enunciado es usada de manera polisémica, y destacan que sus empleos pueden inscribirse en la teoría de la enunciación, en cuyo caso se lo considera como el producto del acto de producción, o simplemente puede verse en el enunciado una secuencia verbal de dimensión variable.

El Dictionnaire de Linguistique (Dubois y otros, 1994: 180) precisa que:

"La clôture de l'énoncé est assurée par une période de silence avant et après la suite des mots, silences réalisés par les sujets parlants. Un énoncé peut être formé d'une ou plusieurs phrases; (...) »

El cierre del enunciado está asegurado por un período de silencio antes y después de la secuencia de palabras, silencios realizados por los hablantes. Un enunciado puede estar formado por una o más oraciones ; (...)

En este trabajo, los segmentos que hemos emparejado o binomios textuales, están representados por enunciados constituidos por una o más oraciones.

\subsubsection{Enunciado elíptico}

José María Brucart define la elipsis como mecanismo limitador de la redundancia léxica de los enunciados (2000: 2789). De allí que, en este trabajo consideramos el enunciado elíptico como aquél en el que se produce una elipsis 


\subsubsection{Producción discursiva, reexpresión, reformulación}

En Traductología, los tres conceptos remiten a procesos análogos que, a partir de un texto original, corresponden a la fase durante la cual el traductor materializa la transferencia en la lengua-cultura meta $[\rightarrow$ Capítulo II, Producción discurisiva].

\subsubsection{Producción palimpséstica}

EI DRAE define palimpsesto como "Manuscrito antiguo que conserva huellas de una escritura anterior borrada artificialmente". Creemos que este término se ajusta a la traducción porque justamente de lo que se trata es de producir un texto con las características del polo meta; sin embargo, muchas veces, aunque se borre el texto original, sus huellas aparecen con más o menos fuerza. Hemos preferido este término en lugar de las nociones de intertextualidad de J.Kristeva, transtextualidad e intertextualidad de G.Genette porque ellas remiten a las presencias de otros textos en un nuevo texto, como recurso para su producción.

Nosotros consideramos que la producción palimpséstica son las huellas de un texto ajeno que obstaculizan la lectura fluida del texto traducido, lo que genera una disminución de su libertad y la consiguiente referencia de consulta al texto original.

Antes de pasar al Capítulo VI que presenta el análisis realizado, recordamos que la Figura 7. Instrumento de análisis reúne los elementos que se han tenido en cuenta para este estudio. 


\section{CAPÍTULO VI}

\section{ANÁLISIS}

"Cuantos más rastros de interferencia presenta una traducción, tanto más podemos suponer que dicha traducción se ha ajustado a la configuración del texto origen durante el proceso de traducción." Gideon Toury (2004: 346).

\subsection{Organización del capítulo}

Rosa Rabadán (1991: 43) señala que más allá de que el análisis contrastivo y la traducción persigan metas diferentes puesto que el primero tiende a la descripción interlingüística mientras que la traducción se instala en un contexto concreto, el análisis contrastivo puede aportar datos de interés a la segunda. Como ya hemos señalado, en todo acto de lenguaje y particularmente en la traducción es aplicable la aseveración de Jean-Michel Adam, entre otros, según la cual una lingüística de la lengua debe estar necesariamente completada por una lingüística del discurso.

El presente capítulo presenta tres partes: la primera reúne los cuarenta (40) binomios provenientes de los textos traducidos al castellano y de los textos originales en francés, que hemos seleccionado para su análisis, correspondiendo los primeros veintiuno (21) a la fuente www.genethique.org o Gènéthique y los diecinueve (19) restantes a Au bazar du vivant y su traducción El racismo del gen. La segunda parte se inicia con una breve introducción sobre las características de la fuente textual www.genethique.org y está seguida del análisis de los binomios. La tercera parte toma una estructura análoga a la de la segunda parte, es decir una introducción general sobre las obras Au bazar du vivant/El racismo del gen seguida del análisis de los binomios que hemos seleccionado de esas publicaciones.

Cabe destacar que el análisis de los enunciados provenientes de los textos traducidos al castellano (TT) y de sus correspondientes originales (TO) sigue los lineamientos de la Figura 7. Instrumento de análisis del capítulo anterior y presenta 
reiteraciones conceptuales como así también estilísticas que dificultan una lectura fluida pero que a su vez responden a uno de nuestros objetivos, si no el esencial, que es la búsqueda de regularidades.

Desde el punto de vista grafémico, hemos utilizado las comillas latinas («») y los caracteres en cursiva cuando citamos partes de los textos en francés y solamente las comillas inglesas (") en los constituyentes de los textos traducidos al castellano, elección que fundamos en el uso que el castellano y el francés hacen de ellas. En el caso de que los elementos textuales estén entre paréntesis, utilizaremos únicamente la cursiva en las palabras en francés y los caracteres regulares en castellano, separados por la barra de contraste.

En resumen, los binomios textuales en los que hemos detectado anomalías en la producción discursiva de elipsis se analizarán según las pautas previamente establecidas en el Capítulo V, Metodología. 5.4.4.

Una vez concluido el análisis, sus resultados se ordenan e interpretan en el capítulo VII. 


\subsection{Primera parte: Binomios textuales}

\subsubsection{Binomios textuales de la fuente www.genethique.org o Gènéthique}

A continuación reproducimos la totalidad de los enunciados que hemos considerado para su análisis numerados de 1 a 21. Con la finalidad de facilitar su individualización dentro de las fuentes completas que obran en el Anexo I, hemos utilizado las siglas y abreviaturas que siguen:

Cód. = Código alfanumérico para identificar cada texto [ $\rightarrow$ Anexo 1].

TT = texto traducido (al castellano).

r. = renglones que ocupa el enunciado.

$\mathrm{TO}=$ texto original (en francés)

1

\begin{tabular}{|l|l|l|l|l|}
\hline Cód. & \multicolumn{1}{|c|}{ TT } & r. & \multicolumn{1}{c|}{ TO } & r. \\
\hline 43b) & $\begin{array}{l}\text { El responsable de las investigaciones, el } \\
\text { Dr. Tal Biron-Shental, reconoce (...). }\end{array}$ & - & $\begin{array}{l}\text { Le responsable des recherches, le Dr Tal } \\
\text { Biron-Shental, reconnaît (...). Qui voudrait } \\
\text { avoir comme mère un foetus avorté ? Mais } \\
\text { pour elle, cette technique pourrait être une } \\
\text { nouvelle source d'ovocytes ... }\end{array}$ & $\begin{array}{l}10 \\
\text { feto abortado? Sin embargo, para este } \\
\text { equipo israelí-holandés podría ser una } \\
\text { nueva fuente de ovocitos... }\end{array}$ \\
\hline
\end{tabular}

2

\begin{tabular}{|l|l|l|l|l|}
\hline Cód. & \multicolumn{1}{|c|}{ TT } & r. & \multicolumn{1}{|c|}{ TO } & r. \\
\hline 43b) & $\begin{array}{l}\text { La mayor controversia de estos trabajos } \\
\text { fue sin duda el presentado por el Centro } \\
\text { de Reproducción...” }\end{array}$ & 15 & $\begin{array}{l}\text { Le plus controversé de ces travaux fut sans } \\
\text { doute celui présenté par le Centre de } \\
\text { Reproduction.... }\end{array}$ & . \\
\hline
\end{tabular}

3

\begin{tabular}{|c|c|c|c|c|}
\hline Cód. & TT & r. & TO & r. \\
\hline $43 c)$ & $\begin{array}{l}\text { La dirección general de la salud indicó al } \\
\text { Tribunal que "si se excluye a los } \\
\text { investigadores que trabajan sobre la } \\
\text { pueba de la trisomía } 21 \text { y sus factores } \\
\text { epidemiológicos asociados", "no tiene } \\
\text { conocimiento de ningún equipo de } \\
\text { investigación que se ocupe de la relación } \\
\text { entre la trisomía } 21 \text { y el retraso mental", } \\
\text { precisando que "las únicas } \\
\text { investigaciones clínicas sobre la trisomía } \\
21 \text { son realizadas y difundidas por una } \\
\text { fundación privada y tres equipos } \\
\text { hospitalarios". }\end{array}$ & 39 & $\begin{array}{l}\text { La direction générale de la santé a même } \\
\text { indiqué à la Cour que «si l'on exclut les } \\
\text { équipes de chercheurs qui travaillent sur le } \\
\text { dépistage de la trisomie } 21 \text { proprement dit et } \\
\text { les facteurs épidémiologiques associés à } \\
\text { cette pathologie », elle n'a "connaissance } \\
\text { d'aucune équipe dédiée spécifiquement à la } \\
\text { relation entre trisomie } 21 \text { et retard mental ", } \\
\text { précisant que "les seules recherches } \\
\text { cliniques sur la trisomie } 21 \text { sont menées et } \\
\text { diffusées par une fondation privée et trois } \\
\text { équipes hospitalières" }\end{array}$ & $\begin{array}{l}37 \\
- \\
39\end{array}$ \\
\hline
\end{tabular}




\begin{tabular}{|l|l|l|l|l|}
\hline Cód. & \multicolumn{1}{|c|}{ TT } & r. & \multicolumn{1}{|c|}{ TO } & r. \\
\hline 43c) & $\begin{array}{l}\text { ¿Qué paciente aceptará que el Estado } \\
\text { invierta 100 millones de euros por año en } \\
\text { pruebas de la trisomía privándole de toda } \\
\text { investigación terapéutica? }\end{array}$ & -51 & $\begin{array}{l}\text { Quels patients accepteraient que l'Etat } \\
\text { investisse 100 millions d'euros par an pour les } \\
\text { dépister et les "éradiquer" en les privant de } \\
\text { toute recherche thérapeutique? }\end{array}$ & $\begin{array}{l}\text { 50 } \\
50\end{array}$ \\
\hline
\end{tabular}

\section{5}

\begin{tabular}{|c|c|c|c|c|}
\hline Cód. & TT & $r$. & $\mathrm{TO}$ & r. \\
\hline $44 b)$ & $\begin{array}{l}\text { La ingeniería genética y la creación de } \\
\text { bebés de síntesis poseyendo todos los } \\
\text { genes específicos de características tales } \\
\text { como la inteligencia, la estatura, la } \\
\text { autoestima... conducirá a un suave } \\
\text { eugenismo, respondiendo a la petición de } \\
\text { los padres, que desean lo mejor para sus } \\
\text { hijos y tampoco la obligación impuesta } \\
\text { por un Estado coercitivo. }\end{array}$ & $\begin{array}{l}17 \\
- \\
20\end{array}$ & $\begin{array}{l}\text { L'ingénierie génétique et la création de bébés } \\
\text { de synthèse possédant tous les gènes } \\
\text { spécifiques de caractéristiques telles que } \\
\text { l'intelligence, la taille, l'estime de } \\
\text { soi...conduira à un eugénisme doux, } \\
\text { répondant à la demande des parents qui } \\
\text { désirent le meilleur pour leur enfant, et non } \\
\text { plus à l'obligation imposée par un Etat } \\
\text { coercitif. }\end{array}$ & $\begin{array}{l}18 \\
- \\
21\end{array}$ \\
\hline
\end{tabular}

6

\begin{tabular}{|c|c|c|c|c|}
\hline Cód. & TT & r. & TO & r. \\
\hline 45a) & $\begin{array}{l}\text { En el informe emitido el } 4 \text { de julio de } \\
2002 \text {, el Comité Consultivo Nacional de } \\
\text { Ética se mostró reservado, subrayando } \\
\text { que: « la realidad del proyecto paternal es } \\
\text { el problema esencial y, en consecuencia, } \\
\text { el riesgo de instrumentalizar al niño ». }\end{array}$ & $\begin{array}{l}15 \\
- \\
16\end{array}$ & $\begin{array}{l}\text { Dans un avis rendu le } 4 \text { juillet } 2002 \text {, le Comité } \\
\text { consultatif national d'éthique s'était montré } \\
\text { réservé, soulignant que «le problème } \\
\text { essentiel est celui de la réalité du projet } \\
\text { parental et donc du risque } \\
\text { d'instrumentalisation de l'enfant». }\end{array}$ & $\begin{array}{l}14 \\
- \\
15\end{array}$ \\
\hline
\end{tabular}

\begin{tabular}{|c|c|c|c|c|}
\hline Cód. & TT & r. & TO & r. \\
\hline 45c) & $\begin{array}{l}\text { Las células madre embrionarias humanas } \\
\text { pueden ser aisladas solamente a partir de } \\
\text { embriones supernumerarios cuyos padres } \\
\text { los donaron para la ciencia y fueron } \\
\text { concebidos antes del } 27 \text { de junio de } 2002 \\
\text { fecha adoptada por el sexto programa } \\
\text { marco (con el fin de evitar que la } \\
\text { financiación comunitaria no fomente } \\
\text { indirectamente la producción de } \\
\text { embriones en exceso que no son } \\
\text { necesarios para la fecundación in vitro). }\end{array}$ & 25 & $\begin{array}{l}\text { Les cellules souches embryonnaires } \\
\text { humaines ne peuvent être isolées qu'à partir } \\
\text { d'embryons surnuméraires dont les parents } \\
\text { font don à la science et qui ont été conçus } \\
\text { avant le } 27 \text { juin } 2002 \text { date d'adoption du 6è } \\
\text { Programme Cadre (ceci afin d'éviter que le } \\
\text { financement communautaire n'encourage } \\
\text { indirectement à produire plus d'embryons qu'il } \\
\text { n'est nécessaire pour la fécondation in vitro ; }\end{array}$ & $\begin{array}{l}25 \\
- \\
26\end{array}$ \\
\hline
\end{tabular}

\begin{tabular}{|l|l|l|l|l|}
\hline Cód. & \multicolumn{1}{|c|}{ TT } & r. & TO & r. \\
\hline 45c) & $\begin{array}{l}\text { - La protección de las bases de datos y la } \\
\text { vida privada deben estar garantizados, } \\
\text { así como la trazabilidad de las células } \\
\text { asegurada. }\end{array}$ & 34 & $\begin{array}{l}- \text { La protection des données et de la vie } \\
\text { privée doit être garantie et la traçabilité des } \\
\text { cellules souches assurée ; }\end{array}$ & - \\
34 \\
\hline
\end{tabular}




\begin{tabular}{|c|c|c|c|c|}
\hline Cód. & TT & r. & TO & r. \\
\hline 46b) & $\begin{array}{l}\text { En efecto, podemos pensar que si el } \\
\text { joven Vincent pedía morir y si hubiera } \\
\text { podido evitar alimentarse, habría } \\
\text { provocado una disminución de los } \\
\text { cuidados que le mantenían con vida, en } \\
\text { particular la nutrición. }\end{array}$ & 20 & $\begin{array}{l}\text { En effet, on peut penser que le jeune Vincent, } \\
\text { s'il demandait à mourir et s'il avait pu éviter de } \\
\text { se nourrir, aurait provoqué lui-même une } \\
\text { diminution des soins qui le maintenaient en } \\
\text { vie, en particulier la nutrition. }\end{array}$ & $\begin{array}{l}19 \\
- \\
20\end{array}$ \\
\hline
\end{tabular}

10

\begin{tabular}{|c|c|c|c|c|}
\hline Cód. & TT & r. & $\mathrm{TO}$ & r. \\
\hline 48c) & $\begin{array}{l}\text { El } 2 \text { de diciembre en el periódico le } \\
\text { Figaro, la Profesora Michèle Laure } \\
\text { Rassat se sorprende: "on a du mal, } \\
\text { devant le bon sens d'une semblable } \\
\text { disposition, a comprendre le tollé qu'elle } \\
\text { soulève et l'on ne peut que se demander, } \\
\text { s'il relève d'une totale méconnaissance } \\
\text { par leurs auteurs de ce dont ils } \\
\text { prétendent parler ou d'une volonté } \\
\text { d'agitation de principe" (no se comprende, } \\
\text { ante la sensatez de similar disposición, el } \\
\text { clamor de indignación que levanta y nos } \\
\text { preguntamos, si proviene de una } \\
\text { ignorancia total por parte de los autores } \\
\text { acerca de lo que pretenden expresar o } \\
\text { sencillamente de una voluntad de } \\
\text { agitación"). }\end{array}$ & $\begin{array}{l}25 \\
- \\
27\end{array}$ & $\begin{array}{l}\text { Dans le Figaro du } 2 \text { décembre, le Professeur } \\
\text { Michèle Laure Rassat s'étonne: "on a du mal, } \\
\text { devant le bon sens d'une semblable } \\
\text { disposition, a comprendre le tollé qu'elle } \\
\text { soulève et l'on ne peut que se demander, s'il } \\
\text { relève d'une totale méconnaissance par leurs } \\
\text { auteurs de ce dont ils prétendent parler ou } \\
\text { d'une volonté d'agitation de principe." }\end{array}$ & $\begin{array}{l}22 \\
- \\
25\end{array}$ \\
\hline
\end{tabular}

11

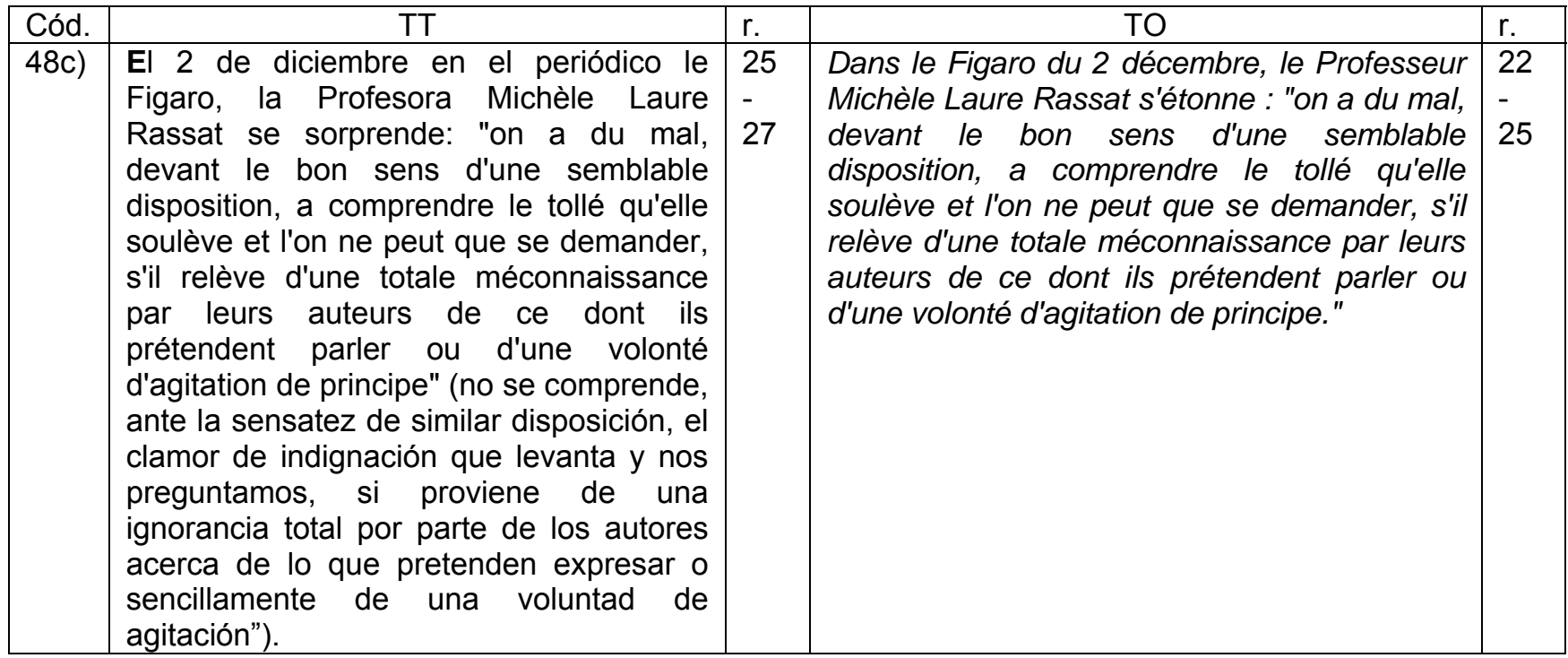




\begin{tabular}{|c|c|c|c|c|}
\hline Cód. & TT & r. & $\mathrm{TO}$ & r. \\
\hline $48 c)$ & $\begin{array}{l}\text { El pasado } 10 \text { de diciembre, una mujer de } \\
\text { nacionalidad francesa denunciaba la } \\
\text { negativa de la jurisdicción francesa para } \\
\text { calificar de homicidio involuntario el } \\
\text { ataque a la vida de su hijo, en el seno } \\
\text { materno, y que perdió como } \\
\text { consecuencia de un error médico (fue } \\
\text { confundida con una mujer que deseaba } \\
\text { retirar su DIU). }\end{array}$ & $\begin{array}{l}38 \\
- \\
40\end{array}$ & $\begin{array}{l}\text { Le } 10 \text { décembre, une Française dénonçait le } \\
\text { refus par la juridiction française de qualifier } \\
\text { d'homicide involontaire l'atteinte à la vie d'un } \\
\text { enfant à naître qu'elle portait et qu'elle a } \\
\text { perdu à la suite d'une erreur médicale (elle a } \\
\text { été confondue avec une femme qui voulait } \\
\text { retirer son stérilet). }\end{array}$ & $\begin{array}{l}34 \\
- \\
36\end{array}$ \\
\hline
\end{tabular}

13

\begin{tabular}{|c|c|c|c|c|}
\hline Cód. & TT & r. & TO & r. \\
\hline 48c) & $\begin{array}{l}\text { Invocando el artículo } 2 \text { (derecho a la vida) } \\
\text { de la Convención europea de derechos } \\
\text { del hombre, recuerda que el Estado tiene } \\
\text { la obligación de establecer una } \\
\text { legislación penal destinada a reprimir y } \\
\text { sancionar tal delito. }\end{array}$ & $\begin{array}{l}41 \\
- \\
42\end{array}$ & $\begin{array}{l}\text { Invoquant l'article } 2 \text { (droit à la vie) de la } \\
\text { Convention européenne des droits de } \\
\text { l'homme, elle rappelle que l'Etat a l'obligation } \\
\text { de mettre en place une législation pénale } \\
\text { visant à réprimer et sanctionner un tel délit. }\end{array}$ & $\begin{array}{l}37 \\
- \\
38\end{array}$ \\
\hline
\end{tabular}

14

\begin{tabular}{|c|c|c|c|c|}
\hline Cód. & TT & r. & TO & r. \\
\hline $50 c)$ & $\begin{array}{l}\text { La FIAMC (Federación Internacional de } \\
\text { Asociaciones de Médicos Católicos) se } \\
\text { opone a este informe; señala que no } \\
\text { define claramente la eutanasia y no } \\
\text { distingue: } \\
\text { - las limitaciones y las supresiones de } \\
\text { tratamientos que han sido inútiles o } \\
\text { rechazados por el paciente (que se } \\
\text { incluye en la buena práctica médica), } \\
\text { - algunas prácticas de alivio a los dolores } \\
\text { resistentes a los medicamentos o } \\
\text { angustias insoportables, que pueden } \\
\text { eventualmente implicar una muerte no } \\
\text { deseada. }\end{array}$ & $\begin{array}{l}15 \\
- \\
16\end{array}$ & $\begin{array}{l}\text { La FIAMC (Fédération Internationale des } \\
\text { Associations de Médecins Catholiques) } \\
\text { s'oppose à ce rapport ; elle fait remarquer que } \\
\text { l'euthanasie n'y est pas clairement définie ; } \\
\text { elle n'est pas distinguée: } \\
\text { - des limitations et arrêts de traitements } \\
\text { devenus inutiles ou refusés par le patient (qui } \\
\text { relèvent d'une bonne pratique médicale), } \\
\text { - ni de certaines pratiques de soulagement } \\
\text { des douleurs réfractaires ou des angoisses } \\
\text { insupportables, qui peuvent éventuellement } \\
\text { entraîner une mort non recherchée. }\end{array}$ & $\begin{array}{l}15 \\
- \\
16\end{array}$ \\
\hline
\end{tabular}

15

\begin{tabular}{|c|c|c|c|c|}
\hline Cód. & TT & r. & TO & r. \\
\hline 50c) & $\begin{array}{l}\text { La FIAMC (Federación Internacional de } \\
\text { Asociaciones de Médicos Católicos) se } \\
\text { opone a este informe; señala que no } \\
\text { define claramente la eutanasia y no } \\
\text { distingue: } \\
\text { - las limitaciones y las supresiones de } \\
\text { tratamientos que han sido inútiles o } \\
\text { rechazados por el paciente (que se } \\
\text { incluye en la buena práctica médica), } \\
\text { - algunas prácticas de alivio a los dolores } \\
\text { resistentes a los medicamentos o } \\
\text { angustias insoportables, que pueden } \\
\text { eventualmente implicar una muerte no } \\
\text { deseada }\end{array}$ & $\begin{array}{l}15 \\
- \\
16\end{array}$ & $\begin{array}{l}\text { La FIAMC (Fédération Internationale des } \\
\text { Associations de Médecins Catholiques) } \\
\text { s'oppose à ce rapport ; elle fait remarquer que } \\
\text { l'euthanasie n'y est pas clairement définie; } \\
\text { elle n'est pas distinguée: } \\
\text { - des limitations et arrêts de traitements } \\
\text { devenus inutiles ou refusés par le patient (qui } \\
\text { relèvent d'une bonne pratique médicale), } \\
\text { - ni de certaines pratiques de soulagement } \\
\text { des douleurs réfractaires ou des angoisses } \\
\text { insupportables, qui peuvent éventuellement } \\
\text { entraîner une mort non recherchée. }\end{array}$ & $\begin{array}{l}15 \\
- \\
16\end{array}$ \\
\hline
\end{tabular}


16

\begin{tabular}{|c|c|c|c|c|}
\hline Cód. & TT & r. & $\mathrm{TO}$ & r. \\
\hline 50c) & $\begin{array}{l}\text { La FIAMC reafirma su compromiso: } \\
-(\ldots) \\
\text { - al acompañamiento de enfermos en } \\
\text { fase terminal }(\ldots) \text { por una petición de } \\
\text { muerte, frente a la cual la eutanasia le } \\
\text { parece un remedio simplista e inhumano. }\end{array}$ & $\begin{array}{l}25 \\
- \\
26\end{array}$ & $\begin{array}{l}\text { La FIAMC réaffirme son attachement: } \\
\text {-(...) } \\
\text { - à l'accompagnement des malades en fin de } \\
\text { vie (...) par une demande de mort, vis-à (...) } \\
\text { vis-à-vis de laquelle l'euthanasie leur paraît } \\
\text { un remède simpliste et inhumain. }\end{array}$ & $\begin{array}{l}25 \\
- \\
26\end{array}$ \\
\hline
\end{tabular}

17

\begin{tabular}{|c|c|c|c|}
\hline Cód. & TT & r. & TO \\
\hline 51a) & $\begin{array}{l}\text { El juez encargado del caso } \\
\text { desconcertado, ya que en ningún lugar } \\
\text { del mundo, en el año 1989, se había } \\
\text { planteado esta cuestión ante un juez. } \\
\text { Hace un llamamiento a testigos científicos } \\
\text { susceptibles de aclararle la calificación de } \\
\text { estos embriones: ¿ser humano o simple } \\
\text { obieto?... }\end{array}$ & 6 & $\begin{array}{l}\text { Le juge chargé de l'affaire est bien } \\
\text { embarrassé ; nulle part au monde, en 1989, } \\
\text { ne s'est posée cette question pour un juge. Il } \\
\text { lance un appel à témoins en direction de } \\
\text { scientifiques susceptibles de l'éclairer quant à } \\
\text { la qualification de ces embryons: être } \\
\text { humain ou simple objet?... }\end{array}$ \\
\hline
\end{tabular}

18

\begin{tabular}{|c|c|c|c|}
\hline Cód. & TT & r. & TO \\
\hline 51a) & $\begin{array}{l}\text { Si se trata de un ser humano, deberá ser } \\
\text { protegido por la ley y si se califica de } \\
\text { bien, nada se opone a su destrucción. }\end{array}$ & 9 & $\begin{array}{l}\text { S'il s'agit d'un être humain, il devra, aux } \\
\text { termes de la loi, être confié à garde; s'il est } \\
\text { qualifié de bien, rien ne s'oppose à sa }\end{array}$ \\
\hline
\end{tabular}

19

\begin{tabular}{|c|c|c|c|c|}
\hline Cód. & TT & r. & $\mathrm{TO}$ & r. \\
\hline 51a) & $\begin{array}{l}\text { El abogado de la madre llama a testificar } \\
\text { a Jérôme Lejeune, conocido en los } \\
\text { Estados Unidos por haber recibido el } \\
\text { premio Kennedy tras descubrir la trisomía } \\
21 \text {, miembro de la Academia Americana } \\
\text { de las Artes y las Ciencias, de la } \\
\text { Academia Pontificia de las Ciencias... y } \\
\text { espera que sus notables conocimientos } \\
\text { de genetista contribuyan a aclarar al } \\
\text { magistrado. }\end{array}$ & $\begin{array}{l}10 \\
- \\
13\end{array}$ & $\begin{array}{l}\text { L'avocat de la mère invite alors à témoigner } \\
\text { Jérôme Lejeune, connu aux Etats-Unis pour } \\
\text { avoir reçu le prix Kennedy à la suite de sa } \\
\text { découverte de la trisomie 21, membre de } \\
\text { l'Académie américaine des Arts et des } \\
\text { Sciences, de l'Académie pontificale des } \\
\text { sciences... et dont il espère que les } \\
\text { remarquables talents de généticien } \\
\text { contribueront à éclairer le magistrat. }\end{array}$ & $\begin{array}{l}10 \\
- \\
13\end{array}$ \\
\hline
\end{tabular}

20

\begin{tabular}{|c|c|c|c|c|}
\hline Cód. & TT & e & TO & r. \\
\hline 51a) & $\begin{array}{l}\text { Al principio de la vida, la información } \\
\text { genética y la estructura molecular del } \\
\text { zigoto, el espíritu y la materia, el alma y el } \\
\text { cuerpo, están íntimamente unidos puesto } \\
\text { que ya constituye un ser humano. }\end{array}$ & $\begin{array}{l}28 \\
- \\
29\end{array}$ & $\begin{array}{l}\text { Au commencement de la vie, l'information } \\
\text { génétique et la structure moléculaire du } \\
\text { zygote, l'esprit et la matière, l'âme et le corps, } \\
\text { sont totalement intriqués puisqu'il s'agit déjà } \\
\text { d'un être humain }\end{array}$ & $\begin{array}{l}27 \\
- \\
28\end{array}$ \\
\hline
\end{tabular}

21

\begin{tabular}{|l|l|l|l|l|}
\hline Cód. & \multicolumn{1}{|c|}{ TT } & r. & \multicolumn{1}{|c|}{ TO } & r. \\
\hline $52 b)$ & $\begin{array}{l}\text { El animal sufrió un gran cambio que le } \\
\text { condujo a tener (...) }\end{array}$ & 13 & $\begin{array}{l}\text { L'animal a subi un véritable travestissement } \\
\text { l'amenant à afficher (...) }\end{array}$ & $\begin{array}{l}13 \\
- \\
14\end{array}$ \\
\hline
\end{tabular}




\subsubsection{Binomios textuales de las fuentes El racismo de gen/ Au bazar du vivant}

Estos enunciados corresponden a las fuentes indicadas en el título y su numeración es de 22 a 40 . Con la finalidad de facilitar su individualización dentro de las fuentes completas que obran en el Anexo II, hemos utilizado siglas y abreviaturas:

$$
\begin{aligned}
& \text { Cód. = Código alfanumérico para identificar cada texto [ } \rightarrow \text { Anexo II]. } \\
& \text { TT = texto traducido } E \text { I racismo de gen. } \\
& \text { p/r = página / renglón en el que se inicia el enunciado. } \\
& \text { TO = texto original Au bazar du vivant. }
\end{aligned}
$$

\begin{tabular}{|c|c|c|c|c|}
\hline Cap. & TT & $\mathrm{p} / \mathrm{r}$ & $\mathrm{TO}$ & $\mathrm{p} / \mathrm{r}$ \\
\hline 1 & $\begin{array}{l}\text { Por lo tanto, tras una breve presentación } \\
\text { de su carrera y de su trabajo, } \\
\text { encararemos sucesivamente esas tres } \\
\text { cuestiones: la metamorfosis de la } \\
\text { biología, la metamorfosis de la medicina y } \\
\text { la crítica de la bioética. }\end{array}$ & $\begin{array}{l}11 / \\
15\end{array}$ & $\begin{array}{l}\text { Donc, après une brève présentation de votre } \\
\text { carrière et de votre travail, nous aborderons } \\
\text { successivement ces trois questions: la } \\
\text { métamorphose de la biologie, la } \\
\text { métamorphose de la médecine et la critique } \\
\text { de la bioéthique. }\end{array}$ & $\begin{array}{l}9 / \\
18\end{array}$ \\
\hline
\end{tabular}

22

\begin{tabular}{|l|l|l|l|l|}
\hline Cód. & \multicolumn{1}{|c|}{ TT } & $\mathrm{p} / \mathrm{r}$ & \multicolumn{1}{|c|}{ TO } & \multicolumn{1}{|c|}{$\mathrm{p} / \mathrm{r}$} \\
\hline 1 & $\begin{array}{l}\text { Ante todo, están las profundas } \\
\text { transformaciones padecidas por la }\end{array}$ & 5 & $\begin{array}{l}\text { II y a d'abord les bouleversements profonds } \\
\text { subis par la biologie moderne : la façon de } \\
\text { pratique la science du vivant aujourd'hui n'a } \\
\text { pas plus grand-chose à voir avec celle de ses } \\
\text { pères fondateurs }\end{array}$ \\
$\begin{array}{l}\text { biología moderna: hoy, la manera de } \\
\text { practicar la ciencia de lo viviente no tiene } \\
\text { mucho que ver con la de sus padres } \\
\text { fundadores. }\end{array}$ & & \\
\hline
\end{tabular}

\begin{tabular}{|c|c|c|c|c|}
\hline Cap. & TT & $p / r$ & TO & $\mathrm{p} / \mathrm{r}$ \\
\hline 1 & $\begin{array}{l}\text { Entonces, su trabajo es la asistencia } \\
\text { médica para la procreación, y como } \\
\text { resultado de este éxito, que a la vez tenía } \\
\text { un valor profesional, mediático y } \\
\text { científico, acaecieron nuevos rechazos y } \\
\text { nuevos interrogantes, y se dio a conocer } \\
\text { al gran público por posiciones éticamente } \\
\text { fuertes, posiciones que sin duda son muy } \\
\text { minoritarias en el medio en que usted } \\
\text { evoluciona, porque rechaza el } \\
\text { pragmatismo que es como su filosofía } \\
\text { natural. }\end{array}$ & $\begin{array}{l}12 / \\
25\end{array}$ & $\begin{array}{l}\text { Donc votre travail, c'est l'AMP comme on dit } \\
\text { en jargon, l'assistance médicale à la } \\
\text { procréation et, à la suite de ce succès, qui } \\
\text { avait valeur à la fois professionnelle, } \\
\text { médiatique et scientifique, de nouveaux refus, } \\
\text { de nouvelles interrogations sont venus et } \\
\text { vous vous êtes fait connaitre dans le grand } \\
\text { public par des positions éthiquement fortes, } \\
\text { des positions qui sont sans doute très } \\
\text { marginales dans le milieu dans lequel vous } \\
\text { évoluez parce que vous refusez le } \\
\text { pragmatisme qui en est comme la philosophie } \\
\text { naturelle. }\end{array}$ & $\begin{array}{l}11 / \\
24\end{array}$ \\
\hline
\end{tabular}

23

24 


\begin{tabular}{|c|c|c|c|c|}
\hline Cap. & TT & $p / r$ & TO & $\mathrm{p} / \mathrm{r}$ \\
\hline 1 & $\begin{array}{l}\text { Entonces, su trabajo es la asistencia } \\
\text { médica para la procreación, y como } \\
\text { resultado de este éxito, que a la vez tenía } \\
\text { un valor profesional, mediático y } \\
\text { científico, acaecieron nuevos rechazos y } \\
\text { nuevos interrogantes, y se dio a conocer } \\
\text { al gran público por posiciones éticamente } \\
\text { fuertes, posiciones que sin duda son muy } \\
\text { minoritarias en el medio en que usted } \\
\text { evoluciona, porque rechaza el } \\
\text { pragmatismo que es como su filosofía } \\
\text { natural. }\end{array}$ & $\begin{array}{l}12 / \\
25\end{array}$ & $\begin{array}{l}\text { Donc votre travail, c'est l'AMP comme on dit } \\
\text { en jargon, l'assistance médicale à la } \\
\text { procréation et, à la suite de ce succès, qui } \\
\text { avait valeur à la fois professionnelle, } \\
\text { médiatique et scientifique, de nouveaux refus, } \\
\text { de nouvelles interrogations sont venus et } \\
\text { vous vous êtes fait connaître dans le grand } \\
\text { public par des positions éthiquement fortes, } \\
\text { des positions qui sont sans doute très } \\
\text { marginales dans le milieu dans lequel vous } \\
\text { évoluez parce que vous refusez le } \\
\text { pragmatisme qui en est comme la philosophie } \\
\text { naturelle. }\end{array}$ & $\begin{array}{l}11 / \\
24\end{array}$ \\
\hline
\end{tabular}

26

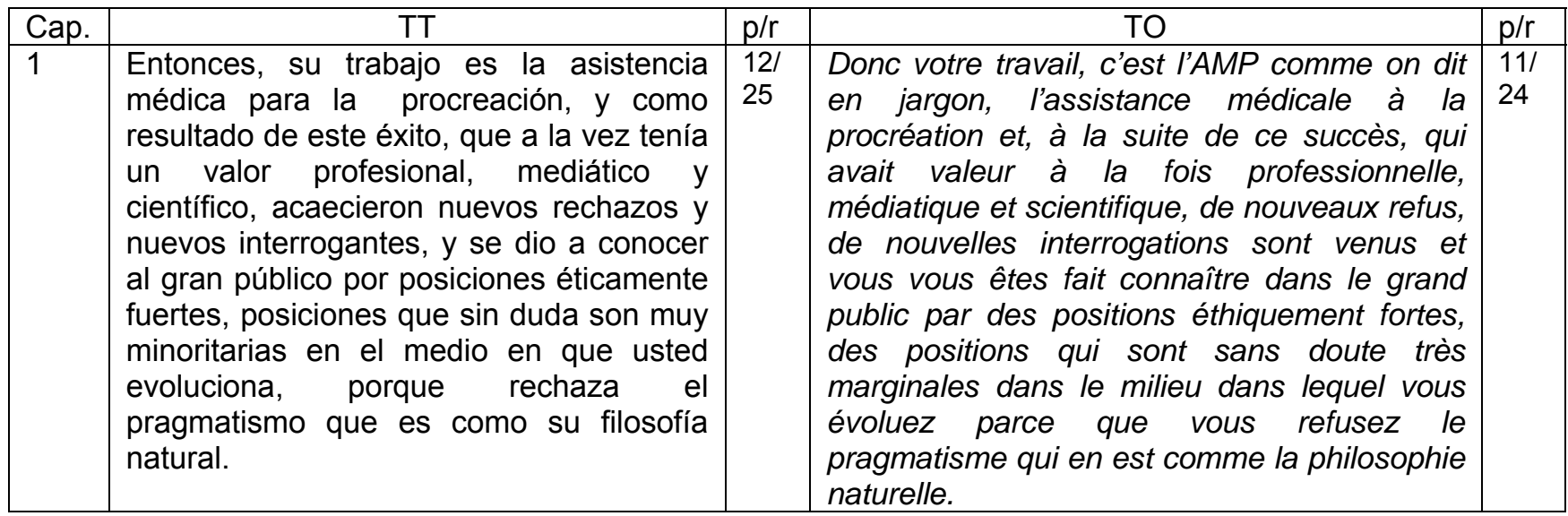

27

\begin{tabular}{|c|c|c|c|c|}
\hline Cap. & TT & $\mathrm{p} / \mathrm{r}$ & TO & $\mathrm{p} / \mathrm{r}$ \\
\hline 1 & $\begin{array}{l}\text { Jacques Testart: Efectivamente, con } \\
\text { frecuencia se hace ideología, pero ¿no es } \\
\text { un poco lo que hace Atlan cuando } \\
\text { pretende que el resultado de una } \\
\text { clonación humana (...). La higiene del } \\
\text { lenguaje, en efecto, permitiría suprimir } \\
\text { palabras fuertes, pero, al mismo tiempo, } \\
\text { ¿no corre el riesgo de volver insulso el } \\
\text { mismo contenido de dichas palabras, es } \\
\text { decir, también las representaciones que } \\
\text { vehiculizan y que no están desprovistas } \\
\text { de sentido? }\end{array}$ & $\begin{array}{l}14 / \\
16\end{array}$ & $\begin{array}{l}\text { Jacques Testart: On fait effectivement de } \\
\text { l'idéologie, mais n'est-ce pas aussi un peu ce } \\
\text { que fait Atlan quand il prétend que le résultar } \\
\text { d'un clonage humain (...). L'hygiène du } \\
\text { langage permettrait, effectivement, de } \\
\text { supprimer des mots forts, mais ne risque-t-on } \\
\text { pas en même temps d'affadir le contenu } \\
\text { même de ces mots, c'est-à-dire aussi les } \\
\text { représentations qu'ils véhiculent et qui ne sont } \\
\text { pas dénuées de sens? }\end{array}$ & $\begin{array}{l}13 / \\
16\end{array}$ \\
\hline
\end{tabular}

\begin{tabular}{|c|c|c|c|c|}
\hline Cód. & TT & $\mathrm{p} / \mathrm{r}$ & TO & $\mathrm{p} / \mathrm{r}$ \\
\hline 1 & $\begin{array}{l}\text { También manifestaba que un investigador } \\
\text { podía formularse preguntas sobre lo que } \\
\text { hace, que hay que dejar de sacralizar la } \\
\text { investigación, que no se hace } \\
\text { investigación porque es implícitamente } \\
\text { legitima, porque se tiene el derecho y el } \\
\text { deber de elegir su objeto de } \\
\text { investigación, y yo había elegido. }\end{array}$ & $\begin{array}{l}18 / \\
7\end{array}$ & $\begin{array}{l}\text { Je disais aussi qu' un chercheur pouvait se } \\
\text { poser des questions sur ce qu'il fait, qu'il faut } \\
\text { arrêter de sacraliser la recherche, qu'on ne } \\
\text { fait pas de la recherche parce que c'est } \\
\text { implicitement légitime, qu'on a le droit et le } \\
\text { devoir de choisir son objet de recherche, et } \\
\text { moi j'avais choisi. }\end{array}$ & $\begin{array}{l}18 / \\
13\end{array}$ \\
\hline
\end{tabular}


29

\begin{tabular}{|l|l|l|l|l|}
\hline Cód. & \multicolumn{1}{|c|}{ TT } & p/r & \multicolumn{1}{|c|}{ TO } & $\mathrm{p} / \mathrm{r}$ \\
\hline 2 & $\begin{array}{l}\text { Es ese concepto de programa lo que } \\
\text { usted impugna formalmente; en efecto, }\end{array}$ & 23 & $\begin{array}{l}\text { C'est ce concept de programme que vous } \\
\text { constatez formellement; il induit en effet une } \\
\text { induce una mala representación de } \\
\text { fausse image, une mauvaise représentation } \\
\text { nuestra existencia, de nuestro ser enistence, de notre être en tant } \\
\text { qu'être humain. }\end{array}$ & \\
cuanto ser humano.
\end{tabular}

30

\begin{tabular}{|c|c|c|c|c|}
\hline Cód. & TT & $\mathrm{p} / \mathrm{r}$ & TO & $p / r$ \\
\hline 3 & $\begin{array}{l}\text { Como usted afirmaba, hay un encuentro } \\
\text { entre un viejo fantasma colectivo y que es } \\
\text { posible comprender -aunque fuera por } \\
\text { responsabilidad para con su niño (¿por } \\
\text { qué desear un niño que tenga un riesgo } \\
\text { de enfermarse si uno es capaz de } \\
\text { engendrar uno que tendría un riesgo } \\
\text { menor?), y la nueva tecnología. }\end{array}$ & $\begin{array}{l}52 / \\
26\end{array}$ & $\begin{array}{l}\text { Comme vous le disiez, il y a une rencontre } \\
\text { entre un vieux fantasme collectif et que l'on } \\
\text { peut comprendre, ne serait-ce que par } \\
\text { responsabilité envers son enfant (pourquoi } \\
\text { souhaiter un enfant qui a un risque d'être } \\
\text { malade si l'on est capable d'en avoir un qui le } \\
\text { risquerait moins?), et la technologie nouvelle. }\end{array}$ & $\begin{array}{l}63 / \\
12\end{array}$ \\
\hline
\end{tabular}

31

\begin{tabular}{|l|l|l|l|l|}
\hline Cap. & \multicolumn{1}{|c|}{ TT } & $\mathrm{p} / \mathrm{r}$ & \multicolumn{1}{c|}{ TO } & $\mathrm{p} / \mathrm{r}$ \\
\hline 3 & $\begin{array}{l}\text { Pero a ese fatalismo se agrega } \\
\text { contradictoriamente una especie de }\end{array}$ & $55 /$ & $\begin{array}{l}\text { Or à ce fatalisme s'adjoint contradictoirement } \\
\text { une espèce de rêve volontariste reposant sur } \\
\text { l'idée (qui est une folle espérance) que l'on } \\
\text { pourrait commander aux gènes et même (en } \\
\text { un sens trivial commercial) commander des } \\
\text { idea (que es una loca esperanza) de que } \\
\text { gènes. }\end{array}$ \\
& $\begin{array}{l}\text { podría gobernarse a los genes e incluso } \\
\text { (en un trivial sentido comercial) encargar } \\
\text { genes. }\end{array}$ & & \\
\hline
\end{tabular}

32

\begin{tabular}{|c|c|c|c|c|}
\hline Cap. & TT & $\mathrm{p} / \mathrm{r}$ & TO & $\mathrm{p} / \mathrm{r}$ \\
\hline 3 & $\begin{array}{l}\text { El aspecto más alienante de la donación } \\
\text { de gametos, dice, usted, no es que el } \\
\text { padre genético no sea el padre social, ni } \\
\text { siquiera el secreto a menudo vinculado } \\
\text { con ese origen atípico, puesto que } \\
\text { muchos niños del adulterio pudieron vivir } \\
\text { felices en todas las épocas. Por lo menos } \\
\text { en Francia, radica en la prohibición legal } \\
\text { de decidir y de saber, porque únicamente } \\
\text { la institución médica se arroga la elección } \\
\text { de un progenitor y es la única poseedora }\end{array}$ & $\begin{array}{l}59 / \\
6\end{array}$ & $\begin{array}{l}\text { L'aspect le plus aliénant du don de gamètes, } \\
\text { dites-vous, n'est pas que le père génétique ne } \\
\text { soit pas le père social, il n'est même pas le } \\
\text { secret souvent attaché à cette origine } \\
\text { atypique puisque nombreux enfants de } \\
\text { l'adultère ont pu vivre heureux à toutes les } \\
\text { époques. II tient, du moins en France, à } \\
\text { l'interdiction légale de décider et de savoir, } \\
\text { car l'institution médicale s'arroge seule le } \\
\text { choix d'un géniteur et demeure seule } \\
\text { détentrice de ce secret. }\end{array}$ & \\
\hline
\end{tabular}

33

\begin{tabular}{|l|l|l|l|l|}
\hline Cód. & \multicolumn{1}{|c|}{ TT } & p/r & \multicolumn{1}{|c|}{ TO } & p/r \\
\hline 3 & El enemigo se aloja en el corazón & $68 /$ & L'ennemi loge au coeur invisible du corps et & $84 /$ \\
& invisible del cuerpo, y como éste apareció & 8 & comme il est apparu au moment de l'acte & 4 \\
& $\begin{array}{l}\text { en el momento del acto sexual de los } \\
\text { padres, induce la noción de una falta } \\
\text { primordial, de un pecado original, que no } \\
\text { está ligado solamente, como se podría } \\
\text { pensar, a la creencia cristiana. }\end{array}$ & & $\begin{array}{l}\text { faute primordiale, d'un péché originel, qui } \\
\text { n'est pas seulement liée, comme on pourrait } \\
\text { le penser, à la croyance chrétienne. }\end{array}$ & \\
& & & \\
\hline
\end{tabular}




\begin{tabular}{|c|c|c|c|c|}
\hline Cód. & TT & $p / r$ & TO & $\mathrm{p} / \mathrm{r}$ \\
\hline 3 & $\begin{array}{l}\text { Si le dicen que tiene un } 52,8 \% \text { de riesgos } \\
\text { de tener un cáncer de pulmón a los } 63 \\
\text { años y medio porque lleva tal o cual vida, } \\
\text { eso es estadísticamente cierto, pero no } \\
\text { es lo que le interesa; lo que sí le interesa } \\
\text { es saber si va o no a padecer de ese } \\
\text { cáncer, y eso nadie puede decírselo. }\end{array}$ & $\begin{array}{l}71 / \\
12\end{array}$ & $\begin{array}{l}\text { Si on vous dit que vous avez } 52,8 \% \text { de } \\
\text { risques d'avoir un cancer du poumon à } 63 \text { ans } \\
\text { et demi parce que vous menez telle ou telle } \\
\text { vie, c'est statistiquement vrai, mais cela ne } \\
\text { vous intéresse pas, ce qui vous intéresse, } \\
\text { c'est de savoir si vous allez ou non souffrir de } \\
\text { ce cancer, et cela personne ne peut vous le } \\
\text { dire. }\end{array}$ & $\begin{array}{l}881 \\
7\end{array}$ \\
\hline
\end{tabular}

35

\begin{tabular}{|l|l|l|l|l|}
\hline Cód. & \multicolumn{1}{|c|}{ TT } & $\mathrm{p} / \mathrm{r}$ & \multicolumn{1}{c|}{ TO } & $\mathrm{p} / \mathrm{r}$ \\
\hline 3 & $\begin{array}{l}\text { Así, usted evoca este caso típico: cuando } \\
\text { se entera de que el 75\% de los pacientes } \\
\text { aquejados de tal enfermedad se cura, la } \\
\text { mayoría de la gente piensa que (...) }\end{array}$ & $\begin{array}{l}\text { Ainsi vous évoquez ce cas d'école : lorsqu'ils } \\
\text { apprennent que 75\% des patients atteints de } \\
\text { telle maladie guérissent, la plupart des gens } \\
\text { pensent que (...) }\end{array}$ & $\begin{array}{l}11 \\
\text { pensen }\end{array}$ \\
\hline
\end{tabular}

36

\begin{tabular}{|c|c|c|c|c|}
\hline Cód. & TT & $\mathrm{p} / \mathrm{r}$ & TO & $\mathrm{p} / \mathrm{r}$ \\
\hline 3 & $\begin{array}{l}\text { Tomado en su obsesión de dominio de la } \\
\text { reproducción, ¿no está el "Hombre" en } \\
\text { vías de convertirse en el otro nombre de } \\
\text { la Madre fálica y omnipotente, imaginada } \\
\text { por el niñito que, como la niña, no pudo } \\
\text { relativizar luego, mediante la } \\
\text { identificación con la madre, la amenaza } \\
\text { que representa en el plano fantasmático } \\
\text { para la afirmación de su identidad? }\end{array}$ & $\begin{array}{l}73 / \\
18\end{array}$ & $\begin{array}{l}\text { Pris dans son obsession de maîtrise de la } \\
\text { reproduction, "l'Homme” n'est-il pas en train } \\
\text { de devenir l'autre nom de la Mère phallique et } \\
\text { toute-puissante, imaginée para le petit garçon } \\
\text { qui n'a pu, comme la fille, relativiser ensuite, } \\
\text { par l'identification à la mère, la menace qu'elle } \\
\text { représente sur le plan fantasmatique pour } \\
\text { l'affirmation de son identité? }\end{array}$ & $\begin{array}{l}91 / \\
8\end{array}$ \\
\hline
\end{tabular}

37

\begin{tabular}{|c|c|c|c|c|}
\hline Cód. & TT & $\mathrm{p} / \mathrm{r}$ & $\mathrm{TO}$ & $\mathrm{p} / \mathrm{r}$ \\
\hline 3 & $\begin{array}{l}\text { Hannah Arendt había dado a la natalidad } \\
\text { un sentido diferente del de la demografía: } \\
\text { para cada ser humano, la posibilidad del } \\
\text { nacimiento es la apertura hacia algo } \\
\text { nuevo, un comienzo absoluto. Retomado } \\
\text { ese concepto de su amiga, Hans Jonas } \\
\text { había visto en la clonación ese } \\
\text { monstruoso peligro: al determinar de } \\
\text { antemano una natalidad, ya que el azar } \\
\text { sería suprimido, privaría al individuo de } \\
\text { esa natalidad inseparable de su libertad. }\end{array}$ & $\begin{array}{l}82 / \\
14\end{array}$ & $\begin{array}{l}\text { Hannah Arendt avait donné à la natalité un } \\
\text { sens différent de celui de la démographie: la } \\
\text { possibilité de la naissance est, pour chaque } \\
\text { être humain, l'ouverture vers quelque chose } \\
\text { de nouveau, un commencement absolu. } \\
\text { Reprenant ce concept de son amie, Hans } \\
\text { Jonas avait vu dans le clonage ce monstrueux } \\
\text { danger: déterminant à l'avance une nature, } \\
\text { puisque le hasard serait supprimé, il priverait } \\
\text { l'individu de cette natalité inséparable de sa } \\
\text { liberté. }\end{array}$ & $\begin{array}{l}102 \\
/ 17\end{array}$ \\
\hline
\end{tabular}

38

\begin{tabular}{|l|l|l|l|l|}
\hline Cód. & \multicolumn{1}{|c|}{ TT } & T/r & TO & p/r \\
\hline 4 & $\begin{array}{l}\text { Sin embargo, desde que existe, ¿qué } \\
\text { impidió hacer la bioética? }\end{array}$ & $\begin{array}{l}99 / \\
18\end{array}$ & $\begin{array}{l}\text { Or, qu'est-ce que la bioéthique, depuis qu'elle } \\
\text { existe, a réussi à empêcher de faire ? }\end{array}$ & $\begin{array}{l}125 \\
/ 16\end{array}$ \\
\hline
\end{tabular}


39

\begin{tabular}{|c|c|c|c|c|}
\hline Cap. & TT & $p / r$ & $\mathrm{TO}$ & $p / r$ \\
\hline 4 & $\begin{array}{l}\text { El lector tiene la sensación de que usted } \\
\text { se refugia en una posición que es la del } \\
\text { sabio individualista aislado en una } \\
\text { sociedad que se acerca a una especie de } \\
\text { abismo; se pregunta, por último, para } \\
\text { retomar esas dos imágenes de sabiduría } \\
\text { que la China tradicional nos legó, si no } \\
\text { está usted constantemente } \\
\text { balanceándose entre el sabio taoísta que } \\
\text { meditaba solo ante su gruta y el sabio } \\
\text { confuciano, que a pesar de todo querría } \\
\text { implicarse en los asuntos públicos. }\end{array}$ & $\begin{array}{l}116 \\
/ 11\end{array}$ & $\begin{array}{l}\text { Il a l'impression que vous vous réfugiez dans } \\
\text { une position qui est celle du sage } \\
\text { individualiste isolé dans une société qui } \\
\text { s'approche à une espèce d'abîme et il se } \\
\text { demande finalement, pour reprendre ces deux } \\
\text { images de sagesse que la Chine traditionnelle } \\
\text { nous a léguées, si vous n'êtes pas } \\
\text { constamment en train de balancer entre le } \\
\text { sage taoïste qui méditait tout seul devant sa } \\
\text { grotte, et le sage confucéen, qui voudrait } \\
\text { malgré tout s'impliquer dans les affaires } \\
\text { publiques. }\end{array}$ & $\begin{array}{l}148 \\
/ 2\end{array}$ \\
\hline
\end{tabular}

40

\begin{tabular}{|l|l|l|l|l|}
\hline Cód. & \multicolumn{1}{|c|}{ TT } & $\mathrm{p} / \mathrm{r}$ & \multicolumn{1}{c|}{ TO } & \multicolumn{1}{|c|}{ p/r } \\
\hline 4 & $\begin{array}{l}\text { "Con heurística del miedo", Hans Jonas } \\
\text { quería decir que se sabe lo que está } \\
\text { amenazado (el ser humano) a partir del } \\
\text { momento en que se sabe que está } \\
\text { amenazado. }\end{array}$ & & $\begin{array}{l}\text { Par heuristique de la peur, Hans Jonas voulait } \\
\text { dire que l'on sait ce qui est menacé (l'être } \\
\text { humain) à partir du moment où l'on sait qu'il } \\
\text { est menacé. }\end{array}$ & /25 \\
\hline
\end{tabular}




\subsection{Segunda parte: Características y análisis de Gènéthique}

Esta parte contiene una breve caracterización de la fuente textual www.genethique.org y está seguida del análisis de los binomios textuales que contienen elipsis con anomalías.

\subsubsection{Características de la fuente digitalizada}

El sitio www.genethique.org que nos ha proporcionado los textos digitalizados de Gènéthique fue creado en el año 2000 por la Fundación Jérôme Lejeune (www.fondationlejeune.org) que lleva el nombre del descubridor del gen de más en los pacientes afectados por el síndrome de Down,

Es el primer sitio francohablante gratuito sobre temas actuales de Bioética; recibe un promedio de 50000 consultas mensuales y se propone ser una herramienta de información, de reflexión y de trabajo a través de distintos tipos de documentos cortos redactados por especialistas. Entre esos documentos, mencionamos la revista de prensa diaria en versión francesa y semanal en versión inglesa, los artículos de revistas y especialmente, la carta mensual que trata los temas bioéticos nacionales e internacionales más importantes de cada mes, en versiones francesa, inglesa y castellana, que es la que hemos elegido para nuestro trabajo. El sitio anuncia que además de Lettres/Cartas, progresivamente se irán incorporando nuevas secciones traducidas al castellano.

Es de destacar que los autores de los textos originales tienen como lengua materna el francés y las traducciones al castellano fueron realizadas y corregidas por biólogos hablantes nativos de español, según los datos proporcionados por los responsables del sitio www.genethique.org.

Como se aprecia, el nombre de fantasía del sitio combina dos términos expresados en idioma francés que están en el centro de los temas vinculados con la Bioética: gène (gen) + éthique (ética) = gènéthique.

Los temas bioéticos de los textos seleccionados refieren a eutanasia, clonación, investigación embrionaria, aborto y están tratados: 
1-desde la Filosofía: TEXTO 44b) El fin del hombre - Francis Fukuyama / La fin de l'homme - Francis Fukuyama, TEXTO 46b) Caso Humbert: ¿Es necesario legislar sobre la eutanasia? / Affaire Humbert: faut-il légiférer sur l'euthanasie?

2-desde la Biología: TEXTO 43b) La creación de un embrión bi-sexual / La création d'un embrión bi-sexué; TEXTO 45b) El embrión reprogramado por violentos mecanismos artificiales / L'embryon reprogrammé par des contraintes mécaniques artificielles; TEXTO 52b) ¿Nacimiento de un ratón por partenogénesis? / Naissance d'une souris par parthénogenèse?

3-desde las Ciencias Jurídicas: TEXTO 46a) Opinión del C.C.N.E. sobre la obligación de informar a su familia de un riesgo genético / Avis du CCNE sur l'obligation d'informer sa familla d'un risque génétique; TEXTO 47c) La O.N.U. no prohíbe la clonación / Pas d'interdiction du clonage humain à l'ONU ; TEXTO 48c) Enmienda Garraud, imposible la protección penal de la mujer embarazada... I Amendement Garraud, impossible protection pénale de la femme enceinte...; TEXTO 46c) El proyecto de investigación sobre los embriones ante la Asamblea Nacional/ Le projet de recherche sur les embryons devant l'Assemblée Nationale; TEXTO 50c) La eutanasia en el Consejo de Europa / L' euthanasie au Conseil de l'Europe.

En algunas ocasiones la versión castellana no nos ha alcanzado para interpretar claramente el sentido y hemos necesitado consultar el texto original para confirmar su interpretación. Por otra parte, hemos observado errores que no consideraremos en nuestro análisis porque éste apunta a detectar las anomalías en la producción de elipsis. Sin embargo, a título ilustrativo ya hemos citado algunos errores terminológicos y ortográficos encontrados [ $\rightarrow$ Capítulo $\vee$, Metodología. 5.4.2.].

Hechas estas aclaraciones, pasamos a los 21 binomios con enunciados elípticos que presentan anomalías, de un total de 40 . 


\subsubsection{Análisis de los binomios textuales}

\section{1}

\begin{tabular}{|c|c|c|c|c|}
\hline Cód. & TT & r. & TO & r. \\
\hline 43b) & $\begin{array}{l}\text { El responsable de las investigaciones, el } \\
\text { Dr. Tal Biron-Shental, reconoce (...). } \\
\text { ¿Quién desearía tener por madre a un } \\
\text { feto abortado? Sin embargo, para este } \\
\text { equipo israelo-holandés podría ser una } \\
\text { nueva fuente de ovocitos destinados a la } \\
\text { fecundación in vitro. }\end{array}$ & $\begin{array}{l}9 \\
- \\
11\end{array}$ & $\begin{array}{l}\text { Le responsable des recherches, le Dr Tal } \\
\text { Biron-Shental, reconnaît (...). Qui voudrait } \\
\text { avoir comme mère un fœetus avorté ? Mais } \\
\text { pour elle, cette technique pourrait être une } \\
\text { nouvelle source d'ovocytes en plus des stocks } \\
\text { disponibles pour les fécondations in vitro. }\end{array}$ & $\begin{array}{l}10 \\
- \\
11\end{array}$ \\
\hline
\end{tabular}

\section{Sintaxis de la lengua meta}

"Sin embargo, para este equipo israelo-holandés podría ser una nueva fuente de ovocitos destinados a la fecundación in vitro."

-Construcción modal con elipsis nominal máxima (argumento externo o sujeto).

-En la oración de base no quedan completamente identificados los rasgos básicos del sujeto ( $¿ 1^{\circ}$ persona?, $¿ 2^{\mathrm{a}}$ persona "usted"?, $¿ 3^{\circ}$ persona?).

-Construcción gramatical.

-El antecedente no es recuperable en el nivel oracional.

\section{Sintaxis del discurso}

El enunciado introducido por el conector contraargumentativo "Sin embargo", seguido del adjunto "para este equipo israelo-holandés" precede a la construcción modal "podría ser". Las virtualidades sobre la persona del argumento sujeto de "podría ser" que se refieren en Sintaxis de la Lengua meta quedan circunscriptas a la $3^{\mathrm{a}}$ persona, puesto que el sujeto informa sobre el resultado de una investigación.

La recuperación del valor léxico de la elipsis conduce de manera indirecta a "tejido ovárico de fetos abortados", actualizado en la oración interrogativa anterior a través de "tener por madre a un feto abortado".

La incertidumbre sobre la utilización de ese tejido está presente en las expresiones: "se presta a controversia", “QQuién desearía?", "podría ser”, este último verbo con el sujeto elíptico en cuestión. La elipsis de sujeto es un medio 
cohesivo muy utilizado en castellano, pero la recuperación transfrástica del antecedente no debe prestar a confusión en los textos pragmáticos cuya función informativa es primordial.

El tema anunciado en el subtítulo “ ¿Es posible utilizar un feto para tratar la infertilidad?" recorre todo el párrafo; sin embargo, la reiteración total o parcial del referente en posición sujeto de "podría ser" aumentaría la cohesión-coherencia, facilitando el pasaje de información, puesto que el antecedente está ubicado en una oración anterior sin ocupar la posición sujeto y hay una construcción intercalada con conector contraargumentativo + adjunto.

\section{Comparación del binomio TO-TT}

TO. La oración está introducida por el conector contraargumentativo « Mais » seguido del adjunto «pour elle » que tiene como correspondiente endofórico al SN sujeto « Le responsable des recherches, le Dr Tal Biron-Shental ». Este SN sujeto identifica el cargo y la profesión de la científica israelí Tal Biron-Shental. El francés no suele utilizar el género femenino en la denominación de los títulos profesionales « le $D r$ », pero sí en la de los cargos administrativos o de gestión; en el caso que nos ocupa, el cargo « responsable des recherches » está determinado por « Le » en lugar de hacerlo con el determinante de género femenino « La », lo cual remite a una inexactitud cultural o informativa con la consiguiente confusión para recuperar el antecedente.

En cuanto al sujeto de " pourrait être », el TO lo resuelve con la expresión léxica " cette technique » que alude indiscutiblemente a los resultados de las investigaciones sobre «l'utilisation de tissu ovarien ».

TT. El enunciado está introducido por el conector contraargumentativo "Sin embargo" seguido del adjunto que hace explícito el término de la preposición "para este equipo israelí-holandés" y no toma la estructura de la oración francesa que se corresponde con una estructura natural del castellano. 
Sospechamos que el problema ha sido la confusión establecida por el TO respecto del género de "Le responsable » retomado por " pour elle», llevando al traductor a buscar como antecedente endofórico femenino a « une équipe ».

En resumen, una confusión microestructural de género en el TO se ha constituido en un problema de traducción microestructural en el TT "El responsable" en lugar de "La responsable" cuya repercusión trasciende la gramática oracional y se instala en la construcción del discurso. Una búsqueda documental hubiera bastado para solucionar el problema.

EI TT produce el adjunto "para este equipo israelo-holandés" y no traduce "cette technique" como SN sujeto sino que utiliza la elipsis del sujeto, instaurando mayor esfuerzo en la búsqueda de antecedente ("feto abortado" o "utilización de tejido ovárico...") y disminuyendo la fluidez en el pasaje de la información.

\section{Mecanismos de producción}

Elevación de la frecuencia de uso de recursos o elementos, ${ }^{1}$ en nuestro caso la elipsis que está asociada a la ausencia léxica.

Descenso del control lingüístico-discursivo: el problema de la inexactitud exofórica del TO tuvo como solución automática la misma imprecisión del TO "EI responsable", de manera análoga a la producción de elipsis en posición sujeto.

\section{Resultado}

Visibilidad de interferencia del sistema lingüístico meta, es decir el castellano.

Visibilidad de interferencia del discurso de partida.

Elipsis de sujeto dentro del sistema con consecuencias discursivas.

Producción palimpséstica.

No se ha cumplido el precepto traducir toda la información con la consiguiente entropía informativa.

\footnotetext{
${ }^{1}$ Este concepto de Carsten Sinner [ $\rightarrow$ Capítulo III, Interferencia. 3.1.3.] es uno de los que explica el descenso de la fluidez en la lectura por efecto de la redundancia de un fenómeno.
} 


\begin{tabular}{|l|l|l|l|l|}
\hline Cód. & TT & r. & TO & r. \\
\hline 43b) & $\begin{array}{l}\text { La mayor controversia de estos trabajos } \\
\text { fue sin duda el presentado por el Centro } \\
\text { de Reproducción humana de Chicago: la } \\
\text { creación de un embrión bisexual. }\end{array}$ & & $\begin{array}{l}\text { Le plus controversé de ces travaux fut sans } \\
\text { doute celui présenté par le Centre de } \\
\text { Reproduction Humaine de Chicago : la } \\
\text { création d'un embryon bisexué. }\end{array}$ & \\
\hline
\end{tabular}

\section{Sintaxis de la lengua meta}

"La mayor controversia de estos trabajos fue sin duda el presentado"

-Construcción predicativa caracterizada por establecer una correferencia entre dos SN (Maingueneau, 1994: 140), en la que se intenta realizar una elipsis nominal parcial (predicativo subjetivo obligatorio): el [Ø] presentado.

-En la oración de base no hay concordancia de género entre el candidato a antecedente y el resto "el presentado".

-Construcción con anomalía sintáctica.

-El antecedente podría recuperarse en el nivel oracional.

\section{Sintaxis del discurso}

En la elipsis de núcleos de sintagmas, se aplican criterios paralelísticos entre los dos sintagmas: el de núcleo elidido y el que contiene antecedente $[\rightarrow$ Capítulo IV, Elipsis. 4.3.2.].

En esta oración tales criterios no se cumplen, pues el resto "el presentado" no retoma los rasgos gramaticales del núcleo del SN sujeto "controversia". Es decir que ha habido cambio de género entre el sustantivo elíptico y su antecedente [ $\rightarrow$ Capítulo IV, Elipsis. 4.4.2.].

El problema de cohesión repercute en la coherencia del discurso. Semánticamente, tal cambio plantea una disyuntiva: ¿El Centro de Reproducción Humana presentó la mayor controversia? ¿El Centro de Reproducción Humana presentó un trabajo que planteaba la mayor controversia? 


\section{Comparación del binomio TO-TT}

TO. Produce el demostrativo " celui » que remite endofóricamente al núcleo de SN sujeto «travail ». La elipsis en el predicado proviene de la superlativa relativa que alude semánticamente a la característica de los trabajos presentados.

TT. Produce como núcleo del SN sujeto el sustantivo "controversia", por lo tanto la elipsis parcial tendría que referir a ella. EI TT presenta transformaciones categoriales (controversé/controversia) que inciden negativamente en su sintaxis y su semántica, sin lograr equivalencia, puesto que no se han generado transformaciones en el predicativo subjetivo a partir del cambio categorial realizado.

La construcción microestructural en la porción problema-solución de traducción incide negativamente en el nivel macroestructural $[\rightarrow$ Capítulo I, Marco teórico y Antecedentes. 1.1.2.].

\section{Mecanismos de producción}

Descenso del control lingüístico: El sistema francés ofrece el sustantivo femenino " la controverse » y el adjetivo « controversé-e » que corresponden en castellano a "controversia" "controvertido/controvertida".

Descenso del control lingüístico-discursivo: traducción automática; no se han generado las transformaciones en el predicativo subjetivo, una vez realizado el cambio categorial.

\section{Resultado}

Visibilidad de interferencia del discurso de partida (celui présenté /el presentado).

Elipsis fuera del sistema: cambio de género respecto del elemento léxico elidido (Rigau, 2000: 359), (Brucart, 2000: 2801).

Descenso de cohesión con consecuencias en la construcción de sentido.

Producción palimpséstica.

Incumplimiento del principio traducir toda la información con la consiguiente entropía informativa. 


\begin{tabular}{|c|c|c|c|c|}
\hline Cód. & TT & r. & TO & r. \\
\hline 43c) & $\begin{array}{l}\text { La dirección general de la salud indicó al } \\
\text { Tribunal que "si se excluye a los } \\
\text { investigadores que trabajan sobre la } \\
\text { pueba de la trisomía } 21 \text { y sus factores } \\
\text { epidemiológicos asociados", "no tiene } \\
\text { conocimiento de ningún equipo de } \\
\text { investigación que se ocupe de la relación } \\
\text { entre la trisomía } 21 \text { y el retraso mental", } \\
\text { precisando que "las únicas } \\
\text { investigaciones clínicas sobre la trisomía } \\
21 \text { son realizadas y difundidas por una } \\
\text { fundación privada y tres equipos } \\
\text { hospitalarios". }\end{array}$ & $\begin{array}{l}38 \\
- \\
39\end{array}$ & $\begin{array}{l}\text { La direction générale de la santé a même } \\
\text { indiqué à la Cour que "si l'on exclut les } \\
\text { équipes de chercheurs qui travaillent sur le } \\
\text { dépistage de la trisomie } 21 \text { proprement dit et } \\
\text { les facteurs épidémiologiques associés à } \\
\text { cette pathologie", elle n'a "connaissance } \\
\text { d'aucune équipe dédiée spécifiquement à la } \\
\text { relation entre trisomie } 21 \text { et retard mental ", } \\
\text { précisant que "les seules recherches } \\
\text { cliniques sur la trisomie } 21 \text { sont menées et } \\
\text { diffusées par une fondation privée et trois } \\
\text { équipes hospitalières" }\end{array}$ & $\begin{array}{l}37 \\
- \\
39\end{array}$ \\
\hline
\end{tabular}

\section{Sintaxis de la lengua meta}

"no tiene conocimiento de ningún equipo de investigación que se ocupe de la relación entre la trisomía 21 y el retraso mental"

-Construcción verbal con elipsis nominal máxima (argumento externo o sujeto).

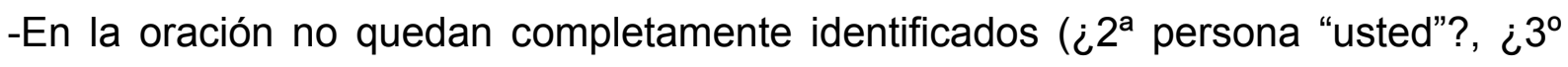
persona?) los rasgos básicos del argumento sujeto.

-Construcción gramatical.

-El antecedente es recuperable en el nivel oracional.

\section{Sintaxis del discurso}

Las virtualidades sobre la persona del argumento sujeto de "no tiene conocimiento" que se refieren en Sintaxis de la lengua meta quedan circunscriptas a la $3^{a}$ persona: la elipsis está incluida en la apódosis "no tiene conocimiento de ningún equipo...", precedida de una prótasis con sujeto impersonal "si se excluye a los investigadores que trabajan sobre la prueba de la trisomía 21 y sus factores epidemiológicos asociados", ambas formas de discurso directo por estar encerradas entre comillas e introducidas por el verbo "indicó", cuyo locutor es "La dirección general de la salud". 
La elipsis de sujeto es un medio cohesivo muy utilizado en castellano, pero en los textos pragmáticos cuya función informativa es primordial, la recuperación transfrástica del antecedente no debe prestar a confusión. La recuperación se ve dificultada por la distancia del elemento elidido y la complejidad del discurso referido. La reiteración total o parcial del referente en posición sujeto de "no tiene conocimiento" aumentaría la cohesión-coherencia, facilitando el pasaje de información (la dirección general de salud/la dirección mencionada/aquella dirección/aquélla).

\section{Comparación del binomio TO-TT}

TO. La característica de la lengua francesa de no dejar vacío el lugar correspondiente al SN sujeto despeja dudas referenciales.

Por otra parte, cumple con la condición de que un pronombre cuya función es sujeto debe tener como antecedente el sujeto de la oración precedente, con la finalidad de lograr rigor en el encadenamiento de las ideas (Delisle, 1984: 120).

Los dos enunciados atribuidos al locutor están encerrados entre comillas y éste está identificado delante del segundo enunciado con el pronombre anafórico « elle ».

TT. La característica de la lengua castellana de dejar vacío el lugar correspondiente al SN sujeto dificulta el pasaje de la información.

En cuanto al uso de elementos grafémicos o convenciones de redacción de primer nivel [ $\rightarrow$ Capítulo II, Producción. 2.6.2.1.1.], vemos que las comillas del primer enunciado atribuido al locutor cumplen con la función de reproducir sus palabras, en cambio, las comillas de apertura del segundo enunciado están desplazadas e incluyen palabras del enunciador y no del locutor, lo cual acentúa la confusión.

\section{Mecanismos de producción}

Elevación de la frecuencia de uso de recursos o elementos, en nuestro caso la elipsis que está asociada a la ausencia léxica. 
Descenso del control lingüístico-discursivo: producción automática de la elipsis sujeto; inexactitud en el uso de elementos grafémicos.

\section{Resultado}

Visibilidad de interferencia del sistema lingüístico meta, es decir el castellano.

Elipsis de sujeto dentro del sistema con consecuencias discursivas.

Descenso de cohesión con consecuencias en la construcción de sentido. 


\begin{tabular}{|l|l|l|l|l|}
\hline Cód. & TT & r. & TO & r. \\
\hline 43c) & $\begin{array}{l}\text { ¿Qué paciente aceptará que el Estado } \\
\text { invierta 100 millones de euros por año en } \\
\text { pruebas de la trisomía privándole de toda } \\
\text { investigación terapéutica? }\end{array}$ & -51 & $\begin{array}{l}\text { Quels patients accepteraient que l'Etat } \\
\text { investisse 100 millions d'euros par an pour les } \\
\text { dépister et les "éradiquer" en les privant de } \\
\text { toute recherche thérapeutique? }\end{array}$ & - \\
50
\end{tabular}

\section{Sintaxis de la lengua meta}

"¿Qué paciente aceptará que el Estado invierta 100 millones de euros por año en pruebas de la trisomía privándole de toda investigación terapéutica?"

-Construcción verbal no personal (gerundio) + clítico dativo con elipsis nominal máxima (argumento interno OD): privándole [Ø].

-En la oración de base, el clítico le no remite a dativo.

-Empleo de leísmo.

-El antecedente es recuperable en el nivel oracional.

\section{Sintaxis del discurso}

El verbo "privar" como "convencer", "basar", entre otros, se asemeja a los verbos ditransitivos porque selecciona dos argumentos: OD y complemento de régimen (Di Tullio, 1997: 117).

Las condiciones de recuperabilidad de los argumentos son estrictas y se aplican a partir del principio general que establece que los rasgos gramaticales de la categoría elidida (persona, casi siempre número y a veces género) deben aparecer en la misma oración en la que ocurre la elipsis. Estas condiciones se manifiestan a través de la concordancia del verbo con el sujeto y el uso de clíticos de acusativo y dativo (Brucart, 2000: 2801). El clítico le deriva del demostrativo dativo latino ILLI y corresponde al objeto indirecto.

El pronombre le que no viene determinado por la posición (o función) sintáctica del antecedente constituye leísmo, siendo el más frecuente y extendido el que refiere a un objeto directo singular masculino que representa a una persona (Fernández-Ordóñez, 2000: 1319). 
Dentro de las variedades del uso del castellano, se comprueban diferencias entre el castellano peninsular y el rioplatense, siendo el anafórico le de uso extendido en España para expresar un SN objeto directo personal, mientras que en las mismas circunstancias, el rioplatense adscribe a las normas del sistema general del castellano utilizando el clítico $l o$.

En el caso de lectores no peninsulares, la recuperabilidad del valor léxico del clítico le como manifestación de leísmo no resulta evidente con el consiguiente descenso de cohesión.

\section{Comparación del binomio TO-TT}

TO. Interrogación retórica expresada en condicional con el valor propio de incertidumbre y con SN sujeto plural generalizador. Utiliza el anafórico « les » $\mathrm{OD}$ que toma los rasgos básicos del plural generalizador endofórico "patients », en la expresión « les 'éradiquer' en les privant ».

TT. Interrogación retórica expresada en futuro del Modo Indicativo, que indirectamente puede cubrir el valor de incertidumbre, también llamado "uso dislocado" (Rojo y Veiga, 2000: 2913). EI SN sujeto está expresado en singular con valor generalizador.

El TT ha encontrado como equivalencia de "dépister » > "pruebas de trisomía", pero no ha logrado una equivalencia completa en "les 'éradiquer' en les privant » puesto que se ha concentrado en producir solamente la forma de gerundio "privándole" en la que el clítico le tiene la función ya comentada en Sintaxis del discurso.

\section{Mecanismos de producción}

Descenso de control lingüístico: utilización de normas operacionales lingüísticas del castellano peninsular como lengua meta.

Ausencia de la idea equivalente a « éradiquer ». 


\section{Resultado}

Visibilidad de interferencia de normas operacionales lingüísticas del castellano peninsular como lengua meta.

Elipsis con clítico dativo "le" con referente humano y función objeto directo.

Incumplimiento del precepto traducir toda la información con la consiguiente entropía informativa. 


\begin{tabular}{|c|c|c|c|c|}
\hline Cód. & TT & r. & TO & r. \\
\hline 44b) & $\begin{array}{l}\text { La ingeniería genética y la creación de } \\
\text { bebés de síntesis poseyendo todos los } \\
\text { genes específicos de características tales } \\
\text { como la inteligencia, la estatura, la } \\
\text { autoestima...conducirá a un suave } \\
\text { eugenismo, respondiendo a la petición de } \\
\text { los padres, que desean lo mejor para sus } \\
\text { hijos y tampoco la obligación impuesta } \\
\text { por un Estado coercitivo. }\end{array}$ & 17 & $\begin{array}{l}\text { L'ingénierie génétique et la création de bébés } \\
\text { de synthèse possédant tous les gènes } \\
\text { spécifiques de caractéristiques telles que } \\
\text { l'intelligence, la taille, l'estime de } \\
\text { soi...conduira à un eugénisme doux, } \\
\text { répondant à la demande des parents qui } \\
\text { désirent le meilleur pour leur enfant, et non } \\
\text { plus à l'obligation imposée par un Etat } \\
\text { coercitif. }\end{array}$ & $\begin{array}{l}18 \\
- \\
21\end{array}$ \\
\hline
\end{tabular}

\section{Sintaxis de la lengua meta}

"...conducirá a un suave eugenismo, respondiendo a la petición de los padres, que desean lo mejor para sus hijos y tampoco la obligación impuesta por un Estado coercitivo."

-Construcción coordinada con elipsis verbal: tampoco [Ø] la obligación impuesta por un Estado coercitivo.

-En la oración de base, la partícula de polaridad "tampoco" no se relaciona con un constituyente negativo previo.

-Construcción con anomalías sintácticas.

-El antecedente es recuperable en el nivel oracional.

\section{Sintaxis del discurso}

El texto es una recensión del libro La fin de l'homme de Francis Fukuyama. El enunciado presenta anomalías sintácticas. En primer lugar, no hay concordancia entre el sujeto compuesto "La ingeniería genética y la creación de bebés de síntesis" y el verbo "conducirá" precedido de puntos suspensivos. En segundo lugar, el empleo del gerundio es determinativo del SN "la creación de bebés de síntesis poseyendo": el castellano utiliza la forma de relativo (que posea).

El segmento en que aparece la elipsis está constituido por el hueco, representado por la ausencia del verbo "respondiendo", y el resto que incluye la partícula de polaridad negativa "tampoco" seguida directamente por el SN "la obligación impuesta por un Estado coercitivo." 
La partícula de polaridad es un adverbio que refuerza la coordinación copulativa y supone un constituyente previo de igual polaridad, en este caso negativa: el resto "tampoco" debe estar contenido en una oración elíptica de polaridad negativa y precedido por una oración de polaridad también negativa (Brucart, 2000: 2829); por otra parte, dentro del resto no aparece la preposición "a" que establece la relación con el SP anterior.

Las anomalías sintácticas señaladas provienen del incumplimiento de las restricciones en el uso de partícula de polaridad y repercuten en la relación cohesión-coherencia discursiva, instaurando confusión en el pasaje de la información, función primordial en los textos pragmáticos.

\section{Comparación del binomio TO-TT}

TO. Produce una falta de concordancia entre el sujeto compuesto "L'ingénierie génétique et la création de bébés de synthèse possédant tous les gènes spécifiques de caractéristiques telles que l'intelligence, la taille, l'estime de soi » y el verbo "conduira » precedido de puntos suspensivos. Además, utiliza la partícula de polaridad " non plus » en una oración elíptica verbal, aunque sintácticamente correspondería la presencia de una oración negativa previa. Existiría una ambigüedad respecto del primer miembro de la coordinación « conduira à un eugénisme doux » o bien "répondant à la demande des parents qui désirent le meilleur pour leur enfant ».

TT. Produce la superficie errónea del TO y omite la preposición "a" correspondiente al régimen de los verbos "conducir" y "responder". Por otra parte, ha habido empleo del gerundio con función determinativa del SN, no apta en castellano.

Una posibilidad para resolver el problema planteado en la oración elíptica del TO, sería la utilización de la negación correctiva (Brucart, 2000: 2830).

\section{Mecanismos de producción}

Descenso de control lingüístico: normas de coordinación de proposiciones relativas. 
Descenso de control lingüístico-discursivo: traducción automática desde niveles bajos.

\section{Resultado}

Visibilidad de interferencia del discurso de partida (non plus / tampoco; possédant / poseyendo).

Elipsis fuera del sistema: partícula de polaridad negativa precedida de enunciado afirmativo.

Descenso de cohesión con consecuencias en la construcción de sentido.

Producción palimpséstica. 


\begin{tabular}{|c|c|c|c|}
\hline Cód. & TT & r. & TO \\
\hline 45a) & $\begin{array}{l}\text { En el informe emitido el } 4 \text { de julio de } \\
\text { 2002, el Comité Consultivo Nacional de } \\
\text { Ética se mostró reservado, subrayando } \\
\text { que: « la realidad del proyecto paternal es } \\
\text { el problema esencial y, en consecuencia, } \\
\text { el riesqo de instrumentalizar al niño ». }\end{array}$ & 15 & $\begin{array}{l}\text { Dans un avis rendu le } 4 \text { juillet 2002, le Comité } \\
\text { consultatif national d'éthique s'était montré } \\
\text { réservé, soulignant que «le problème } \\
\text { essentiel est celui de la réalité du projet } \\
\text { parental et donc du risque } \\
\text { d'instrumentalisation de l'enfant». }\end{array}$ \\
\hline
\end{tabular}

\section{Sintaxis de la lengua meta}

(...) la realidad del proyecto paternal es el problema esencial y (...) el riesgo de instrumentalizar al niño.

-Construcción coordinada con elipsis verbal (verbo cópula).

-En la oración de base hay una estructura copulativa seguida de una coordinación con elipsis del verbo cópula.

-Construcción gramatical.

-El antecedente es recuperable en el nivel oracional.

\section{Sintaxis del discurso}

El verbo cópula (por antonomasia ser y estar) no constituye por sí mismo un predicado semántico sino que actúa como soporte proporcionando las propiedades flexionales (Di Tullio, 1995: 111), pero a su vez tiene valor atributivo, locativo o existencial (Krazem y Soulet, 2008: 52).

En el caso que nos ocupa, "la instrumentalización del niño" no es una "consecuencia" del "problema esencial" sino de la puesta en marcha de un "proyecto parental"; es decir, la dinámica discursiva debería reflejar esa disposición informativa, colocando en posición temática el concepto que debe ser identificado "problema esencial" y remática a su identificación "la realidad del proyecto paternal" y su consecuencia, "el riesgo de instrumentalizar al niño". Dicho de otro modo, una dinámica que vaya en el sentido general a particular.

Como ya dijimos [ $\rightarrow$ Capítulo VI, Análisis. 6.3.], el análisis lexicológico escapa a los objetivos de nuestra investigación, sin embargo observamos que el proyecto a que 
hace alusión este enunciado es "parental y no "paternal", como aparece en la traducción publicada.

\section{Comparación del binomio TO-TT}

TO. Produce una estructura con dos predicativos coordinados y elipsis del verbo « est ». Por otra parte, en el complemento predicativo hay una anaforización « celui de » que remite al SN sujeto, con elipsis nominal parcial.

La construcción del TO muestra una fuerte cohesión, marcada por el pronombre demostrativo y más adelante por el conector de consecuencia « donc »; la posición temática es ocupada por el problema bioético producto de este tipo de intervención y la posición remática por los componentes de tal problema.

TT. Produce una estructura predicativa, sólo que ha modificado el orden de la cláusula que expresa los dichos del Comité Consultivo Nacional. Ha variado la distribución de la información, cambiando de orden la estructura predicativa. Las construcciones francesas de pronombre demostrativo + complemento adnominal encabezado por "de» son gramaticalmente restituidas en español por el artículo determinado (el, la, los, las) + sustantivo "de".

En el TT, los constituyentes aparecen en orden intercalado: lo que en TO se ubica en la posición temática, en el TT se ubica en medio de los dos remas.

La estructura sintáctica del TO es compleja si se la traslada al castellano. En el TT se ha intentado proporcionar fluidez, sin tomar la suficiente libertad para interpretar el concepto subyacente que expresa el TO. Es decir, ha habido, a nuestro criterio, una discusión sobre la estructura superficial que no llegó a plantear el sentido de todo el fragmento: el problema esencial es el que plantea la realidad del proyecto parental que puede llegar a instrumentalizar al niño.

\section{Mecanismos de producción}

Descenso de control lingüístico: lexicológico (parental/paternal; celui delel + sustantivo + de). 
Descenso de control lingüístico-discursivo: modificación de la distribución informativa con el consiguiente matiz de cambio semántico.

\section{Resultado}

Visibilidad de interferencia sintáctico-discursiva al contrastar TT con TO.

Elipsis verbal dentro del sistema.

Entropía informativa causada por la correspondencia desacertada parental /paternal. 


\begin{tabular}{|c|c|c|c|c|}
\hline Cód. & TT & r. & TO & $\mathrm{r}$. \\
\hline 45c) & $\begin{array}{l}\text { Las células madre embrionarias humanas } \\
\text { pueden ser aisladas solamente a partir de } \\
\text { embriones supernumerarios cuyos padres } \\
\text { los donaron para la ciencia y fueron } \\
\text { concebidos antes del } 27 \text { de junio de } 2002 \\
\text { fecha adoptada por el sexto programa } \\
\text { marco (con el fin de evitar que la } \\
\text { financiación comunitaria no fomente } \\
\text { indirectamente la producción de } \\
\text { embriones en exceso que no son } \\
\text { necesarios para la fecundación in vitro). }\end{array}$ & $\begin{array}{l}24 \\
- \\
25\end{array}$ & $\begin{array}{l}\text { Les cellules souches embryonnaires } \\
\text { humaines ne peuvent être isolées qu'à partir } \\
\text { d'embryons surnuméraires dont les parents } \\
\text { font don à la science et qui ont été conçus } \\
\text { avant le } 27 \text { juin } 2002 \text { date d'adoption du 6è } \\
\text { Programme Cadre (ceci afin d'éviter que le } \\
\text { financement communautaire n'encourage } \\
\text { indirectement à produire plus d'embryons qu'il } \\
\text { n'est nécessaire pour la fécondation in vitro; }\end{array}$ & $\begin{array}{l}25 \\
- \\
26\end{array}$ \\
\hline
\end{tabular}

\section{Sintaxis de la lengua meta}

"Las células madre embrionarias humanas pueden ser aisladas solamente a partir de embriones supernumerarios cuyos padres los donaron para la ciencia y fueron concebidos antes del 27 de junio de 2002 (...)"

-Construcción coordinada con elipsis nominal máxima (argumento interno OD representado por relativo): cuyos padres los donaron y [Ø] fueron concebidos.

-En la oración de base, la elipsis del segundo miembro de la coordinación no encuentra un relativo de igual función en el primer miembro.

-Construcción con anomalía sintáctica.

-El antecedente es recuperable en el nivel oracional.

\section{Sintaxis del discurso}

La oración con sujeto pasivo "Las células madre embrionarias humanas" presenta en el SV pasivo dos proposiciones relativas coordinadas en el complemento circunstancial introducido por "a partir de" que refieren a "embriones supernumerarios". Las proposiciones relativas coordinadas "cuyos padres los donaron para la ciencia y fueron concebidos antes del 27 de junio de 2002" no tienen coincidencia funcional: la primera introducida por el pronombre relativo "cuyo" con función determinativa y posesiva y la segunda determinativa sin realización del relativo "que". 
La construcción sintáctica es anómala puesto que puede haber elipsis del pronombre relativo en el segundo miembro de la coordinación sólo si aquél coincide funcionalmente con el pronombre relativo del primer miembro de la coordinación. Por otra parte, la realización del primer pronombre relativo presenta la secuencia redundante "cuyos" + clítico "los", en la que no se ha conservado el hueco correspondiente al complemento adnominal "de los embriones".

La anomalía sintáctica, tanto por redundancia (cuyos + los) como por elipsis [Ø] incide en la instauración de ambigüedad.

\section{Comparación del binomio TO-TT}

TO. Presenta un esquema pasivo y restrictivo « ne peuvent être isolées qu'à partir ", seguido de una coordinación de dos relativas, cada una de las cuales está encabezada por los pronombres correspondientes «dont » y « qui »; el primero con función complemento adnominal y el segundo con función sujeto.

TT. La producción de la coordinación de relativas presenta la anomalía comentada en Sintaxis del discurso, que incide en la construcción de sentido. Una solución podría haber sido la eliminación de las relativas, con mantenimiento de la forma pasiva (a partir de embriones supernumerarios donados por los padres a la ciencia y concebidos antes del 27 de junio de 2002). Propuestas de simplificación de la sintaxis, sin cambio de sentido, facilitarían el pasaje de información, función principal en los textos pragmáticos.

\section{Mecanismos de producción}

Descenso de control lingüístico: normas de coordinación de proposiciones relativas.

Descenso de control lingüístico-discursivo: traducción automática desde niveles bajos.

\section{Resultado}

Visibilidad de interferencia sintáctico-discursiva al contrastar TT con TO. 
Visibilidad de interferencia del discurso de partida.

Elipsis fuera del sistema: dos relativos coordinados con diferentes funciones.

Descenso de cohesión con consecuencias en la construcción de sentido.

Producción palimpséstica. 


\begin{tabular}{|l|l|l|l|l|}
\hline Cód. & TT & r. & \multicolumn{1}{|c|}{ TO } & r. \\
\hline 45c) & $\begin{array}{l}\text { - La protección de las bases de datos y la } \\
\text { vida privada deben estar garantizados, } \\
\text { así como la trazabilidad de las células } \\
\text { asegurada. }\end{array}$ & 34 & $\begin{array}{l}\text { - La protection des données et de la vie } \\
\text { privée doit etre garantie et la traçabilité des } \\
\text { cellules souches assurée ; }\end{array}$ & -33 \\
\hline
\end{tabular}

\section{Sintaxis de la lengua meta}

"La protección de las bases de datos y la vida privada deben estar garantizados"

-Construcción coordinada que no llega a producir una elipsis nominal parcial (argumento externo o sujeto).

-En la oración de base no hay concordancia de género entre el posible núcleo elidido "protección" y el predicativo "garantizados" ubicado en el resto.

-Construcción con anomalía sintáctica.

-El antecedente sería recuperable en el nivel oracional.

\section{Sintaxis del discurso}

Sujeto compuesto con posibilidad de elipsis del núcleo en el segundo miembro de la coordinación. Sin embargo, la estructura que se produce es una coordinada con dos núcleos nominales "la protección" y "la vida privada" sin concordancia en el género del predicativo "garantizados".

\section{Comparación del binomio TO-TT}

TO. Produce « La protection des données et de la vie privée » en donde se ve claramente la elipsis nominal parcial, núcleo del SN sujeto « la protection », seguida del participio singular femenino «garantie ».

TT. Produce dos núcleos "la protección", "la vida" con un verbo en plural y un predicativo sin concordancia de género; la estructura del segundo miembro de la coordinada también debería tomar "protección" como núcleo del SN sujeto: la [Ø] de la vida privada. 
Al no haber considerado "protección" como núcleo de los dos SSNN coordinados, ha habido un cambio de relaciones dentro de la oración con un cambio de sentido ya que lo que se garantiza es la "protección" tanto de las "bases de datos" como de "la vida privada"; en consecuencia, de haberse tomado "protección" como núcleo, el verbo en singular sería el antecedente del hueco de la proposición introducida por "así como", con valor aditivo.

\section{Mecanismos de producción}

Descenso del control lingüístico: no se ha respetado la regla de concordancia.

Descenso del control lingüístico-discursivo: no se han advertido las consecuencias discursivas de los cambios sintácticos producidos en el TT, es decir que ha habido traducción automática.

\section{Resultado}

Visibilidad de interferencia semántica a través del cambio de estructura gramatical (la protection des...et de la ....Aa protección de la y la).

Visibilidad de interferencia del discurso de partida.

Elipsis de argumento externo o sujeto cuya visibilidad surge de la comparación de TT y TO.

Descenso de la cohesión con repercusión en la construcción de sentido.

Producción palimpséstica. 


\begin{tabular}{|c|c|c|c|c|}
\hline Cód. & TT & r. & TO & r. \\
\hline 46b) & $\begin{array}{l}\text { En efecto, podemos pensar que si el } \\
\text { joven Vincent pedía morir y si hubiera } \\
\text { podido evitar alimentarse, habría } \\
\text { provocado una disminución de los } \\
\text { cuidados que le mantenían con vida, en } \\
\text { particular la nutrición. }\end{array}$ & 20 & $\begin{array}{l}\text { En effet, on peut penser que le jeune Vincent, } \\
\text { s'il demandait à mourir et s'il avait pu éviter de } \\
\text { se nourrir, aurait provoqué lui-même une } \\
\text { diminution des soins qui le maintenaient en } \\
\text { vie, en particulier la nutrition. }\end{array}$ & $\begin{array}{l}19 \\
- \\
20\end{array}$ \\
\hline
\end{tabular}

\section{Sintaxis de la lengua meta}

"En efecto, podemos pensar que si el joven Vincent pedía morir y si hubiera podido evitar alimentarse, habría provocado una disminución de los cuidados que le mantenían con vida, en particular la nutrición."

-Construcción con clítico dativo + forma verbal personal con elipsis nominal máxima (argumento interno OD): le mantenían [Ø]

-En la oración de base, el clítico le no remite a dativo.

-Empleo de leísmo.

-El antecedente es recuperable en el nivel oracional.

\section{Sintaxis del discurso}

El verbo "mantener" es ditransitivo, es decir, predicado triádico que selecciona dos argumentos -OD y Ol- siendo el segundo argumento el OD (Di Tullio, 1997: 107).

La elipsis está dentro de la subordinada relativa incluida en la apódosis "habría provocado una disminución de los cuidados que le mantenían con vida".

Las condiciones de recuperabilidad de los argumentos son estrictas y se aplican a partir del principio general que establece que los rasgos gramaticales de la categoría elidida (persona, casi siempre número y a veces género) deben aparecer en la misma oración en la que ocurre la elipsis. Estas condiciones se manifiestan a través de la concordancia del verbo con el sujeto y el uso de clíticos de acusativo y dativo (Brucart, 2000: 2801). 
El clítico le deriva del demostrativo dativo latino ILLI y corresponde al objeto indirecto. El pronombre le que no viene determinado por la posición (o función) sintáctica del antecedente constituye leísmo, siendo el más frecuente y extendido el referido a un objeto directo singular masculino que representa a una persona.

En nuestro caso, el referente "el joven Vincent" está ubicado en la prótasis "si el joven Vincent", incluida, a su vez en la proposición subordinada completiva OD "que si el joven Vincent".

Dentro de las variedades del uso del castellano, se comprueban diferencias entre el castellano peninsular y el rioplatense, siendo el anafórico le de uso extendido en España para expresar un SN objeto directo personal, mientras que en las mismas circunstancias, el rioplatense adscribe a las normas del sistema general del castellano utilizando el clítico lo. En el caso de lectores no peninsulares, la recuperabilidad del valor léxico del clítico le como manifestación de leísmo no resulta evidente con el consiguiente descenso de cohesión.

\section{Comparación del binomio TO-TT}

TO. Produce «le maintenaient » en donde el anafórico «le » OD remite al referente endofórico « le jeune Vincent » SN sujeto, léxicamente pleno.

TT. Produce el enunciado "le mantenían" cuyo anafórico "le" tiene función OD y remite al referente endofórico "el joven Vincent", SN sujeto singular léxicamente pleno.

\section{Mecanismos de producción}

Utilización de normas operacionales lingüísticas del castellano peninsular como lengua meta.

\section{Resultado}

Visibilidad de interferencia de normas operacionales lingüísticas del castellano peninsular como lengua meta.

Elipsis con clítico dativo "le" con referente humano y función objeto directo. 


\begin{tabular}{|c|c|c|c|c|}
\hline Cód. & TT & r. & TO & r. \\
\hline 48c) & $\begin{array}{l}\text { El } 2 \text { de diciembre en el periódico le } \\
\text { Figaro, la Profesora Michèle Laure } \\
\text { Rassat se sorprende: "on a du mal, } \\
\text { devant le bon sens d'une semblable } \\
\text { disposition, a comprendre le tollé qu'elle } \\
\text { soulève et l'on ne peut que se demander, } \\
\text { s'il relève d'une totale méconnaissance } \\
\text { par leurs auteurs de ce dont ils } \\
\text { prétendent parler ou d'une volonté } \\
\text { d'agitation de principe" (no se comprende, } \\
\text { ante la sensatez de similar disposición, el } \\
\text { clamor de indignación que levanta y nos } \\
\text { preguntamos, si proviene de una } \\
\text { ignorancia total por parte de los autores } \\
\text { acerca de lo que pretenden expresar o } \\
\text { sencillamente de una voluntad de } \\
\text { agitación"). }\end{array}$ & $\begin{array}{l}25 \\
- \\
27\end{array}$ & $\begin{array}{l}\text { Dans le Figaro du } 2 \text { décembre, le Professeur } \\
\text { Michèle Laure Rassat s'étonne : "on a du mal, } \\
\text { devant le bon sens d'une semblable } \\
\text { disposition, a comprendre le tollé qu'elle } \\
\text { soulève et l'on ne peut que se demander, s'il } \\
\text { relève d'une totale méconnaissance par leurs } \\
\text { auteurs de ce dont ils prétendent parler ou } \\
\text { d'une volonté d'agitation de principe." }\end{array}$ & $\begin{array}{l}22 \\
- \\
25\end{array}$ \\
\hline
\end{tabular}

\section{Sintaxis de la lengua meta}

"(no se comprende, ante la sensatez de similar disposición, el clamor de indignación que levanta y nos preguntamos, si proviene de una ignorancia total por parte de los autores acerca de lo que pretenden expresar o sencillamente de una voluntad de agitación").

-Proposición relativa con elipsis nominal máxima (argumento externo o sujeto): que [Ø] levanta.

-En la oración no quedan completamente identificados los rasgos básicos del argumento sujeto ( $i 2^{a}$ persona "usted"? $\varkappa^{a}$ persona singular de género femenino?, $¿ 3^{\mathrm{a}}$ persona singular de género masculino?).

-Construcción gramatical.

-El antecedente es recuperable en el nivel oracional.

\section{Sintaxis del discurso}

Es un discurso referido directo en el que identificamos la proposición relativa "que levanta" con elipsis de sujeto. Las virtualidades sobre la persona del argumento sujeto de "levanta" referidas en Sintaxis de la lengua meta quedan circunscriptas a la $3^{a}$ persona del singular de género femenino, al recuperar el valor léxico de la elipsis. 
La recuperación del antecedente conduce al subtítulo retomado léxicamente como "similar disposición" en posición término introducido por la preposición "de" en el adjunto introducido por la preposición "ante".

La recuperación del antecedente no debe prestar a confusión, especialmente en los textos pragmáticos cuya función informativa es primordial. El tema anunciado en el subtítulo "La enmienda Garraud" recorre el párrafo precedente; sin embargo, la recuperación del hueco en función sujeto se ve perturbada porque el valor léxico no está fijado endofóricamente como sujeto, sino que es un constituyente del adjunto "ante la sensatez de similar disposición". La reiteración total o parcial del referente como sujeto de "levanta" aumentaría la cohesión-coherencia, facilitando el pasaje de información.

\section{Comparación del binomio TO-TT}

TO. La característica de la lengua francesa de no dejar vacío el lugar correspondiente al SN sujeto " elle soulève (...) » contribuye a dilucidar dudas referenciales. El primer pronombre anafórico « elle » remite a « disposition ", hiperónimo o genérico de «amendement». Si bien, el antecedente no ocupa la función sujeto que es ocupada por « elle », el género femenino es coincidente.

TT. La carácterística de la lengua castellana de dejar vacío el lugar correspondiente al $\mathrm{SN}$ sujeto genera disminución de la cohesión.

\section{Mecanismos de producción}

Elevación de la frecuencia de uso de recursos o elementos, en nuestro caso la elipsis que está asociada a la ausencia léxica.

Descenso del control lingüístico-discursivo, debido al uso reiterado de elipsis en función sujeto.

\section{Resultado}

Visibilidad de interferencia del sistema lingüístico meta, es decir el castellano.

Elipsis de sujeto dentro del sistema con consecuencias discursivas.

Descenso de la cohesión con repercusión en la construcción de sentido. 
11

\begin{tabular}{|c|c|c|c|c|}
\hline Cód. & TT & r. & TO & $r$. \\
\hline 48c) & $\begin{array}{l}\text { El } 2 \text { de diciembre en el periódico le } \\
\text { Figaro, la Profesora Michèle Laure } \\
\text { Rassat se sorprende: "on a du mal, } \\
\text { devant le bon sens d'une semblable } \\
\text { disposition, a comprendre le tollé qu'elle } \\
\text { soulève et l'on ne peut que se demander, } \\
\text { s'il relève d'une totale méconnaissance } \\
\text { par leurs auteurs de ce dont ils } \\
\text { prétendent parler ou d'une volonté } \\
\text { d'agitation de principe" (no se comprende, } \\
\text { ante la sensatez de similar disposición, el } \\
\text { clamor de indignación que levanta y nos } \\
\text { preguntamos, si proviene de una } \\
\text { ignorancia total por parte de los autores } \\
\text { acerca de lo que pretenden expresar o } \\
\text { sencillamente de una voluntad de } \\
\text { agitación"). }\end{array}$ & $\begin{array}{l}25 \\
- \\
27\end{array}$ & $\begin{array}{l}\text { Dans le Figaro du } 2 \text { décembre, le Professeur } \\
\text { Michèle Laure Rassat s'étonne: "on a du mal, } \\
\text { devant le bon sens d'une semblable } \\
\text { disposition, a comprendre le tollé qu'elle } \\
\text { soulève et l'on ne peut que se demander, s'il } \\
\text { relève d'une totale méconnaissance par leurs } \\
\text { auteurs de ce dont ils prétendent parler ou } \\
\text { d'une volonté d'agitation de principe." }\end{array}$ & $\begin{array}{l}22 \\
- \\
25\end{array}$ \\
\hline
\end{tabular}

\section{Sintaxis de la lengua meta}

"(no se comprende, ante la sensatez de similar disposición, el clamor de indignación que levanta y nos preguntamos, si proviene de una ignorancia total por parte de los autores acerca de lo que pretenden expresar o sencillamente de una voluntad de agitación").

-Proposición interrogativa indirecta introducida por "si" con elipsis nominal máxima (argumento externo o sujeto): si [Ø] proviene.

-En la oración no quedan completamente identificados los rasgos básicos del argumento sujeto $\left(i 3^{a}\right.$ persona singular de género femenino? $i 3^{a}$ persona singular de género masculino?).

-Construcción gramatical.

-El antecedente es recuperable en el nivel oracional.

\section{Sintaxis del discurso}

El hueco en función sujeto forma parte de la proposición interrogativa indirecta introducida por "si" y queda fijada la $3^{\mathrm{a}}$ persona singular de género masculino "el clamor de indignación" como antecedente endofórico también en función sujeto. La coincidencia funcional contribuye a encontrar el valor léxico; sin embargo el empleo 
de la tercera persona en un enunciado que presenta otra elipsis de características semejantes [ $\rightarrow$ Caso 10] opaca la recuperación del antecedente que no debe prestar a confusión, especialmente en los textos pragmáticos cuya función informativa es primordial.

La reiteración total o parcial del referente como sujeto de "proviene" aumentaría la cohesión-coherencia, facilitando el pasaje de información.

\section{Comparación del binomio TO-TT}

TO. El pronombre anafórico « il » remite a "le tollé », ambos en género masculino y función sujeto.

TT. La característica de la lengua castellana de dejar vacío el lugar correspondiente al SN sujeto dificulta el pasaje de la información.

\section{Mecanismos de producción}

Elevación de la frecuencia de uso de recursos o elementos, en nuestro caso la elipsis que está asociada a la ausencia léxica.

Descenso del control lingüístico-discursivo, debido al uso reiterado de elipsis en función sujeto.

\section{Resultado}

Visibilidad de interferencia del sistema lingüístico meta, es decir el castellano.

Elipsis de sujeto dentro del sistema con consecuencias discursivas.

Descenso de la cohesión con repercusión en la construcción de sentido. 
12

\begin{tabular}{|c|c|c|c|c|}
\hline Cód. & TT & r. & TO & r. \\
\hline 48c) & $\begin{array}{l}\text { El pasado } 10 \text { de diciembre, una mujer de } \\
\text { nacionalidad francesa denunciaba la } \\
\text { negativa de la jurisdicción francesa para } \\
\text { calificar de homicidio involuntario el } \\
\text { ataque a la vida de su hijo, en el seno } \\
\text { materno, y que perdió como } \\
\text { consecuencia de un error médico (fue } \\
\text { confundida con una mujer que deseaba } \\
\text { retirar su DIU). }\end{array}$ & $\begin{array}{l}38 \\
- \\
40\end{array}$ & $\begin{array}{l}\text { Le } 10 \text { décembre, une Française dénonçait le } \\
\text { refus par la juridiction française de qualifier } \\
\text { d'homicide involontaire l'atteinte à la vie d'un } \\
\text { enfant à naître qu'elle portait et qu'elle a } \\
\text { perdu à la suite d'une erreur médicale (elle a } \\
\text { été confondue avec une femme qui voulait } \\
\text { retirer son stérilet). }\end{array}$ & $\begin{array}{l}34 \\
- \\
36\end{array}$ \\
\hline
\end{tabular}

\section{Sintaxis de la lengua meta}

"El pasado 10 de diciembre, una mujer de nacionalidad francesa denunciaba la negativa de la jurisdicción francesa para calificar de homicidio involuntario el ataque a la vida de su hijo, en el seno materno, y que perdió como consecuencia de un error médico (fue confundida con una mujer que deseaba retirar su DIU)."

-Coordinación copulativa entre dos proposiciones, la segunda introducida por "que" con elipsis nominal máxima (argumento externo o sujeto): y que [Ø] perdió.

-En la oración no quedan completamente identificados los rasgos básicos del argumento sujeto ( $i 3^{a}$ persona singular de género femenino? $i 3^{a}$ persona singular de género masculino?).

-Construcción coordinada con anomalía sintáctica.

-El antecedente es recuperable en el nivel oracional.

\section{Sintaxis del discurso}

La recuperabilidad del valor léxico del hueco en función sujeto está fijada endofóricamente, pero la cohesión se ve entorpecida por dos razones: por un lado, la acumulación de formas sin flexión verbal (la negativa de la jurisdicción francesa para calificar de homicidio involuntario el ataque a la vida de su hijo, en el seno materno); por otro lado, la anomalía sintáctica de la coordinación copulativa "y", que no está desempeñando su función de unir dos constituyentes de igual nivel (dos proposiciones independientes con núcleos verbales "anunciaba" y "perdió"). 
La coordinación de dos proposiciones independientes ("denunciaba la negativa"... "y"... "perdió como consecuencia de un error médico") instaura una ambigüedad, puesto que lo que la "mujer de nacionalidad francesa" perdió no es la causa judicial sino la vida de su hijo ("fue confundida con una mujer que deseaba retirar su DIU).

\section{Comparación del binomio TO-TT}

TO. La oración comienza con un adjunto extraclausular que determina el marco temporal, seguido de SN sujeto + SV + SN objeto directo complejo. En éste, el caso en estudio son las dos relativas determinativas coordinadas por « et », cuyo contenido es claro como su sintaxis « (...) un enfant à naître qu'elle portait et qu'elle a perdu (...) », ambas precedidas del pronombre anafórico « elle ».

TT. La oración comienza con un adjunto extraclausular que determina el marco temporal, seguido de SN sujeto + SV + SN objeto directo complejo. La primera relativa determinativa "qu'elle portait » es modificada y resuelta en la versión en castellano por un SP "en el seno materno", pero conservando la estructura de la segunda, lo que instaura una coordinación sintácticamente anómala y un opacamiento en la búsqueda del valor léxico de la elipsis.

\section{Mecanismos de producción}

Elevación de la frecuencia de uso de recursos o elementos, en nuestro caso la elipsis que está asociada a la ausencia léxica.

Descenso de control lingüístico: utilización de la coordinación.

Descenso de control lingüístico-discursivo: la modificación del primer miembro de la coordinación no se vio reflejada en la construcción del segundo miembro, con las consecuencias señaladas. Ha habido traducción automática desde niveles bajos.

\section{Resultado}

Visibilidad de interferencia del sistema lingüístico meta, es decir el castellano.

Visibilidad de interferencia del discurso de partida. 
Elipsis fuera del sistema: coordinante "y" que no une constituyentes del mismo nivel.

Descenso de la cohesión con repercusión en la construcción de sentido.

Producción palimpséstica. 


\begin{tabular}{|c|c|c|c|c|}
\hline Cód. & TT & r. & TO & r. \\
\hline 48c) & $\begin{array}{l}\text { Invocando el artículo } 2 \text { (derecho a la vida) } \\
\text { de la Convención europea de derechos } \\
\text { del hombre, recuerda que el Estado tiene } \\
\text { la obligación de establecer una } \\
\text { legislación penal destinada a reprimir y } \\
\text { sancionar tal delito. }\end{array}$ & $\begin{array}{l}41 \\
- \\
42\end{array}$ & $\begin{array}{l}\text { Invoquant l'article } 2 \text { (droit à la vie) de la } \\
\text { Convention européenne des droits de } \\
\text { l'homme, elle rappelle que l'Etat a l'obligation } \\
\text { de mettre en place une législation pénale } \\
\text { visant à réprimer et sanctionner un tel délit. }\end{array}$ & $\begin{array}{l}37 \\
- \\
38\end{array}$ \\
\hline
\end{tabular}

\section{Sintaxis de la lengua meta}

"Invocando el artículo 2 (derecho a la vida) de la Convención europea de derechos del hombre, recuerda que el Estado tiene la obligación de establecer una legislación penal destinada a reprimir y sancionar tal delito."

-Construcción verbal con elipsis nominal máxima (argumento externo o sujeto).

-En la oración no quedan completamente identificados los rasgos básicos del argumentos sujeto ( $¿ 2^{\mathrm{a}}$ persona "usted"? $¿ 3^{\mathrm{a}}$ persona del singular?): [Ø] recuerda.

-Construcción es gramatical.

-El antecedente no es recuperable en el nivel oracional.

\section{Sintaxis del discurso}

El hueco en función sujeto recupera el valor léxico "una mujer de nacionalidad francesa", fijado endofóricamente también como función sujeto, a comienzos del párrafo anterior [ $\rightarrow$ caso 12] que, como dijimos, presenta elipsis de sujeto hacia el final del párrafo y una anomalía sintáctica generadora de incoherencia.

La elipsis de sujeto es un medio cohesivo muy utilizado en castellano, pero la recuperación transfrástica del antecedente no debe prestar a confusión, especialmente en los textos pragmáticos cuya función informativa es primordial. En el caso que nos ocupa, el antecedente está ubicado en una posición alejada y a su vez se han detectado problemas de coherencia, todo lo cual hace que convenga llenar la posición sujeto con el consiguiente aumento de cohesión.

\section{Comparación del binomio TO-TT.}

TO. La oración está introducida por una proposición participial complemento de medio, generalmente expresado por formas de gerundio concertado (Alloa y Torres, 2001: 242-243), seguida de la proposición « elle rappelle ...». 
La característica de la lengua francesa de no dejar vacío el lugar correspondiente al SN sujeto « elle rappelle » contribuye a la cohesión.

TT. La oración está introducida por una proposición gerundiva complemento de medio, con gerundio concertado (Alloa y Torres, 2001: 242-243), seguida de la proposición "recuerda...", es decir, con posición sujeto vacía.

\section{Mecanismos de producción}

Elevación de la frecuencia de uso de recursos o elementos, en nuestro caso la elipsis que está asociada a la ausencia léxica.

Descenso del control lingüístico-discursivo: producción automática de la elipsis.

\section{Resultado}

Visibilidad de interferencia del sistema lingüístico meta, es decir el castellano.

Elipsis de sujeto dentro del sistema con consecuencias discursivas.

Descenso de la cohesión con repercusión en la construcción de sentido. 
14

\begin{tabular}{|c|c|c|c|c|}
\hline Cód. & TT & r. & TO & r. \\
\hline $50 c)$ & $\begin{array}{l}\text { La FIAMC (Federación Internacional de } \\
\text { Asociaciones de Médicos Católicos) se } \\
\text { opone a este informe; señala que no } \\
\text { define claramente la eutanasia y no } \\
\text { distingue: } \\
\text { - las limitaciones y las supresiones de } \\
\text { tratamientos que han sido inútiles o } \\
\text { rechazados por el paciente (que se } \\
\text { incluye en la buena práctica médica), } \\
\text { - algunas prácticas de alivio a los dolores } \\
\text { resistentes a los medicamentos o } \\
\text { angustias insoportables, que pueden } \\
\text { eventualmente implicar una muerte no } \\
\text { deseada. }\end{array}$ & $\begin{array}{l}15 \\
- \\
16\end{array}$ & $\begin{array}{l}\text { La FIAMC (Fédération Internationale des } \\
\text { Associations de Médecins Catholiques) } \\
\text { s'oppose à ce rapport; elle fait remarquer que } \\
\text { l'euthanasie n'y est pas clairement définie ; } \\
\text { elle n'est pas distinguée: } \\
\text { - des limitations et arrêts de traitements } \\
\text { devenus inutiles ou refusés par le patient (qui } \\
\text { relèvent d'une bonne pratique médicale), } \\
\text { - ni de certaines pratiques de soulagement } \\
\text { des douleurs réfractaires ou des angoisses } \\
\text { insupportables, qui peuvent éventuellement } \\
\text { entraîner une mort non recherchée. }\end{array}$ & $\begin{array}{l}15 \\
- \\
16\end{array}$ \\
\hline
\end{tabular}

\section{Sintaxis de la lengua meta}

"La FIAMC (Federación Internacional de Asociaciones de Médicos Católicos) se opone a este informe; señala que no define claramente la eutanasia y no distingue (...)."

-Proposición principal flexionada con elipsis nominal máxima (argumento externo o sujeto) seguida de dos subordinadas conjuntivas función objeto directo coordinadas por "y", la segunda con elipsis del subordinante: $[\varnothing]$ señala que (...)

-En la oración no quedan completamente identificados los rasgos básicos del argumento sujeto ( $i 3^{a}$ persona del singular género masculino?, $3^{3}$ persona del singular género femenino?).

-Construcción gramatical.

-El antecedente es recuperable en el nivel oracional.

\section{Sintaxis del discurso}

Las virtualidades sobre la persona del argumento sujeto de "señala" que se refieren en Sintaxis de la lengua meta quedan circunscriptas a la tercera persona género femenino puesto que el sujeto posible es "La FIAMC". 
La recuperación del primer hueco en función sujeto ([Ø] señala) recupera el valor léxico "La FIAMC" que está fijado endofóricamente también como sujeto del enunciado precedente.

La elipsis de sujeto es un medio cohesivo muy utilizado en castellano, pero la recuperación del antecedente no debe prestar a confusión, especialmente en los textos pragmáticos cuya función informativa es primordial. El tema está anunciado en el subtítulo "Reacción de lo médicos" y recorre todo el párrafo. Sin embargo, la acumulación de oraciones con elipsis de sujeto de la misma persona pero de distinto referente disminuye su cohesión, con la consiguiente posibilidad de ambigüedad informativa.

Tal situación hace que convenga llenar la posición sujeto con algún medio cohesivo, ya sea reiteración léxica o elemento gramatical, por ejemplo pronombre demostrativo.

\section{Comparación del binomio TO-TT.}

TO. La primera parte de la oración presenta el tema y los actantes ( $L a$ FIAMC, ce rapport). La segunda y tercera oración toman la forma de discurso indirecto; la forma es pasiva con elevación de sujeto (l'euthanasie; elle), y asigna a "rapport " la función de complemento de lugar, representada por el pronombre adverbial «y», en « (...) n’y est pas clairement définie ».

Por otra parte, la característica de la lengua francesa de no dejar vacío el lugar correspondiente al $\mathrm{SN}$ sujeto « elle fait remarquer » contribuye a la cohesión.

TT. La primera parte de la oración presenta el tema y los actantes (La FIAMC, este informe). Las dos siguientes están expresadas en voz activa, a diferencia del TO.

La progresión temática respecto del TO (tema-rema) varía, puesto que en las dos coordinadas "define" "y no distingue", el tema se mantiene (el informe), en lugar de que el rema "eutanasia" tome la posición "temática": es decir, el TO explica que la eutanasia no se distingue de las prácticas que el texto enuncia posteriormente; en 
cambio, el TT atribuye al informe el hecho de no distinguir las prácticas que siguen en la enumeración.

\section{Mecanismos de producción}

Elevación de la frecuencia de uso de recursos o elementos, en nuestro caso la elipsis que está asociada a la ausencia léxica.

Descenso del control lingüístico-discursivo: producción automática de la elipsis.

\section{Resultado}

Visibilidad de interferencia del sistema lingüístico meta, es decir el castellano.

Elipsis de sujeto dentro del sistema con consecuencias discursivas.

Descenso de la cohesión con repercusión en la construcción de sentido. 
15

\begin{tabular}{|c|c|c|c|c|}
\hline Cód. & TT & r. & $\mathrm{TO}$ & r. \\
\hline 50c) & $\begin{array}{l}\text { La FIAMC (Federación Internacional de } \\
\text { Asociaciones de Médicos Católicos) se } \\
\text { opone a este informe; señala que no } \\
\text { define claramente la eutanasia y no } \\
\text { distingue: } \\
\text { - las limitaciones y las supresiones de } \\
\text { tratamientos que han sido inútiles o } \\
\text { rechazados por el paciente (que se } \\
\text { incluye en la buena práctica médica), } \\
\text { - algunas prácticas de alivio a los dolores } \\
\text { resistentes a los medicamentos o } \\
\text { angustias insoportables, que pueden } \\
\text { eventualmente implicar una muerte no } \\
\text { deseada. }\end{array}$ & $\begin{array}{l}15 \\
- \\
16\end{array}$ & $\begin{array}{l}\text { La FIAMC (Fédération Internationale des } \\
\text { Associations de Médecins Catholiques) } \\
\text { s'oppose à ce rapport; elle fait remarquer que } \\
\text { l'euthanasie n'y est pas clairement définie ; } \\
\text { elle n'est pas distinguée: } \\
\text { - des limitations et arrêts de traitements } \\
\text { devenus inutiles ou refusés par le patient (qui } \\
\text { relèvent d'une bonne pratique médicale), } \\
\text { - ni de certaines pratiques de soulagement } \\
\text { des douleurs réfractaires ou des angoisses } \\
\text { insupportables, qui peuvent éventuellement } \\
\text { entraîner une mort non recherchée. }\end{array}$ & $\begin{array}{l}15 \\
- \\
16\end{array}$ \\
\hline
\end{tabular}

\section{Sintaxis de la lengua meta}

"La FIAMC (Federación Internacional de Asociaciones de Médicos Católicos) se opone a este informe; señala que no define claramente la eutanasia y no distingue (..)."

-Proposición principal flexionada $[\rightarrow$ Caso 14$]$ seguida de dos subordinadas conjuntivas función objeto directo coordinadas por "y" con elipsis nominal máxima (argumento externo o sujeto): que [Ø] no define y [Ø] no distingue.

-En el primer miembro de la coordinada, no quedan completamente identificados los rasgos básicos del argumento sujeto $\left(i 3^{a}\right.$ persona del singular género masculino?, $\varkappa^{\mathrm{a}}$ persona del singular género femenino?).

-Construcción gramatical.

-El antecedente es recuperable en el nivel oracional.

\section{Sintaxis del discurso}

Las virtualidades sobre la persona de los argumentos sujeto de "señala", "define" y "distingue" que se refieren en Sintaxis de la lengua meta quedan circunscriptas a la tercera persona, puesto que los sujetos posibles son "La FIAMC" o "este informe". 
La recuperación del primer hueco coordinado en función sujeto (que [Ø] no define) retoma el valor léxico "este informe" que está fijado endofóricamente como complemento de régimen del verbo "oponerse".

La elipsis de sujeto es un medio cohesivo muy utilizado en castellano, pero la recuperación del antecedente no debe prestar a confusión, especialmente en los textos pragmáticos cuya función informativa es primordial.

\section{Comparación del binomio TO-TT}

Señalamos que los tres casos de elipsis se presentan en la misma oración y con la finalidad de no atomizar su comparación, la hemos realizado en el caso 14.

\section{Mecanismos de producción}

Elevación de la frecuencia de uso de recursos o elementos, en nuestro caso la elipsis que está asociada a la ausencia léxica.

Descenso del control lingüístico-discursivo: producción automática de la elipsis.

\section{Resultado}

Visibilidad de interferencia del sistema lingüístico meta, es decir el castellano.

Elipsis de sujeto dentro del sistema con consecuencias discursivas.

Descenso de la cohesión con repercusión en la construcción de sentido. 


\begin{tabular}{|c|c|c|c|c|}
\hline Cód. & TT & r. & TO & r. \\
\hline 50c) & $\begin{array}{l}\text { La FIAMC reafirma su compromiso: } \\
-(\ldots) \\
\text { - al acompañamiento de enfermos en } \\
\text { fase terminal, a los cuidados paliativos y } \\
\text { asumir el desamparo profundo que puede } \\
\text { ser expresado por una petición de } \\
\text { muerte, frente a la cual la eutanasia le } \\
\text { parece un remedio simplista e inhumano. }\end{array}$ & $\begin{array}{l}25 \\
- \\
26\end{array}$ & $\begin{array}{l}\text { La FIAMC réaffirme son attachement: } \\
\text {-(...) } \\
\text { - à l'accompagnement des malades en fin de } \\
\text { vie, aux soins palliatifs et à une prise en } \\
\text { charge de la détresse profonde qui peut être } \\
\text { exprimée par une demande de mort, vis-à-vis } \\
\text { de laquelle l'euthanasie leur paraît un remède } \\
\text { simpliste et inhumain. }\end{array}$ & $\begin{array}{l}25 \\
- \\
26\end{array}$ \\
\hline
\end{tabular}

\section{Sintaxis de la lengua meta}

“(...) frente a la cual la eutanasia le parece un remedio simplista e inhumano."

-Construcción verbal con clítico dativo y elipsis nominal máxima (argumento interno Ol duplicado): le parece [Ø].

-En la oración de base, no queda identificado el argumento Ol representado por el clítico le.

-Construcción gramatical.

-El antecedente es recuperable en el nivel oracional.

\section{Sintaxis del discurso}

La oración presenta una enumeración heterogénea en cuanto a las categorías utilizadas (acompañamiento, cuidados paliativos, asumir); las dos primeras están precedidas de la preposición "a", mientras que el último elemento enumerado, es decir el verbo "asumir" está ligado directamente, sin preposición. Al respecto, señalamos que las preposiciones que selecciona preferentemente la palabra "compromiso" son "con" + persona o "en" + persona o cosa, verbo.

En cuanto a la secuencia "le parece", el anafórico no encuentra fácilmente su referente. Habrá que ir hasta el subtítulo (Reacción de los médicos, renglón 14) y la primera oración (renglón 15) que expresan la oposición de los médicos, para poder reconstruir el sentido del pronombre. Éste podrá expresarse en singular (la FIAMC) que es la Federación Internacional de Médicos Católicos, o en plural (los médicos 
que forman parte de la FIAMC). La recuperación del antecedente en los textos pragmáticos cuya función informativa es primordial y no debe prestar a confusión.

El descenso de la cohesión hace que convenga duplicar el argumento interno o utilizar una expresión en la que aparezca explícito el referente comentado.

\section{Comparación del binomio TO-TT}

TO. Produce una enumeración homogénea en cuanto a las categorías utilizadas (sustantivos) todos precedidos de la preposición « à », correspondiente al régimen de " attachement ». En cuanto a la secuencia « (...) leur paraît (...) », el referente del pronombre plural « leur » está ubicado 10 renglones hacia arriba; la elección de la concordancia con la forma plural puede confundir el referente con la forma cotextual « malades » que aparece en el renglón anterior.

TT. Produce la forma pronominal singular con lo cual no confunde el referente con el sustantivo plural más cercano "enfermos"; sin embargo, no ha duplicado el argumento interno, desaprovechando un recurso natural del castellano que facilitaría la recuperabilidad del referente y aumentaría la cohesión.

\section{Mecanismos de producción}

Descenso de control lingüístico: regla de la enumeración y preposiciones.

Descenso de control lingüístico-discursivo: producción automática de la elipsis.

\section{Resultado}

Visibilidad de interferencia del discurso de partida.

Elipsis dentro del sistema, sin utilización del recurso de duplicación natural del español.

Descenso de la cohesión con repercusión en la construcción de sentido.

Producción palimpséstica.

Incumplimiento del precepto traducir toda la información con la consiguiente entropía informativa. 
17

\begin{tabular}{|l|l|l|l|l|}
\hline Cód. & \multicolumn{1}{|c|}{ TT } & \multicolumn{1}{c|}{ r. } & \multicolumn{1}{c|}{ TO } \\
\hline 51a) & $\begin{array}{l}\text { El juez encargado del caso } \\
\text { desconcertado, ya que en ningún lugar } \\
\text { del mundo, en el año 1989, se había } \\
\text { planteado esta cuestión ante un juez. } \\
\text { Hace un llamamiento a testigos científicos } \\
\text { susceptibles de aclararle la calificación de } \\
\text { estos embriones: ¿ser humano o simple } \\
\text { objeto?... }\end{array}$ & & $\begin{array}{l}\text { Le juge chargé de l'affaire est bien } \\
\text { embarrassé; nulle part au monde, en 1989, } \\
\text { ne s'est posée cette question pour un juge. II } \\
\text { lance un appel à témoins en direction de } \\
\text { scientifiques susceptibles de l'éclairer quant à } \\
\text { la qualification de ces embryons : être } \\
\text { humain ou simple objet ?... }\end{array}$ \\
\end{tabular}

\section{Sintaxis de lengua meta}

"Hace un Ilamamiento a testigos científicos susceptibles de aclararle la calificación de estos embriones: ¿ser humano o simple objeto?"

-Construcción verbal con elipsis nominal máxima (argumento externo o sujeto): [Ø] Hace un llamamiento.

-En la oración quedan identificados los rasgos básicos del argumento sujeto elidido ( $3^{\mathrm{a}}$ persona singular género masculino).

-Construcción gramatical.

-El antecedente no es recuperable en el nivel oracional.

\section{Sintaxis del discurso}

El hueco en función sujeto recupera el valor léxico "El juez" que está fijado endofóricamente también como sujeto de la oración principal precedente, cuya sintaxis es anómala, porque hay un vacío -no una elipsis- del verbo cópula.

La elipsis de sujeto es un medio cohesivo muy utilizado en castellano y la recuperación transfrástica del antecedente no debe prestar a confusión, especialmente en los textos pragmáticos cuya función informativa es primordial. En el caso que nos ocupa, el antecedente está ubicado en una oración incompleta, por lo tanto hay un descenso de cohesión con la oración de sujeto elíptico.

\section{Comparación del binomio TO-TT}


TO. Presenta dos proposiciones y una oración yuxtapuestas, la primera describe el estado de incomodidad del juez frente a un caso inédito; la segunda comprueba la originalidad del caso. La oración sin conector informa sobre las medidas que tomará el juez para informarse.

La característica de la lengua francesa de no dejar vacío el lugar correspondiente al SN sujeto « il lance » contribuye a la cohesión.

TT. Presenta una proposición principal y una subordinada de causa seguida de una oración yuxtapuesta. La incompletitud de la primera -vacío del verbo "estar"instaura la ambigüedad ¿caso desconcertante? ¿juez desconcertado? Sigue la subordinada de causa "ya que" y luego la yuxtapuesta "Hace un llamamiento".

EI TO mantiene la yuxtaposición, lo que constituye un estilo. En cambio, el TT usa la yuxtaposición y la subordinación, cuyo resultado es un uso irregular de medios cohesivos.

\section{Mecanismos de producción}

Elevación de la frecuencia de uso de recursos o elementos, en nuestro caso la elipsis que está asociada a la ausencia léxica.

Descenso del control lingüístico-discursivo: producción automática de la elipsis.

\section{Resultado}

Visibilidad de interferencia del sistema lingüístico meta, es decir el castellano.

Elipsis de sujeto dentro del sistema con consecuencias discursivas.

Descenso de la cohesión con repercusión en la construcción de sentido.

Incumplimiento del precepto traducir toda la información con la consiguiente entropía. 


\begin{tabular}{|c|c|c|c|c|}
\hline Cód. & TT & r. & TO & r. \\
\hline 51a) & $\begin{array}{l}\text { Si se trata de un ser humano, deberá ser } \\
\text { protegido por la ley y si se califica de } \\
\text { bien, nada se opone a su destrucción. }\end{array}$ & $\begin{array}{l}8 \\
- \\
9\end{array}$ & $\begin{array}{l}\text { S'il s'agit d'un être humain, il devra, aux } \\
\text { termes de la loi, être confié à garde; s'il est } \\
\text { qualifié de bien, rien ne s'oppose à sa } \\
\text { destruction. }\end{array}$ & $\begin{array}{l}8 \\
- \\
9\end{array}$ \\
\hline
\end{tabular}

\section{Sintaxis de la lengua meta}

"Si se trata de un ser humano, deberá ser protegido por la ley y si se califica de bien, nada se opone a su destrucción."

-Construcción hipotética cuya prótasis contiene la forma "se" pasiva o impersonal con elipsis nominal máxima (argumento interno OD): (...) si se [Ø] califica de bien $(\ldots)$

-Construcción gramatical.

-El antecedente no es recuperable en el nivel oracional.

\section{Sintaxis del discurso}

La oración anterior [ $\rightarrow$ Caso 18] plantea la incertidumbre del juez que debe decidir sobre la calificación de siete embriones congelados: “¿ser humano o simple objeto?"

La recuperación del antecedente es transfrástica (embriones) cuya calificación alcanza a todos los embriones (ser humano, bien), de allí que se utilice el singular.

El incremento pronominal "se" puede ser interpretado como pasiva pronominal o como impersonal, pero en ambos casos, para cohesionar la información, debería aparecer el pronombre OD "los" que retome el antecedente endofórico "embriones", como secuencia "se los".

En cuanto al régimen del verbo calificar, coexisten dos preposiciones: calificar de inmoral y calificar con seis (Olsen y Zorrilla, 1997: 111). 


\section{Comparación del binomio TO-TT}

TO. Utiliza una pasiva sin complemento agente « il est qualifié de bien »; la elevación del sujeto "il » retoma el referente de manera general "embrión" (masculino singular) en lugar de hacerlo según el plural, tal como aparece en el mismo TO $[\rightarrow$ Caso 18]. La producción en singular pudo haber estado inducida por la secuencia impersonal precedente « il s'agit » que sólo tiene forma singular.

TT. Produce la forma "se" de uso muy frecuente y potencialmente polifuncional (Di Tullio, 1997: 172-181). La estructura del TO (si + sujeto pasivo + verbo) seguramente incidió en la solución en castellano, que ha eliminado naturalmente el sujeto seguido directamente por el verbo. Ha omitido el argumento interno, desaprovechando el recurso de la secuencia castellana "se lo" /"se los" que facilitaría la recuperabilidad del referente.

\section{Mecanismos de producción}

Elevación de la frecuencia de uso de recursos o elementos, en nuestro caso la elipsis que está asociada a la ausencia léxica.

Descenso del control lingüístico-discursivo: no se ha producido el clítico OD "lo/los".

\section{Resultado}

Visibilidad de interferencia del sistema lingüístico meta, es decir el castellano (incremento pronominal "se").

Visibilidad de interferencia del discurso del TO.

Elipsis del objeto directo los.

Descenso de la cohesión con repercusión en la construcción de sentido.

Producción palimpséstica. 
19

\begin{tabular}{|c|c|c|c|c|}
\hline Cód. & TT & r. & $\mathrm{TO}$ & r. \\
\hline 51a) & $\begin{array}{l}\text { El abogado de la madre llama a testificar } \\
\text { a Jérôme Lejeune, conocido en los } \\
\text { Estados Unidos por haber recibido el } \\
\text { premio Kennedy tras descubrir la trisomía } \\
21 \text {, miembro de la Academia Americana } \\
\text { de las Artes y las Ciencias, de la } \\
\text { Academia Pontificia de las Ciencias... y } \\
\text { espera que sus notables conocimientos } \\
\text { de genetista contribuyan a aclarar al } \\
\text { magistrado. }\end{array}$ & $\begin{array}{l}10 \\
- \\
13\end{array}$ & $\begin{array}{l}\text { L'avocat de la mère invite alors à témoigner } \\
\text { Jérôme Lejeune, connu aux Etats-Unis pour } \\
\text { avoir reçu le prix Kennedy à la suite de sa } \\
\text { découverte de la trisomie 21, membre de } \\
\text { l'Académie américaine des Arts et des } \\
\text { Sciences, de l'Académie pontificale des } \\
\text { sciences... et dont il espère que les } \\
\text { remarquables talents de généticien } \\
\text { contribueront à éclairer le magistrat. }\end{array}$ & $\begin{array}{l}10 \\
- \\
13\end{array}$ \\
\hline
\end{tabular}

\section{Sintaxis de lengua meta}

"El abogado de la madre llama a testificar a Jérôme Lejeune, conocido en los Estados Unidos por haber recibido el premio Kennedy tras descubrir la trisomía 21, miembro de la Academia Americana de las Artes y las Ciencias, de la Academia Pontificia de las Ciencias... y espera que sus notables conocimientos de genetista contribuyan a aclarar al magistrado."

-Construcción coordinada con elipsis nominal máxima (argumento externo o sujeto): (...) y $[\varnothing]$ espera $(\ldots)$.

-En la coordinada no quedan completamente identificados los rasgos básicos del argumento sujeto elidido ( $¿ 2^{\mathrm{a}}$ persona "usted"?, ¿ $3^{\mathrm{a}}$ persona?).

-Construcción gramatical.

-El antecedente es recuperable en el nivel oracional.

\section{Sintaxis del discurso}

Las virtualidades sobre la persona del argumento sujeto de "espera" que se refieren en Sintaxis de la lengua meta quedan circunscriptas a la $3^{\mathrm{a}}$ persona, puesto que es una estructura coordinada cuyo primer miembro tiene como sujeto a "EI abogado de la madre".

Por lo tanto, el hueco en función sujeto recupera ese valor léxico "El abogado de la madre" fijado endofóricamente como SN sujeto en el primer miembro de la coordinada. 
En oración quedan definidos tres actantes (abogado de la madre, Jérôme Lejeune, magistrado) cuyos rasgos gramaticales son género masculino, número singular. A excepción de Jérôme Lejeune, los dos restantes están solamente individualizados por sus funciones laborales.

El referente se hace borroso, razón por la cual convendría ocupar la posición sujeto, para facilitar el pasaje de la información.

\section{Comparación del binomio TO-TT}

TO. Presenta una extensa proposición principal seguida de una proposición relativa objeto indirecto introducida por " dont » que contribuye a la cohesión, pero precedida por el coordinante « et », que instaura una anomalía sintáctica.

La característica de la lengua francesa de no dejar vacío el lugar correspondiente al SN sujeto contribuye a la cohesión.

TT. Presenta una estructura coordinada que pone en pie de igualdad los núcleos verbales "llama a testificar" y "espera", e intenta que el anafórico posesivo "sus" recupere resuntivamente el largo antecedente "Jérôme Lejeune, conocido en los Estados Unidos....".

El problema de la coordinación del TO ha influido en la solución del TT, que ha cambiado la jerarquización en la exposición de las ideas, con el consiguiente descenso de cohesión.

\section{Mecanismos de producción}

Elevación de la frecuencia de uso de recursos o elementos, en nuestro caso la elipsis que está asociada a la ausencia léxica.

Descenso del control lingüístico: se desdibuja la diferencia entre coordinación y subordinación, a partir de una anomalía sintáctica del TO.

Descenso del control lingüístico-discursivo: producción automática de la elipsis.

\section{Resultado}


Visibilidad de interferencia del sistema lingüístico meta, es decir el castellano. Visibilidad de interferencia del discurso del TO.

Elipsis dentro del sistema con consecuencias discursivas: argumento externo o sujeto.

Producción palimpséstica. 
20

\begin{tabular}{|l|l|l|l|l|}
\hline Cód. & \multicolumn{1}{|c|}{ TT } & r. & \multicolumn{1}{c|}{ TO } & \multicolumn{1}{c|}{ r. } \\
\hline 51a) & $\begin{array}{l}\text { Al principio de la vida, la información } \\
\text { genética y la estructura molecular del } \\
\text { zigoto, el espíritu y la materia, el alma y el } \\
\text { cuerpo, están íntimamente unidos puesto } \\
\text { que ya constituye un ser humano. }\end{array}$ & 29 & $\begin{array}{l}\text { Au commencement de la vie, l'information } \\
\text { génétique et la structure moléculaire du } \\
\text { zygote, l'esprit et la matière, l'âme et le corps, } \\
\text { sont totalement intriqués puisqu'il s'agit déjà } \\
\text { d'un être humain }\end{array}$ & $\begin{array}{l}\text { 28 } \\
\text { s'um }\end{array}$ \\
\hline
\end{tabular}

\section{Sintaxis de lengua meta}

"Al principio de la vida, la información genética y la estructura molecular del zigoto, el espíritu y la materia, el alma y el cuerpo, están íntimamente unidos puesto que ya constituye un ser humano."

-Proposición subordinada causal introducida por la locución conjuntiva "puesto que" con elipsis nominal máxima (argumento externo o sujeto): (...) están íntimamente unidos puesto que [Ø] ya constituye un ser humano.

-Falta de concordancia entre el verbo "constituye" y el sujeto compuesto.

-Construcción con anomalía sintáctica.

-El antecedente -semántico- es recuperable en el nivel oracional.

\section{Sintaxis del discurso}

Las virtualidades sobre la persona del argumento sujeto de "constituye" que se refieren en Sintaxis de la lengua meta, no encuentran un referente para despejar la incertidumbre generada por la anomalía sintáctica: el argumento externo de la subordinada causal elidido tiene como rasgos gramaticales género masculino, número plural, por lo tanto no hay concordancia con el verbo "constituye".

El hueco en función sujeto no puede recuperar, gramaticalmente, el valor léxico debido a la anomalía sintáctica señalada (falta de concordancia), lo cual instaura ausencia de cohesión.

Una lectura semántico-discursiva da cuenta de que el sujeto elíptico refiere al SN sujeto compuesto de la proposición principal "la información genética y la estructura molecular del zigoto, el espíritu y la materia, el alma y el cuerpo". 


\section{Comparación del binomio TO-TT}

TO. La oración compleja comienza con un complemento adjunto extraclausular que determina el marco temporal, seguido de $\mathrm{SN}$ sujeto compuesto + verbo cópula en $3^{a}$ persona del plural + predicativo + subordinada causal + expresión impersonal singular « il s'agit » que funciona resuntivamente.

TT. La oración compleja comienza con un complemento adjunto extraclausular que determina el marco temporal, seguido de $\mathrm{SN}$ sujeto compuesto + Verbo cópula en $3^{a}$ persona del plural + predicativo + subordinada causal introducida por "puesto que" + SV con núcleo en singular.

EI TT refleja la tendencia del sistema del castellano como lengua pro-drop, sin advertir la necesidad de la concordancia plural con un sujeto compuesto o, en su defecto, la posibilidad de retomarlo mediante una forma resuntiva singular del tipo "todo ello".

\section{Mecanismos de producción}

Elevación de la frecuencia de uso de recursos o elementos, en nuestro caso la elipsis que está asociada a la ausencia léxica.

Descenso del control lingüístico: falta de concordancia.

Descenso del control lingüístico-discursivo: la producción automática de la elipsis y la falta de concordancia dificultan la búsqueda del antecedente, que deberá utilizar el camino semántico-discursivo.

\section{Resultado}

Visibilidad de interferencia del sistema lingüístico meta, es decir el castellano.

Visibilidad de interferencia del discurso del TO.

Elipsis fuera del sistema con consecuencias semántico-discursivas.

Producción palimpséstica. 
21

\begin{tabular}{|l|l|l|l|l|}
\hline Cód. & \multicolumn{1}{|c|}{ TT } & r. & \multicolumn{1}{c|}{ TO } & \multicolumn{1}{c|}{ r. } \\
\hline 52b) & $\begin{array}{l}\text { El animal sufrió un gran cambio que le } \\
\text { condujo a tener, a pesar de su sexo, un } \\
\text { patrimonio genético semejante al de un } \\
\text { macho. }\end{array}$ & $\begin{array}{l}\text { L'animal a subi un véritable travestissement } \\
\text { l'amenant à afficher, en dépit de son sexe, un } \\
\text { patrimoine génétique ressemblant à celui d'un } \\
\text { mâle. }\end{array}$ & $\begin{array}{l}\text { - } \\
14\end{array}$ \\
\hline
\end{tabular}

\section{Sintaxis de la lengua meta}

"El animal sufrió un gran cambio que le condujo a tener, a pesar de su sexo, un patrimonio genético."

-Construcción con clítico dativo + forma verbal personal con elipsis nominal máxima (argumento interno OD): Le condujo [Ø].

-En la oración de base, el clítico le no remite a dativo.

-Empleo de Leísmo.

-El antecedente es recuperable en el nivel oracional.

\section{Sintaxis del discurso}

El verbo "conducir" es transitivo, predicado triádico, es decir, selecciona un argumento externo o sujeto y dos argumentos internos o complementos.

La elipsis está dentro de la subordinada relativa "que le condujo a tener...", dependiente de la principal "El animal sufrió un gran cambio".

Las condiciones de recuperabilidad de los argumentos son estrictas y se aplican a partir del principio general que establece que los rasgos gramaticales de la categoría elidida (persona, casi siempre número y a veces género) deben aparecer en la misma oración en la que ocurre la elipsis. Estas condiciones se manifiestan a través de la concordancia del verbo con el sujeto y el uso de clíticos de acusativo y dativo (Brucart, 2000: 2801). El clítico le deriva del demostrativo dativo latino ILLI y corresponde al objeto indirecto.

El pronombre le que no viene determinado por la posición (o función) sintáctica del antecedente constituye leísmo, siendo el más frecuente y extendido el 
referido a un objeto directo singular masculino que representa a una persona (Fernández-Ordóñez, 2000: 1319).

En nuestro caso, el referente "El animal" es SN sujeto de la proposición principal y no responde a la característica más frecuente del leísmo de representación de persona.

Dentro de las variedades del uso del castellano, se comprueban diferencias entre el castellano peninsular y el rioplatense, siendo el anafórico le de uso extendido en España para expresar un SN objeto directo personal, mientras que en las mismas circunstancias, el rioplatense adscribe a las normas del sistema general del castellano utilizando el clítico $l o$.

En el caso de lectores no peninsulares, la recuperabilidad del valor léxico del clítico le como manifestación de leísmo no resulta evidente con el consiguiente descenso de cohesión.

\section{Comparación del binomio TO-TT}

TO. Produce el enunciado « l'amenant » con el anafórico «l' » en función OD que remite endofóricamente a « L' animal », SN sujeto de la proposición principal.

TT. Produce el enunciado "le condujo" con el anafórico "le" en función OD que remite endofóricamente a "El animal", SN sujeto de la proposición principal, cuyo núcleo es animado no humano.

\section{Mecanismos de producción}

Utilización de normas operacionales lingüísticas del castellano peninsular como lengua meta.

Descenso de control lingüístico: cuando el acusativo representado por el pronombre le no es una persona, se lo considera vicio del leísmo (DRAE). 


\section{Resultado}

Visibilidad de interferencia de normas operacionales lingüísticas del castellano peninsular como lengua meta.

Elipsis con clítico dativo "le" con referente no humano y función objeto directo.

Descenso de la cohesión con repercusión en la construcción de sentido. 


\subsection{Tercera parte: Características y análisis de El racismo del gen, traducción de Au bazar du vivant}

\subsubsection{Características de las fuentes}

Las dos fuentes textuales que se analizan a continuación son $A u$ bazar $d u$ vivant, de autoría de Jacques Testart y Christian Godin (2001) editada por Seuil y la traducción al castellano de Víctor Goldstein, bajo el título El racismo del gen (2002), realizada en Argentina y publicada por el Fondo de Cultura Económica.

El texto objeto de análisis es una entrevista, género discursivo secundario o complejo, que cuenta entre sus características la presencia de marcas de oralidad. Las expresiones informales familiares se cuelan entre los complejos conceptos que desarrollan dos participantes del intercambio dialógico -un filósofo y un investigador en Biología- durante el juego intersubjetivo, tratando de restituir la espontaneidad del intercambio directo en las formas escritas (Arfuch, 1995).

La especialidad es la Bioética, enfocada como intersección entre la Biología y la Filosofía, por lo tanto, se observa terminología de esas áreas, unida a expresiones informales. A título ilustrativo, mencionamos la ocurrencia de términos específicos y siglas en el texto traducido (partenogénesis, Introducción, página 14, renglón 14; IVG interrupción voluntaria del embarazo, por las iniciales de la expresión francesa interruption volontaire de la grossesse / capítulo 3, página 45, renglón 25). Al lado de de la terminología señalada, encontramos formas familiares como la palabra "cosa" (Introducción, página 17, renglón 11; capítulo 2, página 29, renglón 21; capítulo 2 , página 31, renglón 5) que traduce ocurrencias de «ça » en el texto original (Introduction, page 17, ligne 7; chapitre 2, page 34, ligne 9; chapitre 2, page 36, ligne 9) mo a conceptos cuya designación familiar no está fijada lexicológicamente como « manip » (TO Introduction, page 16, ligne 7) "cosa" (TT Introducción, página 16, renglón 15). ${ }^{2}$

Al comparar el título del libro original en francés con su traducción al castellano Au bazar du vivant / El racismo del gen, se observa que en ambos casos

\footnotetext{
${ }^{2}$ Hemos dado algunos ejemplos de designaciones que se alejan de las consagradas en el Capítulo V, Metodología. 5.4.2.
} 
se han utilizado construcciones nominales. Ahora bien, su significado difiere desde una lectura pragmático-discursiva: la palabra "bazar », además de evocar en los idiomas en cuestión el lugar de venta de artículos diversos en Oriente, se lo vincula tanto en Francia como en Argentina al espacio de venta de toda clase de objetos, en especial de utensilios. Pero además, en francés, la palabra "bazar " tiene un uso frecuente en el registro familiar que evoca "gran desorden"; es decir que el título francés reúne, por un lado, significados ligados a una transacción comercial y a un estado caótico o de desorden, y por el otro el concepto de vida o de ser vivo. Una de las consecuencias potenciales dentro de semejante desorden podría ser la búsqueda del biotipo "normal", mediante acciones de segregación e incluso de destrucción dirigidas a la nueva entidad del gen. En contrapartida, la traducción del título aumenta el nivel de previsibilidad del contenido de la obra, a la vez que baja el tono coloquial debido a la eliminación de la semiosis aportada por « bazar » en el TO en francés. ${ }^{3}$

A continuación, pasamos a los enunciados elípticos que presentan anomalías sintácticas y discursivas en el texto traducido, a partir del caso 22 y hasta el 40.

\footnotetext{
${ }^{3}$ Como ya hemos dicho, el nivel lexicológico/terminológico no está dentro de los objetivos de nuestra investigación, aunque llegado el caso haremos comentarios.
} 


\subsubsection{Análisis de los binomios textuales}

22

\begin{tabular}{|c|c|c|c|c|}
\hline Cap. & TT & $p / r$ & $\mathrm{TO}$ & $p / r$ \\
\hline 1 & $\begin{array}{l}\text { Ante todo, están las profundas } \\
\text { transformaciones padecidas por la } \\
\text { biología moderna: hoy, la manera de } \\
\text { practicar la ciencia de lo viviente no tiene } \\
\text { mucho que ver con la de sus padres } \\
\text { fundadores. }\end{array}$ & $\begin{array}{l}11 / \\
5\end{array}$ & $\begin{array}{l}\text { Il y a d'abord les bouleversements profonds } \\
\text { subis par la biologie moderne: la façon de } \\
\text { pratiquer la science du vivant aujourd'hui n'a } \\
\text { pas plus grand-chose à voir avec celle de ses } \\
\text { pères fondateurs. }\end{array}$ & $\begin{array}{l}11 / \\
6\end{array}$ \\
\hline
\end{tabular}

\section{Sintaxis de la lengua meta}

"hoy, la manera de practicar la ciencia de lo viviente no tiene mucho que ver con la de sus padres fundadores."

-Complemento régimen con elipsis nominal parcial (argumento externo o sujeto): la [Ø] de sus padres fundadores.

-En la oración de base no quedan claramante identificados los criterios paralelísticos.

-Construcción gramatical.

-El antecedente es recuperable en el nivel oracional.

\section{Sintaxis del discurso}

En la elipsis de núcleos de sintagmas, se aplican criterios paralelísticos entre los dos sintagmas: el de núcleo elidido y el que contiene antecedente $[\rightarrow$ Capítulo IV, Elipsis. 4.3.2.].

En la elipsis parcial, el hueco puede incluir sólo el núcleo o cualquier proyección de éste (Brucart, 2000: 2805); en nuestro caso, la proyección del núcleo incluye toda la determinación de "manera".

El adverbio "Hoy" es un adjunto extraclausular que establece el marco temporal en que se interpreta toda la oración que juzga "la manera de practicar la ciencia de lo viviente", que es el hueco, en relación con lo que hacían los fundadores 
de la biología moderna que es el resto, y que el TT expresa como "la de sus padres fundadores". Es decir que hoy se advierte que la manera de practicar la biología difiere de lo que hacían sus fundadores, lo que instaura una cohesión borrosa.

\section{Comparación del binomio TO-TT}

TO. Produce el adverbio « aujourd'hui » dentro del sujeto, lo que implica que el juicio que se está dando consiste en comparar cómo se practica la biología actualmente en relación a como lo hacían "ses pères fondateurs », que constituye el resto. La elipsis « celle de » es parcial puesto que no refiere al sujeto completo sino al núcleo « façon » con parte de sus proyecciones.

TT. Produce el adverbio "Hoy" como adjunto extraclausular, como se indicó en Sintaxis del discurso, y no logra entonces la equivalencia, que es la comparación de los dos momentos (hoy y antes) en la práctica de la biología. Por le contrario, el sentido del TT es que hoy se advierte que ha habido un cambio en las maneras de practicar biología.

La construcción microestructural en el segmento problema-solución de traducción incide negativamente en el nivel macroestructural $[\rightarrow$ Capítulo I, Marco teórico y Antecedentes. 1.1.2.].

\section{Mecanismos de producción}

Elevación de la frecuencia de uso de recursos o elementos, ${ }^{4}$ en nuestro caso la elipsis que está asociada a la ausencia léxica.

Descenso del control lingüístico: la movilidad del adjunto a la posición extraclausular cambia el marco temporal que no es recuperado con un tiempo verbal en pasado, por ejemplo la que tenían sus padres fundadores.

Descenso del control lingüístico-discursivo: la elipsis trae aparejado un cambio en el sentido, con respecto al mensaje del TO.

\footnotetext{
${ }^{4}$ Este concepto de Carsten Sinner [ $\rightarrow$ Capítulo III, Interferencia. 3.1.3.] es uno de los que explica el descenso de la fluidez en la lectura por efecto de la redundancia de un fenómeno.
} 


\section{Resultado}

Visibilidad de interferencia del sistema lingüístico meta, es decir el castellano (movilidad de adjuntos).

Elipsis de sujeto dentro del sistema con consecuencias discursivas.

Descenso de cohesión con consecuencias en la construcción de sentido. 
23

\begin{tabular}{|c|c|c|c|c|}
\hline Cap. & TT & $\mathrm{p} / \mathrm{r}$ & $\mathrm{TO}$ & $\mathrm{p} / \mathrm{r}$ \\
\hline 1 & $\begin{array}{l}\text { Por lo tanto, tras una breve presentación } \\
\text { de su carrera y de su trabajo, } \\
\text { encararemos sucesivamente esas tres } \\
\text { cuestiones: la metamorfosis de la } \\
\text { biología, la metamorfosis de la medicina y } \\
\text { la crítica de la bioética. }\end{array}$ & $\begin{array}{l}11 / \\
15\end{array}$ & $\begin{array}{l}\text { Donc, après une brève présentation de votre } \\
\text { carrière et de votre travail, nous aborderons } \\
\text { successivement ces trois questions: la } \\
\text { métamorphose de la biologie, la } \\
\text { métamorphose de la médecine et la critique } \\
\text { de la bioéthique. }\end{array}$ & $\begin{array}{l}9 / \\
18\end{array}$ \\
\hline
\end{tabular}

\section{Sintaxis de la lengua meta}

"Por lo tanto, tras una breve presentación de su carrera y de su trabajo, encararemos sucesivamente esas tres cuestiones: la metamorfosis de la biología, la metamorfosis de la medicina y la crítica de la bioética."

-Adjunto extraclausular temporal con elipsis nominal parcial (argumento de sustantivo): su carrera [Ø], su trabajo [Ø].

-En la oración no quedan identificados los rasgos básicos del poseedor $\left(¿ 3^{\mathrm{a}}\right.$ persona del singular género masculino?, $i^{\mathrm{a}}$ persona del singular género femenino?, $i 2^{\mathrm{a}}$ persona "usted", $3^{\mathrm{a}}$ persona plural?).

-Construcción gramatical.

-El antecedente no es recuperable en el nivel oracional.

\section{Sintaxis del discurso}

El posesivo tiene dos rasgos característicos: es determinante del sustantivo y también es pronombre. Dicho de otro modo, el posesivo constituye una proyección del pronombre y toma la posición de especificador, concordando con el número del núcleo del SN; por lo tanto en todo determinante posesivo hay presente una relación anafórica con el poseedor.

El posesivo antepuesto realiza la función semántica del argumento del nombre que corresponde al genitivo (poseedor, agente o tema) (Picallo y Rigau, 2000: 980). 
La recuperación de un referente puede realizarse ya sea endofóricamente, por los mecanismos de anáfora (antecedente) o catáfora (consecuente), o bien en el contexto en que se produce el enunciado; en este último caso el antecedente se interpreta deícticamente.

El género discursivo original fue la entrevista que tiene a la ostensión como una de las características de oralidad. El texto analizado es producto de la transcripción de la entrevista, por lo tanto, aquella característica desaparece.

En el caso analizado, la recuperación del posesivo "su" es transfrástica pues el antecedente "usted" aparece 15 renglones antes.

La recuperación de la referencia se debilita por dos causas: la imposibilidad de ostensión y la morfología idéntica del posesivo "su" que remite tanto a la $3^{\text {a }}$ persona (él/ella y sus plurales) como a la $2^{\text {a }}$ (usted/es).

\section{Comparación del binomio TO-TT}

TO. Produce la forma posesiva « votre » correspondiente a la $2^{a}$ persona que se diferencia de la de $3^{a}$ persona, lo que facilita la recuperación del antecedente, aunque no haya ostensión.

TT. Produce la forma "su" con un debilitamiento de la cohesión como se ha explicado en Sintaxis del discurso.

\section{Mecanismos de producción}

Elevación de la frecuencia de uso de recursos o elementos, en nuestro caso la elipsis que está asociada a la ausencia léxica.

Descenso de control lingüístico-discursivo: el uso de posesivos "su/sus" repercute en la cohesión de la oración. Se ha realizado traducción automática, desde niveles bajos.

\section{Resultado}

Visibilidad de interferencia del sistema lingüístico meta (uso de su/sus). 
Visibilidad de interferencia del discurso de partida (votre/su).

Elipsis dentro del sistema con consecuencias discursivas: argumento de sustantivo.

Descenso de la cohesión con consecuencias en la búsqueda del referente.

Producción palimpséstica. 
24

\begin{tabular}{|c|c|c|c|c|}
\hline Cap. & TT & $p / r$ & $\mathrm{TO}$ & $\mathrm{p} / \mathrm{r}$ \\
\hline 1 & $\begin{array}{l}\text { Entonces, su trabajo es la asistencia } \\
\text { médica para la procreación, y como } \\
\text { resultado de este éxito, que a la vez tenía } \\
\text { un valor profesional, mediático y } \\
\text { científico, acaecieron nuevos rechazos y } \\
\text { nuevos interrogantes, y se dio a conocer } \\
\text { al gran público por posiciones éticamente } \\
\text { fuertes, posiciones que sin duda son muy } \\
\text { minoritarias en el medio en que usted } \\
\text { evoluciona, porque rechaza el } \\
\text { pragmatismo que es como su filosofía } \\
\text { natural. }\end{array}$ & $\begin{array}{l}12 / \\
25\end{array}$ & $\begin{array}{l}\text { Donc votre travail, c'est l'AMP comme on dit } \\
\text { en jargon, l'assistance médicale à la } \\
\text { procréation et, à la suite de ce succès, qui } \\
\text { avait valeur à la fois professionnelle, } \\
\text { médiatique et scientifique, de nouveaux refus, } \\
\text { de nouvelles interrogations sont venus et } \\
\text { vous vous êtes fait connaître dans le grand } \\
\text { public par des positions éthiquement fortes, } \\
\text { des positions qui sont sans doute très } \\
\text { marginales dans le milieu dans lequel vous } \\
\text { évoluez parce que vous refusez le } \\
\text { pragmatisme qui en est comme la philosophie } \\
\text { naturelle. }\end{array}$ & $\begin{array}{l}11 / \\
24\end{array}$ \\
\hline
\end{tabular}

\section{Sintaxis de la lengua meta}

"Entonces su trabajo es la asistencia médica para la procreación (...)"

-Construcción copulativa con elipsis nominal parcial (argumento de sustantivo): su trabajo [Ø].

-En la oración de base no quedan identificados los rasgos básicos del poseedor

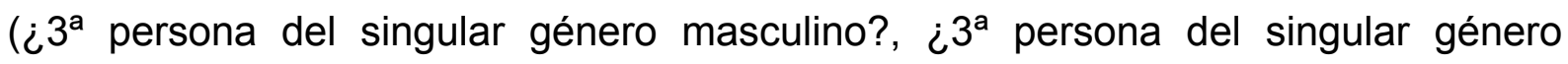
femenino?, ¿2 $2^{a}$ persona "usted", $3^{a}$ persona plural?)

-Construcción gramatical

-El antecedente no es recuperable en el nivel oracional.

\section{Sintaxis del discurso}

El posesivo tiene dos rasgos característicos: es determinante del sustantivo y también es pronombre. Dicho de otro modo, el posesivo constituye una proyección del pronombre y toma la posición de especificador, concordando con el número del núcleo del SN; por lo tanto en todo determinante posesivo hay presente una relación anafórica con el poseedor.

El posesivo antepuesto realiza la función semántica del argumento del nombre que corresponde al genitivo (poseedor, agente o tema) (Picallo y Rigau, 2000:980). 
La recuperación de un referente puede realizarse ya sea endofóricamente, por los mecanismos de anáfora (antecedente) o catáfora (consecuente), o bien en el contexto en que se produce el enunciado; en este último caso el antecedente se interpreta deícticamente.

El género discursivo original fue la entrevista que tiene a la ostensión como una de las características de oralidad. El texto analizado es producto de la transcripción de la entrevista, por lo tanto, aquella característica desaparece.

En el caso analizado, la recuperación del posesivo "su" es transfrástica ya que el referente agente remite endofóricamente al antecedente "usted" que aparece 13 renglones antes, retomado por el anafórico "lo" ("lo condujo") 6 renglones antes y el catafórico "usted" 8 renglones después. El hecho de que el conector consecutivo o de deducción "Entonces" inicie el párrafo, ayuda a cohesionar el anafórico "su" ubicado inmediatamente después de ese conector.

Sin embargo, la recuperación de la referencia se debilita por dos causas: la imposibilidad de ostensión y la morfología idéntica del posesivo "su" que remite tanto a la $3^{a}$ persona (él/ella y sus plurales) como a la $2^{a}$ (usted/es).

\section{Comparación del binomio TO-TT}

TO. Produce la forma posesiva « votre » correspondiente a la $2^{a}$ persona que se diferencia de la de $3^{a}$ persona, lo que facilita la recuperación del antecedente, aunque no haya ostensión. El posesivo tiene dos rasgos característicos: es determinante del sustantivo y también es pronombre. Dicho de otro modo, el posesivo constituye una proyección del pronombre y toma la posición de especificador, concordando con el género y el número de la cabeza del SN.

En el TO, el « attribut » o predicativo subjetivo obligatorio está denominado de dos maneras: con la sigla AMP, que es utilizada en la jerga de la especialidad, y con la denominación completa de la sigla mencionada.

El TT. Presenta una producción con cohesión debilitada por las razones explicadas en Sintaxis del discurso. El posesivo español, a diferencia del francés, no 
hace concordancia de género con el objeto poseído (Mi casa, mi perro/ Ma maison, mon chien).

En el TT hay un vacío informativo pues en el predicativo subjetivo obligatorio no aparece la sigla AMP con la consiguiente modificación del ritmo del TO, ligado a la oralidad.

\section{Mecanismos de producción}

Elevación de la frecuencia de uso de recursos o elementos, en nuestro caso la elipsis que está asociada a la ausencia léxica.

Descenso de control lingüístico-discursivo: el uso de posesivos "su/sus" repercute en la cohesión de la oración. Se ha realizado traducción automática, desde niveles bajos.

Salto de información: no se ha proporcionado la sigla AMP.

\section{Resultado}

Visibilidad de interferencia del sistema lingüístico meta (uso de su/sus).

Visibilidad de interferencia del discurso de partida (votre/su).

Elipsis dentro del sistema con consecuencias discursivas: argumento de sustantivo.

Descenso de la cohesión con consecuencias en la búsqueda del referente.

Producción palimpséstica.

Incumplimiento del principio traducir toda la información con la consiguiente entropía informativa. 
25

\begin{tabular}{|c|c|c|c|c|}
\hline Cap. & TT & $p / r$ & $\mathrm{TO}$ & $\mathrm{p} / \mathrm{r}$ \\
\hline 1 & $\begin{array}{l}\text { Entonces, su trabajo es la asistencia } \\
\text { médica para la procreación, y como } \\
\text { resultado de este éxito, que a la vez tenía } \\
\text { un valor profesional, mediático y } \\
\text { científico, acaecieron nuevos rechazos y } \\
\text { nuevos interrogantes, y se dio a conocer } \\
\text { al gran público por posiciones éticamente } \\
\text { fuertes, posiciones que sin duda son muy } \\
\text { minoritarias en el medio en que usted } \\
\text { evoluciona, porque rechaza el } \\
\text { pragmatismo que es como su filosofía } \\
\text { natural. }\end{array}$ & $\begin{array}{l}12 / \\
25\end{array}$ & $\begin{array}{l}\text { Donc votre travail, c'est l'AMP comme on dit } \\
\text { en jargon, l'assistance médicale à la } \\
\text { procréation et, à la suite de ce succès, qui } \\
\text { avait valeur à la fois professionnelle, } \\
\text { médiatique et scientifique, de nouveaux refus, } \\
\text { de nouvelles interrogations sont venus et } \\
\text { vous vous êtes fait connaître dans le grand } \\
\text { public par des positions éthiquement fortes, } \\
\text { des positions qui sont sans doute très } \\
\text { marginales dans le milieu dans lequel vous } \\
\text { évoluez parce que vous refusez le } \\
\text { pragmatisme qui en est comme la philosophie } \\
\text { naturelle. }\end{array}$ & $\begin{array}{l}11 / \\
24\end{array}$ \\
\hline
\end{tabular}

\section{Sintaxis de la lengua meta}

“(...), y se dio a conocer al gran público por posiciones éticamente fuertes, posiciones que sin duda son muy minoritarias en el medio en que usted evoluciona $(\ldots) . "$

-Construcción coordinada con elipsis nominal máxima (argumento externo o sujeto): $[\varnothing]$ y se dio a conocer.

-En la oración no quedan identificados los rasgos básicos del argumento sujeto elidido ( ¿2a persona "usted"?, ¿ $3^{a}$ persona singular?).

-Construcción gramatical.

-El antecedente es recuperable en el nivel oracional.

\section{Sintaxis del discurso}

Las virtualidades sobre la persona del argumento sujeto de "se dio a conocer" referidas en Sintaxis de la Lengua meta quedan circunscriptas a la $2^{\mathrm{a}}$ persona "usted", al recuperar el valor léxico de la elipsis.

La recuperación del SN sujeto de "se dio a conocer" es ambigua (usted, su trabajo). La recuperación endofórica más cercana es catafórica (usted), pero no es evidente porque su ocurrencia está dentro del adjunto de lugar "en el medio en que usted evoluciona". Por otra parte, la recuperación catafórica sólo puede remitir a un 
consecuente que esté dentro de la misma oración, cuya estructura preferencial es predicativa o atributiva [ $\rightarrow$ Capítulo IV, Elipsis. 4.3.3.].

El capítulo en que está contenido el caso en estudio, es la Introducción donde el filósofo Christian Godin presenta al investigador Jacques Testart y los trabajos que éste ha realizado. Si bien la función semántica agente es más prominente que la de instrumento, la relación entre el antecedente o consecuente [ $\rightarrow$ Capítulo IV, Elipsis. 4.3.] y la categoría elidida es borrosa porque el discurso previo a "y se dio a conocer" contiene una sucesión de proposiciones coordinadas y subordinadas, y especialmente porque el sujeto que encabeza el párrafo, fuertemente cohesionado al párrafo anterior por el conector "Entonces", es "su trabajo".

Todo ello indica la necesidad de que aparezca un medio cohesivo como la reiteración léxica total o parcial del referente o un pronombre personal como sujeto de "se dio a conocer" para restablecer la cohesión-coherencia y facilitar el pasaje de información.

\section{Comparación del binomio TO-TT}

TO. Presenta marcas de oralidad que indican que el discurso se va construyendo espontáneamente; por ejemplo, desde el enunciado anterior [ $\rightarrow$ Caso 26], va apareciendo la reiteración del coordinante « et ». En cuanto a los actantes, quedan definidos en el desarrollo, en parte, porque los lugares del sujeto han sido ocupados especialmente por el pronombre personal « vous », como en el caso que nos ocupa.

TT. Presenta una estructura similar al TO, con reiteración del coordinante "y". En cuanto a los actantes, algunos no quedan bien definidos en el desarrollo, en parte, porque la flexión verbal no alcanza para recuperar el referente.

\section{Mecanismos de producción}

Elevación de la frecuencia de uso de recursos o elementos, en nuestro caso la elipsis que está asociada a la ausencia léxica. 
Descenso del control lingüístico-discursivo: en la elipsis, la recuperación catafórica tiene restricciones que no se han observado. Ha habido traducción automática desde niveles bajos.

\section{Resultado}

Visibilidad de interferencia del sistema lingüístico meta, es decir el castellano.

Visibilidad de interferencia del discurso de partida.

Elipsis de sujeto dentro del sistema con consecuencias discursivas.

Descenso de la cohesión con consecuencias en la construcción de sentido sin ambigüedad.

Producción palimpséstica. 
26

\begin{tabular}{|c|c|c|c|c|}
\hline Cap. & TT & $\mathrm{p} / \mathrm{r}$ & TO & $\mathrm{p} / \mathrm{r}$ \\
\hline 1 & $\begin{array}{l}\text { Entonces, su trabajo es la asistencia } \\
\text { médica para la procreación, y como } \\
\text { resultado de este éxito, que a la vez tenía } \\
\text { un valor profesional, mediático y } \\
\text { científico, acaecieron nuevos rechazos y } \\
\text { nuevos interrogantes, y se dio a conocer } \\
\text { al gran público por posiciones éticamente } \\
\text { fuertes, posiciones que sin duda son muy } \\
\text { minoritarias en el medio en que usted } \\
\text { evoluciona, porque rechaza el } \\
\text { pragmatismo que es como su filosofía } \\
\text { natural. }\end{array}$ & $\begin{array}{l}12 / \\
25\end{array}$ & $\begin{array}{l}\text { Donc votre travail, c'est l'AMP comme on dit } \\
\text { en jargon, l'assistance médicale à la } \\
\text { procréation et, à la suite de ce succès, qui } \\
\text { avait valeur à la fois professionnelle, } \\
\text { médiatique et scientifique, de nouveaux refus, } \\
\text { de nouvelles interrogations sont venus et } \\
\text { vous vous êtes fait connaître dans le grand } \\
\text { public par des positions éthiquement fortes, } \\
\text { des positions qui sont sans doute très } \\
\text { marginales dans le milieu dans lequel vous } \\
\text { évoluez parce que vous refusez le } \\
\text { pragmatisme qui en est comme la philosophie } \\
\text { naturelle. }\end{array}$ & $\begin{array}{l}11 / \\
24\end{array}$ \\
\hline
\end{tabular}

\section{Sintaxis de la lengua meta}

(...) porque rechaza el pragmatismo (...)

-Proposición subordinada conjuntiva causal con elipsis nominal máxima (argumento externo o sujeto): porque [Ø] rechaza el pragmatismo.

-En la oración no quedan identificados los rasgos básicos del argumento sujeto elidido ( ¿2 $2^{\mathrm{a}}$ persona “usted”?, ¿ $3^{\mathrm{a}}$ persona singular?).

-Construcción gramatical.

-El antecedente es recuperable en el nivel oracional.

\section{Sintaxis del discurso}

Las virtualidades sobre la persona del argumento sujeto de "rechaza el pragmatismo" referidas en Sintaxis de la lengua meta quedan circunscriptas a la $2^{\mathrm{a}}$ persona "usted".

La recuperación del SN sujeto de la subordinada conjuntiva causal "porque rechaza el pragmatismo" es ambigua (usted, su trabajo), por dos razones: la recuperación endofórica más cercana es anafórica (usted) que precede inmediatamente a la subordinada, pero esa ocurrencia está dentro de un adjunto de lugar ("en el medio en que usted evoluciona"); la función semántica agente es más prominente que la de instrumento, sin embargo la relación entre el antecedente y la 
categoría elidida es borrosa porque el sujeto que encabeza el párrafo, fuertemente cohesionado al párrafo anterior por el conector "Entonces", es "su trabajo".

La aparición de un medio cohesivo como la reiteración léxica total o parcial del referente o un pronombre personal como sujeto de "rechaza" aumentaría la cohesión-coherencia, facilitando el pasaje de información.

\section{Comparación del binomio TO-TT}

TO. Producción fuertemente cohesionada, tanto en lo que se refiere a la posición sujeto " vous " como a la ocurrencia de « en " que relaciona el pragmatismo (« la philosophie naturelle ») con el medio en que se desarrolla el investigador Jacques Testart.

TT. La flexión verbal no alcanza para recuperar claramente al referente. Por otra parte, el TT resuelve el problema de « en » con la ocurrencia del posesivo "su filosofía natural", lo cual aporta ambigüedad puesto que no sabemos si ese posesivo está vinculado con la $2^{\mathrm{a}}$ persona "usted" (su/de usted) o con la $3^{\mathrm{a}}$ persona singular (su/del medio en que usted evoluciona).

\section{Mecanismos de producción}

Elevación de la frecuencia de uso de recursos o elementos, en nuestro caso la elipsis que está asociada a la ausencia léxica.

Descenso del control lingüístico-discursivo: en la elipsis de sujeto, la recuperación anafórica prefiere un antecedente en posición sujeto. Ha habido traducción automática desde niveles bajos.

\section{Resultado}

Visibilidad de interferencia del sistema lingüístico meta, es decir el castellano.

Visibilidad de interferencia del discurso de partida.

Elipsis de sujeto dentro del sistema con consecuencias discursivas.

Descenso de cohesión con consecuencias en la construcción de sentido.

Producción palimpséstica. 
27

\begin{tabular}{|c|c|c|c|c|}
\hline Cap. & TT & $p / r$ & TO & $\mathrm{p} / \mathrm{r}$ \\
\hline 1 & $\begin{array}{l}\text { Jacques Testart: Efectivamente, con } \\
\text { frecuencia se hace ideología, pero ¿no es } \\
\text { un poco lo que hace Atlan cuando } \\
\text { pretende que el resultado de una } \\
\text { clonación humana (...). La higiene del } \\
\text { lenguaje, en efecto, permitiría suprimir } \\
\text { palabras fuertes, pero, al mismo tiempo, } \\
\text { ¿no corre el riesgo de volver insulso el } \\
\text { mismo contenido de dichas palabras, es } \\
\text { decir, también las representaciones que } \\
\text { vehiculizan y que no están desprovistas } \\
\text { de sentido? }\end{array}$ & $\begin{array}{l}14 / \\
16\end{array}$ & $\begin{array}{l}\text { Jacques Testart: On fait effectivement de } \\
\text { l'idéologie, mais n'est-ce pas aussi un peu ce } \\
\text { que fait Atlan quand il prétend que le résultar } \\
\text { d'un clonage humain (...). L'hygiène du } \\
\text { langage permettrait, effectivement, de } \\
\text { supprimer des mots forts, mais ne risque-t-on } \\
\text { pas en même temps d'affadir le contenu } \\
\text { même de ces mots, c'est-à-dire aussi les } \\
\text { représentations qu'ils véhiculent et qui ne sont } \\
\text { pas dénuées de sens? }\end{array}$ & $\begin{array}{l}13 / \\
16\end{array}$ \\
\hline
\end{tabular}

\section{Sintaxis de la lengua meta}

“¿no corre el riesgo de volver insulso el mismo contenido de dichas palabras (...)?”

-Construcción verbal con elipsis nominal máxima (argumento externo o sujeto): ¿no $\varnothing$ corre el riesgo...?

-En la oración no quedan identificados los rasgos básicos del argumento sujeto elidido ( $¿ 2^{\mathrm{a}}$ persona "usted"?, $¿ 3^{\mathrm{a}}$ persona singular?).

-Construcción gramatical.

-El antecedente no es recuperable en el nivel oracional.

\section{Sintaxis del discurso}

Las virtualidades sobre la persona del argumento sujeto de "corre el riesgo" referidas en Sintaxis de la lengua meta quedan circunscriptas a la $3^{a}$ persona singular, correspondiente a la forma impersonal.

A pesar de que la interrogación retórica está sintácticamente bien construida en el nivel oracional, al pasar a la dinámica discursiva, no es posible la recuperación endofórica del SN sujeto de "corre el riesgo", que remite transfrásticamente al inicio de la intervención de Jacques Testart: "Efectivamente, con frecuencia se hace ideología". 
Si se tomara automáticamente como SN sujeto a "La higiene del lenguaje", el resultado sería semánticamente incoherente puesto que la higiene del lenguaje no es el agente que "corre el riesgo" sino el medio que puede dar como resultado "correr el riesgo de" debilitar el contenido de ciertas palabras.

\section{Comparación del binomio TO-TT}

TO. La palabra que abre la intervención de Jaques Testart es el pronombre indefinido cuya función es sujeto « On », que se repite en la interrogación retórica « ne risque-t-on pas », lo que delimita precisamente el alcance de cada uno de los sujetos de la oración (On fait, (...) L'hygiène du langage, ne risque -t-on).

TT. El lugar sujeto está vacío, siendo posible identificar que esa carencia fue resuelta con el incremento de la partícula "se" en función de sujeto impersonal, al comienzo de la intervención de Jacques Testart, lo cual nos lleva a considerar este caso como una falsa elipsis. La posición tendría que llenarse con una forma de valor semántico-referencial indeterminada (se corre el riesgo/la gente corre el riesgo/uno corre el riesgo).

\section{Mecanismos de producción}

Elevación de la frecuencia de uso de recursos o elementos, en nuestro caso la elipsis que está asociada a la ausencia léxica.

Descenso del control lingüístico-discursivo: la ausencia léxica no instaura elipsis de sujeto pues no es posible recuperar anafóricamente un antecedente. Ha habido traducción automática desde niveles bajos.

\section{Resultado}

Visibilidad de interferencia del sistema lingüístico meta, es decir el castellano.

Falsa elipsis dentro del sistema con consecuencias discursivas: argumento externo o sujeto elipsis (ne risque-t-on pas / corre el riesgo). Se pone en evidencia al comparar el TT con el TO.

Descenso de cohesión con consecuencias en la construcción de sentido. 


\begin{tabular}{|c|c|c|c|c|}
\hline Cap. & TT & $p / r$ & TO & $p / r$ \\
\hline 1 & $\begin{array}{l}\text { También manifestaba que un investigador } \\
\text { podía formularse preguntas sobre lo que } \\
\text { hace, que hay que dejar de sacralizar la } \\
\text { investigación, que no se hace } \\
\text { investigación porque es implícitamente } \\
\text { legitima, porque se tiene el derecho y el } \\
\text { deber de elegir su objeto de } \\
\text { investigación, y yo había elegido. }\end{array}$ & $\begin{array}{l}18 / \\
7\end{array}$ & $\begin{array}{l}\text { Je disais aussi qu' un chercheur pouvait se } \\
\text { poser des questions sur ce qu'il fait, qu'il faut } \\
\text { arrêter de sacraliser la recherche, qu'on ne } \\
\text { fait pas de la recherche parce que c'est } \\
\text { implicitement légitime, qu'on a le droit et le } \\
\text { devoir de choisir son objet de recherche, et } \\
\text { moi j'avais choisi. }\end{array}$ & $\begin{array}{l}18 / \\
13\end{array}$ \\
\hline
\end{tabular}

\section{Sintaxis de la lengua meta}

"También manifestaba que un investigador podía formularse preguntas sobre lo que hace, que hay que dejar de sacralizar la investigación, que no se hace investigación porque es implícitamente legítima, porque se tiene el derecho y el deber de elegir su objeto de investigación, y yo había elegido. “

-Construcción verbal con elipsis nominal máxima (argumento externo o sujeto):

También $[\varnothing]$ manifestaba $(\ldots)$

-En la oración no quedan identificados los rasgos básicos del argumento sujeto

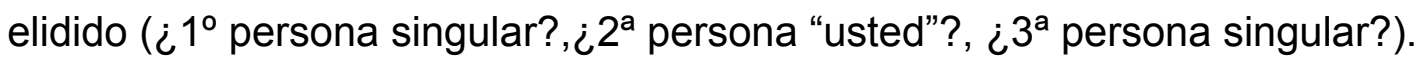

-Construcción gramatical.

-El antecedente es recuperable en el nivel oracional.

\section{Sintaxis del discurso}

Las virtualidades sobre la persona del argumento sujeto de "manifestaba" referidas en Sintaxis de la Lengua meta quedarían circunscriptas a la $1^{a}$ persona singular.

Es un discurso referido, en el que del verbo "manifestaba" dependen varias proposiciones completivas OD, las que, a su vez, presentan una estructura compleja con subordinaciones con sujetos indefinidos. La recuperación del SN sujeto de "manifestaba" es ambigua (yo, usted, libro) si bien en los párrafos anteriores el 
enunciador ya se ha manifestado en primera persona y el párrafo está iniciado por el conector de confirmación "También".

La elipsis de sujeto es un medio cohesivo muy utilizado en castellano, pero la recuperación transfrástica del antecedente no debe prestar a confusión, especialmente en los textos pragmáticos cuya función informativa es primordial.

Por ello, la reiteración total o parcial del referente en posición sujeto de "manifestaba" aumentaría la cohesión-coherencia, facilitando el pasaje de información.

\section{Comparación del binomio TO-TT}

TO. La palabra de apertura del discurso referido es el pronombre personal « Je», con lo cual se despeja cualquier ambigüedad.

TT. Ha conservado la progresión del discurso de partida, pero la ambigüedad está instaurada en el hecho de que flexión verbal no alcanza para recuperar naturalmente al referente.

\section{Mecanismos de producción}

Elevación de la frecuencia de uso de recursos o elementos, en nuestro caso la elipsis que está asociada a la ausencia léxica.

Descenso del control lingüístico-discursivo: producción automática de la elipsis.

\section{Resultado}

Visibilidad de interferencia del sistema lingüístico meta, es decir el castellano.

Elipsis de sujeto dentro del sistema con consecuencias discursivas.

Descenso de cohesión con consecuencias en la construcción de sentido. 
29

\begin{tabular}{|c|c|c|c|c|}
\hline Cap. & TT & $\mathrm{p} / \mathrm{r}$ & $\mathrm{TO}$ & $\mathrm{p} / \mathrm{r}$ \\
\hline 2 & $\begin{array}{l}\text { Es ese concepto de programa lo que } \\
\text { usted impugna formalmente; en efecto, } \\
\text { induce una mala representación de } \\
\text { nuestra existencia, de nuestro ser en } \\
\text { cuanto ser humano. }\end{array}$ & $\begin{array}{l}38 / \\
23\end{array}$ & $\begin{array}{l}\text { C'est ce concept de programme que vous } \\
\text { constatez formellement; il induit en effet une } \\
\text { fausse image, une mauvaise représentation } \\
\text { de notre existence, de notre être en tant } \\
\text { qu'être humain. }\end{array}$ & \begin{tabular}{|l|}
$46 /$ \\
5
\end{tabular} \\
\hline
\end{tabular}

\section{Sintaxis de la lengua meta}

“(...) en efecto, induce una mala representación de nuestra existencia (...)"

-Construcción verbal con elipsis nominal máxima (argumento externo o sujeto): [Ø] induce $(\ldots)$

-En la oración no quedan completamente identificados los rasgos básicos del argumentos sujeto ( $¿ 2^{\mathrm{a}}$ persona "usted"? $¿ 3^{\mathrm{a}}$ persona del singular?).

-Construcción gramatical.

-El antecedente es recuperable en el nivel oracional.

\section{Sintaxis del discurso}

Las virtualidades sobre la persona del argumento sujeto de "induce" referidas en Sintaxis de la lengua meta quedarían circunscriptas a la $3^{a}$ persona.

La recuperación del hueco es ambigua (SN objeto directo focalizado en cláusula hendida "concepto de programa" o SN sujeto "usted").

La función semántica agente es más prominente que la de instrumento, pero, en caso de duda, el contexto discursivo y situacional fija el valor léxico de la categoría elíptica. En este caso, la función semántica instrumento está focalizada, por lo tanto compiten dos antecedentes para ocupar la categoría elidida. Semánticamente, es el "programa" genético el que induce una mala representación de nuestra existencia y de nuestro ser humano, porque no puede explicar las conductas humanas. Estos conceptos están expresados en enunciados previos. 
Tal situación hace que convenga la presencia de un sujeto pleno de manera de cohesionar la información con respecto al referente de "induce" puesto que la ambigüedad influye negativamente en el pasaje de la información, función primordial de todo texto informativo.

\section{Comparación del binomio TO-TT}

TO. Comienza con la cláusula hendida frecuentemente utilizada como marca de oralidad. En la oración yuxtapuesta siguiente, el verbo « induit » está precedido por el pronombre personal « il » que refiere a « ce concept ».

TT. Utiliza una estructura análoga con cláusula hendida "Es ese concepto de programa lo que usted (...)", pero la flexión verbal no alcanza para recuperar claramente al referente.

\section{Mecanismos de producción}

Elevación de la frecuencia de uso de recursos o elementos, en nuestro caso la elipsis que está asociada a la ausencia léxica.

Descenso del control lingüístico-discursivo, debido al uso reiterado de elipsis en función sujeto, cuya traducción ha sido automática, en conformidad a la característica de la lengua de llegada.

\section{Resultado}

Visibilidad de interferencia del sistema lingüístico meta, es decir el castellano.

Visibilidad de interferencia del discurso de partida.

Elipsis de sujeto dentro del sistema con consecuencias discursivas.

Descenso de cohesión con consecuencias en la construcción de sentido.

Producción palimpséstica. 
30

\begin{tabular}{|l|l|l|l|l|}
\hline Cap. & \multicolumn{1}{|c|}{ TT } & p/r & \multicolumn{1}{|c|}{ TO } & p/r \\
\hline 3 & $\begin{array}{l}\text { Como usted afirmaba, hay un encuentro } \\
\text { entre un viejo fantasma colectivo y que es } \\
\text { posible comprender aunque fuera por } \\
\text { responsabilidad para con su niño (¿por } \\
\text { qué desear un niño que tenga un riesgo } \\
\text { de enfermarse si uno es capaz de } \\
\text { engendrar uno que tendría un riesgo } \\
\text { menor?), y la nueva tecnología. }\end{array}$ & & & $\begin{array}{l}\text { Comme vous le disiez, il y a une rencontre } \\
\text { entre un vieux fantasme collectif et que l'on } \\
\text { peut comprendre, ne serait-ce que par } \\
\text { responsabilité envers son enfant (pourquoi } \\
\text { souhaiter un enfant qui a un risque d'être } \\
\text { malade si l'on est capable d'en avoir un qui le } \\
\text { risquerait moins ?), et la technologie nouvelle. }\end{array}$ \\
\end{tabular}

\section{Sintaxis de la lengua meta}

“(...) aunque fuera por responsabilidad para con su niño (...)"

-Construcción prepositiva con elipsis nominal parcial (argumento de sustantivo): su niño [Ø].

-En la oración de base no quedan identificados los rasgos básicos del poseedor $\left(i 3^{a}\right.$ persona del singular género masculino? $3^{a}$ persona del singular género femenino?, $\iota^{\mathrm{a}}$ persona "usted", $3^{\mathrm{a}}$ persona plural?).

-Construcción gramatical

-El antecedente es recuperable en el nivel oracional.

\section{Sintaxis del discurso}

El posesivo tiene dos rasgos característicos: es determinante del sustantivo y también es pronombre. Dicho de otro modo, el posesivo constituye una proyección del pronombre y toma la posición de especificador, concordando con el número del núcleo del SN; por lo tanto en todo determinante posesivo hay presente una relación anafórica con el poseedor.

El posesivo antepuesto realiza la función semántica del argumento del nombre que corresponde al genitivo (poseedor, agente o tema) (Picallo y Rigau, 2000: 980).

La recuperación de un referente puede realizarse ya sea endofóricamente, por los mecanismos de anáfora (antecedente) o catáfora (consecuente), o bien en el 
contexto en que se produce el enunciado, donde el antecedente se interpreta deícticamente.

El género discursivo original fue la entrevista que ha sido transcripta en la publicación analizada, de allí que desaparezca el rasgo ostensión.

En el caso que se analiza, la recuperación del referente pronombre es endofórica pero débil puesto que la morfología del posesivo "su" remite tanto a la $3^{a}$ persona (él/ella y sus plurales) como a la $2^{a}$ (usted/es). Justamente, en la oración habría dos candidatos: "usted" en posición extraclausular y un indefinido borroso insinuado en "fantasma colectivo".

\section{Comparación del binomio TO-TT}

TO. Produce un enunciado con fuerte presencia de indeterminación: ocurrencias de « on », de artículo indeterminado " un », léxico « fantasme collectif ». El posesivo en tercera persona es apto para relacionarse con los indeterminados, de modo que el antecedente de la forma posesiva « son » es el sujeto indeterminado « on $»$.

TT. Produce un enunciado con presencia de formas impersonales e indeterminadas: ocurrencias de artículo indeterminado "un", léxico "fantasma colectivo", pronombre indefinido "uno (es capaz)". La morfología de "su" instaura ambigüedad; por otra parte, el adjetivo posesivo "su" no necesariamente entra en correlación con pronombres indefinidos (Alloa y Torres, 2001: 69-70); en su reemplazo, el castellano suele utilizar el artículo determinado.

\section{Mecanismos de producción}

Elevación de la frecuencia de uso de recursos o elementos, en nuestro caso la elipsis que está asociada a la ausencia léxica.

Descenso de control lingüístico-discursivo: el uso de posesivos "su/sus" repercute en la cohesión de la oración. Se ha realizado traducción automática, desde niveles bajos. 


\section{Resultado}

Visibilidad de interferencia del sistema lingüístico meta (uso de su/sus).

Visibilidad de interferencia del discurso de partida (votre/su).

Elipsis dentro del sistema con consecuencias discursivas: argumento de sustantivo.

Descenso de la cohesión con consecuencias en la búsqueda del referente.

Producción palimpséstica. 
31

\begin{tabular}{|c|c|c|c|c|}
\hline Cap. & TT & $\mathrm{p} / \mathrm{r}$ & TO & $\mathrm{p} / \mathrm{r}$ \\
\hline 3 & $\begin{array}{l}\text { Pero a ese fatalismo se agrega } \\
\text { contradictoriamente una especie de } \\
\text { sueño voluntarista que descansa en la } \\
\text { idea (que es una loca esperanza) de que } \\
\text { podría gobernarse a los genes e incluso } \\
\text { (en un trivial sentido comercial) encargar } \\
\text { genes. }\end{array}$ & $\begin{array}{l}55 / \\
17\end{array}$ & $\begin{array}{l}\text { Or à ce fatalisme s'adjoint contradictoirement } \\
\text { une espèce de rêve volontariste reposant sur } \\
\text { l'idée (qui est une folle espérance) que l'on } \\
\text { pourrait commander aux gènes et même (en } \\
\text { un sens trivial commercial) commander des } \\
\text { gènes. }\end{array}$ & $\begin{array}{l}671 \\
4\end{array}$ \\
\hline
\end{tabular}

\section{Sintaxis de la lengua meta}

"(...) la idea (que es una loca esperanza) de que podría gobernarse a los genes e incluso (en un trivial sentido comercial) encargar genes."

-Construcción coordinada cuyo segundo miembro produce elipsis del verbo modal y elipsis nominal máxima (argumento externo o sujeto): podría gobernarse a los genes e incluso (...) [Ø] encargar genes.

-En la oración de base no quedan identificados los criterios paralelísticos.

-Construcción con anomalía sintáctica.

-El antecedente es recuperable en el nivel oracional.

\section{Sintaxis del discurso}

La coordinación está incluida en una conjuntiva tradicionalmente llamada completiva "la idea (...) de que (...)". En el primer miembro de la coordinación, el infinitivo "gobernar" incluye la partícula clítica polifuncional "se".

Al respecto, Di Tullio (1997: 178) observa que la forma "se" instaura ambigüedad de análisis cuando el verbo está en singular, según la función que se le atribuya al SN: si se lo toma con función sujeto, "se" + verbo conforman pasivas pronominales; en cambio, si el SN es analizado como OD, el "se" es impersonal. Sin embargo, como el SN OD "a los genes" está introducido por la preposición "a", no puede transformarse en sujeto de pasiva pronominal, por lo tanto la partícula "se" es impersonal. 
El análisis es distinto en el segundo miembro: el SN plural está en posición pospuesta al verbo, introducido directamente, sin preposición ni determinante. En cuanto a la concordancia del verbo modal poder elidido, hay divergencia de opiniones: María Luisa Olsen y Alicia María Zorrilla (1997: 934) consideran que en la pasiva refleja con se, el auxiliar modal seguido de infinitivo con complemento directo debe concordar con el número del objeto directo. En cambio, Amaya Mendikoetxea (2000: 1711) sostiene que si bien en una construcción con se pasivo el verbo modal generalmente concuerda con el objeto nocional del verbo infinitivo, al mismo tiempo propone una doble estructura sintáctica con y sin concordancia.

La coordinación es una relación simétrica apta para la elipsis, a diferencia de la subordinación que es asimétrica. Una condición fundamental para lograr una elipsis es el paralelismo estricto entre sintagma con núcleo elidido y sintagma que contiene el antecedente: ambos deben contener los mismos especificadotes, complementos y adjuntos del núcleo. Los que tengan valor coincidente forman el hueco y el resto está integrado por unidades que adoptan valores distintos a los de la oración que contiene el antecedente (Brucart, 2000: 2807). Dentro del concepto amplio de elipsis, la reducción de sintagma verbal coordinado es el mecanismo que afecta al verbo y al sujeto en las estructuras coordinadas [Capítulo IV, Elipsis. 4.5.].

En este caso, el hueco está constituido por el modal "podría" y el incremento pronominal "se", siendo el resto "encargar genes" en el segundo miembro de la coordinada que no tiene la misma estructura -ausencia de determinante y de preposición- del primer miembro de la coordinación "a los genes"; es decir, no hay paralelismo entre los miembros de la coordinación.

\section{Comparación del binomio TO-TT}

El TO utiliza el sujeto indefinido " on » + verbo modal « pourrait » + infinitivo, + SP $(\grave{a}+l e s=a u x)+$ gènes coordinado al segundo verbo infinitivo con elipsis del modal y del sujeto indefinido pero con la presencia del infinitivo "commander" seguido del determinante " des ». Es decir, utiliza los dos regímenes aptos par el mismo verbo « commander » indirecto (aux gènes) y directo (des gènes), y obtiene una expresión simétrica y cohesiva. 
El TT presenta una estructura análoga a la del TO, con el auxiliar modal podría + el infinitivo "gobernar" incrementado con la partícula "se", como equivalencia del pronombre indefinido o arreferencial « on » + SN OD con preposición "a los genes". Sigue la coordinación "e incluso" como equivalencia de « et même » + el segundo verbo infinitivo "encargar" con elipsis del auxiliar modal + OD "genes", sin determinante, como traducción automática del indeterminado " des ». A diferencia del TO, el TT no puede obtener un verbo como « commander », con los dos significados según el régimen directo o indirecto. El TT obtiene dos formas equivalentes a los significados evocados por el TO pero sin hacer las transformaciones sintácticas necesarias para su funcionamiento en el texto de llegada.

\section{Mecanismos de producción}

Elevación de la frecuencia de uso de recursos o elementos, en nuestro caso la elipsis que está asociada a la ausencia léxica.

Descenso del control lingüístico: El sistema francés ofrece el verbo « commander à » $\mathrm{y}$ " commander ॥ que pueden corresponden en castellano a "gobernar" y "encargar", con las transformaciones sintácticas que la producción necesite. La forma plural de los artículos indeterminados en francés es « des »= "unas", "unos" en castellano. El uso difiere: en francés, generalmente, los núcleos están determinados, mientras que el castellano admite más frecuentemente formas nominales sin determinantes -especialmente los indeterminados-, al menos en la variante rioplatense.

Descenso del control lingüístico-discursivo: traducción automática, puesto que no se han generado las transformaciones correspondientes al cambio de verbo "gobernarse", "encargar", ni tampoco evaluado las consecuencias de la ausencia del indeterminado "unas", "unos" o la posibilidad de su reemplazo por el determinado "los".

\section{Resultado}

Visibilidad de interferencia de la lengua de partida (on ). 
Visibilidad de interferencia del discurso de partida (commander aux/ commander des).

Falsa elipsis fuera del sistema con consecuencias discursivas: argumento externo o sujeto elipsis que se pone en evidencia al comparar el TT con el TO. Inexistencia de paralelismo.

Descenso de cohesión con consecuencias discursivas.

Producción palimpséstica. 


\begin{tabular}{|c|c|c|c|c|}
\hline Cap. & TT & $\mathrm{p} / \mathrm{r}$ & TO & $\mathrm{p} / \mathrm{r}$ \\
\hline 3 & $\begin{array}{l}\text { El aspecto más alienante de la donación } \\
\text { de gametos, dice, usted, no es que el } \\
\text { padre genético no sea el padre social, ni } \\
\text { siquiera el secreto a menudo vinculado } \\
\text { con ese origen atípico, puesto que } \\
\text { muchos niños del adulterio pudieron vivir } \\
\text { felices en todas las épocas. Por lo menos } \\
\text { en Francia, radica en la prohibición legal } \\
\text { de decidir y de saber, porque únicamente } \\
\text { la institución médica se arroga la elección } \\
\text { de un progenitor y es la única poseedora } \\
\text { de tal secreto. }\end{array}$ & $\begin{array}{l}59 / \\
6\end{array}$ & $\begin{array}{l}\text { L'aspect le plus aliénant du don de gamètes, } \\
\text { dites-vous, n'est pas que le père génétique ne } \\
\text { soit pas le père social, il n'est même pas le } \\
\text { secret souvent attaché à cette origine } \\
\text { atypique puisque nombreux enfants de } \\
\text { l'adultère ont pu vivre heureux à toutes les } \\
\text { époques. Il tient, du moins en France, à } \\
\text { l'interdiction légale de décider et de savoir, } \\
\text { car l'institution médicale s'arroge seule le } \\
\text { choix d'un géniteur et demeure seule } \\
\text { détentrice de ce secret. }\end{array}$ & $\begin{array}{l}72 / \\
1\end{array}$ \\
\hline
\end{tabular}

\section{Sintaxis de la lengua meta}

"Por lo menos en Francia, radica en la prohibición legal de decidir y de saber, porque únicamente la institución médica se arroga la elección de un progenitor y es la única poseedora de tal secreto."

-Construcción verbal con elipsis nominal máxima (argumento externo o sujeto): [Ø] radica en la prohibición legal de decidir y de saber.

-En la oración con elipsis quedan identificados los rasgos básicos del argumento sujeto elidido ( $3^{\mathrm{a}}$ persona singular).

-Construcción gramatical.

-El antecedente no es recuperable en el nivel oracional.

\section{Sintaxis del discurso}

EI SN sujeto recuperable está presente en un discurso referido "El aspecto más alienante de la donación de gametos" que abre la oración precedente a la que contiene la elipsis y está construida por una serie de secuencias negativas "no es", "no sea", "ni siquiera" y subordinadas "no es que", "puesto que" que complican la sintaxis.

La oración que contiene la elipsis de sujeto se inicia con el reformulador de distanciamiento "Por lo menos" cuya función es negar la pertinencia de lo dicho anteriormente (Alloa y Torres, 2001: 327). 
La elipsis de sujeto es un medio cohesivo muy utilizado en castellano, pero la recuperación transfrástica del antecedente no debe prestar a confusión, especialmente en los textos pragmáticos cuya función informativa es primordial.

Por ello, la reiteración total o parcial del referente en posición sujeto de "radica" aumentaría la cohesión-coherencia, facilitando el pasaje de información.

\section{Comparación del binomio TO-TT}

TO. Produce un discurso referido iniciado en el enunciado anterior con el sujeto «L'aspect le plus aliénant du don de gamètes », construido por una serie de secuencias negativas " n'est pas », " ne soit pas » " il n'est même pas » y subordinadas «n'est pas que », "puisque ».

Sigue luego el enunciado que se inicia con la posición sujeto ocupada y remitiendo al comienzo del enunciado anterior " II tient » y el reformulador de distanciamiento « du moins en France » cuya función es negar la pertinencia de lo dicho anteriormente (Alloa y Torres, 2001: 327).

TT. Produce una equivalencia de la expresión « II tient » > "radica", pero un pronombre anafórico o la reiteración léxica total o parcial del referente contribuiría al pasaje de la información.

\section{Mecanismos de producción}

Elevación de la frecuencia de uso de recursos o elementos, en nuestro caso la elipsis que está asociada a la ausencia léxica.

Descenso del control lingüístico-discursivo, debido al uso reiterado de elipsis en función sujeto, cuya traducción ha sido automática, en conformidad con la característica de la lengua de llegada.

\section{Resultado}

Visibilidad de interferencia del sistema lingüístico meta, es decir el castellano.

Visibilidad de interferencia del discurso de partida. 
Elipsis de sujeto dentro del sistema con consecuencias discursivas.

Descenso de la cohesión con repercusión en la construcción de sentido.

Producción palimpséstica. 


\begin{tabular}{|c|c|c|c|c|}
\hline Cap. & TT & $\mathrm{p} / \mathrm{r}$ & TO & $\mathrm{p} / \mathrm{r}$ \\
\hline 3 & $\begin{array}{l}\text { El enemigo se aloja en el corazón } \\
\text { invisible del cuerpo, y como éste apareció } \\
\text { en el momento del acto sexual de los } \\
\text { padres, induce la noción de una falta } \\
\text { primordial, de un pecado original, que no } \\
\text { está ligado solamente, como se podría } \\
\text { pensar, a la creencia cristiana. }\end{array}$ & $\begin{array}{l}68 / \\
8\end{array}$ & $\begin{array}{l}\text { L'ennemi loge au coeur invisible du corps et } \\
\text { comme il est apparu au moment de l'acte } \\
\text { sexuel des parents, il induit la notion d'une } \\
\text { faute primordiale, d'un péché originel, qui } \\
\text { n'est pas seulement liée, comme on pourrait } \\
\text { le penser, à la croyance chrétienne. }\end{array}$ & $\begin{array}{l}84 / \\
4\end{array}$ \\
\hline
\end{tabular}

\section{Sintaxis de la lengua meta}

"El enemigo se aloja en el corazón invisible del cuerpo, y como éste apareció en el momento del acto sexual de los padres, induce la noción de una falta primordial, de un pecado original, que no está ligado solamente, como se podría pensar, a la creencia cristiana."

-Construcción verbal con elipsis nominal máxima (argumento externo o sujeto): [Ø] induce.

-En la oración no quedan completamente identificados ( $¿ 2^{\circ}$ persona "usted"?, ¿ $3^{\circ}$ persona?) los rasgos básicos del argumento sujeto.

-Construcción gramatical.

-El antecedente es recuperable en el nivel oracional.

\section{Sintaxis del discurso}

Las virtualidades sobre la persona de los argumentos sujeto de "induce" que se refieren en Sintaxis de la Lengua meta quedan circunscriptas a la tercera persona, puesto que antecedentes posibles son "El enemigo" o "cuerpo".

La recuperación del valor léxico del hueco es ambigua puesto que puede remitir al sujeto "El enemigo" o bien a "el cuerpo", debido a la aparición del demostrativo "éste".

La función semántica agente es más prominente que la de instrumento, pero en el caso que nos ocupa, el demostrativo "éste" está remitiendo -aparentemente- al 
elemento más cercano, es decir el instrumento "cuerpo". Si se hubiera utilizado el demostrativo "aquél" el referente indiscutible remitiría a "El enemigo", por lo tanto la relación entre el antecedente y la categoría elidida es borrosa.

La elipsis de sujeto es un medio cohesivo muy utilizado en castellano, pero la recuperación del antecedente no deber prestar a confusión, especialmente en los textos pragmáticos cuya función informativa es primordial.

Tal situación hace que convenga llenar la posición sujeto con algún medio cohesivo, ya sea reiteración léxica o elemento gramatical, por ejemplo pronombre demostrativo adecuado al contexto.

\section{Comparación del binomio TO-TT}

TO. La progresión temática se ha realizado a través de la repetición del pronombre personal función sujeto «il» que remite naturalmente al SN sujeto « L'ennemi », por lo tanto no ofrece ambigüedades.

TT. Utiliza una estructura análoga a la del TO, con la salvedad de que ha elegido el demostrativo "éste", en la primera ocurrencia del pronombre personal función sujeto « il » y utiliza elipsis en la segunda ocurrencia de « il », con la confusión referencial señalada en Sintaxis del discurso.

La flexión verbal no alcanza para recuperar claramente al referente, con la consiguiente entropía informativa.

\section{Mecanismos de producción}

Elevación de la frecuencia de uso de recursos o elementos, en nuestro caso la elipsis que está asociada a la ausencia léxica.

Descenso del control lingüístico-discursivo: producción automática de la elipsis.

\section{Resultado}

Visibilidad de interferencia del sistema lingüístico meta, es decir el castellano.

Elipsis de sujeto dentro del sistema con consecuencias discursivas.

Descenso de la cohesión con repercusión en la construcción del discurso. 
34

\begin{tabular}{|c|c|c|c|c|}
\hline Cap. & TT & $\mathrm{p} / \mathrm{r}$ & TO & $\mathrm{p} / \mathrm{r}$ \\
\hline 3 & $\begin{array}{l}\text { Si le dicen que tiene un } 52,8 \% \text { de riesgos } \\
\text { de tener un cáncer de pulmón a los } 63 \\
\text { años y medio porque lleva tal o cual vida, } \\
\text { eso es estadísticamente cierto, pero no } \\
\text { es lo que le interesa; lo que sí le interesa } \\
\text { es saber si va o no a padecer de ese } \\
\text { cáncer, y eso nadie puede decírselo. }\end{array}$ & $\begin{array}{l}71 / \\
12\end{array}$ & $\begin{array}{l}\text { Si on vous dit que vous avez } 52,8 \% \text { de } \\
\text { risques d'avoir un cancer du poumon à } 63 \text { ans } \\
\text { et demi parce que vous menez telle ou telle } \\
\text { vie, c'est statistiquement vrai, mais cela ne } \\
\text { vous intéresse pas, ce qui vous intéresse, } \\
\text { c'est de savoir si vous allez ou non souffrir de } \\
\text { ce cancer, et cela personne ne peut vous le } \\
\text { dire. }\end{array}$ & $\begin{array}{l}881 \\
7\end{array}$ \\
\hline
\end{tabular}

\section{Sintaxis de la lengua meta}

"Si le dicen que tiene (...) pero no es lo que le interesa; lo que sí le interesa es saber si va o no a padecer de ese cáncer, y eso nadie puede decírselo."

-Construcciones verbales indefinidas con elipsis nominal máxima (argumento interno OI): le dicen [Ø], lo que le interesa [Ø], lo que sí le interesa [Ø], decírselo [Ø].

-En la oración no quedan completamente identificados ( $2^{\circ}$ persona "a usted"?, ¿ $3^{\circ}$ persona singular "a alguien"?) los rasgos básicos del argumento sujeto.

-Construcciones gramaticales.

-El antecedente no es recuperable en el nivel oracional.

\section{Sintaxis del discurso}

Las construcciones indefinidas recorren todo el enunciado oración que presenta una subordinada condicional, en cuya prótasis aparece "le dicen". Sigue a la apódosis la conjunción contraargumentativa "pero" con orden marcado "pero no es lo que le interesa"; una oración predicativa cuyo sujeto es "lo que sí le interesa" y por último la oración con auxiliar modal "eso nadie puede decírselo".

La recuperabilidad endofórica es transfrástica y remite a la oración inmediatamente anterior "La probabilidad tiene sentido para una población, pero no para un individuo".

Es un enunciado que generaliza una información, para lo cual se ha utilizado el pronombre dativo "le" de tercera persona del singular y su alomorfo "se". Estas 
formas podrían corresponder a la segunda persona "usted", con un valor de generalización análogo (Alloa y Torres, 2001: 107).

\section{Comparación del binomio TO-TT}

TO. Produce una forma del discurso coloquial que combina « on » de referencia inespecífica + el pronombre deíctico "vous », OI, en cuya referencia quedan incluidos el enunciador y el coenunciador (Alloa y Torres, 2001: 102). Una referencia similar, pero en forma negativa, aparece en "personne ne peut vous le dire ». EI TO ha mantenido la referencia con el pronombre dativo «vous» (cela ne vous intéresse pas, ce qui vous intéresse).

TT. Produce una forma híbrida entre "usted" y "alguien", pero sin incidencia en la transmisión de la información. Solamente al comparar el TO y el TT, puede advertirse la diferencia.

De todos modos, habría mayor cohesión si apareciera el pronombre indefinido "Si a alguien le dicen" o incluyendo al enunciador y el coenunciador "si a uno le dicen" que remitiría anafóricamente a la oración contigua, o bien una producción nueva, deíctica con la utilización de "usted".

\section{Mecanismos de producción}

Elevación de la frecuencia de uso de recursos o elementos, en nuestro caso la elipsis que está asociada a la ausencia léxica.

Descenso de control lingüístico-discursivo: traducción automática desde niveles bajos.

\section{Resultado.}

Visibilidad de interferencia del discurso original.

Elipsis de objeto indirecto dentro del sistema con consecuencias discursivas.

Descenso de la cohesión con repercusión en la construcción de sentido.

Producción palimpséstica. 


\begin{tabular}{|c|c|c|c|c|}
\hline Cap. & TT & $\mathrm{p} / \mathrm{r}$ & TO & $\mathrm{p} / \mathrm{r}$ \\
\hline 3 & $\begin{array}{l}\text { Así, usted evoca este caso típico: cuando } \\
\text { se entera de que el } 75 \% \text { de los pacientes } \\
\text { aquejados de tal enfermedad se cura, la } \\
\text { mayoría de la gente piensa que, si } \\
\text { contrae dicha enfermedad tendrá tres } \\
\text { posibilidades sobre cuatro de zafar. }\end{array}$ & $\begin{array}{l}72 / \\
8\end{array}$ & $\begin{array}{l}\text { Ainsi vous évoquez ce cas d'école : lorsqu'ils } \\
\text { apprennent que } 75 \% \text { des patients atteints de } \\
\text { telle maladie guérissent, la plupart des gens } \\
\text { pensent que s'ils sont personnellement } \\
\text { frappés par cette maladie, ils auront trois } \\
\text { chances sur quatre de s'en sortir. }\end{array}$ & $\begin{array}{l}89 / \\
11\end{array}$ \\
\hline
\end{tabular}

\section{Sintaxis de la lengua meta}

“(...) cuando se entera de que el $75 \%$ de los pacientes aquejados de tal enfermedad se cura, la mayoría de la gente piensa que (...)"

-Proposición subordinada conjuntiva temporal con elipsis nominal máxima (argumento externo o sujeto): [Ø] se entera.

-En la oración no quedan completamente identificados ( $¿ 2^{\circ}$ persona "usted"?, $¿ 3^{\circ}$ persona singular?) los rasgos básicos del argumento sujeto.

-Construcción gramatical.

-El antecedente es recuperable en el nivel oracional.

\section{Sintaxis del discurso}

Las virtualidades sobre la persona del argumento sujeto de "se entera" que se refieren en Sintaxis de la lengua meta no quedan claramente circunscriptas en el discurso.

La recuperación del valor léxico del hueco es ambigua puesto que puede remitir anafóricamente al sujeto de la primera oración "usted" o bien catafóricamente "la gente". En principio, la relación anafórica es más frecuente que la catafórica, por lo tanto remitiría a "usted".

La elipsis de sujeto es un medio cohesivo muy utilizado en castellano, pero la recuperación del antecedente no debe prestar a confusión, especialmente en los textos pragmáticos cuya función informativa es primordial. 
Tal situación hace que convenga llenar la posición sujeto con algún medio cohesivo, ya sea reiteración léxica o elemento gramatical, por ejemplo pronombre indefinido.

\section{Comparación del binomio TO-TT}

TO. En el discurso referido, la subordinada temporal tiene su posición sujeto ocupada con el pronombre personal "ils " de valor indefinido que remite catafóricamente al SN sujeto « des gens », puesto que es una palabra que responde al género masculino plural. ${ }^{5}$

TT. No resuelve el problema planteado por el TO. El TT ha utilizado el incremento pronominal "se" que funciona como reflexivo y debería ocupar la posición sujeto con una forma indefinida (la gente, uno) o haber utilizado el verbo en la $3^{a}$ persona del plural (se enteran).

\section{Mecanismos de producción}

Elevación de la frecuencia de uso de recursos o elementos, en nuestro caso la elipsis que está asociada a la ausencia léxica.

Descenso del control lingüístico: producción de sujetos indefinidos.

Descenso del control lingüístico-discursivo: producción automática de la elipsis.

\section{Resultado}

Visibilidad de interferencia del sistema lingüístico meta, es decir el castellano.

Elipsis de sujeto dentro del sistema con consecuencias discursivas.

Descenso de la cohesión con repercusión en la construcción de sentido.

\footnotetext{
${ }^{5}$ Gens es una palabra de género masculino, pero si está precedida de adjetivos, éstos toman el plural femenino. "Ces vieilles gens sont ennuyeux. » (Petit Robert)
} 
36

\begin{tabular}{|c|c|c|c|c|}
\hline Cap. & TT & $\mathrm{p} / \mathrm{r}$ & TO & $\mathrm{p} / \mathrm{r}$ \\
\hline 3 & $\begin{array}{l}\text { Tomado en su obsesión de dominio de la } \\
\text { reproducción, ¿no está el "Hombre" en } \\
\text { vías de convertirse en el otro nombre de } \\
\text { la Madre fálica y omnipotente, imaginada } \\
\text { por el niñito que, como la niña, no pudo } \\
\text { relativizar luego, mediante la } \\
\text { identificación con la madre, la amenaza } \\
\text { que representa en el plano fantasmático } \\
\text { para la afirmación de su identidad? }\end{array}$ & $\begin{array}{l}73 / \\
18\end{array}$ & $\begin{array}{l}\text { Pris dans son obsession de maîtrise de la } \\
\text { reproduction, “l'Homme” n'est-il pas en train } \\
\text { de devenir l'autre nom de la Mère phallique et } \\
\text { toute-puissante, imaginée para le petit garçon } \\
\text { qui n'a pu, comme la fille, relativiser ensuite, } \\
\text { par l'identification à la mère, la menace qu'elle } \\
\text { représente sur le plan fantasmatique pour } \\
\text { l'affirmation de son identité? }\end{array}$ & $\begin{array}{l}91 / \\
8\end{array}$ \\
\hline
\end{tabular}

\section{Sintaxis de la lengua meta}

“ ¿(...) la amenaza que representa en el plano fantasmático para la afirmación de su identidad?"

-Proposición subordinada relativa con elipsis nominal máxima (argumento externo o sujeto): la amenaza que [Ø] representa.

-En la oración no quedan completamente identificados los rasgos básicos del argumentos sujeto ( $¿ 2^{\mathrm{a}}$ persona "usted"? $¿ 3^{\mathrm{a}}$ persona del singular?).

-Construcción gramatical.

-El antecedente es recuperable en el nivel oracional.

\section{Sintaxis del discurso}

Las virtualidades sobre la persona del argumento sujeto de "representa" que se refieren en Sintaxis de la Lengua meta quedan circunscriptas a la $3^{\text {a }}$ persona singular femenino o masculino.

La recuperación del valor léxico del hueco es borrosa puesto que puede confundir el referente anafórico porque el párrafo en cuestión contiene varios elementos lexicales ("Hombre", "niñito", "niña”, "Madre fálica y omnipotente", "identificación con la madre") referentes potenciales, pues reúnen los rasgos gramaticales de la $3^{\mathrm{a}}$ persona del singular.

Hemos señalado que el valor léxico de la elipsis debe aparecer en el discurso inmediatamente previo, siempre que no haya ningún otro antecedente más 
adecuado. En el caso del argumento sujeto, la función semántica agente es más prominente que la de instrumento, pero, en caso de duda, el contexto discursivo y situacional fija el valor léxico de la categoría elíptica.

El problema aparece dentro de una interrogación retórica iniciada por el verbo cópula "está" en forma negativa, que pone en espejo la designación "Hombre" con la de "Madre fálica y omnipotente". De esta manera los dos referentes quedan reducidos a uno solo por razones de identidad. Sigue luego una forma pasiva "imaginada por el niño", es decir que de las dos designaciones anteriores, se ha elegido la forma femenina que remite a "Madre fálica y omnipotente". Luego una relativa determinativa "que no pudo relativizar la amenaza que representa en el plano fantasmático para la afirmación de su identidad." En esta simplificación hemos dejado de lado la comparación "como la niña" y el adjunto de medio "mediante la identificación con la madre", con la finalidad de circunscribir el antecedente a "Madre fálica y omnipotente".

La elipsis de sujeto es un medio cohesivo muy utilizado en castellano, pero la recuperación del antecedente no debe prestar a confusión, especialmente en los textos pragmáticos cuya función informativa es primordial.

La complejidad de la sintaxis de este enunciado hace que convenga llenar la posición sujeto con algún medio cohesivo, ya sea reiteración léxica o elemento gramatical, por ejemplo pronombre demostrativo.

\section{Comparación del binomio TO-TT}

TO. La sintaxis es compleja pero la progresión temática se ha realizado a través del pronombre « elle » que remite anfóricamente al referente más cercano « Mère phallique et toute-puissante ».

TT. Por lo visto en Sintaxis del discurso, la flexión verbal no es suficiente para recuperar al referente y la ambigüedad se reduciría con la ocurrencia de un medio cohesivo que no implique ausencia léxica, como la elipsis. 


\section{Mecanismos de producción}

Elevación de la frecuencia de uso de recursos o elementos, en nuestro caso la elipsis que está asociada a la ausencia léxica.

Descenso del control lingüístico-discursivo: producción automática de la elipsis.

\section{Resultado}

Visibilidad de interferencia del sistema lingüístico meta, es decir el castellano.

Elipsis de sujeto dentro del sistema con consecuencias discursiva.

Descenso de la cohesión con repercusión en la construcción de sentido. 


\section{7}

\begin{tabular}{|c|c|c|c|c|}
\hline Cap. & TT & $p / r$ & TO & $\mathrm{p} / \mathrm{r}$ \\
\hline 3 & $\begin{array}{l}\text { Hannah Arendt había dado a la natalidad } \\
\text { un sentido diferente del de la demografía: } \\
\text { para cada ser humano, la posibilidad del } \\
\text { nacimiento es la apertura hacia algo } \\
\text { nuevo, un comienzo absoluto. } \\
\text { Retomando ese concepto de su amiga, } \\
\text { Hans Jonas había visto en la clonación } \\
\text { ese monstruoso peligro: al determinar de } \\
\text { antemano una natalidad, ya que el azar } \\
\text { sería suprimido, privaría al individuo de } \\
\text { esa natalidad inseparable de su libertad. }\end{array}$ & $\begin{array}{l}82 / \\
14\end{array}$ & $\begin{array}{l}\text { Hannah Arendt avait donné à la natalité un } \\
\text { sens différent de celui de la démographie: la } \\
\text { possibilité de la naissance est, pour chaque } \\
\text { être humain, l'ouverture vers quelque chose } \\
\text { de nouveau, un commencement absolu. } \\
\text { Reprenant ce concept de son amie, Hans } \\
\text { Jonas avait vu dans le clonage ce monstrueux } \\
\text { danger: déterminant à l'avance une nature, } \\
\text { puisque le hasard serait supprimé, il priverait } \\
\text { l'individu de cette natalité inséparable de sa } \\
\text { liberté. }\end{array}$ & $\begin{array}{l}102 \\
/ 17\end{array}$ \\
\hline
\end{tabular}

\section{Sintaxis de la lengua meta}

“(...) al determinar de antemano una natalidad, ya que el azar sería suprimido, privaría al individuo de esa natalidad inseparable de su libertad."

-Construcción verbal con elipsis nominal máxima (argumento externo o sujeto): [Ø] privaría.

-En la oración no quedan completamente identificados ( $i^{\mathrm{a}}$ persona singular?, ¿ $2^{\mathrm{a}}$ persona "usted"?, ¿ $3^{a}$ persona singular?) los rasgos básicos del argumento sujeto.

-Construcción gramatical.

-El antecedente es recuperable semánticamente en el nivel oracional.

\section{Sintaxis del discurso}

Las virtualidades sobre la persona del argumento sujeto de "privaría" que se refieren en Sintaxis de la lengua meta quedan circunscriptas a la $3^{a}$ persona.

El lugar sujeto no ha sido ocupado, pudiendo entenderse como una elipsis que endofóricamente remite al antecedente SP (en la clonación) + SN OD (ese monstruoso peligro), o bien como un vacío que tendría que llenarse con una forma de valor semántico-referencial indeterminada (se privaría).

Tal situación hace que convenga llenar la posición sujeto con algún medio cohesivo, como la reiteración léxica total o parcial. 


\section{Comparación del binomio TO-TT}

TO. La posición sujeto está ocupada por el pronombre « il » que remite al valor léxico en « dans le clonage ce monstrueux danger ».

TT. Sigue la estructura del TO pero recurre automáticamente a la supresión del sujeto con el consiguiente descenso cohesivo.

\section{Mecanismos de producción}

Elevación de la frecuencia de uso de recursos o elementos, en nuestro caso la elipsis que está asociada a la ausencia léxica.

Descenso del control lingüístico-discursivo: producción automática de la elipsis.

\section{Resultado}

Visibilidad de interferencia del sistema lingüístico meta, es decir el castellano.

Elipsis de sujeto dentro del sistema con consecuencias discursivas.

Descenso de la cohesión con repercusión en la construcción de sentido. 
38

\begin{tabular}{|l|l|l|l|l|}
\hline Cap. & \multicolumn{1}{|c|}{ TT } & p/r & TO & p/r \\
\hline 4 & $\begin{array}{l}\text { Sin embargo, desde que existe, ¿qué } \\
\text { impidió hacer la bioética? }\end{array}$ & $\begin{array}{l}99 / \\
18\end{array}$ & $\begin{array}{l}\text { Or, qu'est-ce que la bioéthique, depuis qu'elle } \\
\text { existe, a réussi à empêcher de faire? }\end{array}$ & $\begin{array}{l}125 \\
/ 16\end{array}$ \\
\hline
\end{tabular}

\section{Sintaxis de la lengua meta}

"Sin embargo, desde que existe, ¿qué impidió hacer la bioética?"

-Proposición subordinada temporal con elipsis nominal máxima (argumento externo o sujeto): desde que [Ø] existe, ¿qué [Ø] impidió hacer la bioética?

-En la oración no quedan completamente identificados ( $¿ 2^{a}$ persona "usted"?, $¿ 3^{a}$ persona singular?) los rasgos básicos del argumento sujeto.

-Construcción gramatical.

-El consecuente es recuperable semánticamente en el nivel oracional.

\section{Sintaxis del discurso}

Las virtualidades sobre la persona del argumento sujeto de "existe" que se refieren en Sintaxis de la lengua meta quedan circunscriptas a la $3^{\mathrm{a}}$ persona.

El lugar sujeto no ha sido ocupado; por otro lado, la catáfora, sólo remite a un consecuente que esté dentro de la misma oración, cuya estructura preferencial es predicativa o atributiva $[\rightarrow$ Capítulo IV, Elipsis].

Además, y especialmente, en la interrogación "¿qué impidió hacer la bioética?", hay ambigüedad sobre la función de "la bioética": ¿sujeto u objeto directo? De esto se desprende, la necesidad de la presencia del sujeto pleno "la bioética" que fortalecerá la relación cohesión-coherencia para el pasaje de la información.

\section{Comparación del binomio TO-TT}

TO. « Or, qu'est-ce que la bioéthique, depuis qu'elle existe " produce el sujeto completo, que luego retoma con el pronombre sujeto " elle ", cohesionando la información. 
TT. Presenta una cohesión débil que instaura ambigüedad: no utiliza sujeto pleno recurriendo a la característica del castellano como lengua pro-drop.

Por otra parte, no ha producido la idea de "logro" que está dada por el verbo « réussir ".

\section{Mecanismos de producción}

Elevación de la frecuencia de uso de recursos o elementos, en nuestro caso la elipsis que está asociada a la ausencia léxica.

Descenso de control lingüístico: sesgo entre gramática y semántica que acarrea ambigüedad sobre la función sujeto u objeto directo; además, está ausente la noción equivalente a « réussir ».

Descenso del control lingüístico-discursivo por producción automática de dos elipsis.

\section{Resultado}

Visibilidad de interferencia del sistema lingüístico meta, es decir el castellano.

Elipsis con consecuencias discursivas: argumento externo o sujeto.

Descenso de cohesión con repercusión en la construcción de sentido.

Incumplimiento del precepto traducir toda la información con la consiguiente entropía informativa. 
39

\begin{tabular}{|c|c|c|c|c|}
\hline Cap. & TT & $\mathrm{p} / \mathrm{r}$ & TO & $\mathrm{p} / \mathrm{r}$ \\
\hline 4 & $\begin{array}{l}\text { El lector tiene la sensación de que usted } \\
\text { se refugia en una posición que es la del } \\
\text { sabio individualista aislado en una } \\
\text { sociedad que se acerca a una especie de } \\
\text { abismo; se pregunta, por último, para } \\
\text { retomar esas dos imágenes de sabiduría } \\
\text { que la China tradicional nos legó, si no } \\
\text { está usted constantemente } \\
\text { balanceándose entre el sabio taoísta que } \\
\text { meditaba solo ante su gruta y el sabio } \\
\text { confuciano, que a pesar de todo querría } \\
\text { implicarse en los asuntos públicos. }\end{array}$ & $\begin{array}{l}116 \\
/ 11\end{array}$ & $\begin{array}{l}\text { Il a l'impression que vous vous réfugiez dans } \\
\text { une position qui est celle du sage } \\
\text { individualiste isolé dans une société qui } \\
\text { s'approche à une espèce d'abîme et il se } \\
\text { demande finalement, pour reprendre ces deux } \\
\text { images de sagesse que la Chine traditionnelle } \\
\text { nous a léguées, si vous n'êtes pas } \\
\text { constamment en train de balancer entre le } \\
\text { sage taoïste qui méditait tout seul devant sa } \\
\text { grotte, et le sage confucéen, qui voudrait } \\
\text { malgré tout s'impliquer dans les affaires } \\
\text { publiques. }\end{array}$ & $\begin{array}{l}148 \\
12\end{array}$ \\
\hline
\end{tabular}

\section{Sintaxis de la lengua meta}

“(...) se pregunta, por último, para retomar esas dos imágenes de sabiduría que la China tradicional nos legó, si no está usted constantemente balanceándose entre el sabio taoísta que meditaba solo ante su gruta y el sabio confuciano, que a pesar de todo querría implicarse en los asuntos públicos."

-Construcción verbal con elipsis nominal máxima (argumento externo o sujeto): [Ø] se pregunta.

-En la oración no quedan completamente identificados ( ¿2 $2^{a}$ persona "usted"?, ¿ $3^{a}$ persona singular?) los rasgos básicos del argumento sujeto.

-Construcción gramatical.

-El consecuente no es recuperable semánticamente en el nivel oracional.

\section{Sintaxis del discurso}

Las virtualidades sobre la persona del argumento sujeto de "existe" que se refieren en Sintaxis de la lengua meta quedan circunscriptas a la $3^{a}$ persona.

La recuperación endofórica más cercana es anafórica (usted); sin embargo, la progresión temática esclarecería el valor léxico del antecedente "El lector" pues éste ocupa la posición sujeto. 
La elipsis de sujeto es un medio cohesivo muy utilizado en castellano pero la recuperación del antecedente no deber prestar a confusión, especialmente en los textos pragmáticos cuya función informativa es primordial.

La reiteración total o parcial del referente en posición sujeto de "existe" aumentaría la cohesión, facilitando el pasaje de información.

\section{Comparación del binomio TO-TT}

TO. Llena el lugar sujeto con « il » en correferencia con « il » anterior que a su vez remite a « le lecteur » la primera -y única vez- que aparece ese actante.

TT. Presenta dos ocurrencias de "El lector" en comienzo de oración y dos elipsis. La primera es clara porque el único referente es ese actante. En la segunda elipsis, que es nuestro caso, también está presente el actante "usted", lo cual indicaría que flexión verbal no es suficiente para recuperar indudablemente al referente.

\section{Mecanismos de producción}

Elevación de la frecuencia de uso de recursos o elementos, en nuestro caso la elipsis que está asociada a la ausencia léxica.

Descenso del control lingüístico-discursivo: producción automática de la elipsis.

\section{Resultado}

Visibilidad de interferencia del sistema lingüístico meta, es decir el castellano.

Elipsis de sujeto con consecuencias discursivas leves.

Descenso de la cohesión sin repercusión en la construcción de sentido. 
40

\begin{tabular}{|l|l|l|l|l|}
\hline Cap. & \multicolumn{1}{|c|}{ TT } & $\mathrm{p} / \mathrm{r}$ & \multicolumn{1}{c|}{ TO } & $\mathrm{p} / \mathrm{r}$ \\
\hline 4 & "Con heurística del miedo", Hans Jonas & 116 & $\begin{array}{l}\text { Par heuristique de la peur, Hans Jonas voulait } \\
\text { dire que l'on sait ce qui est menacé (l'être } \\
\text { humain) à partir du moment où l'on sait qu'il } \\
\end{array}$ & $\begin{array}{l}\text { quería decir que se sabe lo que está } \\
\text { est menacé. }\end{array}$ \\
& $\begin{array}{l}\text { amenazado (el ser humano) a partir del } \\
\text { momento en que se sabe que está } \\
\text { amenazado. }\end{array}$ & 133 & \\
\hline
\end{tabular}

\section{Sintaxis de la lengua meta}

"Con heurística del miedo, Hans Jonas quería decir que se sabe lo que está amenazado (el ser humano) a partir del momento en que se sabe que está amenazado."

-Proposición subordinada completiva incluida en una subordinada circunstancial temporal, con elipsis nominal máxima (argumento externo o sujeto): que [Ø] está amenazado.

-En la oración no quedan completamente identificados ( $¿ 2^{\mathrm{a}}$ persona "usted"?, $3^{\mathrm{a}}$ persona singular?) los rasgos básicos del argumento sujeto.

-Construcción gramatical.

-El antecedente es recuperable en el nivel oracional.

\section{Sintaxis del discurso}

Las virtualidades sobre la persona del argumento sujeto de "está amenazado" que se refieren en Sintaxis de la lengua meta quedan circunscriptas a la $3^{a}$ persona.

La recuperación endofórica más cercana es anafórica "lo que está amenazado" = "el ser humano".

La elipsis de sujeto es un medio cohesivo muy utilizado en castellano, pero la recuperación del antecedente no deber prestar a confusión, especialmente en los textos pragmáticos cuya función informativa es primordial.

La reiteración total (el propio ser humano) o parcial del referente en posición sujeto de "existe" aumentaría la cohesión, facilitando el pasaje de información. 
Entendemos que el valor del pronombre "lo" en "lo que está amenazado" indica el alcance de la amenaza: nada más ni nada menos que el ser humano.

Es una sintaxis compleja, un juego de palabras, con un contenido denso que exige exactitud y claridad para transmitir el mensaje.

\section{Comparación del binomio TO-TT}

TO. La ocurrencia de « il » en " à partir du moment où l'on sait qu'il est menacé » remite a « ce qui est menacé ('être humain) ».

TT. La flexión verbal no es suficiente para recuperar el referente, de allí que sea necesario hacer explícito el sujeto de "está amenazado "

\section{Mecanismos de producción}

Elevación de la frecuencia de uso de recursos o elementos, en nuestro caso la elipsis que está asociada a la ausencia léxica.

Descenso del control lingüístico-discursivo: producción automática de la elipsis.

\section{Resultado}

Visibilidad de interferencia del sistema lingüístico meta, es decir el castellano.

Elipsis de sujeto con consecuencias discursivas; la elipsis se pone en evidencia al comparar el TT con el TO.

Descenso de cohesión con repercusión en la construcción de sentido. 



\section{CAPÍTULO VII}

\section{RESULTADOS E INTERPRETACIÓN}

\subsection{Determinación de las anomalías para su estudio}

Como hemos explicado en el capítulo $\vee$ Metodología, los criterios de análisis evolucionaron desde la primera consideración amplia que tomaba en cuenta las porciones de enunciados que dificultaban el pasaje fluido de la información en los textos traducidos, siendo 118 casos para Gènéthique y 145 casos para El racismo del gen, que ordenamos según el criterio clásico de series de categorías abiertas y cerradas, pero concentrándonos exclusivamente en las anomalías sintácticas y dejando de lado las terminológicas.

Al cabo de algunos ensayos de análisis desechamos este criterio de clasificación por considerar que nos impedía llegar a explicaciones generales; sin embargo, resultó ser una herramienta que nos permitió detectar los fenómenos más frecuentes, que identificamos como ausencias o vacíos, representados por 67 los casos en Gènéthique y 28 casos en El racismo del gen.

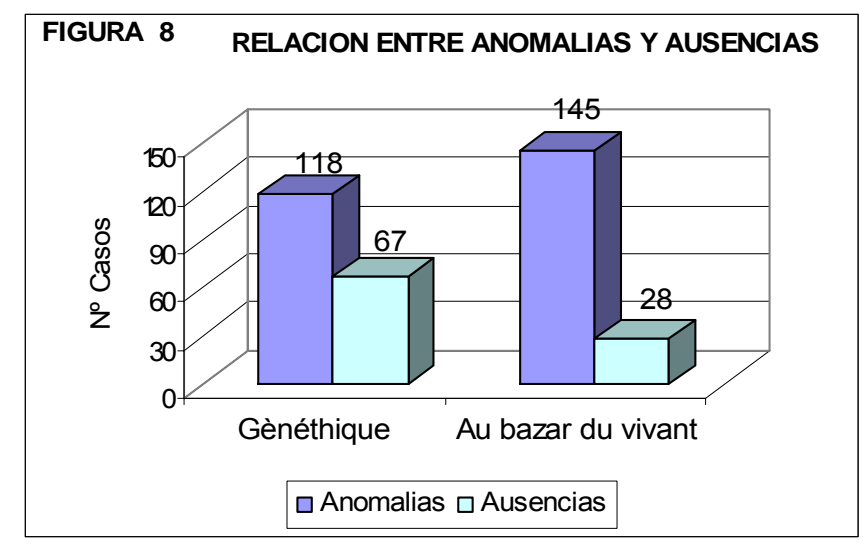

Una vez establecidas las ausencias o vacíos aludidos, los confrontamos con los criterios de recuperabilidad que definen estructuralmente a la elipsis y así llegamos a 21 casos para Gènéthique, y 19 para El racismo del gen: 


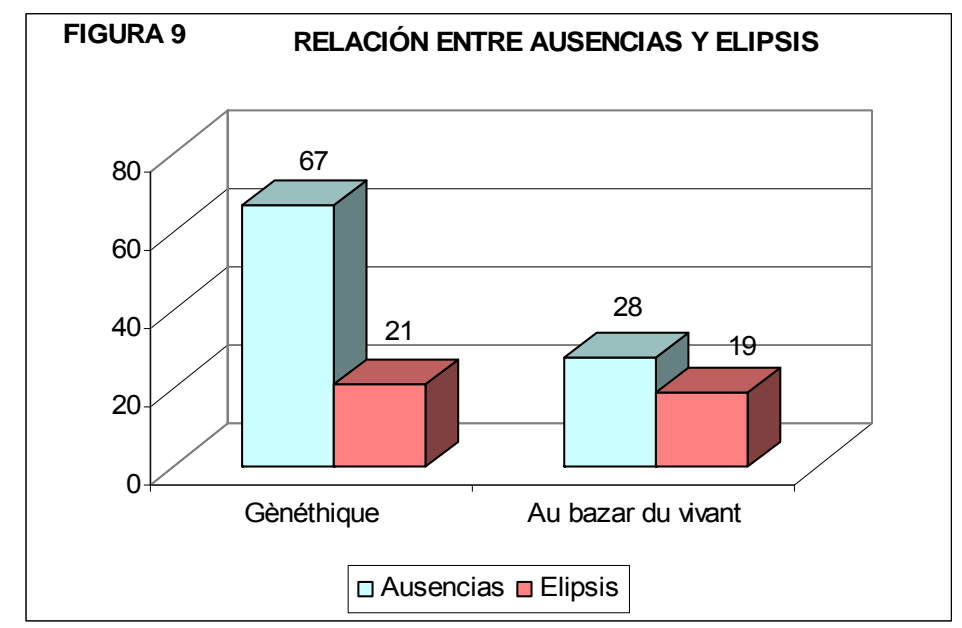

Los datos correspondientes a la elipsis son finalmente los que hemos analizado, según el instrumento presentado en el capítulo $\vee$ Metodología, que nos proporciona la información que ha sido organizada en las siguientes tablas: 1) Distribución de las elipsis con anomalías 2) Distribución de las elipsis nominales 3) Funciones de las elipsis nominales máximas, 4) Funciones de las elipsis nominales parciales, 5) Elipsis con anomalías sintácticas y discursivas, 6) Elipsis nominal y recuperabilidad oracional o transfrástica, 7) Elipsis verbal y recuperabilidad oracional o transfrástica, 8) Mecanismos observables en relación con la elipsis, 9) Visibilidad de la interferencia, 10) Repercusión de la interferencia.

En las tablas referidas, los números de los enunciados 1 al 21 , que pertenecen al corpus textual Gènéthique publicado en Internet en varios idiomas, han sido escritos con caracteres en negrita, mientras que los números de los enunciados 22 al 40, provenientes del libro El racismo del gen cuyo original es $A u$ bazar du vivant, están escritos en caracteres sin formato especial.

Recordamos que la totalidad de las elipsis consideradas inciden negativamente en el objetivo mayor de los textos pragmáticos que es el pasaje de la información, puesto que responden al concepto operativo de anomalía; éste abarca, por un lado, las elipsis construidas sin observar las reglas del sistema lingüístico de referencia, que hemos denominado anomalías sintácticas o gramaticales, y por el otro, las elipsis resueltas dentro del sistema lingüístico de referencia, pero que así y 
todo inciden negativamente en la cohesión, en la construcción del sentido y por consiguiente en el pasaje de la información, que hemos denominado anomalías discursivas [ $\rightarrow$ Capítulo V, Metodología. 5.6.].

Los resultados absolutos están presentados en tablas y las figuras muestran su distribución; la lectura e interpretación sigue a cada figura, excepto en la Tabla 7. Elipsis verbal y recuperabilidad oracional o transfrástica que sólo contiene 2 casos, por lo tanto no se los ha graficado. 
7.1.1. Las elipsis con anomalías

TABLA 1. Distribución de las elipsis con anomalías

\begin{tabular}{|c|c|c|}
\hline Enunciado & Elipsis nominal & Elipsis verbal \\
\hline 1 & $\mathbf{X}$ & \\
\hline 2 & $\mathbf{x}$ & \\
\hline 3 & $\mathbf{x}$ & \\
\hline 4 & $\mathrm{x}$ & \\
\hline 5 & & $\mathrm{x}$ \\
\hline 6 & & $\mathrm{x}$ \\
\hline 7 & $x$ & \\
\hline 8 & $x$ & \\
\hline 9 & $\mathbf{X}$ & \\
\hline 10 & $\mathbf{X}$ & \\
\hline 11 & $\mathbf{x}$ & \\
\hline 12 & $\mathbf{x}$ & \\
\hline 13 & $\mathbf{x}$ & \\
\hline 14 & $\mathrm{x}$ & \\
\hline 15 & $x$ & \\
\hline 16 & $\mathbf{x}$ & \\
\hline 17 & $\mathbf{x}$ & \\
\hline 18 & $\mathbf{x}$ & \\
\hline 19 & $\mathbf{x}$ & \\
\hline 20 & $\mathbf{x}$ & \\
\hline 21 & $\mathbf{x}$ & \\
\hline 22 & $x$ & \\
\hline 23 & $\mathrm{X}$ & \\
\hline 24 & $\mathrm{X}$ & \\
\hline 25 & $X$ & \\
\hline 26 & $X$ & \\
\hline 27 & $\mathrm{X}$ & \\
\hline 28 & $\mathrm{X}$ & \\
\hline 29 & $x$ & \\
\hline 30 & $x$ & \\
\hline 31 & $\mathrm{X}$ & \\
\hline 32 & $\mathrm{X}$ & \\
\hline 33 & $\mathrm{x}$ & \\
\hline 34 & $\mathrm{X}$ & \\
\hline 35 & $X$ & \\
\hline 36 & $\mathrm{X}$ & \\
\hline 37 & $x$ & \\
\hline 38 & $\mathrm{X}$ & \\
\hline 39 & $\mathrm{X}$ & \\
\hline 40 & $x$ & \\
\hline TOTAL & 38 CASOS & 2 CASOS \\
\hline
\end{tabular}




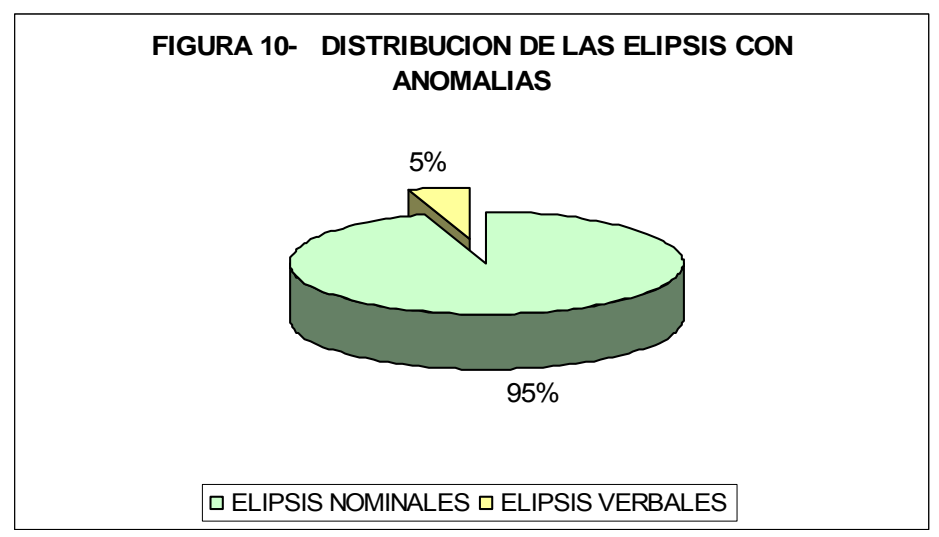

Según hemos definido en el Capítulo IV, las elipsis pueden ser nominales o verbales, clasificación que volcamos en la Tabla 1, con anomalías tanto sintácticas como discursivas.

La Figura 10 muestra la gran diferencia de distribución de las elipsis con anomalías nominales, 95\%, y verbales, 5\%. De todos modos, en algunos casos, entre ellos el 23, el hueco está representado por un sustantivo, es decir elipsis nominal, pero su proyección incluye un verbo en una clara elipsis verbal; sin embargo, la hemos contabilizado como elipsis nominal puesto que la proyección verbal elidida depende del núcleo nominal, también elidido. 
7.1.1.1. Extensión de las elipsis nominlaes

TABLA 2. Distribución de las elipsis nominales

\begin{tabular}{|c|c|c|}
\hline Enunciado & Elipsis nominal máxima & Elipsis nominal parcial \\
\hline 1 & $x$ & \\
\hline 2 & & $x$ \\
\hline 3 & $x$ & \\
\hline 4 & $\mathrm{X}$ & \\
\hline 7 & $x$ & \\
\hline 8 & & $\mathrm{X}$ \\
\hline 9 & $x$ & \\
\hline 10 & 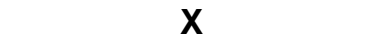 & \\
\hline 11 & $\mathrm{X}$ & \\
\hline 12 & $x$ & \\
\hline 13 & $x$ & \\
\hline 14 & $\mathbf{x}$ & \\
\hline 15 & $x$ & \\
\hline 16 & $x$ & \\
\hline 17 & $x$ & \\
\hline 18 & $x$ & \\
\hline 19 & $x$ & \\
\hline 20 & $x$ & \\
\hline 21 & $\mathrm{X}$ & \\
\hline 22 & & $x$ \\
\hline 23 & & $x$ \\
\hline 24 & & $x$ \\
\hline 25 & $X$ & \\
\hline 26 & $x$ & \\
\hline 27 & $x$ & \\
\hline 28 & $X$ & \\
\hline 29 & $X$ & \\
\hline 30 & & $\mathrm{X}$ \\
\hline 31 & $x$ & \\
\hline 32 & $X$ & \\
\hline 33 & $x$ & \\
\hline 34 & $x$ & \\
\hline 35 & $x$ & \\
\hline 36 & $x$ & \\
\hline 37 & $x$ & \\
\hline 38 & $x$ & \\
\hline 39 & $X$ & \\
\hline 40 & $x$ & \\
\hline TOTAL & 32 CASOS & 6 CASOS \\
\hline
\end{tabular}




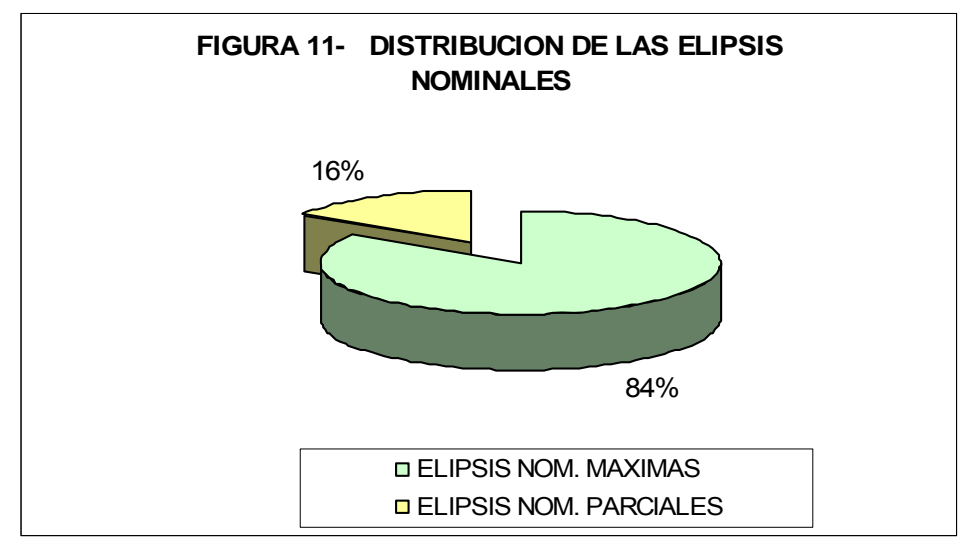

Como se explicó en el Capítulo IV de Elipsis, el mecanismo puesto en juego puede ser máximo o parcial. En el primer caso, el hueco abarca todo el sintagma; en cambio, cuando la elipsis es parcial, su alcance es el núcleo léxico de un sintagma que es obligatorio para generar un $\mathrm{SN}$, pudiendo incluir además del núcleo tanto complementos como adjuntos, siempre y cuando haya uno que funcione como resto.

De allí que hayamos considerado como elipsis máxima, los casos de leísmo puesto que el clítico le representa un SN completo.

En cambio, los posesivos representan elipsis parcial, por las características intrínsecas de esta categoría léxica que funciona como determinante y como pronombre en la relación genitiva de posesión. Esta última función es especialmente compleja en los casos de la forma castellana su/sus, ya que puede remitir, por ejemplo, a de usted, de él, de ellos, generando ambigüedades a la hora de la construcción de sentido en discursos que presentan diversos candidatos como antecedentes de este anafórico.

Si bien la relación de posesión también es compleja en francés, al menos la diversidad de formas de los posesivos de tercera persona, son/sa/ses, leur/leurs y de segunda persona votre/vos incide en la precisión del genitivo de pertenencia.

La Figura 11 muestra que las anomalías en elipsis de mecanismo máximo, es decir de sintagmas nominales completos, tienen mayor incidencia, 84\%, que las de mecanismo parcial, $14 \%$. 
7.1.1.2. Funciones de las elipsis nominales máximas

TABLA 3. Funciones de las elipsis nominales máximas

\begin{tabular}{|c|c|c|c|}
\hline Enunciado & Sujeto & $O D$ & $\mathrm{OI}$ \\
\hline 1 & $X$ & & \\
\hline 3 & $\mathbf{X}$ & & \\
\hline 4 & & 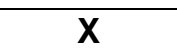 & \\
\hline 7 & & 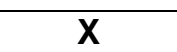 & \\
\hline 9 & & $\mathbf{X}$ & \\
\hline 10 & $X$ & & \\
\hline 11 & 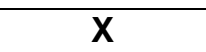 & & \\
\hline 12 & $x$ & & \\
\hline 13 & $X$ & & \\
\hline 14 & $\mathrm{X}$ & & \\
\hline 15 & $X$ & & \\
\hline 16 & & & $X$ \\
\hline 17 & $X$ & & \\
\hline 18 & & $X$ & \\
\hline 19 & $X$ & & \\
\hline 20 & $\mathbf{X}$ & & \\
\hline 21 & & $X$ & \\
\hline 25 & $X$ & & \\
\hline 26 & $\mathrm{X}$ & & \\
\hline 27 & $X$ & & \\
\hline 28 & $x$ & & \\
\hline 29 & $\mathrm{X}$ & & \\
\hline 31 & $X$ & & \\
\hline 32 & $X$ & & \\
\hline 33 & $X$ & & \\
\hline 34 & & & $X$ \\
\hline 35 & $\mathrm{X}$ & & \\
\hline 36 & $x$ & & \\
\hline 37 & $X$ & & \\
\hline 38 & $x$ & & \\
\hline 39 & $X$ & & \\
\hline 40 & $\mathrm{X}$ & & \\
\hline TOTAL & 25 CASOS & 5 CASOS & 2 CASOS \\
\hline
\end{tabular}




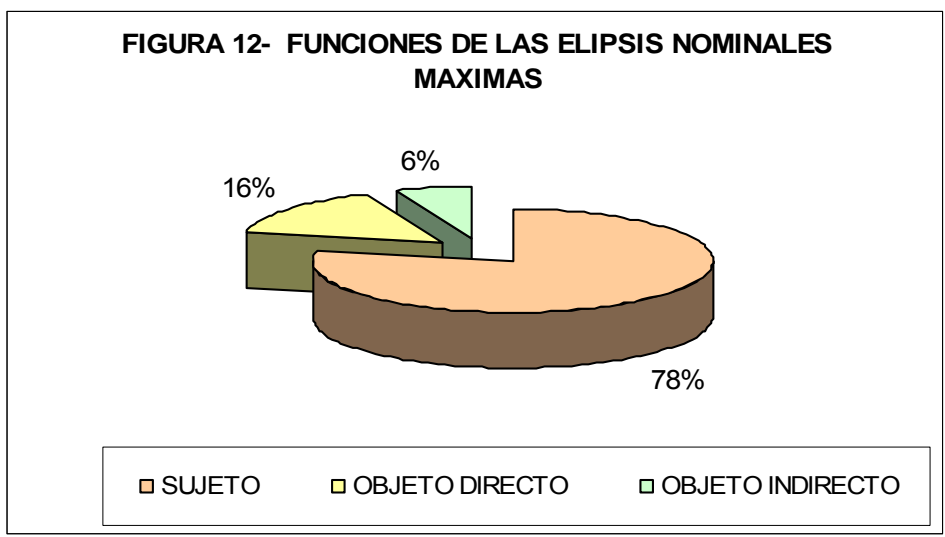

Las funciones de las elipsis nominales máximas con anomalías, que afectan a todo el sintagma nominal, se distribuyen cuantitativamente en mayor medida en la función de argumento externo o sujeto, $78 \%$, seguidas por las de argumentos internos, objeto directo, $16 \%$ y objeto indirecto, $6 \%$. 


\subsubsection{Funciones de las elipsis nominales parciales}

TABLA 4. Funciones de las elipsis nominales parciales

\begin{tabular}{|c|c|c|c|c|c|c|}
\hline Enunciado & Sujeto & OD & Ol & $\begin{array}{c}\text { Compl. } \\
\text { régimen }\end{array}$ & Predicativo & $\begin{array}{c}\text { Comp. } \\
\text { Sustantivo }\end{array}$ \\
\hline 2 & & & & & $\mathbf{X}$ & \\
\hline 8 & $\mathbf{X}$ & & & & & \\
\hline 22 & $\mathrm{X}$ & & & & & \\
\hline 23 & & & & & & $\mathrm{X}$ \\
\hline 24 & & & & & & $\mathrm{X}$ \\
\hline 30 & & & & & & $\mathrm{X}$ \\
\hline TOTAL & 2 CASOS & - & - & - & 1 CASO & 3 CASOS \\
\hline
\end{tabular}

FIGURA 13 - FUNCIONES DE LAS ELIPSIS NOMINALES PARCIALES
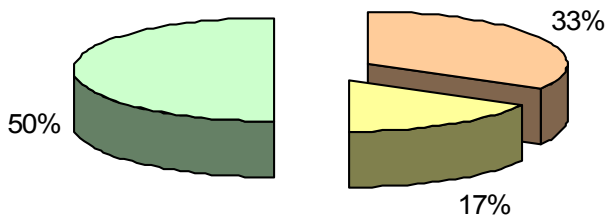

La cantidad total de 6 casos no es numéricamente importante. En cuanto a las funciones de las elipsis nominales parciales con anomalías, es decir las que afectan a los núcleos de los sintagmas nominales, presentan una distribución encabezada por la función complemento del sustantivo, $50 \%$, que está expresado por el posesivo su/sus, luego la función sujeto, 33\% y por último objeto indirecto, $17 \%$. 


\subsubsection{Tipos de anomalías de las elipsis}

TABLA 5. Elipsis con anomalías sintácticas y discursivas ${ }^{1}$

\begin{tabular}{|c|c|c|c|c|}
\hline Enunciado & $\begin{array}{c}\text { Elipsis nominal } \\
\text { con anomalías } \\
\text { discursivas }\end{array}$ & $\begin{array}{c}\text { Elipsis nominal } \\
\text { con anomalías } \\
\text { sintácticas }\end{array}$ & $\begin{array}{c}\text { Elipsis verbal con } \\
\text { anomalías } \\
\text { discursivas }\end{array}$ & $\begin{array}{c}\text { Elipsis verbal con } \\
\text { anomalías } \\
\text { sintácticas }\end{array}$ \\
\hline 1 & $x$ & & & \\
\hline 2 & & ${ }^{*} X$ & & \\
\hline 3 & $\mathbf{X}$ & & & \\
\hline 4 & & ?X & & \\
\hline 5 & & & & ${ }^{*} X$ \\
\hline 6 & & & $x$ & \\
\hline 7 & & *X & & \\
\hline 8 & & *X & & \\
\hline 9 & & ?X & & \\
\hline 10 & $x$ & & & \\
\hline 11 & $\mathbf{X}$ & & & \\
\hline 12 & & *X & & \\
\hline 13 & $\mathbf{X}$ & & & \\
\hline 14 & $\mathbf{X}$ & & & \\
\hline 15 & $\mathbf{X}$ & & & \\
\hline 16 & $\mathbf{X}$ & & & \\
\hline 17 & $\mathbf{X}$ & & & \\
\hline 18 & $\mathbf{X}$ & & & \\
\hline 19 & $\mathbf{X}$ & & & \\
\hline 20 & & ${ }^{*} X$ & & \\
\hline 21 & & ?X & & \\
\hline 22 & $\mathbf{X}$ & & & \\
\hline 23 & $X$ & & & \\
\hline 24 & $\mathrm{X}$ & & & \\
\hline 25 & $X$ & & & \\
\hline 26 & $\mathrm{X}$ & & & \\
\hline 27 & $\mathrm{X}$ & & & \\
\hline 28 & $\mathrm{X}$ & & & \\
\hline 29 & $\mathrm{X}$ & & & \\
\hline 30 & $\mathrm{X}$ & & & \\
\hline 31 & & ${ }^{*} X$ & & \\
\hline 32 & $X$ & & & \\
\hline 33 & $\mathrm{X}$ & & & \\
\hline 34 & $X$ & & & \\
\hline 35 & $X$ & & & \\
\hline 36 & $\mathrm{X}$ & & & \\
\hline 37 & $X$ & & & \\
\hline 38 & $X$ & & & \\
\hline 39 & $\mathrm{X}$ & & & \\
\hline 40 & $X$ & & & \\
\hline TOTAL & 29 CASOS & 9 CASOS & 1 CASOS & 1 CASO \\
\hline
\end{tabular}

\footnotetext{
${ }^{1}$ Las convenciones de *: agramaticalidad y ?: grado de agramaticalidad se explican después de la tabla.
} 


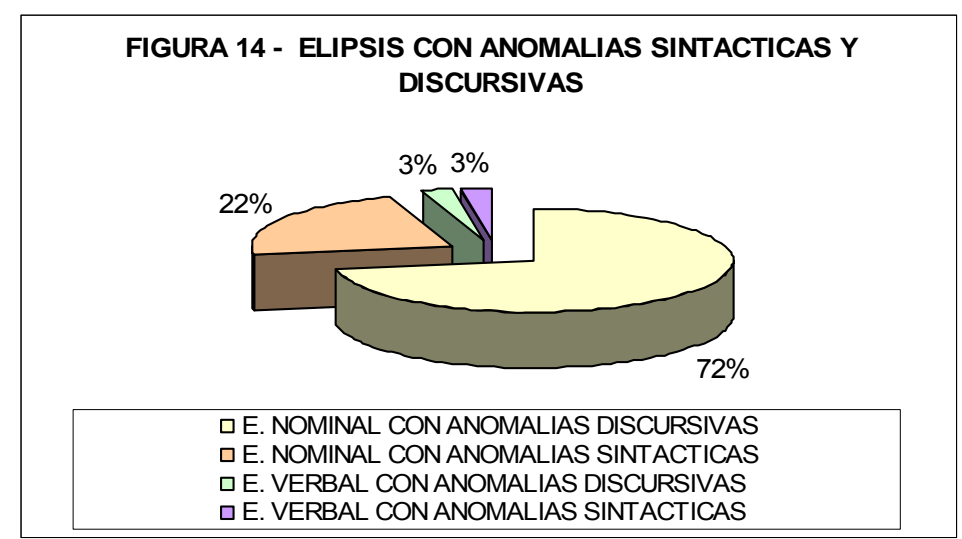

Al comienzo de este capítulo, recordábamos que el concepto operativo anomalía distingue, por un lado, las anomalías sintácticas cuya construcción estructural infringe las reglas constitutivas del sistema, y por el otro, las anomalías discursivas, que responden a las reglas del sistema lingüístico de referencia, no obstante lo cual afectan la cohesión, la construcción del sentido y por consiguiente el pasaje de la información.

Las primeras, es decir las anomalías sintácticas, están relacionadas con la gramaticalidad, que Ángela Di Tullio toma como noción clave que permite diferenciar construcciones bien formadas o gramaticales, de las secuencias agramaticales, que se ha convenido hacerlas preceder de astericos (1997: 17). Por su parte, Dominique Maingueneau da cuenta de que existen grados de agramaticalidad, que son representados con un signo de interrogación (?), dos signos de interrogación (??), un signo de interrogación y asterisco $\left(?^{*}\right)$, según el grado de duda que presente la construcción gramatical, reservando el asterisco $\left(^{*}\right)$ para la agramaticalidad indiscutida (1994: 23).

En la Tabla 5 que antecede, la mayoría de las elipsis con anomalías discursivas corresponde a la función sujeto, hecho que surge de la comparación con las Tablas 3 y 4 que recogen las funciones de las elipsis nominales máximas y parciales.

En la columna de las elipsis con anomalías sintácticas, hemos decidido agrupar los casos de leísmo con un signo de interrogación (?), considerándolo como el grado más bajo de agramaticalidad. 
Ahora bien, ¿cómo hemos calculado el grado de agramaticalidad? Por un lado, sabemos que le deriva del demostrativo dativo latino ILLI y corresponde al objeto indirecto, por lo tanto el leísmo infringe las reglas del sistema español. Sin embargo, socialmente su uso es extendido en España para expresar un SN objeto directo personal, es decir que un uso que no se corresponde con el sistema, responde, en cambio, a selecciones que encuentran su explicación dentro de las normas iniciales de aceptabilidad, y por consiguiente como norma lingüístico-textual, según la terminología touriana.

Por el contrario, el rioplatense adscribe a las normas del sistema general del castellano utilizando el clítico lo cuando la referencia es un objeto directo. Con estos datos estructurales y sociales, decidimos ubicar los casos de leísmo en la columna de las anomalías sintácticas, por las razones lingüísticas evocadas al tomar a la lengua como sistema, pero marcándolo solamente con un signo de interrogación (?) porque su uso es preferido en España, es decir que la elección individual del traductor o habla, responde a una norma pragmático-semántica, aplicando el modelo tripartito de Coseriu.

En la tabla 1, se vio que es mínima la aparición de elipsis verbales anómalas; al mismo tiempo, vemos que los dos casos identificados se reparten entre anomalías sintácticas y discursivas.

En la tabla actual, se aprecia que la mayor parte de las anomalías se presentan en los textos traducidos del sitio www.genethique.org, 6 casos de agramaticalidad indiscutida y 3 casos de leísmo, frente a un solo caso en El racismo del gen. Interpretamos que la persistencia de las agramaticalidades indiscutidas en la publicación final está relacionada con el carácter provisorio que generalmente se asocia a la producción virtual; con respecto al leísmo, su aparición es normal en un texto producido por un hablante cuya lengua materna es el castellano ibérico. 


\subsubsection{Recuperabilidad en las elipsis nominales}

TABLA 6. Elipsis nominal y recuperabilidad oracional o transfrástica

\begin{tabular}{|c|c|c|c|c|}
\hline \multirow[t]{2}{*}{ Enunciado } & \multicolumn{2}{|c|}{$\begin{array}{c}\text { Elipsis nominal con anomalías } \\
\text { discursivas }\end{array}$} & \multicolumn{2}{|c|}{$\begin{array}{l}\text { Elipsis nominal con anomalías } \\
\text { sintácticas }\end{array}$} \\
\hline & $\begin{array}{l}\text { Recuperabilidad } \\
\text { Oracional }\end{array}$ & $\begin{array}{c}\text { Recuperabilidad } \\
\text { transfrástica }\end{array}$ & $\begin{array}{c}\text { Recuperabilidad } \\
\text { oracional }\end{array}$ & $\begin{array}{l}\text { Recuperabilidad } \\
\text { transfrástica }\end{array}$ \\
\hline 1 & & $X$ & & \\
\hline 2 & & & $X$ & \\
\hline 3 & $X$ & & & \\
\hline 4 & & & $\mathrm{X}$ & \\
\hline 7 & & & $X$ & \\
\hline 8 & & & $\mathbf{X}$ & \\
\hline 9 & & & $\mathrm{X}$ & \\
\hline 10 & $\mathbf{X}$ & & & \\
\hline 11 & $X$ & & & \\
\hline 12 & & & $\mathbf{X}$ & \\
\hline 13 & & $X$ & & \\
\hline 14 & $\mathrm{X}$ & & & \\
\hline 15 & $X$ & & & \\
\hline 16 & $\mathbf{X}$ & & & \\
\hline 17 & & $X$ & & \\
\hline 18 & $\mathrm{X}$ & & & \\
\hline 19 & $\bar{x}$ & & & \\
\hline 20 & & & $\mathrm{X}$ & \\
\hline 21 & & & $X$ & \\
\hline 22 & $\mathrm{X}$ & & & \\
\hline 23 & & $\mathrm{X}$ & & \\
\hline 24 & & $\mathrm{X}$ & & \\
\hline 25 & $\mathrm{X}$ & & & \\
\hline 26 & $\mathrm{X}$ & & & \\
\hline 27 & & $\mathrm{X}$ & & \\
\hline 28 & $\mathrm{X}$ & & & \\
\hline 29 & $\mathrm{X}$ & & & \\
\hline 30 & $\mathrm{X}$ & & & \\
\hline 31 & & $\mathrm{X}$ & & \\
\hline 32 & & $X$ & & \\
\hline 33 & $\mathrm{X}$ & & & \\
\hline 34 & & $\mathrm{X}$ & & \\
\hline 35 & $X$ & & & \\
\hline 36 & $\mathrm{X}$ & & & \\
\hline 37 & $X$ & & & \\
\hline 38 & $\mathrm{X}$ & & & \\
\hline 39 & & $\mathrm{X}$ & & \\
\hline 40 & $X$ & & & \\
\hline TOTAL & 20 CASOS & 10 CASOS & 8 CASOS & \\
\hline
\end{tabular}



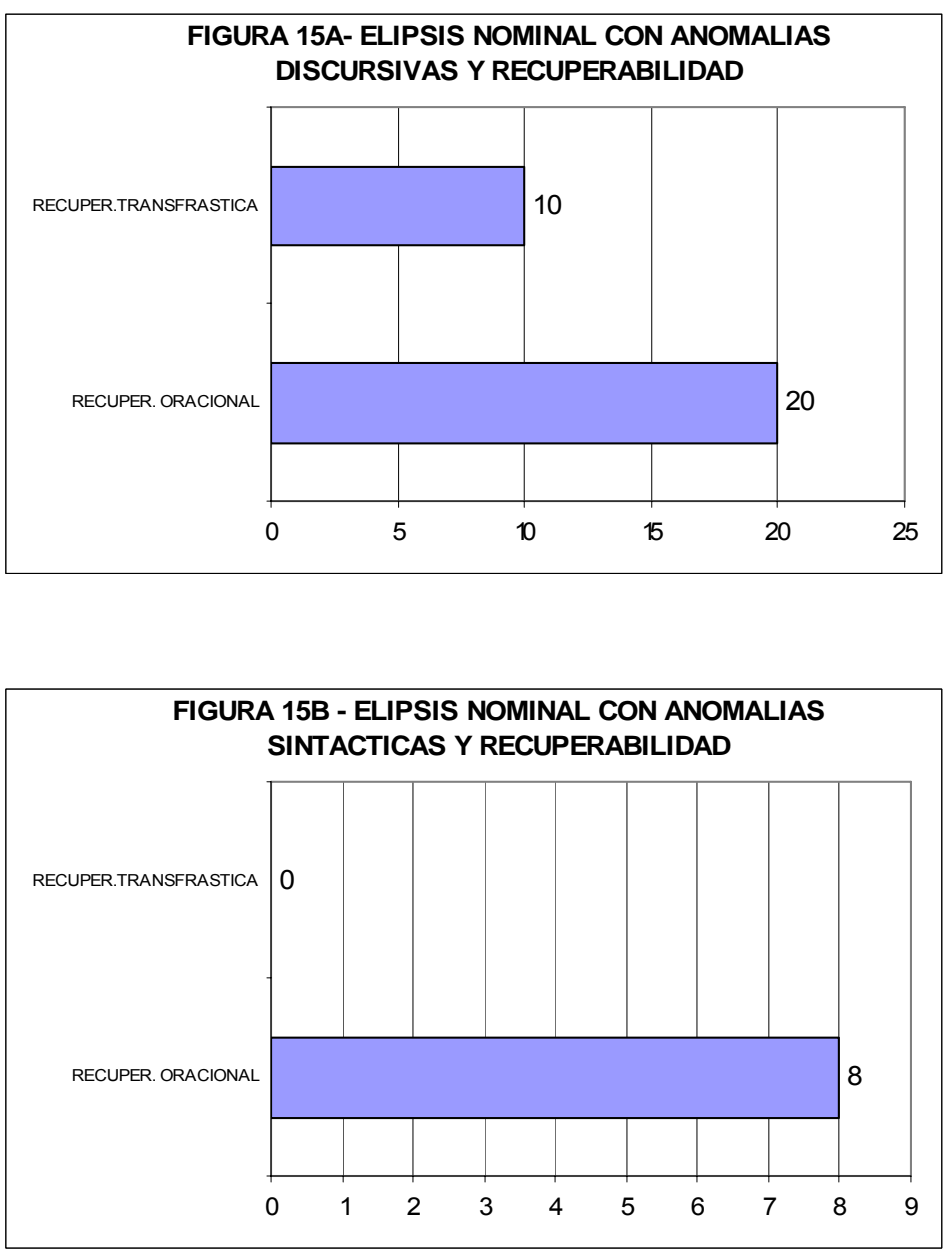

La Tabla 6 reúne los datos provenientes de la posibilidad de que las elipsis con anomalías discursivas y con anomalías sintácticas, recuperen el antecedente del elemento elidido dentro o fuera de los límites de la oración. Hemos convenido que la unidad de análisis está dada por los enunciados de los TT y TO separados por punto $[\rightarrow$ Capítulo V, Metodología. 5.6.]. Si la recuperabilidad del antecedente o consecuente se presenta dentro de esos límites será oracional, en cambio será transfrástica cuando se establezca en otros enunciados.

Los resultados de las dos primeras columnas provienen de elipsis con anomalías discursivas pero que tienen resuelta la sintaxis oracional, mientras las columnas tercera y cuarta recogen los datos de las elipsis con anomalías sintácticas; dentro de estas últimas, la tercera columna refleja los datos de las elipsis cuya recuperabilidad es oracional y hemos previsto la cuarta columna para reunir los datos de las elipsis con anomalías sintácticas cuya recuperabilidad es transfrástica. 
Para observar su distribución, hemos realizado las figuras $15 \mathrm{~A}$ y $15 \mathrm{~B}$, la primera retomando las dos primeras columnas y la segunda las dos últimas.

Los resultados cuantitativos demuestran una distribución decreciente, siendo las más numerosas las elipsis con anomalías discursivas cuyo antecedente es recuperable en el nivel oracional (20 casos) seguidas por las elipsis con anomalías discursivas que recuperan su antecedente en otros enunciados (10 casos). Menos numerosas aún son las elipsis con anomalías sintácticas con recuperabilidad del antecedente dentro de los límites de la oración (8 casos), para finalizar con inexistencia de casos de elipsis con anomalías sintácticas y recuperabilidad transfrástica.

En la elipsis con anomalías discursivas y recuperabilidad oracional, las elipsis máximas con función sujeto, por ejemplo los casos $3,10,11,14,15,19,25,26,28$, $29,33,35,36,37$, tienen en común la dificultad de establecer los rasgos básicos del argumento sujeto dentro de la unidad oracional, generalmente debido a la extensión oracional o a la coexistencia de más de un candidato a referente, lo cual instaura ambigüedad. También las elipsis máximas pueden remitir de manera no precisa, o al menos no cohesiva a un antecedente o consecuente semántico en oraciones cortas, en las que la función del elemento elidido es ambigua, como el caso 38.

Las elipsis parciales con anomalías discursivas cuya recuperabilidad es oracional, como el caso 30, tienen en común con las anteriores el hecho de no poder establecer con exactitud los rasgos básicos del antecedente debido a la ocurrencia de más de un candidato como antecedente.

En todos los casos de recuperabilidad transfrástica la causa común a las anomalías discursivas radica en el hecho de que hay un descenso de la cohesión por ausencia del antecedente dentro de la oración. En algunos casos de la transcripción de esta entrevista, por ejemplo el 23 y el 24, el debilitamiento de la recuperabilidad se debe también a la pérdida deíctica de la posibilidad de ostensión, que es una característica de oralidad del género discursivo original.

En la elipsis con anomalías sintácticas y recuperabilidad oracional, identificamos cuatro casos de leísmo según lo comentado en la tabla 5 , falta de concordancia (casos 2 y 20) y construcción coordinada desacertada (casos 7, 12 y 31). 


\subsubsection{Recuperabilidad en las elipsis verbales}

TABLA 7. Elipsis verbal y recuperabilidad oracional o transfrástica

\begin{tabular}{|c|c|c|c|c|}
\hline \multirow{2}{*}{ Enunciado } & Elipsis verbal sin secuencias anómalas & \multicolumn{2}{|c|}{ Elipsis verbal con secuencias anómalas } \\
\cline { 2 - 5 } & $\begin{array}{c}\text { Recuperabilidad } \\
\text { Oracional }\end{array}$ & $\begin{array}{c}\text { Recuperabilidad } \\
\text { Transfrástica }\end{array}$ & $\begin{array}{c}\text { Recuperabilidad } \\
\text { oracional }\end{array}$ & $\begin{array}{c}\text { Recuperabilidad } \\
\text { transfrástica }\end{array}$ \\
\hline $\mathbf{5}$ & & & $\mathbf{X}$ & \\
\hline $\mathbf{6}$ & $\mathbf{X}$ & & & \\
\hline TOTAL & $\mathbf{1}$ CASO & - & $\mathbf{1}$ CASO & - \\
\hline
\end{tabular}

De manera análoga a la tabla 6 para las elipsis nominales, la presente tabla reúne los datos provenientes de la posibilidad de que las elipsis verbales con anomalías discursivas y sintácticas recuperen el antecedente del elemento elidido dentro o fuera de los límites de la oración.

Los dos casos encontrados se distribuyen en las dos grandes divisiones Elipsis verbal sin secuencias anómalas y Elipsis verbal con secuencias anómalas y, en ambos casos la recuperabilidad es oracional.

El primero se aprecia al contrastar las dos producciones TT y TO, porque se advierte la secuencia lógica entre el problema esencial, el proyecto inscripto en ese problema y la instrumentalización del niño.

En el segundo caso se utiliza desacertadamente la partícula de polaridad. 
7.2. Mecanismos en la producción de elipsis con anomalías

TABLA 8. Mecanismos observables en relación con la elipsis

\begin{tabular}{|c|c|c|c|}
\hline Enunciado & $\begin{array}{c}\text { Elevación de la } \\
\text { frecuencia de elipsis }\end{array}$ & $\begin{array}{l}\text { Descenso del control } \\
\text { lingüístico }\end{array}$ & $\begin{array}{l}\text { Descenso del control } \\
\text { lingüístico-discursivo }\end{array}$ \\
\hline 1 & $\mathbf{X}$ & & $\mathbf{X}$ \\
\hline 2 & & $X$ & $\mathbf{X}$ \\
\hline 3 & $\mathbf{X}$ & & $\mathbf{X}$ \\
\hline 4 & & $\mathbf{x}$ & \\
\hline 5 & & $\mathbf{X}$ & $\mathbf{X}$ \\
\hline 6 & & $\mathbf{X}$ & $X$ \\
\hline 7 & & $\mathrm{X}$ & $X$ \\
\hline 8 & & $\mathbf{X}$ & $\mathbf{X}$ \\
\hline 9 & & $\mathbf{x}$ & \\
\hline 10 & $\mathbf{X}$ & & $\mathbf{X}$ \\
\hline 11 & $\mathbf{X}$ & & $\mathbf{X}$ \\
\hline 12 & $\mathbf{X}$ & $\mathbf{x}$ & $\mathbf{X}$ \\
\hline 13 & $\mathbf{X}$ & & $\mathbf{X}$ \\
\hline 14 & $\mathbf{X}$ & & $\mathbf{X}$ \\
\hline 15 & $x$ & & $X$ \\
\hline 16 & & $\mathrm{X}$ & $\mathbf{X}$ \\
\hline 17 & $\mathbf{X}$ & & $\mathbf{X}$ \\
\hline 18 & $\mathbf{X}$ & $\mathbf{X}$ & $\mathbf{X}$ \\
\hline 19 & $\mathbf{X}$ & $\mathrm{X}$ & $\mathbf{X}$ \\
\hline 20 & $\mathbf{X}$ & $\mathbf{X}$ & $\mathbf{X}$ \\
\hline 21 & & $\mathbf{X}$ & \\
\hline 22 & $X$ & $X$ & $X$ \\
\hline 23 & $X$ & & \\
\hline 24 & $\mathrm{X}$ & & $\mathrm{X}$ \\
\hline 25 & $X$ & & $X$ \\
\hline 26 & $x$ & & $\mathrm{X}$ \\
\hline 27 & $\mathrm{X}$ & & $\mathrm{X}$ \\
\hline 28 & $\mathrm{X}$ & & $\mathrm{X}$ \\
\hline 29 & $\mathrm{X}$ & & $\mathrm{X}$ \\
\hline 30 & $\mathrm{X}$ & & $\mathrm{X}$ \\
\hline 31 & $\mathrm{X}$ & $X$ & $\mathrm{X}$ \\
\hline 32 & $X$ & & $X$ \\
\hline 33 & $\mathrm{X}$ & & $\mathrm{X}$ \\
\hline 34 & $\mathrm{X}$ & & $\mathrm{X}$ \\
\hline 35 & $X$ & $X$ & $X$ \\
\hline 36 & $\mathrm{X}$ & & $\mathrm{X}$ \\
\hline 37 & $\mathrm{X}$ & & $\mathrm{X}$ \\
\hline 38 & $X$ & $X$ & $X$ \\
\hline 39 & $X$ & & $\mathrm{X}$ \\
\hline 40 & $\mathrm{X}$ & & $X$ \\
\hline TOTAL & 27 CASOS & 18 CASOS & 36 CASOS \\
\hline
\end{tabular}




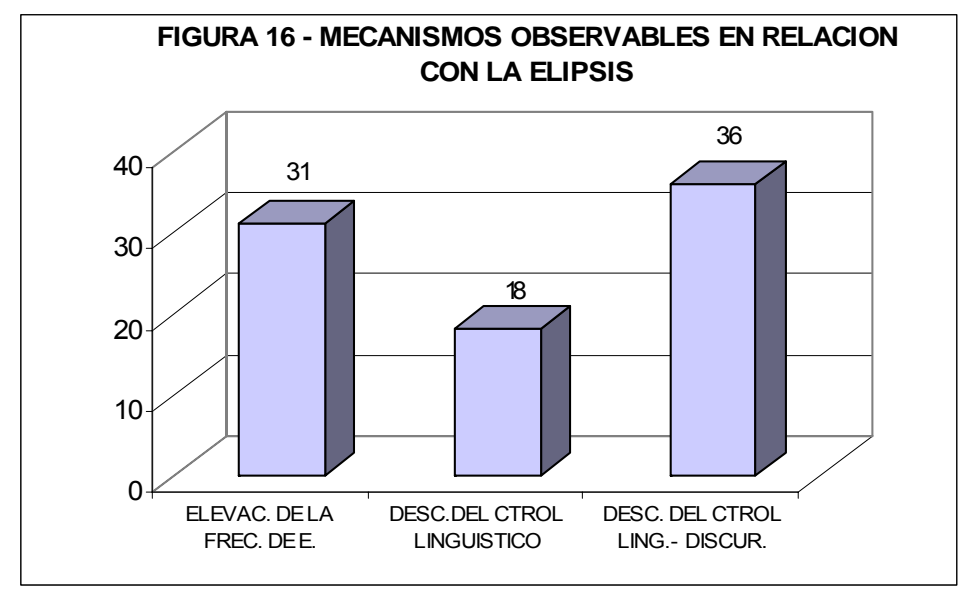

Hemos definido al mecanismo como la dirección inconsciente, automática, regular, de poner en marcha o continuar un proceso o un subproceso $[\rightarrow$ Capítulo $\mathrm{V}$, Metodología. 5.6.].

Por otra parte, hemos visto que la memoria es un mecanismo presente en la puesta en juego del control, como lo explica Daniel Gile en la metáfora del escritorio y adscribimos a la postura según la cual los procesos de producción se materializan en mecanismos de emisión de las formas lingüísticas, por lo tanto su estudio es indirecto y limitado.

Con estos presupuestos, hemos elaborado la Tabla 8 que recoge los mecanismos materializados en anomalías que hemos agrupado en tres grandes grupos: elevación de la frecuencia de ausencia léxica; descenso del control lingüístico y descenso del control lingüístico discursivo $[\rightarrow$ Capítulo $\mathrm{V}$, Metodología. 5.4.4.].

Como se aprecia en la Tabla 8, los casos de leísmo han sido considerados como emergentes del descenso del control lingüístico, por las razones comentadas en la Tabla 5, teniendo presente que una de las tensiones en la producción discursiva en traducción es, justamente, la elección del sistema o de la norma pragmático-semántica.

En el resto de los casos, se aprecia que los mecanismos considerados se manifiestan simultáneamente de a dos o de a tres y no individualmente. 
De esta manera, los casos $1,3,10,11,13,14,15,17,23,24,26$ al 30, 32, $33,34,36,37,39$ y 40, comparten los mecanismos de elevación de la frecuencia de elipsis y de descenso del control lingüístico-discursivo. En ninguno de estos casos se han detectado anomalías del sistema lingüístico, según la Tabla 5.

Además, estos casos cumplen la función sujeto, según los datos de la Tabla 3 , con excepción del 34 que es objeto indirecto y de los casos 23,24 y 30 que se refieren al uso del posesivo su/sus. En cuanto a la recuperabilidad oracional o transfrástica referida en la Tabla 6 , no encontramos una tendencia especial, ya que algunos tienen su antecedente dentro de la misma oración, como el 3, 10, 14, 15 y otros no, por ejemplo el 1, 13, 27, 32, 34 .

Con esta información, decimos que el recurso natural de la lengua castellana de uso de sujeto elíptico ha sido elevado, lo que evidentemente ha repercutido en la esfera discursiva. Con respecto al caso 34 , el objeto indirecto elíptico se ha reiterado en 4 oportunidades, con un antecedente transfrástico borroso. Los casos 23,24 y 30 remiten a la complejidad referencial del posesivo su/sus comentada en la Tabla 2.

Los casos 2, 5, 6, 7, 8, 16, comparten los mecanismos de descenso del control lingüístico y de descenso del control lingüístico-discursivo.

Dentro de los casos mencionados, el conjunto conformado por 2, 5, 7, 8 acusa anomalías sintácticas vinculadas con la elipsis y la consiguiente incidencia en la esfera discursiva. Los restantes, es decir 6 y 16, no presentan anomalías sintácticas de construcción de la elipsis, pero sí de otros elementos lingüísticos dentro de los cuales está realizada la elipsis, por ejemplo en el 16 la regla de enumeración y las preposiciones.

Los casos 12, 18, 19, 20, 22, 31, 35, 38 comparten los tres mecanismos considerados, es decir la elevación de la frecuencia de ausencia léxica, el descenso del control lingüístico y el descenso del control lingüístico-discursivo. Se advierten anomalías sintácticas vinculadas con la construcción de la elipsis en los casos 12 , 20 y 31 , todos con función sujeto en construcciones coordinadas, 12 y 31 , y el restante en construcción subordinada. 
En los casos 18, 19, 22 y 38 no hay expresas anomalías sintácticas de construcción de elipsis, pero se advierten diversos fenómenos: en los casos 18 y 35 aparecen dificultades en la producción de la forma "se", el caso 19 tiene como causa la propia anomalía del texto original, el caso 22 recurre a la movilidad de los adjuntos y el 38 presenta un sesgo entre gramática y semántica.

La distribución de la Figura 16 indica que la mayor parte de las anomalías se deben a un descenso de los mecanismos de control lingüístico-discursivo, seguidos por la tendencia a elevar la frecuencia de elipsis y, por último el descenso del control lingüístico, aun cuando hemos afirmado que en muchos casos, los mecanismos señalados están compartidos.

Con estos datos, estamos en condiciones de afirmar que, excepción hecha del leísmo, ha habido traducción automática, en términos de Daniel Gouadec, lo cual comienza a indicar que el mecanismo básico de memoria de las formas lingüísticas ha sufrido desestabilización. 


\subsection{Visibilidad de la interferencia negativa}

TABLA 9. Visibilidad de la interferencia

\begin{tabular}{|c|c|c|c|}
\hline Enunciado & $\begin{array}{c}\text { Visibilidad del } \\
\text { sistema lingüístico } \\
\text { meta }\end{array}$ & $\begin{array}{l}\text { Visibilidad del } \\
\text { discurso origen }\end{array}$ & Otra \\
\hline 1 & $\mathbf{X}$ & $\bar{X}$ & \\
\hline 2 & & $X$ & \\
\hline 3 & $\mathbf{X}$ & & \\
\hline 4 & & & $X$ \\
\hline 5 & & $X$ & \\
\hline 6 & & & $X$ \\
\hline 7 & & $\mathbf{X}$ & \\
\hline 8 & & $\mathbf{X}$ & $X$ \\
\hline 9 & & & $\mathrm{X}$ \\
\hline 10 & $X$ & & \\
\hline 11 & $X$ & & \\
\hline 12 & $X$ & $X$ & \\
\hline 13 & $X$ & & \\
\hline 14 & $X$ & & \\
\hline 15 & $X$ & & \\
\hline 16 & & $\bar{X}$ & \\
\hline 17 & $x$ & & \\
\hline 18 & $X$ & $\bar{X}$ & \\
\hline 19 & $X$ & $X$ & \\
\hline 20 & $\mathbf{X}$ & 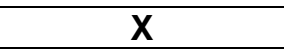 & \\
\hline 21 & & & $X$ \\
\hline 22 & $\mathrm{X}$ & & \\
\hline 23 & $X$ & $X$ & \\
\hline 24 & $\mathrm{X}$ & $\mathrm{X}$ & \\
\hline 25 & $X$ & $X$ & \\
\hline 26 & $\mathrm{X}$ & $\mathrm{X}$ & \\
\hline 27 & $\mathrm{X}$ & & \\
\hline 28 & $\mathrm{X}$ & & \\
\hline 29 & $\mathrm{X}$ & $X$ & \\
\hline 30 & $X$ & $X$ & \\
\hline 31 & & $\mathrm{X}$ & \\
\hline 32 & $X$ & $X$ & \\
\hline 33 & $X$ & & \\
\hline 34 & & $\mathrm{X}$ & $X$ \\
\hline 35 & $X$ & & \\
\hline 36 & $\mathrm{X}$ & & \\
\hline 37 & $\mathrm{X}$ & & \\
\hline 38 & $X$ & & \\
\hline 39 & $\mathrm{X}$ & & \\
\hline 40 & $\mathrm{X}$ & & \\
\hline TOTAL & 29 CASOS & 19 CASOS & 6 CASOS \\
\hline
\end{tabular}




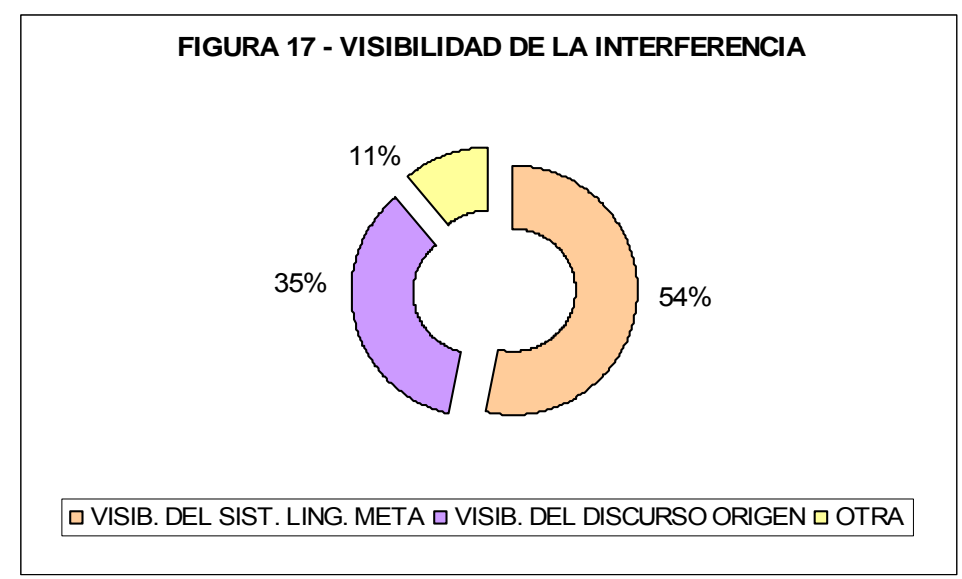

Hemos enunciado en diversas oportunidades que la interferencia es un universal o mecanismo por defecto que se halla presente a lo largo del macroproceso de traducción y que, por lo tanto, incide en los mecanismos discursivos relacionados con la memoria lingüística y la memoria extralingüística.

En la Tabla 9 volcamos los datos sobre el tipo de interferencia que gobierna cada uno de los enunciados traducidos, con la salvedad de que nos instalamos en la visibilidad de transferencias negativas, ya que nos hemos propuesto identificar y analizar las anomalías vinculadas con la producción de elipsis.

Con estos presupuestos, hemos catalogado las interferencias según provengan del sistema lingüístico meta, del discurso original y hemos dejado una categoría amplia, para los casos que se expliquen de otra manera.

Con la primera categoría, VIsibilidad del sistema lingüístico meta, nos referimos a la respuesta inmediata, que proviene de la memoria lingüística y que se concreta en una sintaxis oracional dentro de las reglas del sistema lingüístico meta, pero que tiene consecuencias discursivas no deseadas. Esta primera categoría está en línea con una de las hipótesis específicas de nuestra investigación que indica que en los productos discursivos traducidos se visualizan enunciados elípticos anómalos, gobernados por el universal de interferencia, según una influencia de la lengua materna del traductor.

La segunda categoría, Visibilidad del discurso origen, refiere a los calcos que se producen de manera no reflexiva y que son los casos más patentes de 
interferencia, evocada en otra de las hipótesis específicas que enuncia que en los productos discursivos traducidos se visualizan enunciados elípticos anómalos, gobernados por el universal de interferencia, según una influencia del discurso de partida sobre el de llegada.

Como ya dijimos, la tercera categoría integra los casos que no responden a ninguna de las categorías anteriores, pero que entendemos como interferencia.

En la Tabla 9, vemos que algunos casos corresponden únicamente a una de las categorías de visibilidad de interferencia (del sistema lingüístico meta, del discurso origen u otro) y otros casos se distribuyen en más de una de esas categorías.

De este modo, en la Visibilidad del sistema lingüístico meta aparece la producción de oraciones sin sujeto explícito, en los casos $3,10,11,13,14,15,17$, $27,28,33$ y 35 a 40 , el incremento pronominal se en el caso 18 y la movilidad de adjuntos, en el 22.

La Visibilidad del discurso origen, individualmente considerado en los casos 2 , 5 y 7 muestra anomalías sintácticas respecto de la concordancia del determinante con función demostrativa en el caso 2 , partícula de polaridad y gerundio en el caso 5 y pronombre relativo en el 7 . En cambio, el caso 16 lo consideramos una anomalía discursiva pues no utiliza la duplicación del argumento interno para identificar el antecedente.

En la categoría Otra, hemos consignado el leísmo visible en los casos 4, 9 y 21 que, como hemos ya explicado en la Tabla 5, responde a una norma pragmáticosemántica y no a una regla del sistema lingüístico castellano. El caso 6 es de complejidad en la distribución de la información que se visualiza al comparar el TT con el TO.

El resto de los casos son combinaciones de Visibilidad del sistema lingüístico meta y visibilidad del discurso de origen $(1,12,18,19,20,23$ al 26, 29, 30 y 32) y Visibilidad del discurso de origen y la categoría Otra (8 y 34). 


\subsection{Repercusión de la interferencia negativa}

\section{TABLA 10. Repercusión de la interferencia}

\begin{tabular}{|c|c|c|c|c|c|c|c|c|}
\hline \multirow[t]{2}{*}{ Enunc. } & \multicolumn{2}{|c|}{ Elipsis visible } & \multicolumn{2}{|c|}{ Alcance discursivo } & \multicolumn{2}{|c|}{ Producción palimpséstica } & \multicolumn{2}{|c|}{ Entropía informativa } \\
\hline & dentro del sistema & fuera del sistema & Microestructural & Macroestructural & sí & no & sí & no \\
\hline 1 & Sujeto de auxiliar modal & & & $\mathrm{x}$ & $\mathrm{x}$ & & $\mathrm{X}$ & \\
\hline 2 & & $\begin{array}{c}\text { Núcleo } \\
\text { de predicativo } \\
\text { subjetivo obligatorio }\end{array}$ & & $\mathrm{X}$ & $\mathrm{X}$ & & $\mathrm{X}$ & \\
\hline 3 & Sujeto de apódosis & & & $\mathrm{X}$ & & $\mathrm{X}$ & & $x$ \\
\hline 4 & & Objeto directo/ Leísmo & $\mathrm{X}$ & & & $\mathrm{X}$ & $\mathrm{X}$ & \\
\hline 5 & & $\begin{array}{c}\text { Verbo con partícula de } \\
\text { polaridad }\end{array}$ & & $\mathrm{X}$ & $\mathrm{X}$ & & & $\mathrm{X}$ \\
\hline 6 & $\begin{array}{c}\text { Verbo cópula y } \\
\text { distribución de la } \\
\text { información }\end{array}$ & & & $\mathrm{x}$ & & $\mathrm{x}$ & $\mathrm{X}$ & \\
\hline 7 & & $\begin{array}{l}\text { Objeto directo en } \\
\text { coordinada }\end{array}$ & & $\mathrm{x}$ & $x$ & & & $\mathrm{X}$ \\
\hline 8 & & Sujeto en coordinada & & $\mathrm{X}$ & $\mathrm{X}$ & & & $\mathbf{X}$ \\
\hline 9 & & Objeto directo/ Leísmo & $\mathrm{X}$ & & & $\mathbf{X}$ & $\mathrm{X}$ & \\
\hline 10 & $\begin{array}{c}\text { Sujeto de prop. sub. } \\
\text { relativa }\end{array}$ & & & $\mathrm{X}$ & & $\mathrm{X}$ & & $\mathbf{x}$ \\
\hline 11 & $\begin{array}{l}\text { Sujeto en prop. interr. } \\
\text { indirecta }\end{array}$ & & & $\mathrm{X}$ & & $\mathbf{X}$ & & $\mathbf{X}$ \\
\hline 12 & & Sujeto en coordinada & & $\mathrm{X}$ & $\mathrm{X}$ & & & $\mathbf{x}$ \\
\hline 13 & Sujeto de prop. principal & & & $\mathrm{X}$ & & $\mathbf{X}$ & & $\mathbf{X}$ \\
\hline 14 & Sujeto de prop. principal & & & $\mathrm{X}$ & & $\mathbf{X}$ & & $\mathrm{X}$ \\
\hline 15 & Sujeto de prop. principal & & & $x$ & & $\mathbf{x}$ & & $\mathbf{x}$ \\
\hline 16 & Ol en compl. prepositivo & & & $\mathrm{X}$ & $\mathrm{X}$ & & $\mathrm{X}$ & \\
\hline 17 & Sujeto de prop. principal & & & $\mathrm{x}$ & & $\mathbf{X}$ & $\mathrm{X}$ & \\
\hline 18 & OD en prótasis, & & & $\mathrm{X}$ & $\mathrm{X}$ & & & $\mathbf{X}$ \\
\hline
\end{tabular}




\begin{tabular}{|c|c|c|c|c|c|c|c|c|}
\hline & precedido de se & & & & & & & \\
\hline 19 & Sujeto en coordinada & & & $\mathrm{X}$ & $\mathrm{X}$ & & & $\mathrm{x}$ \\
\hline 20 & & $\begin{array}{c}\text { Sujeto en proposición } \\
\text { subordinada causal }\end{array}$ & & $\mathrm{X}$ & $\mathrm{x}$ & & $\mathrm{X}$ & \\
\hline 21 & & Objeto directo/ Leísmo & $\mathrm{X}$ & & & $\mathrm{x}$ & & $\mathrm{x}$ \\
\hline 22 & $\begin{array}{l}\text { Núcleo del sujeto en } \\
\text { complemento de } \\
\text { régimen. Relación con } \\
\text { adjunto extraclausular } \\
\end{array}$ & & & $\mathrm{X}$ & & $\mathrm{X}$ & & $\mathrm{x}$ \\
\hline 23 & $\begin{array}{l}\text { Compl. sustantivo en } \\
\text { adjunto extraclausular }\end{array}$ & & & $\mathrm{X}$ & $\mathrm{X}$ & & & $\mathrm{X}$ \\
\hline 24 & $\begin{array}{c}\text { Compl. } \\
\text { sustantivo en } \\
\text { construcción copulativa }\end{array}$ & & & $\mathrm{X}$ & $\mathrm{X}$ & & $\mathrm{X}$ & \\
\hline 25 & Sujeto de coordinada & & & $\mathrm{X}$ & $\mathrm{X}$ & & & $\mathrm{x}$ \\
\hline 26 & $\begin{array}{l}\text { Sujeto de proposición } \\
\text { subordinada causal }\end{array}$ & & & $\mathrm{X}$ & $\mathrm{X}$ & & & $\mathrm{X}$ \\
\hline 27 & $\begin{array}{l}\text { Sujeto de proposición } \\
\text { principal interrogativa }\end{array}$ & & & $\mathrm{X}$ & & $\mathrm{X}$ & & $\mathrm{X}$ \\
\hline 28 & $\begin{array}{l}\text { Sujeto de prop. principal } \\
\text { precedido de conector } \\
\text { de adición o de } \\
\text { confirmación }\end{array}$ & & & $\mathrm{X}$ & & $\mathrm{X}$ & & $\mathrm{X}$ \\
\hline 29 & $\begin{array}{l}\text { Sujeto en prop. principal } \\
\text { precedido de conector } \\
\text { de confirmación }\end{array}$ & & & $\mathrm{X}$ & $\mathrm{X}$ & & & $\mathrm{X}$ \\
\hline 30 & $\begin{array}{c}\text { Compl. } \\
\text { sustantivo en } \\
\text { construcción prepositiva }\end{array}$ & & & $\mathrm{X}$ & $\mathrm{X}$ & & & $\mathrm{X}$ \\
\hline 31 & & Sujeto en coordinada & & $\mathrm{X}$ & $\mathrm{X}$ & & & $\mathrm{x}$ \\
\hline 32 & $\begin{array}{l}\text { Sujeto de prop. principal } \\
\text { precedido de } \\
\text { reformulador de } \\
\text { distanciamiento }\end{array}$ & & & $\mathrm{X}$ & $\mathrm{X}$ & & & $\mathrm{X}$ \\
\hline 33 & $\begin{array}{l}\text { Sujeto en prop. principal } \\
\text { precedido de } \\
\text { subordinada causal. }\end{array}$ & & & $\mathrm{X}$ & & $\mathrm{X}$ & & $\mathrm{X}$ \\
\hline 34 & $\begin{array}{c}\text { Ol en prótasis, y en } \\
\text { posiciones focalizadas }\end{array}$ & & & $\mathrm{X}$ & $\mathrm{X}$ & & & $\mathrm{X}$ \\
\hline 35 & $\begin{array}{l}\text { Sujeto de prop. sub. } \\
\text { temporal }\end{array}$ & & & $\mathrm{X}$ & & $\mathrm{X}$ & & $\mathrm{x}$ \\
\hline 36 & $\begin{array}{c}\text { Sujeto en prop. sub. } \\
\text { relativa }\end{array}$ & & & $\mathrm{X}$ & & $\mathrm{X}$ & & $\mathrm{X}$ \\
\hline 37 & Sujeto de prop. principal & & & $\mathrm{X}$ & & $\mathrm{X}$ & & $\mathrm{X}$ \\
\hline
\end{tabular}




\begin{tabular}{|c|c|c|c|c|c|c|c|c|}
\hline & $\begin{array}{l}\text { precedido de sub. } \\
\text { condicional }\end{array}$ & & & & & & & \\
\hline 38 & $\begin{array}{c}\text { Sujeto de prop. sub. } \\
\text { temporal }\end{array}$ & & & $\mathrm{x}$ & & $x$ & $x$ & \\
\hline 39 & Sujeto en yuxtaposición & & $\mathrm{X}$ & & & $\mathrm{X}$ & & $\mathrm{X}$ \\
\hline 40 & $\begin{array}{l}\text { Sujeto de prop. sub. } \\
\text { completiva }\end{array}$ & & & $\mathrm{X}$ & & $\mathrm{X}$ & & $\mathrm{x}$ \\
\hline TOTAL & 30 CASOS & 10 CASOS & 4 CASOS & 36 CASOS & 19 CASOS & 21 CASOS & 10 CASOS & 30 CASOS \\
\hline
\end{tabular}

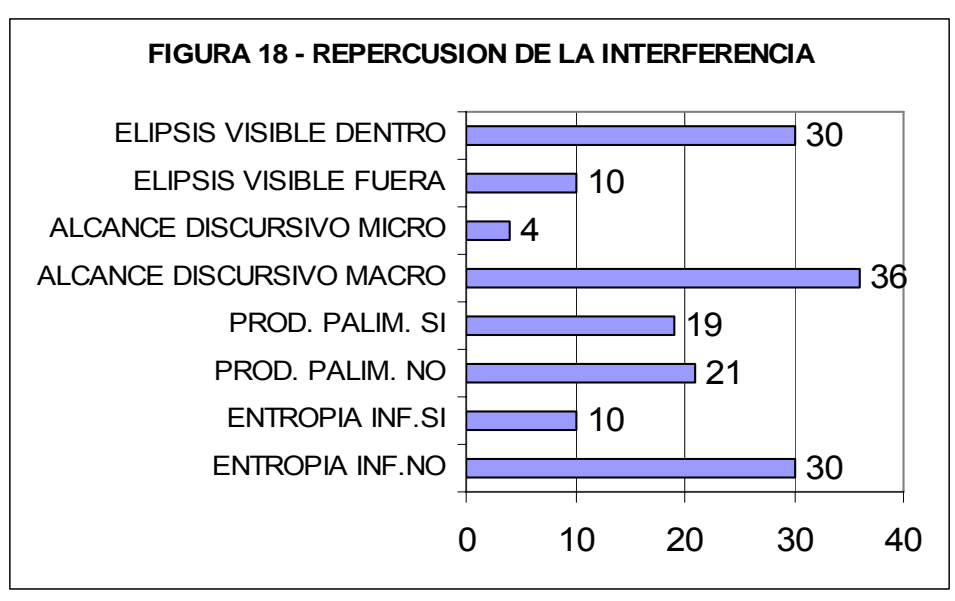


La Tabla 10 recoge las consecuencias de los análisis representados en las Tablas y Figuras precedentes.

Está constituida por los cuatro ítems planteados en el instrumento de análisis del capítulo V Metodología, a saber: elipsis visible, alcance discursivo, producción palimpséstica y entropía informativa.

En la primera columna, Elipsis visible, tomamos los datos de las Tablas $3,4 \mathrm{y}$ 5 , volcando las funciones de los sintagmas nominales elididos y la construcción gramatical en la que se realizó la elipsis, coordinación o subordinación, entre otras; en el caso de las elipsis verbales, mencionamos el fenómeno asociado a ellas.

Estos datos han sido ubicados según el modo de producción de las elipsis, ya sea dentro del sistema, es decir anomalías discursivas, o bien, fuera de él lo que acarrea anomalías sintácticas.

La segunda columna, Alcance discursivo intenta indicar hasta dónde influye la anomalía de producción de elipsis. No hemos perdido de vista que la microestructura es un integrante de la macroestructura y de la superestructura y el grado de repercusión de una anomalía, sea ésta sintáctica o discursiva, se vincula con los niveles que quedan afectados. Sin embargo, las características del corpus constituido por textos originales y traducciones integrales sin cambios superestructurales, son propicias para realizar un estudio que relacione problemas microestructurales con las consecuencias semánticas o macroestructurales [ $\rightarrow$ Capítulo I, Marco Teórico. 1.1.2.], de allí que hayamos subdividido esta columna en los dos tipos de alcance microestructural o macroestructural que pueden tener las elipsis anómalas.

La tercera columna, Producción palimpséstica, toma como eje la presencia de huellas del discurso original o de partida, en lo concerniente al mecanismo de elipsis, según lo que informa la Tabla 9 sobre visibilidad de la interferencia y su relación con las hipótesis específicas que hemos enunciado en este trabajo.

Esta columna está dividida en dos ítems: hemos marcado con sí la presencia de huellas del discurso origen y con no, su ausencia; ahora bien, los enunciados seleccionados que no presentan indicios del discurso origen también presentan 
anomalías, sólo que se han generado en otras interferencias, como lo indica la Tabla 9, en la que hemos volcado enunciados elípticos con anomalías que provienen del sistema lingüístico meta, del discurso origen como así también de su combinación.

Por último, la cuarta columna informa sobre la entropía o pérdida informativa que hemos asociado solamente con el principio traducir toda la información que no significa que haya que traducir la totalidad de las palabras, puesto que estaríamos contradiciendo el principio mismo de la traducción que venimos sosteniendo desde el comienzo del trabajo.

Los resultados cuantitativos finales informan que: la mayor parte de las anomalías encontradas en la producción de elipsis se han realizado dentro del sistema lingüístico meta, 30 casos o 75\%; en la casi totalidad de los casos, 36 casos o casi el 99\%, su incidencia es macroestructural; es pareja la distribución entre producción con anomalías en enunciados elípticos con huellas del texto original y sin ellas; la mayor parte de los enunciados estudiados, 30 casos o 75\%, han traducido la totalidad de la información del texto original.

En base a los resultados consignados y en relación con el resto de nuestro trabajo, formularemos las conclusiones finales. 


\section{CAPÍTULO VIII}

\section{CONCLUSIONES}

\subsection{Introducción}

Las traducciones en el ámbito de la formación académica o en el de la circulación social a través de la red electrónica y de las publicaciones editoriales presentan generalmente fragmentos que parecen ajenos al texto que los contiene, de allí que hayamos anunciado en el Prólogo el desarrollo de una investigación traductológica, intentando profundizar la comprensión del proceso de producción discursiva de traducciones absolutas o integrales.

La traducción de textos pragmáticos apunta a reproducir toda la información de partida, pero en ese proceso resulta poco probable calcular cómo y cuántas modificaciones de las categorías lingüísticas del texto original realizará el traductor en función del sentido que necesita reexpresar, para ir produciendo discursivamente la traducción según las normas preestablecidas. Es decir, si bien es cierto que la problemática traductológica supone una aproximación lingüístico-contrastiva puesto que se ponen dos lenguas-cultura en contacto, al mismo tiempo esa aproximación se ve sobrepasada por la dinámica propia del discurso que el traductor va construyendo en lengua-cultura meta, pues ella va guiando cada una de sus elecciones. Por eso, nuestro punto de partida no ha sido la selección apriorística de un fenómeno lingüístico en el texto de origen para contrastarlo luego con la solución en las producciones discursivas en lengua-cultura meta, sino los textos traducidos, desde los enunciados cuya lectura no era intrínsecamente libre sino que necesitaba volver al texto original para verificar lo dicho. Es que a veces el traductor decide en función de las reglas del sistema lingüístico meta y otras veces éstas le son insuficientes, todo ello como 
producto de la activación de la memoria con la constante participación del universal de interferencia.

Ampliando lo dicho, en este gran marco constituido por la memoria y la interferencia, las decisiones que va tomando el traductor tanto léxicas como sintácticas y pragmáticas acusan una matriz de doble condicionamiento: por un lado, la necesidad de asignar equivalencias en lengua-cultura meta a la totalidad de las informaciones contenidas en el texto original procesándolas según las direcciones ascendente y descendente, el conocimiento del mundo, el conocimiento lingüístico de la lenguacultura origen, el conocimiento lingüístico de la lengua-cultura meta; por el otro, la conveniencia de que tales equivalencias se solucionen según las exigencias establecidas entre el solicitante y el traductor que, cognitivamente estarán vinculadas con la decisión de deshacerse de los significantes del texto original y el esfuerzo de controlar la producción durante y una vez finalizada la producción según las normas preliminares que se hayan adoptado.

Habrá que sumar a todo ello el grado de acabamiento de una producción discursiva que, en traducción depende en gran medida de los plazos de entrega que fijen las partes, solicitante y traductor, en el pliego de condiciones o encargo de traducción. Este factor no ha sido posible medirlo en el presente trabajo porque hemos partido de traducciones ya elaboradas; sin embargo inferimos que las correspondientes a Gènéthique se realizan en plazos reducidos pues se trata de información mensual de actualización.

Con estos presupuestos y volviendo a las hipótesis de partida llegamos a las siguientes conclusiones que son producto del presente estudio cuyos resultados se ven en el capítulo precedente.

\subsection{Marco de la interferencia}

Nuestra hipótesis general enuncia:

Los productos discursivos resultantes de la traducción absoluta de textos pragmáticos francés/castellano, presentan transferencias sintáctico-discursivas gobernadas por el universal de interferencia. 
La interferencia en la producción en general y en la producción discursiva en traducción, a la luz de los estudios sobre su alcance, es un mecanismo por defecto en toda situación de lenguas en contacto; es decir que ella involucra no sólo la presencia de elementos ajenos a la lengua-cultura de llegada o poco familiares dentro del texto traducido sino que está activa permanentemente, incidiendo en las decisiones que va tomando el traductor relacionadas con la memoria.

De todos modos, como nuestro estudio nace de los enunciados con anomalías, la visibilidad de la interferencia se ha inclinado en el sentido negativo, dando lugar a la siguiente hipótesis específica.

\subsubsection{Enunciados elípticos anómalos}

La producción discursiva resultante de la traducción de textos pragmáticos francés/castellano, exhibe enunciados elípticos anómalos gobernados por el universal de interferencia.

Como se desprende de lo anterior, el estudio ha quedado inscripto en la hipótesis general, pero acotado a la producción discursiva de textos traducidos informativos con anomalías en la formulación de elipsis, que es una manera de hacer visible la interferencia como transferencia negativa. Es decir, hemos instaurado como herramienta de estudio el concepto operativo general de anomalía dentro del cual hemos distinguido, por un lado, las anomalías sintácticas cuya construcción infringe las reglas constitutivas del sistema, y por el otro, las anomalías discursivas, que responden a las reglas del sistema lingüístico de referencia, no obstante lo cual afectan la cohesión, la construcción del sentido y por consiguiente el pasaje de la información.

Cuantitativamente hablando, los enunciados traducidos que requirieron más de una lectura o directamente una vuelta al texto original con la finalidad de ajustar lo expresado con el contenido transmitido, revelaron la ocurrencia de elipsis con los dos tipos de anomalías arriba señaladas, es decir, sintácticas y discursivas. Como era de prever, las anomalías sintácticas han arrojado resultados menos abultados que las discursivas, lo cual es consistente con el presupuesto de que quien asume la responsabilidad de traducir conoce las reglas de los sistemas lingüísticos puestos en juego. Además, ya señalamos que la mayor cantidad de anomalías sintácticas de nuestro corpus textual se han presentado en las publicaciones electrónicas del sitio 
www.genethique.org, es decir, agramaticalidades que han persistido en la versión final publicada y que interpretamos como emergente del carácter provisorio que generalmente se asocia a la producción virtual [ $\rightarrow$ Capítulo VII, Resultados e Interpretación. 7.1.1.4.].

Un criterio central en la construcción de elipsis es la recuperabilidad, que puede ser oracional o transfrástica, según lo que hemos volcado en la Tabla 6 y Figuras 15A y 15B. Si es oracional, el elemento elidido aparece dentro del enunciado separado por punto del anterior y el posterior. En cambio, la recuperabilidad es transfrástica cuando el antecedente o consecuente no está dentro de ese límite grafémico sino en otros enunciados. La consecuencia directa de la producción de elipsis con anomalías discursivas y sintácticas es la dificultad de recuperar el elemento elidido, ya sea dentro o fuera de los límites oracionales, debido a la coexistencia de más de un candidato a antecedente y a la distancia entre hueco y elemento elidido, todo lo cual contribuye a instaurar ambigüedad. Sin embargo, por corta que sea la oración, tiene especial incidencia el hecho de que la función del elemento elidido no esté claramente expresada: pensemos en Sin embargo, desde que existe, ¿qué impidió hacer la bioética? que hemos analizado como caso 38 en El racismo del gen. También en esta fuente textual, que es una transcripción del género entrevista, hemos detectado debilitamiento de la recuperabilidad por pérdida deíctica de ostensión, especialmente en la producción del posesivo su/sus, que ha sido analizada, por ejemplo en los casos 23 y 24.

Detectadas las anomalías y clasificadas según: clases (nominal y verbal) y subclases (nominales máximas y parciales), funciones (sujeto, OD, OI, complemento de régimen, predicativo, complemento del sustantivo), tipos (sintáctica y discursiva), recuperabilidad (oracional y transfrástica), hemos establecido los grandes mecanismos que se observan en relación con la elipsis (elevación de la frecuencia, descenso de control lingüístico y lingüístico-discursivo), repercusión de la elipsis a partir de los fenómenos concretos (alcance discursivo, producción palimpséstica y entropía informativa) y visibilidad (sistema lingüístico meta, discurso de origen y otro).

A continuación veremos cómo ha influido el texto original en la traducción. 


\subsubsection{Influencia del discurso de partida sobre el de llegada}

La segunda hipótesis específica trata sobre la interferencia del discurso de partida:

En los productos discursivos resultantes de la traducción de textos pragmáticos francés/castellano, se visualizan enunciados elípticos anómalos gobernados por el universal de interferencia, según una influencia del discurso de partida sobre el de llegada.

\subsubsection{Anomalías sintácticas}

Nos referimos, en primer lugar, a los calcos que se producen de manera no reflexiva y que son los casos más patentes de transferencia negativa manifestados en nuestro corpus en forma de anomalías sintácticas, que como ya dijimos son pocas y provienen de la fuente Gènéthique. Recordemos, de manera ilustrativa: La mayor controversia de estos trabajos fue sin duda el presentado (caso 2), que comenzó con la transformación categorial controversia/controversé y no fue acompañada de transformaciones en el predicativo presentado. o bien el enunciado que desean lo mejor para sus hijos y tampoco la obligación impuesta por un Estado coercitivo/ qui désirent le meilleur pour leur enfant, et non plus à l'obligation imposée par un Etat coercitif (caso 5), que reproduce la sintaxis errónea del texto original respecto del empleo de la partícula de polaridad.

\subsubsection{Anomalías discursivas}

En segundo lugar, como anomalías discursivas hemos considerado la no utilización del recurso natural del castellano de duplicación del argumento interno que facilitaría la recuperabilidad del antecedente aumentando la cohesión en la eutanasia le parece un remedio simplista e inhumano/l'euthanasie leur paraît un remède simpliste et inhumain, dentro del enunciado 16 en el que coexisten candidatos en número singular y plural. Este mismo fenómeno se ha visto en la prótasis de subordinadas condicionales, como el caso 18 si se califica de bien en el que el incremento pronominal se puede ser interpretado como pasiva pronominal o como impersonal, pero cualquiera sea su interpretación, convendría cohesionar la información mediante el pronombre OD los que retome el antecedente endofórico embriones, como secuencia se los. Una situación análoga se aprecia en los Ol contenidos en el caso 34 le dicen, lo que le 
interesa, lo que sí le interesa, decírselo, cuya cohesión aumentaría si apareciera el pronombre indefinido a alguien le dicen o, incluyendo al enunciador y el coenunciador, a uno le dicen que remite anafóricamente a la oración contigua. El recurso natural de reiteración no utilizado que tiene como finalidad cohesionar la información es una clara interferencia del discurso original.

En resumen, la transferencia negativa se ha materializado en la re-producción discursiva de anomalías sintácticas del texto original en francés y en anomalías discursivas que han incidido en la dificultad de recuperar el antecedente, entorpeciendo el pasaje de la información que es esencial en los textos pragmáticos, fenómenos que hemos denominado producción palimpséstica, como aparece en la Tabla 10.

\subsubsection{Influencia del sistema de la lengua materna}

Nos interesa ahora comprobar si el sistema de la lengua meta ha interferido negativamente en la producción discursiva en traducción según la tercera hipótesis específica:

En los productos discursivos resultantes de la traducción de textos pragmáticos francés/castellano, se visualizan enunciados elípticos anómalos gobernados por el universal de interferencia, según una influencia del sistema de la lengua materna del traductor.

Al realizar la distribución entre elipsis nominales y verbales con anomalías, los datos de la Tabla 1 y la Figura 10 muestran que el $95 \%$ son nominales y, dentro de ellas el $82 \%$ afectan a todo el sintagma nominal o elipsis máximas mientras que el $18 \%$ restante representa a las elipsis parciales tal como aparece en la Tabla 2 y la Figura 11 del capítulo precedente. Veamos qué tipo de anomalía hemos encontrado.

\subsubsection{Anomalías sintácticas}

Los pocos casos que hemos contabilizado de elipsis nominal máxima o parcial en función sujeto con anomalías sintácticas, se distribuyen en: estructuras coordinadas que no unen constituyentes de igual nivel, como el caso 12 ...ataque a la vida de su hijo, en el seno materno, y que perdió.../ l'atteinte à la vie d'un enfant à naître qu'elle portait et qu'elle a perdu en donde se ha modificado el primer constituyente y se ha instaurado una coordinación sintácticamente anómala y un opacamiento en la 
búsqueda del valor léxico de la elipsis nominal máxima sujeto; relaciones entre los constituyentes cuyo resultado no produce un equivalente semántico respecto del texto original, como en el caso 8 La protección de las bases de datos y la vida privada deben estar garantizados/ La protection des données et de la vie privée doit être garantie puesto que, además de haber una falta de concordancia, al no considerar protección como núcleo de los dos SSNN coordinados las relaciones y el sentido dentro de la oración han cambiado con respecto al original francés en donde se garantiza la protección tanto de las bases de datos como de la vida privada; problema de concordancia como en el caso 20 puesto que ya constituye un ser humano/ puisqu'il s'agit déjà d'un être humain en donde hay elipsis de sujeto compuesto no acompañada por un verbo en plural; criterios paralelísticos deficientes para la formulación de elipsis nominales parciales (caso 31) podría gobernarse a los genes e incluso (en un trivial sentido comercial) encargar genes/on pourrait commander aux gènes et même (en un sens trivial commercial) commander des gènes, en donde se ve que a diferencia del francés, el texto traducido no obtiene un verbo como commander con dos significados según el régimen directo o indirecto, sino que ofrece dos formas equivalentes a los significados evocados por el texto original, pero no hace las transformaciones sintácticas necesarias para su funcionamiento en el texto de llegada.

La anomalía sintáctica de leísmo (casos 4, 9, 21) es un caso especial puesto que si bien éste no observa las reglas estructurales del castellano, sí cumple con las normas sociales de uso del castellano peninsular. Explicado según el modelo coseriano, el leísmo representa una elección individual del traductor basada en una norma pragmático-semántica, que se aparta de la regla del sistema; o bien, siguiendo la terminología touriana es una selección de las normas iniciales de aceptabilidad para una comunidad, y por consiguiente actúa como norma lingüístico-textual, lo cual encuentra su explicación en que la traducción fue realizada por un hablante cuya lengua materna es el castellano ibérico [ $\rightarrow$ Capítulo $V$, Metodología. 5.5.1.1.].

\subsubsection{Anomalías discursivas}

En nuestro corpus, las elipsis nominales máximas se presentan en la función sujeto en el $78 \%$ [Tabla 3, Figura 12] y en general acusan anomalías discursivas, es decir que se han realizado dentro del sistema lingüístico de referencia como lo idican la 
Tabla 10 y la Figura 18. Sabemos que existe una diferencia contrastiva global entre los sistemas lingüísticos francés/castellano según la cual las construcciones oracionales del primero implican la conservación el SN sujeto mientras que el castellano puede elidirlo, ya que su rico sistema de desinencias verbales recupera los rasgos de persona y número del sujeto pronominal que no aparece con forma fonética en la oración, característica que la gramática generativa denomina lenguas pro-drop. De allí que la elipsis nominal máxima de sujeto sea la más frecuente, como también lo recoge la investigación traductológica sobre medios cohesivos comentada en la Introducción. ${ }^{1}$

De todos modos, tal riqueza flexiva del castellano no es ilimitada puesto que existe igualdad morfológica en tiempos y personas de verbos del primer grupo (él lava, usted lava, ellos lavan, ustedes lavan), del segundo grupo (él teme, usted teme; ellos temen, ustedes temen), del tercer grupo (yo decía, ella decía, usted decía). Este hecho explica que las anomalías de las elipsis en función sujeto sean habitualmente discursivas, puesto que una morfología verbal idéntica genera un producto discursivo ambiguo, si el enunciado en el que está contenido el verbo en cuestión admite más de un candidato como sujeto; es decir, que aunque estructuralmente la producción responda a las reglas del sistema, la cohesión disminuye.

En resumen, la mayor frecuencia en nuestro corpus está en la elipsis del argumento o sujeto, con incidencia discursiva, lo que constituye la interferencia intralingüística o las reglas del sistema lingüístico meta que obstaculizan la fluidez en el pasaje de la información. Dicho de otro modo, la memoria ha activado reglas del sistema lingüístico meta que han interferido intralingüísticamente la construcción del discurso.

\subsection{Enunciados anómalos e interferencia bidireccional ${ }^{2}$}

La Tabla 9 y la Figura 17 muestran la distribución de las transferencias negativas según que se hayan originado en el sistema lingüístico meta, en nuestro caso la lengua materna castellano, como producción inmediata que proviene de la memoria lingüística y se concreta en una sintaxis oracional dentro de las reglas del sistema lingüístico meta

\footnotetext{
${ }^{1}$ En la introducción, señalamos los resultados cuantitativos de frecuencia de elipsis en los textos traducidos al castellano, con respecto a los originales franceses (Sánchez, 1994: 102).

${ }^{2}[\rightarrow$ Capítulo III, Interferencia. 3.1.].
} 
con consecuencias discursivas no deseadas; por supuesto, esta primera categoría está en línea con la tercera hipótesis específica $[\rightarrow 8$.2.3.]. La tabla en cuestión también contempla las transferencias negativas originadas en el discurso de partida y refieren a las re-producciones no reflexivas que responden a la segunda hipótesis específica $[\rightarrow 8.2 .2$.$] . Sin embargo, no en todos los casos hemos podido establecer con nitidez$ dónde se ha generado la transferencia negativa porque hay indicios tanto del discurso original en francés como del sistema lingüístico meta en castellano lengua materna.

Para su ilustración recordemos que las elipsis parciales con función complemento del sustantivo pueden estar representadas por el posesivo antepuesto al nombre ${ }^{3}$ que reúne los rasgos de determinante del sustantivo y de pronombre, puesto que toma la posición de especificador y a su vez constituye una proyección del pronombre. Por lo tanto, en todo determinante posesivo está presente una relación endofórica con un poseedor que puede ser recuperado por los mecanismos de anáfora o catáfora, o exofórica en una relación deíctica que remite al contexto o situación.

Estos casos de elipsis parcial $(23,24$ y 30$)$ han sido analizados como anomalías discursivas pues generan ambigüedad o debilitamiento de la recuperación endofórica, oracional o transfrástica, por dos razones: morfológica, ya que el posesivo su remite tanto a la $3^{a}$ persona (él/ella y sus plurales) como a la $2^{a}$ (usted/es) y discursiva propiamente dicha, pues dentro del corpus textual se consignan entrevistas transcriptas que han perdido características de la oralidad como la ostensión, sin que se la haya compensado con otro recurso lingüístico-discursivo. La influencia bidireccional se explica por un lado, en el respeto de la forma del texto original que utiliza un posesivo (votre) y por el otro, en la búsqueda de la correspondencia del posesivo su en el sistema lingüístico meta, sin haber previsto la posibilidad de más de un candidato como antecedente.

En la Tabla 9, también hemos considerado que ha habido interferencia bidireccional en los casos 12, 18,19, 20, 25, 26, 29, que responden a otros fenómenos, pero en todos ellos se comprueba que ha habido excesivo respeto de la forma del texto

\footnotetext{
3 "El posesivo antepuesto puede realizar la función semántica del argumento del nombre en particular en los sintagmas nominales interpretados como poseedor, agente o tema, cuando vienen introducidos por la preposición de" (Picallo y Rigau, 2000: 980).
} 
original y una producción que se basa en la asignación de correspondientes que surgen del sistema lingüístico meta.

La información que precede nos ha permitido establecer, por un lado los grandes mecanismos que se observan en relación con los enunciados elípticos anómalos que hemos caracterizado como elevación de la frecuencia, descenso de control lingüístico y descenso de control lingüístico-discursivo [ $\rightarrow$ Tabla 8 , Figura 16] y, por otro lado, su repercusión que hemos clasificado como alcance discursivo, producción palimpséstica y entropía informativa, a partir de la visibilidad de cada uno de los fenómenos concretos según se ha expuesto en la Tabla 10, Gráfico 18.

\subsection{Mecanismos observables}

Si bien hemos acordado en que el problema de la transferencia en traducción es una mirada desde la mente del que traduce y plantea el estudio de las representaciones conceptuales, lingüísticas, morfosintácticas y de todas aquellas imágenes mentales con sentido, no es menos cierto que su visibilidad se realiza a través de las elecciones léxicas y sintácticas. Hemos adscripto pues, por un lado, a la postura según la cual los procesos de producción se materializan en mecanismos de emisión de las formas lingüísticas, por lo tanto su estudio es indirecto y limitado, y por otro lado, al hecho de que la memoria es un mecanismo que está presente en la puesta en juego de mecanismos que controlan la visibilidad de la transferencia negativa [ $\rightarrow$ Capítulo II, Producción discursiva. 2.6.4.]. Dicho de otro modo: las habilidades que conforman la competencia traductora se resumirían en la puesta en relación controlada de los mecanismos de memoria e interferencia. Ello significa que la activación de las reglas sintácticas que tienen su ámbito de aplicación en la oración, quedará supeditada a las necesidades que gravitan en la producción del discurso de llegada, generalmente en lengua-cultura vernácula.

Volviendo a los casos palpables de nuestro corpus, los hemos agrupado según que acusen la elevación de la frecuencia de la elipsis, el descenso de control lingüístico y el descenso de control lingüístico-discursivo [ $\rightarrow$ Tabla 8, Figura 16]. 
Sintetizando la descripción realizada en esa tabla, hemos considerado al leísmo como emergente del descenso del control lingüístico pero teniendo presente que una de las tensiones en la producción discursiva en traducción es la elección del sistema o de la norma pragmático-semántica.

En los demás casos de la Tabla 8, se aprecia que los mecanismos observables considerados se han manifiestado simultáneamente de a dos o de a tres y no individualmente, por ejemplo la frecuencia de elipsis y de descenso del control lingüístico-discursivo engloban a los que no han mostrado anomalías del sistema lingüístico (casos 1, 3, 10, 11, 13, 14, 15, 17, 23, 24, 26 al 30, 32, 33, 34, 36, 37, 39 y 40). De manera análoga, hemos visto simultaneidad entre descenso del control lingüístico y descenso del control lingüístico-discursivo (casos 2, 5, 6, 7, 8, 16), mientras que otros comparten los tres mecanismos (casos 12, 18, 19, 20, 22, 31, 35, 38).

La distribución de la Figura 16 ha indicado que la mayor parte de las anomalías se deben a un descenso de los mecanismos de control lingüístico-discursivo, seguidos por la tendencia a elevar la frecuencia de elipsis y por último, el descenso del control lingüístico, si bien es cierto que varios casos muestran que ambos mecanismos actúan igualmente.

Como ya señalamos en el capítulo anterior, estos datos nos permiten afirmar que, excepción hecha del leísmo, en los casos de nuestro corpus ha habido traducción automática (Gouadec, 1989: 27), lo cual indica que el mecanismo básico de memoria de las formas lingüísticas ha sufrido desestabilización por influencia de la interferencia, tomada en su sentido negativo.

\subsection{Repercusión de los enunciados elípticos anómalos}

Habiendo estudiado los enunciados elípticos anómalos del corpus a través de la distribución, las funciones, los tipos y la recuperbilidad, por un lado, y considerado su visibilidad y los mecanismos observables, ${ }^{4}$ por el otro, estamos en condiciones de

\footnotetext{
${ }^{4}$ Nos referimos a los resultados ordenados en las Tablas 2 a 9 y las Figuras que les corresponden.
} 
informar sobre la repercusión de esos enunciados en la producción discursiva, que es nuestro problema central.

La Tabla 10 y la Figura 18 dan cuenta del fenómeno concreto estudiado y su alcance discursivo, partiendo de que la microestructura integra la macroestructura y, a su vez, la superestructura. Como ya hemos dicho, el grado de repercusión de una anomalía, sea ésta sintáctica o discursiva, se vincula con los niveles que quedan afectados o alcance discursivo. Ahora bien, las características de nuestro corpus, constituido por textos originales y traducciones integrales sin cambios superestructurales, son propicias para interpretar las relaciones entre problemas microestructurales y las consecuencias semánticas o macroestructurales.

Sin tener en cuenta el origen de las anomalías (texto original o sistema lingüístico meta), hemos utilizado el esfuerzo en la recuperabilidad del antecedente como criterio para estimar la repercusión en niveles superiores, lo que incide en la disminución de la fluidez en el pasaje de la información. ${ }^{5}$ Es decir que instauramos la relación de proporcionalidad inversa: a mayor esfuerzo en la recuperabilidad del antecedente menor fluidez en el pasaje de la información.

Además, hemos observado la repercusión en la macroestructura de aquéllos fragmentos que muestran una distribución de constituyentes que no perturba la lectura, pero cuyo resultado es una información no equivalente a la brindada en el texto original, fenómeno que sólo se aprecia al confrontar el TT con el TO, como en el caso 6: la realidad del proyecto paternal es el problema esencial y, en consecuencia, el riesgo de instrumentalizar al niñol le problème essentiel est celui de la réalité du projet parental et donc du risque d'instrumentalisation de l'enfant donde, además de la inexactitud terminológica que no hemos estudiado (paternal/parental) la modificación de la distribución informativa muestra un matiz de cambio semántico; o en el caso 22: hoy, la manera de practicar la ciencia de lo viviente no tiene mucho que ver con la de sus padres fundadores/ la façon de pratiquer la science du vivant aujourd'hui n'a pas plus grand-chose à voir avec celle de ses pères fondateurs, el desplazamiento del adverbio

\footnotetext{
${ }^{5} \operatorname{casos} 1,2,3,5,7,8,10,11,12,13,14,15,16,17,18,19,20,23,24,25,26,27,28,29,30,32,33,34$,
} $35,36,37,39,40$. 
hoy como adjunto extraclausular no logra la equivalencia, que es la comparación de los dos momentos (hoy y antes) en la práctica de la biología.

Por último, hemos considerado si hubo tanto producción palimpséstica, asociada a la presencia del discurso original, como entropía o pérdida informativa que hemos vinculado únicamente con el precepto traducir toda la información sin que ello signifique traducir todas las palabras del texto original.

Los resultados cuantitativos que surgen de la Tabla 10, Figura 18, confirman que la mayor parte de las anomalías encontradas en la producción de elipsis son discursivas, es decir, $75 \%$ se han realizado dentro del sistema lingüístico meta y la casi totalidad de los casos, alrededor del 99\%, inciden en el nivel macroestructural. Esto indica que, en nuestro corpus, la traducción de textos pragmáticos se ha revelado como campo propicio para un procesamiento preferentemente ascendente en lugar de holístico, con consecuencias semánticas. En cuanto a la producción palimpséstica, los resultados cuantitativos muestran que es pareja la distribución de enunciados elípticos anómalos con y sin huellas del texto original, lo cual explicaría la bidireccionalidad de la interferencia en los enunciados estudiados. En cuanto a la entropía, los resultados han dado cuenta de que un $25 \%$ de los enunciados de este trabajo no han traducido la totalidad de la información del texto original, lo cual reviste importancia especialmente en la traducción de textos pragmáticos.

\subsection{Perspectivas}

En el Prólogo anunciábamos la realización de un estudio partiendo de las anomalías palpables de un único fenómeno lingüístico-discursivo, con la esperanza de que, a través de él, pudiéramos contribuir a explicar cómo producimos en traducción, más allá de la elipsis.

Como lo han demostrado los estudios cognitivos de la Teoría Interpertativa de la Traducción, la memoria es un mecanismo básico que permite la comprensión (Lederer, 2006: 141-162) y el razonamiento analógico que se activa para la búsqueda de la reexpresión ajustada (Delisle, 1995: 78). La memoria como mecanismo único que razones de índole analítica han dividido en memoria de corto plazo y de largo plazo, 
esta última dividida a su vez en memoria semántica, episódica y procesual, es indispensable para el conocimiento complejo pues ella realiza la recuperación de la información en diferentes niveles de procesamiento. Es asi como esta unidad cognitiva superior participa de todo el proceso traductivo y completa magistralmente los momentos de la recreación informativa de modo personal, marcando rítmicamente los hallazgos de unidades linguísticas necesarias para completar conceptualmente los datos que la lengua meta necesita en la transferencia de informacion de la lengua de origen.

El segundo mecanismo por defecto es la interferencia que ha dado lugar a diversas clasificaciones y ha sido especialmente estudiada por Gideon Toury (2004) en el terreno de la Traductología. Hemos valorado en particular la interferencia bidireccional que, en el ámbito de la traducción, la entendemos como vaivén entre el discurso de partida y reglas del sistema de la lengua meta, en nuestro caso el castellano que coincide con la lengua materna del traductor. Así, en nuestro corpus hemos podido comprobar que la bidireccionalidad se ha manifestado negativamente cuando el discurso de origen ha sido excesivamente respetado con una producción basada en una correspondencia únicamente lingüística, que ciertamente está vinculada con un modo de procesamiento ascendente, revelador de soluciones automáticas. De allí que consideremos que en la producción discursiva de traducciones de textos cuya principal función es informativa, se estimule el esfuerzo para atender los criterios paralelísticos en la construcción de elipsis o sencillamente se la reemplace por la reiteración del referente o por la presencia pronominal que despeje las ambigüedades de posibles referencias anafóricas y catafóricas. Es que si bien la elipsis es un medio cohesivo de gran impacto, también puede transformarse, como hemos visto, en un elemento que obstaculice la claridad de información.

También en el Prólogo identificábamos dos núcleos intercomunicados que nos motivaron a realizar este estudio: el profesional que comprende tanto la actividad de traducción propiamente dicha como su enseñanza, y el especulativo que problematiza las diversas observaciones planteadas por la traducción, intentando una descripción organizada y, en el mejor de los casos, una explicación convincente. Creemos que es provechoso para ambos núcleos el hecho de comprobar que la producción apela a la 
memoria para expresarse lingüística y discursivamente, pero que a su vez la interferencia la desestabiliza, aun cuando el texto traducido reproduzca soluciones que responden al sistema y las normas de la lengua de llegada; con esto queremos decir que la desestabilización se hace patente en el terreno de las anomalías. Al mismo tiempo, afirmamos que la lectura del texto traducido, intentando considerarlo como producción discursiva de primera mano y confrontado luego con el texto original, es fuente válida de investigación, cuyas conclusiones, organizadas con el propósito de una generalización constituye una herramienta para la formación de traductores.

Para avanzar en el problema general de la producción discursiva en traducción francés/castellano, creemos conveniente continuar estudiando otros factores lingüístico-discursivos, como es el caso, por ejemplo, de la expresión de la designación a través de diversos paradigmas, entre ellos el sistema demostrativo, ya iniciado por otros investigadores. En este camino, creemos que el desarrollo analítico que hemos generado puede contribuir, con las modificaciones del caso, a su descripción y quizás a su explicación. 


\section{BIBLIOGRAFÍA GENERAL}

\section{A}

Academia Argentina de Letras (2003). Diccionario del habla de los argentinos, Buenos Aires, Planeta/Espasa.

ADAM, Jean-Michel (1990). Éléments d'une linguistique textuelle, Lieja, Mardaga.

ADAM, Jean-Michel (1999). Linguistique textuelle. Des genres de discours aux textes, París, Nathan.

ALLIAUD, Alicia; CAGNOLATI, Beatriz; FORTE MÁRMOL, Amalia; GENTILE, Ana María; URRUTIA, María Inés, dirigido por FREYRE, María Luisa (2001). "Traducción científico-técnica francés-español: Criterios de evaluación”, en: Cuadernos de Lenguas Modernas, No3, Departamento de Lenguas y Literaturas Modernas, La Plata, FaHCE, UNLP.

ALLIAUD, Alicia; CAGNOLATI, Beatriz; GENTILE, Ana María; URRUTIA, María Inés, dirigido por FREYRE, María Luisa (1999), Textos especializados: comprensión y traducción por profesionales del área científico-técnica y por traductores, Serie Estudios e Investigaciones $n^{\circ} 36$, ISSN 15140075, Secretaría de Extensión Facultad de Humanidades y Ciencias de la Educación, La Plata, Departamento de Medios Audiovisuales de la FaHCE, UNLP.

ALLOA, Hugo y MIRANDA de TORRES, Silvia (2001). Hacia una lingüística contrastiva francés-español, Córdoba, Comunicarte Editorial.

ARFUCH, Leonor (1995). La entrevista, una invención dialógica, Barcelona, Paidós.

AUSTIN, John L. (1970). Quand dire c'est faire, traducido al francés, París, Seuil.

B

BAGGE, Christine (1990). “Equivalence lexicale et traduction”, en: Meta, Vol. 35, n¹, Montreal, Presses de l'Université de Montreal. 
BAKER, Mona (1998). "Réexplorer la langue de la traduction : une approche par corpus", en: Meta, vol. 43, $\mathrm{n}^{\circ}$ 4, Presses de l'Université de Montreal, Montreal.

BALLY, Charles (1951). Traité de stylistique française, París, Klincksieck.

BASSNETT-MC GUIRE, Susan (1980). Translation Studies, Londres, Methuen.

BECKER, Annette (2002). "Análisis de la Estructura pragmática de la cláusula en el español de Mérida", en: Estudios de Lingüística Española, vol. 17, ISSN: 1139-8736, Mérida, Universidad de Los Andes.

BÉDARD, Claude (1986), "Les lectures d'observation: la moisson du traducteur technique", en: Meta XXXI, 4, Montréal, Presses de l'Université de Montréal.

BÉDARD, Claude (1986). "Les lectures d'observation: la moisson du traducteur technique", en: Meta XXXI, n4, Montréal, Presses de l'Université de Montréal.

BÉLA SZÉKELY, L.C. (1958). Diccionario Enciclopédico de la Psique. Buenos Aires, Claridad.

BENJAMIN, Walter (1971). "La tarea del traductor", en: Angelus Novus, Barcelona, Edhasa.

BERMAN, Antoine (1994). Pour une critique des traductions: John Donne, París Gallimard.

BIGOT, Michèle (2008a). "Introduction", en: Ellipse et effacement. Du schème de phrase aux règles discursives. Obra colectiva dirigida por Jean-Christophe Pitavy y Michèle Bigot, Saint-Étienne, PUSE.

BIGOT, Michèle (2008b). "Effacement et ellipse: du schème phrastique à l'organisation discursive" en: Ellipse et effacement. Du schème de phrase aux règles discursives. Obra colectiva dirigida por Jean-Christophe Pitavy y Michèle Bigot, Saint-Étienne, PUSE.

BOSQUE, Ignacio (1990). Las categorías gramaticales. Relaciones y diferencias, Madrid, Síntesis.

BRISSET, Annie (1990). Sociocritique de la traduction. Théâtre et altérité au Québec. Editions du Préambule, Longueil.

BRUCART, José María (2000). “La elipsis", en: Gramática descriptiva de la lengua española. Obra colectiva dirigida por Ignacio Bosque y Violeta Demonte, vol. 2, Madrid, Real Academia Española / Espasa Calpe. 
BYK, Christian (2000). "La bioéthique: langage médiateur ou langage médiatique?", en: La Bioéthique: un langage pour mieux se comprendre? Obra colectiva bajo la dirección de Christian Byk, París, ESKA.

C

CAGNOLATI, Beatriz (2001). "Réflexions sur l'articulation entre compréhension et expression", en: Cuadernos de Lenguas Modernas, $\mathrm{N}^{\circ} 3$, Departamento de Lenguas y Literaturas Modernas, FaHCE, UNLP, La Plata, Grafitos.

CAGNOLATI, Beatriz (2008). "Discurso de la bioética: un estudio contrastivo francéscastellano", en: La Traducción. Hacia un encuentro de lenguas y culturas. ISBN ES: 978-987-602-076-3 Córdoba. Ed. Comunicarte.

CAGNOLATI, Beatriz (2008). "Traducción publicada y producciones de estudiantes avanzados: un estudio contrastivo", en: Actas del I Congreso Internacional de Traducción Especializada. Colegio de Traductores Públicos de la Ciudad de Buenos Aires. ISBN 10-98796910-7-5; ISBN 13-978987969107-6.

CAGNOLATI, Beatriz (2009), "Relación entre producción y producción discursiva en traducción", en: Actas de las II Jornadas Internacionales de Traductología. Centro de Investigación en Traducción, Facultad de Lenguas, UNCórdoba.

CALSAMIGLIA, Helena y TUSÓN, Amparo (2001). Las cosas del decir. Manual de Análisis del discurso. Barcelona, Ariel.

CARTAGENA, Nelson (1992). "Las tareas de la lingüística contrastiva en España en el próximo lustro", en: Actas del Congreso de Sevilla: La lengua española, Sociedad y enseñanza Centro Virtual Cervantes, cvc.cervantes.es/obref/aih/pdf/06/aih_06_1_080 [consultado el 20/02/06].

CARY, Edmond (1956). La traduction dans le monde moderne, Ginebra, Librairie de l'Université.

CATFORD, John C. (1965). Linguistic Theory of Translation, Londres, Oxford University Press.

CIAPUSCIO, Guiomar (1994). Tipos textuales, Buenos Aires, Universidad Nacional de Buenos Aires. 
COIRIER, Pierre ; GAONACH, Daniel; PASSERAULT, Jean-Michel (1996). Psicholinguistique textuelle. Une approche cognitive de la compréhension et de la production des textes. Université de Poitiers. Laboratoire de langage et Communication (CNRS. URA 1607), París, Armand Colin.

CORDER, Stephen (1991). "La importancia de los errores del que aprende una lengua segunda", en: La adquisición de las lenguas extranjeras, obra colectiva compilada por Juana Muñoz Liceras, Madrid, Visor.

CORMIER, Monique (1990). "Proposition d'une typologie pour l'enseignement de la traduction technique ", en: Etudes traductologiques, París, Minard.

COSERIU, Eugenio (1977). “Lo erróneo y lo acertado en la teoría de la traducción”, en: El hombre y su lenguaje, Madrid, Gredos.

COSERIU, Eugenio (1989). Teoría del lenguaje y Lingüística general, Madrid, Gredos.

\section{$\mathrm{CH}$}

CHARAUDEAU, Patrick; MAINGUENEAU, Dominiqiue (2005). Diccionario de análisis del discurso, traducción al castellano de Irene Agoff y supervisión de Elvira Arnoux, Amorrortu, Buenos Aires.

CHARAUDEAU, Patrick (1991). Grammaire du sens et de l'expression, París, Hachette.

CHOMSKY, Noam (1970). Aspectos de la teoría de la sintaxis, traducción española, Madrid, Aguilar.

D

DANCETTE, Jeanne (1995). Parcours de traduction, Lille, Presses Universitaires de Lille.

DE BEAUGRANDE, Robert (1978). Factors in a Theory of Poetic Translating, Van Gorcum, Assen

DE BEAUGRANDE, Robert (1993). Linguistic Theory: The Discourse of Fundamental Works, Longman, Londres y Nueva York.

DE KOCK, Josse (1996). Gramática española, enseñanza e investigación. Apuntes metodológicos, Salamanca, Universidad de Salamanca.

DELBECQUE, Nicole (1996). "La posición del adjetivo adnominal en francés y en español”, en: Lingüística contrastiva. Gramática española. Enseñanza e investigación. Apuntes metodológicos, dirigida por Josse De Kock, Salamanca, Ediciones Universidad de Salamanca. 
DELISLE, Jean (1984). L'analyse du discours comme méthode de traduction, Ottawa, Ed. de l'Université d'Ottawa.

DELISLE, Jean y BASTIN, Georges (1997). Iniciación a la traducción, Caracas, Universidad Central de Venezuela, Consejo de Desarrollo Científico y Humanístico.

DEPIANTE, Marcela y HANKAMER, Jorge (2005). "La condición de identidad en la elipsis: El caso del truncamiento", en: Actas del Congreso de la Sociedad Argentina de Lingüística, eqaula.org/eva/file.php/850/.../data/.../Trncamiento._ejemplos.pdf [consultado el 26 - 02 -09].

DE VEGA, Manuel (1995). Introducción a la psicología cognitiva, Salamanca, Alianza Editorial.

DIFABIO DE ANGLAT, Hilda (2009). "El test cloze en la evaluación de la comprensión del texto informativo de nivel universitario", en: Revista de lingüística teórica y aplicada, vol. 46, no.1, Concepción, Universidad de Concepción, http://www.scielo.cl/scielo.php?script=sci arttext\&pid=S0718-

48832008000100007\&lng=es\&nrm=iso. ISSN 0718-4883. [consultado el 10/01/09].

DI TULLIO, Angela (1997). Manual de gramática española, Buenos Aires, Edicial.

DOMÍNGUEZ VÁZQUEZ, María José (2001). "En torno al concepto de interferencia", en: Círculo de Lingüística Aplicada a la Comunicación, Universidad Complutense de Madrid, ISSN 1576-4737, www.ucm.es/info/circulo/no5/dominguez.htm [consultado el 20/02/07].

DUBOIS, Danièle y WEIL-BARAIS, Annick (1999). "Comment l'homme communique-til”, en: L'homme cognitif, obra colectiva dirigida por Annick Weil-Barais, París, PUF.

DUBOIS, Jean y otros (1983). Diccionario de Lingüística. Traducción al castellano de Inés Ortega y Antonio Domínguez. Dirección y adaptación de Alicia Yllera. Madrid, Artes Gráficas Ibarra S.A.

DUBOIS, Jean y otros (1994). Dictionnaire de linguistique et des sciences du langage. Paris, Larousse.

DUCROT, Oswald; SCHAEFFER, Jean-Marie (1995). Nouveau Dictionnaire Encyclopédique des Sciences du Langag, París, Ed. Du Seuil.

DURIEUX, Christine (1987). “Qu'est-ce qu'une bonne traduction?”, en: Recueil de tirés à part, Centre de recherche en traductologie, París, ESIT. 
ESTANY, Anna (2001). "La conceptualización de la realidad" en: Terminología y cognición, Barcelona, Institute Universitari de lingüística aplicada Universitat Pompeu Fabra.

$\mathbf{F}$

FEDOROV, Andrei (1953). Introduction à la théorie de la traduction, Moscú, Instituto de Literaturas en lenguas extranjeras.

FERNÁNDEZ-ORDÓÑEZ, Inés (2000). "Leísmo, laísmo y loísmo", en: Gramática descriptiva de la lengua española. Obra colectiva dirigida por Ignacio Bosque y Violeta Demonte, vol. 1, Madrid, Real Academia Española / Espasa Calpe.

FOUCAULT, Michel (2002). La arqueología del saber, traducción al castellano de Garzón del Camino Aurelio, Avellaneda, Siglo XXI Editores.

G

GARCÍA YEBRA, Valentín (1989). En torno a la traducción, Madrid, Gredos.

GARCÍA YEBRA, Valentín (1997). Teoría y práctica de la traducción, Madrid, Gredos.

GENTILE, Ana María (2006). "Relaciones entre la traducción como actividad intrapsíquica y los procesos de adquisición de la lengua extranjera en clases de lecto-comprensión: el caso del aprendiz de lecto-comprensión en francés", en : Revue de la SAPFESU, año XXIIV, n 29.

GENTILE, Ana María, Forte Mármol, Amalia y Perroud, María Inés (2008).

"La traduction en tant que stratégie de lecture dans les cours de FOS en français", en : Actas del $10^{\circ}$ Congreso nacional de profesores de francés, Crisol Ediciones, Salta.

GENTILE, Ana María (2007). Tesis de doctorado «La circulation sociale du discours de la psychanalyse en langue espagnole: un fonctionnement polynomique? » Servicio Nacional de Tesis, Lille, Francia, ISSN 0294-1767, 394 microfichas.

GIACOBBE, Jorge (1990). "Le recours à la langue première. Une approche cognitive", en: Le Français dans le monde. Recherches et applications, París, EDICEF. 
GILE, Daniel (1986). "La compréhension des énoncés spécialisés chez le traducteur: quelques réflexions", en: Meta, XXXI, N4, Montreal, Presses de l'Université de Montreal.

GILE, Daniel (1990). "La traduction et l'interprétation comme révélateurs des mécanismes de production et de compréhension du discours", en : Meta, XXXV, $n^{\circ} 1$, Montreal, Presses de l'Université de Montreal.

GILE, Daniel (2005). La traduction. La comprendre, l'apprendre, PUF, París.

GOANAC'H, Daniel (1987). Théories d'apprentissage et acquisition d'une langue étrangère, Hatier, Coll, "LAL", Paris.

GOANAC'H, Daniel (1990). “Acquisition et utilisation d'une langue étrangère. L'approche cognitive", en: Le Français dans le Monde. Recherches et applications, París, Clé International.

GOMEZ CAPUZ, Juan (2001) "Usos discursivos anglicados en los doblajes al español de películas y seriales norteamericanos: hacia una perspectiva pragmática", en: C.VALERO et al (eds) La Lingüística Aplicada a finales del siglo XX: ensayos y propuestas, tomo II, Alcalá, Universidad/AESLA. www.valesco.es/bibl_prestling.html [consultado 10/02/2009].

GOUADEC, Daniel (1989). Le traducteur, la traduction et l'entreprise, París, AFNOR.

GREIMAS, Algirdas (1989). Del sentido II. Ensayos semióticos, Madrid.Editorial, Gredos.

$\mathbf{H}$

HALLIDAY, Michael y HASAN, Ruqaiya (1976). Cohesion in English, Londres, Longman.

HAMERS, J. y BLANC, M. (1983). Bilingualité et bilinguisme, Bruselas, Pierre Mardaga.

HARRIS, Zellig (1969). "Analyse du discours", traducción al francés de "Discourse Analysis" (1952), en: Langages, vol. 4, n 13, París, Armand Colin. www.persee.fr/web/revues/home.

HATIM, Basil; MASON, Ian (1989). Discourse and the Translator, Londres, Longman.

HERNÁNDEZ Sampieri, Roberto; FERNÁNDEZ COLLADO Carlos; BAPTISTA Lucio Pilar (1998). Metodología de la investigación, McGrawHill, Santa Fe de Bogotá.

HOLMES, James (ed.) (1970). The Nature of Translation, La Haya-París, Mouton. 
HURTADO ALBIR, Amparo (1994). "Perspectivas de los estudios sobre la traducción", en: Estudis sobre la Traducció, Castellón, Universitat Jaume I.

HURTADO ALBIR, Amparo (1996). “La traductología: lingüística y la traductología”, en: TRANS, Revista de Traductología, № 1, Departamento de Traducción e Interpretación, Universidad de www.trans.uma.es/trans1/trans1debate3.pdf [consultado 27/01/2007].

HURTADO ALBIR, Amparo (2004). Traducción y Traductología, Madrid, Cátedra.

HURTADO ALBIR, Amparo (2005). "La Théorie Interprétative de la Traduction; sa place en traductologie", en: La théorie Interprétative de la Traduction, obra colectiva dirigida por Fortunato Israël y Marianne Lederer, tomo I. ParísCaen, Lettres Modernes Minard.

ISRAËL, Fortunato (2005). "Une théorie en mouvement", en: La théorie Interprétative de la Traduction, obra colectiva dirigida por Fortunato Israël y Marianne Lederer, tomo I. París-Caen, Lettres Modernes Minard.

IZQUIERDO, Iván (2008). El arte de olvidar, traducción al castellano por Mónia Herrero, Buenos Aires, Edhasa.

J

JAKOBSON, Roman (1975). Ensayos de Lingüística General, Barcelona, Seix Barral.

K

KRAZEM, Mustapha y SOULET, Valérie (2008: 52). "Ellipse et phrase averbale", en : Ellipse et effacement. Du schème de phrase aux règles discursives. Obra colectiva dirigida por Jean-Christophe Pitavy y Michèle Bigot, SaintÉtienne, PUSE.

$\mathbf{L}$

LADMIRAL, Jean-René (1994). Traduire: théorèmes pour la traduction, París, Petite Bibliothèque Payot.

LADMIRAL, Jean-René (2005). "Cousinages intellectuels", en: La théorie Interprétative de la Traduction, obra colectiva dirigida por Fortunato Israël y Marianne Lederer, tomo I. París-Caen, Lettres Modernes Minard. 
LAROSE, Robert (1989). Théories contemporaines de la traduction, Québec, PUQ.

LARSON, Mildred (1989). La traducción basada en el significado, traducción al castellano de Donald Bum y Rodolfo von Moltke, Buenos Aires, Eudeba.

LEDERER, Marianne; SELESKOVITCH, Danica y otros (1987). Recueil de tirés à part, Centre de recherche en traductologie, París, ESIT.

LEDERER, Marianne; PERGNIER Maurice y otros (1990). Etudes traductologiques, Lettres modernes, París, Minard.

LEDERER, Marianne; ISRAËL, Fortunato y otros (1991). La liberté en traduction, París Didier Erudition.

LEDERER, Marianne (2003). "De l'interdépendence de la théorie et de la pratique en traduction", en: Revue de la SAPFESU (Sociedad Argentina de Profesores de Francés de la Enseñanza Superior y Universitaria), año XXI, n²6, Buenos Aires, Araucaria editora.

LEDERER, Marianne (2005a). "Défense et illustration de la Théorie Interprétative de la Traduction", en: La théorie Interprétative de la Traduction, obra colectiva dirigida por Fortunato Israël y Marianne Lederer, tomo I. París-Caen, Lettres Modernes Minard.

LEDERER, Marianne (2005b). "La place de la théorie dans l'enseignement", en: La théorie Interprétative de la Traduction, obra colectiva dirigida por Fortunato Israël y Marianne Lederer, tomo III. París-Caen, Lettres Modernes Minard.

LEONETTI, Manuel (2000). "El artículo", en: Gramática descriptiva de la lengua española. Obra colectiva dirigida por Ignacio Bosque y Violeta Demonte, vol. 1, Madrid, Real Academia Española / Espasa Calpe.

M

MAINETTI, José Alberto (2001). Quirón, número aniversario: Bioética narrativa, vol. 32, n¹, La Plata, Editorial Quirón.

MANCHÓN RUIZ, Rosa María (2001). Acercamiento psicolinguistico al fenómeno de la transferencia, Madrid, Aguilar.

MAINGUENEAU, Dominique (1994). Syntaxe du français, París, Hachette.

MARINKOVICH, Juana (2002). "Enfoques de proceso en la producción de textos escritos", en: Revista signos, v.35 n.51-52. Valparaíso ISSN 07180934, versión en línea [consultado el 05/ 06/09]. 
MENDIKOETXEA, Amaya (2000). "Construcciones inacusativas y pasivas", en: Gramática descriptiva de la lengua española, Obra colectiva dirigida por Ignacio Bosque y Violeta Demonte, vol. 2, Madrid, Real Academia Española / Espasa Calpe.

MIGUEL, Elena (2000). "El aspecto léxico", en: Gramática descriptiva de la lengua española, Obra colectiva dirigida por Ignacio Bosque y Violeta Demonte, vol. 2, Madrid, Real Academia Española / Espasa Calpe.

MOIRAND, Sophie (1992). "Des choix méthodologiques pour une linguistique de discours comparative", en: Langages, vol.26, n 105, París, Armand Colin.

MOLINER, María (1996). Diccionario de uso del español, CD-Rom, Madrid Gredos/Novell.

MORRIS, Charles (1938). Foundations of the Theory of Signs, Chicago, Chicago University Press.

MOUNIN, Georges (1963). Les problèmes théoriques de la traduction, París, Gallimard.

MOUNIN, Georges (2000). Dictionnaire de la linguistique, París, Quadrige/PUF.

MOYA, Virgilio (2004). La selva de la traducción. Teorías traductológicas contemporáneas, Madrid, Cátedra.

MÚGICA, Nora y SOLANA, Zulema (1989). La gramática modular. Buenos Aires, Hachette.

$\mathbf{N}$

NEMSER, William (1991). Los sistemas aproximados de los que aprenden lenguas segundas, en: La adquisición de las lenguas extranjeras, obra colectiva compilada por Juana Muñoz Liceras, Madrid, Visor.

NEWMARK, Peter (1992). Manual de Traducción. Traducción al castellano de Virgilio Moya, Madrid, Cátedra.

NICOLAS, Serge (1993). “Comment l'homme conseve-t-il des souvenirs”, en: L'homme cognitif, obra colectiva dirigida por Annick Weil-Barais, París, PUF.

NIDA, Eugene (1988).Toward a Science of Translating. Leiden, E.J. Brill.

NIDA, Eugene y TABER, Charles (1969). Theory and Practice of Translation. Leiden, E.J. Brill. 
NOAILLY, Michèle (2008). "Sur une place vide", en: Ellipse et effacement. Du schème de phrase aux règles discursives. Obra colectiva dirigida por JeanChristophe Pitavy y Michèle Bigot, Saint-Étienne, PUSE.

NORD, Christiane (1994). "Traduciendo funciones", en: Estudis sobre la traducció, Amparo Hurtado Albir (ed.), Castellón, Universitat Jaume I, http://www.bib.uab.es/pub/quaderns/11385790n10p023.pdf [consultado el 25/02/06].

NORD, Christiane (1998). "La unidad de traducción en el enfoque funcionalista", en: Quaderns. Revista de traducció 10, Barcelona, Universidad Autónoma de Barcelona, ddd.uab.cat/pub/quaderns/11385790n1p65.pdf [consultado el 10/05/08].

NORD, Christiane (2003). "El análisis contrastivo y cultural en la clase de lengua", en: Quaderns. Revista de traducció 1, Barcelona, Universidad Autónoma de Barcelona, http://www.bib.uab.es/pub/quaderns/11385790n10p023.pdf. [consultado el 28/02/06].

NOYAU, Colette; PAPROCKE, Urszula (1998). La représentation des structures événementielles par les apprenants: granularité et condensation, París, Université de Paris.

0

OLSEN, María Luisa; ZORRILLA, Alicia María (1997). Diccionario de los usos correctos del español, San Pablo, Estrada.

$\mathbf{P}$

PAZ, Octavio (1971). Traducción: literatura y literalidad, Barcelona, Tusquets.

PERGNIER, Maurice (1993). Les fondements sociolinguistiques de la traduction, Lille, Presses Universitaires de Lille.

PÉTROFF, André (1984). "Sémiologie de la reformulation dans le discours scientifique et technique, en: Langue française, no.64, París, Larousse.

PICALLO, María Carmen; RIGAU, Gemma (2000). "El posesivo y las relaciones posesivas" en: Gramática descriptiva de la lengua española, Bosque, Ignacio / Demonte, Violeta (editores), vol. 1, Madrid, Real Academia Española / Espasa Calpe.

PITAVY, Jean-Christophe (2008). "N'y voyez pas surtout rien de personnel : quand les instances énonciatives (clitiques, pronom, flexion) s'effacent dans le 
discours", en: Ellipse et effacement. Du schème de phrase aux règles discursives. Obra colectiva dirigida por Jean-Christophe Pitavy y Michèle Bigot, Saint-Étienne, PUSE.

POLLOCK, Jean-Yves (1997), Langage et cognition, PUF, París.

$\mathbf{R}$

RABADÁN, Rosa (1991). Equivalencia y traducción, Zamora, Universidad de León.

RAJAUD, Virginie y BRUNETTI, Mireille (1992). Traducir. Initiation à la pratique de la traduction. París, Dunod.

Real Academia Española (1992). Diccionario de la lengua española, Madrid, Espasa Calpe.

Real Academia Española (2000). Gramática descriptiva de la Lengua Española, dirigida por Ignacio Bosque y Violeta Demonte, Madrid, Espasa Calpe.

REISS, Katharina; VERMEER, Hans (1996). Fundamentos para una teoría funcional de la traducción. Traducción al castellano de Sandra García Reina y Celia Martín de León, Akal Universitaria, Madrid.

REY, Joëlle (2007). "Traduction et adaptation des éléments culturels dans les textes scientifiques", en: Babel, volumen 53, Fédération Internationale de la Traduction.

RIGAU, Gemma (2000). "La estructura del sintagma nominal: los modificadores del nombre”, en: Gramática descriptiva de la lengua española. Obra colectiva dirigida por Ignacio Bosque y Violeta Demonte, vol. 1, Madrid, Real Academia Española / Espasa Calpe.

ROBERT, Paul (1992). Le Petit Robert 1, París, Dictionnaires Le Robert.

ROJO, Guillermo y VEIGA, Alexandre (2000). "El tiempo verbal. Los tiempos simples", en: Gramática descriptiva de la lengua española. Obra colectiva dirigida por Ignacio Bosque y Violeta Demonte, vol. 2, Madrid, Real Academia Española / Espasa Calpe.

S

SÁEZ HERMOSILLA, Teodoro (1994). El sentido de la traducción: reflexión crítica, Universidad de León y Universidad de Salamaca.

SALAMA-CARR, Myriam (2005). Théorie interprétative et contrastivité, en: La théorie Interprétative de la Traduction, obra colectiva dirigida por Fortunato Israël y Marianne Lederer, tomo II, París-Caen, Lettres Modernes Minard. 
SANCHEZ, Ida Sonia (1994). Etude de la cohésion textuelle dans la traduction de quatre textes philosophiques du français à l'espagnol, Montréal, Universidad de Montréal.

SÁNCHEZ, Sonia (2000). Traducción, lengua y cultura, Facultad de Filosofía y Letras, Tucumán, Universidad Nacional de Tucumán.

SÁNCHEZ, Sonia (2005a). "La Traductología: Estudio de Lenguas en Contacto", en: Hermeneus, $\mathrm{n}^{\circ} 7$, Valladolid, Universidad de Soria.

SÁNCHEZ, Sonia (2005b). "Representaciones y contextualización en la producción discursiva en traducción" en: Actas de las $V$ Jornadas Internacionales de Linguística Contrastiva, Universidad de Leipzig, Romanistische-VerlagBonn

SANTOS MALDONADO, María Jesús (2002). El error en las producciones escritas de francés lengua extranjera: análisis de interferencias léxicas y propuestas para su tratamiento didáctico. Tesis de doctorado. Universidad de Valladolid. Biblioteca Virtual Miguel de Cervantes, www.cervantesvirtual.com/.../FichaOrigenDeTesis?id [consultado el 15/ 09/09].

SÁNCHEZ TRIGO, Elena (2002), Teoría de la Traducción: convergencias y divergencias, Universidad de Vigo.

SECO, Manuel (1992). Diccionario de dudas y dificultades de la lengua española, Madrid, Espasa Calpe.

SEIB, Jörg (2001). La variedad bilingüe del español hablado en Cataluña caracterizada por interferencias y convergencias con el catalán. Mannheim: Universität Mannheim, Diplomarbeit, http://carstensinner.de/castellano/trabajosineditos.html, [consultado el 05/08/07].

SELESKOVITCH, Danica y LEDERER, Marianne (1984). Interpréter pour traduire, París, Didier Erudition.

SILVESTRI, Adriana (2000). La adquisición discursivo-cognitiva en la escuela secundaria. Habilidades de reformulación y estrategias de memoria. Buenos Aires. Facultad de Filosofía y Letras de la Universidad de Buenos Aires.

SINNER, Carsten (2004). El castellano de Cataluña Estudio empírico de aspectos léxicos, morfosintácticos, pragmáticos y metalingüísticos, Tubinga, Max Niemeyer Verlag GMBH. 
STEINER, George (1981). Después de Babel, traducción al castellano, México, Fondo de Cultura Económica.

\section{$\mathbf{T}$}

TABER, Charles (1972). "Traduire le sens, traduire le style", en: número especial de la revista Langages sobre la Traducción, $n^{\circ} 28$, París, Didier-Larousse.

TIBERGHIEN, Guy (1997). La mémoire oubliée, Sprimont, Mardaga.

TOURY, Gideon (1980). In search of a Theory of Translation, The Porter Institute for Poetics and Semiotics, Tel Aviv.

TOURY, Gideon (2004). Los estudios descriptivos de traducción y más allá. Metodología de la investigación en estudios de traducción, traducción al castellano de Rosa Rabadán y Raquel Merino, Madrid, Cátedra.

\section{V}

VAN DIJK, Teun (1983). La ciencia del texto. Un enfoque interdisciplinario, Barcelona, Paidós.

VAZQUEZ-AYORA, Gerardo (1977). Introducción a la traductología, Washington, Georgetown University Press.

VEGA, Miguel Angel (1994). Autores clásicos de teoría de la traducción, Madrid, Cátedra.

VENUTI, Lawrence (1995). The Translator's Invisibility, Londres-Nueva York, Routledge.

VINAY, Jean-Paul; DARBELNET Jean (1958). Stylistique comparée du français et de l'anglais, París, Didier.

\section{W}

WARREN, Howard C., editor (1956). Diccionario de Psicología. Traducción y revisión al castellano de E. Imaz, A. Alatorre, L. Alaminos. Buenos Aires, Fondo de Cultura Económica.

WARDHAUGH, Ronald (1991). "La hipótesis del análisis contarstivo", en: La adquisición de las lenguas extranjeras, obra colectiva compilada por Juana Muñoz Liceras, Madrid, Visor. 
WEIL-BARAIS, Annick (1999). L'homme cognitif, obra colectiva dirigida por Annick Weil-Barais, París, PUF.

WEINREICH, Uriel (1963: 1). Languages in Contact, La Haya, Mouton \& Co.

WILLSON, Patricia (2004). La constelación del sur, traductores y traducciones en la literatura argentina del siglo XX, Siglo XXI editores, Buenos Aires.

WULF, Judith (2008). "Ellipse et configuration stylistique du parcours interpretative", en: Ellipse et effacement. Du schème de phrase aux règles discursives. Obra colectiva dirigida por Jean-Christophe Pitavy y Michèle Bigot, SaintÉtienne, PUSE.

\section{BIBLIOGRAFÍA DEL CORPUS TEXTUAL}

\section{Textos del ANEXO I (provenientes del sitio www.genethique.org)}

La création d'un embryon bi-sexué/ La creación de un embrión bi-sexual (julio 2003).

Les chiffres du rapport de la Cour des comptes sur le handicap mental/Las cifras del informe del Tribunal de cuentas sobre la minusvalía psíquica (julio 2003).

La fin de l'homme - Francis Fukuyama/ El fin del hombre - Francis Fukuyama (agosto 2003).

«Bébés médicaments» ou l'extension du diagnostic préimplantatoire »/« Bebés medicamentos » o la extensión del diagnóstico preimplantatorio

(septiembre 2003).

Financement européen de la recherche sur l'embryon humain ?/¿Financiación europea de la investigación sobre el embrión humano ? (septiembre 2003).

Affaire Humbert : faut-il légiférer sur l'euthanasie ?/Caso Humbert: ¿Es necesario legislar sobre la eutanasia? (octubre 2003).

Amendement Garraud, impossible protection pénale de la femme enceinte/ Enmienda Garraud, imposible la protección penal de la mujer embarazada (diciembre 2003).

L'euthanasie au Conseil de l'Europe/La eutanasia en el Consejo de Europa (febrero 2004).

Embryon, mon amour, Jérôme Lejeune à Maryville - Céline Soriac/ Embryon, mon amour, Jérôme Lejeune en Maryville - Céline Soriac (marzo 2004). 
Naissance d'une souris par parthénogenèse ?/¿Nacimiento de un ratón por partenogénesis? (abril 2004).

\section{Textos del ANEXO II}

TESTART, Jacques y GODIN, Christian (2001). Au bazar du vivant, París, Seuil.

TESTART, Jacques y GODIN, Christian (2002). El racismo del gen, traducción al español de Víctor Goldstein, Buenos Aires, Fondo de Cultura Económica. 


\section{Au bazar du vivant}

Biologie, médecine, bioéthique sous la coupe libérale

\section{Éditions du Seuil}

L'ancien mode de procréer,

Nous le déclarons vaine plaisanterie.

Le point délicat d'où jaillissait la vie,

La douce force qui s'élançait de l'intérieur, [...]

Tout cela est maintenant déchu de sa dignité. [...]

D'abord un grand dessein paraît insensé ;

Mais à l'avenir nous rirons du hasard

Et un cerveau qui devra penser parfaitement

Sera désormais l'œuvre d'un penseur.

J. W. Goethe, Faust II.

Texte intégral

ISBN : 2-02-051234-3

(C) Septembre 2001, Éditions du Seuil

Le Code de la proprizle intellectuelle interdit les copies ou reproductions destinées à une
urilisation collective. Toute representation ou reprod unilisation collective. Toute representation ou reproduction int $t$ grale oud partielle faite par quelque procedé que ce soit, sans le consentement de l'auteur ou de ses ayants cause, est illicite et constitue une contrefaçon sanctionnee par les articles L. 335-2 et suivanis du Code de la propriéte intellectuelle.

www.seuil.com 
Ce petit livre est né d'un entretien tenu au musée des Beaux-Arts de Lille, en novembre 1999, dans le cadre de Citéphilo où, chaque année, se rencontrent des penseurs aux spécialités les plus variées.

Le point de départ de cet entretien était le dernier ouvrage paru de Jacques Testart, Des hommes probables, qui reprenait, à travers l'itinéraire personnel du biologiste, les grands thèmes de réflexion touchant les manipulations biologiques, les changements d'orientation en médecine, et la manière dont l'éthique en son domaine tend a renoncer à son rôle critique au profit d'un rôle d'accompagnement. $\grave{A}$ travers toutes ces questions, un enjeu majeur : l'homme et son avenir.

Il y a presque cinq siècles, un médecin flamand, Vésale, faisait entrer l'anatomie dans son âge scientifique en publiant un livre intitule La Fabrique du corps humain. Nous sommes aujourd'hui dans

ttre fabrique, car il ne s'agit plus seulement Inaître ce qui existe mais de faire ce qui te pas encore. Et comme l'industrie ne va is le commerce, nous sommes dans un mar;alement. Nous voici donc confrontés à un me radical, qui réclame une analyse critique esure, donc radicale elle aussi.

est l'objectif de ce petit livre : moins faire u faire rêver que faire penser.

\section{Introduction}

Christian Godin : Jacques Testart, les travaux que vous menez aussi bien sur le front de la recherche que sur celui de la réflexion posent des questions si nombreuses qu'il convient de les ordonner et de les mettre en perspective.

Il y a d'abord les bouleversements profonds subis par la biologie moderne : la façon de pratiquer la science du vivant aujourd'hui n'a plus grand-chose à voir avec celle de ses pères fondateurs. Il y a ensuite, et cette question est liée à la précédente, les bouleversements non moins profonds subis par la médecine moderne qui n'est plus, comme auparavant, une simple application de la connaissance du corps humain pour guérir celui-ci lorsqu'il est malade. Et enfin, il y a une réflexion sur l'éthique née de ces bouleversements, activité que l'on connaît sous le nom de bioéthique. Donc, après une brève présentation de votre carrière et de votre travail, nous aborderons 
successivement ces trois questions : la métamorphose de la biologie, la métamorphose de la médecine et la critique de la bioéthique.

Votre formation, je crois, est l'agronomie. Vous avez d'abord été ingénieur agronome et vous avez fait de la recherche et de la pratique biotechnologique sur des animaux. Dans un ouvrage intitulé De l'éprouvette au bébé spectacle, vous disiez vous être rendu compte un jour que ce que vous faisiez était de la pataphysique: « Je m'occupais à engrosser par force de méfiantes femelles bovines, au moyen d'une catapulte propulsant dans l'utérus des pauvres bêtes des embryons qu'elles ne connaissaient ni d'Ève ni d'Adam. Un jour que j'avais mis ma catapulte au vestiaire, je parcourus un traité du Collège de pataphysique et, dès le lendemain, mon outil se dénommait "pataculte" tandis que j'écrivais sur la porte de mon bureau : "J. T., pataculteur ${ }^{1 ", . » ~ L a ~ p a t a p h y s i q u e, ~}$ telle qu'elle est définie par son inventeur, Alfred Jarry, c'est la théorie des solutions imaginaires. Est-ce en relation avec ce sens-là que vous vous êtes détourné de votre premier métier? Dans l'avant-propos de votre dernier ouvrage, Des hommes probables, parlant des absurdités dans lesquelles l'agronomie tombe aujourd'hui, vous

1. J. Testart, De l'éprouvette au bébé spectacle, Éditions Complexe, 1984, p. 15 .

FIVETE m'a amené à écrire sur la porte de mon nouveau bureau : "J. T. Éprouveur. Inventreur"." » Vous rejetez avec détermination le lâche argument convenu du «si je ne le fais pas, d'autres, de toute façon, le feront ${ }^{2} »$, c'est, dites-vous, l'argument du flic qui matraque les manifestants. Vous me direz si je simplifie de manière excessive, mais ce qui paraît caractériser votre position, c'est le refus du pragmatisme au nom de principes que l'on peut qualifier d'humanistes.

Récemment, dans un hebdomadaire, Henri Atlan affirmait qu'«il est impossible d'avoir une réflexion sur ces problèmes-là en restant au niveau des grands mots tels qu'eugénisme, manipulations génétiques sur l'Homme, génome humain, clonage humain, toutes formules qui déclenchant des représentations confuses et folles chez beaucoup. Quand ce sont ces représentations elles-mêmes qui alimentent les débats, c'est gênant ${ }^{3}$.» Toutes ces expressions, donc, si l'on suit cette ligne critique, seraient absolument hors de pensée, elles brouilleraient toute possibilité de penser.

Est-ce un point de vue que vous partagez? Comment parler de ces choses qui s'appellent aujourd'hui biotechnologie, clonage et procréa-

1. J. Testart, De l'éprouvette au bébé spectacle, op. cit., p. 11.
2. Ibid., p. 116.

3. Marianne, n 133, 8-14 nov. 1999, p. 68. écrivez : «Je m'esquivais en 1977 vers la recherche médicale, laquelle devait être au-dessus de telles médiocres finalités ${ }^{1 . » ~ V o u s ~ p e n s i e z ~ t r o u v e r ~ u n ~}$ domaine qui était moins «tératogène » (ou « testarogène », comme vous dites plaisamment), c'est-à-dire moins monstrueux, en vous orientant vers la recherche médicale. Donc vous êtes passé des animaux aux hommes, et cela vous a conduit en 1982 à être le «père», le terme est évidemment d'une force symbolique extrême, du premier bébé éprouvette français, Amandine. Cela s'est produit quatre années après la première mondiale, un bébé nommé Louise Brown, qui est née en 1978.

Donc votre travail, c'est la AMP comme on dit en jargon, l'assistance médicale à la procréation et, à la suite de ce succès, qui avait valeur à la fois professionnelle, médiatique et scientifique, de nouveaux refus, de nouvelles interrogations sont venus et vous vous êtes fait connaître dans le grand public par des positions éthiquement fortes, des positions qui sont sans doute très marginales dans le milieu dans lequel vous évoluez parce que vous refusez le pragmatisme qui en est comme la philosophie naturelle. Dès 1984, soit deux années seulement après la naissance d'Amandine, vous écrivez: «Mon activité de recherche sur la

1. J. Testart, Des hommes probables, Le Seuil, 1999, p. 12.

tion médicalement assistée, etc., des expressions, donc, qui sont en quelque sorte tombées dans le domaine public? Est-ce que véritablement on parle, avec ces mots, d'objets scientifiquement assignables ou bien est-ce que l'on ne fait que de l'idéologie?

Jacques Testart : On fait effectivement souvent de l'idéologie, mais n'est-ce pas aussi un peu ce que fait Atlan quand il prétend que le résultat d'un clonage humain ne serait pas un embryon, lequel ne pourrait être conçu que par la fécondation? Il existe des animaux (par exemple les pucerons) qui connaissent alternativement des phases sexuées et asexuées (parthénogenèse), ce qui n'empêche pas tout puceron d'être d'abord un embryon de puceron... L'hygiène du langage permettrait effectivement de supprimer des mots forts, mais ne risque-t-on pas en même temps d'affadir le contenu même de ces mots, c'est-àdire aussi les représentations qu'ils véhiculent et qui ne sont pas dénuées de sens? L'exemple du mot « eugénisme » (sur lequel nous reviendrons) est éloquent : inventé par des scientifiques, il a été conservé par les nazis, mais c'est bien parce que dans l'une et l'autre situations il définissait la même obsession de pureté. Vouloir aujourd'hui effacer le mot, c'est prétendre effacer cette obsession, laquelle est loin de disparaître... C'est 
s'exposer à recommencer, à vivre d'autres is.

loudrais, puisque vous m'y invitez, récapiIn peu mon parcours... Je suis effectivement mation agronomique. J'ai fait des études de gie, et ne suis pas médecin, même si je me ve depuis pas mal de temps dans un circuit al, mais c'est peut-être parce que je ne suis lédecin, que je n'ai pas prêté le serment pocrate en particulier, que je n'ai pas non e sens de cette confraternité spéciale au médical, que j'ai pu me permettre un certain re de critiques. C'est aussi parce que dans emière existence de chercheur, j'ai fait dans herche agronomique ce que j'appelle mon ence bovine, qui portait essentiellement sur lioration des races bovines par le moyen de lantations d'embryons. Je me suis aperçu chercheur peut être amené, presque sur en tout cas sur conseil des autorités qui ecruté, à faire un travail stupide.

a a duré une douzaine d'années : on m'avait Idé d'améliorer la production laitière des s par des voies qui n'étaient pas la sélection onnelle. Il s'agissait d'obtenir une descenabondante pour une vache de haute qualité. la vache, comme chez la femme, la gestation ıuf mois et donne naissance à un seul petit. la sélection n'est pas très efficace. Le tau-

Issi à le faire par chirurgie au même moment is j'ai mis au point une méthode très simple z j'ai appelée pataculture. Je me promenais zc ma caisse à outils dans les coopératives llevage et seul je faisais absolument tout : je ueillais les embryons... enfin je faisais toute la lanip ». Et puis, au bout d'une douzaine d'anss, quand j'ai passé ma thèse, parce que ce ups était celui où l'on faisait des thèses en 10 , 20 ans, je me suis aperçu que j'avais travaillé Ir un objectif absurde : au moment où j'ai comncé ce projet, c'est-à-dire en 1964, des direcss européennes demandaient déjà de limiter les sédents de lait, et moi j'avais travaillé pour il y en ait davantage!

tlors je me suis tourné vers mon organisme, VRA, et j'ai dit «mais vous m'avez fait faire travail idiot!», ils m'ont répondu «mais pas tout, monsieur, le but n'est pas de faire plus de , mais de faire des animaux dont la productis est augmentée ». Ça voulait dire qu'avec le me nombre de vaches, ou moins de vaches, on ait autant de lait. Bon, j'ai quand même dit : lais c'est des techniques qui coûtent cher, il y a tucoup d'éleveurs que je connais qui sont deve; chômeurs parce qu'ils ne peuvent pas particià cette compétition des productions et est-ce : c'est vraiment bien utile ce qu'on a fait? » :f, comme personne ne comprenait, je suis parti reau, on peut le multiplier par l'insémination artificielle, mais la vache a un mauvais rendement en termes de reproduction, c'est-à-dire de procréation (je pense qu'il faut parler de procréation, même pour les vaches ${ }^{1}$ ). On peut considérer comme très insuffisant le fait qu'une vache qui produit du lait en abondance ne puisse avoir que quelques veaux. Donc il fallait trouver un système d'amélioration, et ce système a été appliqué ensuite à la femme sous le nom de «mère porteuse » : il s'agissait de faire émettre de nombreux ovules à une femelle, de les féconder in vivo, c'est-à-dire dans le corps, par insémination artificielle (on ne savait pas encore réaliser la fécondation in vitro, sauf chez les rongeurs). L'objectif vétérinaire étant d'obtenir beaucoup de petits à partir de cette vache, on récupérait ces embryons, issus de géniteurs mâle et femelle de haute qualité génétique, pour les distribuer dans la matrice de femelles ordinaires (des génisses parce que ça coûte moins cher à élever), et faire ainsi naître plusieurs veaux au bout de neuf mois, lesquels devaient hériter des qualités génétiques d'origine.

Tout cela paraissait logique techniquement; je me suis donc attaché à ce travail, et ça a marché. J'ai fait les premiers essais réussis en 1972, j'ai décrit des techniques nouvelles. D'autres ont

1. Voir infra. et, comme vous le disiez, je me suis tourné vers le monde médical. J'ai assez vite été sollicité parce qu'il y avait très peu de gens dans ce milieu médical qui connaissaient la fécondation, qui savaient ce qu'est un ovule ou un spermatozoïde. Il régnait alors une ignorance crasse en « reproduction» humaine, il faut reconnaître que ça commence à changer un peu, essentiellement grâce à la procréation assistée.

On avait besoin de gens comme moi, et je me suis alors tourné vers l'hôpital en me disant «ça va être autre chose, là on ne va pas me parler de compétition, de quota et de productivité... », mais je me suis aperçu assez vite que c'était à peu près le même type de discours que j'entendais. Pour tout dire : les gynécologues s'intéressaient à mon savoir-faire comme les maquignons que j'avais derrière moi quand j'étais avec les vaches. J'étais préparé pour réagir, non seulement parce que je n'étais pas médecin, mais grâce à cette expérience bovine qui m'avait laissé très amer : avoir mené une action absurde avec succès, et pour laquelle on m'a félicité ! Il est très difficile d'accepter cela quand on aspire au statut d'honnête homme.

Donc j'ai été vigilant, et il ne $\mathrm{m}$ 'a fallu que quelques années pour me rendre compte que se rejouait à peu près la même histoire. Pas tout à fait identique cependant, parce que permettre à un couple stérile d'avoir un gamin, c'est quand 
même une activité utile. Il n'est pas illégitime de vouloir un enfant, même quand on est stérile, et c'est pourquoi d'ailleurs je continue de travailler dans cette voie. Mais la façon dont s'en emparait le monde médical, avec des priorités pour certains patients, avec des inventions stupides pour essayer de capter les clients ou faire payer davantage, avec une suffisance grotesque, enfin tout ce qu'on peut connaître de la médecine « de pointe » quand on travaille dans un hôpital... Cela ne m'a pas vraiment plu et je l'ai dit dans $L^{\prime} C$ Euf transparent, en particulier, livre publié en 1986.

Je disais aussi qu'un chercheur pouvait se poser des questions sur ce qu'il fait, qu'il faut arrêter de sacraliser la recherche, qu'on ne fait pas de la recherche parce que c'est implicitement légitime, qu'on a le droit et le devoir de choisir son objet de recherche, et moi j'avais choisi. Non pas de ne pas faire de recherche, comme on m'en a fait la réputation, mais de ne pas me lancer dans n'importe quoi. J'avais eu l'intuition que la fécondation in vitro, capable d'exposer l'embryon humain hors du corps et de le rendre accessible à des analyses, n'avait pas été inventée seulement pour assister la procréation de certains couples, heureusement minoritaires. Je ne suis pas loin de reconnaître que cette intuition, aussi peu scientifique soit-elle, fut ma contribution la plus importante à la société.

insectes ou les poissons. On n'a fait que reproduire des procédures que des espèces différentes de nous connaissent depuis très longtemps: la fécondation hors du corps est assez banale dans le monde animal, et n'existe jamais chez les mammifêres. Chez l'être humain, c'était nouveau et je me disais que ça ne pouvait pas en rester là, ça ne servirait pas seulement à permettre à un couple stérile de faire un bébé : puisque les embryons étaient là dans l'éprouvette et pas encore dans le ventre, viendrait la tentation de les identifier pour choisir le meilleur afin d'en faire un enfant.

Alors, quand j'ai écrit dans $L^{\prime}$ CEuf transparent que je ne ferai jamais ça et que pour moi, la rencontre de la médecine de la procréation que je pratiquais, avec la médecine génétique d'identification qui commençait à apparaître, était potentiellement très grave pour l'avenir de l'humanité, on s'est beaucoup moqué. Des généticiens, en particulier, ont montré qu'ils ne croyaient pas à la génétique en disant que c'était impossible, que jamais, à partir d'un embryon de 4,6 ou 8 cellules, on ne pourrait réaliser une identification sérieuse. Il a fallu attendre quatre ans seulement pour que les Anglais nous démontrent que c'était possible. Suivez les Britanniques... c'est souvent là qu'il se passe du nouveau, aussi bien les brebis clonées que la fécondation in vitro ou les greffes d'ovaires et bien d'autres choses. Bref, il a fallu
J'avais à ce moment-là senti que la perspective de l'aide aux couples stériles allait forcément évoluer, parce que non seulement l'embryon se trouvait exposé hors du corps mais aussi parce qu'on produisait beaucoup d'ovules (et donc d'embryons) pour une seule femme, comme on l'avait fait auparavant pour les vaches. On obtient, en moyenne, dix ovules par femme, mais $j$ 'en ai vu produire jusqu'à quatre-vingts. On fabrique des embryons pour une bonne moitié de ces ovules, donc on se retrouve très souvent avjec une dizaine d'embryons pour un seul couple. Or, les couples modernes dans les pays développés veulent environ 1,4 enfant; c'est aussi vrai pour les gens qui passent par la fécondation in vitro (dans un tiers des cas, on leur en fait deux à la fois, comme ça, ils ont leur dose !).

Je me disais que ça ne pouvait pas être innocent d'avoir extrait l'ovule du corps de la femme, de l'avoir mis en bocal, d'avoir fait un peu comme font les grenouilles. En fin de compte, tout ça, ce sont des inventions relatives, toutes ces inventions de la médecine de la procréation ne font qu'imiter des processus qui existent chez l'animal, ce qui laisse perplexe : la superovulation, l'insémination artificielle, la conservation de sperme et d'embryons, et bien d'autres «techniques de pointe » recopient de nombreuses pratiques bien connues dans le monde animal, en particulier chez les

19

quelques années avant que cette technique ne commence à se développer, elle est balbutiante comme toute nouvelle technique, parce qu'elle coûte encore cher, parce qu'il faut sortir de la mise au point.

Quelques centaines de bébés sont déjà nés, après avoir été triés dans l'œuf, au sein de l'éprouvette, sur des critères génétiques, et l'on assistera, cela me paraît complètement évident, au développement de la médecine de procréation sélective. On fabriquera des enfants qu'on dirả probablement plus en bonne santé que la moyenne des enfants faits au petit bonheur la chance. 
C. G. : On abordera, vos propos y conduisent, le problème des transformations de la science biologique, en reprenant toutes les questions que vous venez de mentionner.

Vous évoquez l'histoire burlesque du dernier des perroquets, qui illustre la manière dont la biologie moléculaire vole au secours d'une écologie qui n'en demandait pas tant. En 1990, dans la forêt amazonienne, est aperçu en liberté un ara de spix, une espèce que l'on croyait disparue à l'état sauvage. Afin de lui donner un compagnon pour repeupler la forêt, il importait de connaître le sexe de l'oiseau solitaire, chose non évidente s'agissant d'un perroquet. D'où le recours à la science moléculaire : on entreprit de ramasser des plumes perdues par l'oiseau et d'en extraire l'ADN. L'échantillon fut alors comparé à de l'ADN prélevé chez quelques-uns des 26 aras de spix vivant en captivité dans le monde, et dont le sexe était

23

u. Le perroquet sauvage étant avéré mâle, reprise scientifique s'acheva par le lâcher e femelle. «Nul ne semble avoir imaginé, -vous, que s'il s'agissait réellement de placer suple d'aras de spix en liberté, le mieux eût l'apporter dans la forêt deux cages recelant : un mâle et l'autre une femelle, puis d'ouvrir ortes. Mais pourquoi faire simple quand on sse des biotechnologies ${ }^{1}$ ? »

y a un beau texte de Nietzsche, un texte court, lit qu'on a justifié la science pour trois raitrois motivations : la joie pure de la connais:, l'utilité sociale, et enfin la gloire de Dieu, re harmonieux de la nature. Et Nietzsche terson aphorisme par ces mots : « trois raisons, erreurs ». On devine, quand on connaît גun ¿e philosophe, que la véritable motivation à zlle il pensait, mais qu'il n'a pas expressé: mentionnée, c'est la volonté de puissance. ce plan, comme sur beaucoup d'autres, 'sche ne s'est pas seulement montré bon inter, il s'est avéré bon prophète. Tout au long du er siècle, la volonté de puissance a animé la ure partie de l'activité en physique. À présent, ais a été pris par la biologie. Depuis les der$\mathrm{s}$ décennies surtout, cette science a radicaletransformé son orientation. Il paraît loin le

Testart, Des hommes probables, op. cit., p. 28. temps où un Leibniz prenait soin de replacer sur la feuille de l'arbre où il l'avait trouvée une chenille, après l'avoir observée, car il ne voulait pas, disait-il, détruire une petite vie.

La biologie actuelle semble ne plus s'inscrire dans une recherche de type fondamental mais elle est une véritable volonté de puissance en acte. Pour utiliser le concept de Nietzsche, elle est l'expression même, non plus des besoins humains, ni même des besoins du savoir, mais d'un véritable désir de puissance. Ce qui fait que les manipulations, le contournement, la ruse par rapport à tout ce qui est vivant, tout cela prend le dessus par rapport au travail de la recherche, au travail de l'idée.

Dans l'introduction à l'ouvrage collectif intitulé Le Magasin des enfants, que vous avez coordonné, vous écrivez que la recherche fondamentale en biologie est en régression relative et qu'elle se nourrit seulement de projets technologiques ${ }^{1}$. Vous dites que le rêve du chercheur est de voir en l'hôpital un élevage, dans les patients des cobayes et dans les infirmières des animaliers ${ }^{2}$. Vous rappelez que le fait de savoir contourner l'ignorance ne crée pas une véritable connaissance. On a l'impression, en effet, qu'une

1. J. Testart, Le Magasin des enfants, ouv. coll., François Bourin, 1990, p. 11.

2. J. Testart, Des hommes probables, op. cit., p. 104. 
bonne part de la recherche biologique contemporaine tient dans une sorte de stratégie de la ruse au bout de laquelle la vie est toujours manquée, mais le vivant toujours attrapé. Il y a dans De l'éprouvette au bébé spectacle un passage saisissant où l'on comprend que la fébrilité du chercheur en biologie dans l'imminence de sa découverte est d'une nature différente de celle du mathématicien, et même de celle du physicien : «Quand une tentative semblait favorable, dans la hâte de savoir, je retournais de nuit à l'hôpital, à l'heure présumée où le résultat se voit par la première division de l'œuf. J'ouvrais alors la porte du laboratoire selon des rites superstitieux absolument étrangers à l'éducation scientifique, mais symptomatiques de la personnalité inquiète du chercheur. Pour goûter plus longtemps mon exaltation, je me préparais un café à deux pas du tube qui me livrerait la vérité en noir et blanc. J'absorbais une ou deux gorgées brûlantes avant de pénétrer en salle de culture. Souvent, dans une dernière manœuvre pour retarder le verdict que j'étais venu chercher, je contemplais à l'œil nu le liquide rose en faisant tourner le tube entre mes doigts. Et soudain, avec avidité, j'observais, les yeux rivés dans les oculaires de la loupe ${ }^{\prime}$. » On comprend, grâce à des témoignages comme ceux-ci, que l'image de la

1. J. Testart, De l'éprouvette au bébé spectacle, op. cit., p. 27.

phalographique en laboratoire n'est plus le singe qui saute de branche en branche dans la forêt.

La génomique est un terme nouveau qui a été inventé pour désigner ce mariage, cette alliance de l'informatique et de la biologie moléculaire. Ce que vous montrez, c'est qu'avec l'informatique se développe ce que l'on pourrait appeler une véritable «illusion de totalité », c'est-à-dire l'illusion selon laquelle à partir du moment où tous les éléments d'un ensemble sont répertoriés, on aurait accès à une connaissance totale. Comme s'il suffisait de savoir que les arbres de la forêt des Landes sont des pins pour connaître en entier la forêt! Je vous cite encore : «L'affection qui unissait le naturaliste au vivant lui rappelait sans cesse que la vie est inépuisable par la description. Au contraire, la scientificité du chercheur le porte à réduire la globalité au cumul de ce qu'en perçoivent les techniques disponibles 1 .»

La seconde révolution, liée à cette révolution informatique, est la révolution moléculaire. Là, on peut voir, en effet, depuis cent ou cent cinquante ans, puisque la biologie est l'une des plus jeunes parmi les sciences, que l'on est passé des ensembles les plus vastes, les organismes vivants, jusqu'aux unités élémentaires, les gènes, en passant par les organes et les cellules. Renversement com-

1. J. Testart, Des hommes probables, op. cit., p. 23. chasse n'est pas seulement une métaphore pour la recherche. La biologie met en branle des processus qu'elle ne crée évidemment pas, mais peut-être est-ce ce mélange de puissance et de fatalité qui lui donne son caractère de prométhéisme éperdu.

Pour revenir aux métamorphoses de la biologie, directement liées, bien sûr, à la façon dont nous concevons le vivant, et dont nous vivons avec la vie, on peut, semble-t-il, distinguer deux révolutions : la révolution informatique et la révolution moléculaire.

De la première, il est encore relativement peu question dans les études et les ouvrages d'épistémologie biologique. Il parait que, dans les laboratoires aujourd'hui, il y a plus d'ordinateurs que de chercheurs, d'où cette impression de puissance mais aussi de désolation. Cela ne peut pas ne pas avoir d'impact sur la façon de comprendre, car, comme on sait, en matière de recherche, l'instrument $n$ 'est pas un simple moyen, il entre luimême dans le processus et fait partie de la finalité d'ensemble. «On n'a pas encore évalué, ditesvous, le pas épistémologique qui sépare l'observation directe d'un organisme de la perception numérisée qu'en communique la machine ${ }^{1}$. " Le chiffre, c'est-à-dire le signe, a fini par remplacer le corps. Le singe dont on mesure le tracé encé-

1. J. Testart, Des hommes probables, op. cit., p. 22.

27

plet de perspective : alors que Goethe cherchait dans le développement le secret de l'origine, la biologie moderne cherche dans l'origine le secret du développement. Or cette avancée dans l'infime induit elle aussi toute une philosophie. Comme si le sens de la littérature devait se trouver dans les lettres, le sens de la musique dans les notes, et le sens de l'histoire dans les dates! La biologie a commencé par les corps, ensuite elle a pénétré dans les corps pour regarder du côté des organes et des tissus, puis elle est allée encore à une plus petite échelle du côté des cellules et enfin nous en sommes maintenant à un plan de réalité qui est le stade microscopique des gènes. Si bien qu'en fait, aujourd'hui, du moins si je vous ai bien lu, on a l'impression qu'il n'y a plus d'anatomie, qu'il n'y a plus de physiologie, et que la biologie moléculaire, dominée par ceux que vous nommez les conquistadores de la molécule, a fini par envahir la totalité du champ de la biologie. Est-ce exact?

J. T. : Oui, mais ce n'est même pas un champ microscopique parce que les gènes, on ne les voit pas. C'est un champ, on pourrait presque dire subjectif, un champ virtuel : par des recoupements, on imagine que l'objet qui est là est conformé de telle ou telle façon. C'est assez extraordinaire pour des biologistes parce qu'il y a 
là le risque d'une abstraction terrible. Et il y a assez sûrement des risques d'erreur importants. En tout cas, le rapport au vivant a disparu. Les molécules ne sont pas vivantes, contrairement à ce que l'on essaye de faire croire - la molécule d'ADN est une molécule inerte comme toutes les autres molécules, comme du cuivre, comme de l'eau.

La vie est bien autre chose que de l'ADN. L'ADN est l'un des éléments qui participent du vital $^{\prime}$ et de l'information, mais ce n'est pas le seul, il y en a d'autres et aujourd'hui l'on assiste ̀̀ la naissance d'un nouveau réductionnisme autour de la molécule d'ADN. Ce qui est inquiéant, c'est l'illusion de maîtrise qui accompagne ze réductionnisme car, cette molécule qu'on ne voit pas, on la décrit dans tous ses détails et on fait nine d'en posséder tous les secrets. La démarche appelle un peu celle des anatomistes de la Renaissance, qui ouvraient les corps (malgré les nterdits de l'époque) et dessinaient les organes, :'était assez esthétique, ils faisaient de beaux lessins. Avec l'ADN, l'art est impossible, la eprésentation physique de la molécule n'a pas 'raiment de sens, on ne peut que la décrire par des ormules adaptées. Finalement le décryptage du rénome, une entreprise que tout le monde ima-

1. Il y a bien de la différence du vital au vivant!

30 gine être la pointe du progrès, le fin du fin en matière de connaissance, est une science d'ânes, c'est une activité seulement descriptive qui se contente d'un inventaire, de l'anatomie de choses que l'on ne voit pas. C'est très pointu techniquement, mais seulement techniquement. Pour atteindre au sens, il faut d'abord que les biologistes moléculaires conçoivent qu'ils ne sont que des anatomistes de la molécule. Placés au pied du mur, devant cette «carte du génome » qui n'explique rien, certains commencent à s'interroger et voudraient renouer avec la physiologie, les fonctions, la vie, c'est-à-dire rencontrer la complexité.

Quelles sont les autres pratiques de la biologie? Celles dont on parle, ici et partout, absorbent l'essentiel des crédits, si bien que les laboratoires qui ne travaillent pas dans la génétique moléculaire, l'analyse du génome, sont réduits à la portion congrue. C'est le cas par exemple des recherches qui visent à comprendre des fonctions essentielles, telle la fécondation. Savez-vous combien de laboratoires en France travaillent sur l'ovule et la fécondation, en recherche médicale, a l'INSERM? Il n'y en a qu'un (c'est le mien). Nous ne sommes plus que quatre, le plus jeune chercheur a cinquante ans, et on ne peut pas en recruter de nouveaux parce que les objets sur lesquels nous travaillons ne sont pas prioritaires. Notre laboratoire va d'ailleurs disparaître en

31
'2, sans même que l'élimination de nos thèmes echerche ait été décidée quelque part. Simpleit parce que la priorité donnée à des sujets schés » tient lieu de politique de recherche, et damne ainsi les thèmes non prioritaires à l'asxie progressive, sans aucune interrogation des consables. En revanche, si vous faites une ıerche génétique en rapport avec les patholoi du rein, du foie, du cerveau ou même des lètes, alors là vous avez des moyens, vous utez. C'est une «politique de recherche » qui pas vraiment été discutée dans la transparence. isulte de tout cela une espèce d'engouement, node, pour aboutir à quoi ? Pour le moment à simple description. Pourquoi pas? Il faut en ier par là, j'imagine. Je ne suis pas un adver₹ de la description du génome, mais peut-on ifier le fait qu'elle s'accompagne d'une mté de tromper les citoyens? Or, les citoyens : trompés quand on leur raconte qu'il y a des apies géniques en plein développement et qui : efficaces. Il y a bien des essais de thérapie ique depuis une dizaine d'années, mais ça n'a ais marché 1 .

Alors que les tentatives en matière de thérapie génique fortement médiatisées (cela encourage les investisseurs et fait grimper les actions en Bourse), les échecs sont en ıche soigneusement cachés.
C. G. : Excusez-moi de vous interrompre, mais nos critiques ne seraient-elles pas, une fois de plus, dépassées par la réalité qui, en l'occurrence, n'est autre que la pensée elle-même? Le récent succès d'une équipe française en thérapie génique sur un cas de DICS lié au chromosome $X$ ne remet-il pas en question votre scepticisme sur ce type de pratique médicale?

Par ailleurs, certains observateurs ont pointé le fait qu'un tel succès avait eu lieu en France justement parce que l'AFM (l'Association française contre les myopathies) organise le Téléthon et permet ainsi d'injecter beaucoup d'argent dans des recherches sur des maladies qui n'intéressent pas les financiers de la nouvelle biologie à cause de leur rareté.

J. T. : Le récent succès d'Alain Fischer est un événement important mais il passe par une stratégie de modification cellulaire in vitro, ces cellules étant ensuite réimplantées chez le malade. Or, une telle stratégie ne peut s'appliquer qu'à certaines maladies, celles du système immunitaire en particulier, et il ne faudrait pas laisser croire qu'on pourrait traiter ainsi la myopathie, la mucoviscidose, ou même la trisomie 21 , comme certains l'ont prétendu... C'est la moindre des choses que l'argent recueilli par le Téléthon ait joué un rôle dans cette recherche. Cela ne justifie absolument 
pas la substitution de la mendicité publique à une véritable politique de recherche.

Tout ça, finalement, est en train de tourner un peu en eau de boudin, si cette description-là ne mène à rien de pratique ou de médical. Alors, j'imagine que l'investissement considérable qui a été fait dans la génomique, il faudra bien le payer un jour. Ainsi les praticiens s'orientent de plus en plus vers le diagnostic, vers l'identification; et ça marche, on sait identifier parce qu'il s'agit de constater la présence ou l'absence d'une conformation moléculaire connue, parce que c'est encore de l'anatomie. On peut identifier, sur une personne, sur un enfant, sur un fœetus, sur un embryon juste féconde, de plus en plus de choses, et je ne doute pas qu'un jour on pourra identifier toutes les caractéristiques qu'on aura envie d'identifier, et pourquoi pas la totalité du génome, même sur un embryon âgé de deux jours. Mais on peut estimer inquiétant que les énormes moyens investis dans la génétique favorisent une espèce de police génomique plutôt qu'une médecine de soins.

Mais, pour poursuivre la discussion sur la nature de la biologie, il faut dire qu'elle n'est pas seulement cela. Il existe d'autres domaines qui ne disposent d'à peu près aucun moyen, et qui innovent. Là, c'est une autre dimension, c'est le bricolage, la fécondation in vitro, l'injection d'un

rien est sorti ce mouton! Mais cette révolution n'a rien de conceptuel. Si la même tentative avait été faite il y a trente ans, le résultat aurait été le même ! Je voudrais insister là-dessus et j'imagine qu'ils se sont retrouvés un peu décontenancés, car pour des scientifiques, c'est toujours un peu difficile de ne pas maîtriser un résultat... Donc il leur a fallu trouver une explication savante. Et ils ont trouvé, ils ont dit : « Ça a marché parce que nous avons mis au point une technique de culture des noyaux cellulaires en les privant d'albumine [l'albumine, généralement d'origine bovine, est placée dans toutes les cultures cellulaires, elle permet aux cellules de vivre] on les a privés d'albumine et c'est comme ça que le noyau de la mamelle de la maman de Dolly est devenu capable de refaire tout le programme génétique quand il a été placé dans un ovule. » Là, tout le monde a dit « chapeau ! », il y avait une invention tout de même. Et puis ensuite, d'autres chercheurs ont fait la même chose mais sans priver les cellules d'albumine et le résultat était le même ! Autrement dit, l'hypothèse que les pères de Dolly avaient fabriquée, pas pour tromper leur monde mais parce qu'ils ne pouvaient pas croire euxmêmes qu'ils avaient fait quelque chose que n'importe qui aurait pu réussir il y a trente ans, cette hypothèse était fausse ! Et c'est comme ça que se construit la biologie de bricolage, à laquelle je spermatozoïde... Ces actes ne font appel à aucun principe nouveau mais simplement à des techniques nécessaires pour manipuler les gamètes, pour les cultiver, pour les faire fusionner, techniques qui sont assez pointues, certes, assez performantes mais, je le répète, aucun concept nouveau. Il en va de même à propos de ce qui ne se fait pas encore chez l'humain, mais qui a été réalisé chez le mouton: je fais allusion à l'histoire de Dolly, «fille» de Ian Wilmut (on dit bien que je suis le «père » d'Amandine...). Le succès "du clonage ne mettait pas en jeu des connaissances nouvelles, c'est un résultat qui a surpris l'équipe écossaise elle-même. On savait qu'avec un noyau de cellule embryonnaire introduit dans un ovule, on peut arriver a faire un petit, on le sait depuis trente ans, chez toutes les espèces animales où cela a été essayé. Les Écossais ont voulu savoir à partir de quel moment cela ne marche plus dans le développement, puisqu'il était convenu jusque-là que lorsqu'on introduit dans l'ovule le noyau d'une cellule prélevée chez un adulte, le résultat est négatif. En fait, l'expérience n'avait jamais été tentée sérieusement. Les Écossais l'ont réalisée, leur groupe contrôle (noyaux de mamelle de brebis) ne devait pas engendrer, et puis Dolly est sortie de là ! L'histoire est assez extraordinaire parce que Dolly est un produit de l'ignorance, finalement. Du groupe témoin qui ne devait aboutir à

35

participe, à côté de cette biologie d'investigation anatomique qu'est l'analyse moléculaire du génome.

C. G. : Vous parlez de «génomanie » et même de «totalitarisme ${ }^{1}$ » et de «fétichisme » génétiques. Ce terme de fétichisme est d'ailleurs à prendre au sens littéral et non comme simple métaphore. Dans votre dernier livre, vous faites allusion aux «amulettes génétiques » imaginées par Kary Mullis, prix Nobel: il propose des médailles contenant des fragments d'ADN clonés provenant de stars du rock ou d'athlètes célèbres ${ }^{2}$. Qu'une molécule puisse se substituer à une photographie et comme elle valoir pour un être ne manque évidemment pas de faire sens.

Les Américains appellent genohype cette « folie du gène » qui semble avoir touché une bonne partie d'entre eux - chercheurs et grand public confondus. Il y a là plusieurs illusions et plusieurs dangers repérables. Nous avons déjà évoqué l'illusion de totalité, cette illusion qui fait croire qu'une énumération exhaustive signifie automatiquement une connaissance totale. Vous avez ainsi des collectionneurs - ce ne sont ni des touristes ni à plus forte raison des voyageurs - qui ont

1. J. Testart, Des hommes probables, op. cit., p. 39.

2. Ibid., p. 38 . 
onçu le projet de « voir » tous les pays du monde. s seraient incapables de distinguer une église othique d'une église de style Renaissance, mais ils roient qu'en « allant » dans les deux cents régions u monde qu'on appelle pays, ils connaîtront la :rre entière! L'illusion épistémologique que parIge le projet dit Génome humain n'est pas très loignée de cette lubie : puisqu'il existe quelque uarante mille gènes ${ }^{1}$, leur séquençage exhaustif orrespondra à une connaissance totale du génome, onc à un savoir complet sur l'être humain puisque elon le naturalisme sous-jacent à ce projet, homme est le produit de ses gènes, et il n'est que $e^{2}{ }^{2}$. Le réductionnisme commence par mettre la lus grande partie de la réalité entre parenthèses et nit par exhiber le quadrillage du secteur choisi omme l'image même du monde. Certes, il n'y a as de travail de connaissance, a fortiori scientique, sans analyse ni abstraction - mais l'illusion pparaît lorsque cette abstraction, cette analyse, récisément, sont oubliées comme telles (on oublie ue ce sont des abstractions, des analyses).

Le cas du sida est éclairant à cet égard. D'un

1. Leur nombre est en fait beaucoup plus petit que ce qui a é longtemps envisagé (100 000 était le nombre communément :tenu).

2. Â l'heure actuelle (2001), seuls $20 \%$ des gènes humains nt une structure connue et le nombre de ceux dont on connaît la fois la structure et la fonction dépasse à peine quelques entaines.

mes et les atomes de particules, il ne s'ensuit :mment pas qu'une cathédrale n'est qu'un de particules. La génétique, aspirée par ne qu'elle a creusé elle-même, finit par ir que la réalité est un ensemble diversifié de et que le passage de l'un à l'autre s'effectue ıut. L'analyse chimique de l'eau d'un fleuve us informera jamais sur son parcours, et la ₹ d'un style d'architecture n'est pas logée au des quarks.

sette critique du réductionnisme, vous ajou: qui pourrait bien représenter l'aporie fonntale du projet Génome Humain : ou bien l'ensemble des caractéristiques de l'humaui devrait figurer à l'inventaire, et la cartoie ne sera jamais achevé, ou bien nombre ividus apparemment humains recèlent un ne hors la carte, c'est-à-dire qu'ils n'apparznt pas à l'humanité telle que va la définir la ze génétique. Le choix est donc entre un proshaustif et matériellement infaisable et un $t$ exclusif et éthiquement inadmissible. Voilà nène, concluez-vous, le développement ue d'un discours totalitaire et triomphaliste ${ }^{1}$. convient d'évoquer à présent une autre asion de cette recherche, et qui est peut-être nension essentielle, je veux parler de l'éco-

. Testart, Des hommes probables, op. cit., p. 35-36. côté, son virus n'a plus rien de secret : la séquence de son génome est connue depuis 1984 , ses gènes (au nombre de 12 seulement) ont été répertoriés et étudiés; 1'action de ses protéines a été analysée. Et pourtant, on en est toujours à se demander quel rapport les molécules du virus entretiennent avec la vie et la mort. Le virus du sida nous montre comment on peut en même temps savoir «tout » et comprendre si peu.

Vous dites (je vous cite), qu' ' il se pourrait que la génomanie, en instituant la molécule comme unique référence de la biologie, en vienne à prendre les outils de laboratoire pour des concepts, et leur maniement adroit pour de l'intelligence ${ }^{1} »$. De fait, nous l'avons dit tout à l'heure, dans les centres de séquençage, les machines sont beaucoup plus nombreuses que les hommes : ce sont elles qui font le gros du travail. Or, nous n'avons encore jamais vu de machines élaborer des hypothèses ou faire d'elles-mêmes des inductions. La réduction est une nécessité méthodologique qui doit (qui devrait) laisser entièrement ouverte la question de la nature ainsi étudiée. Ce n'est évidemment ni dans la composition de l'encre d'imprimerie ni dans la forme des lettres que l'on ira chercher le secret du style de Racine et de ce qu'une cathédrale est faite de pierres, les pierres

\section{J. Testart, Des hommes probables, op. cit., p. 26.}

39

nomique. La biologie moderne coûte très cher. On est loin des grenouilles auxquelles l'abbé Spallanzani avait mis des culottes. La recherche actuelle est conçue en termes d'investissement : la logique du profit a recouvert celle de la découverte. Or la spéculation sur le vivant (il est significatif, notons-le au passage, que le même mot de «spéculation » serve à désigner aussi bien la pensée la plus désintéressée que l'activité la plus financièrement intéressée) passe par une appropriation de ce vivant. Nous assistons de nos jours à un processus entièrement nouveau, et dont nous n'avons pas fini de mesurer les implications : le monde de la vie est en train d'être intégralement transformé en capital et en marchandise - c'est-à-dire en source de profit et en objet d'échange. Aux ÉtatsUnis, la thérapie génique fait partie de la nouvelle économie et elle est cotée en Bourse. Avec la révolution informatique, cette capitalisation et cette marchandisation de la vie signent le plus grand triomphe du capitalisme dans sa forme contemporaine. D'autant que les grandes institutions suivent. En 1980, la Cour suprême américaine a déclaré brevetable une bactérie transgénique, mangeuse d'hydrocarbures, manipulée par un chercheur. Pour des raisons de sécurité, le microbe n'est jamais sorti de son laboratoire pour combattre une marée noire. Mais il est entré dans l'histoire comme le premier organisme vivant breveté. 
Parce que son génome avait été modifié de main d'homme, il était passé du monde des produits naturels (non brevetables) à celui des inventions (brevetables). Récemment, l'Office américain des brevets a accordé à Incyte un brevet sur 44 gènes humains. Le seul travail de la firme avait consisté à découvrir un fragment de chacun de ces 44 gènes, sans même que leur fonction précise fût identifiée. Mais ces gènes sont désormais leur propriété exclusive : nul ne pourra les exploiter sans l'accord, c'est-à-dire des droits financiers qu'on imagine élevés, d'Incyte. Les bureaux de brevets ont déjà enregistré un million de demandes de brevets sur les gènes - ce qui fait une moyenne de vingt-cinq demandes par gène... Celera Genomics, l'entreprise dirigée par Craig Venter, ce flibustier du gène, a déposé à elle seule entre 10000 et 20000 demandes de brevets '. Cette appropriation de l'objet découvert, en supprimant la démarcation entre la découverte et l'invention, est quelque chose de nouveau dans la science. Imagine-t-on Cuvier réclamer des droits sur les fossiles ou Marie Curie faire breveter l'uranium?

Cette mainmise des intérêts privés sur le génome humain fait penser à la conquête des ter-

1. Aucun, jusqu'à présent (mars 2000), n'a encore été délivié. Peut-être les récentes déclarations des responsables politiques aideront-elles les bureaux américains et européens des brevets à réfléchir sur ce qui est brevetable et sur ce qui ne l'est pas.

42

qui par ailleurs est une notion positive, était vécu véritablement comme un destin. À cet égard, la transformation des mentalités est radicale. Pour des raisons idéologiques, les sciences humaines et la philosophie des cinquante dernières années ont massivement ignoré, voire nié, la génétique. Il est à ce sujet frappant de constater à quel point, tournant le dos aux indications de Freud lui-même, lequel avait toujours pensé qu'il existait un substrat biologique à l'inconscient, la psychanalyse a refoulé le corps réel du patient au profit de son corps symbolique '. Cet éloignement, cette ignorance, ce préjugé n'ont pas peu contribué à rendre inaudible la voix de ces «sages». En outre, avec l'effondrement du marxisme, a disparu le support principal de la théorie de l'acqưlis. Les découvertes génétiques ont accrédité l'idée, auprès du grand public, que l'existence humaine tout entière est déterminée par les gènes. Car ce que la science pense comme déterminisme, l'opinion le comprend comme destin. La génétique, en effet, ne peut que raviver le fatalisme - qui est comme la philosophie spontanée des humiliés et des offensés, partout et depuis toujours. Le déterminisme de la science n'est pas le fatalisme des religions mais l'opinion ne fait pas la différence. En un

1. Chez Lacan, c'est l'absence du père, et non un gène déficient, qui explique la psychose. ritoires par les marins européens lors des grandes découvertes : sous prétexte qu'il était le premier Blanc à y mettre le pied, tel navigateur prenait possession de l'île au nom de Sa Majesté - au mépris, évidemment, des populations indigènes. Semblablement, la compagnie Celera Genomics a déposé ses demandes en vue d'obtenir une exclusivité d'exploitation. À ceux qui lui objectent que le gène n'est pas l'objet d'une invention mais d'une découverte, Craig Venter répond que des investissements considérables 'en intelligence et en argent ont été nécessaires pour cette découverte. Semblablement, au prétexte que la caractérisation d'un gène et l'établissement de sa séquence nécessitent de le sortir préalablement de son état naturel par les techniques de génie génétique, la réglementation européenne n'oppose aucune limite aux brevets sur les gènes et sur la connaissance de ceux-ci. Selon cette logique, les navigateurs de Sa Majesté qui se sont emparés des îles du Pacifique auraient aussi bien pu justifier leur impérialisme par les risques encourus et l'investissement en matériel.

Maintenant, il y a autre chose. On peut dire, pour reprendre le vieux débat en termes simples, que l'innéisme, la théorie de l'inné, semble l'avoir complètement emporté sur la théorie de l'acquis, comme si l'être humain était un pur produit de ses gènes, et comme si le déterminisme scientifique,

43 sens, cette hégémonie de l'inné constitue un achèvement de l'individualisme (nous n'attendons plus rien du social). Il y a là quelque chose de contradictoire également, car c'est dans ce qu'il y a d'impersonnel en nous (nos gènes hérités de nos parents) que nous tendons à fixer notre singularité. Le fait même, maintenant bien connu, que nous partageons $99 \%$ de notre patrimoine génétique avec le chimpanzé ${ }^{1}$ devrait achever de nous convaincre que l'essentiel est ailleurs. Si génétiquement, il n'y a qu'un pour cent qui sépare un chimpanzé de Shakespeare, c'est bien la preuve que ce ne sont pas les gènes de Shakespeare qui ont écrit Hamlet.

On observe aussi dans les représentations communes, auxquelles les chercheurs ne sont pas toujours étrangers, une large confusion entre les caractères physiques et le comportement. De ce que les gènes peuvent déterminer la forme des oreilles, on en infère qu'ils détermineront aussi une forme de vie. Mais où a-t-on vu un ovule alcoolique ou un spermatozoïde homosexuel? Un ovule amateur de montagne, un spermatozoïde préférant la mer? Il y a une mauvaise application de l'idée de causalité dans cette théorie selon laquelle tel gène va produire tel caractère ou tel

1. Et aussi le faît que nous ne possédons «que 40000 gènes alors que le grain de riz en a $50000 \ldots$ 
ortement, comme si le schéma de la causanilinéaire simple était applicable dans ce ine comme dans celui de la mécanique clas, c'est-à-dire comme si l'être humain n'était 'et que le produit d'un programme! C'est ce spt de programme que vous contestez forment; il induit en effet une fausse image, nauvaise représentation de notre existence, itre être en tant qu'être humain. Avec Henri I, vous dénoncez le caractère trompeur de expression de programme génétique et vous :lez que le génome n'est qu'une source ormations $^{1}$ : le génome, dites-vous, est à ume ce que le calendrier est à la météoroloEst-ce que vous pouvez dire en quoi cette de programme, telle qu'elle est appliquéoà ime, est une simplification outrancière?

\section{r. : Comme vous le rappelez, les généticiens} :rnes, ainsi que leurs aînés, ont tendance à ir beaucoup plus de poids au génome qu'au $\mathfrak{u}$, mais ils ne le disent pas ouvertement, $c$ 'est ue chose dont ils sont persuadés mais si vous iterrogez, ils vous diront en général : «mais mais non, l'important c'est le milieu! ». On déceler une véritable mystique génétique

. Testart, Des hommes probables, op. cit., p. 99. bid., p. 231.

46 dans de petites réflexions. Je pense à celles de Daniel Cohen, pionnier du Généthon ${ }^{1}$ et que ses collègues soupçonnent de prendre des brevets sur le génome aux États-Unis parce qu'il ne peut pas les prendre en France. Il a déclaré dans un grand hebdomadaire à propos des gens qui ont des problèmes psychologiques, qui sont un peu «tarés », qu'aussitôt après qu'on en aura fini avec les grandes maladies, il faudra faire des «pichenettes génétiques » pour corriger tout ça. Mais il n'y a pas que les généticiens purs et durs comme Daniel Cohen qui colportent ce point de vue, je pense par exemple à Jean-Pierre Changeux, alors président du Comité national d'éthique qui a écrit, il y a quelques années, que dans dix ans on n'aura plus besoin de la psychanalyse parce qu'on trouvera une drogue adaptée à chaque trouble du comportement.

Nous avons donc affaire à une tendance réductionniste qui, chez les scientifiques, est assez répandue. Il y a à la fois la confiance absolue dans les capacités de la science et puis, de façon plus précise, au niveau des fonctions biologiques, cette idée que finalement c'est dans l'ADN qu'on trouvera tous les secrets. C'est évidemment une idée plus que contestable, mais je pense qu'elle a été induite par l'expérience des grandes maladies

1. Le laboratoire Généthon a été créé en 1990 pour identifier les gènes impliqués dans les maladies héréditaires.

47

abondamment relayés par les journalistes, vous servent la métaphore suivante : l'ADN, c'est un peu comme une partition musicale, il n'y a plus qu'à la jouer; mais en même temps ils concèdent que le milieu est très important. Pour interpréter une partition musicale, il faut avoir un instrument de musique, mais l'on reconnaît toujours le morceau, même s'il y a mille et une façons de le jouer. Donc, comparer l'ADN à une partition musicale, en proclamant la liberté de l'interprète, c'est tout de même pousser un peu loin la métaphore! D'ailleurs cette idée de programme a été combattue par certains généticiens eux-mêmes, des Américains, notamment. Il faut dire qu'ils sont très minoritaires, quatre ou cinq, mais depuis une bonne dizaine d'années, ils se battent contre cette idée. Ils ont été relayés en France par Henri Atlan pour condamner cette idée simpliste que finalement il $\mathrm{y}$ a tout dans nos gènes et que la suite est toute d'exécution. En fait, il y a des informations, pas un programme. Il y a des informations dans le génome, mais elles jouent beaucoup plus pour les traits physiques que pour le comportement, et même pour les traits physiques, ce n'est pas si simple, l'ADN ne gouverne pas tout. Cette idée de programme devrait reculer devant les évidences, mais elle est nécessaire à la justification du régime de faveur dont bénéficient chercheurs et praticiens de certaines maladies. Demander aux 
citoyens de donner de l'argent pour des enfants malades parce qu'il y a un espoir de guérison..., ça fait dix ans qu'on nous le sert... Ces quatre cents millions ramassés en une seule journée par le Téléthon, c'est l'équivalent du budget utile de toute la recherche médicale sur une année en France.

Le budget de la recherche médicale est en effet plutôt maigre : quand on a payé les hommes, les laboratoires et les machines, il reste quatre cents millions, pour travailler dans trois cent cinquante unités de recherche. Alors les gens du Téléthon arrivent et font des propositions à ces unités de recherche. Normalement on se donne beaucoup de mal pour réclamer à l'institution des crédits qui soient à la fois justifiés et acceptables par les instances scientifiques. Et puis, derrière, vous avez le caritatif, il y a l'AFM, il y a l'ARC, le cancer, le sida, la myopathie, il y a toutes les grandes machines qui arrivent et qui apportent beaucoup plus d'argent que tout ce que peut vous donner l'État. Évidemment cela conduit aussi à orienter les programmes de recherche qui auraient été décidés par l'institution ou par les citoyens s'ils étaient bien informés. Tout ça est un peu clandestin et on souffre aussi du manque de transparence. Je ne dis pas que cet argent est gaspillé, comme on l'a vu pour l'ARC par des gens peu scrupuleux, mais il est mis essentiellement au service

$$
50
$$

là-dessus très peu de chose. L'ovule (nom donné à l'ovocyte mûr) demeure la cellule la plus grande, la plus rare, et la plus mystérieuse chez les mammifères. Toute conception (sexuée, parthénogenèse, clonage) nécessite un ovule mais pas nécessairement un spermatozoïde. Or les rares laboratoires de recherche sur les gamètes s'intéressent seulement au gamète masculin. La dérive s'aggrave avec la génétique qui est en train de tout s'approprier, et de nous priver d'autres domaines plus généralistes de recherche. C'est un peu ce qui est arrivé en médecine avec les spécialisations à outrance, au point qu'on essaie de faire du généraliste un spécialiste parce que l'on voit bien qu'il y a un manque. En recherche biologique, un problème analogue se pose mais je ne sais pas où l'on va prendre les hommes, parce que les vieux cadres dans mon genre sont en train de disparaître et que l'on ne forme plus de jeunes. Il n'y a plus que des chercheurs hyperspécialisés, très performants, des techniciens de haute volée, qui travaillent avec des robots pour faire ce que les décideurs prétendent être la science et la médecine de demain. des laboratoires de génétique pour le décryptage du génome, pour des publications scientifiques, pour des congrès internationaux, bref cet argent est dépensé pour des activités qui peuvent être utiles mais qui ne sont pas certainement ce pour quoi on vous les présente quand on vous demande de l'argent, c'est-à-dire guérir des petits enfants malades.

Tout cela participe, je pense, de l'usurpation générale de la génétique. Mon point de vue n'est pas qu'il faille arrêter la recherche en génétique, mais il faut la remettre à sa juste place, il faudrait qu'elle soit analysée et soutenue comme les autres domaines de recherche, et surtout, il ne faudrait pas qu'avec cette obsession génétique on en arrive à paralyser complètement la recherche sur d'autres sujets. Je disais tout à l'heure que mon laboratoire est le seul à l'INSERM qui s'intéresse à l'ovule et à la fécondation chez les mammifères, le plus jeune chercheur sur ces sujets, en France, a donc cinquante ans, imaginez ce que cela veut dire : dans dix, quinze ans, il n'y aura plus personne pour continuer ce travail.

Cela donne à penser qu'on aurait admis en haut lieu (ces gens-là ont-ils été clonés?) que la fécondation n'est pas une fonction si importante pour la vie des humains, pour leur santé..., alors que l'on voit bien par ailleurs qu'il y a beaucoup de problèmes de stérilité, et que l'on sait finalement

51

\section{Les métamorphoses de la médecine}

C. G.: Le corps ayant remplacé et même chassé l'âme, la médecine a pour elle de reposer sur la seule grande valeur créée par le siècle écoulé : la santé. Seulement la santé, dont le concept remonte à Hippocrate et à l'Antiquité chinoise, et que l'on définissait par l'équilibre et l'harmonie, est sans doute en train de changer de sens assez radicalement. Et d'abord probablement parce que ce que Michel Foucault appelait le biopouvoir est en train de rendre les gens comme étrangers à leur propre corps. La médecine actuelle tend à faire de tous les hommes des assistés. Symptomatique de ce biopouvoir, ce fait entre cent qu'à l'hôpital le personnel soignant ne désigne pas les patients par le nom de leur affection mais par celui du travail médical opéré sur eux : ainsi, il n'y a pas de femmes stériles ou désireuses d'avorter à l'hôpital mais des FIVETE et des IVG. Au moins, dans un restaurant, le « bœuf 
e pour le 5 » ou les «profiteroles pour le petit sieur à moustaches » appellent les demandes eurs clients et pas seulement les réponses in leur apporte. Cette dépossession du patient : la médecine actuelle est quelque chose de amental.

Jus assignez à la médecine trois figures sucives. La médecine traditionnelle a d'abord été tive, elle a soigné des malades, puis elle est :nue préventive, elle s'est efforcée d'empêles hommes de tomber malades, enfin elle aujourd'hui à devenir de plus en plus prédic. c'est-à-dire qu'elle touche aux conditions iori de possibilité de tomber malade, elle sera navant et toujours davantage une médecine née non vers l'état de fait mais vers les condi; et les antécédents, une médecine qui comme nouvelle économie » a substitué la dimension utur à celles du présent et du passé. Dans le e de cette médecine prédictive, le virtuel s'est titué au réel, ou plutôt il est devenu le réel lui1e. On aura reconnu le passage du physioloe au génétique, qui rend invisible le corps en ıe temps qu'il le dématérialise. La médecine elle ne se contente plus d'apaiser, de soigner z guérir - toutes activités de recouvrement veut engendrer l'homme nouveau.

ette prise de corps en amont de l'existence ne que pas de poser toute une série de questions.

r des dommages, s'ils tombaient malades, à : de leur travail : la preuve génétique dira $\mathrm{s}$ y étaient prédisposés. Les employeurs It d'adapter les hommes aux outils. Avec les génétiques, ils renversent la charge de la ıution. Au lieu d'assurer des situations de il sans risque, ils sélectionneront des salariés ant à ces risques.

: concert avec les entreprises, les compagnies urances élimineront sans l'avouer des clients cause de mauvais gènes ou bien leur feront r une cotisation supplémentaire : délit de sale - La discrimination génétique risque ainsi de nir la principale discrimination dans le siècle 'annonce. Imaginons chaque individu muni * carte génétique dont les puces contionnt l'état de son compte en gènes, un peu à la ère dont sa carte bancaire contient l'état de :ompte courant. Tous les actes économiques rtants (recherche d'un travail' ${ }^{1}$, souscription à issurance, emprunt financier) seraient soumis résentation de cette carte. Il est clair qu'une situation serait la négation la plus radicale rrincipes démocratiques et républicains qui, éorie, gouvernent notre société.
Traiter le sujet comme potentiellement malade, n'est-ce pas (outre un approfondissement d'une certaine trouvaille du docteur Knock), comme mettre en prison des criminels avant qu'ils ne passent à l'acte? Le rapprochement n'est pas aussi farfelu qu'il en a l'air : on a entendu des chercheurs déclarer sérieusement que la société aurait tout intérêt à réduire à l'impuissance les criminels potentiels avant que ceux-ci ne commettent leur forfait! Comme si un homme pouvait être dit criminel avant même qu'il n'accomplisse un acte que le droit appelle crime! Jean-Jacques Moscowitz a fait remarquer qu'avec la notion d'empreinte génétique on est passé de la filiation à la filature. Sans compter qu'il existe des situations humainement dramatiques où la prévision ne peut déboucher (encore) sur aucune prévention, on voit bien comment la généralisation des tests génétiques conduira les entreprises et les compagnies d'assurances à des pratiques discriminatoires ${ }^{1}$. Dès maintenant, nous pouvons écrire la chronique d'une inégalité annoncée. Dans un avenir proche, sinon déjà présent, les employeurs seront évidemment tentés de tester génétiquement leurs salariés. Histoire d'éviter un procès ou de ne pas avoir à

1. Lesquelles pourraient bien réveiller le racisme traditionnel car il est certain que des populations entières sont en dehors du génétiquement correct.

55
La médecine prédictive est une médecine eugénique, elle ne se contente plus de chasser le mal mais prétend dicter le bien. Vous faites allusion, au sujet de cette troisième figure, au fait que le philosophe américain John Rawls a associé la conception que les hommes se font d'une situation juste dans une démocratie à ce qu'il appelle "l'hypothèse du voile d'ignorance ", qu'il faut être dans une certaine ignorance du futur, de la condition future, du sort possible qui pourrait être celui de son existence, pour pouvoir juger d'une situation qui serait juste pour l'ensemble de la société. Cette médecine, qui ne se contente plus de soigner la maladie mais qui prétend dicter le bien pour l'existence même de l'être humain, met en péril les deux valeurs de liberté et de justice et risque d'aboutir à une transformation de l'homme.

Vous soulignez que dans cette dérive il existe une véritable demande de la part du public, que cette transformation ne se fait pas contre lui mais avec lui et pour lui en grande partie. Le public ne se contente pas, en effet, d'accepter passivement, il pousse à la médicalisation croissante de l'existence humaine. Il sait que ses héros médiatiques (sportifs, chanteurs, acteurs, journalistes de télévision) sont drogués, non seulement il ne s'en offusque pas, mais il l'accepte très bien. Cela dit, la recherche qui présente la demande des particuliers comme un fait originaire auquel elle répond 
feint d'oublier le caractère induit de cette demande. Le public a ceci de stö̈cien qu'il veut ce qui existe.

Est-ce que, finalement, il n'y aurait pas là un jeu d'entraînement mutuel entre une science qui est de moins en moins fondamentale, de plus en plus interventionniste et puis une demande du public qui n'est plus de l'ordre du besoin mais qui serait de l'ordre du désir, voire de l'ordre du fantasme? Et l'on pourrait se demander, en effet, si aujourd'hui nous ne sommes pas en train d'assister à une transformation de l'image de la science qui, dans son rôle traditionnel (évidemment je ne parle ici que des sciences expérimentales), satisfaisait les besoins de l'être humain, qui ensuite, lorsque ces besoins élémentaires, primaires, ont été satisfaits, s'est portée de plus en plus vers les désirs (on pense évidemment à toutes les technologies d'information et de communication) et qui, aujourd'hui, arrive peut-être à une autre étape qui est finalement la possibilité d'assouvir des fantasmes, c'est-à-dire des représentations issues de l'inconscient qui, normalement, sont impossibles à réaliser mais que la science, cette science-là du moins, rend possibles ou tend à faire croire possibles. Ces fantasmes (que l'on songe à la duplication de soi, à la grossesse masculine, ou à la « victoire » sur la mort) sont entretenus par les médias qui, évidemment, se soucient de la science

58 comme d'une guigne mais en revanche ont le culte de l'exploit. En deçà de la science, il y a la technique, mais en deçà de la technique, il y a la virtuosité pure de l'exploit : la fécondation d'une femme de 70 ans est à la science ce qu'est au sport la traversée de l'Europe à cloche-pied mais elle sera présentée comme un incontestable progrès. On observe par ailleurs que les biotechnologies permettent des promotions symboliques et sans pareilles, qui sont de véritables usurpations de titre. C'est ainsi que les médecins cliniciens travaillant à la procréation médicalement assistée (PMA), ignorant à peu près tout de la recherche, se voient honorés du titre de savants.

J. T. : Je crois que le marché de la médecine de demain, c'est la fabrication de l' homme sans qualités, comme dirait Musil, c'est-à-dire de l'homme normal, de l'homme qui ne déborde pas trop, de l'homme moyen. Au début il s'agira d'éviter tout ce qui est en dessous de la moyenne, et puis on pourra envisager de monter un peu la norme. C'est un phénomène tout à fait nouveau, non pas le fantasme en lui-même, mais les moyens techniques d'y parvenir. Si l'on parle de cela, on est obligé d'évoquer l'eugénisme et de rappeler un peu l'histoire de cette vieille tradition, bien que le mot n'apparaisse qu'à la fin du xix' siècle. Certes la pratique était déjà présente chez les Grecs,

59

et de faire avec la variété, pour le dire vite. Galton, lui, était plus interventionniste, il était médecin et statisticien', et il est assez intéressant de voir comment on retrouve ces deux spécialités dans toute l'histoire de l'eugénisme, jusque chez les nazis. Médecine et statistiques, tels sont les deux piliers de l'eugénisme, médecine pour le rapport avec le vivant, avec la maladie, le trouble, l'anomalie, et statistiques pour la mécanique de l'esprit qui mesure, évalue et place sur une courbe un individu pour savoir s'il est en haut, en bas ou au milieu. Donc Galton avait les deux casquettes, il a créé des sociétés d'eugénisme, sociétés savantes sous l'égide desquelles on a stérilisé des gens en masse, ce qui était bête et pas seulement méchant. Bête parce qu'il existe de telles loteries génétiques naturelles quand un homme et une femme font un enfant qu'il est illusoire d'imaginer qu'en stérilisant une personne, on va changer quelqúe chose à la composition génétique de l'humanité à venir. On sait que les nazis ont repris l'idée (l'idéologie) et appliqué le programme à grande échelle pour en faire une façon d'éliminer un

1. Cela n'est pas allé sans névrose, mais la névrose est aussi le nerf de la curiosité. Galton conçut, entre beaucoup d'autres, l'idée loufoque de mesurer le coefficient de charme des femmes rencontrées dans la rue : lorsqu'il croisait une femme attirante, il trouait une fiche dans sa poche gauche, quand il en croisait une peu attirante, il trouait une fiche dans sa poche droite... 
nd nombre d'individus d'abord à cause de rs pathologies puis à cause de leurs cultures de leurs origines ethniques. C'était le comble l'absurde et de l'horreur mais l'absurde et le ne étaient déjà en place grâce aux médecins et éticiens, pour la plupart «progressistes» qui ient lancé des programmes de «purification de ace humaine ». Après la guerre, le mot « eugéne » a traîné cette mauvaise réputation, on l'a scié à son pire mandataire, le nazisme. Certes, n'est pas un hasard si les nazis ont été aussi énistes mais l'on ne peut pas dire que Galton $t$ nazi, non plus que les médecins qui ont parpé à ces campagnes : sait-on que nombre de médecins étaient de gauche, et que ce sont entiellement des socialistes qui ont œuvré à ıénisme dans certains pays démocratiques, ame la Suède? Bref, le mot a été, pendant un tain temps de purgatoire, mal connoté. Or il est rain de dépasser son refoulement. Il y a aujourui des gens comme Pierre-André Taguieff, phisphe de l'antiracisme, pour expliquer que ce st pas parce qu'il y a eu les nazis que l'eugéne n'a pas un sens constructif pour l'histoire l'humanité. Il y a des gens qui commencent à rendre le mot et il y en a des plus malins qui aient de le modifier, je pense à un gynécologue it j'ai été proche un temps et qui parle aujourui de «progénisme », une façon de masquer le

62 problème, qui est d'ailleurs un peu inquiétante ( «progénisme» cela veut dire «je suis pour le gène $"$, c'est presque pire qu'eugénisme...). Il y a aussi d'autres mots comme «orthogénie» ou «eubiotique», toutes sortes de bizarreries de vocabulaire pour dire la même chose avec plus ou moins de pudeur. Ce qui est nouveau, ce n'est pas le fantasme, il est toujours là, tous les gens ont envie d'avoir un enfant qui soit plutôt «bien » parce qu'il sera plus heureux sans maladie, d'une taille au moins normale, peut-être un peu plus grand que le voisin (ça peut servir). Comme vous le disiez, il y a une rencontre entre un vieux fantasme collectif et que l'on peut comprendre, ne serait-ce que par responsabilité envers son enfant (pourquoi souhaiter un enfant qui a un risque d'être malade si l'on est capable d'en avoir un qui le risquerait moins?), et la technologie nouvelle. Celle-ci passe forcément, pour le moment, par la fécondation in vitro (qui nous permet, je l'évoquais tout à l'heure, puisqu'on dispose d'un certain nombre d'embryons, de choisir le meilleur) et les techniques de procréation assistée. Je décris dans mon dernier livre, et en me fondant sur ce qui se fait déjà en recherche animale, sur des souris, des moutons, des vaches ou autres, comment on pourrait décupler l'efficacité de ce système et comment un couple pourrait en une année produire des centaines d'enfants potentiels (embryons)

63 on pourrait ensuite trier dans l'éprouvette. Tout . est faisable, et l'on résoudra les problèmes licaux liés au recueil d'ovules dont le faible ctif constitue pour le moment la principale te. On s'achemine vers une véritable possibide choix de l'enfant à venir, grâce à la génée diagnostique, puisque, comme nous l'avons dit, autant la génétique est nulle pour soigner, nt elle est performante pour analyser. Ainsi, sourra identifier des centaines, des milliers de imètres, et pourquoi pas tout le génome, chez mbryon de deux jours. Il est évident que, dans ans ou dans vingt ans, on fera cela très facileit, ce qui induira une incitation supplémentaire $r$ ce vieux fantasme dont on parlait. Ainsi les ples, ne serait-ce que par devoir envers l'enà venir, ne le feront plus bêtement au hasard ime ils l'ont toujours fait mais essaieront de lonner le plus de chances possibles au départ. développement où la procréation se dégage iplètement de la sexualité, chaque fonction It sa propre finalité, me paraît inévitable.

our beaucoup, le mot « eugénisme » ne s'apuerait pas à de tels projets. Pourquoi? Parce l'eugénisme était une pratique de masse, idée par un État qui posait des directives zernant le normal et l'anormal. Par exemple, érilisation d'un jeune atteint de nanisme était :e nécessaire à cause du risque futur d'engen- drer des nains, c'était une mesure d'État. Aujourd'hui, il n'en irait plus de même, parce que la malformation serait prise en compte par le couple et il s'agirait donc de décisions individuelles.

Je pose la question : est-ce que vous connaissez beaucoup de gens qui souhaiteraient avoir un enfant mesurant un mètre quarante, ou qui soit bossu, aveugle, ou qui ait un risque de cancer précoce...? Il est évident que le consensus sur la santé existe, que tout le monde se fait à peu près la même image de l'enfant qu'il voudrait àvoir (la couleur des yeux ou d'autres caractères non pathologiques sont des détails) sur le plan de la santé générale : tout le monde voudrait un enfant en bonne santé, pour qu'il soit heureux, qu'il se développe bien. Autrement dit, que cela relève de l'État ou bien que cela soit décidé lors d'un colloque singulier entre le médecin et son patient, cela revient exactement au même, le profil sanitaire de l'enfant choisi est toujours le même, c'est celui de la norme en attendant d'être celui, je ne veux pas dire du «surhomme», mais de l'enfant « idéal » pour le moins, si ce n'est « parfait ». Ceci est tout à fait important pour l'histoire future de l'humanité : nous nous donnons les moyens aujourd'hui de réaliser ce type de tri et cela ne peut que se développer, pour bien des raisons analysées ailleurs, parce que c'est conforme aux vieux fantasmes (beauté, pureté, norme, performance, etc.), 
conforme aussi à l'intérêt du .monde médical (cela correspond à davantage d'actes), conforme à l'intérêt de l'industrie (cela va développer de nouveaux outils, génétiques en particulier, pour affiner les identifications), et ce sera sûrement un jour conforme aux intérêts de la santé publique parce que ce qui lui coûte le plus cher, c'est un enfant handicapé.

C. G.: On se rend compte à vous entendre que la «pulsion eugénique ${ }^{1}$ », j'utilise ici l'une de vos expressions, balance entre deux pôles, deux objectifs : la moyenne statistique et la supériorité. Telle est d'ailleurs l'ambivalence contenue dans la notion même de norme : la norme peut être aussi bien l'idéal, très rare par définition parce que difficile à atteindre, que la banalité, le plus grand nombre : mathématiquement, elle s'inscrit dans l'arrondi de la courbe de Gauss - les gens de taille normale sont les plus nombreux, ils ne sont ni très grands ni très petits. Or il semble que la génétique soit en train d'abolir la frontière entre l'anomalie (simple écart par rapport à la norme) et l'anormalité (suppression de la norme). Avec la génétique, toutes les anomalies tendent à devenir des anormalités.

Nous avons évoqué le fatalisme que les travaux actuels induisent de manière presque spontanée

1. J. Testart, Des hommes probables, op. cit., p. 59.

en parlant froidement d' « anthropotechnique », d'élevage humain. On comprend l'émoi suscité dans un pays, l'Allemagne, dont la mémoire historique est encore marquée - espérons, à la différence de Sloterdijk, qu'elle le restera à jamais par la catastrophe nazie. Il convient, en effet, de prendre conscience que la barbarie eugéniste du national-socialisme n'a pas été improvisée sur le terrain expérimental et historique mais qu'elle a été rêvée, projetée, prévue, décrite avant d'être réalisée.

Dans Le Désir du gène", vous évoquez le cas d'un certain Binet-Sanglé, auteur d'un ouvrage intitulé Les Haras humains, tout un programme (1918), où il propose le placement de 40 «bons générateurs » dans des haras où ils dewront féconder, à raison de 108 par an (on admirera au passage la précision, évidemment scientifique), les femmes célibataires appartenant aux élites nationales et provinciales. Quarante mille trois cent vingt femmes d'élite seront ainsi annuellement engrossées. Quant aux « dégénérés fatigués de la vie » (sic), on créera à leur intention un institut d'euthanasie où ils seront anesthésiés à mort avec du protoxyde d'azote. Ces propositions ont alors provoqué des sourires... .

André Pichot fait remarquer que si les théories

1. J. Testart, Le Désir du gène, François Bourin, 1992, p. 42. dans l'esprit des gens. Or à ce fatalisme s'adjoint contradictoirement une espèce de rêve volontariste reposant sur l'idée (qui est une folle espérance) que l'on pourrait commander aux gènes et même (en un sens trivial commercial) commander des gènes. Tout se passe comme si l'homme moderne, ayant renoncé à diriger son histoire collective (l'ère des révolutions politiques semble close et personne ne croit plus à un changement social voulu), avait réinvesti son potentiel de volonté dans le champ exclusif de l'histoire personnelle. L'eugénisme repose sur une illusion terriblement dangereuse, une illusion qu'il véhicule aussi : celle de croire que le bien-être (ne parlons pas du bonheur) réside seulement dans la santé physique. Comme dit le psychologue Ehrenberg, une société dont l'horizon est le mieux-être ne peut être qu'une société du mal-être.

Les premiers programmes eugénistes, nous disons bien programmes et non simplement projets, figurent dans les utopies philosophiques et littéraires - dont nous avons fini par ailleurs par reconnaître rétrospectivement le caractère totalitaire. Au début du XVII ${ }^{\mathrm{e}}$ siècle, Campanella, dans sa Cité du Soleil, s'indigne de ce que nous prenions soin des animaux dans nos élevages mais que nous négligions les hommes : une inconséquence absurde, selon le moine révolutionnaire. Sloterdijk a récemment soulevé une tempête

racistes ont quasiment disparu après la guerre, ce n'est pas seulement en raison des horreurs nazies, mais aussi à cause de la domination de la génétique moléculaire qui a éclipsé la génétique des populations. Or il va arriver que cette génétique moléculaire produira des informations capables de ressusciter une nouvelle génétique des populations. Il ne s'agirait plus de qualification ethnique dérivée de critères physiques mais de qualification génétique tirée d'évaluations moléculaires des génomes. C'est pourquoi, malgré une crainte largement partagée, ce n'est pas la « manipulation génétique » qui nous menace mais bien la qualification. La référence à un modèle virtuel (la carte du génome humain) et le pouvoir de caractériser les déviances de chacun par rapport à cette cartographie ouvrent l'ère de nouveaux classements et donc de nouvelles hiérarchies entre les hommes ${ }^{1}$. Vous concluez ce paragraphe ainsi : « le racisme du gène pourrait remplacer, mais cette fois scientifiquement, le racisme de la peau ou de l'origine ${ }^{2} \gg$.

Deux facteurs ont par conséquent changé le sens de l'eugénisme, et, ce faisant, l'ont rendu tout à fait acceptable aux yeux du plus grand nombre : d'une part, il n'est plus le rêve de l'utopiste ni 
lui du savant fou, mais un projet raisonnable puyé sur les dernières découvertes de la science; ıutre part, il s'est détaché de l'élitisme et du isme totalitaires pour revêtir l'apparence de tilité et du bien-être de tous. L'eugénisme est venu rationnel et démocratique. Qui aurait sore le cœur de s'y opposer?

Rationnel. Qui a dit: «aucun enfant nouveaune devrait être reconnu humain avant d'avoir ssé un certain nombre de tests portant sur sa tation génétique [...]. S'il ne réussit pas ces ts, il perd son droit à la vie»? Sir Francis cck, l'un des codécouvreurs de la structure de DN 1 .

Jémocratique. Le cas suédois, que vous évozz, est effectivement troublant et devrait nous srtir. Car dans le cadre de cette démocratie, que uccoup ont longtemps présentée comme un 'dèle, une politique systématique d'eugénisme menée avec l'aval de tous les partis politiques. ıles quelques voix isolées ont protesté lorsque ent votées les lois eugénistes en 1934 et en $H 1$ - soit en pleine période nazie en Allemagne. $r$ tel est le second aspect troublant de l'affaire : Jarbarie nazie n'a pas joué son rôle de contredèle, et même lorsque son aspect le plus

. Cité par J. Rifkin et T. Howard, Les Apprentis sorciers, ısay, 1979.

70

poques. Il tient, du moins en France, à l'interon légale de décider et de savoir, car l'institumédicale s'arroge seule le choix d'un géniet demeure seule détentrice de ce secret. Le de sperme nie la personne du donneur en taison nom et son histoire, pour une éternité rique. Mais il magnifie son pedigree puisque juête médicale pénètre l'intimité génétique et snéalogie de l'étalon de substitution d'une a qu'on jugerait obscène si le cadre hospitale servait pas de paravent. Quel(le) amant(e) ait s'enquérir avec autant de minutie des uts bien cachés dans l'ADN de son parte, avant de l'accepter aux fins de procréation? :térilité sollicite la médecine, qui impose orme. Avec l'air de négliger l'importance 'identité génétique («la paternité, c'est our "), la banque de sperme exalte la fonction onneur, c'est-à-dire son potentiel héritable. :ntité d'abord réduite au génome, c'est tout le :t de construction de l'homme probable ${ }^{1}$. ançois Dagognet a écrit à propos de l'eugée qu'il est «à la fois une erreur et une hor'». L'horreur, nous la connaissons par les :cins nazis. Voici l'erreur : «On peut manipu$s$ plantes et les animaux, parce qu'on ne vise

. Testart, Des hommes probables, op. cit., p. 129-130.

?. Dagognet, Corps réfléchis, Odile Jacob, 1990, p. 79. affreux fut révélé au monde, après sa chute, les stérilisations forcées au nom de la biologie raciale se sont poursuivies en Suède, tout au long des années cinquante. Il est politiquement intéressant de voir comment les deux partis opposés ont justifié leur aval. À droite, chez les conservateurs, jouait l'impératif de la pureté raciale, à gauche, chez les sociaux-démocrates, c'est le contrôle des naissances et la qualité de la politique sociale qui étaient mis en avant : l'eugénisme était conçu par ces progressistes comme un moyen de prévenir les problèmes sociaux. Ainsi deux idéologies contraires peuvent-elles sur une question capitale touchant l'ensemble de la société et, au-delà, l'idée que l'on se fait de la civilisation, se rejoindre et légitimer l'inacceptable.

Il est à cet égard instructif de voir avec quelle facilité nous acceptons aujourd'hui les présupposés d'un acte médical désormais banalisé, l'insémination artificielle avec donneur (IAD). Le fameux principe d'anonymat rabaisse le donneur au rôle d'étalon. Certes, il ménage en apparence le narcissisme blessé des couples stériles mais au prix d'un déni dont peu osent s'étonner. L'aspect le plus aliénant du don de gamètes, dites-vous, n'est pas que le père génétique ne soit pas le père social, il n'est même pas le secret souvent attaché à cette origine atypique puisque de nombreux enfants de l'adultère ont pu vivre heureux à toutes

71

qu'à améliorer un seul aspect - le volume, le poids, la vitesse de croissance, la couleur, bref les facteurs économiques, mais quand il s'agit de l'Homme, que viser et pourquoi ${ }^{1}$ ? » Albert Jacquard semblablement a fait observer qu'avec les chevaux de course on a amélioré la capacité de l'animal à courir vite, mais qu'on n'a pas amélioré le cheval lui-même. Encore une fois, on prend la partie pour le tout. Il n'est, à ce propos, pas excessif de soutenir que les "génies » qui proposent du sperme de Nobel qu'ils croient de qualité supérieure pour produire de futurs surdoués tombent dans ce que les logiciens anglosaxons appellent une contradiction performative. Car cette proposition même, censée faire triompher la plus haute intelligence, n'est-elle pas un signe irréfutable d'imbécillité? En 1979, Robert Graham, un ophtalmologue américain, rêvant de voir naître une humanité d'élite, avait fondé en Californie une banque de sperme de prix Nobel ou de champions sportifs. Le professeur William Shockley, prix Nobel de physique en 1956 pour ses travaux sur les transistors, avait pour cette entreprise beaucoup payé de sa personne. Il s'était répandu aussi en projets mirifiques : il ne proposait rien moins que l'instauration d'un système de primes à la stérilisation pour les mauvais sujets

1. F. Dagognet, Corps réfléchis, Odile Jacob, 1990. 
dotés d'un QI inférieur à 100 . À 1000 dollars le point de déficit par rapport à ce seuil, cela mettait le QI de 70 à 30000 dollars, offre non négligeable, même pour des imbéciles. On vient d'apprendre que des ovules de mannequins ont été mis aux enchères sur Internet. Pour une centaine de milliers de francs, une femme ou un homme (parfois les deux) pourront se payer l'illusion que sa (leur) fille sera aussi belle que les photographies de couverture de leur magazine préféré. Autre exemple encore plus burlesque: un couple a mis une annonce sur Internet, offrant une somme coquette pour un ovule beau et intelligent ( $\mathrm{sic}$ ), avec la précision que la donneuse doit être étudiante dans un collège réputé mais aussi sportive. Il n'a pas été ajouté que l'ovule devait savoir cuisiner...

Pour répondre à ces inepties, il suffirait de citer ce trait d'esprit de George Bernard Shaw. Un jour, l'écrivain irlandais participait à un dîner mondain. Il était laid mais son esprit compensait largement ce défaut. Shaw était assis à côté d'une femme très belle mais qui tenait un discours absolument consternant. Entre deux plats, celle-ci dit à l'écrivain :

- Voyez-vous, monsieur Shaw, nous devrions avoir un enfant ensemble. Il aurait ma beauté et votre intelligence.

- Oh, surtout pas, répondit tout à trac Shaw, j'aurais trop peur que ce ne fût l'inverse!
L'eugénisme est impossible pour l'homme, cela devrait suffire à l'exclure. Cela dit, il est de tradition, à présent, de distinguer un eugénisme négatif et un eugénisme positif, l'eugénisme négatif consistant à éliminer les malformations et les pathologies potentielles les plus graves et l'eugénisme positif consistant à œuvrer dans un sens interventionniste en faveur d'un idéal ou d'une norme posés au départ, $a$ priori. Est-ce que, à votre sens, cette distinction entre eugénisme positif et eugénisme négatif est pertinente au point de nous faire adopter une position éthique claire, c'est-à-dire que, par exemple, on pourrait être pour un type d'eugénisme et contre l'autre ou bien, à votre avis, y a-t-il une continuité, un passage insensible de l'un à l'autre et dès lors que l'on accepte l'eugénisme négatif, c'est déjà un engrenage d'eugénisme positif qui se trouve mis en marche?

J. T. : Je crois que cette distinction était pertinente au moment où l'eugénisme lui-même n'était pas pertinent, lorsque l'on pouvait catégoriser des gens assez facilement par leur apparence, par leur comportement, et ainsi les ranger sur une échelle arbitraire d'acceptabilité. Ça ne changeait absolument rien à ce que pourrait devenir l'humanité si l'on appliquait systématiquement cet eugénisme. En revanche, aujourd'hui la distinction entre les

75 deux formes d'eugénisme n'a plus aucun sens, parce que l'on a affaire à une véritable population avec les embryons d'un couple. Si l'on a quinze ou vingt embryons disponibles, on peut dire qu'on pratique l'eugénisme négatif en éliminant certains embryons mais il est clair qu'on pratique simultanément l'eugénisme positif en favorisant les autres. Autrement dit, on n'est plus en présence de la même notion, on agit sur une population de frères et sœurs, qui sont du même âge et qu'on doit sortir de l'éprouvette comme on sort du chapeau d'un prestidigitateur le meilleur lapin possible, parce qu'il en suffit d'un. La différence est que l'eugénisme classique visait l'individu (ou le couple) alors que le tri embryonnaire vise déjà sa descendance, laquelle est multiple. Ceux qui refusent de reconnaître l'eugénisme dans le tri des embryons, au prétexte que l'eugénisme visait des populations, devraient méditer cette contradiction... En même temps, le tri embryonnaire s'avère être un moyen scientifique de permettre sans risque la procréation à des individus porteurs d'anomalies graves, ou même (c'est l'image du lapin sorti du chapeau) de faire advenir le « meilleur » possible de chaque couple «normal » ou « anormal ». Ce «meilleur enfant » n'aurait eu que des chances infimes d'exister par les moyens naturels, ce qui peut permettre de considérer l'intervention technique comme «positive » globale- ment, si l'on néglige les nombreux embryons éliminés dans ce processus. Dit autrement, le tri embryonnaire est un eugénisme positif sur le couple géniteur et négatif sur la quasi-totalité de ses embryons. Il reste cependant que c'est bien l'embryon et non son géniteur qui est la cible du nouvel eugénisme, et ce ciblage inédit se trouve justifié de plusieurs façons : non seulement on intervient ainsi sur le génome achevé du futur enfant, en dépassant les loteries génétiques de la gamétogenèse et de la fécondation et donc l'aléatoire de l'eugénisme classique, mais on peut aussi déjouer les mutations qui affecteraient l'embryon sans que ses géniteurs en soient porteurs. Tant de charmes apparents évoquent la pomme empoisonnée mais tellement belle offerte à Blanche Neige... De la sorcière aux « sorciers de la vie », de la naïve jeune fille à la société confiante, la méchante reine n'est peut-être pas nécessaire à la dramaturgie...

Avec un embryon, on peut être sûr, compte tenu des techniques dont on dispose déjà, de fabriquer au moins un enfant, en passant par le clonage embryonnaire. Il faut tenir compte de la convergence de nombreuses techniques en passe d'être maîtrisées pour imaginer que cette perspective est bien prometteuse. On a déjà autorisé trois centres en France à pratiquer ce tri des embryons. Pour le moment, et pendant quelques années, on le fera 
r de bonnes raisons, c'est-à-dire les mêmes qui ient justifié un avortement qu'on appelle śdical » pendant la grossesse, en cas de pathoes graves. Le débordement que je décris se dans dix, dans vingt, dans trente ans, peu orte finalement, puisque c'est forcément ainsi ça finira.

n octobre 1999 , le premier dossier de DPI gnostic préimplantatoire) étudié à l'hôpital lère de Clamart, exposait un cas de maladie de henne. Cette maladie ne concerne que les ons (les filles sont seulement porteuses, 1d elles le sont) et induit une prescription ii systématique d'avortement si on la décèle. est-ce qui se passe quand on fait un diagnostic atal ? Chez une femme enceinte dont on sait lle court ce risque, on recherche le gène muté. $n$ le trouve, et que l'enfant va être un garçon, rocède à l'avortement. Si c'est une fille, elle 'ectrice, c'est-à-dire qu'elle porte ce gène, elle era pas elle-même malade, mais elle risque emment d'avoir des enfants exposés aux les problèmes, pourtant on n'a pas recours à srtement. Ces généticiens-là ne sont pas du les mêmes que ceux dont je parlais précément. Là il s'agit de génétique médicale, ces ecins sont en rapport direct avec la douleur zouples, avec les vrais problèmes, ce ne sont des chercheurs dans la molécule, ils sont

78 encore dans l'humanité, et ils ne conseillent pas aux couples de faire un avortement dans ce cas de figure. Pour le DPI, l'équipe de Béclère s'est posé la question: que faire si l'on obtient une douzaine d'embryons? On décrit tous les cas possibles, dont le cas de la petite fille encore à l'état embryonnaire qui serait vectrice, se portant bien mais pouvant avoir elle-même des enfants malades. Là, on s'aperçoit immédiatement que le diagnostic préimplantatoire n'a rien à voir avec le diagnostic prénatal : une bonne partie des praticiens amenés à juger le dossier disaient : «mais enfin, c'est quand même idiot, on a là des embryons sains, on a aussi des embryons qui sont porteurs de pathologie, on prend un risque pour la génération d'après, il vaut bien mieux ne garder que les embryons sains ». Ça paraît complètement logique, on voit pourtant dans quel système on s'engage. Dans le cas de la myopathie de Duchenne, il s'agit d'une maladie grave, sans aucun doute, mais que se passera-t-il quand on détectera un risque statistique de diabète ou de cancer du foie, ou simplement de myopie? L'avenir de la génétique n'est pas dans cette voie simpliste qui consiste à reconnaître les gènes des maladies monogéniques, il est dans l'identification des facteurs polygéniques, par combinaisons de plusieurs gènes qui, en rapport avec le milieu, peuvent provoquer des pathologies. C'est dire que nous sommes tous

79 ncernés, c'est dire aussi la suspicion qui affectera is les embryons. Imaginez comment pourra se :ouler cet examen de dossier par les généticiens l'avenir, quand ils disposeront d'embryons en Ind nombre, et de sondes capables d'identifier ; caractères innombrables de l'ADN...

C. G. : Cette « génomanie » engendre des illuns, aussi bien chez les médecins que dans le ınd public. Du côté de la recherche, il y a une ision, qu'on pourrait appeler une «illusion de itude » et qui n'est pas sans rappeler l'illusion as laquelle étaient tombés un certain nombre biologistes et de médecins, au XIX ${ }^{e}$ siècle sque, avec le triomphe de certaines vaccinans à partir de la découverte de Jenner jusqu'à steur, ils pensaient qu'il existait un nombre erminé de maladies fixé une fois pour toutes que les vaccins, selon le paradigme militaire la cible atteinte, allaient détruire ces maladies a par une à la manière dont les pipes en plâtre, is une baraque foraine, peuvent être cassées. $\mathrm{ec}$ les gènes, on tombe dans une illusion nblable puisque penser que la détermination nplète des gènes aujourd'hui nous permettrait :mbrasser la totalité du champ des maladies, a veut dire que l'on suppose a priori que ttes les maladies possibles qui pourraient ecter l'être humain sont déjà déterminées; or il n'en est rien, c'est-à-dire que les maladies du $\mathrm{XXI}^{\mathrm{e}}$ siècle, du XXII', du XXII' ${ }^{e}$ siècle, nous n'en avons aucune idée; le monde des maladies est, sinon infini, du moins indéfini. Les médecins du siècle dernier croyaient à un état de santé idéale comme les utopistes croyaient à un état de satiété idéale : d'ailleurs la santé n'est-elle pas à l'ordre physiologique ce qu'est l'abondance à l'ordre économique? C'était sans compter avec les maladies qui n'avaient pas encore eu la possibilité de s'exprimer. Croire aujourd'hui qu'on pourrait sélectionner les «bons» et les «mauvais » gènes, c'est tomber dans la même erreur que les médecins du XIXe siècle qui croyaient à la possibilité prochaine d'inventer tous les vaccins. Puisque nous ne savons pas quelles seront les maladies de demain, nous ignorons quels sont les « bons " gènes face à ces maladies. Inversement, nous pourrions, dans notre zèle eugéniste, vouloir éliminer aujourd'hui un gène que nous déclarerions «mauvais » ou « inutile » mais qui serait très précieux à l'avenir en cas d'investissement de l'espèce humaine par une nouvelle maladie encore inconnue. Corollairement, nous n'avons aucune preuve que les animaux transgéniques, produits pour des qualités spécifiques reconnues, ne souffrent pas d'un déficit qui se manifestera à long terme dans des conditions particulières. Les généticiens réalisent leurs expé- 
riences en faisant abstraction de l'environnement, alors même que c'est le facteur environnemental qui, la plupart du temps, se révèle décisif. Un point de vue résolument statique sur une réalité dynamique peut à cet égard se révéler particulièrement désastreux. L'adoption à grande échelle d'une norme-moyenne au nom d'une idée préconçue de l'efficacité et de la performance pourrait à terme être biologiquement suicidaire. L'écologie scientifique prouve que la force d'un écosystème tient à sa diversité. Il y a là un enseignement tiré de l'observation du monde végétal et animal et qui peut être transposé à l'espèce humaine.

Il serait erroné de croire qu'il existe d'un côté un ensemble de gènes, de l'autre côté,un ensemble de qualités et de défauts, et qu'à l'un des gènes correspond un seul défaut ou une seule qualité. Les maladies monogéniques (causées par un seul gène) sont rares ${ }^{1}$. La plupart des maladies sont

1. Certes, on a répertorié pas moins de 5000 maladies génétiques, unifactorielles (on les appelle aussi « maladies orphelines " parce qu'elles touchent moins de 5 individus sur 10000 ). Ce sont des maladies qui impliquent des gènes dont l'anomalie ou le dérèglement suffit à lui seul, sans qu'aucun facteur extérieur intervienne de manière déterminante, à provoquer l'apparition d'une maladie gravissime. L'hémophilie, la mucoviscidose, la myopathie de Duchenne, la chorée de Huntington sont les plus célèbres de ces maladies. Mais l'ensemble des 5000 maladies génétiques ne touche qu'un demi pour cent

82 polygéniques (causées par plusieurs gènes) et réclament la faveur, si l'on peut dire, de l'environnement. En matière de séquençage, tout a un caractère évident; ce qui ne l'est pas, c'est mettre au jour les implications d'un gène. Les maladies exclusivement génétiques (comme les maladies pas du tout génétiques) ne représentent qu'une petite partie de l'ensemble des maladies, mais elles seules méritent le nom de maladies génétiques. La plupart des maladies sont ou bien à dominante génétique (lorsque le facteur génétique est le plus important) ou bien à composante génétique (lorsque le facteur génétique existe sans être le plus important) 1 . Or, même les maladies à dominante génétique ont besoin de facteurs extérieurs pour se développer. Quant aux maladies à composante génétique, elles sont d'abord environnementales ou comportementales, c'est-à-dire qu'elles sont conditionnées par le milieu et le mode de vie.

Comme pour tout ce qui touche le corps, la dimension psychologique ne doit pas être négli-

de la population, et une dizaine d'entre elles seulement représentent le tiers des cas.

1. De graves maladies génétiques échapperont à jamais à toute entreprise eugénique: un tiers des myopathies, par exemple, ne sont pas héréditaires ; elles surgissent accidentellement, par une mutation spontanée du génome, susceptible de survenir à tout moment, à n'importe quelle génération.

83 gée, puisque c'est elle qui produit les demandes et les angoisses. La maladie génétique est celle qui fait le mal le plus mystérieux puisqu'il ne vient pas de l'extérieur. L'ennemi loge au cœur invisible du corps et comme il est apparu au moment de l'acte sexuel des parents, il induit la notion d'une faute primordiale, d'un péché originel, qui n'est pas seulement liée, comme on pourrait le penser, à la croyance chrétienne. La culpabilité est omniprésente dans les maladies génétiques - aussi bien chez les témoins proches que chez les victimes. Car nous retrouvons ici ce qui, probablement, représente l'une des lignes de force de la psyché humaine: on ne croit pas au hasard abhorré, à la loterie des gènes, on préfêre trouver un sens, qui ne peut être que de malédiction. Nous avons tendance à raisonner en termes de nécessité et d'impossibilité, parce que cela paraît correspondre à notre expérience la plus commune. D'un côté, la nécessité : la chose aura lieu, quoi qu'il arrive. De l'autre, l'impossibilité : elle n'aura pas lieu, quoi qu'on fasse. Or la biologie, et en particulier la génétique, travaille dans la zone moyenne du «possible» et du plus ou moins «probable ». Un cancer par exemple n'est jamais ni totalement nécessaire (100\% de risques) ni totalement impossible ( $0 \%$ de risques). Seulement, ce n'est pas ainsi que l'opinion commune reçoit les «enseignements » de la génétique : au lieu de raisonner en termes de plus et de moins, elle le fait en termes de tout et de rien. D'où ce malentendu : alors qu'elle devrait nous inviter à la prudence, la génétique suscite en nous une idée de fatalité. Nous ne parvenons pas à intégrer le hasard dans notre conception de la vie. Cette distorsion nous met en porte à faux dans nos jugements pratiques 1 .

Enfin il convient, pour dissiper l'illusion d'une tyrannie des gènes, de prendre en compte la diversité de leurs formes: cé que nous disons être le «même » gène n'est en réalité pas identique d'un individu à l'autre. Pour prendre une image, nous dirions que deux individus ont beau avoir tous deux les yeux marron, la couleur de leurs yeux n'est pas en réalité identique. Dans la vie, il n'y a que des différences, même s'il est vrai que pour comprendre et classer, nous avons besoin avec nos mots et nos concepts de les oublier quelque peu. Vous mettez à juste titre en question la métaphore du programme, mais prenons le mot au mot: à partir d'un même programme de musique, on n'a jamais entendu deux interprétations rigoureusement identiques quand

1. Soit le gène BCRA 1 identifié il y a 6 ou 7 ans. Les possibilités pour une femme de développer un cancer en cas de mutation de ce gène varient de $50 \%$ a $85 \%$ selon le nombre de cancers antérieurs dans sa famille. Quelle conclusion pratique peut-on tirer d'une telle information? 
bien même elles étaient données par le même chef et le même orchestre. Un gène n'est ni bon ni mauvais dans l'absolu.

J. T. : Effectivement, on connaît même quatre ou cinq exemples de gènes de maladies graves, tont on sait que, pourvu qu'ils ne soient pas présents à l'état homozygote, c'est-à-dire en deux exemplaires (on développe alors la maladie), on Jeut être, grâce à eux, mieux protégé que le sommun des mortels contre d'autres maladies. Ce łui veut dire que l'on doit être prudent plutôt que Jrésomptueux en génétique, plus encore que dans es autres domaines. Même en dehors de cet ispect-là, l'on devrait finalement tolérer une ceraine marge d'anormalité, ne serait-ce que pour Jrévoir, comme vous le disiez, des situations qui l'existent pas, des maladies nouvelles. Si l'on rrend l'exemple du sida, on sait qu'il y a des ndividus (à peu près $10 \%$ de l'ensemble des ıumains), qui sont naturellement protégés, parce ju'ils ont un gène qui joue sur le récepteur du 'irus. Ces gens-là sont minoritaires, donc ils ont anormaux pour un statisticien, ce sont des nutants. Mais ils sont protégés. Imaginez qu'on it eu les moyens d'éliminer; dans le passé, tout ce ui était en variance par rapport à la norme, ces orteurs sains naturellement protégés ne seraient Ius là; or, et c'est pour cela que l'humanité

86 existe encore, il y a pour toutes les grandes maladies, la peste noire ${ }^{1}$ par exemple, toutes les épidémies que l'humanité a pu connaître dans son histoire, il y a toujours eu au moins $10 \%$ de la population qui a résisté, même en des lieux très infectés; en fait, ces gens-là étaient des mutants et l'on découvre aujourd'hui en quoi consistait leur mutation si, en décrivant le génome, on arrive à trouver des relations. Cela veut dire finalement que la marge est peut-être ce qui sauvera l'humanité. Voilà déjà un élément important pour être très prudent et assez humble par rapport aux déterminations de la génétique. Mais il y a autre chose, c'est l'illusion de la causalité unique : en dehors des systèmes simples «un gène, une pathologie » (il y en a, mais c'est tout à fait minoritaire dans le champ de la maladie) il y a des systèmes, des combinatoires complexes entre gènes et éléments du milieu (l'alimentation, la température, toutes sortes de facteurs) qui font que l'on a plus ou moins de risques d'être malade, cela veut dire qu'on est dans la probabilité, on n'est pas du tout dans la certitude. La médecine d'aujourd'hui, celle de demain encore plus, tend à être une médecine de probabilité. Quand on va chercher le

1. L'une des plus grandes épidémies de l'Histoire. Dans $l^{\prime} E$ Europe des $\mathrm{XIV}^{\mathrm{e}}$ et $\mathrm{XV}^{\mathrm{e}}$ siècles, elle a tué la moitié de la population.

87 ıeilleur embryon, qu'on élimine ceux qui ont de rosses pathologies potentielles, on tient compte zs probabilités de telle ou telle pathologie, en sbliant qu'il y a des moyennes qui fragilisent et is exceptions qui sauvent.

La probabilité a un sens pour une population ais pas pour un individu. Si on vous dit que sus avez $52,8 \%$ de risques d'avoir un cancer du Jumon à 63 ans et demi parce que vous menez lle ou telle vie, c'est statistiquement vrai, mais la ne vous intéresse pas, ce qui vous intéresse, est de savoir si vous allez ou non souffrir de ce ncer, et cela personne ne peut vous le dire. De us en plus ce que l'on développe avec des arguznts scientifiques, ce sont des probabilités, d'où titre de mon dernier livre Des hommess probles, parce que l'homme que l'on va construire, sst l'homme qui a une probabilité d'être comme zi ou comme cela, mais qui peut très bien xapper à ce que l'on prévoit pour lui, qui peut ıser des surprises, nécessairement une décepn. Actuellement se met en place une médecine $\approx c$ un très fort investissement technologique, It un apparat scientifique mais qui finalement pourra pas vraiment se tenir à la hauteur de ses ımesses, définitivement.

. G.: Ces effets d'annonce miraculeuse, qui ibuent à la recherche des pouvoirs qu'elle n'a pas et des exploits qu'elle ne réalise pas risquent à terme de se retourner contre la recherche ellemême : un enthousiasme déçu se change en scepticisme et en ressentiment. Avec l'extension de la médecine prédictive, on peut s'attendre à une véritable explosion des médecines parallèles et des pratiques irrationnelles. Dans ce domaine -hargé d'émotions, parce que la souffrance et la mort y sont toujours présentes, les statistiques ne sont pas comprises dans leur froideur impersonnelle, elles engendrent des malentendus. Ainsi vous évoquez ce cas d'école : lorsqu'ils apprennent que $75 \%$ des patients atteints de telle maladie guérissent, la plupart des gens pensent que s'ils sont personnellement frappés par cette maladie, ils auront trois chances sur quatre de s'en sortir. On applique de manière illégitime une donnée statistique globale à un cas individuel.

Le titre de votre ouvrage, Des hommes probables, peut se comprendre en deux sens : d'une part, la biologie travaille à la venue d'hommes préconçus, d'autre part, il est probable que ces hommes préconçus voient le jour un jour. Dans le sous-titre de l'ouvrage, « De la procréation aléatoire à la reproduction normative», "procréation » s'oppose à « reproduction » et « aléatoire » s'oppose à «normatif ». De l'art (la création) à l'industrie (la production), la norme chasse le hasard. Et avec le hasard, la liberté, et donc, 
comme c'est à craindre, l'humanité même. Le philosophe Hans Jonas, dans son Principe Responsabilité, écrit que le pouvoir que nous avons acquis dans la maîtrise de la vie s'accompagne de la responsabilité de la préserver et de la transmettre aux générations futures. Notre grande responsabilité n'est pas de garder un dépôt intact ou encore de l'améliorer, mais de veiller à transmettre un monde indéterminé. Plus précisément, écrit Jonas, nous devons dans chacun de nos choix veiller à ne pas fermer des possibilités pour les générations futures; nous leur devons un monde de liberté dans lequel elles puissent choisir entre différents avenirs possibles, comme nous en avons encore le choix aujourd'hui. Or, c'est cela précisément qui est menacé, cette ouverture des possibles.

Alors que la procréation invente, la reproduction répète ${ }^{1}$. De fait, ne voyons-nous pas la naissance changer de sens? On a commencé par éliminer le père, puis la mère, enfin on se passe des deux. D'un coup, la parenté et la sexualité se trouvent éliminées.

Dans Le Magasin des enfants, ouvrage collectif dirigé par vous, il est fait appel à une interprétation de type psychanalytique pour dégager le sens de

1. «Le résultat de la procréation est la création de génomes variés à l'infini, objets ainsi exclus du champ de la maîtrise génétique » (J. Testart, Des hommes probables, op. cit., p. 64).

90

conforte la femme ou l'homme stérile avec l'idée qu'ils peuvent quand même enfanter, et les difficultés opposées par l'administration au désir d'adoption.

«L'homme naît dette », dit un texte sanskrit. Il est probable que le désir de transmettre la vie soit la reconnaissance inconsciente d'une dette d'existence ${ }^{1}$. L'homme enfante parce que lui-même a été enfanté. Vous écrivez que « la nature a inventé bien des trucs pour limiter notre aptitude à faire des enfants ${ }^{2} »$. On peut raisonnablement se poser la question de savoir si la PMA ne va pas contribuer à répandre la stérilité des individus humains. À répandre aussi l'idée que la sexualité doit être stérile (Aldous Huxley avait fort bien deviné cette tendance).

Par ailleurs, la maîtrise de la «procréation » déporte le phénomène du côté du droit, droit de pour les médecins, droit à pour les parents - et sans doute bientôt chez les enfants : on voit désormais des enfants (surtout aux États-Unis, mais cela commence à arriver en France) intenter à leurs parents des procès pour les avoir laissés naître sciemment avec tel ou tel handicap. Jusqu'à présent, nul ne pouvait reprocher à ses géniteurs le fait d'être géné-

1. Inversement le refus, de plus en plus large et inquiétant, de cette transmission serait le signe d'une absence de reconnaissance de dette à l'égard des géniteurs.

2. J. Testart, Des hommes probables, op. cit., p. 142. cette révolution. Toutes ces techniques visent finalement à la mise hors jeu des parents au profit d'une puissance. "Extinction ou extermination douce, autoprogrammée, de l'être humain, race inférieure ou imparfaite parce que née d'une femme au profit d'un mutant d'une espèce supérieure, enfant des hommes ou plutôt de l'Homme. Pris dans son obsession de maîtrise de la reproduction, "l'Homme" n'est-il pas en train de devenir l'autre nom de la Mère phallique et toute-puissante, imaginée par le petit garçon qui n'a pu, comme la fille, relativiser ensuite, par l'identification à la mère, la menace qu'elle représente sur le plan fantasmatique pour l'affirmation de son identité ${ }^{1}$ ? 》 Avec les techniques qui sont encore de procréation mais qui seront bientôt de reproduction, la femme est chassée du lieu symbolique où elle dominait d'incontestable manière au profit d'une puissance impersonnelle (la Mère avec majuscule) qui ne correspond à aucun être concret de chair et de sang. Se profile dans ces tendances en cours une éviction des femmes dont on n'a pas encore pris la mesure.

Par ailleurs, loin de libérer l'homme de l'imaginaire des liens du sang, les biotechnologies font tout pour l'y reconduire. On ne peut en effet manquer d'être frappé par le contraste existant entre l'acharnement procréatif d'une part, qui

1. Le Magasin des enfants, ouv. coll., op. cit., p. 154.

91

tiquement trop humain : l'homme est le produit d'un hasard et d'une nécessité aveugles. Avec le pouvoir biotechnologique, les choses changent, et l'on peut très bien imaginer le descendant reprochant à l'ascendant d'avoir modifié son «être» -ou, à l'inverse, lui reprocher de ne pas l'avoir fait, s'il considère que des avantages possibles donc dus ne lui ont pas été accordés. On peut s'inquiéter, dites-vous, de la menace qui plane sur les déshérités du génome, depuis la privation de liberté pour les individus susceptibles de développer des troubles mentaux, jusqu'à la vindicte majoritaire à l'encontre de ceux qui n'auraient pas accepté de conformer leur comportement à l'exigence des prédictions génétiques.

Une certaine défaite intellectuelle et politique semble paradoxalement accompagner les victoires sociales. "En gagnant des libertés et des droits dans leur conflit avec les pouvoirs centraux, les individus préparent à chaque fois simultanément une inscription tacite, mais toujours plus profonde, de leur vie dans l'ordre étatique, offrant ainsi une assise nouvelle et plus terrible au pouvoir souverain dont ils voudraient s'affranchir » écrit Giorgio Agamben qui dénonce «l'étrange relation de contiguïté qui unit la démocratie au totalitarisme ${ }^{1} »$. Sans doute n'y a-t-il pas lieu de

1. Cité J. Testart, Des hommes probables, op. cit., p. 263. 
redouter dans nos sociétés démocratiques un eugénisme étatique à l'image de la contre-utopie d'Aldous Huxley ou à celle de l'Allemagne nazie. Mais un imaginaire collectif, unifié par les formes les plus pauvres de la publicité, de la télévision et du cinéma commercial, de millions d'individualités toutes pensées et posées comme indépendantes et libres, ne serait pas moins redoutable ni moins totalitaire. Il n'est pas très difficile de deviner de quel côté pencherait le surhomme promis : plus personne ne veut être Beethoven ni même l'avoir pour fils. Un champion olympique ou un acteur porno ont des destins plus enviés.

Et si l'on se place à présent dans la psychologie possible de ces hommes probables qui auront été imaginés avant d'exister, il n'est pas non plus très difficile de deviner qu'en dehors du suicide ils s'adonneront de manière massive aux drogues destructrices : dans ce contexte, ce sera pour eux une protestation inconsciente contre le rêve social des hommes parfaits.

Pour revenir à la question philosophiquement décisive du passage de l'aléatoire au normatif, on peut considérer que l'un des grands sens de la recherche scientifique depuis qu'elle existe, et aussi de façon plus large, l'un des grands sens de l'Histoire, est la suppression du hasard. On peut raisonnablement supposer que l'homme a une véritable haine du hasard et qu'il n'arrête pas de

J. T. : Le comble du plan de maîtrise humaine or la science est peut-être en cours. Il s'agirait de ire de l'homme une entité biologique sous ntrôle double, grâce à un génome choisi et à un vironnement programmé. Car, si tout être vivant : le produit complexe de l'inné et de l'acquis, on it bien que le progrès correspond à un nivelle:nt au sein de l'espèce. C'est vrai pour les jèces domestiques, animales ou végétales, qui -dent à la fois leur biodiversité génétique et leurs :asions de gambader hors de la ferme indus11e. C'est vrai aussi pour l'espèce humaine dont bonne conformation génomique à venir sera Ifrontée à un milieu uniforme, où la langue parla culture, l'alimentation, le costume, le mode vie sont en voie de standardisation. Dans ces ditions, on peut remettre en question la capacité iberté, vécue quand l'acquis permet de ménager certaine expression de l'inné. N'arrivera-t-on à s'autoriser à ne vivre seulement que notre in? Et celui-ci ne sera-t-il pas dramatiquement
lé d'un individu à l'autre?

Iais je voudrais revenir un peu sur l'opposition :es couples de mots, en particulier procréa/reproduction, parce qu'ils sont très souvent condus, à cause, d'ailleurs, des spécialistes : enseignements en médecine sont dits de roduction humaine $»$. La reproduction, pour le monde, c'est faire du même, c'est la photo- le pourchasser quand il le reconnaît, ou bien de le nier grâce à ses illusions, par exemple sous l'idée de destin. On pourrait dire que les grandes découvertes, les grandes inventions culturelles ont toujours correspondu à la substitution de la volonté humaine au hasard naturel. Prenons l'exemple de la première grande révolution de la civilisation humaine, la révolution du néolithique, lorsque les hommes sont passés de la cueillette à l'agriculture et de la chasse à l'élevage, il y avait déjà une façon de supprimer le hasard et de remplacer ce hasard insupportable par une volonté, parce que la volonté, c'est ce qui permet de faire des projets, d'avoir une maîtrise sur son propre avenir, alors que le hasard par définition est quelque chose de non maîtrisable. Alors ma question est un peu une provocation : on se rend bien compte ici que les biotechnologies modernes sont à la recherche de l'abolition de tout hasard, que l'eugénisme, c'est la négation du hasard, que la reproduction qui se profile, c'est la négation du hasard, mais à cet égard est-ce que cela ne s'inscrit pas dans une tradition à très long terme, et qui est le sens même de l'aventure humaine, l'homme qui ne supporte pas l'imprévu et qui cherche toujours, en toute occasion, à imposer sa volonté ? Est-il tenable de parler, comme le fait Hans Jonas, d'un « droit à l'ignorance » inséparable de la liberté ?

95 copie, le bouturage, c'est le clonage si on l'applique aux animaux, mais il ne s'agit pas de cela dans nos pratiques d'engendrement. Ce que l'on désigne par reproduction, ce n'est pas de la reproduction, c'est le fait qu'un mâle et une femelle (je ne dis pas homme et femme parce que c'est vrai de beaucoup d'animaux, en tout cas de tous les mammifères) se mettent ensemble pour faire des petits, que ces petits sont différents des parents, et sont différents entre eux, exception faite de quelques rares vrais jumeaux. Donc, c'est merveilleux, et totalement aléatoire à la fois, mais appeler cela de la reproduction, c'était déjà prêter le flanc à toute la fantasmatique qui a suivi la naissance de Dolly, laquelle est effectivement le premier mammifère reproduit d'un adulte et non pas procréé 1 . Pour ce qui est de l'aléatoire et du normatif, en écrivant « de la procréation aléatoire », je renvoie à ce que l'on vit encore aujourd'hui, et cela inclut le bébé fécondé in vitro: la procréation est aléatoire, parce que le bébé a tous les risques et toutes les chances. Une éprouvette

1. La langue arabe possède, comme la nôtre, les mots « reproduction » (naskh) et «procréation » (injab) mais elle les utilise avec rigueur. En arabe, tous les mammifères procréent alors que nous réservons cette honorable fonction à l'espèce humaine (c'est vrai du français mais aussi de toutes les langues occidentales). En arabe, la reproduction s'applique seulement à la photocopie ou au bouturage végétal, et le mot naskh a ainsi été employé d'emblée pour qualifier le clonage de Dolly. 
est comme un lit, il en sort de la surprise car on ne trie pas les embryons pour le moment. « Reproduction normative » : dans « normatif» il y a l'idée d'un canevas, d'un cadre dans lequel on va mettre l'embryon.

Pourquoi la «reproduction»? Parce qu'un embryon humain que l'on fabrique en éprouvette n'a qu'une chance sur dix de devenir un enfant et l'un des grands problèmes de l'eugénisme par le tri d'embryons tient là : se donner tout ce mal d'identification afin de trouver le meilleur embryon parmi une cohorte, pour un taux final de réussite d'un sur dix, ce n'est pas tenable! C'est pourquoi je crois que l'on va avoir besoin du clonage embryonnaire, lequel, bien que « reproductif », n'est pas la même chose que le clonage condamné par le Comité d'éthique. Le clonage embryonnaire pourrait très bien devenir acceptable. Il s'agirait, à partir d'un embryon, d'en faire plusieurs, le but étant de faire naître un seul enfant qui soit conforme à cet embryon. Le clonage d'un embryon, on peut en faire des dizaines, on sait déjà le faire depuis longtemps, on ne le fait pas chez l'humain mais cela fonctionne avec toutes les espèces étudiées. Or l'humain est beaucoup plus «facile» à travailler, plus malléable que les autres mammifères. On pourra produire ainsi des dizaines d'embryons identiques, les congeler, et puis, les sortir du

antiégalitaire sont déjà inscrits initialement dans la technique elle-même.

C. G. : Kant avait donné pour critère du juste et du bien l'universalisation possible : pour savoir si une action est moralement juste et bonne, il faut et il suffit de savoir dans quelle mesure elle supporterait sans inconvénient sa généralisation à l'ensemble des hommes. En d'autres termes, et plus simplement dit, si à la question : « et si tout le monde en faisait autant ?», la réponse est que la situation serait meilleure, alors on peut conclure que l'action est moralement bonne, mais si, à la même question, la réponse est que la situation serait pire, alors on peut conclure que l'action est mauvaise. Or il n'est pas malaisé de constater que la pratique du clonage est le type même de l'action non universalisable, aussi bien pour des raisons économiques, que vous évoquez, que pour des raisons psychologiques, dont je voudrais juste dire ici un mot. En effet, on se rend bien compte qu'il y a, à la fois, des motivations thérapeutiques, qui seront probablement celles qui feront accepter par le plus grand nombre ce type de pratique, et puis également des motivations psychologiques sans doute inconscientes. Aux États-Unis, le clonage reproductif ${ }^{1}$ est

1. À la différence de la plupart des pays européens, les ÉtatsUnis n'interdisent pas le clonage reproductif. congélateur un par un pour les introduire dans l'utérus de la future mère jusqu'à ce qu'un enfant se développe. Après la naissance, on éliminerait les clones congelés, du moins dans un premier temps, pour éviter d'être accusé d'avoir fabriqué des cohortes d'êtres semblables. Tout cela techniquement est déjà faisable et relève de la « reproduction » véritable, puisqu'on recopie, et cette reproduction est «normative», parce qu'on ne va pas recopier n'importe qui.

À ce propos, un mot sur le cloriage, dont on parle beaucoup et dont certains commencent à se demander s'il est légitime de l'interdire. Aujourd'hui, même des philosophes tiennent ce discours : « Estce qu'il est vraiment légitime d'interdire le clonage, lequel pourrait avoir certains avantages? Il faut réfléchir, ne pas jeter le bébé avec l'eau du bain... » Pourtant, il y a une façon très simple de poser la question : est-ce que si l'on pratiquait le clonage humain, il s'appliquerait à tout demandeur? Accepterait-on de cloner les six milliards d'individus qui peuplent aujourd'hui la terre s'ils en faisaient la demande? Un tel projet serait évidemment absurde et infaisable, ce qui révèle le caractère nécessairement élitiste d'un éventuel recours au clonage dans notre espèce. La fiction a déjà montré le potentiel totalitaire d'une société s'adonnant à une telle instrumentalisation des humains, mais le déficit démocratique, le cadre

99

justifié à l'avance par la «nécessité » de venir en «aide» aux couples homosexuels infertiles et aux parents qui ont perdu un enfant. Cette technique paraît donc tout à fait conforme à l'exigence d'égalité et d'équité : elle est, pour tout dire, considérée comme suprêmement juste.

L'eugénisme est l'aboutissement de la biologie et le clonage, l'aboutissement de l'eugénisme. Celui-ci est déjà présent, vous l'avez souligné, avec la sélection des embryons dans l'acte de la procréation médicalement assistée. Mais un clonage productif d'êtres humains irait plus loin encore en prédéterminant l'ensemble des caractéristiques génétiques d'un futur être humain : un destin (biologique) serait ainsi, pour la première fois dans l'Histoire, conditionné par la volonté libre. Chez l'animal, le clonage des variétés jugées les plus performantes risquerait à terme de faire disparaître la variété génétique. Il n'y a pas de raison de penser qu'il en irait autrement pour l'homme si le clonage humain devait être pratiqué sur une grande échelle.

En 1982, R. Edwards, le père du premier bébé FIVETE, a proposé que chaque enfant FIVETE eût son double congelé. Disposant d'un jumeau de réserve, chacun pourrait ainsi trouver des organes de rechange au moment où les siens le lâcheraient. Le clone, cette espèce de jumeau désynchronisé, serait la meilleure assurance contre la maladie. 
Dans son Meilleur des mondes, Huxley imagine Ine société future dans laquelle la reproduction umaine se fait de manière exclusivement artifiielle et où la procréation naturelle apparaît omme le comble de l'obscénité. Vous écrivez vec une évidente et ironique jubilation que l'exigence de concevoir l'enfant au cours d'un cte charnel place aujourd'hui le Vatican en vant-garde du sexe en péril ${ }^{~} »$. Suppression de la exualité, suppression de la fécondité, suppression e la parenté, suppression du hasard, suppression e la liberté, suppression de l'identité - il est difcile de ne pas penser que les biotechnologies ont our fin un ensemble de suppressions et qu'au sm d'on ne sait quelle santé, c'est à notre exisnce même qu'elles attentent.

Hannah Arendt avait donné à la natalité un sens ifférent de celui de la démographie : la possibité de la naissance est, pour chaque être humain, ouverture vers quelque chose de nouveau, un mmencement absolu. Reprenant ce concept de in amie, Hans Jonas ${ }^{2}$ avait vu dans le clonage ce onstrueux danger: déterminant à l'avance une Iture, puisque le hasard serait supprimé, il prive-

1. J. Testard, Des hommes probables, op. cit., p. 162.

2. Hans Jonas pensait que le génie génétique introduit une sture d'importance métaphysique et il parlait d'«horreur :taphysique » devant les conséquences possibles de certaines inipulations génétiques, il y a plus de trente ans déjà.

102

fois avant toutes choses et au centre de toutes choses? Ne représente-t-il pas la promesse que l'autre est désormais une passion inutile'? S'engendrer soi-même, n'était-ce pas l'apanage des dieux tout-puissants? Le double n'est plus imaginé comme une menace mais comme.la chance de vivre une autre vie, non plus dans l'au-delà promis par les religions mais dans l'ici-bas assuré par la science. Son désir vient de celui de la réincarnation : le clone, comme l'enfant, mais mieux que l'enfant, serait la continuation de soi au-delà de la mort. Fantasme de tous ceux qui se jugent suffisamment uniques pour devoir être répliqués, le clonage vient aussi d'un désir de domination car ceux qui sont déjà entrés en imagination dans ce scénario ne se situent pas, évidemment, ducôté de la copie, mais de celui de la version originale ${ }^{2}$.

1. Rappelons à ce propos que le fantasme du double est un fantasme, justement, et ne correspond à rien d'observable dans la réalité objective. Il n'y a pas d'identité possible entre deux êtres dans le réel : même chez deux jumeaux vrais, ni l'organisation cérébrale ni le système immunitaire ne sont absolument
identiques.

2. J. Testart fait remarquer l'absence de substantif pour désizner l'individu à l'origine du clone. L'expression « être cloné » 'applique indistinctement au sujet d'origine et à ceux qui en lérivent comme si l'identité supposée de l'un et des autres jusifiait une appellation commune. Aussi J. Testart propose-t-il l'appeler «préclone * l'individu de départ (J. Testart, « Telle cience, tel clone», Faut-il vraiment cloner l'homme ?, ouv. oll., Forum Diderot, PUF, 1999, p. 47). rait l'individu de cette natalité inséparable de sa liberté.

La suppression de l'identité est la conséquence la moins immédiate peut-être mais comme elle semble résumer toutes les autres, il convient d'y porter une attention particulière.

L'identité est ce qui se supprime en se multipliant. Mais cela n'est pas toujours su. Dans un article récent ${ }^{1}$, le psychanalyste Daniel Sibony, du genre malin-à-qui-on-ne-la-fait-pas, s'amuse des angoisses que les biotechnologies nouvelles sus citent. Sur le clonage, il écrit : « angoisse, entre gêne et horreur, selon les cas ; certes, angoisse du double, d'être doublé; désir de la norme, angoisse du monstre, de l'étrange identité ». Tout cela, évidemment, donne l'idée d'un tabou à abattre. Mais le ridicule de l'angoisse du clonage supprime-t-il le caractère inquiétant du désir du clonage ? N'estce pas, finalement, ce désir qui l'emporte aujour$\mathrm{d}^{\prime}$ hui ${ }^{2}$ ? Sous la dénégation pointe le désir, comme toujours. Le clonage n'est-il pas l'aboutissement logique du narcissisme - lequel est l'expression affective (émotionnelle, sentimentale) de l'individualisme contemporain qui met l'individu à la

1. D. Sibony, «Quoi de neuf à l'origine du monde? », Libération, 25 octobre 1999 , p. 4 .

2. Une firme américaine vient d'inventer le jumeau ludique : My Twin est une poupée personnalisée, fabriquée à l'image de chaque enfant à partir de sa photographie.

103

Vous écrivez que «chez l'animal, la tendance de la technoscience est de faire l'économie de la procréation au profit de la reproduction ${ }^{1} »$. En somme les techniques modernes de reproduction, aidées par les moyens les plus modernes, feraient régresser l'homme au plan de l'animal, voire à celui de la plante (le clonage est un bouturage). Dans Le Désir du gène, vous vous interrogiez déjà : «et si la logique qui nous échappe en tout cela était de revenir jusqu'au départ ${ }^{2}$ ? . Peut-être là se joue ce que Freud appelait la compulsion de répétition et qui est l'autre nom de l'instinct de mort. On peut se demander à cet égard si la profonde angoisse et en même temps la non moins profonde fascination que le clonage exerce dans l'esprit du public ne sont pas cette expression plus ou moins consciente de la disparition possible de l'humanité telle qu'elle est. 


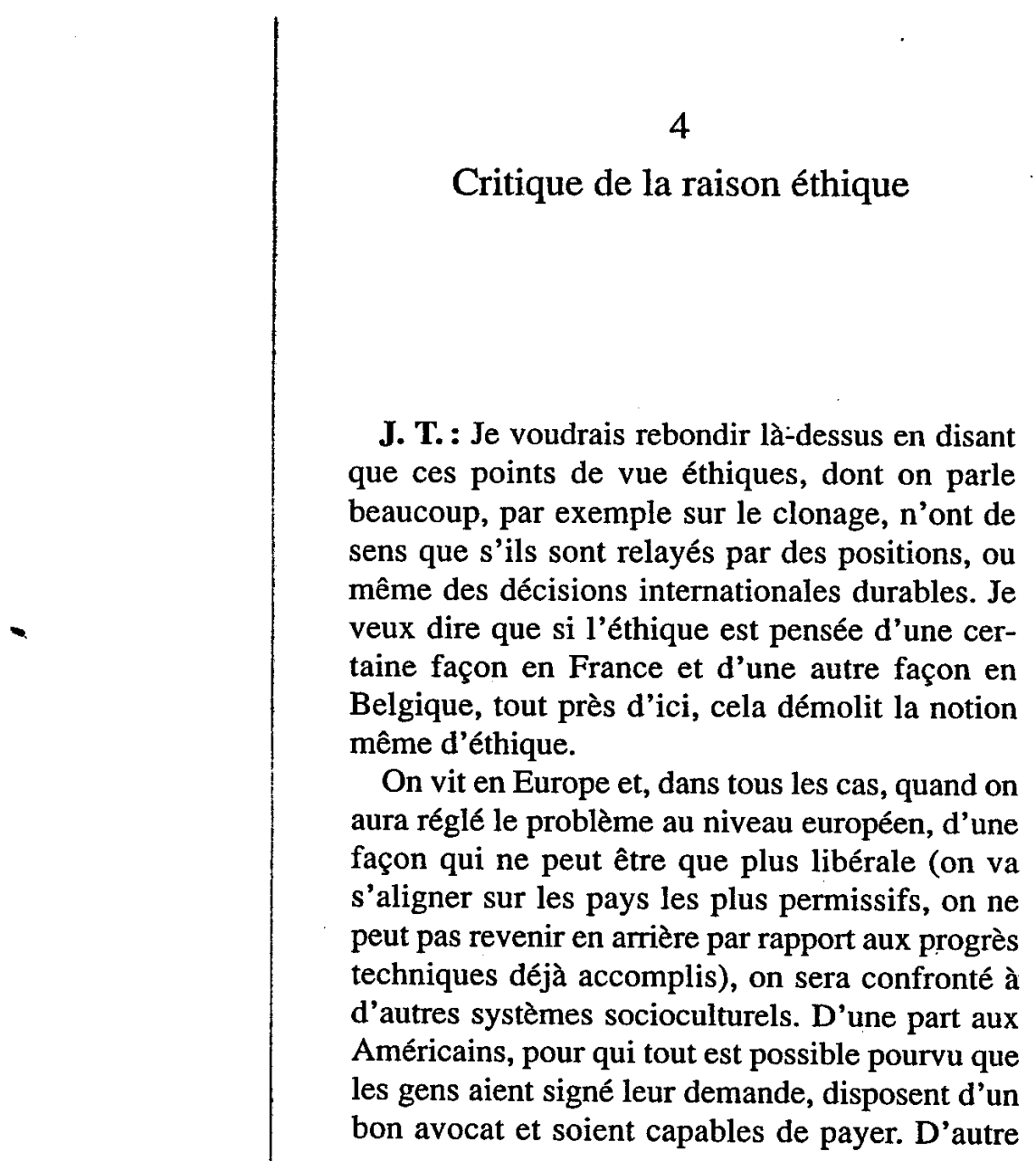

part aux pays asiatiques pour lesquels il n'y a pas de réelle compréhension de ce que nous appelons une personne, avec sa dignité (ça ne veut pas dire qu'ils méprisent les individus mais les philosophies asiatiques, bien que multiples et différentes les unes des autres, sont plutôt étrangères à la notion que nous avons de l'éthique, l'éthique médicale en particulier). Une éthique planétaire paraît pourtant indispensable pour échapper aux discours posés les uns à côté des autres mais qui servent peu. On voit déjà des chercheurs qui vont faire dans d'autres pays ce qu'ils n'ont pas le droit de faire chez eux, ou bien des patients qui vont chercher ailleurs ce qu'on ne leur donne pas ici. Ces divergences géoculturelles concernent des actes aussi variés que le clonage, te brevetage des gènes, ou le don de gamètes. Mais il y a l'autre aspect qui est l'éthique durable. À propos du clonage par exemple, presque tout le monde y est apparemment opposé, profitons-en, et interdisonsle dans la loi, parce que si on ne s'engage pas clairement, on prépare insidieusement les esprits à une acceptation prochaine. Il y a une espèce d'accoutumance qui se fait par l'usure des mots, par les exemples à la marge qui sont presque tolérables, voire la fameuse casuistique qui propose d'étudier les cas un à un : il est évident que si l'on fait cela pendant quelques années, ensuite on l'accepte nécessairement par habitude et, pro-

gressivement, on passe à l'acceptation tacite de manipulations qui faisaient frémir un peu plus tôt. De plus, la casuistique suppose la reconnaissance du statut des «sages » qui disent le possible dans chaque situation (quelque chose comme l'alliance du gourou et du confesseur) ce qui revient à déposséder les citoyens des enjeux éthiques de société.

Je crois qu'il faut refuser la casuistique pour les grands problèmes, tel le clonage, et avoir le courage d'écrire dans la loi, dans les résolutions internationales, que le clonage humain dit « reproductif» est définitivement interdit. Or ce n'est pas écrit et apparemment cela ne le sera pas. Certains objectent «mais, on ne peut pas savoir de quoi il retournera dans un siècle ou deux, peut-être qu'alors les hommes seront libérés d'un tas de choses, par exemple de la volonté de rendre les autres esclaves et le clonage ne pourra plus être un moyen de domination. Si on l'interdit aujourd'hui, on se prive d'une possibilité d'avenir car, éventuellement, le clonage aura des usages médicaux intéressants. » $\grave{A}$ cela on peut aussi bien répondre qu'il eût fallu en d'autres temps ne pas interdire l'esclavage, le travail des enfants... On ne sait pas, peut-être que dans deux trois siècles, l'esclavage aura du sens... Voilà bien des arguments félons qui autorisent la lâcheté et préparent des attitudes irréparables. 
Il y a une grande hypocrisie chez les responsables qui prétendent raisonner sur ces problèmes pour prendre des décisions mais qui s'interdisent des options claires et définitives. Mieux vaut parfois la caricature des risques plutôt que leur négation lénifiante. Voyez la position sur le clonage. Quand Dolly est née, ce n'était jamais qu'un mouton, mais tout le monde est monté au créneau, c'est la première fois que des chefs d'État, tels que Chirac ou Clinton, faisaient des déclarations, dès le lendemain, pour dire : «il faut interdire ça dans l'espèce humaine $»$, puis après ils ont nommé des comités de réflexion, ils ont consulté leur comité d'éthique. Au début, les experts śtaient contre, absolument contre, puis on a vu apparaître des scientifiques mais aussi des philosophes, toutes sortes de gens, pour dire : «Attenion! il faut réfléchir, on ne peut pas interdire :omme ça, cette volonté d'interdiction unanime st suspecte. » Il existe une résolution européenne le janvier 1998 qui dit: «Les recherches sur le :lonage de l'être humain sont interdites. » Ça araît carré mais d'un autre côté, l'expression :être humain » est affectée d'une clause molle jui précise : «Il appartient à chaque pays de défiir l'être humain. » Pour nos collègues anglais, 'être humain commence à partir de 14 jours après a fécondation... Or le clonage commence forcélent dans l'œuf, bien avant 14 jours. Conclusion :

110

ations; les dangereuses et les absurdes seront 'elles-mêmes éliminées. Vous et moi, nous ne ommes pas de ceux qui partagent ce bel optilisme de l'utilité automatique, tellement caraciristique du libéralisme contemporain : laissez ire, laissez passer, le dieu marché y reconnaîtra $s$ siens.

Dans L'Euf transparent, vous en appeliez à un moratoire révolutionnaire sur l'idée même : progrès ${ }^{1} »$. Vous ne cessez de condamner la infusion implicite, entretenue par les chercheurs IX-mêmes, qui est faite entre la nécessité logique : la découverte et la nécessité pratique de l'acin. La biologie contemporaine est prise par une pèce de démesure. C'est d'ailleurs ce qui la pare du monde dont elle s'occupe. À la difféıce de la vie, qui possède sa propre régulation erne (les excès et les défauts inadaptables au lieu sont automatiquement éliminés), le travail main comprend une violence spécifique qui ne ıcontre pas nécessairement sa régulation. Je us cite : «Au moins, quand on conseillait de re l'amour sur le côté droit pour engendrer un çon, cela marchait une fois sur deux. Combien nos traitements sont-ils aussi efficaces? Est-il ement différent d'agir sans rien savoir ou en ne hant pas tout? Au fond, il faudrait prouver que

. J. Testart, L'CEuf transparent, Flammarion, 1986, p. 162. le clonage de l'être humain n'est pas interdit en Europe. Imaginez que la recherche sur le clonage de l'être humain ne soit pas interdite, comme il est dit, que ferait-on dans les laboratoires si vraiment on voulait faire aboutir le clonage humain? On ferait de la recherche sur le clonage, en travaillant comme d'habitude avec des souris, et si on a les moyens, avec des vaches, des moutons, peut-être avec des singes, puisqu'on ne dispose pas du matériel biologique en abondance, essentiellement les ovules humains, pour se permettre l'approche de la technique dans notre espèce. Donc on le ferait sur l'animal. Alors à quoi sert l'interdiction ${ }^{1}$ ? Vous voyez que tout ça, finalement, c'est surtout pour rassurer les foules, mais ça n'a pas beaucoup de portée réelle.

C. G. : Certains adoptent ${ }^{2}$ ce point de vue $:$ il faut, disent-ils, faire tout ce qu'il est possible de. faire, toutes les expériences, toutes les manipu-

1. Un récent (début 2001) projet ministériel de révision des lois de bioéthique de 1994 vise à autoriser le «clonage thérapeutique » chez l'espèce humaine, tout en rappelant fermement son opposition au «clonage reproductif ». Approuvée par le Comité national d'éthique, cette modification de la loi pourrait aussi permettre la mise au point de toutes les techniques biologiques nécessaires au clonage reproductif. Tout se passerait donc comme si les recherches pour le clonage thérapeutique
étaient autorisées...

2. Francis Bacon dans son utopie de la Nouvelle Atlantide fut le premier chantre de ce prométhéisme déchaîné.

111

le peu que nous savons est suffisant pour décider l'action avec la même cohérence qu'à l'époque où l'on ne savait rien [...]. Il se pourrait que notre époque, victorieuse aux jeux moléculaires, se révèle historiquement la plus impuissante pour aider l'homme à vivre avec lui-même, avec les autres et dans le monde. Et que l'avenir se montre favorable à l'ignorance prétentieuse, c'est-à-dire à l'erreur, au mépris, à l'indifférence, dans l'énorme amoncellement des faits scientifiques ${ }^{1}$.» Vous avez écrit par ailleurs dans Le Désir du gène qu'il n'est pas de démocratie sans tolérance, pas de tolérance sans innocence, et pas d'innocence sans incommensurable ${ }^{2}$. À ce niveau, éthique et politique sont inséparables. Pourquoi avoir tellement sacrifié à mon amour-propre et pendant si longtemps, dites-vous dans De l'éprouvette au bébé spectacle, si $\mathrm{j}$ 'accepte aujourd'hui mon premier compromis, qui en appellera d'autres, avec la machine étatique ${ }^{3}$ ? Enfin vous achevez votre dernier ouvrage par une postface où vous militez en faveur d'une réconciliation entre la science et le sens: «L'une des plus grandes trahisons des hommes, contre leurs efforts de civilisation, c'est la séparation récente des rôles par l'abandon aux

1. J. Testart, Des hommes probables, op. cit., p. 268.

2. J. Testart, Le Désir du gène, op. cit., p. 246.

3. J. Testart, De l'éprouvette au bébé spectacle, op. cit., p. 54. 
uns des moyens objectifs de démonstration, et aux autres, des vertus culturelles du sens ${ }^{1}$. » Or, toute l'éthique est fondée sur une valeur que la biologie ignore absolument: le respect de la personne humaine ${ }^{2}$.

Il n'y a, pour la biologie, pas de différence de nature entre une amibe et un embryon humain. L'humanité de l'homme est par définition absente de l'univers biologique. La notion de dignite est évidemment fondamentale, tant du point de vue éthique que politique, or elle n'a aucune traduction biologique. Dès lors, certains chercheurs se croient autorisés à toutes les manipulations. Un certain nombre de biologistes pensent même (ils ne l'avouent pas souvent, pour des raisons évidentes) que la vie d'un embryon humain a moins de valeur que celle d'un bovin, parce que celui-ci a un prix alors que celui-là n'en a pas. Non seulement l'humanisme ne peut pas être déduit de la biologie, mais une bonne part de la force de celleci (l'ardeur de ses chercheurs) vient d'un antihumanisme plus ou moins reconnu, plus ou moins conscient : il y a de la jubilation dans la manière

1. J. Testart, Des hontmes probables, op. cit., p. 272.

2. Il est à cet égard caractéristique que l'inventeur du concept de bioéthique, Van Rensselaer Potter, loin de le confiner aux questions de la médecine et de la biologie humaine, se proposait de fonder une éthique de la biosphère qui englobât l'écologie aussi bien que la médecine.

\section{4}

dont certains chercheurs, oubliant qu'aucun animal ne penserait cela, aiment à rappeler qu'après tout l'homme n'est qu'un animal. Le plus inquiétant reste confidentiel. Voici ce que l'éditeur du principal périodique destiné aux gynécologues américains écrit : «Il est possible que les mauvaises répondeuses à répétition, frustrées par ces essais futiles pour les stimuler, réalisent que le clonage de leurs rares embryons est susceptible de leur donner tout ce dont elles auraient jamais besoin - et ceci dans un seul cycle ! Avec l'irruption de cette idée, ce sous-groupe de patientes ${ }^{1}$ peut constituer un levier significatif pour introduire les techniques de clonage à partir de cellules embryonnaires. Un moyen certain pour que cette idée se répande est d'essayer de la cacher. Si on vous interroge, ne dites pas que vous l'avez lu ici $^{2}$. » La science n'est pas seulement amorale - elle conduit explicitement à l'immoralité. L'IAD a poussé la loi à la dissimulation (le donneur de sperme est anonyme) et au mensonge (l'acte est nié puisqu'il est inscrit dans l'acte de naissance que l'enfant est né du père).

Vous écrivez - diagnostic que nul ne peut mettre en question : «Force est de constater que,

1. Rappelons que le matériel de recherche issu de l'homme est le seul à être pratiquement gratuit.

2. Cité par J. Testart, Des hommes probables, op. cit., p. 249.

115

départ de l'animation. On comprendra dès lors que le judaïsme admet plus facilement que l'Église catholique (laquelle, on l'a vu, ne les admet pas du tout) les manipulations et les recherches sur l'embryon humain.

Le Comité national d'éthique français a créé en 1986 le concept de personne potentielle pour désigner l'embryon. Il est évident que ce concept n'a aucun répondant biologique indiscutable. La personne, par opposition à l'individu, est une notion morale, et l'idée de potentialité implique une finalité, donc un dépassement proprement méta-physique de la physique du corps ou des cellules. La notion de personne potentielle permet de poser un statut intermédiaire, pour l'embryon humain, entre la réduction matérialiste à un amas de cellules et la sacralisation du corps humain dès l'origine, qui le rend intouchable'. Les comités d'éthique ont prétendu renvoyer dos à dos les marchands et les prêtres ${ }^{2}$. Seulement entre les deux, la partie n'est pas égale : en l'absence des prêtres, les marchands ont tout pouvoir.

1. J. Testart propose d'appeler « préembryon » l'ovule en phase de fécondation avant qu'il ne constitue un embryon proprement dit (J. Testart, L'E Euf transparent, op. cit., p. 123).

2. L'expression est de Dominique Memmi («Que faire du corps aujourd 'hui ? ", La Bioéthique est-elle de mauvaise foi ?, ouv. coll., Forum Diderot, PUF, 1999, p. 21). 
Vous l'avez dit dans L'CEuf transparent: L'enjeu est de savoir mais aussi de prévoir ce e l'humain peut supporter d'artifices, collages, codages, sans que soit aliénée son identité!.» us faites observer que puisque la recherche sur ; êtres humains est autorisée, dans des condiins spécifiées, à tous les stades préimplanoires (fœtus, enfant, adulte, cadavre), l'interdit i frappe la recherche sur l'embryon in vitro est e décision d'exception et non justifiée dans son ncipe $^{2}$. Dans De l'éprouvette au bébé spec$' l e$, vous écriviez que l'éthique « doit tendre à venir une science» par opposition à la morale ui est souvent une doctrine ${ }^{3}$ ». C'est une poion que, je crois, vous ne soutiendriez plus ourd'hui. Dans Des hommes probables on uve cette critique forte : la bioéthique - on le $t$ bien avec le Comité international d'éthique ıdé sous l'égide de l'Unesco - ne ferait que pétuer le mythe d'une vérité scientifique fonrice de devoirs. Vous rappelez ${ }^{4}$ que la majorité membres du Comité consultatif national thique (CCNE) sont des chercheurs ou des decins - et vous vous demandez comment on It tenir une position équitable lorsqu'on est à la

. J. Testart, L'ELuf transparent, op. cit., p. 144.

. J. Testart, Des hommes probables, op. cit., p. 163.

J. Testart, De l'éprouvette au bébé spectacle, op. cit., p. 122

. J. Testart, Des hommes probables, op. cit., p. 151.

118 fois juge et partie. En outre, la présence d'experts dans les comités d'éthique ne contribue pas peu à l'illusion d'une éthique d'experts - comme s'il suffisait de fonder une éthique de la science pour forger une science de l'éthique. À cela il faut ajouter ce que l'on pourrait bien appeler une méfiance épistémologique des hommes de science vis-à-vis d'une éthique qu'ils perçoivent comme le masque de la religion et de la politique : la science a mis des siècles à se libérer des formes étrangères de pensée et de pouvoir, sous couvert d'éthique elle assisterait à un retour en force de ces forces. Nombre de membres experts des comités d'éthique sont plus ou moins consciemment tirés par ce double lien : ils doivent rendre des avis au nom d'un système de valeurs que finalement ils jugent dépassé.

Pour ce qui est de la recherche elle-même, le danger, disiez-vous dans un article ${ }^{1}$, ne vient ni de Frankenstein ni du savant Cosinus : le premier est trop pervers, le second, trop naïf, et les deux sont trop isolés pour avoir une quelconque influence. Le chercheur dans nos sociétés démocratiques a, ce sont vos termes, une «certitude d'innocence ${ }^{2}$ » car il n'a ni l'intention de nuire

1. J. Testart, « Science et conscience», La Responsabilité, ouv. coll., Autrement, 1995, p. 269.

2. Ibid. ni la conscience qu'il pourrait nuire. Ainsi est-il $a$ priori dégagé de toute responsabilité et $a$ fortiori de toute culpabilité. Le pouvoir de la science n'a pas de visage, c'est un collectif anonyme. Le caractère collectif des travaux dilue les responsabilités. C'est vrai de la recherche comme c'est vrai de la guerre. L'article présentant la séquence génomique de Drosophila melanogaster (la mouche vedette des laboratoires) fut signé par près de 200 coauteurs. Or, si un collectif est souvent moins intelligent qu'un individu, il est toujours plus insensible que lui - on l'a encore vu récemment avec l'affaire du sang contaminé. Au rétrécissement du champ de compétence (passage du savant de jadis au scientifique ou chercheur d'aujourd'hui) correspond l'émiettement de la conscience morale et politique, donc celui du sens des responsabilités. Du zôté de l'éthique, cela induit une difficulté spésifique : comment lutter contre un adversaire qui n'a pas de visage, qui n'a pas même de nom? La technoscience est notre destin (lui non plus n'a jas de nom ni de visage), elle sécrète sa nécessité propre. On voit avec quelle facilité aujourI'hui on passe du possible au réel, et du réel au lécessaire, aussi bien dans l'opinion publique que du côté des différents comités d'éthique. Sautant par-dessus le réel, la recherche actuelle 'end nécessaire tout ce qui n'était que possible.
L'opinion publique peut bien s'émouvoir au départ contre une certaine pratique, finalement, avec l'usage, qui d'ailleurs n'a pas besoin de s'étaler sur un long laps de temps (quelques années, quelques mois), elle se retourne. Je vous suis totalement lorsque vous faites une critique sévère de ces comités d'éthique qui n'ont pas le courage ou qui n'ont pas la possibilité d'adopter des positions de principe fermes. L'autorisé ou le toléré se faufile entre le prescrit et le proscrit. Certes, l'apparence est à la fermeté mais c'est une apparence seulement. N'est-ce pas, foncièrement, le sens même de l'éthique, par opposition à la morale, cette incapacité à se situer dans l'universel, et à oser prononcer des interdits définitifs? Alors que la morale avait le culte de la fidélité (à la tradition, aux valeurs, à soi-même), l'éthique ne cesse d'aller de reniements en trahisons, et elle appelle cela progrès.

L'histoire de ces trahisons et de ces reniements est déjà bien fournie. Le Comité consultatif national d'éthique, dans son rapport au président de la République, en avril 1997, avait écrit que le clonage humain «ne peut susciter qu'une condamnation éthique véhémente, catégorique et définitive. Une telle pratique, mettant en cause de manière générale l'autonomie et la dignité de la personne constituerait une grave involution morale dans l'histoire de la civilisation. Aussi y a-t-il lieu de 
se demander s'il ne conviendrait pas de le qualifier juridiquement, en vue de son interdiction universelle. » Même prise de position de la part du Conseil pour l'éthique auprès de la Commission européenne (mai 1997) : «Des considérations qui reposent sur l'instrumentalisation ou l'eugénisme rendent chacun de ces actes [ceux qui ont trait au clonage reproductif] inacceptable sur le plan éthique. » Par ailleurs, la Commission consultative nationale américaine sur la bioéthique, dans son rapport remis en juin 1997 au président des États-Unis, a déclaré : «Il est moralement inacceptable pour quiconque dans le secteur public comme privé, aussi bien dans la recherche que dans les applications médicales, de tenter de créer un enfant par clanage, selon la méthode du transfert de noyau de cellules somatiques. » L'Organisation mondiale de la santé a de son côté adopté une résolution affirmant le caractère inacceptable sur le plan éthique de l'utilisation du clonage des êtres humains. En 1997, le Comité international de bioéthique (CIB), rattaché à l'Unesco, adoptait en séance plénière une Déclaration universelle sur le génome humain, dans laquelle il est affirmé (art. 11) que «des pratiques qui sont contraires à la dignité humaine, telles que le clonage à des fins de reproduction d'êtres humains ne doivent pas être permises ». Enfin, l'Académie nationale

122 de médecine, en juin 1997, appuie sa résolution à la fois sur une thèse kantienne et sur un argument biologique en affirmant que le clonage « constituerait une atteinte à la dignité humaine », dans la mesure où l'être humain ne serait plus considéré comme une fin mais comme un moyen, non comme une personne mais comme un objet manipulable; le clonage s'opposerait, est-il précisé, à « cette loi biologique fondamentale reposant sur la diversité qui fait la richesse évolutive de l'humanité ». Seulement ces déclarations d'intention ne concernent que le clonage humain reproductif et sont immédiatement annulées par toute une série de clauses lénifiantes.

Remarquons en premier lieu que tout se passe comme si les comités d'éthique répugnaient à exercer l'autorité qu'ils devraient avoir et que, ce faisant, ils ne l'ont plus. Leurs conclusions se présentent sous la forme d'avis et de conseils qui, sur le plan théorique, sont beaucoup moins que des études ou des rapports, et sur le plan pratique, beaucoup moins que des décisions. En second lieu, ces avis, incitatifs et non impératifs (excepté, on l'a vu, pour ce qui concerne le clonage humain reproductif), s'inscrivent d'emblée dans le régime de l'éphémère. Les lois elles-mêmes, et c'est plus grave encore, beaucoup plus grave, s'inscrivent aussi d'emblée dans le régime de l'éphémère. Le premier texte de loi en matière de bioéthique,

123 en France, voté en 1994, était assorti d'une clause de révision au bout de 5 ans'. Dans l'Antiquité, les lois étaient écrites sur de l'airain, l'illusion des législateurs étant qu'elles devaient être éternelles. Aujourd'hui, elles sont écrites sur du sable, ce sont des lois mort-nées dont on sait qu'elles seront abolies si elles ne sont pas transgressées. Un peu comme si un architecte voyait déjà la ruine du bâtiment qu'il n'a pas encore fini de construire. Mais cette infinie révisabilité de la loi a une fonction idéologique : elle conforte les sociétés démocratiques dans leur illusion du progrès et leur fait croire que leurs transgressions et régressions sont des progressions. Rien de tel pour nous rassurer dans notre idée de liberté aujourd'hui que cette mise en scène du tabou violé.

Mais il y a plus (et pire). Il n'est pas rare que les textes se contredisent d'un paragraphe à l'autre. Ainsi l'article 5 de la directive européenne 98/44 CE, adopté en mai 1998, stipule dans son premier alinéa que la simple découverte de l'un des éléments du corps humain «y compris la séquence ou la séquence partielle d'un gène » ne peut être assimilée à une invention brevetable. Mais au second alinéa, le texte ajoute qu'« un élément isolé ou autrement produit par un procédé

1. Les lois de bioéthique de 1994 seront révisées en 2002 , avec trois ans de retard, par conséquent. technique, y compris la séquence ou la séquence partielle d'un gène, peut constituer une invention brevetable, même si la structure de cet élément est identique à celle d'un élément naturel ». Seulement, comme par définition tout objet de recherche doit être isole par des moyens techniques, on finit par autoriser ce qu'on avait commencé par interdire. Ce régime de semblant d'interdiction est tout à fait caractéristique de nos sociétés.

Il est de la nature de l'action éthique dans le champ des recherches technoscientifiques d'être seulement, exclusivement négative. Nous l'avons dit, ni le respect ni la dignité n'ont de sens biologique. Dès lors, les recommandations des comités d'éthique, comme celles du démon de Socrate, ne peuvent être que des empêchements. Or, qu'est-ce que la bioéthique, depuis qu'elle existe, a réussi à empêcher de faire? Il semble que son action soit seulement de nature dilatoire : on commence par feindre d'interdire pour finir par autoriser. Entre les deux, on se sera donné l'impression d'avancer. Nombre de scientifiques sont favorables au clonage humain mais, ayant conscience que la société n'est pas encore psychologiquement et politiquement prête, ils ont adopté une attitude de prudente expectative. L'opinion doit mûrir. Tel est le signe de l'hypocrite lâcheté en démocratie.

Il y a en gros, dans tous les comités d'éthique, deux approches en conflit : une approche déonto- 
logique et une approche pragmatique et d'ailleurs pour un philosophe, ce partage rappelle la grande confrontation, dans l'Antiquité, au sujet de l'idée de bien, entre Aristote et Platon. L'approche déontologique se fait à partir des principes, l'approche pragmatique se fait à partir des résultats. L'approche déontologique veut que nos devoirs et nos principes conditionnent la finalité et les conséquences de nos actions; elle est universelle et a priori. L'approche utilitaire ou pragmatique implique que les actions humaines soient évaluées en fonction des moyens et des fins poursuivies ou de leurs conséquences; elle est particulière et $a$ posteriori. C'est de cette confrontation que surgissent le compromis et la politique du moratoire.

La conception anglo-saxonne de la « loi souple » (soft law) - qu'on pourrait aussi bien traduire par « loi molle»- l'emporte sur la conception fraņ̧aise (et kantienne) des principes commandant la loi. Mireille Delmas-Marty parle d'ensembles flous au sujet des nouvelles règles qui se consti:uent à l'échelle internationale. De même que la héorie des ensembles flous pense tout l'espace symbolique pouvant exister entre la relation d'apJartenance et celle de non-appartenance (dans la héorie classique des ensembles, en revanche, il l'y a rien entre les deux : ou bien un élément tppartient à un ensemble donné ou bien il ne lui sppartient pas), de même il serait possible d'envi-

126 sager des normes avec du diffus : lorsque la règle est édictée, sont prévus les cas où les écarts seraient autorisés ou tolérés. Ne seraient alors franchement interdits que les extrêmes. Toujours davantage, la législation aujourd'hui se fait ou se transforme à partir de cas particuliers, voire singuliers.

Les avis des comités d'éthique appartiennent à un genre historiquement bien connu et auquel vous avez déjà fait allusion : la casuistique. La casuistique, où les jésuites étaient passés maîtres, est née de la nécessité d'adapter aux cas particuliers de la vie courante les principes de la religion et de la morale chrétiennes. Pascal, dans Les Provinciales, a eu beau jeu de montrer qu'en fait d'adaptation, c'est bien à une destruction des principes que la casuistique se livre. N'est-ce pas très exactement la situation actuelle? Nous sommes bien entrés dans l'air de la différance - de la diversion et de la différence. N'ayant pas les moyens d'empêcher l'action, l'éthique ne peut prétendre qu'à la différer. C'est pourquoi moratoire est devenu le mot clé d'une éthique honteuse d'elle-même qui n'ose plus poser d'interdits. Les lois de bioéthique sont en perpétuel réexamen. Les comités d'éthique s'essoufflent en courant derrière la science.

Certes, en un sens, toute morale est une manière de mettre l'angoisse de l'existence entre paren- thèses, de la dompter et de la sublimer. Mais ce qui caractérise les éthiques contemporaines, c'est d'être des réactions directes aux angoisses et aux peurs non seulement ravivées mais suscitées par les développements des technosciences. Comme les biotechnologies sont le domaine où les angoisses et les désirs sont le plus inextricablement mêlés, une idée qui fait scandale à un moment paraît «normale » dix ans plus tard. Qui aujourd'hui remet en question l'avortement artificiel ou la procréation médicalement assistée ? Il suffit à présent qu'une chose existe pour paraître normale. Ici comme ailleurs, on jouera sur les mots. Les manipulations biologiques ne vont pas sans manipulation lexicale: ainsi la zréation d'un embryon devient-elle «clonage de zellules ». Du côté du public, la question est de moins en moins posée en termes de bien, de plus en plus en termes de droit: droit d'avoir un enfant, droit de choisir le sexe de son enfant, etc. À l'instrumentalisation de l'embryon, jusqu'ici interdite, on ne cesse d'opposer le droit des malades, et l'on peut très bien imaginer, dans le zadre actuel de la judiciarisation croissante de la société, des associations de malades trainnant les ?ouvoirs publics devant les tribunaux : l'interdiction des recherches sur l'embryon humain jourrait alors être attaquée au titre de «nonassistance à personne en danger ». Ajoutons à cela le fait que les médias s'entendent aujourd'hui fort bien à mettre en scène l'émotion : que n'accorderait-on pas à un couple en pleurs? Dans l'écran de télévision, qui n'a jamais autant mérité son nom (la télévision est effectivement ce qui fait écran), la singularité de l'émotion l'emportera toujours sur l'universalité du principe. A-t-on jamais vu l'image d'un principe? Les médias prospèrent sous le régime de la mauvaise foi : ils partent en guerre contre certaines pratiques (la vivisection par exemple) mais sont les premiers à crier au miracle pour des résultats obtenus grâce à ces mêmes pratiques.

Hippocrate disait : « Je ne donnerai pas de poison à un homme, même s'il me le demande.» Nombre de médecins aujourd'hui pensent l'inverse : «Je lui donnerai ce qu'il me demande, même s'il s'agit d'un poison, pourvu qu'il me paie et qu'il ait signé une décharge. » Vous prévoyez que l'opinion admettra le clonage par le biais de la compassion 1 - la « résurrection » d'un enfant, par exemple. En cette matière, la question n'est plus celle du permis et du défendu, du licite et de l'illicite mais celle du possible et de l'impossible. Or le clonage humain est, si l'on peut dire, d'autant plus historiquement nécessaire que l'espèce humaine, non seulement n'op- 
pose aucune difficulté pratique à cette technique, mais s'y prête, au contraire, particulièrement bien. L'utilitarisme, qui est la philosophie dominante dans les pays anglo-saxons, et qui fonde leur conception de la démocratie, considère qu'un projet est juste dès lors qu'il améliore le bien-être futur du plus grand nombre. On liera les manipulations à des avantages apparemment indiscutables. En outre, beaucoup de chercheurs se sentent à l'abri du pire car ils croient que le caractère démocratique des gouvernements et des sociétés suffit à garantir les avancées futures contre les abus et dérives possibles. Ils raisonnent de la manière suivante: les risques sont réels en régime totalitaire, or nous ne sommes pas en régime totalitaire, donc il n'y a pas de risque à craindre. Nous avons vu, avec la question de l'eugénisme, à quel point était illusoire une telle façon de penser. Mais on se rend bien compte aujourd'hui, dans les différents comités d'éthique, dont les membres, répétons-le, sont à la fois juge et partie, puisque la plupart des comités d'éthique sont formés par les scientifiques eux-mêmes, qui ont donc un intérêt immédiat intellectuel, économique et autre dans ces types de recherches, que c'est le point de vue pragmatique qui l'a emporté, c'est-à-dire, en fait, le point de vue économique.

130
J. T. : Oui, tout à fait, le comité le plus exemplaire étant quand même le Comité national d'éthique français, que je critique assez souvent parce que c'est le nôtre, mais dont je pense qu'il est l'un des meilleurs dans sa composition comme dans son élaboration. Cela dit, plus de $70 \%$ des membres de ce comité sont des chercheurs en sciences dures ou des médecins et cela fausse un peu les débats. Ce comité est le seul qui ait une position claire sur le clonage : il faut interdire définitivement le clonage humain, c'est le seul comité dans le monde qui l'ait dit. Tous les autres se sont contentés d'un «il faudrait un interdit temporaire, trois ans, cinq ans ». Le plus souvent la fonction du Comité d'éthique n'est pas d'interdire. J'ai fini par comprendre que la fonction de l'éthique institutionnelle est d'habituer les gens aux développements technologiques pour les amener à désirer bientôt ce dont ils ont peur aujourd'hui. En ce sens, il n'y a pas grande différence entre des attitudes (des stratégies?) d'accoutumance qui posent soit un interdit temporaire (le moratoire), soit une autorisation temporaire (mise à l'essai), soit une adaptation au coup par coup (la casuistique). Ce sont des façons d'accoultumer, par l'usure des mots et des idées, jusqu'à ce que les gens finissent par ne plus être choqués par ce que l'on pourrait faire. Le Comit d'éthique est d'abord un comité de bienveillance de l'essor

131 technoscientifique. Certaines technologies seraient très mal acceptées aujourd'hui, mais si, dans quinze ou vingt ans, elles sont bien acceptées, ce sera en partie grâce aux comités d'éthique, qui auront dit : «il faut développer la recherche, il faut faire attention, il faut attendre un peu, il faut un moratoire... », toutes sortes de propositions qui n'ont rien à voir avec un interdit et qui permettent de s'accoutumer à l'idée. Je parle à ce sujet d'une éthique d'habituation soluble dans le temps. Nadine Fresco, historienne, dit « jardin d'acclimatation des idées », c'est une belle image, un jardin d'acclimatation, cela évoque les animaux exotiques que l'on va chercher, que l'on met là et que l'on arrive à faire survivre dans un environnement artificiel; on fait un peu ça avec les idées dans le discours d'éthique et on arrive à les acclimater. Alors on peut s'interroger: quels reproches faire aux comités d'éthique si les gens finissent par subir le «progrès » avec plaisir, ou du moins sans souffrance?

Comme nous l'avons déjà dit, il est bien difficile de construire une éthique universelle puisque les interêts ou les cultures ne poussent pas à la convergence internationale. Pourtant, je suis frappé de constater l'indifférence des éthiciens français devant la permissivité d'autres pays, parfois voisins. Tout se passe comme au football, nous soutenons une éthique nationale et ne jouons que pour notre équipe. Ce provincialisme ne devrait pas avoir cours quand il s'agit du futur de l'espèce.

C. G. : Notons au passage ce paradoxe : tandis que les digues se rompent du côté de l'homme, elles se reconstruisent du côté de l'animal. Toujours plus de voix s'élèvent contre l'expérimentation animale ' et tel qui ne supporte pas l'idée d'une expérience sur un chien accepte sans état d'âme particulier sinon avec enthousiasme l'idée d'une manipulation génétique sur l'être humain. En l'absence d'argumentaire rigoureux qui conforterait leur point de vue, les partisans d'une manipulation sans règle ni frein cherchent à discréditer leurs adversaires par leur caractère supposé : frileux, peureux, timides, conservateurs, passéistes. Il est évidemment plus facile de disqualifier l'adversaire que sa cause. Mais ils peuvent aussi arguer du fait que la biologie est par définition une action sur le vivant (il n'y a pas de science expérimentale purement théorique) et donc que la tendance serait de stigmatiser toutes les recherches nouvelles en biologie sous le nom d'eugénisme. Ainsi (je me fais l'avocat de ce diable sans croire personnellement

1. Certains rejettent cette expérimentation parce que l'animal ne peut donner son consentement par écrit... 
à son innocence) les opposants aux recherches fétichiseraient l'humain jusque dans son origine et sa nature. Et si le mot embryon évoque un enfant en miniature, c'est que, fondamentalement, les gens sont restés préformationnistes : ils pensent que le développement va seulement dans le sens quantitatif d'un accroissement; ils ont beau avoir vu les photographies de l'embryogenèse, ils sont dans le fond persuadés que l'embryon est déjà un fœus. Aussi l'expression de «destruction des embryons humains » évoque't-elle immanquablement un massacre de grande ampleur. Ainsi les thuriféraires de la recherche sans entraves (c'est-à-dire sans autre entrave que le manque d'argent) retournent-ils contre leurs adversaires l'argument de la manipulation lexicale.

Autre point : les opposants aux recherches expérimentales sur l'homme soutiennent qu'Homo sapiens est resté biologiquement le même depuis Cro-Magnon, soit depuis 40000 ans, et demandent si l'on peut envisager froidement une mutation de l'espèce humaine en l'espace d'une génération ou deux. Vous-même, Jacques Testart, vous écrivez : « En 50000 ans d'histoire humaine, des hommes semblables à ceux d'aujourd'hui furent confrontés à une infinité de technologies, de la massue ou l'art du feu à la bombe atomique ou la fécondation externe. Aucune de ces technolo-

$$
134
$$

ıurait en aucune circonstance être justifié ou léré par aucune société humaine quelle qu'elle it, car il équivaut à une violation grave des oits fondamentaux de l'homme ».

Il existe deux façons de concevoir la distinction tre le clonage reproductif et le clonage thérasutique. Ou bien ces deux types sont réellement pposés (le clonage thérapeutique est non reproIctif) et alors l'autorisation de ce dernier ne :gage en rien la voie de l'autre, ou bien ces deux pes sont en continuité telle qu'admettre l'un (le in reproductif), c'est s'ouvrir la voie de l'autre. Jus adoptez, logiquement, le second point de ı. Vous écrivez: « Voltaire fut peut-être le preier homme libre. Qu'on me l'amène, je me arge de lui expliquer la FIVETE en une heure de l'y faire consentir. Mais je doute qu'un biogiste de l'an 3000, convoquant le même Jitaire, puisse obtenir qu'il applaudisse au cloge $^{1}$. » Les biotechnologies pourraient donner à mort de l'homme un sens propre. Mais avec la 1 de l'identité humaine, c'est la démocratie elleı̀me qui sombrerait. L'eugénisme serait pour la mocratie un coup fatal, car nul ne peut le conceir, à présent, en dehors de la logique capitaliste marché, et il aboutirait immanquablement à e inégalité infranchissable.

1. J. Testart, Des hommes probables, op. cit., p. 184. gies ne fut capable de modifier notre humanité, ne serait-ce que d'un iota ${ }^{1}$. On pourrait vous demander : est-ce si sûr? De plus, n'est-il pas paradoxal et même contradictoire de s'opposer à des pratiques qui s'en tiennent au seul niveau biologique alors même que cette prise de position hostile ne cesse d'affirmer le caractère culturel, historique, social de l'être humain? Peut-on adopter sur le clonage une attitude d'absolue opposition et confondre ce faisant le clonage reproductif qui donne naissance à un enfant et le clonage non reproductif qui constitue des cellules à des fins de transplantation ${ }^{2}$ ? Le clonage reproductif est (pour l'instant) expressément interdit : nous avons cité la «Déclaration universelle sur le génome humain ». Le Parlement européen, quelques mois plus tôt, avait déclaré dans le même sens que «le clonage des êtres humains, que ce soit à des fins expérimentales (traitement de la stérilité, diagnostic avant implantation, transplantation de tissus) ou à toute autre fin, ne

1. J. Testart, Des hommes probables, op. cit., p. 187.

2. Le clonage non reproductif utilise la capacité des ovocytes énucléés de reprogrammer les cellules somatiques de l'adulte. Les cellules embryonnaires dérivées de ces cellules somatiques pourraient se différencier in vitro et être transplantées chez des parents pour guérir de nombreuses maladies, mais le clonage non reproductif peut aller plus loin en produisant des embryons dont le développement est arrêté à un stade plus ou moins précoce.

\section{5}

Résumons votre position sur les biotechnologies, qui est parfaitement claire : outre le clonage, vous êtes contre le DPI (diagnostic préimplantatoire) parce qu'il aboutit à l'eugénisme, contre l'IAD (insémination avec donneur) parce qu'elle avalise le mensonge social mais vous êtes favorable à la pratique de l'ICSI (micro-injection d'un spermatozoïde dans un ovule). Donc, en fait, la seule pratique que vous acceptiez, c'est l'ICSI. Alors, est-ce que vous pouvez dire où, selon vous, passe véritablement la ligne de démarcation?

J. T. : L'ICSI, pour intracytoplasmic sperm injection, signifie l'injection d'un spermatozoïde dans un ovule, tout le monde en a vu des images à la télévision. C'est une technique très sophistiquée, la plus sophistiquée des techniques de fécondation in vitro. Au lieu de laisser les spermatozoïdes se débrouiller seuls avec les ovules dans l'éprouvette, on prend un spermatozoïde dans une aiguille de verre très fine (de l'ordre de quelques dixièmes de millimètre), on travaille sous microscope, et l'on introduit l'aiguille dans l'ovule. On y injecte le spermatozoïde, et l'on ressort. Miracle! d'une part l'ovule survit, d'autre part l'embryon se développe et ça fait des bébés normaux. Quand cette technique a été développée par les Belges en 1992, j'ai été parmi les plus véhéments pour dire : «c'est scandaleux ! », car il 
n'y avait eu aucune expérience animale équivalente! Après un an, on nous a montré des centaines de bébés, ils étaient normaux. Très vite, il y a eu un débat en France, pour savoir si l'on pouvait faire chez l'homme une manipulation qui n'avait pas été réalisée sur la souris, je pense à Axel Kahn en particulier, qui était véhément là-dessus. À cela je répondais : «On ne va pas faire naître deux douzaines de souris, déjà un millier d'enfants sont nés, même s'ils sont belges, l'expérience vaut bien des souris!» On est donc passé à l'acte et c'est dans mon laboratoire que l'on a conçu par cette technique le premier bébé en France, en 1994. Pourquoi y suis-je favorable? J'étais d'abord opposé à la façon dont cela avait été initié parce qu'il y avait un risgue considérable, une effraction de l'ovule, qui est une cellule très délicate mais, c'est assez extraordinaire, l'ovule résiste à ce traumatisme. Cette technique est le comble de l'artifice dans la médecine de la procréation, puisqu'on va carrément introduire un spermatozoïde qu'on a choisi, dans l'ovule. On ne le choisit pas sur des critères génétiques, mais simplement parce qu'il a l'air normal. Déposer le gamète mâle au cour de l'ovule, on ne peut pas faire plus intrusif. De plus, on parvient ainsi au rapport de un sur un pour les gamètes alors que naturellement, il y a un ovule par mois chez la femme et plus de cent millions de spermatozoïdes par jour chez l'homme. Cette technique représente le triomphe de la parité! Je crois qu'on est arrivé là au bout de toute la stratégie de procréation assistée, dans le fil d'une logique qui est une logique médicale : un couple n'a pas d'enfant, pour des raisons qui tiennent à l'homme ou à la femme ou aux deux à la fois, et par des procédés hormonaux et mécaniques, on arrive à concevoir un enfant, qui est cependant toujours un enfant du hasard. Car on ne choisit rien, simplement on aide le hasard, on prend les gamètes, on les rapproche, on les mélange et ça fonctionne comme dans l'organisme. Pourquoi s'opposer à l'ICSI qui est un aboutissement technologique mais en aucune façon une nouvelle voie de procréation susceptible de générer des interrogations inédites ?

Il y a un point litigieux, il faut le dire, c'est le risque que les enfants soient stériles comme le père car, si l'on pratique cette technique, c'est que le géniteur fabrique très peu de spermatozoïdes. On connaît mal la stérilité, masculine ou féminine, et ses bases génétiques, mais il est vraisemblable que, dans certains cas, le père souffre d'une particularité génétique dont l'enfant risque d'hériter, surtout si c'est un garçon. On se retrouverait alors avec un enfant qui devrait avoir recours à la même technique pour avoir à son tour des enfants; cela a indigné beaucoup de gens. Pourtant, si l'on refuse ce procédé pour cette raison, sachant que la myopie est héréditaire, il faudrait renvoyer chez eux les myopes qui viennent pour une fécondation in vitro, parce que l'on va colporter le handicap: vous voyez la trace de l'eugénisme qui arrive toujours insidieusement.

Je suis favorable à l'ICSI pour une autre raison : l'ICSI est venue remplacer une technique, que j'estime vétérinaire, qui n'est pas du tout sophistiquée, l'insémination artificielle avec le sperme de donneur (qui n'est pas le mari mais un homme volontaire et anonyme). Il n'y a là aucune technologie médicale (sauf qu'on congèle le sperme) : il s'agit seulement d'introduire des spermatozoïdes dans l'utérus d'une femme. Mais il est instructif de voir comment les journalistes ou la population réagissent à ces différentes techniques. L'ICSI fait peur à beaucoup parce que c'est une effraction de l'ovule, parce que c'est très sophistiqué techniquement. L'insémination est un acte technique banal et donc inquiète moins, on ne voit pas que le danger est beaucoup plus sûrement du côté de l'insémination avec sperme de donneur que de celui de l'ICSI. L'insémination avec sperme de donneur recèle des risques psychologiques, lesquels commencent seulement à apparaître; la technique s'est développée depuis 1974, essentiellement, lorsqu'on a su congeler le sperme; donc les premiers bébés commencent à arriver sur le divan des analystes, lesquels avaient parfois déjà vu le papa (le père social). Même s'il a donné son accord pour que sa femme soit engrossée par un autre, anonyme, l'homme vit piarfois mal l'adultère biologique et la blessure narcissique. L'IAD est une véritable manipulation de l'humanité, et pas simplement une manipulation des gamètes, comme l'ICSI. La manipulation de l'humanité me paraît plus grave : elle crée délibérément des enfants qui, dans la loi française, sont orphelins de père, puisque jamais ils n'auront le droit de connaître le père génétique, savọir qui il est. Il ne s'agit pas de s'accrocher à la génétique comme étant déterminante (l'inné contre l'acquis), mais de constater que tous les enfants, tous les humains ont besoin de savoir d'où ils viennent. Si un enfant perçoit qu'il n'est pas de son père ou de sa mère (puisque aujourd'hui, les deux situations sont possibles), il risque d'en être affecté. Si on devait absolument recourir au don de gamètes, mieux vaudrait peut-être que cela ne soit pas anonyme, mais dans tous les cas, le mieux est de s'en passer, et on peut s'en passer assez souvent grâce

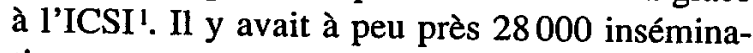
tions avec sperme de donneur en France au moment où l'ICSI est arrivée, aujourd'hui il y en

1. Il est à ce titre surprenant que le texte interministériel de révision des lois dites de «bioéthique » (1994) reste muet sur ce problème malgré l'abondance des réflexions qu'il suscite dans la société. 
1 moins de 10000 . Je pense que c'est un succès śthique, parce que, outre l'économie du mensonge social et des problèmes psychologiques, la praique de l'insémination avec sperme de donneur a léveloppé des tendances eugéniques caractériiées, dictées aux médecins pourvus des intentions es meilleures. Par souci d'éviter de colporter des isques sanitaires (on refuse bien sûr un donneur jui a le sida), l'IAD va beaucoup plus loin, jusju'à « apparier » (c'est le terme même qu'utilisent es banquiers de sperme) tel homme avec telle emme en fonction de risques génétiques partagés, lonc jusqu'à concevoir des enfants qui devraient itre «mieux » que ceux que l'on fait dans un lit. Zela, c'est une démarche typiquement eugénique, :lle est généreuse mais elle exalte la norme et le jénome. Je suis favorable à l'ICSI qui supprime ous ces problèmes. D'ailleurs, je peux vous dire jue lorsque l'on propose le choix entre l'ICSI et e remplacement de l'homme stérile par un donleur de passage, les hommes (et les femmes) ı'hésitent absolument pas.

C. G.: Que répondez-vous à ceux qui vous eprocheraient de ne vous être pas posé de quesion dès le départ, lorsque vous travailliez sur des 'aches? Que répondez-vous aussi à ceux qui vous eprocheraient de ne pas voir de problèmes Iumains dans la pratique de l'ICSI, d'ignorer ou

142

Ir les anciens, ce que l'on peut lire et entendre, est bien, mais tant qu'on ne l'a pas vécu, ça n'a is beaucoup de poids. Et je dois dire que, dans milieu où je travaillais, aussi bien qu'à l'extézur, personne ne voyait alors un problème dans bjectif d'augmenter la production de lait. Je m'étais absolument pas posé la question, pernne ne me l'avait posée, y compris les gens li étaient dans un univers complètement diffént de celui que je fréquentais. Jamais personne m'a dit : « Mais c'est idiot ce que tu fais, il $\exists$ déjà trop de lait. " Je m'en suis aperçu douze $s$ plus tard, tout seul. C'est terrible de s'apervoir après coup que, alors même que je lisais ns les journaux qu'il y avait une surproduction tière, je n'arrivais pas à appliquer ce sawoir à que j'étais en train de faire. C'est pourquoi crois beaucoup plus à la stimulation qui peut rtir d'une discussion collective. Je crois qu'un dividu isolé est très vite aliéné par ce qu'il fait, s'enferme dans son système et il est tellement is, en particulier dans ces technologies de brilage pour la mise au point de procédés, qu'il a pas le goût ou la possibilité de réfléchir, si elqu'un ne lui donne pas des coups de pied de nps en temps.

C. G.: Vous avez publié, en compagnie d'un rtain nombre d'autres scientifiques (Albert Jac- de feindre d'ignorer qu'entre cette pratique et la sélection génétique de l'ADN du spermatozoïde, il n'y a pas de solution de continuité ? Certains peuvent être choqués par le caractère véritablement « vétérinaire » de l'ICSI et ne manquent pas de dénoncer dans votre attitude ce qui, tout compte fait, ne serait qu'un humanisme de façade. Il va de soi qu'en disant cela, je n'exprime pas du tout mon point de vue personnel, je me fais seulement le porte-parole de certaines inquiétudes.

J. T.: Un point technique : on ne peut pas reconnaître l'ADN du spermatozoïde ou celui de l'ovule avant la fécondation. Pour reconnaître le message génétique d'un spermatozoïde, on le tue. Alors on peut faire des analyses mais comme il est mort, il ne peut plus servir à la fécondation. De plus, il vaut bien mieux enquêter sur l'embryon directement : l'embryon, c'est déjà le futur bébé, plus rien ne changera génétiquement, s'il faut sélectionner scientifiquement, ce ne peut être que sur les embryons.

On me reproche parfois d'avoir bricolé sur les vaches sans réfléchir à ce que je faisais ou même d'avoir été pionnier de la fécondation in vitro. Je pense qu'on réfléchit à partir du moment où l'on est en possession de sa propre histoire. C'est aussi ma façon d'élever les enfants, il faut qu'ils fassent leurs expériences avec des risques, la leçon donnée

143

quard, J.-M. Lévy-Leblond) un manifeste ${ }^{1}$ qui se termine par ces phrases: "Nous croyons que la lucidité doit primer sur l'efficacité et la direction sur la vitesse. Nous croyons que la réflexion doit précéder le projet scientifique, plutôt que de succéder à l'innovation. Nous croyons que cette réflexion est de caractère philosophique avant d'être technique et doit se mener dans la transdisciplinarité et l'ouverture à tous les citoyens. » Dans votre dernier ouvrage, vous écrivez: «Le marché, la technologie ou même la science n'ont aucun droit à dicter nos choix de vie. Tout véritable projet politique doit d'abord empêcher que l'homme redevienne une espèce seulement naturelle, ce qui nous menace si notre ambition de civilisation, ce comble de l'artifice, reflue sous les poussées de la force, des hormones et de la territorialité $^{2}$. » Seulement face à l'empire industriel, la «République des savants » dont on a vu que bien peu en font partie, peut-elle être autre chose qu'une principauté d'opérette? Vous dites que la bioéthique a besoin des citoyens du monde. Gramsci parlait de l'optimisme de la volonté face au pessimisme de l'intelligence. Vous avez le pessimisme de l'intelligence, mais avez-vous l'optimisme de la volonté? En 1984, vous terminiez votre livre, $D e$

1. Publié dans Nature et dans Le Monde en 1988.

2. J. Testart, Des hommes probables, op. cit., p. 152. 
l'éprouvette au bébé spectacle, par ces mots : «Le genre humain va mourir puisque notre survivant sera culturellement incomparable; ce suicide n'a pas été décidé, il est le résultat d'un consensus auquel tous participent car il n'y a pas d'autre façon de durer qu'en avançant. Alors la régulation éthique de notre fin devient l'essentiel ${ }^{1}$... » Kant posait cette question : que nous est-il permis d'espérer? Je voudrais citer encore ce passage qui, par le sens de la poésie qu'il manifeste, n'est pas sans faire songer à ce vieux maître un peu oublié, mais pas par vous, Jean Rostand : «Par professionnalisme j'agis, je réfléchis, j'écris selon les évidences de la raison raisonnante. Ainsi ai-je rédigé ce livre. Je peux faire l'esprit fort, narguer les timides, confondre les ignorants. J'avance dans le monde avec l'air du temps qui gagne et nul ne peut me chercher noise. Je sais défendre l'ICSI et réfuter le DPI comme certains collègues savent faire l'inverse en utilisant la même panoplie de principes irréprochables : prudence et dignité mais aussi assistance et efficacité. Nous sommes incontournables, sauf par nous-mêmes. Et puis, je lis une réflexion anthropologique à propos de la vie et de la mort, un article sur la culture inca, égyptienne ou mélanésienne, une analyse historique

1. J. Testart, De l'éprouvette au bébé spectacle, op. cit., p. 124-125.

146 du pouvoir ou de l'aliénation, ou encore je discute de la procréation assistée avec mes vieux complices "humanistes" du Magasin des enfants ou simplement je m'éveille d'une nuit où mes songes m'ont fait perdre le contrôle ou le goût des arguments imparables... Soudain je ne sais plus rien avec certitude mais je comprends presque tout, j'éprouve très fort que le sensible est plus vrai que la vérité. Lors de telles trêves de la pensée compétitive, quelqu'un au-dedans du technicien s'indigne des récentes concessions, des accointances médiocres, s'interroge sur l'intelligence du monde, et se découvre persuadé que le cercle de ce qu'on éprouve enveloppe celui de ce qu'on démontre. Puis vient l'angoisse existentielle : vite refouler ce double qui ne sait rien que l'intuition. Agir pour maîtriser. Alors, l'homme sensible rechute dans les nécessités de l'homme probable ${ }^{1}$.»

Nous voici arrivés à la dernière question. Dans cette conclusion de votre ouvrage, Des hommes probables, il y a cette envolée littéraire lyrique, très belle et en même temps, le lecteur a l'impression que vous êtes dans une espèce d'état de fuite par rapport à votre propre travail. Il sent que vous êtes tenté par une position politique rigoureuse et en même temps, il perçoit que vous êtes sceptique

\section{J. Testart, Des hommes probables, op. cit., p. 270.}

\section{7}

l'histoire du risque, et qu'inquiéter peut être la seule façon d'éviter certains dangers. Une chose m'a beaucoup frappé, c'est qu'on ne peut pas être technicien et philosophe au même moment. On ne peut pas, c'est impossible à l'homme, et $\mathrm{j}$ 'ai intitulé ce chapitre que vous évoquez et qui est assez décalé par rapport au reste du livre (je l'avais écrit à part d'ailleurs) : « Jean au four et Pierre au moulin ». On peut penser à Jean-Pierre Changeux, qui, comme vous le savez, est à la fois le chef de file des neurobiologistes, professeur tout à fait éminent au Collège de France, mais qui est aussi un remarquable connaisseur d'art. Ce qui me frappe chez un personnage comme lui, et il y en a quelques autres dans ce milieu, c'est ce découplage des fonctions mentales. Dans la journée il peut être au labo, il peut faire de la bonne recherche mais je crois qu'il ne peut pas, en même temps, s'intéresser aux abbayes cisterciennes, qu'il connaît parfaitement, c'est autre chose. Il est alors un autre que lui, donc il y a Jean et il y a Pierre. J'ai essayé de vivre ça, et je me suis aperçu que chez moi également, depuis que je fais de la recherche et depuis que j'essaye de réfléchir, ce n'est jamais simultané d'où peut-être un grand danger pour l'éthique que de laisser, finalement, les décisions et le choix aux scientifiques. Il y a des scientifiques qui possèdent le goût ou la capacité d'être l'un et l'autre, mais je dis que ce n'est 
jamais en même temps et pour la plupart, ils sont l'un ou l'autre, c'est-à-dire qu'au moment où ils sont scientifiques, ils sont seulement techniciens, et ça c'est dramatique. Prenons les plus riches d'entre eux, dont Jean-Pierre Changeux, ils sont soit au four soit au moulin, ils ne peuvent être aux deux en même temps. Disons qu'il y a peut-être dans les cerveaux droit et gauche, dans le substrat de l'identité humaine, une incapacité à faire et à penser de manière simultanée. Quand on fait la révolution, on peut faire autre chose et là on pense en même temps, mais quand on est dans le progrès technologique, dans le développement des techniques, dans la description du vivant, on n'est pas philosophe, on peut le devenir cinq minutes après, dans le meilleur des cas, pas touj@urs. Ça me paraît être une carence naturelle de notre espèce, laquelle n'a aucune raison d'être parfaite. Peut-être cela reflète-t-il, au niveau d'une seule personne et de ses deux cerveaux, une division des tâches entre le sensible et l'efficace, les sciences humaines et les sciences dures. C'est pourquoi on les réunit pour des colloques, pour tenter d'en tirer une vérité entière.

\section{Table}

Avant-propos ............. 7

1. Introduction .............. 9

2. Les métamorphoses

de la biologie . . . . . . . . . . .

3. Les métamorphoses

de la médecine ............ 53

4. Critique de la raison éthique ...... 107

Des mêmes auteurs

\section{Christian Godin}

La Totalité

8 volumes ( 5 parus)

Champ Vallon, 1997-2000

Le Cours de philosophie Éditions du Temps, 1998

Au fil de la philosophie Editions du Temps, 1999

Faut-il réhabiliter l'utopie? Pleins Feux, 2000

Négationnisme et totalitarisme Pleins Feux, 2000

\section{Jacques Testart}

De l'éprouvette au bébé spectacle Complexe, «Le genre humain », 1984

L'Euf transparent

Flammarion, « Champs », 1986

Simon l' embaumeur ou la solitude du magicien F. Bourin, 1987; Gallimard, « Folio », 1989

Le Magasin des enfants

François Bourin, 1990; Gallimard, « Folio Actuel », 1994

Le Désir du gène

François Bourin, 1992; Flammarion, 1994 
La Procréation médicalisée

Flammarion, « Dominos », 1993

L'Enfant de l'absente

en collaboration avec Thierry Jonquet et Jacques Tardi

Le Seuil, « La Dérivée », 1994 ; « Points », 1999

Des grenouilles et des hommes:

conversations avec Jean Rostand

Stock, 1995; Le Seuil, « Points Sciences », 2000

Pour une éthique planétaire

En collaboration avec Jens Georg Reich Mille et une nuits, 1997

Ève ou la répétition

Odile Jacob, 1998

Des hommes probables :

de la procréation aléatoire d̀ la reproduction normative

$$
\text { Le Seuil, } 1999
$$

Procréation et manipulation du vivant Sand, France Loisirs, 2000 
Traducción de VICTOR GOLDSTEIN

Serie Breves

dirigida por

ENRIQUE TANDETER
Jacques Testart

Christian Godin

\title{
El racismo del gen
}

\author{
Biología, medicina y bioética \\ bajo la férula liberal
}

\section{grof}

\section{FONDO DE CUlTuRA ECONOMICA}

México - Argentina - Brasil - Chile - Colombia - España Estados Unidos de América - Guatemala - Peri - Venezuela

Fotocopiar libros está penado por la ley. Prohibida su

Al antiguo modo de procrear lo declaramos vana broma, el punto delicado de donde la vida surgia, la suave fuerza que desde el interior se lanzaba, [...] De todo eso la dignidad se ha derrumbado. [...] Al principio, un gran designio parece insensato; pero en lo venidero nos reiremos del azar. $\mathrm{Y}$ un cerebro que deberá pensar a la perfección en lo sucesivo será obra de un pensador. reproducción total o parcial por cualquierr medio de impresión o digital, en forma idéntica, extractada o modificada, en castellano o cualquier otro idioma sin autorización expresa de la editorial.

\section{(1) 2001, Seuil}

Au bazar du vivant

ISBN de la edición original: 2-02-051234-3

(1) 2001, Fondo de Cultura Económica S. A.

El Salvador 5665; 1414 Buenos Aires

fondo@fce.com.ar www.fce.com.ar

Av. Picacho Ajusco 227; Delegación Tlalpan,

14.200 México D. F.

ISBN: 950-557-517-3 


\section{Prefacio}

Este librito nació de una entrevista mantenida en el Museo de Bellas Artes de Lille, en noviembre de 19.99 , en el marco de Citéphilo, donde, todos los años, se en:cuentran pensadores de las especialidades más variadas.

El punto de partida de esta entrevista fue la última obra de Jacques Testart, Des hommes probables, que, a lo largo del itinerario personal del biólogo, retomaba los grandes temas de reflexión en lo referente a las manipulaciones biológicas, los cambios de orientación en medicina y la manera en que la ética, en su campo, tiende a renunciar a su papel critico en provecho de un papel de acompañamiento. $Y$ a través de todas estas cuestiones, un desafio mayor: el hombre y su porvenir.

Hace casi cinco siglos, un médico flamenco, Vesale, hacia entrar a la anatomía en su edad científica al publicar un libro titulado La fabrique du corps humain. Hoy nos encontramos en otra fábrica, pues ya no se trata tan sólo de conocer lo que existe sino de hacer lo que no existe todavia. Y como la industria no funciona sin el comercio, tambièn nos hallamos en un mercado. Asi, pues, estamos enfrentados a un problema radical, que reclama un análisis crítico a su medida $y$, por consiguiente, asimismo radical.

Tal es el objetivo de este librito: no tanto dar miedo o hacer soñar como hacer pensar.

CHRISTIAN GODIN

\section{Introducción}

Christian Godin: Jacques Testart, los trabajos que usted lleva a cabo tanto en el frente de la investigación como en el de la reflexión plantean cuestiones tan numerosas que conviene ordenarlas y relacionarlas.

Ante todo, están las profundas perturbaciones padecidas por la biología moderna: hoy, la manera de practicar la ciencia de lo viviente no tiene mucho que ver con la de sus padres fundadores. Luego $-y$ esta cuestión se relaciona con la anterior- están las perturbaciones no menos profundas padecidas por la medicina moderna que ya no es, como antaño, una simple aplicación del conocimiento del cuerpo humano para curarlo cuando está enfermo. Y por último, hay una reflexión sobre la ética nacida de estas perturbaciones, actividad conocida con el nombre de "bioética". Por lo tanto, tras una breve presentación de su carrera y de su trabajo, encararemos sucesivamente esas tres cuestiones: la metamorfosis de la biología, la metamorfosis de la medicina y la critica de la bioética.

Si no me equivoco, su formación es la agronomia. Primero fue ingeniero agrónomo y llevó a cabo una investigación y una práctica biotecnológicas sobre animales. En una obra titulada De l'éprouvette au bébé spectacle, decia usted que un dia se dio cuenta de que lo que hacia era patafisica:

Mi ocupación era embarazar por la fuerza a desconfiadas hembras bovinas, mediante una catapulta que 
propulsaba al útero de los pobres animales a unos embriones que no conocian ni por asomo. Un dia que habia guardado mi catapulta, me encontré hojeando un tratado del Colegio de Patafisica, por lo cual, desde el dia siguiente, mi herramienta pasó a llamarse "pataculta" al tiempo que en la puerta de mi oficina escribia: "J. T., patacultor".'

La patafisica, tal y como la define su inventor, Alfred Jarry, es la teoria de las soluciones imaginarias. ¿Fue en relación con dicho sentido como se desvió usted de su primer oficio? En el prefacio de su última obra, Des hommes probables, al hablar de los disparates en los que cae hoy la agronomia, usted escribe: "en 1977, exploraba por el lado de la investigación médica, que debia estar por encima de tales mediocres finalidades". ${ }^{2}$ Pensaba que encontraria un campo que fuera menos "teratogénico" (o "testarogénico", como dice en broma), o sea, no tan monstruoso, orientándose hacia la investigación médica. Por lo tanto, pasó de los animales a los hombres, y en 1982 eso lo condujo a ser el "padre" -a todas luces el término posee una fuerza simbólica extrema- de la primera bebé de probeta francesa, Amandine. Esto se produjo cuatro años después de la première mundial, una beba llamada Louise Brown, que nació en 1978.

Entonces, su trabajo es la asistencia médica para la procreación, y como resultado de este éxito, que a la vez tenia un valor profesional, mediático y cientifico, acaecieron nuevos rechazos y nuevos interrogantes, y se dio a conocer al gran público por posiciones éticamente fuer-

I J. Testart, De l'éprouvette au bébé spectacle, Bruselas, Complexe, 1984, p. 15.

2 J. Testart, Des hoinmes probables, Paris, Seuil, 1999, p. 12. tes, posiciones que sin duda son muy minoritarias en el medio en que usted evoluciona, porque rechaza el pragmatismo que es como su filosofia natural. A partir de 1984 , o sea, tan sólo dos años después del nacimiento de Amandine, usted escribe: " $\mathrm{mi}$ actividad de investigación sobre la FIVETE* me llevó a escribir en la puerta de mi nueva oficina: 'J. T. Probador. Invientror'". ${ }^{3}$ Usted rechaza con determinación el cobarde argumento convencional del "si no lo hago yo, de todas maneras otros to harán", el cual, dice usted, es el argumento del cana que aporrea a los manifestantes. Me dirá si simplifico excesivamente, pero lo que parece caracterizar su posición es el rechazo del pragmatismo en nombre de principios que pueden calificarse de humanistas.

Hace poco, en un semanario, Henri Atlan afirmaba:

Es imposible hacer una reflexión sobre esos problemas permaneciendo en el nivel de las grandes expresiones como "eugenismo", "manipulaciones genèticas sobre el Hombre", "genoma humano", "clonación humana", fórmulas todas que desencadenan representaciones confusas y locas en muchos. Cuando lo que alimenta los debates son esas mismas representaciones, es molesto. 5

Asi, pues, todas esas expresiones, si se sigue esa línea critica, estarian absolutamente fuera de pensamiento, interferirian toda posibilidad de pensar.

* FIVETE es la sigla correspondiente a fécondation in vitro et transfert embryonnaire (fecundación in vitro y transferencia embrionaria), también llamada FIV. [N. del T.]

3 J. Testart, De l'éprouvette..., ob. cit., p. 11.

1 Ibidem, p. 116.

3 Marianne, núm. 133, 8-14 de noviembre de 1999, p. 68.
¿Se trata de un punto de vista que usted comparte? ¿Cómo hablar de esas cosas que hoy se llaman "biotecnologia", "clonación y procreación médicamente asistida", etc., expresiones que de alguna maneraccayeron en el dominio público? ¿Realmente se habla, con tales palabras, de objetos científicamente representables o bien sólo se está haciendo ideologia?

Jacques Testart: Efectivamente, con frecuencia se hace ideologia, pero ¿no es un poco tambièn lo que hace Atlan cuando pretende que el resultado de una clonación humana no seria un embrión, el que únicamente podria ser concebido por la fecundación? Existen animales (por ejemplo, los pulgones) que conocen alternativamente fases sexuadas y asexuadas (partenogénesis), cosa que no impide que cualquier pulgón sea primero un embrión de pulgón... La higiene del lenguaje en efecto, permitiria suprimir palabras fuertes, pero, al mismo tiempo, ¿no corre el riesgo de volver insulso el mismo contenido de dichas palabras, es decir, también las representaciones que vehiculizan y que no están desprovistas de sentido? El ejemplo de la palabra "eugenismo" (sobre la cual volveremos) es elocuente: inventada por cientificos, fue conservada por los nazis, pero realmente lo fue porque tanto en una como en otra situación definía la misma obsesión de pureza. Querer borrar hoy la palabra es pretender borrar dicha obsesión, que dista mucho de desaparecer... Y, por lo tanto, exponerse a volver a empezar, a vivir otras derivas.

Ya que usted me invita a hacerlo, me gustaria recapitular un poco mi recorrido... En efecto, mi formación es agronómica. Hice estudios de biologia, y no soy médico, aunque desde hace bastante tiempo me encuentro en un circuito médico, pero fue tal vez por el hecho de no serlo -de no haber prestado el juramento de $\mathrm{Hi}$ - pócrates en particular- que tampoco tengo el sentido de esa confraternidad especial con el cuerpo médico, por lo que pude permitirme cierta cantidad de criticas. Y también porque en mi primera existencia de investigador hice en la investigación agronómica lo que llamo "mi experiencia bovina", que recaia esencialmente en la mejora de las razas bovinas mediante transplantes de embriones. Me di cuenta de que un investigador puede verse llevado, casi bajo órdenes -en todo caso, aconsejado por las autoridades que lo reclutaron-, a realizar un trabajo estúpido.

La cosa duró unos doce años: me habian pedido que mejorara la producción láctea de las vacas por métodos que no fueran de selección tradicional. Se trataba de lograr una descendencia abundante para una vaca de alta calidad. En la vaca, como en la mujer, la gestación dura nueve meses y engendra un solo hijo. Por lo tanto, la selección no es muy eficaz. Al toro se lo puede multiplicar mediante la inseminación artificial, pero la vaca tiene un mal rendimiento en términos de reproducción, es decir, de procreación (me parece que hay que hablar de procreación, incluso para las vacas). ${ }^{6}$ Puede considerarse como muy insuficiente el hecho de que una vaca que produce leche en abundancia únicamente pueda tener algunos terneros. Por consiguiente, había que encontrar un sistema de mejora, $y^{\prime}$ ese sistema fue aplicado luego a la mujer con el nombre de "madre portadora": se trataba de hacer que una hembra emitiera muchos óvulos y fecundarlos in vivo, es decir, en el cuerpo, por inseminación artificial (todavía no se sabia realizar la fecundación in vitro, salvo entre los roedores). Como el objetivo veterinario era obtener muchos hijos a partir de esa

\footnotetext{
6 Véase infra.
} 
vaca, se recuperaban esos embriones, surgidos de progenitores macho y hembra de alta calidad genética, para distribuirlos en la matriz de hembras comunes (novillas porque su cria es menos costosa), y engendrar asi varios becerros al cabo de nueve meses, los que debian heredar las cualidades genéticas de origen.

Todo esto parecia lógico técnicamente; por lo tanto, me enfrasqué en el trabajo y la cosa funcionó. Hice los primeros ensayos exitosos en 1972; describi técnicas nuevas. Otros lograron hacerlo mediante cirugía en el mismo momento, pero yo puse a punto un método muy sencillo que llamé patacultura. Me paseaba con mi caja de herramientas por las cooperativas de cria y hacia absolutamente todo solo: recogía los embriones... en fin, hacia toda la cosa. Luego, al cabo de unos doce años, cuando pasé mi tesis -porque ése era el tiempo en que se hacian tesis en diez, quince, veinte años-, me percaté de que habia trabajado para un objetivo absurdo: en la época en que comencé este proyecto, es decir, en 1964 , algunas directivas europeas ya pedian limitar los excedentes de leche, iy yo habia trabajado para que hubiera más!

Entonces me volvi hacia la gente de mi organismo, el INRA," y le dije: "ipero me hicieron hacer el trabajo de un idiota!"; ellos me respondieron: "de ninguna manera, señor, el objetivo no es hacer más leche sino hacer animales cuya productividad esté aumentada". Lo cual significaba que con la misma cantidad de vacas, o menos, harian la misma cantidad de leche. Bueno, en todo caso, cọmenté a esas personas: "pero son técnicas que cuestan

INRA es la sigla correspondiente a Institur National de la Recherche Agronomique (Instituto Nacional de Investigación Agronómica). [N. del T.] caro, hay muchos criadores que conozco que están desocupados porque no pueden participar en esta competencia de producciones, iy realmente es muy útil lo que hicimos?". En resumen, como nadie entendia, me fui $y$, como usted afirmaba, me volvi hacia el mundo médico. Rápidamente me solicitaron porque habia muy poca gente en ese medio médico que conociera la fecundación, que supiera qué cosa es un óvulo o un espermatozoide. Entonces reinaba una ignorancia crasa en materia de "reproducción" humana; hay que reconocer que la cosa empieza a cambiar un poco, esencialmente gracias a la procreación asistida.

Se necesitaba gente como yo; me orienté hacia el medio hospitalario repitiéndome: "será otra cosa, alli no van a hablarme de competencia, de cuotas y de productividad", pero bastante rápido me di cuenta de que lo que oía era poco más o menos el mismo tipo de discurso. Para decirlo brevemente: los ginecólogos se interesaban en mi experiencia del mismo modo que los criadores que tenia a mis espaldas cuando estaba con las vacas. Yo me sentía preparado para reaccionar, no sólo porque no era médico, sino gracias a esa experiencia bovina que me había dejado un gusto muy amargo: ihaber llevado adelante una acción absurda con éxito, y por la cual me felicitaron! Resulta muy dificil aceptar eso cuando uno aspira al status de hombre honesto.

Asi que abri los ojos, y pocos años me hicieron falta para darme cuenta de que se reproducia la historia; sin embargo, no totalmente idéntica, porque permitir que una pareja estéril tenga un chico, en todo caso, es una actividad útil. No es ilegitimo querer un niño, aunque uno sea estéril, y además por eso sigo trabajando en esa senda. Pero la manera en que se adueñaba de esto el mundo médico, con prioridades para ciertos pacientes, con in- venciones estúpidas para tratar de captar clientes o cobrar más caro, con una suficiencia grotesca, en fin, todo cuanto puede conocerse de la medicina "de punta" cuando se trabaja en un hospital... Realmente la cosa no me gustó, y lo dije en L'eeuf transparent, en particular, libro publicado en 1986.

También manifestaba que un investigador podia formularse preguntas sobre lo que hace, que hay que dejar de sacralizar la investigación, que no se hace investigación porque es implicitamente legitima, porque se tiene el derecho y el deber de elegir su objeto de investigación, y yo habia elegido. No habia elegido no hacer investigación, según la repputación que me labraron, sino que había elegido no lanzarme a cualquier cosa. Yo habia tenido la intuición de que la fecundación in vitro, capaz de exponer al embrión humano fuera del cuerpo y tornarlo accesible al análisis, no habia sido inventada solamente para asistir a la procreación de ciertas parejas, felizmente minoritarias. No disto mucho de reconocer que tal intuición, por poco cientifica que resulte, fue mi contribución más importante a la sociedad.

En ese momento, senti que la perspectiva de la ayuda a las parejas estériles iba a evolucionar forzosamente, porque no sólo el embrión se hallaba expuesto fuera del cuerpo sino tambièn porque se producian muchos óvulos (y, por ende, embriones) para una sola mujer, como antes se lo habia hecho para las vacas. En promedio, se obtienen diez óvulos por mujer, pero yo he visto producir hastá ochenta. Se fabrican embriones para una buena mitad de dichos óvulos; por lo tanto, con mucha frecuencia se encuentra uno con una decena de embriones para una sola pareja. Sin embargo, en los paises desarrollados las parejas modernas quieren alrededor de 1,4 ninos; lo mismo ocurre para la gente que pasa por la fe- cundación in vitro (en uno de cada tres casos les hacen dos a la vez, jasi tienen su dosis!).

Yo me decia que no podia ser inocente haber extraido el óvulo del cuerpo de la mujer, haberlo puesto en un frasco, haber hecho un poco como hacen las ranas. Al fin y al cabo, todas esas son invenciones relativas; las invenciones de la medicina de la procreación no hacen sino imitar procesos que existen en el animal, cosa que deja a uno estupefacto: la superovulación, la inseminación artificial, la conservación de esperma y de embriones, y muchas otras "técnicas de punta" copian numerosas prácticas bien conocidas en el mundo animal, en particular entre los insectos o los peces. Lo único que se hizo fue reproducir procedimientos que algunas especies diferentes de nosotros conocen desde hace tiempo: la fecundación fuera del cuerpo es bastante común en el mundo animal, y jamás existe entre los mamiferos. En el ser humano era nueva, y yo me decía que la cosa no podía quedar ahi, no serviria únicamente para permitir que una pareja estéril tuviera un bebé: puesto que los embriones estaban alli en la probeta y todavia no en el vientre, llegaria la tentación de identificarlos para escoger el mejor y asi convertirlo en un niño.

Entonces, cuando escribi en L'œuf transparent que jamás haría eso y que, para mi, el encuentro de la medicina de la procreación que yo practicaba con la medicina genética de identificación que empezaba a aparecer era potencialmente muy grave para el porvenir de la bumanidad, se burlaron notablemente. Algunos genetistas, en particular, mostraron que no creían en la genética al decir que era imposible, que jamás, a partir de un embrión de cuatro, seis u ocho células, se podria realizar una identificación seria. Hubo que esperar cuatro años solamente para que los ingleses nos demostraran que era 
posible. Sigan a los británicos... A menudo es allá donde pasan las cosas nuevas, tanto las ovejas clonadas como la fecundación in vitro o los injertos de ovarios. En resumen, hicieron falta algunos años antes de que esta técnica comenzara a desarrollarse; es balbuciente como toda nueva técnica, porque todavia cuesta caro, porque hay que salir de la puesta a punto.

Ya nacieron algunos cientos de bebés, luego de haber sido seleccionados en el huevo, en el seno de la probeta, sobre criterios genéticos; esto me parece totalmente evidente: se asistirá al desarrollo de la medicina de procreación selectiva. Se fabricarán niños, y probablemente se diga que tienen mejor salud que la media de los niños hechos a la buena de Dios.

\section{Las metamorfosis de la biología}

C. G.: Como sus palabras nos llevan en ese sentido, vamos a encarar el problema de las transformaciones de la ciencia biológica, retomando todas las cuestiones que acaba de mencionar.

Usted evoca la historia trágica y cómica a la vez del último de los loros, que ilustra la manera en que la biologia molecular vuela en ayuda de una ecologia que no pedia tanto. En 1990, en la selva amazónica, se divisa en libertad un guacamayo de spix, una especie que se creía desaparecida en estado salvaje. Con el objeto de darle un compañero para repoblar la selva, era importante conocer el sexo del pájaro solitario, cosa no evidente tratándose de un loro. Entonces se recurre a la ciencia molecular: se emprende la tarea de juntar plumas perdidas por el pajjaro para extraer su ADN. La muestra se compara con el ADN tomado de algunos de los 26 guacamayos de spix vivos en cautiverio en el mundo, y cuyo sexo era conocido. Como el loro salvaje resultó ser macho, la empresa cientifica culminó con soltarle una hembra. "Nadie parece haber imaginado" -dice usted- "que si realmente se trataba de ubicar una pareja de guacamayos de spix en libertad, lo mejor hubiera sido llevar a la selva dos jaulas, con un macho en una y una hembra en la otra, y luego abrir las puertas. Pero ¿por qué hacer las cosas simplemente cuando se dispone de biotecnologías?"'

I J. Testart, Des hommes probables, Parls, Seuil, 1999, p. 28
Hay un bello texto de Nietzsche, un texto corto, que dice que se ha justificado la ciencia por tres razones, tres motivaciones: la dicha pura del conocimiento, la utilidad social y, por último, la gloria de Dios, el orden armonioso de la naturaleza. Nietzsche termina su aforismo con estas palabras: "tres razones, tres errores". Cuando uno conoce un poco a este filósofo, se adivina que la verdadera motivación en la que pensaba, pero que no mencionó expresamente, es la voluntad de poder. En ese plano, como en muchos otros, Nietzsche no se mostró solamente como buen intérprete: tambièn resultó un buen profeta. A lo largo del siglo $X X$, la voluntad de poder animó la mayor parte de la actividad en física. Ahora, la biologia tomó el relevo. Sobre todo desde las últimas décadas, esta ciencia transformó radicalmente su orientación. Parece lejano el tiempo en que un Leibniz tenía el cuidado de volver a colocar una oruga sobre la hoja del árbol donde la habia encontrado, luego de observarla, porque, según sus palabras, no queria destruir una pequeña vida.

La biologia actual parece no inscribirse ya en una investigación de tipo fundamental, sino que es una verdadera voluntad de poder en acto. Para utilizar el concepto de Nietzsche, es la expresión misma no ya de las necesidades humanas, ni siquiera de las necesidades del saber, sino de un verdadero deseo de poder. Eso lleva a que las manipulaciones, la deformación y la astucia respecto de todo lo que está vivo tomen la delantera con respecto al trabajo de la investigación, al trabajo de la idea.

En la introducción a la obra colectiva titulada $L e$ magasin des enfants, que usted coordinó, escribe que la investigación fundamental en biologia está en retroceso relativo y que sólo se nutre de proyectos tec- nológicos. ${ }^{2}$ Dice que el sueño del investigador es ver en el hospital un establecimiento ganadero, cobayos en los pacientes y cuidadores en las enfermeras. ${ }^{3}$ Recuerda que el hecho de saber soslayar la ignorancia no crea un verdadero conocimiento. En efecto, uno tiene la impresión de que una buena parte de la investigación biológica contemporánea consiste en una suerte de estrategia de la astucia al cabo de la cual la vida siempre se malogra, pero lo viviente cae siempre en las redes. En De l'éprouvette au bébé spectacle hay un pasaje conmovedor donde se comprende que la fiebre del investigador en biologia en la inminencia de su descubrimiento es de una naturaleza diferente de la del matemático, e incluso de la del fisico:

Cuando una tentativa parecia favorable, en la prisa de saber, volvia de noche al hospital, a la hora presunta en que el resultado se ve por la primera división del huevo. Abria entonces la puerta del laboratorio según ritos supersticiosos absolutamente ajenos a la educación cientifica, pero sintomáticos de la personalidad inquieta del investigador. Para saborear más tiempo mi exaltación, me preparaba un café a dos pasos del tubo que me entregaria la verdad en negro sobre blanco. Tomaba uno o dos tragos hirvientes antes de penetrar en la sala de cultivo A menudo, en una última maniobra para retrasar el veredicto que habia venido a buscar, contemplaba a ojo desnudo el líquido rosa haciendo girar el tubo entre mis dedos. Y de pronto, con avidez, observaba con los ojos remachados en los oculares de la lupa. ${ }^{4}$

2 J. Testart et al., Le magasin des enfants, Paris, François Bourin, 1990, p. 11.

3 J. Testart, Des hommes..., ob. cit., p. 104.

4 J. Testart, De l'éprouvette au bébé spectacle, Bruselas, Com. plexe, 1984, p. 127 
Gracias a testimonios como éstos, se comprende que la imagen de la caza no es únicamente una metáfora para la investigación. La biologia pone en movimiento procesos que a todas luces no crea, pero acaso sea esa mezcla de poder y de fatalidad lo que le dé su carácter de prometeismo extraviado.

Para volver a las metamorfosis de la biología -directamente ligadas, por supuesto, a la manera en que concebimos lo viviente y en que vivimos con la vida-, es posible, al parecer, distinguir dos revoluciones: la informática y la molecular.

De la primera todavia se habla relativamente poco en los estudios y en las obras de epistemologia biológica. Parece que, en los laboratorios de hoy, hay más computadoras que investigadores, de donde proviene esa impresión de poder pero también de desolación. No es posible que esto no tenga un impacto sobre el modo de comprender, ya que, como es sabido, en materia de investigación, el instrumento no es un simple medio: él mismo entra en el proceso y forma parte de la finalidad de conjunto. "Aún no se ha evaluado" - dice usted-"el paso epistemológico que separa la observación directa de un organismo de la percepción numérica que la máquina comunica acerca de èl."' La cifra, es decir, el signo, terminó por reemplazar al cuerpo. El mono cuyo trazado encefalográfico se mide en el laboratorio no es ya el mono que salta de rama en rama en la selva.

El tèrmino nuevo "genómica" fue inventado para designar ese matrimonio, esa alianza entre la informática y la biologia molecular. Lo que usted muestra es que con la informática se desarrolla lo que podria llamarse una verdadera "ilusión de totalidad", o sea, la ilusión según

J. Testart, Des hommes..., ob. cit., p. 22. la cual, a partir del momento en que todos los elementos de un conjunto estén inventariados, se tendria acceso a un conocimiento total. $\underset{i}{ }$ Como si bastara con saber que los árboles del bosque de Landes son pinos para conocer el bosque por completo! Lo cito una vez más: "el afecto que unia al naturalista con lo viviente le recordaba sin cesar que la vida no se agota con la descripción. Por el contrario, el cientificismo del investigador lo lleva a reducir la globalidad al cúmulo de lo que perciben de ella las técnicas disponibles".6

La segunda revolución, ligada a esta revolución informática, es la molecular. Aqui, en efecto, puede verse, desde hace cien o ciento cincuenta años -ya que la biología es una de las ciencias más jóvenes-, que se llegó de los conjuntos más amplios, los organismos vivientes, a las unidades elementales, los genes, pasando por los órganos y las células. Inversión completa de perspectiva: mientras Goethe buscaba en el desarrollo el secreto del origen, la biologia moderna busca en el origen el secreto del desarrollo. Pero esta avanzada en lo infimo tambièn induce toda una filosofia. iComo si el sentido de la literatura debiera encontrarse en las letras, el de la música, en las notas, y el de la historia, en las fechas! La biologia comenzó por los cuerpos, penetró luego en ellos para mirar por el lado de los órganos y los tejidos, más tarde se dirigió otra vez a una escala más pequeña todavia por el lado de las células y por último nos encontramos ahora en un plano de realidad que es la fase microscópica de los genes. De tal modo que, de hecho, hoy, por lo menos si lo lei bien, se tiene la impresión de que ya no hay anatomia, que ya no hay fisiologia, y que la biologia molecular, dominada por quienes usted lama "los

6. Jestart, Des hommes..., ob. cit., p. 23. conquistadores" de la molécula", terminó por invadir la totalidad del campo de la biología. ¿Es exacto?

J. T.: Sí, pero ni siquiera es un campo microscópico, porque los genes no se ven. Casi podria decirse que es un campo subjetivo, un campo virtual: atando cabos, uno imagina que el objeto ahi presente está conformado de tal o cual manera. Es bastante extraordinario para los biólogos porque aqui existe el riesgo de una abstracción terrible. $\mathrm{Y}$ con seguridad hay riesgos de error importantes. En todo caso, la relación con lo viviente ha desaparecido. Las moléculas no están vivas, contraria. mente a lo que intentan hacer creer; la molécula de ADN es una molécula inerte como todas las otras moléculas, como el cobre, como el agua.

La vida es algo muy diferente del ADN. El ADN es uno de los elementos que participan de lóvital ${ }^{7}$ y de la información, pero no el único; existen otros, y hoy se asiste al nacimiento de un nuevo reduccionismo en torno a la molécula de ADN. Lo inquietante es la ilusión de dominio que acompaña ese reduccionismo, ya que esa molécula que no se ve es descripta en todos sus detalles y se simula poseer todos sus secretos. La actitud recuerda un poco la de los anatomistas del Renacimiento, que abrian los cuerpos (a pesar de las prohibiciones de la época) y dibujaban los órganos; era bastante estético, hacian bellos dibujos. Con el ADN el arte es imposible y la representación fisica de la molécula realmente carece de sentido; sólo puede describirsela mediante fórmulas adaptadas. Finalmente, el desciframiento del genoma, una empresa que todo el mundo imagina como la cúspide del progreso, lo mejor de lo mejor en mate-

- En español en el original. [N. del T.]

¡Hay mucha diferencia entre lo vital y lo viviente! ria de conocimiento, es una ciencia de asnos, una actividad únicamente descriptiva que se contenta con un inventario, con la anatomia de cosas que no se ven. Es muy "de punta" técnicamente, pero sólo técnicamente. Para llegar al sentido, ante todo es necesario que los biólogos moleculares conciban que no son más que anatomistas de la molécula. Ubicados al pie del muro, ante ese "mapa del genoma" que no explica nada, algunos comienzan a interrogarse y quisieran reanudar lazos con la fisiologia, las funciones, la vida, es decir, encontrar la complejidad.

¿Cuáles son las otras prácticas de la biologia? Aquellas de las que hablamos, aqui y en todos lados, absorben lo esencial de los créditos, de tal modo que los laboratorios que no trabajan en genética molecular -el análisis del genoma- están reducidos a la porción congrua. Es lo que ocurre, por ejemplo, con las investigaciones que apuntan a comprender funciones esenciales, como la fecundación. ¿Sabe cuántos laboratorios en Francia trabajan sobre el óvulo y la fecundación, en investigación médica, en el INSERM?* Uno solo (el mio). No somos más que cuatro, el investigador más joven tiene 50 años, y no se pueden reclutar nuevos porque los objetos sobre los que trabajamos no son prioritarios. Por otro lado, nuestro laboratorio va a desaparecer en 2002, sin que la eliminación de nuestros temas de investigación haya sido decidida siquiera en alguna parte; sencillamente porque la prioridad otorgada a temas "de punta" ocupa el lugar de politica de investigación, y de esa manera condena los temas no prioritarios a la asfixia progresiva, sin ningưn

* INSERM es la sigla correspondiente a Institut National de la Santé et de la Recherche Médical (Instituto Nacional de la Salud y la Investigación Médica). [N. del T.] 
cuestionamiento de los responsables. En cambio, si usted hace una investigación genètica relacionada con las patologias del riñon, del higado, del cerebro o incluso de los gametos, entonces ahi sí que tiene los medios, puede reclutar. Es una "politica de investigación" que realmente no fue discutida con transparencia. De todo esto resulta una especie de capricho, de moda, ¿para desembocar en qué? Por el momento, en una simple descripción. ¿Por qué no? Hay que pasar por eso, me imagino. No soy un adversario de la descripción del genoma, pero ¿puede justificarse el hecho de que traiga aparejada una voluntad de engañar a los ciudadanos? Éstos son engañados cuando les cuentan que hay terapias genéticas en pleno desarrollo y que son eficaces. Hay muchos ensayos de terapias genéticas desde hace una decena de años, pero la cosa nunca funcionó. ${ }^{B}$

C. G.: Discúlpeme que lo interrumpa, pero, una vez más, ino se verian superadas nuestras críticas por la realidad, que, en esta circunstancia, no es otra sino el propio pensamiento? El reciente éxito de un equipo francés en terapia genética sobre un caso de DICS ligado al cromosoma $X$, ¿no pone en entredicho su escepticismo sobre este tipo de práctica médica?

Por otra parte, algunos observadores destacaron el hecho de que tal éxito habia tenido lugar justamente en Francia porque la $\mathrm{AFM}^{7}$ organiza el Téléthon y asi permite inyectar mucho dinero en investigaciones sobre

B Mientras que las tentativas en materia de terapia genética son fuertemente difundidas por los medios (lo cual alienta a los inversores $y$, por lo tanto, hace subir las acciones en la bolsa), los fracasos, en cambio, son cuidadosamente ocultados.

AFM es la sigla correspondiente a Association Française contre les Myopathies (Asociación Francesa contra las Miopatías). [N. del T.] enfermedades que no interesan a los financistas de la nueva biologia debido a su rareza."

J. T.: El reciente éxito de Alain Fischer es un acontecimiento importante pero pasa por una estrategia de modificación celular in vitro; dichas células luego fueron reimplantadas en el enfermo. Sin embargo, tal estrategia sólo puede aplicarse a ciertas enfermedades, en particular las del sistema inmunitario, y no seria conveniente que la gente creyera que se podrian tratar de esa manera la miopatia, la mucoviscidosis, o incluso la trisomia 21 como algunos lo pretendieron... Es lo de menos que el dinero recogido por el Téléthon haya representado un papel en esta investigación. En modo alguno justifica eso el reemplazo de una verdadera politica de investigación por la mendicidad pública.

Por último, todo eso va a terminar un poco en agua de borrajas, si esa descripción no conduce a nada práctico o médico. Entonces, me imagino que realmente habrá que pagar algún dia la considerable inversión que se hizo en genómica. Asi, los expertos se orientan cada vez más hacia el diagnóstico, hacia la identificación; y la cosa funciona, se sabe identificar porque se trata de comprobar la presencia o la ausencia de una conformación molecular conocida, porque sigue siendo anatomía. Es posible identificar cada vez más cosas en una persona, en un nino, en un feto, en un embrión apenas fecundado; no me caben dudas de que un dia se podrán identificar todas las caracteristicas que se quiera identificar, y por qué no la totalidad del genoma, incluso en un embrión de dos dias. Pero puede considerarse inquietante que los cuantiosos

El Téléthon es una colecta lanzada en 1987 en Francia por la AFM, que se realiza todos los años y destina el dinero recaudado para la lucha contra las miopatías. [N. del T.] medios invertidos en la genética favorezcan una especie de policia genómica más que una medicina asistencial.

Sin embargo, para proseguir la discusión sobre la indole de la biologia, hay que decir que no es solamente eso. Existen otros campos que no disponen casi de ningún medio, y que innovan. Aqui tenemos otra dimensión, el trabajo casero, la fecundación in vitro, la inyección de un espermatozoide... Estos actos no apelan a ningún principio nuevo sino simplemente a técnicas necesarias para manipular los gametos, para cultivarlos, para que se fusionen, técnicas que son bastante "de punta", por cierto, bastante competentes, pero, lo repito, ningún concepto nuevo. Lo mismo ocurre a propósito de lo que no se realiza todavía en el humano, pero si en la oveja: aludo a la historia de Dolly, "hija" de Ian Wilmut (bien dicen que yo soy el "padre" de Amandine...). El éxito de la clonación no ponia en juego conocimientos nuevos; fue un resultado que sorprendió al propio equipo escocés. Se sabia que con un núcleo de célula embrionaria introducido en un óvulo se puede llegar a hacer un hijo; es sabido desde hace treinta años, en todas las especies animales donde se lo intentó. Los escoceses quisieron saber a partir de qué momento la cosa deja de funcionar en el desarrollo, ya que se reconocia hasta entonces que cuando se introduce en el óvulo el núcleo de una célula extraida de un adulto, el resultado es negativo. De hecho, la experiencia nunca habia sido intentada seriamente. Los escoceses la realizaron, su grupo control (núcleos de mama de oveja) no debía engendrar, iy luego Dolly salió de ahí La historia es bastante extraordinaria porque Dolly es un producto de la ignorancia, finalmente. ¡Del grupo testigo que no debia desembocar en nada salió esa oveja! Pero esa revolución no tiene nada de conceptual. iSi la misma tentativa hubiera sido hecha hace treinta años, el resultado habria si- do el mismo! Me gustaria insistir en esto, y me imagino que se sintieron un poco desconcertados, porque para los cientificos siempre es un poco dificil no dominar un resultado... Por consiguiente, tuvieron que encontrar una explicación erudita. Y la encontraron; dijeron: "la cosa funcionó porque pusimos a punto una técnica de cultivo de núcleos celulares privándolos de albúmina [la albúmina, generalmente de origen bovino, existe en todos los cultivos celulares y permite que las células vivan], los privamos de albúmina y asi fue como el núcleo de la mama de la mamá de Dolly se volvió capaz de rehacer todo el programa genético cuando fue instalado en un óvulo". Ahi, todo el mundo dijo “ibravo!”; en todo caso, habia una invención. Luego, otros investigadores hicieron lo mismo pero sin privar a las células de albúmina, iy el resultado fue el mismo! En otras palabras, la hipótesis que habian fabricado los padres de Dolly, no para engañar a la gente, sino porque ni ellos mismos podian creer que habian hecho algo que cualquiera hubiera podido lograr hace treinta años, iesa hipótesis era falsa! $Y$ asi es como se construye la biologia casera, en la cual yo participo, al lado de esa biologia de investigación anatómica que es el análisis molecular del genoma.

C. G.: Usted habla de "genomania" y hasta de "totalitarismo ") y "fetichismo" genéticos. Ese término de fetichismo, por otra parte, debe tomarse en el sentido literal y no como simple metáfora. En su último libro, usted hace alusión a los "amuletos genéticos" imaginados por Kary Mullis, premio Nobel: él propone medallas que contengan fragmentos de ADN clonados provenientes de estrellas del rock o de atletas famosos. ${ }^{10} \mathrm{El}$ hecho de

9 J. Testart, Des hommes..., ob. cit., p. 39.

10 Ibidem, p. 38 
que una molécula pueda reemplazar a una fotografia y como ella valer para una persona, a todas luces, no carece de sentido.

Los norteamericanos llaman genohype a esta "locura del gen" que parece haber impactado en una buena parte de ellos, investigadores y gran público mezclados. Aqui tenemos varias ilusiones y varios peligros localizables. Ya evocamos la ilusión de totalidad, esa ilusión de creer que una enumeración exhaustiva significa automáticamente un conocimiento total. De esta manera, tenemos coleccionistas - no se trata ni de turistas ni de viajeros- que han concebido el proyecto de "ver" todos los paises del mundo. Serian incapaces de distinguir una iglesia gótica de otra de estilo Renacimiento, ipero creen que "yendo" a las doscientas regiones del mundo que se llaman "pais" conocerán toda la Tierra! La ilusión epis temológica compartida por el Proyecto Genoma Humano no está muy alejada de esta chifladura: dado que existen unos 40 mil genes, " su secuencia exhaustiva corresponderá a un conocimiento total del genoma; por lo tanto, corresponderá a un saber completo sobre el ser humano, puesto que, según el naturalismo subyacente a este proyecto, el hombre es el producto de sus genes, y no más que eso. ${ }^{12} \mathrm{El}$ reduccionismo comienza por poner la mayor parte de la realidad entre paréntesis y termina por exhibir la cuadricula del sector escogido como la imagen misma del mundo. Por cierto, no hay un trabajo de conocimiento, a fortiori cientifico, sin análisis ni abs-

"De hecho, su cantidad es bastante menor que la generalmente considerada a lo largo de mucho tiempo ( $100 \mathrm{mil}$ ).

12 En el año 2001 , únicamente el $20 \%$ de los genes humanos tiene una estructura conocida, y la cantidad de aquellos cuya estructura y función a la vez son conocidas apenas supe-
ra algunos centenares. tracción, pero Ia ilusión aparece cuando dicha abstracción y dicho análisis, precisamente, son olvidados como tales (se olvida que son abstracciones, análisis).

Al respecto, el caso del sida es esclarecedor. Por un lado, su virus ya no tiene nada de secreto: la secuencia de su genoma es conocida desde 1984, sus genes (ünicamente en número de 12) fueron inventariados y estudiados, y la acción de sus proteinas fue analizada. No obstante, la gente se sigue preguntando qué relación mantienen las moléculas del virus con la vida y la muerte. El virus del sida nos muestra cómo al mismo tiempo es posible saberlo "todo" y comprender tan poco.

Usted dice (lo cito) que "podria ser que la genomania, al instituir la molécula como única referencia de la bio. logía, llegue a tomar las herramientas de laboratorio por conceptos, y su hábil manejo por inteligencia". ${ }^{3}$ De hecho, hace un rato lo comentamos, en los centros de investigación las máquinas son mucho más cuantiosas que los hombres: ellas son las que hacen el trabajo pesado. Sin embargo, hasta ahora jamás hemos visto que las máquinas elaboren hipótesis o hagan inducciones por sí mismas. La reducción es una necesidad metodológica que debe (que deberia) dejar totalmente abierta la cuestión de la naturaleza asi estudiada. Evidentemente, no será ni en la composición de la tinta de imprenta ni en la forma de las letras donde se irá a buscar el secreto del estilo de Racine, y del hecho de que una catedral está hecha de piedras, las piedras, de átomos, y los átomos, de particulas, a todas luces no resulta que una catedral no es más que un montón de particulas. La genética, aspirada por el abismo que ella misma cavó, termina por olvidar que la realidad es un conjunto diversificado de planos,

13 J. Testart, Des hommes..., ob. cit., p. 26. y que el pasaje de uno a otro se efectúa por saltos. El análisis químico del agua de un río jamás nos informará acerca de su recorrido, y la magia de un estilo arquitectónico no está alojada en el corazón de los quarks.

A esta critica del reduccionismo usted añade lo que realmente podria representar la aporia fundamental del Proyecto Genoma Humano: o bien es el conjunto de las caracteristicas de la humanidad lo que deberia figurar en el inventario, y la cartografia jamás estará terminada, o bien una cantidad de individuos aparentemente humanos encierran un genoma fuera del mapa, o sea, no pertenecen a la humanidad tal y como va a definirla la ciencia genética. Así, pues, la elección es entre un proyecto exhaustivo y materialmente imposible y uno exclusivo y éticamente inadmisible. Ahí es donde conduce, concluye usted, el desarrollo lógico de un discurso totalitario y triunfalista. ${ }^{14}$

Conviene evocar ahora otro aspecto de esta investigación, que acaso sea el aspecto esencial; me estoy refiriendo a lo económico. La biologia moderna cuesta muy caro. Lejos estamos de las ranas a las que el padre Spallanzani habia puesto calzones. La investigación actual es concebida en términos de inversión: la lógica del beneficio tapó la del descubrimiento. Sin embargo, la especulación sobre lo viviente (es significativo, observémoslo de pasada, que la misma palabra "especulación" sirva para designar tanto el pensamiento más desinteresado como la actividad más financieramente interesada) pasa por una apropiación de eso viviente. En nuestros dias, asistimos a un proceso totalmente nuevo, cuyas implicaciones no hemos terminado de medir: el mundo de la vida está en vias de ser integramente transformado en capital y en

14 J. Testart, Des hommes..., ob. cit., pp. 35-36. mercancia, es decir, en fuente de beneficios y en objeto de intercambio. En los Estados Unidos, la terapia genética es parte de la nueva economía y cotiza en la bolsa. Con la revolución informática, esta capitalización y esta mercantilización de la vida rubrican el mayor triunfo del capitalismo en su forma contemporánea, y las grandes instituciones van a la zaga. En 1980, la Corte Suprema de los Estados Unidos declaró patentable una bacteria transgénica, comedora de hidrocarburos, manipulada por un investigador. Por razones de seguridad, el microbio jamás salió de su laboratorio para combatir una marea negra, pero entró en la historia como el primer organismo viviente patentado. Como su genoma habia sido modificado por la mano del hombre, habia pasado del mundo de los productos naturales (no patentables) al de las invenciones (patentables). Recientemente, la Oficina de Patentes de los Estados Unidos concedió a Incyte una patente sobre $\mathbf{4 4}$ genes humanos. El único trabajo de la firma habia consistido en descubrir un fragmento de cada uno de los 44 genes, sin que se identificara siquiera su función precisa. En adelante, estos genes son su propiedad exclusiva: nadie podrá explotarlos sin el acuerdo -o sea, derechos financieros que pueden imaginarse elevados- de Incyte. Las oficinas de patentes ya registraron un millón de solicitudes de patentes sobre los genes, lo que hace una media de 25 solicitudes por gen... Celera Genomics, la empresa dirigida por Craig Venter, ese filibustero del gen, presentó ella sola entre 10 mil y 20 mil solicitudes de patentes. ${ }^{15}$ Esta

15 Hasta marzo de 2000 , ninguna fue concedida todavia. Tal vez las recientes declaraciones de los responsables politicos ayudarán a las oficinas norteamericanas y europeas de patentes a reflexionar acerca de lo que es patentable y lo que no lo es. 
apropiación del objeto descubierto, al suprimir el limite entre el descubrimiento y la invención, es algo nuevo en la ciencia. ¿Puede usted imaginarse a Cuvier reclamando derechos sobre los fósiles, o a Marie Curie haciendo patentar el uranio?

Esta confiscación de los intereses privados sobre el genoma humano hace pensar en la conquista de los territorios por los marinos europeos durante los grandes descubrimientos: so pretexto de que era el primer blanco que ponia el pie en ese.lugar, tal navegante tomaba posesión de la isla en nombre de Su Majestad, evidentemente con desprecio por las poblaciones indigenas. De modo similar, la compañia Celera Genomics presentó sus solicitudes con miras a obtener una exclusividad de explotación. A quienes le objetan que el gen no es el objeto de una invención sino de un descubrimiento, Craig Venter les responde que para este descubrimiento fueron necesarias considerables inversiones en inteligencia y dinero. De la misma manera, con la excusa de que la caracterización de un gen y el establecimiento de su secuencia requieren sacarlo previamente de su estado natural mediante las técnicas de genetistas renombrados, la reglamentación europea no pone ningún limite a las patentes sobre los genes y sobre su conocimiento. Segun esta lógica, los navegantes de $\mathrm{Su}$ Majestad que se adueñaron de las islas del Pacifico también habrian podido justificar su imperialismo por los riesgos corridos y la inversión en material.

Ahora, hay otra cosa. Para retomar el viejo debate en términos sencillos, puede decirse que el innatismo, la teoria de lo innato, parece haber ganado por completo la partida sobre la teoría de lo adquirido, como si el ser humano fuera un mero producto de sus genes, y como si el determinismo cientifico, que por lo demás es una . noción positiva, fuera vivido verdaderamente como un destino. Al respecto, la transformación de las mentalidades es radical. Por razones ideológicas, las ciencias humanas y la filosofia de los últimos cincuenta años ignoraron masivamente la genética, y hasta la negaron. En relación con esto, resulta impactante comprobar hasta qué punto-volviendo las espaldas a las indicaciones del propio Freud, quien siempre habia pensado que existia un sustrato biológico para el inconsciente- el psicoanálisis reprimió el cuerpo real del paciente en provecho de su cuerpo simbólico. ${ }^{16}$ Este alejamiento, esta ignorancia y este prejuicio no contribuyeron poco en tornar inaudible la voz de esos "sabios". Además, con el derrumbe del marxismo, desapareció el soporte principal de la teoria de lo adquirido. Los descubrimientos genéticos acreditaron la idea, ante el gran público, de que la existencia humana en su totalidad está determinada por los genes; pues lo que la ciencia piensa como determinismo, la opinión lo comprende como destino. La genética, en efecto, no puede sino reavivar el fatalismo, que es como la filosofia espontánea de los humillados y los ofendidos, en todas partes y desde siempre. El determinismo de la ciencia no es el fatalismo de las religiones, pero la opinión no hace distingos. En un sentido, esta hegemonia de lo innato constituye una culminación del individualismo (ya no esperamos nada de lo social). Aqui también tenemos algo contradictorio, ya que es en aquello que existe de impersonal en nosotros (nuestros genes heredados de nuestros padres) donde tendemos a fijar nuestra singularidad. El hecho mismo, ahora bien conocido, de que compartimos el $99 \%$ de nuestro patrimo-

16 En Lacan, es la ausencia del padre, y no un gen deficiente, lo que explica la psicosis. nio genético con el chimpancé" deberia terminar de convencernos de que lo esencial está en otra parte. Si genéticamente no hay más que un $1 \%$ que separa a un chimpance de Shakespeare, reałmente es la prueba de que no fueron los genes de Shakespeare los que escribieron Hamlet.

En las representaciones comunes, a las que no siempre los investigadores son ajenos, asimismo se observa una gran confusión entre los caracteres fisicos y la conducta. A partir del hecho de que los genes pueden determinar la forma de las orejas se infiere que también determinarán una forma de vida. Pero ¿dónde se ha visto un óvulo alcohólico o un espermatozoide homosexual? ¿Un óvulo aficionado a la montaña o un espermatozoide que prefiere el mar? Hay una mala aplicación de la idea de causalidad en esta teòria según la cual tal gen va a producir tal carácter o tal conducta, como si el esquema de la causalidad unilineal simple fuera aplicable tanto en ese campo como en el de la mecánica clásica, es decir, icomo si el ser humano, concretamente, no fuera más que el producto de un programa! Es ese concepto de programa lo que usted impugna formalmente; en efecto, induce una imagen falsa, una mala representación de nuestra existencia, de nuestro ser en cuanto ser humano. Con Henri Atlan, usted denuncia el carácter engañoso de esa expresión de programa genético y recuerda que el genoma no es más que una fuente de informaciones: ${ }^{\text {H }}$ el genoma, dice usted, es al hombre lo que el calendario es a la meteorologia. ${ }^{19}{ }^{\text {PPuede explicar }}$

1) Y también el hecho de que "sólo" poseemos $40 \mathrm{mil} \mathrm{ge-}$ nes, mientras que el grano de arroz tiene $50 \mathrm{mil}$.

in J. Testart, Des hommes..., ob. cit. 99

19. Ibidem, p. 231. acaso en qué esta idea de programa, tal y como es aplicada al hombre, es una simplificación desmedida?

J. T.: Como usted lo recuerda, los genetistas modernos, asi como sus mayores, tienen la tendencia a dar mucho más peso al genoma que al medio, pero no lo dicen abiertamente; es algo de lo que están persuadidos, pero si usted los interroga, en general le responderán: "¡claro que no, lo fundamental es el medio!". Podemos descubrir una verdadera mistica genética en pequeñas reflexiones. Pienso en las de Daniel Cohen, pionero del Généthon ${ }^{21}$ y de quien sus colegas sospechan que registra patentes sobre el genoma en los Estados Unidos porque no puede hacerlo en Francia. El declaró en un importante semanario que, apenas se haya terminado con las grandes enfermedades, habrá que dar algunos "papirotazos genéticos" para corregir todo eso. Y se estaba refiriendo a los que tienen problemas psicológicos, los que son un poco "defectuosos". Pero no sólo los genetistas puros y duros como Daniel Cohen divulgan ese punto de vista; pienso, por ejemplo, en Jean-Pierre Changeux, entonces presidente del Comité Nacional de Ética, quien escribió, hace algún tiempo, que en diez años ya no se necesitará el psicoanálisis porque se encontrará una droga adaptada a cada trastorno de la conducta.

Por lo tanto, nos enfrentamos con una tendencia reduccionista que, entre los cientificos, estâ bastante extendida. A la vez está la confianza absoluta en las capacidades de la ciencia y además, de manera más precisa en el nivel de las funciones biológicas, esa idea de que finalmente es en el ADN donde se encontrarán todos los secretos. A todas luces, se trata de una idea más que

20 El laboratorio Généthon fue creado en 1990 para identificar los genes implicados en las enfermedades hereditarias. 
discutible, pero pienso que fue inducida por la experiencia de las grandes enfermedades cuyo origen genético simple fue descubierto, como la mucoviscidosis, la miopatía y muchas otras. Cantidad de enfermedades se deben a un gen que es posible identificar, y efectivamente, nos hallamos en presencia de una verdadera ecuación: la mutación acarrea la enfermedad. De hecho, esas enfermedades son bastante raras, felizmente. Pero al generalizar un modelo semejante se llega rápido a la noción de norma, porque si se piensa en todo lo que es un individuo, quien nunca es idéntico al vecino, podria considerarse que uno $u$ otro es anormal. Sabrá usted que todos poseemos cuatro o cinco genes de enfermedades graves, que no se expresan porque están presentes en un solo ejemplar, pero que pueden ser transmitidos a la descendencia. Por consiguiente, todos somos "defectuosos", no debido a esas enfermedades dramáticas, sino sobre todo porque nos exponemos a enfermedades para las cuales se encubren "factores de riesgo", todos... Hay afecciones no tan graves -por ejemplo, la miopía o el asma-, todos tenemos debilidades de ese tipo por fuerza, y luego, como todos vamos a morir un dia, ies que uno era "defectuoso" al comienzo porque no era inmortal! Pueden combinarse todos esos signos en una mitologia que pretende que en el $A D N$, en esa molécula que es realmente legendaria, estarian todos los secretos de aquello en lo que uno puede convertirse, de donde proviene esa idea de que el ADN es un programa. Todos los genetistas, que en esto se turnan con los periodistas, se sirven de la siguiente metáfora: el ADN es un poco como una partitura musical, lo único que hay que hacer es tocarla; pero al mismo tiempo conceden que el medio es muy importante. Para interpretar una partitura musical hay que tener un instru- mento de música, pero siempre se reconoce el fragmento, aunque haya mil y una maneras de tocarlo. Por lo tanto, comparar el ADN con una partitura musical, proclamando la libertad del intérprete, ien todo caso es llevar un poco lejos la metáfora! Por lo demás, esa idea de programa fue combatida incluso por algunos genetistas, sobre todo norteamericanos. Hay que decir que son muy minoritarios, cuatro o cinco, pero desde hace una buena decena de años luchan contra esta idea. En Francia tomó el relevo Henri Atlan para condenar esa idea simplista de que finalmente está todo en nuestros genes y que la continuación depende de cómo se ejecute la partitura. De hecho, hay informaciones, no un programa. En el genoma hay informaciones, pero juegan mucho más para los rasgos fisicos que para la conducta; $e$ incluso para los rasgos fisicos no es tan sencillo: el ADN no lo gobierna todo. Esta idea de programa deberia retroceder ante las evidencias, pero es necesaria para la justificación del régimen de favor del que se benefician investigadores y expertos de ciertas enfermedades. Pedir a los ciudadanos que donen dinero para niños enfermos porque hay una esperanza de curación..., hace diez años que nos vienen con eso... Esos 400 millones recolectados en una sola jornada por el Téléthon son el equivalente del presupuesto útil de toda la investigación médica de un año en Francia.

En efecto, el presupuesto de la investigación médica es más bien escaso: cuando se terminó de pagar a los hombres, los laboratorios y las máquinas, quedan 400 millones, para trabajar en 350 unidades de investigación. Entonces llega la gente del Téléthon y hace propuestas a esas unidades de investigación. Normalmente uno se toma muchas molestias para reclamar a la institución créditos que estén justificados y seàn acepta- bles a la vez para las instancias cientificas. $Y$ luego, detrás, están la caridad, la AFM, la ARC, ${ }^{*}$ el cáncer, el sida, la miopatia, todos los grandes fulanos que llegan y traen mucho más dinero que el que puede darles el Estado. Evidentemente, esto conduce también a orientar los programas de investigación que habrian sido decididos por la institución o por los ciudadanos si estuvieran bien informados. Todo esto es un poco clandestino y además existe la falta de transparencia. No digo que ese dinero se derroche, como ocurrió en la ARC por gente poco escrupulosa, pero esencialmente es puesto al servicio de los laboratorios de genética para el desciframiento del genoma, para publicaciones cientificas para congresos internacionales. En resumen, ese dinero es gastado para realizar actividades que pueden ser útiles, pero que, por cierto, no son aquello para lo cual se las presenta cuando nos piden dinero, o sea, para curar a niñitos enfermos.

Todo eso, pienso, participa de la usurpación general de la genética. Mi punto de vista no es que haya que detener la investigación en genética, pero hay que ponerla en su justo lugar; seria necesario que fuera analizada y sostenida como los otros campos de la investigación, y, sobre todo, seria importante que con esa obsesión genética no se llegue a paralizar por completo la investigación sobre otros temas. Hace un rato, yo comentaba que mi laboratorio es el único en el INSERM que se interesa en el óvulo y en la fecundación de los mamiferos, y que el investigador más joven sobre estos temas, en Francia, tiene 50 años; imaginese usted lo que significa

* Association pour le développement de la Recherche sur le Cancer (Asociación para el desarrollo de la Investigación sobre el Cáncer). [N. del T.] esto: dentro de diez o quince años, ya no habrá nadie que continúe este trabajo.

Esto hace pensar que en las altas esferas (¿esa gente habrá sido clonada?) se habria admitido que la fecundación no es una función tan importante para la vida de los humanos, para su salud..., mientras que, por otro lado, se ve a las claras que hay muchos problemas de esterilidad y que, finalmente, se sabe sobre esto muy poca cosa. El óvulo (nombre dado al ovocito maduro) sigue siendo la célula más grande, la más rara y la más misteriosa en los mamiferos. Toda concepción (sexuada, partenogénesis, clonación) requiere un óvulo pero no necesariamente un espermatozoide. Sin embargo, los escasos laboratorios de investigación sobre los gametos se interesan solamente en el gameto masculino. La deriva se agrava con la genética, que está en vias de apropiárselo todo y de privarnos de otros campos más clinicos de investigación. Es un poco lo que ocurrió en medicina con las especializaciones a ultranza, al punto que tratan de hacer del clinico un especialista porque ven bien que hay una falta. En investigación biológica se plantea un problema análogo, pero no sé dónde se va a reclutar gente, porque los viejos cuadros de mi tipo están desapareciendo y se ha dejado de formar a los jóvenes. No hay más que investigadores hiperespecializados, muy capaces, técnicos de alto vuelo, que trabajan con robots para hacer aquello que quienes toman las decisiones pretenden que sea la ciencia y la medicina del mañana. 


\section{Las metamorfosis de la medicina}

C. G.: Como el cuerpo reemplazó y hasta expulsó al alma, la medicina tiene la responsabilidad de descansar en el único gran valor creado por el siglo que acaba de transcurrir: la salud. Sólo que la salud, cuyo concepto se remonta a Hipócrates y a la Antigüedad china, y que se definia por el equilibrio y la armonia, sin duda está cambiando de sentido bastante radicalmente. $Y$ ante todo quizá porque lo que Michel Foucault llamaba "el biopoder" está volviendo a la gente como ajena a su propio cuerpo. La medicina actual tiende a hacer de todos los hombres asistidos. Un hecho sintomático de este biopoder, entre otros cien, es que en el hospital el personal sanitario no designa a los pacientes por el nombre de su afección, sino por el del trabajo médico realizado sobre ellos: asi, no hay mujeres estériles o deseosas de abortar en el hospital sino FIVETE e IVG.* En un restaurante, por lo menos, "el estofado para la 5" o "los profiteroles para el hombrecito de bigotes" apelan a los pedidos de los clientes y no solamente a las respuestas que les dan. Esta desposesión del paciente en la medicina actual es algo primordial.

Usted asigna a la medicina tres figuras sucesivas. La medicina tradicional fue primero curativa, o sea, curó a los enfermos; luego, se volvió preventiva, esto es, se es-

- IVG, intemuption volontaire de grossesse (internupción voluntaria del embarazo)

forzó por impedir que los hombres se enfermaran; por último, hoy tiende a ser cada vez más predictiva, es decir, encara las condiciones a priori de la posibilidad de enfermarse. En adelante y cada vez más, será una medicina vuelta no hacia el estado de hecho condiciones y los antecedentes, hna mecho sino hacia las la "nueva economin", reemplas, una medicina que, como sente y el pasado por la deemplazó las dimensiones del presente y el pasado por la del futuro. En el marco de esta medicina predictiva, lo virtual reemplazó a lo real, o más bien se convirtió en lo propio real. Se habrá reconocido el pasaje de lo fisiológico a lo genético, que torna invisible el cuerpo al mismo tiempo que lo desmaterializa. La medicina actual no se contenta ya con apaciguar, cuidar y curar-actividades todas de recuperación-; quiere
engendrar al hombre nuevo.

Esta toma del cuerpo más allá de ła existencia no deja de plantear toda una serie de cuestiones. ¿Tratar al sujeto como potencialmente enfermo no es (además de una profundización de cierto hallazgo del doctor Knock) como meter en la cárcel a criminales antes de que pasen al acto? La comparación no es tan extravagante como parece: ise ha oido a algunos investigadores que deen reducir a la imperiamente la sociedad tendria gran interés antes de que impotencia a los criminales hipotéticos hombre pudiestos cometan su fechoria! ¿Como si un que lleve a Jean-Jacques Mo un acto que el derecho llama "crimen"! huella qeética con la noción de huella genética se pasó de la procedencia a la vigilancia. dramátion que existen situaciones humanamente dramáticas donde la previsión no puede. desembocar (todavia) en ninguna prevención, vemos claramente cómo la generalización de los tests genéticos conducirá a las empresas y compañias de seguros a prácticas discri- minatorias.' Desde ya, podemos escribir la crónica de una desigualdad anunciada. En un porvenir cercano, cuando no ya rresente, los empleadores, a todas luces, estarán tentados de realizar exámenes genéticos a sus asalariados, cosa de evitar un juicio o no tener que pagar daños si cayeran enfermos a causa de su trabajo: la prueba genética dirá que tenian una predisposición para ello. Los empleadores sueñan con adaptar los hombres a las herramientas. Con los exámenes genéticos, invierten la carga de la precaución. En vez de garantizar situaciones de trabajo sin riesgo, seleccionarản asalariados resistentes a dichos riesgos.

De común acuerdo con las empresas, y sin confesarlo, las compañias de seguros eliminarán a clientes debido a genes malos o bien les harán pagar una cotización suplementaria: delito de gen ınalo. Asi, la discriminación genética amenaza con convertirse en la principal discriminación en el siglo que comienza. Imaginemos a cada individuo provisto de una cartilla genética que contendria el estado de su cuenta en genes, un poco a la manera en que su libreta bancaria contiene el estado de su cuenta corriente. Todos los actos económicos importantes (búsqueda de un trabajo, ${ }^{2}$ suscripción de un seguro, préstamo financiero) estarian sometidos a la presentación de dicha cartilla. Está claro que tal situación seria la negación más radical de los principios democráticos y republicanos que, en teoria, gobiernan nuestra sociedad.

Que bien podrian despertar el racismo tradicional, porque es seguro que poblaciones enteras están fu sra de lo g-néticamente correcto.

2 En los Estados Unidos, actualmente, se considera que rerca del tercio de las contrataciones se decide tras la búsqueda de informaciones genéticas. 
La medicina predictiva es una medicina eugenésica; no se contenta con expulsar el mal, sino que pretende dictar el bien. Respecto de esta tercera figura, usted alude al hecho de que el filósofo norteamericano John Rawls asoció la concepción que los hombres se hacen de una situación justa en una democracia con lo que él llama "la hipótesis del velo de ignorancia". Esa hipótesis consiste en que hay que estar en cierta ignorancia del futuro, de la condición futura, del destino posible que podria ser el de su existencia, para poder juzgar acerca de una situación que seria justa para el conjunto de la sociedad. Esta medicina, que no se contenta ya con curar la enfermedad sino que pretende dictar el bien para la existencia misma del ser humano, pone en peligro los valores de libertad y de justicia y corre el riesgo de desembocar en una transformación del hombre.

Usted subraya que en esta desviación existe una verdadera demanda de una porción del público, que esta transformación no se hace contra él sino con él y para él en gran parte. En efecto, el público no se contenta con aceptar pasivamente, sino que lleva a la "medicalización" creciente de la existencia humana. Sabe que sus héroes mediáticos (deportistas, cantantes, actores, periodistas de televisión) están drogados; no sólo no le molesta, sino que lo acepta muy bien. Dicho esto, la investigación que presenta la demanda de los particulares como un hecho originario al que ella responde finge olvidar el carácter inducido de esta actitud. El püblico tiene eso de estoico, que quiere lo que existe.

Acaso, finalmente, ¿no habria aqui un juego de mutuo arrastre entre una ciencia que es cada vez menos fundamental, cada vez más intervencionista, y una demanda del público que no es ya del orden de la necesidad sino que seria del orden del deseo, hasta del orden del fantasma? $Y$ en efecto, uno podria preguntarse si no estamos asistiendo hoy a una transformación de la imagen de la ciencia que, en su papel tradicional (evidentemente, sólo hablo aqui de las ciencias experimentales), satisfacia las necesidades del ser humano; que luego, cuando esas necesidades elementales, primarias, fueron satisfechas, se dirigió cada vez más hacia los deseos (seguramente, pensamos en todas las tecnologias de información y de comunicación) y que hoy llega tal vez a otra etapa, la posibilidad de saciar fantasmas, es decir, representaciones surgidas del inconsciente que, por lo general, son imposibles de realizar pero que la ciencia, por lo menos esta ciencia, posibilita o tiende a hacer creer posibles. Estos fantasmas (piénsese en la duplicación de si, en el embarazo masculino o en la "victoria" sobre la muerte) son mantenidos por los medios, a quienes, a todas luces, les importa un ápice la ciencia pero en cambio tienen el culto de la hazaña. Más acá de la ciencia está la técnica, pero más acá de la técnica está el virtuosismo puro de la hazaña: la fecundación de una mujer de 70 años es a la ciencia lo que es al deporte la travesia por Europa con una pata coja, pero será presentada como un progreso innegable. Por otro lado, se observa que las biotecnologias permiten promociones simbólicas y sin igual, que son verdaderas usurpaciones de título. Así es como los médicos clinicos que trabajan en la PMA, que ignoran poco más o menos todo de la investigación, se ven honrados con el titulo de sabios.

J. T.: Creo que el mercado de la medicina del mañana es la fabricación del hombre sin cualidades, como diria Musil, o sea, el hombre normal, el hombre que no desborda demasiado, el hombre medio. Al comienzo, se tratará de evitar todo cuanto esté por debajo de la media, y luego existirá la preocupación por "subir" un po- co la norma. El fenómeno totalmente nuevo no es el fantasma en si mismo, sino los medios técnicos para lograrlo. Si se habla de esto, uno está obligado a evocar el eugenismo y recordar brevemente la historia de esta vieja tradición, aunque la palabra sólo aparezca a fines del siglo XIX. Por cierto, la práctica ya estaba presente entre los griegos, porque los niños que nacian con malformaciones eran eliminados, pero constituía una práctica artesanal. El eugenismo se proclamó cientifico a principios del siglo $\mathrm{XX}$, mucho antes del poderio nazi, en paises democráticos como los Estados Unidos, Suecia y Suiza, donde centenares de miles de personas fueron esterilizadas porque no se las consideraba aptas para engendrar niños de calidad. En ocasiones, esas personas padecian de enfermedades muy graves y hereditarias, pero también se trataba de sordomudos, por ejemplo, de quienes hoy se sabe que en un medio adaptado pueden tener una vida normal, desarrollarse y ser creativos; asimismo se tenia en cuenta a opositores politicos, alcohólicos o deficientes mentales, en fin, todo tipo de gente que no merecia tener niños porque su herencia podia perjudicar el porvenir de la especie.

Conviene recordar que el inventor del eugenismo moderno, el que inventó la palabra "eugenismo", Galton, era primo de Darwin. Él se habia sentido impresionado por lo que Darwin observaba acerca de la selección del mundo animal, aunque Darwin jamás fue eugenista (no pretendió que se debía aplicar artificialmente a la especie humana lo que habia comprobado entre los animales en el curso de la evolución natural). Darwin pensaba que el hombre tenía un destino diferente, que era capaz de hacerse cargo y de convivir con la variedad, en resumidas cuentas. Galton, en cambio, era más intervencionista, y se desempeñaba como mé- dico y estadistico; ${ }^{3}$ es bastante interesante ver cómo se encuentran esas dos especialidades en toda la historia del eugenismo, hasta en los nazis. Medicina y estadistica: tales son los dos pilares del eugenismo; medicina para la relación con lo viviente, con la enfermedad, el trastorno, la anomalia, y estadistica para la mecánica del espiritu que mide, evalúa y ubica en una curva a un individuo para saber si está arriba, abajo o en el medio. Asi que Galton tenia "las dos gorras": creó sociedades de eugenismo, sociedades eruditas bajo cuya égida se esterilizó gente"en masa, cosa que era necia y no solamente malvada. Necia porque existen tales loterias genéticas naturales cuando un hombre y una mujer hacen un niño que es ilusorio imaginar que al esterilizar a una persona se va a cambiar algo en la composición genética de la humanidad venidera. Es sabido que los nazis retomaron la idea (la ideologia) y aplicaron el programa en gran escala para convertirlo en una manera de eliminar a una gran cantidad de individuos, primero a causa de sus patologias y luego, a causa de sus culturas o de sus origenes étnicos. Era el colmo del absurdo y del horror, pero el absurdo y el crimen ya estaban instalados gracias a los médicos y a los genetistas, en su mayoria "progresistas", que habían lanzado programas de "purificación de la raza humana". Después de la guerra, la palabra "eugenismo" arrastró esa mala reputación y fue asociada a su peor mandatario, el nazismo. Por cierto, no es un azar si los nazis también fueron eu-

3 Esto trajo aparejada la neurosis, pero la neurosis también es el nervio de la curiosidad. Entre muchas otras cosas, Galton concibió la idea extravagante de medir el coeficiente de encanto de las mujeres encontradas en la calle: cuando se cruzaba con una mujer atractiva, perforaba una ficha en su bolsillo izquierdo; cuando se trataba de una poco atractiva, perforaba otra en su bolsillo derecho... 
genistas, pero no puede decirse que Galton era nazi, asi como tampoco los médicos que participaron en esas campañas: ¿acaso se sabe que una gran cantidad de dichos médicos era de izquierda, y que esencialmente fueron los socialistas quienes utilizaron el eugenismo en ciertos países democráticos, como Suecia? En suma, la palabra, durante cierto tiempo de purgatorio, fue mal relacionada. Sin embargo, ahora está superando su represión. Hoy hay individuos como Pierre-André Taguieff, filósofo del antirracismo, que explican que la existencia de los nazis no hace que el eugenismo carezca de un sentido constructivo para la historia de la humanidad. Hay personas que empiezan a retomar la palabra y hay algunas más vivas que tratan de modificarla; pienso en un ginecólogo de quien estuve cerca un tiempo y que habla hoy de "progenismo", una manera de gcultar el proble$\mathrm{ma}$, que por otra parte es un poco inquietante ("progenismo" significa "estoy a favor del gen", es casi peor que "eugenismo"...). Tambièn hay otras palabras como "ortogenia" o "eubiótica", todas ellas una suerte de extravagancias de vocabulario para decir la misma cosa con mayor o con menor pudor. Lo nuevo no es el fantasma: ése siempre está presente; toda la gente desea tener un niño que sea más bien "aceptable", porque será más feliz sin enfermedades, con una altura normal, tal vez un poco más grande que el vecino (eso puede servir). Como usted afirmaba, hay un encuentro entre un viejo fantasma colectivo y que es posible comprender -aunque fuera por responsabilidad para con su niño (¿por qué desear un niño que tenga un riesgo de enfermarse si uno es capaz de engendrar uno que tendría un riesgo menor?)-, y la nueva tecnologia. Por el momento, ésta pasa forzosamente por la fecundación in vitro -que nos permite (hace un rato lo evocaba), puesto que uno dispone de cierta canen cuenta por la pareja y, por lo tanto, se trataria de de-
cisiones individuales.

Yo le hago a usted una pregunta: ¿conoce a mucha gente que desearía un niño que mida un metro cuarenta, o que sea jorobado o ciego, o que tenga un riesgo de cáncer precoz?. Resulta evidente que el consenso sobre la salud existe, que todo el mundo se forma poco más o menos la misma imagen del niño que querria tener (el color de los ojos u otras caracteristicas no patológicas son detalles) en el plano de la salud general: todos desearian un niño con buena salud, para que sea feliz y se desarrolle bien. En otras palabras, ya dependa esto del Estado o se decida durante un coloquio singular entre el médico y su paciente, equivale exactamente a lo mismo: el perfil sanitario del niño escogido es siempre el mismo, es el de la norma o, mejor aún, ese otro, no quiero decir del "superhombre", sino del niño "ideal", cuando no "perfecto". Esto es totalmente importante para la historia futura de la humanidad: hoy nos damos los medios para realizar ese tipo de selección y la cosa no puede sino desarrollarse, por muchas razones analizadas en otra parte, porque está de acuerdo con los viejos fantasmas (belleza, pureza, norma, cualidades, etc.), de acuerdo también con el interés del mundo médico (esto corresponde a más episodios), de acuerdo con el interés de la industria (va a desarrollar nuevas herramientas, genéticas en particular, para afinar las identificaciones) y, seguramente, un dia estará de acuerdo con los intereses de la salud pública porque lo que le cuesta más caro es un niño disminuido

C. G.: Al oirlo, nos damos cuenta de que la "pulsión eugenésica"t -utilizo aqui una de sus expresiones- oscila entre dos polos, dos objetivos: la media estadistica y la

\footnotetext{
4 J. Testart, Des hommes probables, Paris, Seuil, 1999, p. 59.
}

tidad de embriones, elegir el mejor-y las técnicas de procreación asistida. En mi último libro, y basándome en lo que ya se hace en investigación animal sobre ratones, ovejas, vacas u otros, yo describo cómo podría decuplicarse la eficacia de ese sistema y cómo una pareja en un año podria producir centenares de niños potenciales (embriones) que luego se podrian seleccionar en la probeta. Todo eso es factible, y se resolverian los problemas médicos ligados a la recolección de óvulos, cuyo principal limite, por el momento, está constituido por su baja cantidad. Nos encaminamos hacia una verdadera posibilidad de elección del niño venidero, gracias a la genética diagnóstica, porque, como ya hemos manifestado, asi como la genética es nula para curar, en la misma medida es competente para analizar. De ese modo podrán identificarse centenares, miles de parámetros, y por qué no todo el genoma, en un embrión de dos dias. Es evidente que, dentro de diez o veinte años, eso se hará muy fácilmente, lo que inducirá una incitación suplementaria para ese viejo fantasma del que habläbamos. Las parejas, aunque más no fuera por deber para con el niño venidero, dejarán de concebirlo tontamente al azar, como siempre lo hi ieron, y tratarán de darle la mayor cantidad de posibili ades al comienzo. Ese desarrollo en el que la procreacion se deslinda completamente de la sexualidad, donde cada función tiene su propia finalidad, me parece inevitable.

Para muchos, la palabra "eugenismo" no se aplicaria a tales proyectos. ¿Por qué? Porque el eugenismo era una práctica masiva, decidida por un Estado que planteaba directivas referentes a lo normal y a lo anormal. Por ejemplo, la esterilización de un joven afectado de enanismo era considerada necesaria debido al riesgo futuro de engendrar enanos; era una medida estatal. Hoy no ocurriria lo mismo, porque la malformación seria tenida superioridad. Por lo demás, tal es la ambivalencia contenida en la propia noción de norma. La norma puede ser tanto el ideal, muy raro por definición por dificil de alcanzar, como la generalidad, el mayor número: matemáticamente, se inscribe en el redondeo de la curva de Gauss; las personas de altura normal son las más numerosas, no son ni muy grandes ni muy pequeñas. Sin embargo, pareceria que la genética estả aboliendo la frontera entre la anomalia (simple desvio respecto de la norma) y la anormalidad (supresión de la norma). Con la genética, todas las anomalias tienden a volverse anormalidades.

Hemos evocado el fatalismo que los trabajos actuales inducen de manera casi espontánea en la mentalidad de la gente. Pero a ese fatalismo se agrega contradictoriamente una especie de sueño voluntarista que descansa en la idea (que es una loca esperanza) de que podria gobernarse a los genes e incluso (en un trivial sentido comercial) encargar genes. Todo ocurre como si el hombre moderno, al haber renunciado a dirigir su historia colectiva (la era de las revoluciones politicas parece cerrada, y nadie cree ya en un cambio social deseado), hubiera reinvertido su potencial de voluntad en el campo exclusivo de la historia personal. El eugenismo se sustenta en una ilusión terriblemente peligrosa, una ilusión que también vehiculiza: la de creer que el bienestar (no hablemos de la felicidad) reside solamente en la salud fisica. Como afirma el psicólogo Ehrenberg, una sociedad cuyo horizonte es el "mejor estar" sólo puede ser una sociedad del malestar.

Los primeros programas eugenésicos, y decimos bien programas y no sencillamente proyectos, figuran en las utopias filosóficas y literarias, cuya indole totalitaria, por otra parte, terminamos por reconocer retrospectivamente. A comienzos del siglo XVII, Campanella, en su libro 
Ciudad del sol, se indigna de que cuidemos a los animales en nuestras ganaderías pero que descuidemos a los hombres: una inconsecuencia absurda, según el monje revolucionario. Recientemente, Sloterdijk suscitó una tempestad al hablar friamente de "antropotécnica" de cria humana. Es comprensible la conmoción suscitada en un pais, Alemania, cuya memoria histórica aún está marcada-esperemos, a diferencia de Sloterdijk, que seguirá estándolo para siempre- por la catástrofe nazi. En efecto, conviene tomar conciencia de que la barbarie eugenésica del nacionalsocialismo no fue improvisada sobre el terreno experimental e histórico sino que fue pensada, proyectada, prevista, descripta antes de ser llevada a cabo.

En Le désir du gène, ${ }^{5}$ usted evoca el caso de cierto $\mathrm{Bi}$ net-Sanglé, autor de una obra titulada Les haras humains (1918), todo un programa, donde propone instalación de 40 "buenos procreadores" en haras donde deberán fecundar, a razón de 108 por año (se admirará de paso la precisión, evidentemente cientifica), a las mujeres célibes pertenecientes a las elites nacionales y provinciales. Asi, anualmente serán embarazadas 40.320 mujeres de elite. En cuanto a los "degenerados fatigados de la vida" (sic), se creará para su propósito un instituto de eutanasia donde serán anestesiados hasta la muerte con protóxido de nitrógeno. Entonces, esas propuestas provocaron sonrisas...

André Pichot observa que si las teorias racistas casi desaparecieron tras la guerra; no fue solamente en virtud de los horrores nazis, sino también debido a la dominación de la genética molecular, que eclipsó a la genética de las poblaciones. Pero va a ocurrir que esa genética molecular producirá informaciones capaces de resucitar una nue-

5 J. Testart, Le désir du gène, Paris, François Bourin, 1992, p. 42. va genética de las poblaciones. Ya no se trataria de cualificación étnica derivada de criterios físicos sino de cualificación genética extraída de evaluaciones moleculares de los genomas. Por eso, pese a un temor ampliamente compartido, no es la "manipulación genética" lo que nos amenaza: es la cualificación. La referencia a un modelo virtual (el mapa del genoma humano) y el poder de caracterizar las desviaciones de cada uno respecto de esta cartografia abren la era de nuevas clasificaciones y, por lo tanto, de nuevas jerarquias entre los hombres. ${ }^{6}$ Usted concluye este párrafo de la siguiente manera: "el racismo del gen podria reemplazar, pero esta vez cientificamente, al racismo de la piel o del origen".'

En consecuencia, dos factores cambiaron el sentido del eugenismo, $y$, asi, lo hicieron totalmente aceptable al modo de ver del mayor número: por un lado, ha dejado de ser el sueño del utopista o del sabio loco para convertirse en un proyecto razonable apoyado en los últimos descubrimientos de la ciencia; por el otro, se ha separado del elitismo y del racismo totalitarios para revestir la apariencia de la utilidad y el bienestar de todos. El eugenismo se ha vuelto racional y democrático. ¿Quién tendria ánimos todavía para oponerse?

Racional. ¿Quién ha dicho "ningún niño recién nacido debería ser reconocido como humano antes de haber pasado cierta cantidad de exámenes referidos a su dotación genética. [...] Si no pasa esos exámenes, pierde su derecho a la vida"? Sir Francis Crick, uno de los codescubridores de la estructura del ADN. ${ }^{\mathrm{B}}$

6 J. Testart, Des hommes..., ob. cit., pp. 36-38.

7 lbidem, p. 37

8 Citado por J. Rifkin y T. Howard, Les apprentis sorciers, Paris, Ramsay, 1979.
Democrático. El caso sueco, que usted evoca, efectivamente es perturbador y deberia advertirnos. el marco de pen el marco de esa democracia, que muchos presentaron durante largo tiempo como un modelo, una politica sistemática de eugenismo fue llevada a cabo con el aval de todos los partidos politicos. Únicamente algunas voces aisladas protestaron cuando fueron votadas las leyes eugenésicas en 1934 y en 1941, es decir, en pleno periodo nazi en Alemania. Porque ése es el segundo aspecto perturbador del asunto: la barbarie nazi no representó su papel de contramodelo; e incluso cuando su aspecto más espantoso fue revelado al mundo, tras su caida, las esterilizaciones forzusas en nombre de la biologia racial prosiguieron en Suecia, a todo lo largo de los años cincuenta. Es politicamente interesante ver cómo los dos partidos opuestos justificaron su aval. A to derecha, entre los conservadores, jugaba el imperativo de la pureza racial; a la izquierda, entre los socialdemócratas, lo que se ponia de manifiesto era el control de los nacimientos y la calidad de la politica social: el eugenismo era concebido por esos progresistas como un medio para prevenir los problemas sociales. Asi, dos ideologias contrarias -sobre una cuestión capital referente al conjunto de la sociedad y, más allá, a la idea que uno se hace de. la civilización-pueden reunirse y legitimar lo inaceptable.

Al respecto, es instructivo ver con qué facilidad aceptamos hoy los presupuestos de una práctica médica ya remanida, la IAD.* El famoso principio de anonimato rebaja al dador al papel de semental. Por cierto, en apariencia vela por el narcisismo herido de las parejas estériles, pero al precio de una negación de la que pocos

* IAD es la sigla correspondiente a insémination artificielle avec donneur (inseminación artificial con dador]. [N. de] T.] se atreven a sorprenderse. El aspecto más alienante de la donación de gametos, dice usted, no es que el padre genético no sea el padre social, ni siquiera el secreto a menudo vinculado con ese origen atípico, puesto que muchos niños del adulterio pudieron vivir felices en todas las épocas. Por lo menos en Francia, radica en la prohibición legal de decidir y de saber, porque únicamente la institución médica se arroga la elección de un progenitor y es la única poseedora de tal secreto. La donación de esperma niega a la persona del dador, al callar su nombre y su historia por una eternidad teórica. Pero magnifica su pedigri, ya que la investigación médica penetra en la intimidad genética y en la genealogia del semental de reemplazo de una manera que se consideraria obscena si el marco hospitalario no sirviera de pantalla. ¿Qué amante osaria informarse con tanta minucia de los defectos bien ocultos en el ADN de su compañero(a), antes de aceptarlo(a) para los fines de la procreación? La esterilidad solicita a la medicina, que impone la norma. Con aires de desdeñar la importancia de la identidad genética ("la paternidad es el amor"), el banco de esperma exalta la función del dador, o sea, su potencial heredable. La identidad primero reducida al genoma es todo el proyecto de construcción del hombre probable.?

A propósito del eugenismo, François Dagognet escribió que es "un error y un horror a la vez". ${ }^{10} \mathrm{El}$ horror lo conocemos por los médicos nazis. El error es el siguiente: "es posible manipular las plantas y los animales porque sólo se apunta a mejorar un único aspecto: el volumen, el peso, la velocidad de crecimiento, el color... en

9 J. Testart, Des hommes..., ob. cit., pp. 129-130.

10 F. Dagognet, Corps reflechis, Paris, Odile Jacob, 1990, 
suma, los factores económicos; pero cuando se trata del Hombre, ¿a qué apuntar, y por qué?"." De un modo similar, Albert Jacquard observó que con los caballos de carrera se mejoró la capacidad del animal de correr rápido, pero no se mejoró al propio caballo. Una vez más, se toma la parte por el todo. Al respecto, no es excesivo sos tener que los "genios" que proponen esperma de Nobel -al que creen de calidad superior para producir futuros superdotados- caigan en lo que los lógicos anglosajones llaman una "contradicción competitiva". Porque esta misma propuesta, que en apariencia hará triunfar la inteligencia más alta, ¿no es un signo irrefutable de imbecilidad? En 1979, Robert Graham, un oftalmólogo norteamericano, con el sueño de ver nacer una humanidad selecta, fundó en California un banco de esperma de premios Nobel o de campeones deportivos. El profesor William Shockley, premio Nobel de Física en 1956 por sus trabajos sobre los transistores, se sentia muy pagado de si mismo para esta empresa. También se habia multiplicado en proyectos portentosos: proponía nada menos que la instauración de un sistema de primas a la esterilización para los malos sujetos dotados de un coeficiente intelectual $(\mathrm{Cl})$ inferior a cien. A mil dólares cada punto de déficit respecto de ese umbral, el CI de 70 se cotizaba a 30 mil dólares, oferta nada desdeñable, incluso para imbéciles. Acabamos de enterarnos de que en Internet se ofrecen en subasta óvulos de modelos: por unos $100 \mathrm{mil}$ francos, una mujer o un hombre (en ocasiones, los dos) podran obsequiarse la ilusión de que su hija sea tan hermosa como las modelos de las fotos de tapa de su revista preferida. Otro ejemplo todavia más gracioso: una pareja puso un anuncio en Internet en el que ofrece una

13 Ibidem bonita suma por un óvulo bello e inteligente (sic), con la aclaración de que la dadora debe ser estudiante en un colegio famoso pero también deportivo; lo que no se aclaró es si el óvulo debia saber cocinar...

Para responder a estas necedades bastaria con citar esta agudeza de George Bernard Shaw. Un dia, el escritor irlandés participaba en una cena mundana. Él era feo, pero su ingenio compensaba ampliamente ese defecto. Shaw estaba sentado al lado de una mujer muy bonita pero que tenia una conversación absolutamente lamentable. Entre plato y plato, ésta le dijo al escritor: "fijese usted, señor Shaw, nosotros deberiamos concebir un niño juntos. Tendría $\mathrm{mi}$ belleza y su inteligencia". "¡Oh! ¡Nada de eso", respondió Shaw sin pensarlo dos veces, "me aterrorizaria que fuera a la inversa!".

El eugenismo es imposible para el hombre, y eso deberia ser suficiente para excluirlo. Dicho esto, en la actualidad es tradición distinguir un eugenismo negativo y uno positivo. El primero consistiria en eliminar las malformaciones y patologias potenciales más graves; el segundo, en manipular en un sentido intervencionista en favor de un ideal o de una norma planteados al comienzo, a priori. A su juicio, ¿esa distinción entre eugenismo positivo y eugenismo negativo es pertinente al punto de hacernos adoptar una posición ética clara (es decir que, por ejemplo, uno podria estar a favor de un tipo de eugenismo y en contra del otro)? O bien, en su opinión, ¿hay una continuidad, un pasaje insensible de uno a otro, y desde el instante en que uno acepta el eugenismo negativo, ya se estaría poniendo en marcha un engranaje del eugenismo positivo?

J. T.: Creo que esa distinción era pertinente en el momento en que el mismo eugenismo no lo era, cuando se podia categorizar a la gente con suma facilidad por su apariencia y por su conducta, y ordenarla de ese modo en una escala arbitraria de aceptabilidad. Esto no modificaba absolutamente nada de aquello en lo que podria volverse la humanidad si se aplicara ese eugenismo de manera sistemática. En cambio, hoy la distinción entre ambas formas de eugenismo carece ya de todo sentido, porque nos enfrentamos a una verdadera población con los embriones de una pareja. Si tenemos 15 o 20 embriones disponibles, podemos decir que estamos practicando el eugenismo negativo al eliminar algunos embriones, pero está claro que al mismo tiempo estamos practicando el eugenismo positivo al favorecer a los otros. Ya no estamos en presencia de la misma noción: actuamos sobre una población de hermanos y hermanas, que tienen la misma edad y que debemos sacar de la probeta como se saca de la galera de un prestidigitador el mejor conejo posible porque un prestidigitadiferencia es que el posible, porque basta con uno. $L$ du duo (o a la pareja), mientras que la selección embrionaria apunta ya a su descendencia, la cual es múltiple. Los que se niegan a reconocer el eugenismo en la selección de embriones, so pretexto de que éste se dirige expresamente a poblaciones, deberian meditar esta contradicción... Al mismo tiempo, la selección embrionaria resulta un medio científico para permitir la procreación sin riesgo a individuos portadores de anomalias graves, $o$ incluso (es la imagen del conejo que sale de la galera) traer al mundo al "mejor posible" de cada pareja "normal" o "anormal". Ese "mejor niño" sólo habria tenido infimas posibilidades de existir por los medios naturales, lo que permite considerar que la intervención técnica es "positiva" globalmente, si se desdeñan los cuantiosos embriones eliminados en este proceso. En otras palabras, la selección embrionaria es un eugenismo po- sitivo sobre la pareja progenitora y es un eugenismo negativo sobre la casi totalidad de sus embriones. No obstante, sigue siendo el embrión -y no su progenitor- el blanco del nuevo eugenismo, y esa centralidad inédita se ve justificada de varias maneras: no solamente se interviene asi sobre el genuma acabado del futuro nin̄o, superando las loterias genéticas de la gametogénesis y la fecundación ( $y$, por lo tanto, la aleatoria del eugenismo clásico), sino que también es posible desbaratar las mutaciones que afectarian al embrión sin que sus progenitores fueran portadores. Tantos encantos aparentes evocan la manzana envenenada pero tan bella ofrecida a Blancanieves... De la bruja a los "brujos de la vida", de la ingenua muchacha a la sociedad confiada, tal vez la reina malvada no sea necesaria para la dramaturgia...

Con un embrión, uno puede estar seguro -habida cuenta de las técnicas de las que ya se dispone- de fabricar por lo menos un niño, pasando por la clonación embrionaria. Hay que considerar la convergencia de numerosas técnicas en vias de ser dominadas para imaginar que esta perspectiva es muy prometedora. Ya se autorizaron tres centros en Francia para practicar esta selección de embriones. Por el momento, y durante algunos años, se hará esto por buenas razones, es decir, las mismas que habrian justificado un aborto llamado "médico" durante el embarazo, en caso de patologías graves. El desborde que describo se producirá dentro de diez, veinte o treinta años; en el fondo poco importa, porque forzosamente asi terminará.

En octubre de 1999, la primera historia de DPI* estudiada en el Hospital Béclère de Clamart exponia un

* DPI es la sigla correspondiente a diagnostic préimplantatoire (diagnóstico preimplantatorio). [N. del T.] 
caso de enfermedad de Duchenne. Esta enfermedad sólo involucra a los varones (las chicas únicamente son portadoras, cuando lo son) e induce una prescripción casi sistemática de aborto si se la descubre. ¿Qué ocurre cuando se hace un diagnóstico prenatal? En una mujer encinta de quien se sabe que corre tal riesgo, se busca el gen mutado. Si se lo encuentra, y el niño será un varón. se procede a realizar un aborto. Si es una chica, es portadora, lleva el gen, no se enfermará ella misma pero a todas luces se arriesga a tener niños expuestos a los mismos problemas; sin embargo, no se recurre al aborto. Estos genetistas de ningún modo son los mismos de quienes hablaba anteriormente. Acá se trata de genética médica: estos médicos están en relación directa con el dolor de las parejas, con los verdaderos problemas, no son investigadores de la molécula, todavia están en la humanidad, y no aconsejan a las parejas un aborto en este caso particular. Para el DPI, el equipo del Béclère se preguntó: "¿qué hacer si se obtiene una docena de embriones?". Se describen todos los casos posibles; entre ellos, el de la niñita aún en estado embrionario que seria portadora, que no se verá afectada pero que podrá ella misma tener niños enfermos. Aqui, inmediatamente percibimos que el DPI nada tiene que ver con el diagnóstico prenatal; una buena parte de los profesionales a quienes se les pidió que juzgaran el expediente decia: "bueno, es una tonteria, tenemos embriones sanos y también otros que son portadores de patologia, estariamos corriendo un riesgo para la generación posterior, más vale conservar solamente los embriones sanos". Parece completamente lógico, pero no obstante vemos en qué sistema nos internamos. En el caso de la miopatia de Duchenne, se trata de una enfermedad grave, sin duda alguna, pero ¿qué pasará cuando se detecte un ries- go estadistico de diabetes, de cáncer de hígado o simplemente de miopia? El porvenir de la genética no está en esa senda simplista que consiste en reconocer los genes de las enfermedades monogénicas; está en la identificación de los factores poligénicos, por combinaciones de varios genes que, en relación con el medio, pueden provocar patologias. Eso significa que todos estamos involucrados, o sea, que la sospecha también afectará a todos los embriones. Imaginese usted cómo los genetistas del futuro podran desarrollar ese examen de la historia, cuando dispongan de embriones en gran cantidad y sondas capaces de identificar innumerables caracteristicas del ADN...

C. G.: Esta "genomania" engendra ilusiones, tanto entre los médicos como entre el gran público. Por el lado de la investigación hay una, que podría llamarse una "ilusión de finitud"; no deja de recordar a aquella en la que habían caido algunos biólogos y médicos, en el siglo XIX cuando, con el triunfo de ciertas vacunas a partir del descubrimiento de Jenner hasta Pasteur, pensaban que existía una cantidad determinada de enfermedades fijada de una vez y para siempre a las que las vacunas, según el paradigma militar del blanco alcanzado, iban a destruir una por una, a la manera en que se puede disparar a los platos en una barraca de feria. Con los genes, se cae en una ilusión semejante, porque pensar que la determinación completa de los genes hoy nos permitiria abarcar la totalidad del campo de las enfermedades significa que se supone a priori que todas las enfermedades posibles que podrian afectar al ser humano ya están determinadas. Pero eso no ocurre: no tenemos ninguna idea acerca de las enfermedades del siglo XXI, del XXII, del XXIII; el mundo de las enfermedades es, si no infinito, por lo menos indefinido. Los médicos del siglo pasado creian en un esta- do de salud ideal, asi como los utopistas creian en un estado de saciedad ideal: por lo demás, ino es la salud al orden fisiológico lo que la abundancia es al orden económico? Sin embargo, lo hacian sin contar con las enfermedades que todavía no habian tenido la posibilidad de expresarse. Creer actualmente que se podrian seleccionar los genes "buenos" y "malos" es caer en el mismo error que los médicos del siglo XIX que creian en la posibilidad cercana de inventar todas las vacunas. Como no sabemos cuâles serán las enfermedades de mañana, ignoramos cuáles son los genes "buenos" frente a ellas. A la inversa, en nuestro celo eugenésico, podriamos querer eliminar un gen que hoy declarariamos "malo" o "inútil" pero que seria muy precioso en el futuro como inversión de la especie humana para una nueva enfermedad aún desconocida. Como corolario, no tenemos ningừna prueba de que los animales transgénicos, producidos por cualidades especificas reconocidas, no padezcan un déficit que se manifestará a largo plazo en condiciones particulares. Los genetistas realizan sus experiencias haciendo abstracción del entomo, precisamente cuando es el factor ambiental el que, las más de las veces, resulta decisivo. Un punto de vista demasiado estático sobre una realidad dinamica, al respecto, puede ser particularmente desastroso. Llegado el momento, seria biológicamente suicida la adopción en gran escala de una norma media en nombre de una idea preconcebida de la eficacia y de la capacidad. La ecologia cientifica prueba que la fuerza de un ecosistema radica en su diversidad. Aqui hay una enseñanza extraida de la observación del mundo vegetal y del mundo animal, que puede ser transpuesta a la especie humana.

Seria erróneo creer que de un lado existe un conjunto de genes y del otro, un conjunto de cualidades y de- fectos, y que a uno de los genes corresponde un único defecto o una única cualidad. Las enfermedades monogénicas (causadas por un único gen) son raras. ${ }^{12} \mathrm{La}$ mayoría de las enfermedades son poligénicas (provocadas por varios genes) y requieren la ayuda, si cabe decirlo, del entorno. En materia de encadenamiento, todo tiene un carácter evidente; lo que no lo tiene es poner de manifiesto las implicaciones de un gen. Las enfermedades exclusivamente genéticas (como las que de ninguna manera lo son) sólo representan una pequeña parte del conjunto de las enfermedades, pero únicamente ellas merecen el nombre de "enfermedades genéticas". La mayoria de las enfermedades son o bien de dominante genético (cuando el factor genético es el más importante) o bien de componente genético (cuando dicho factor existe sin ser el más importante). ${ }^{13}$ Pero hasta las enfermedades con dominante genético requieren factores externos para desarrollarse. En cuanto a las enfermedades

12 Por cierto, se inventariaron no menos de 5 mil enfermedades genéticas, unifactoriales (también se las llama "enfermedades huérfanas" porque involucran a menos de 5 individuos sobre $10 \mathrm{mil}$ ). Implican genes cuya anomalia o desarreglo basta por sí solo, sin que intervenga ningún factor exterior de manera determinante, para provocar la aparición de una enfermedad gravisima. La hemofilia, la mucoviscidosis, la miopatia de Duchenne y la corea de Huntington son las más famosas de tales enfermedades. Pero el conjunto de las $5 \mathrm{mil}$ enfermedades genéticas únicamente concierne al $0,5 \%$ de la población, y sólo una decena de ellas representa un tercio de los casos.

13 Ciertas graves enfermedades genéticas escaparán para siempre de toda empresa eugenésica: un tercio de las miopatías, por ejemplo, no es hereditario; surge accidentalmente, por una mutación espontánea del genoma, capaz de acaecer en cualquier momento y en cualquier generación. 
con componente genético, primero son ambientales tienen que ver con el comportamiento, o sea, están condicionadas por el medio y por el modo de vida.

Como para todo lo que concierne al cuerpo, la dimensión psicológica no debe ser desdeñada, pues es ella la que produce las demandas y las angustias. La enfermedad genética es la que inflige el daño más misterioso porque no proviene del exterior. El enemigo se aloja en el corazón invisible del cuerpo, y como éste apareció en el momento del acto sexual de los padres, original que noción de una falta primordial, de un pecado original, que no está ligado solamente, como se podria pensar, a la creencia cristiana. La culpabilidad está omnipresente en las enfermedades genéticas, tanto entre los testigos cercanos como entre las víctimas. Pues aqui nos cruzamos con aquello que, probablemente, simbolice una de las lineas de fuerza de la psiquts humana: no creemos en el azar aborrecido, en la loteria de los geser; preferimos encontrar un sentido que sólo puede ser de maldición. Tenemos una tendencia a razonar en recminos de necesidad e imposibilidad, porque eso paPor un lado, la necesidad experiencia más común. que se haga. Pero la biologia cosa ocurrira, se haga lo ca, trabaja en la zona intermedia y en particular la genétimás o menos la zona intermedia de "lo posible" y "lo es totalmente probable". Un cáncer, por ejemplo, nunca te imposible $(0 \%$ de rio ( $100 \%$ de riesgo) ni totalmenmo la opinión nética: en vez de lica recibe las "enseñanzas" de la gemenos, lo hace de razonar en términos de más y de proviene este en términos de todo y de nada. De aqui a la prudencia, la genética: cuando deberia invitarnos de fatalidad. concepción de la vida. Esta distorsión nos pone en una

Por último, y parastros juicios prácticos. ${ }^{14}$

los genes, conviene disipar la ilusión de una tirania de

formas: lo que llamamer en cuenta la diversidad de sus es idéntico de un individ "el mismo" gen en realidad no driamos decir que por más a otro. Como imagen, poojos marrones, en verdad que dos individuos tengan idéntico. En la vida verdad el color de sus ojos no es es cierto que para no hay más que diferencias, aunque con nuestras palabras y conder y clasificar precisamos, Con justa razon grama, pero tomémod cuestiona la metáfora del promismo programa de murtir de un pretaciones rigurosamente idamás se oyeron dos interconducidas por el mismo idénticas aunque hayan sido la misma orquesta. absoluto.

J. T: sos de genes de enferme se conocen cuatro o cinco caque, con tal de que no estén graves, de los que se sabe mocigota -es decir, en dos ejempentes en el estado hosarrolla la enfermedad) mejor protegido que el gracias a ellos uno puede estar otras enfermedades. dente antes que presuntugnifica que uno debe ser pruen otros campos. Inclutuoso en genética, más aún que te uno deberia tolerar cierto de tal aspecto, finalmen-

cierto margen de anormalidad, ce seis o siete años. Para una mujer, las posibilidades de desa-
rrollar un cáncer en caso de mutación de este gen varian del
$50 \%$ al $85 \%$ según la cantidad de cánceres anteriores en su fa-
milia. ¿Qué conclusión práctica puede extraerse de tal infor-
mación? aunque más no sea para prever, como usted lo dice, situaciones que no existen, enfermedades nuevas. Si tomamos el ejemplo del sida, es sabido que hay individuos (cerca del 10\% del conjunto de los humanos) que están naturalmente protegidos, porque tienen un gen que juega sobre el receptor del virus. Esas personas son minoria; por lo tanto, son anormales para un estadistico, ya se trata de mutantes. No obstante, están protegidas. Imaginese usted que se haya contado con los medios pación resper, en el pasado, todo cuanto tenia cierta variación respecto de la norma: esos portadores sanos naturalmente protegidos ya no estarian presentes. Sin embargo, y precisamente por eso, la humanidad sigue existiendo. Ante todas las grandes enfermedades -por ejemplo, la peste negra- ${ }^{15}$, todas las epidemias que la humanidad pudo conocer en su historia, siempre hubo por lo menos un $10 \%$ de la población que resistió, incluso en lugares muy infectados; de hecho, esas personas eran mutantes: hoy se podria descubrir en qué consistía su mutación si, al describir el genoma, se llegaran a encontrar relaciones. Por último, esto significa que tal vez sea el margen lo que salve a la humanidad. Aqui ya tenemos un elemento importante para ser muy prudentes y bastante humildes respecto de las determinaciones de la genética. Pero hay otra cosa, y es la ilusión de la causalidad única: fuera de los sistemas simples -"un gen, una patologia" (los hay, pero son totalmente minoritarios en el campo de la enfermedad)- hay sistemas, combinatorias complejas entre genes y elementos del medio (la alimentación, la temperatura, toda suerte de facto-

15 Esta fue una de las más grandes epidemias de la historia. En la Europa de los siglos XIV y XV, mató a la mitad de la po-
blación. res) que hacen que se tengan riesgos posibles de contraer una enfermedad, lo cual implica que estamos en la probabilidad, pero de ningún modo en la certeza. La medicina de hoy, y todavia más la de mañana, tiende a ser una medicina probabilistica. Cuando se va a buscar el mejor embrión y se eliminan aquellos que presentan grandes patologias potenciales, se tienen en cuenta las probabilidades de tal o cual patologia, por lo que se olvida que hay promedios que debilitan y excepciones que salvan.

La probabilidad tiene sentido para una población, pero no para un individuo. Si le dicen que tiene un $52,8 \%$ de riesgos de tener un cáncer de pulmón a los 63 años y medio porque lleva tal o cual vida, eso es estadisticamente cierto, pero no es lo que le interesa; lo que sí le interesa es saber si va o no a padecer de ese cáncer, y eso nadie puede decirselo. Cada vez más, lo que uno desarrolla con argumentos científicos son probabilidades; de ahi el título de mi último libro, Des hommes probables, ${ }^{*}$ porque el hombre que se va a construir es el hombre que tiene una probabilidad de ser asi o asá, pero que muy bien puede escapar a lo que uno prevé para él y provocar sorpresas y, seguramente, una decepción. En la actualidad, se está instalando una medicina con una inversión tecnológica muy fuerte, toda una aparatologia cientifica que -al fin y al cabo y definitivamente- en verdad no podrá sostenerse a la altura de sus promesas.

C. G.: Esos efectos de anuncio milagroso, que atribuyen a la investigación poderes que no tiene $\mathrm{y}$ hazañas que no realiza, corren el riesgo en su debido momento de volverse contra la propia investigación; un entusiasmo decepcionado se transforma en escepticismo y en re-

* Hombres probables. [N. del T.] 
sentimiento. Con la difusión de la medicina predictiva, uno puede esperar una verdadera explosión de las medicinas paralelas y de las prácticas irracionales. En ese cam po cargado de emociones, porque el sufrimiento y muerte siempre estón presentes, las estadisticas no son comprendidas en su frialdad impersonal y engendran malentendidos. Asi, usted evoca este caso tipico: cuando se entera de que el $75 \%$ de los pacientes aquejados de tal enfermedad se cura, la mayoria de la gente piensa que, si contrae dicha enfermedad, tendrá tres posibilidades sobre cuatro de zafar. Se aplica de manera ilegitima un dato estadistico global a un caso individual.

El titulo de su obra, Des hommes probables, puede comprenderse en dos sentidos: por un lado, la biologia trabaja en la llegada de hombres preconcebidos; por el otro, es probable que tales hombres preconcebidos alguna vez vean la luz del sol. En el subtitulo del libro, "De la procreación aleatoria a la reproducción normativa", "procreación" se opone a "reproducción" y "aleatoria" se opone a "normativa". Del arte (la creación) a la industria (la producción), la norma expulsa el azar. $\mathrm{Y}$ con el azar, la libertad y, por consiguiente, como es de temer, la propia humanidad. El filósofo Hans Jonas, en su Principe responsabilité, escribe que el poder que hemos adquirido en el dominio de la vida trae aparejada la responsabilidad de preservarla y transmitirla a las futuras generaciones. Nuestra gran responsabilidad no es conservar intacto un depósito o incluso mejorarlo, sino velar por transmitir un mundo indeterminado. Más precisamente, escribe Jonas, en cada una de nuestras elecciones debemos velar por no cerrar posibilidades para las generaciones futuras; nosotros les debemos un mundo de libertad en el que ellas puedan escoger entre diferentes porvenires posibles, opción que todavia tene- mos hoy. Pero justamente es eso lo que está amenazado, esa apertura de las posibilidades.

Mientras que la procreación inventa, la reproducción repite ${ }^{16}$ De hecho, ino vemos que el nacimiento cambia de sentido? Primero se empezó por eliminar al padre, luego se siguió con la madre y, por último, se prescindió de ambos. De golpe, el parentesco y la sexualidad se ven eliminados.

En Le magasin des enfants, obra colectiva que usted dirigió, se apela a una interpretación de tipo psicoanalitico para deslindar el sentido de esta revolución. Finalmente, todas esas técnicas apuntan a poner fuera de juego a los padres en provecho de una potencia:

Extinción o exterminio suave, autoprogramado, del ser humano, raza inferior o imperfecta por haber nacido de una mujer en provecho de un mutante de una especie superior, hijo de los hombres o más bien del Hombre. Tomado en su obsesión de dominio de la reproducción, ino está el "Hombre" en vias de convertirse en el otro nombre de la Madre fálica y omnipotente, imaginada por el niñito que, como la niña, no pudo relativizar luego, mediante la identificación con la madre, la amenaza que representa en el plano fantasmático para la afirmación de su identidad?"

Con las técnicas que todavia son de procreación pero que pronto serán de reproducción, la mujer es expulsada del lugar simbólico en que dominaba de manera in-

16 "El resultado de la procreación es la creación de genomas variados al infinito, objetos asi excluidos del campo del dominio genético" (J. Testart, Des hommes..., ob. cit., p. 64).

17 J. Testart et al, Le magasin des enfants, Paris, François Bourin, 1990, p. 154 discutible en provecho de una potencia impersonal (la Madre con mayúscula) que no corresponde a ningún ser concreto de carne y hueso. En estas tendencias en curso se perfila una desposesión de la mujer que aún no se ha mensurado.

Por otra parte, lejos de liberar al hombre del imaginario de los lazos de la sangre, las biotecnologias hacen todo lo que pueden para regresarlo a eso. En efecto, no es posible dejar de sentirse impactado por el contraste existente entre el encarnizamiento procreativo, por un lado, que alienta a la mujer o al hombre estéril con la idea de que de todos modos pueden engendrar, $y$ las dificultades, por otro lado, que la administración opone al deseo de adopción.

"El hombre nace deuda", reza un texto sánscrito. Es probable que el deseo de transmitir la vida sea el reconocimiento inconsciente de una deuda de existencia. ${ }^{18}$ El hombre engendra porque él mismo fue engendrado. Usted escribe que "la naturaleza inventó muchos trucos para limitar nuestra aptitud de hacer niños". '" Razonablemente, uno puede preguntarse si la PMA* no va a contribuir a extender la esterilidad de los individuos humanos, asi como a extender la idea de que la sexualidad debe ser estéril (Aldous Huxley habia adivinado muy bien esta tendencia).

Por otro lado, el dominio de la "procreación" desplaza el fenómeno del lado del derecho, derecho de para los

is A la inversa, el rechazo -cada vez mayor e inquietantede dicha transmisión sería el signo de una ausencia de reconocimiento de deuda para con los progenitores.

19. J. Testart, Des hommes..., ob. cit., p. 142:

PMA es la sigla correspondiente a procréation médicalmen assistée (procreación médicamente asistida). [N. del T.] médicos, derecho a para los padres; y sin duda muy pronto entre los niños: ya se ven niños (sobre todo en los Estados Unidos, pero empieza a suceder en Francia) que entablan juicios a sus padres por haberlos dejado nacer a sabiendas con tal o cual disminución. Hasta ahora, nadie podia reprochar a sus progenitores el hecho de ser genéticamente demasiado humano: el hombre es el producto de un azar y de una necesidad ciegos. Con el poder biotecnológico, las cosas cambian y es posible imaginar al descendiente que reprocha al ascendiente haber modificado su "ser"; o, a la inversa, que le reprocha no haberlo hecho, si considera que no le fueron concedidas algunas ventajas que se le debian. Cabe inquietarse, dice usted, ante la amenaza que planea sobre los desheredados del genoma, desde la privación de la libertad para los individuos capaces de desarrollar trastornos mentales hasta la venganza mayoritaria para con aquellos que no habrian aceptado adaptar su conducta a la exigencia de las predicciones genéticas.

Paradójicamente, cierto fracaso intelectual y político parece acompañar las victorias sociales. "Al ganar libertades y derechos en su conflicto con los poderes centrales, los individuos preparan sin cesar y simultáneamente una inscripción tácita, pero cada vez más profunda, de su vida en el orden estatal, ofreciendo asi un asidero nuevo y más terrible al poder soberano del que querrian liberarse", escribe Giorgio Agamben, quien denuncia "la extraña relación de contigüidad que une la democracia con el totalitarismo"..$^{20} \mathrm{~A}$ no dudarlo: no hay cabida en nuestras sociedades democráticas para un eugenismo estatal a imagen de la contrautopia de Aldous Huxley o de la Alemania nazi. Sin embargo, no seria ni menos temible ni

20 Citado por J. Testart, Des hommes..., ob. cit., p. 263. 
menos totalitario un imaginario colectivo -unificado por las formas más pobres de la publicidad, la televisión y el cine comercial- de millones de individualidades pensadas y planteadas todas como independientes y libres. No resulta muy dificil adivinar de qué lado se inclinaria el superhombre prometido: ya nadie quiere ser Beethoven, ni siquiera tenerlo de hijo. Un campeón olimpico o un actor porno tienen destinos más envidiados.

Y si ahora nos ubicamos en la psicología posible de esos hombres probables que habrán sido imaginados antes de existir, tampoco es muy difícil adivinar que fuera del suicidio se entregarán masivamente a las drogas destructivas: en este contexto, será para ellos una protesta inconsciente contra el sueño social de los hombres perfectos.

Para volver a la cuestión filosóficamente decisiva del pasaje de lo aleatorio a lo normativo, cabe considerar que uno de los grandes sentidos de la investigación cientifica desde que existe -y también, de manera más amplia, uno de los grandes sentidos de la historia- es la supresión del azar. Puede suponerse razonablemente que el hombre odia de verdad el azar y que no deja de perseguirlo cuando lo reconoce, o bien de negarlo gracias a sus ilusiones (por ejemplo, ante la idea del destino). Podría decirse que los grandes descubrimientos y las grandes invenciones culturales siempre correspondieron a la sustitución del azar natural por la voluntad humana. Tomemos el ejemplo de la primera gran revolución de la civilización humana, la revolución del Neolítico, cuando los hombres pasaron de la recolección a la agricultura y de la caza a la cria; ya habia un modo de suprimir el azar y reemplazar ese azar insoportable por una voluntad, porque la voluntad es lo que permite hacer proyectos, tener un dominio sobre el propio porvenir, mientras que el azar, por defini-

76 ción, es algo no manejable. Entonces, mi pregunta es un poco una provocación: bien nos damos cuenta aquí de que las biotecnologias modernas están en busca de la abolición de todo azar, de que el eugenismo es la negación del azar, de que la reproducción que se perfila es la negación del azar; pero al respecto, ino se inscribe eso en una tradición a muy largo plazo, y que es el sentido mismo de la aventura humana, el hombre que no soporta lo imprevisto y que sigue tratando, en toda ocasión, de imponer su voluntad? ¿Es defendible hablar, como lo hace Hans Jonas, de un "derecho a la ignorancia" inseparable de la libertad?

J. T.: El colmo del plan de la ciencia para dominar lo humano tal vez esté en curso. Se trataria de hacer del hombre una entidad biológica bajo control doble, gracias a un genoma escogido y a un entorno programado. Porque si todo ser viviente es el producto complejo de lo innato y de lo adquirido, vemos que el progreso corresponde a una nivelación en el seno de la especie. Esto es cierto para las especies domésticas, animales o vegetales, que a la vez pierden su biodiversidad genética y sus ocasiones de brincar fuera de la granja industrial. También lo es para la especie humana, cuya buena conformación genómica venidera será confrontada con un medio uniforme, donde la lengua hablada, la cultura, la alimentación, la vestimenta y el modo de vida están én vias de estandarización. En tales condiciones, puede cuestionarse la capacidad de libertad, que ocurre cuando lo adquirido permite velar por una cierta expresión de lo innato. ¿No llegará a ocurrir que uno esté autorizado a no vivir otra cosa que su destino? ¿Y no estará ese destino dramáticamente clonado de un individuo a otro?

Pero me gustaría volver un poco sobre la oposición de esos pares de palabras -en particular, "procreación"/"re- producción"-, porque con mucha frecuencia están confundidos, a causa, por otra parte, de los especialistas: las lecciones de medicina hacen referencia a la "reproducción humana". La reproducción, para todo el mundo, es hacer lo mismo -la fotocopia y el desqueje; la clonación si se aplica a los animales-, pero no se trata de eso en nuestras prácticas de engendramiento. Lo que se designa como reproducción no es la reproducción, sino el hecho de que un macho y una hembra (no digo un hombre y una mujer porque esto ocurre con muchos animales, con todos los mamiferos) se juntan para hacer crios; esos crios son diferentes de los padres y diferentes entre sí, a excepción de algunos raros gemelos verdaderos. Por lo tanto, es maravilloso y completamente aleatorio a la vez, pero llamar a eso "reproducción" es ya dar asidero a toda la fantasmática que siguió al nacimiento de Dolly, que efectivamente es el primer mamifero reproducido de un adulto y no procreado." En cuanto a lo aleatorio y a lo normativo, al escribir "De la procreación aleatoria a la reproducción normativa", el subtitulo de la obra Des hommes probables, la expresión "de la procreación aleatoria" remite a lo que se vive todavia hoy; esto incluye al bebé fecundado in vitro: la procreación es aleatoria, porque el bebé tiene todos los riesgos y todas las posibilidades. Una probeta es como una cama; de ella saldrá una sorpresa porque por el momento no se seleccionan los embriones.

21 La lengua árabe posee las palabras "reproduccion" (naskh) y "procreación" (injab), pero las utiliza con rigor. En árabe, todos los mamiferos procrean, mientras que nosotros reservamos esa honorable función a la especie humana (es cierto en francés, pero también lo es en todas las lenguas occidenta les). En árabe, "reproducción" se aplica solamente a la fotocopia o al desqueje vegetal, y la palabra naskh, de este modo, se empleo de entrada para calificar la clonación de Dolly.
"Reproducción normativa": en "normativo" está la idea de una red, de un marco donde se va a poner el embrión.

¿Por qué la "reproducción"? Porque un embrión humano fabricado en probeta sólo tiene una posibilidad sobre diez de convertirse en un niño, y uno de los grandes problemas del eugenismo por la selección de embriones radica en eso: tomarse todo ese trabajo de identificación para encontrar el mejor embrión entre una cohorte, para una tasa final de éxito de uno sobre diez, ino se justifica! Por eso creo que se va a necesitar la clonación embrionaria, la cual, aunque "reproductiva", no es lo mismo que la clonación condenada por el Comité de Ética. La clonación embrionaria muy bien podria volverse aceptable. Se trataria, a partir de un embrión, de hacer muchos; el objetivo seria engendrar un único niño que sea conforme a dicho embrión. Uno puede hacer decenas de clonaciones de un embrión, ya se sabe hacerlo desde hace tiempo; no se realiza en el humano pero funciona con todas las especies estudiadas. No obstante, el humano es mucho más "fácil" de trabajar, más maleable que los otros mamiferos. Asi, se podrán producir decenas de embriones idénticos, congelarlos y luego sacarlos del congelador uno por uno para introducirlos en el útero de la futura madre hasta que se desarrolle un niño. Tras el nacimiento, se eliminarian los clones congelados, por lo menos en un primer tiempo, para evitar la acusación de fabricar cohortes de seres semejantes. Todo esto es ya técnicamente factible y tiene que ver con la "reproducción" verdadera, ya que se copia; esta reproducción es "normativa", porque no se va a copiar cualquier cosa.

Al respecto, diré unas palabras sobre la clonación, de la que mucho se habla y cuya prohibición algunos comienzan a preguntarse si es legitima. Hoy, hasta algunos 
filósofos sostienen ese discurso: "¿realmente es legitimo prohibir la clonación, que podria tener ciertas ventajas? Hay que reflexionar, no hay que arrojar al bebé con el agua que se usó para bañarlo...". Sin embargo, hay una manera muy sencilla de formular la pregunta: "si se practicara la clonación humana, ¿se aplicaría a cualquier solicitante? ¿Se aceptaría clonar los 6 mil millones de individuos que pueblan hoy el mundo si lo pidieran?". A todas luces, un proyecto semejante seria absurdo e imposible, cosa que revela la indole necesariamente elitista de echar eventualmente mano de la clonación en nuestra especie. La ficción ya mostró el potencial totalitario de una sociedad entregada a tal "instrumentalización" de los humanos, pero el déficit democrático y el marco antiigualitario ya están inscriptos inicialmente en la propia técnica.

C. G.: Kant ya habia dado como criterio de lo justo y del bien la universalización posible; para saber si una acción es moralmente justa y buena, se debe y basta con saber en qué medida soportaria sin inconvenientes su generalización al conjunto de los hombres. En otros términos, y dicho con más sencillez, si la respuesta a la pregunta " ¿y si todo el mundo hiciera lo mismo?" es que la situación seria mejor, entonces puede inferirse que la acción es moralmente buena; pero si la respuesta a la misma pregunta es que la situación seria peor, entonces puede inferirse que la acción es moralmente mala. Ahora bien, no cuesta mucho comprobar que la práctica de la clonación es el tipo mismo de la acción no universalizable, tanto por razones económicas, que usted evoca, como por razones psicológicas, acerca de las que justamente me gustaria decir aqui unas palabras. En efecto, nos damos cuenta de que hay motivaciones terapéuticas -que probablemente sean las que harán que el gran público acepte este tipo de práctica- $\mathrm{y}$ además motivaciones psicológicas sin duda inconscientes. En los Estados Unidos, la clonación reproductiva ${ }^{22}$ está justificada de antemano por la "necesidad" de acudir en "ayuda" de las parejas homosexuales, infértiles, $y$ de los padres que han perdido un hijo. Esta técnica, pues, parece totalmente de acuerdo con la exigencia de igualdad y equidad: para decirlo con brevedad, es considerada superlativamente justa.

El eugenismo es el desenlace de la biología; la clonación es el desenlace del eugenismo. Éste ya está presente, usted lo ha subrayado, con la selección de los embriones en el acto de la PMA. Pero una clonación productiva de seres humanos iria más lejos todavia, predeterminando el conjunto de las caracteristicas genéticas de un futuro ser humano: asi, un destino (biológico), por primera vez en la historia, seria condicionado por la voluntad libre. En el animal, la clonación de las variedades consideradas más aptas, a largo plazo, correria el riesgo de hacer desaparecer la variedad genética. No hay razones para pensar que otra cosa ocurriría en el hombre si la clonación humana debiera ser practicada en una gran escala.

En 1982, R. Edwards, el padre del primer bebé FIVE$T E$, propuso que cada niño FIVETE tuviera su doble congelado. Al disponer de un gemelo de reserva, cada uno podria encontrar asi órganos de recambio en el momento en que los suyos fallaran. El clon, esa especie de gemelo desincronizado, seria el mejor seguro contra la enfermedad.

En Un mundo feliz, Huxley imagina una sociedad futura donde la reproducción humana se hace de manera exclusivamente artificial y donde la procreación natural

22 A diferencia de la mayoria de los paises europeos, los Estados Unidos no prohiben la clonación reproductiva. aparece como el colmo de la obscenidad. Con un evidente e irónico regocijo, usted escribe que "la exigencia de concebir al niño en el curso de un acto carnal instala hoy al Vaticano en la vanguardia del sexo en peligro". ${ }^{23}$ Supresión de la sexualidad, supresión de la fecundidad, supresión del parentesco, supresión del azar, supresión de la libertad, supresión de la identidad: resulta dificil no pensar que las biotecnologias tienen como objetivo un conjunto de supresiones y que en nombre de vaya a saber qué salud atentan contra nuestra propia existencia.

Hannah Arendt habia dado a la natalidad un sentido diferente del de la demografia: para cada ser humano, la posibilidad del nacimiento es la apertura hacia algo nuevo, un comienzo absoluto. Retomando ese concepto de su amiga, Hans Jonas ${ }^{24}$ habia visto en la clonación ese monstruoso peligro: al determinar de antemano una naturaleza, ya que el azar seria suprimido, p̧rivaria al individuo de esa natalidad inseparable de su libertad.

La supresión de la identidad es la consecuencia menos inmediata tal vez, pero, como parece que resume a las demás, conviene prestarle una atención particular.

La identidad es lo que se suprime al multiplicarse. Sin embargo, esto no siempre se sabe. En un articulo reciente, ${ }^{25}$ el psicoanalista Daniel Sibony, del tipo "a-mino-me-vengan-con-ésas", se divierte con las angustias que suscitan las nuevas biotecnologias. Sobre la clona-

23 J. Testart, Des hommes..., ob. cit., p. 162.

Hans Jonas pensaba que el talento genético introduce una ruptura de importancia metafisica; hablaba de "horror metafisico" ante las consecuencias posibles de ciertas manipulaciones genéticas, hace ya más de treinta años.

" D. Sibony, "Quoi de neuf à l'origine du monde?" en: bération, 25 de octubre de 1999, p. 4. ción escribe: "angustia, entre malestar y horror, según los casos; por cierto, angustia del doble, de ser duplicado; deseo de la norma, angustia del monstruo, de la extraña identidad". Todo eso, evidentemente, da la idea de un tabú que se debe derribar. Pero ¿suprime el ridiculo de la angustia de la clonación la indole inquietante del deseo de la clonación? Finalmente, ¿no es ese deseo lo que hoy se impone? ${ }^{26}$ Bajo la negación despunta el deseo, como siempre. ¿No es la clonación el desenlace lógico del narcisismo, el cual es la expresión afectiva (emocional, sentimental) del individualismo contemporáneo que pone al individuo, al mismo tiempo, antes de todas las cosas y en el centro de todas las cosas? ¿No representa la clonación la promesa de que el otro es en adelante una pasión inútil? ?27 Engendrarse uno mismo, ¿no era el atributo de los dioses omnipotentes? El doble no es imaginado ya como una amenaza sino como la posibilidad de vivir otra vida, no ya en el más allá prometido por las religiones sino en el aqui y ahora garantizado por la ciencia. Su deseo viene del deseo de la reencarnación: el clon, como el niño, pero más que él, seria la continuación de si más allá de la muerte. La clonación, como fantasma de todos aquellos que se consideran suficientemente únicos para ser replicados, también proviene de un deseo

26 Una firma norteamericana acaba de inventar el gemelo lúdico: My Twin es un muñeco personalizado, fabricado a imagen de cada niño a partir de su fotografía.

${ }_{27}$ Recordemos al respecto que el fantasma del doble es un fantasma, justamente, y no corresponde a nada observable en la realidad objetiva. No hay identidad posible entre dos seres en lo real: incluso entre dos gemelos verdaderos, ni la organización cerebral ni el sistema inmunitario son absolutamente idénticos. 
de dominio, porque quienes ya imaginaron esa escena no se ubican, obviamente, del lado de la copia sino del lado de la versión original. ${ }^{28}$ Usted escribe que "en el animal, la tendencia de la tecnociencia es economizar la procreación en provecho de la reproducción". 29 En suma, las técnicas modernas de reproducción, ayudadas por los medios más novedosos, harian regresar al hombre al plano del animal, hasta al de la planta (la clonación es un desqueje). En Le désir du gène, usted ya se interrogaba: " ¿y si la lógica que se nos escapa en todo esto fuera volver al punto de partida?". ${ }^{30}$ Tal vez alli se juega lo que Freud llamaba "la compulsión a la repetición" y que es el otro nombre del instinto de muerte. Cabe preguntarse al respecto si la profunda angustia y, al mismo tiempo, el casi tan profundo embeleso que la clonación ejerce en el espiritu del público no están manifestando de manera más o menos consciente ta posible desaparición de la humanidad tal y como es.

28 J. Testart observa la ausencia de un sustantivo para designar al individuo en el origen del clon. La expresión "ser clona do" se aplica indistintamente al sujeto de origen y a clonaél se derivan; como si la identidado de origen y a los que de otros justificara un apelativo comud supuesta de uno y de los ne llamar "preclon" al individuo común. Por eso, J. Testart propo"Telle preclon" al individuo de partida (J. Testart et al. "Telle science, tel clone", en: Faut-il vraiment cloner l'homme?, Forum Diderot, Paris, PUF, 1999, p. 47).

2.9 J. Testart, Des hommes..., ob. cit., p. 14

3n J. Testart, Le désir du gène, ob. cit., p. 16.

\section{La crítica de la razón ética}

J. T.: Me gustaria detenerme un poco en esto para decir que esos puntos de vista éticos, de los que tanto se habla -por ejemplo, sobre la clonación-, sólo tienen sentido si son sustituidos por posiciones o incluso decisiones internacionales duraderas. Eso significa que si la ética es pensada de cierta manera en Francia y de otra diferente en Bélgica, muy cerca de aquí, eso desbarata la noción misma de ética.

Vivimos en Europa; en todos los casos, cuando se haya zanjado el problema en el nivel europeo, de un modo que sólo puede ser más liberal (la alineación se hará con los paises más permisivos, no se puede volver atrás respecto de los progresos técnicos ya realizados), nos enfrentaremos con otros sistemas socioculturales. Por un lado, con los norteamericanos, para quienes todo es posible con tal de que la gente haya firmado su solicitud, disponga de un buen abogado y sea capaz de pagar. Por otra parte, con los paises asiáticos, para quienes no hay una real comprensión de lo que llamamos "persona", con su dignidad (esto no significa que desprecien a los individuos, pero las filosofias asiáticas, aunque múltiples y diferentes unas de otras, son más bien ajenas a la noción que nosotros tenemos de la ética, en particular la ética médica). Sin embargo, una ética planetaria parece indispensable para escapar de los discursos planteados unos al lado de los otros pero que de poco sirven. Ya vemos in- vestigadores que van a hacer en otros paises lo que no tienen el derecho de hacer en el suyo, o pacientes que van a buscar a otra parte lo que no les dan aqui. Estas divergencias geoculturales involucran actos tan variados como la clonación, el patentamiento de los genes o la cesión de gametos. También está el otro aspecto, que es la ética duradera. A propósito de la clonación, por ejemplo, casi todo el mundo en apariencia se opone; entonces aprovechemos y prohibámosla en la ley, porque si uno no se compromete con claridad, insidiosamente prepara los ánimos para una aceptación inmediata. Hay una especie de acostumbramiento provocado por el desgaste de las palabras, por los ejemplos al margen que son casi tolerables, hasta la famosa casuistica que propone estudiar los casos uno a uno: es evidente que si hacemos eso durante algunos años, luego lo admitipos necesariamente por costumbre y, en forma progresiva, pasamos a la aceptación tácita de manipulaciones que nos hacian estremecernos poco tiempo antes. Además, la casuistica supone el reconocimiento del status de los "sabios" que dicen lo que se puede hacer en cada situación (algo asi como la alianza entre el guru y el confesor), lo que equivale a desposeer a los ciudadanos de los desafios éticos de la sociedad.

Creo que hay que rechazar la casuistica para los grandes problemas, tales como la clonación, y tener el coraje de escribir en la ley, en las resoluciones internacionales, que la clonación humana llamada "reproductiva" está definitivamente prohibida. Pero eso no está escrito y, en apariencia, no lo estará. Algunos objetan:

Pero no se puede saber qué ocurrirá dentro de un siglo o dos; tal vez entonces los hombres estarán liberados de un montón de cosas - por ejemplo, de la voluntad de esclavizar a los otros-y la clonación ya no podrá ser un medio de dominación. Si se prohibe hoy, nos privamos de una posibilidad de futuro porque, eventualmente, la clonación tendrá usos médicos interesantes.

A esto también puede responderse que hubiera sido necesario no prohibir en otros tiempos la esclavitud, el trabajo de los niños... No lo sabemos: es posible que, dentro de dos o tres siglos, la esclavitud tenga sentido... Argumentos infames que autorizan la cobardia y dejan el camino expedito para actitudes irreparables.

Hay una gran hipocresia entre los responsables que pretenden razonar sobre estos problemas para tomar decisiones pero que no se permiten opciones claras y definitivas. En ocasiones, más vale la caricatura de los riesgos que su negación lenitiva. Fijese usted en la postura sobre la clonación. Cuando nació Dolly, no era más que una oveja, pero todo el mundo se subió a la cúspide, y fue la primera vez que jefes de Estado como Chirac o Clinton declararon de inmediato que "hay que prohibir la clonación en la especie humana"; después, nombraron comités de reflexión y consultaron a sus comités de ética. Al principio, los expertos estaban en contra, absolutamente en contra; luego, aparecieron científicos pero también filósofos, todo tipo de gente que decia: "jatención! Hay que reflexionar, no se puede prohibir algo asi como asi, esa voluntad de prohibición unánime es sospechosa". Existe una resolución europea de enero de 1998 que afirma: "las investigaciones sobre la clonación del ser humano están prohibidas". Parece categórico, pero, por otro lado, la expresión "ser humano" está afectada por una cláusula flexible que puntualiza: "es atributo de cada pais definir al ser humano". Para nuestros colegas ingleses, el ser humano se origina a partir de los 14 dias de la fecundación... Sin embargo, la clonación empieza por fuerza 
en el huevo, mucho antes de los 14 dias. Conclusión: la clonación del ser humano no está prohibida en Europa. Imaginese usted que la investigación sobre la clonación del ser humano no esté prohibida, como se dice; harian en los laboratorios si verdaderamente quisieran desembocar en la clonación humana? Harian investigación sobre la clonación, trabajando como de costumbre con ratas -y si tienen los medios, con vacas, ovejas y tal vez monos, porque no se dispone de material biológico en abundancia, esencialmente los óvulos humanos-, para permitirse la aproximación de la técnica a nuestra especie. Así que lo harian sobre el animal. Entonces, qué sirve la prohibición?' Ya ve que todo eso, finalmente, sirve en especial para tranquilizar a las multitudes, pero no tiene mucho alcance real.

C. G.: Algunos ${ }^{2}$ adoptan este punto de wista. Según afirman, es necesario hacer todo cuanto es posible hacer, todas las experiencias, todas las manipulaciones; las peligrosas y las absurdas serản eliminadas por si mismas. Usted y yo no somos del grupo de quienes comparten ese hermoso optimismo de la utilidad automática, tan caracteristica del liberalismo contemporáneo: "dejen hacer, dejen pasar, el dios mercado reconocerá a los suyos".

Un proyecto ministerial de comienzos de 2001 sobre la revisión de las leyes de bioética de 1994 apunta a autorizar la "clonación terapéutica" en la especie humana, al tiempo que recuerda firmemente su oposición a la "clonación reproductiva". Aprobada por el Comité Nacion a la clonación reproductición de la ley también das las técnicas podria permitir la puesta a punto de todas clonación reproductiva. Todo ocurriria entonces como si las clonación nes para la clonación terapéutica como si las investigacio-

2 F la cion tuvieran autorizadas.. el primer cis Bacon, en su utopia de la Nouvelle Atlantide, fue 88
En L'œuf transparent, usted apela a "una moratoria revolucionaria sobre la idea misma de progreso", 3 y no deja de condenar la confusión implícita, mantenida por los propios investigadores, que existe entre la necesidad lógica del descubrimiento y la necesidad práctica de la acción. La biologia contemporánea está desbordada por una especie de desmesura. Por otra parte, es lo que la separa del mundo del que se ocupa. A diferencia de la vi$\mathrm{da}$, que posee su propia regulación interna (los excesos $\mathrm{y}$ las faltas inadaptables al medio son automáticamente eliminados), el trabajo humano comprende una violencia especifica que no necesariamente encuentra su regulación. Lo cito a usted mismo:

Por lo menos, cuando se aconsejaba hacer el amor sobre el lado derecho para engendrar un varón, la cosa funcionaba una vez de cada dos. ¿Cuántos de nuestros tratamientos son tan eficaces? ¿Es tan diferente actuar sin saber nada o sin saberlo todo? En el fondo, habria que probar que lo poco que sabemos es suficiente para decidir la acción con la misma coherencia que en la época en que no se sabia nada. [...] Podria darse que nuestra época, victoriosa en los juegos moleculares, resulte históricamente la más impotente para ayudar al hombre a vivir consigo mismo, con los otros y en el mundo. $Y$ que el porvenir se muestre favorable a la ignorancia presuntuosa, es decir, al error, al desprecio, a la indiferencia, en el enorme amontonamiento de los hechos cientificos. ${ }^{4}$

Por lo demás, usted escribió en Le désir du gène que no existe democracia sin tolerancia, no existe tolerancia sin inocencia y no existe inocencia sin lo inconmensu-

3 J. Testart, L'ouf transparent, Paris, Flammarion, 1986, p. 162 - J. Testart, Des hommes probables, Paris, Seuil, 1999, p. 268. rable. ${ }^{5}$ En ese nivel, ética y politica son inseparables. " $\mathrm{Pa}$ ra qué haber sacrificado tanto y durante tanto tiempo a mi amor propio" -pregunta usted en De l'éprouvette au bëbé spectade-"si hoy acepto mi primer compromiso, que suscitará otros, con la máquina estatal?".6 Concluye su última obra con un epilogo donde milita en favor de una reconciliación entre la ciencia y el sentido: "una de las mayores traiciones de los hombres contra sus esfuerzos de civilización es la separación reciente de los roles por la cesión de los medios objetivos de demostración en manos de unos y por la entrega de las virtudes culturales del sentido en manos de los otros".' Sin embargo, toda la ética está fundada sobre un valor que la biologia ignora absolutamente: el respeto por la persona humana. ${ }^{\mathrm{B}}$

Para la biología, no hay diferencia de naturaleza entre una ameba y un embrión humano. Por definición, la humanidad del hombre está ausente del universo biológico. La noción de dignidad es fundamental, tanto desde el punto de vista ético como desde el punto de vista politico, pero no tiene ninguna traducción biológica. A partir de entonces, algunos investigadores se creen autorizados a realizar todas las manipulaciones. Cierta cantidad de biólogos piensa incluso (no lo confiesa con frecuencia, por razones evidentes) que la vida de un 246.

3 J. Testart, Le désir du gène, Paris, François Bourin, 1992, p.

(i J. Testart, De l'éprouvette au bëbé spectacle, Bruselas, Complexe, 1984, p. 54

J. Testart, Des hommes..., ob. cit., p. 272.

* A este respecto, es caracteristico que el inventor del concepto de bioética, Van Rensselaer Potter, lejos de confinarlo a las cuestiones de la medicina y de la biologia humanas, se propusiera fundar una ética de la biosfera que englobaba tanto la ecologia como la medicina. embrión humano tiene menos valor que la de un bovino, porque éste tiene un precio, mientras que el otro no. No sólo el humanismo no puede ser deducido de la biologia, sino que una buena parte de su fuerza (el ardor de sus investigadores) proviene de un antihumanismo más o menos reconocido, más o menos consciente: hay un regocijo en la manera en que a algunos investigadores -olvidando que ningún animal pensaria eso- les gusta recordar que, después de todo, el hombre no es más qué un animal. Lo más inquietante es confidencial. Fijese usted lo que escribe el editor del principal periódico destinado a los ginecólogos norteamericanos:

Es posible que las malas parturientas repetitivas, frustradas por esos inutiles ensayos para estimularlas, se den cuenta de que la clonación de sus escasos embriones es capaz de darles todo cuanto ellas hubieran querido, iy esto en un solo ciclo! Con la irrupción de esta idea, ese subgrupo de pacientes ${ }^{9}$ puede constituir una palanca significativa para introducir las técnicas de clonación a partir de células embrionarias. Un medio seguro para que esta idea se extienda es tratar de ocultarla. Si los interrogan, no digan que lo leyeron aqui. ${ }^{10}$

La ciencia no es solamente amoral; explicitamente, conduce a la inmoralidad. La IAD llevó la ley al disimulo (el dador de esperma es anónimo) y a la mentira (el acto es negado porque en la partida de nacimiento se inscribe que el niño nació del padre).

Usted escribe (diagnóstico que nadie puede cuestionar): "forzosamente debemos comprobar que, a pesar

- Recordemos que el material de investigación surgido del hombre es el único prácticamente gratuito

10 Citado por J. Testart, Des hommes..., ob. cit., p. 249 
de la abundancia de variados comités, hoy no existe una linea clara sobre lo que conviene hacer o dejar de hacer..."." La Iglesia Católica es la única institución que escapa a ese nihilismo ético.

En la Edad Media, los teólogos y los padres de la Iglesia disputaron largamente acerca de en qué momento el alma entraba en el cuerpo. Algunos pensaban que debia ser en el nacimiento; otros, en la concepción. Finalmente, fueron estos últimos los que se impusieron. Un debate análogo, suscitado por la ley que autorizaba el aborto, se efectuó en su tiempo: si es cierto que un hijo de hombre es ya una persona, ¿a partir de cuándo comienza la persona? ¿Cómo puede uno estar seguro de que el aborto no es un crimen? La posición de la Iglesia Católica es conocida: en su enciclica sobre la vida, Evangelium vitae, Juan Pablo II escribe que Ta utilización de embriones o fetos humanos como objetos de experimentación constituye un crimen contra su dignidad de seres humanos. Los embriones tienen derecho a un respeto igual al que se debe al niño ya nacido y a toda persona". A diferencia de la tradición judia, que fija el comienzo de la animación del embrión en el dia cuarenta, el cristianismo, desde los primeros siglos, hizo de la concepción el punto de partida de la animación. Es comprensible entonces que el judaismo admita más fácilmente que la Iglesia Católica las manipulaciones e investigaciones sobre el embrión humano (la cual, lo hemos visto, no las admite de ninguna manera).

El Comité Nacional de Ética francés creó en 1986 el concepto de persona potencial para designar al embrión. Es evidente que dicho concepto no tiene ningún garante biológico indiscutible. La persona, por oposición al in-

"Ibidem, p. 159. dividuo, es una noción moral; la idea de potencialidad implica una finalidad $y$, por lo tanto, una superación propiamente metafisica de la física del cuerpo o de las células. La noción de persona potencial permite plantear un status intermedio, para el embrión humano, entre la reducción materialista a un montón de células y la sacralización del cuerpo humano desde el origen, que lo torna intocable. ${ }^{12}$ Los comités de ética pretendieron despachar con las manos vacías a los mercaderes y a los sacerdotes. ${ }^{13}$ Sólo que, entre los dos, la partida no es pareja: en ausencia de los sacerdotes, los mercaderes tienen todo el poder.

Usted lo dijo en L'œuf transparent: "el desafio es saber pero también prever aquello que lo humano puede soportar en cuanto a artificios, enredos, desciframientos, sin que se aliene su identidad".14 Usted advierte que la prohibición que aqueja a la investigación sobre el embrión in vitro es una decisión de excepción y no justificada en su principio, ya que la investigación sobre los seres humanos está autorizada, en condiciones especificadas, en todas las fases preimplantatorias (feto, niño, adulto, cadáver). ${ }^{15}$ En De l'éprouvette au bébé spectacle, escribia que la ética "debe tender a volverse una ciencia" por oposición a la moral, "que con frecuencia es una doctrina". ${ }^{16}$ Es una posición que, a mi juicio, usted ya no sos-

12 J. Testart propone llamar "preembriơn" al óvulo en fase de fecundación antes de que constituya un embrión propiamente dicho (J. Testart, L'oeuf..., ob. cit., p. 123).

${ }_{13}$ La expresión es de Dominique Memmi ("Que faire du corps aujourd'hui", en: Dominique Memmi et al., La bioethique est-elle de mauvaise foi?, Forum Diderot, Paris, PUF, 1999, p. 21).

14 J. Testart, L'oeuf..., ob. cit., p. 144.

15 J. Testart, Des hommes..., ob. cit., p. 163.

16 J. Testart, De l'éprouvette..., ob. cit., p. 122 tendria hoy. En Des hommes probables se encuentra esta critica fuerte: la bioética -se lo ve claramente con el Comité Internacional de Ética establecido bajo la égida de la Unesco- no haria más que perpetuar el mito de una verdad cientifica fundadora de deberes. Usted recuerda" que la mayoria de los miembros del CCNE* son investigadores o médicos, y se pregunta cómo es posible sostener una posición equitativa cuando se es a la vez juez y parte. Además, la presencia de expertos en los comités de ética no contribuye poco a la ilusión de una ética de expertos, como si bastara con fundar una ética de la ciencia para forjar una ciencia de la ética. A esto debe añadirse lo que bien podria llamarse "una desconfianza epistemológica de los hombres de ciencia frente a una ética a la que perciben como la máscara de la religión y de la politica": la ciencia tafdó siglos en liberarse de las formas ajenas de pensamiento y de poder; so pretexto de ética, asistiria a un retorno violento de tales fuerzas. $\mathrm{Nu}$ merosos miembros expertos de los comités de ética están más o menos conscientemente tironeados por ese doble lazo: deben dar opiniones en nombre de un sistema de valores al que finalmente consideran superado.

En lo que respecta a la propia investigación, el peligro, según usted decía en un articulo, ${ }^{18}$ no proviene ni de Frankenstein ni del sabio Cosinus: el primero es demasiado perverso; el segundo, demasiado ingenuo, y ambos están demasiado aislados para tener cualquier in-

17 J. Testart, ob: cit. en nota 4, p. 151.

* CCNE es la sigla correspondiente a Comité Consultatif National d'Etique (Comité Consultivo Nacional de Etica).
[N. del T.]

ik J. Testart, "Science et conscience", en: J. Testart et al., La responsabilite, Paris, Autrement, 1995, p. 269. fluencia. En nuestras sociedades democráticas, el investigador tiene (estos términos le pertenecen a usted) una "certeza de inocencia", ${ }^{19}$ pues no pósee ni la intención de hacer daño ni la conciencia de que podria hacerlo. Asi, a priori está liberado de toda responsabilidad y a fortioni está liberado de toda culpabilidad. El poder de la ciencia carece de rostro, es un anónimo colectivo. La indole colectiva de los trabajos diluye las responsabilidades. Eso es tan cierto acerca de la investigación como acerca de la guerra. El artículo que presenta la secuencia genómica de Drosophila melanogaster fla mosca vedette de los laboratorios) fue firmado por cerca de doscientos coautores. Ahora bien, si un ente colectivo con frecuencia es menos inteligente que un individuo, siempre es más insensible que él; lo vimos hace poco con el caso de la sangre contaminada. Al achicamiento del campo de competencia (pasaje del sabio de antaño al cientifico o investigador de hoy) corresponde el desmenuzamiento de la conciencia moral y política; por consiguiente, el desmenuzamiento del sentido de las responsabilidades. Por el lado de la ética, esto induce una dificultad especifica: ¿cómo luchar contra un adversario que no tiene rostro, que ni siquiera tiene nombre? La tecnociencia es nuestro destino (él tampoca tiene nombre ni rostro); segrega su misma necesidad. Vemos con qué facilidad hoy se pasa de lo posible a lo real y de lo real a lo necesario, tanto en la opinión pública como en los diferentes comités de ética. Saltando por encima de lo real, la investigación actual torna necesario todo cuanto no era sino posible. La opinión pública bien puede reaccionar al comienzo contra cierta práctica; finalmente, con el uso -que, por otra parte, no requiere ex-

19 Ibidem. 
tenderse demasiado (algunos años, algunos meses)-, la opinión pública se da vuelta. Estoy totalmente con usted cuando hace una critica severa a esos comités de ética que no tienen el coraje o la posibilidad de adoptar posiciones de principios firmes. Lo autorizado o lo tolerado se escurre entre lo prescripto y lo proscripto. Por cierto, la apariencia está a favor de la firmeza, pero es sólo una apariencia. En el fondo, ino es el sentido mismo de la ética, por oposición a la moral, esa incapacidad de situarse en lo universal y de atreverse a enunciar prohibiciones definitivas? Mientras que la moral tenia el culto a la fidelidad (a la tradición, a los valores, a uno mismo), la ética no deja de avanzar de negación en traición, y a eso lo llama "progreso".

La historia de dichas traiciones y negaciones ya es bien nutrida. El CCNE, en su Informe ahPresidente de la República, en abril de 1997, habia manifestado que la clonación humana

no puede suscitar más que una condena ética vehemente, categórica y definitiva. Una práctica semejante, que cuestiona de manera general la autonomia y la dignidad de la persona, constituiria una grave involución moral en la historia de la civilización. Por eso es el momento de preguntarse si no convendria calificarla juridicamente, con miras a su prohibición universal.

El Consejo para la Ética ante la Comisión Europea (mayo de 1997) asume la misma posición: "ciertas consideraciones que descansan sobre la 'instrumentalización' o el eugenismo tornan cada uno de dichos actos [aquellos que se relacionan con la clonación reproductiva] inaceptable en el plano ético". Por lo demás, la Comisión Consultiva Nacional de los Estados Unidos sobre la Bioética, en su Informe al Presidente de los Estados 96
Unidos, en junio de 1997, declaró: "es moralmente inaceptable para cualquiera en el sector público y en el sector privado, tanto en la investigación como en las aplicaciones médicas, tratar de crear un niño por clonación, según el método de transferencia dé núcleo de células somáticas". La OMS," por su lado, adoptó una resolución que afirma la indole inaceptable en el plano ético del uso de la clonación en los seres humanos. En 1997, el CIB** vinculado a la Unesco, emitia en sesión plenaria la Declaración Universal sobre el Genoma Humano, en la cual se enuncia (articulo 11) que "ciertas prácticas que son contrarias a la dignidad humana, tales como la clonación con fines de reproducción de seres humanos, no deben ser permitidas". Por último, la Academia Nacional de Medicina, en junio de 1997, apoya su resolución sobre una tesis kantiana al mismo tiempo que sobre un argumento biológico, al asegurar que la clonación "constituiria un ataque a la dignidad humana", en la medida en que el ser humano no seria ya considerado un fin sino un medio, no una persona sino un objeto manipulable; la clonación se opondría, se puntualiza, "a esa ley biológica fundamental que descansa en la diversidad que hace a la riqueza evolutiva de la humanidad". Sólo que tales declaraciones de intención no conciernen sino a la clonación humana reproductiva y son inmediatamente anuladas por toda una serie de cláusulas lenitivas.

Observemos en primer lugar que todo ocurre como si a los comités de ética les repugnara ejercer la autoridad que deberian tener y que, de este modo, abandonan.

* OMS es la sigla correspondiente a Organisation Mondiale de la Santé (Organización Mundial de la Salud). [N. del T.]

* CIB es la sigla correspondiente a Comité Intemational de Bioéthique (Comité Internacional de Bioética). [N. del T.]
Sus conclusiones se presentan en forma de opiniones y consejos que, en el plano teórico, son mucho menos que estudios o informes y que, en el plano práctico, son mucho menos que decisiones. En segundo lugar, esas opiniones, incitativas y no imperativas (excepto, lo hemos visto, en lo que respecta a la clonación humana reproductiva), se inscriben de entrada en el régimen de lo efimero. Las propias leyes -y esto es más grave todavia, mucho más grave- hacen exactamente lo mismo. El primer texto de ley en materia de bioética, en Francia, fue votado en 1994 y venia acompañado de una cláusula de revisión al cabo de cinco años..$^{20}$ En la Antigüedad, las leyes se escribian sobre bronce, porque la ilusión de los legisladores era que debian ser eternas. Hoy se escriben sobre la arena: son leyes que nacen muertas y cuya abolición se llevará a cabo, es sabido, si no se lass transgrede. Es un poco como si un arquitecto viera ya las ruinas del edificio que todavia no terminó de construir. No obstante, esta infinita "revisabilidad" de la ley tiene una función ideológica: tranquiliza a las sociedades democráticas en su ilusión de progreso y les hace creer que sus transgresiones y sus regresiones son avances. Nada semejante para apaciguarnos hoy en nuestra idea de libertad que esa puesta en escena del tabú violado.

Pero hay algo más ( $y$ peor). No es raro que los textos se contradigan de un párrafo a otro. Asi, el articulo $5^{\circ}$ de la directiva europea 98/44 CE, adoptado en mayo de 1998, estipula en su primer apartado que el simple descubrimiento de uno de los elementos del cuerpo humano "incluida la secuencia o la secuencia parcial de un gen" no puede ser asimilado a una invención patentable.

20. Las leyes de bioética de 1994 serán revisadas en el transcurso de 2002; por consiguiente, con tres años de retraso.
En su segundo apartado, el texto añade que "un elemento aislado o producido de otro modo mediante un procedimiento técnico, incluida la secuencia o la secuencia parcial de un gen, puede constituir una invención patentable, aunque la estructura de dicho elemento sea idéntica a la de un elemento natural". Solamente que, como por definición todo objeto de investigación debe ser aislado por medios técnicos, se termina por autorizar lo que se habia empezado por prohibir. Ese régimen de apariencia de prohibición es totalmente caracteristico de nuestras sociedades.

A la naturaleza de la acción ética en el campo de las investigaciones tecnocientificas le corresponde ser única y exclusivamente negativa. Lo hemos dicho: ni el respeto ni la dignidad tienen un sentido biológico. A partir de entonces, las recomendaciones de los comités de ética, como las del demonio de Sócrates, no pueden sino ser impedimentos. Sin embargo, desde que existe, ¿qué impidió hacer la bioética? Pareciera que su acción fuera sólo de indole dilatoria: se empieza por fingir que se prohíbe para terminar por autorizar. Entre ambas eventualidades, uno habrá tenido la impresión de avanzar. Cantidad de cientificos están a favor de la clonación humana, pero, como tienen conciencia de que la sociedad aún no está psicológica y politicamente lista, han adoptado una actitud de prudente expectativa. La opinión debe madurar. Tal es el signo de la hipócrita cobardia en democracia.

A grandes rasgos, en todos los comités de ética hay dos aproximaciones en conflicto: una deontológica y una pragmática; por otro lado, para un filósofo, esa división recuerda el gran enfrentamiento durante la Antigüedad entre Aristóteles y Platón, respecto de la idea del bien. La aproximación deontológica se hace a partir de los principios, y la pragmática, a partir de los resultados. La 
aproximación deontológica quiere que nuestros deberes y principios condicionen la finalidad y las consecuencias de nuestras acciones; es universal y a priori. La aproximación utilitaria o pragmática implica que las acciones humanas sean evaluadas en función de los medios y fines perseguidos o de sus consecuencias; es particular y $a$ posteriori. Precisamente de este enfrentamiento surgen el compromiso y la politica de la moratoria.

La concepción anglosajona de la "ley flexible" (soft law) -que también podría traducirse por "ley blanda"-se impone sobre la concepción francesa (y kantiana) de los principios que gobiernan la ley. Mireille Delmas-Marty habla de conjuntos vagos respecto de las nuevas reglas que se constituyen a escala internacional. Del mismo modo que la teoria de los conjuntos vagos piensa todo el espacio simbólico que puede existir entre la relación de pertenencia y la de no pertenencia -èn la teoría clásica de los conjuntos, en cambio, no hay nada entre las dos: un elemento pertenece o no pertenece a un conjunto determinado-, seria posible encarar normas difusas: una vez dictada la regla, se prevén los casos en que las desviaciones serian autorizadas o toleradas. Entonces sólo serian francamente prohibidos los extremos. Cada vez más, la legislación de hoy se hace o se transforma a partir de casos particulares, hasta singulares.

Las opiniones de los comités de ética pertenecen a un género históricamente bien conocido $y$ al que usted ya hizo alusión: la casuística. La casuística, en la que los jesuitas se destacaban como maestros, nació de la necesidad de adaptar a los casos particulares de la vida corriente los principios de la religión y de la moral cristianas. Para Pascal, en Les provinciales, fue pan comido mostrar que en lo que atañe a la adaptación, en realidad la casuistica se entrega a una destrucción de los principios. ¿No es con exactitud la situación actual? Verdaderamente, entramos en el espacio de la diferancia: de la distracción y de la diferencia. Como la ética no tiene los medios para impedir la acción, su única pretensión es diferirla. Por eso, moratoria se ha convertido en la palabra clave de una ética vergonzosa de si misma que ya no se atreve a plantear prohibiciones. Las leyes de bioética están en perpetuo examen. Los comités de ética se quedan sin aliento corriendo tras la ciencia.

Indudablemente, en cierto sentido, toda moral es una manera de poner la angustia de la existencia entre paréntesis, de domarla y sublimarla. Sin embargo, lo que caracteriza a las éticas contemporáneas es que son reacciones directas a las angustias y a los miedos no sólo reavivados sino suscitados por los desarrollos de las tecnociencias. Como las biotecnologias son el campo donde las angustias y los deseos están más confusamente mezclados, una idea que escandaliza en un momento determinado parece "normal" diez años más tarde. ¿Quién cuestiona hoy el aborto artificial o la PMA? En la actualidad, basta con que una cosa exista para que parezca normal. Aqui, como en otras partes, se jugará con las palabras. Las manipulaciones biológicas no carecen de una manipulación en cuanto al léxico: así, la creación de un embrión se convierte en "clonación de células". Por el lado del público, la cuestión es planteada cada vez menos en términos de bien, y cada vez más en términos de derecho: derecho a tener un hijo, derecho a escoger el sexo del hijo, etc. A la "instrumentalización" del embrión, hasta ahora prohibida, no deja de oponérsele el derecho de los enfermos, y muy bien pueden imaginarse, en el marco actual de la "judicialización" creciente de la sociedad, asociaciones de enfermos que llevan a los poderes públicos ante los tribunales: la prohibición de las investigaciones sobre el embrión humano podria entonces ser atacada bajo el titulo de "no asistencia a persona en peligro". Añadamos a esto el hecho de que los medios tienen muy claro hoy cómo se pone en escena la emoción: ¿qué no concederian a una pareja deshecha en lágrimas? En la pantalla de televisión, que nunca mereció tanto su nombre (en efecto, la televisión es lo que forma pantalla), la singularidad de la emoción siempre se impondrá sobre la universalidad del principio. ¿Alguna vez se vio la imagen de un principio? Los medios prosperan bajo el régimen de la mala fe: declaran la guerra contra ciertas prácticas (por ejemplo, la vivisección), pero son los primeros en maravillarse por los resultados obtenidos gracias a esas mismas prácticas.

Hipócrates decía: "no le daré veneno a un hombre, ni siquiera si me lo pide". Hoy en dia, cantidad de médicos piensan a la inversa: "le daré lo que me prida, aunque se trate de un veneno, con tal de que me pague y haya firmado una autorización". Usted prevé que la opinión admitirá la clonación por el sesgo de la compasión: ${ }^{21}$ la "resurrección" de'un niño, por ejemplo. En esta materia, la cuestión ha dejado de ser lo permitido y lo prohibido, lo licito y lo ilicito, para pasar a ser lo posible y lo imposible. Pero la clonación humana, si se puede decir, es tanto más históricamente necesaria, que la especie humana no sólo no opone ninguna dificultad práctica a esta técnica, sino que, por el contrario, se presta a ella particularmente bien. El utilitarismo -que es la filosofía dominante en los paises anglosajones y que funda su concepción de la democracia- considera que un proyecto es justo desde el momento en que mejora el bienestar futuro de la mayoria. Se relacionarán las manipulaciones

21 J. Testart, Des hommes..., ob. cit., p. 72, con ventajas aparentemente indiscutibles. Además, muchos investigadores se sienten a resguardo de lo peor porque creen que la indole democrática de los gobiernos y de las sociedades basta para garantizar las avanzadas futuras contra los abusos y las posibles derivas. Razonan del siguiente modo: "en un régimen totalitario, los riesgos son reales, pero no estamos en un régimen totalitario; por lo tanto, no hay que temer ningún riesgo". Con la cuestión del eugenismo, hemos visto hasta qué punto tal manera de pensar era ilusoria. Sin embargo, hoy, en los diferentes comités de ética -cuyos miembros, repitámoslo, son a la vez juez y parte, ya que la mayoria de los comités de ética están formados por los propios cientifi$\cos$, quienes, por ende, tienen un inmediato interés intelectual, económico y de otra indole en estos tipos de investigaciones-, los cientificos se dan cuenta de que lo que prevaleció es el punto de vista pragmático, es decir, de hecho, el punto de vista económico.

J. T.: Si, totalmente; de todas formas, el comité más ejemplar es el Comité Nacional de Ética francés, que con bastante frecuencia critico porque es el nuestro, pero del que pienso que es uno de los mejores tanto en su composición como en su elaboración. Dicho esto, más del $70 \%$ de los miembros de este comité son investigadores en ciencias duras o médicos, y eso falsea un poco los debates. Este comité es el único en el mundo que tiene una posición clara sobre la clonación y la ha expresado públicamente: prohibir definitivamente la clonación humana. Los demás se contentaron con un "habria que dictar una prohibición temporaria, tres años, cinco años". Las más de las veces, la función del comité de ética no es prohibir. Yo terminé por comprender que la función de la ética institucional es acostumbrar a la gente a los desarrollos tecnológicos para llevarla a desear pronto aque- 
llo a lo que hoy le tiene miedo. En este sentido, no hay gran diferencia entre ciertas actitudes (¿estrategias?) de acostumbramiento que plantean una prohibición temporaria (la moratoria), una autorización temporaria (la puesta a prueba) o una adaptación al caso por caso (la casuistica). Son maneras de acostumbrar a la gente, a través del desgaste de las palabras y de las ideas, hasta que deja de sentirse ofendida por lo que se podria hacer. El comité de ética es primero un comité de benevolencia del desarrollo tecnocientifico. Algunas tecnologias serian muy mal aceptadas hoy, pero si, dentro de quince o veinte años, son bien aceptadas, será en parte gracias a los comités de ética, que habrán manifestado: "hay que desarrollar la investigación, hay que prestar atención, hay que esperar un poco, hay que hacer una moratoria..."; éstas son todas una suerte de proposiciones que nada tienen que ver con una prohibición y que permiten acostumbrarse a la idea. Hablo al respecto de una ética de acostumbramiento soluble en el tiempo. La historiadora Nadine Fresco ha utilizado la expresión "jardin botánico de las ideas", que es una bella imagen; un jardin botánico evoca las plantas exóticas que uno va a buscar, que se ponen ahi y que se logra que sobrevivan en un entorno artificial. Algo de eso se hace con las ideas en el discurso de la ética y se llega a aclimatarlas. Entonces uno puede interrogarse: "¿qué reprochès se les puede hacer a los comités de ética si la gente termina por experimentar el 'progreso' con placer, o por lo menos sin sufrimiento?".

Como ya hemos dicho, es muy dificil construir una ética universal, puesto que los intereses o las culturas no llevan a la convergencia internacional. Sin embargo, me impacta comprobar la indiferencia de los éticos franceses ante la permisividad de otros paises, en ocasiones vecinos. Todo ocurre como en el fútbol: nosotros sostene- mos una ética nacional y sólo jugamos para nuestro equipo. Ese provincialismo no deberia ser válido cuando se trata del futuro de la especie.

C. G.: De paso, observemos esta paradoja; mientras se rompen los diques por el lado del hombre, se reconstruyen por el lado del animal. Cada vez más voces se alzan contra la experimentación animal, ${ }^{22}$ y uno que no soporta la idea de una experiencia sobre un perro acepta, sin experimentar, un estado de ánimo particular, cuando no con entusiasmo, la idea de una manipulación genética sobre el ser humano. En ausencia de argumentos rigurosos que fortalecerían su punto de vista, los partidarios de una manipulación sin regla ni freno tratan de desacreditar a sus adversarios por su carácter supuesto: friolentos, miedosos, tímidos, conservadores, nostálgicos. Resulta a todas luces más fácil descalificar al adversario que a su causa. Pero también los partidarios de una manipulación pueden alegar el hecho de que la biologia es, por definición, una acción sobre lo viviente (no hay ciencia experimental meramente teórica) y que, por lo tanto, la tendencia seria estigmatizar todas las nuevas investigaciones en biologia bajo el nombre de "eugenismo". Asi (me convierto en el abogado de ese diablo sin creer personalmente en su inocencia), los opositores de las investigaciones "fetichizarian" lo humano hasta en su origen y naturaleza. Y si la palabra embrión remite a un niño en miniatura, es porque, fundamentalmente, la gente es preformacionista: piensa que el desarrollo va sólo en el sentido cuantitativo de un incremento; por mucho que haya visto las fotografias de la embriogénesis, en el fondo está persuadida de que el embrión es ya un feto.

22 Algunos rechazan esta experimentación porque el animal no puede dar su consentimiento por escrito...
Por eso, la expresión "destrucción de los embriones humanos" evoca indefectiblemente una matanza de gran magnitud. De esa manera, los adulones de la investigación sin trabas (o sea, sin otra traba que la falta de dinero) vuelven contra sus adversarios el argumento de manipulación del léxico.

Otro punto: los opositores a las investigaciones experimentales sobre el hombre sostienen que el homo sapiens permaneció biológicamente igual desde Cro-Magnon, o sea, desde hace 40 mil años, y preguntan si es posible encarar fríamente una mutación de la especie humana en el espacio de una generación o dos. Usted mismo, Jacques Testart, escribe: "en 50 mil años de historia humana, hombres semejantes a los de hoy se enfrentaron a una infinidad de tecnologias, desde la maza o el arte del fuego hasta la bomba atómica o la fecundación externa. Ninguna de esas tecnologías fue capaz de modificar nuestra humanidad ni lo más minimo". ${ }^{23}$ Seria posible preguntarle: "ies tan asi?". Además, ¿no es paradójico y hasta contradictorio oponerse a prácticas que se atienen únicamente al nivel biológico cuando esa toma de posición hostil no deja de afirmar la indole cultural histórica y social del ser humano? ¿Puede adoptarse sobre la clonación una actitud de absoluta oposición y, al hacerlo, confundir la clonación reproductiva que engendra a un niño y la no reproductiva que consiste en células con fines de transplante? ${ }^{24} \mathrm{La}$ clonación reproductiva

23 J. Testart, Des hommes..., ob. cit., p. 187.

24 La clonación no reproductiva utiliza la capacidad de los ovocitos enucleados para reprogramar las células somáticas del adulto. Las células embrionarias las células somáticas somáticas podrian diferenciarse in vitrodas de estas células entre parientes parter y ser transplantadas entre parientes para curar numerosas enfermedades pero clonación no reproductiva puede ir más lejos, produciendo está (por el momento) expresamente prohibida: hemos citado la "Declaración Universal sobre el Genoma Humano". El parlamento europeo, algunos meses antes (en 1997), habia manifestado en el mismo sentido que

la clonación de seres humanos, ya sea con fines experimentales (tratamiento de la esterilidad, diagnóstico antes de implantación, transplante de tejidos) o con cualquier otro fin, en ninguna circunstancia puede ser justificada o tolerada por ninguna sociedad humana, cualquiera que sea, porque equivale a una violación grave de los derechos funda. mentales del hombre.

Existen dos maneras de concebir la distinción entre la clonación reproductiva y la clonación terapéutica. $O$ bien estos dos tipos son realmente opuestos (la clonación terapéutica es no reproductiva), y entonces la autorización para realizar esta última de ningún modo libera la senda de la otra, o bien ambos tipos se encuentran en tal continuidad que admitir una (la clonación no reproductiva) es abrir el camino a la otra. Lógicamente, usted adopta el segundo punto de vista y escribe: "Voltaire fue acaso el primer hombre libre. Que me lo traigan, yo me encargo de explicarle la FIVETE en una hora y de que la apruebe. Pero dudo de que un biólogo del año 3000 , convocando al mismo Voltaire, pueda lograr que aplauda la clonación". ${ }^{25}$ Las biotecnologias podrian dar a la muerte del hombre un sentido propio. No obstante, con el fin de la identidad humana lo que se vendria a pique seria la propia democracia. El eugenismo sería para la democracia un golpe fatal, pues nadie, en la actualidad, puede conce-

embriones cuyo desarrollo sea detenido en una fase más o menos precoz.

25 J. Testart, Des hommes..., ob. cit., p. 184. 
birlo fuera de la lógica capitalista del mercado, e indefectiblemente devendria en una desigualdad infranqueable

Resumamos su posición sobre las biotecnologias, que es perfectamente clara: fuera de la clonación, usted está contra el DPI porque desemboca en el eugenismo y contra la IAD porque avala la mentira social, pero está a favor de la práctica de la ICSI.* Por lo tanto, de hecho, la única práctica que acepta es la ICSI. Entonces, ipuede decir por dónde, a su juicio, pasa verdaderamente la linea de demarcación?

J. T.: La ICSI, por intracytoplasmic sperm injection, consiste en la inyección de un espermatozoide en un óvulo; todo el mundo vio imágenes de esto en la televisión. Es una técnica muy sofisticada, la más sofisticada de las técnicas de fecundación in vitro. En vez de dejar que los espermatozoides se las arreglen solos con los óvulos en la probeta, se toma un espermatozoide en una aguja de vidrio muy fina (del orden de algunas décimas de milimetro), se trabaja bajo microscopio y se introduce la aguja en el óvulo. Se inyecta el espermatozoide y se vuelve a salir. iMilagro! Por un lado, el óvulo sobrevive, por el otro, el embrión se desarrolla, y esto produce bebés normales. Cuando esta técnica fue aplicada por los belgas en 1992, yo estuve entre los más vehementes que decian “ies escandaloso!”... iporque no hubo ninguna experiencia animal equivalente! Un año después, nos mostraron centenares de bebés, y eran normales. Muy pronto hubo un debate en Francia para saber si se podia hacer en el hombre una manipulación que no habia sido realizada sobre el ratón; pienso en particular en Axel Kahn, que en

ICSI es la sigla correspondiente a micro-injection d'un spermatozoïde dans un ovule (microinyección de un espermatozoide en un óvulo). [N. del T.] esto era muy impetuoso. Yo respondia: "no van a engendrar dos docenas de ratones, ya nacieron un millar de niños, y aunque sean belgas, ila experiencia bien vale los ratones!". Entonces pasaron al acto y fue en mi laboratorio donde se concibió con esta técnica el primer bebé en Francia, en 1994. ¿Por qué estoy a favor? Primero me oponia a la forma en que el método habia sido iniciado porque existia un riesgo considerable, una fractura del óvulo, que es una célula muy delicada; pero -algo bastante extraordinario- el óvulo resiste ese traumatismo. Esta técnica es el colmo del artificio en la medicina de la procreación, porque uno va resueltamente a introducir en el óvulo un espermatozoide escogido. No se lo escoge con criterios genéticos, sino simplemente porque parece normal. Ir a depositar el gameto masculino en el corazón del óvulo: no puede hacerse nada más invasivo. Además, asi se logra la relación de uno a uno para los gametos cuando naturalmente hay un óvulo por mes en la mujer y más de 100 millones de espermatozoides por dia en el hombre. ¡Esta técnica representa el triunfo de la paridad! Creo que aqui llegamos al final de toda la estrategia de procreación asistida, en el filo de una lógica que es una lógica médica: una pareja no tiene hijos, por razones atinentes al hombre, a la mujer o a los dos a la vez, y mediante procedimientos hormonales y mecánicos se llega a concebir un niño, que sin embargo es siempre un niño del azar. Porque no se escoge nada, simplemente se ayuda al azar: se toman los gametos, se los acerca, se los mezcla y eso funciona como en el organismo. ¿Por qué oponerse a la ICSI, que es un resultado tecnológico pero de ninguna manera una nueva vía de procreación susceptible de generar interrogantes inéditos?

Hay un punto litigioso, preciso es decirlo, y es el riesgo de que los niños sean estériles como el padre, ya que, si se practica esta técnica, es porque el progenitor fabrica muy pocos espermatozoides. La esterilidad -masculina o femenina- y sus bases genéticas son mal conocidas, pero es verosimil que, en ciertos casos, el padre padezca de una particularidad genética que el niño corre el riesgo de heredar, sobre todo si es un varón. Nos encontrariamos entonces con un niño que deberia recurrir a la misma técnica para tener niños a su vez; esto indignó mucha gente. Sin embargo, si se rechaza este procedimiento por esa razón, sabiendo que la miopía es hereditaria, habria que mandar de vuelta a los miopes que vienen para una fecundación in vitro, porque vamos propalar la disminución: puede verse la huella del eugenismo, que siempre llega insidiosamente.

Estoy a favor de la ICSI por otra razón; la ICSI vino a reemplazar una técnica, que yo considero veterinaria y que no es nada sofisticada: la insemiñación artificial con el esperma de dador (que no es el marido sino un hombre voluntario y anónimo). Aqui no hay ninguna tecnologia médica (salvo que se congela el esperma): se trata tan sólo de introducir espermatozoides en el útero de una mujer. Pero es instructivo ver cómo los periodistas o la población reaccionan a estas diferentes têcnicas. La ICSI da miedo a muchos porque es una fractura del óvulo, porque es muy sofisticada técnica. mente. La inseminación es un acto técnico banal y, por lo tanto, inquieta menos; no se ve que el peligro está mucho más seguramente del lado de la inseminación con esperma de dador que del lado de la ICSI. Aquélla encubre riesgos psicológicos que recièn ahora aparecen. La técnica se desarrolló a partir de 1974, esencialmente cuando se supo congelar el esperma; por consiguiente, los primeros bebés comienzan a llegar al diván de los analistas, los que en ocasiones ya habian recibido al papá (el padre social). Aunque haya dado su consentimiento para que su mujer sea embarazada por otro, anónimo, a veces el hombre vive mal el adulterio biológico y la herida narcisista. La IAD es una verdadera manipulación de la humanidad, y no simplemente una manipulación de los gametos, como la ICSI. La manipulación de la humanidad me parece más grave: deliberadamente crea niños que, en la ley francesa, son huèrfanos de padre, porque jamás tendrán el derecho de conocer al padre genético, saber quién es. No se trata de aferrarse a la genética como algo determinante (lo innato contra lo adquirido), sino de comprobar que todos los niños -todos los humanos- necesitan saber de dónde vienen. Si un niño percibe que no proviene de su padre o de su madre (porque hoy, las dos situaciones son posibles), corre el riesgo de sentirse afectado. Si se debiera absolutamente recurrir a la cesión de gametos, más valdria tal vez que no sea anónima, pero en todos los casos lo mejor es abstenerse, y con bastante frecuencia se puede hacerlo gracias a la ICSI. ${ }^{26}$ Habia cerca de $\mathbf{2 8}$ mil inseminaciones con esperma de dador en Francia en el momento en que llegó la ICSI; hoy hay menos de 10 mil. Creo que es un éxito ético, porque, además del ahorro de la mentira social y los problemas psiccológicos, la práctica de la inseminación con esperma de dador desarrolló tendencias eugenésicas caracterizadas, dictadas a los médicos provistos de las mejores intenciones. Preocupada por evitar la propagación de los riesgos sanitarios (por supuesto, se rechaza a un da-

$26 \mathrm{Al}$ respecto, es sorprendente que el texto interministerial de revisión de las leyes llamadas "de bioética" (1994) no abra juicio sobre este problema, a pesar de la abundancia de reflexiones que suscita en la sociedad. 
dor que tenga sida), la IAD va mucho más lejos, hasta "aparear" (es el término mismo que utilizan los bancos de esperma) a tal hombre con tal mujer en función de riesgos genéticos compartidos y, por lo ende, hasta concebir niños que deberían ser "mejores" que los que se hacen en una cama. Esta es una actitud tipicamente eugenésica: es generosa, pero exalta la norma y el genoma. Estoy a favor de la ICSI, que suprime todos esos problemas. Por otra parte, puedo asegurar que cuando se propone la elección entre la ICSI y la sustitución del hombre estéril por un dador de paso, los hombres (y las mujeres) no tienen ninguna vacilación.

C. G.: ¿Qué responde a quienes le reprocharian no haberse hecho preguntas desde el comienzo, cuando trabajaba con vacas? ¿Qué responde también a quienes le reprocharian no ver problemas humanos en la práctica de la ICSI, e ignorar o fingir ignorar que entre esta práctica y la selección genética del ADN del espermatozoide no hay solución de continuidad? Algunos pueden sentirse ofendidos por la indole verdaderamente "veterinaria" de la ICSI y no dejan de denunciar en su actitud aquello que, al fin y al cabo, no seria más que un humanismo de fachada. Es evidente que, al decir esto, no estoy en modo alguno expresando mi perspectiva personal; solamente me hago eco de ciertas inquietudes.

J. T.: Un punto técnico; no es posible reconocer el ADN del espermatozoide o del óvulo antes de la fecundación. Para reconocer el mensaje genético de un espermatozoide, se lo mata. Entonces se pueden hacer análisis, pero como está muerto, no puede servir para la fecundación. Asimismo, más vale informarse sobre el embrión directamente: el embrión es ahora el futuro bebé, ya nada cambiará en forma genética; si hay que seleccionar cientificamente, sólo puede ser sobre los embriones.
A veces, me reprochan haber chapuceado con las vacas sin reflexionar en lo que hacia o incluso haber sido pionero de la fecundación in vitro. Creo que uno reflexiona a partir del momento en que está en posesión de su propia historia. Es también mi manera de educar a los niños: tienen que hacer sus experiencias con riesgos, la lección que dan los ancianos es que se puede leer y entender, está bien, pero mientras no se lo ha vivido, no tiene mucho peso. $Y$ debo decir que, tanto en el medio en que yo trabajaba como en el exterior, nadie veia entonces un problema en el objetivo de aumentar la producción de leche. De ningún modo me habia planteado la pregunta; nadie lo habia hecho, incluso la gente que estaba en un universo completamente diferente de aquel que yo frecuentaba. Nadie me señaló nunca: "pero lo que estás haciendo es una idiotez, ya hay demasiada leche". Yo me di cuenta de eso doce años más tarde, solito. Es terrible percatarse con posterioridad de que, precisamente cuando leia en los diarios que habia una superproducción lechera, no lograba aplicar ese saber a lo que estaba haciendo. Por eso creo mucho más en la estimulación que puede salir de una discusión colectiva. Pienso que un individuo aislado se aliena muy pronto con lo que hace, se encierra en su sistema y se encuentra tan atrapado -en particular, en esas tecnologias chapuceras para la puesta a punto de procedimientos-, que no tiene el gusto o la posibilidad de reflexionar, si alguien no le da unos buenos puntapiés de tanto en tanto.

C. G.: En compañia de cierta cantidad de otros cientificos (Albert Jacquard, J.-M. Lévy-Leblond), usted publicó un manifiesto ${ }^{27}$ que termina con estas frases:

27 Publicado en Nature y en Le Monde en 1988. creemos que la lucidez debe primar sobre la eficacia y que la dirección debe primar sobre la velocidad. Creemos que la reflexion debe preceder al proyecto cientifico, más que suceder a la innovación. Creemos que esta reflexión es de indole filosöfica antes de ser técnica y debe llevarse a cabo en un contexto interdisciplinario y de apertura a todos los ciudadanos.

En su última obra, usted escribe:

El mercado, la tecnologia o incluso la ciencia no tienen ningún derecho a dictar nuestras opciones de vida. Todo verdadero proyecto politico debe ante todo impedir que el hombre vuelva a convertirse en una especie solamente natural, cosa que nos amenaza si nuestra ambición de civilización, ese colmo del artificio, refluye bajo los empujes de la fuerza, de las hormonas y de la territorialidad. ${ }^{28}$

Únicamente frente al imperio industrial, cpuede la "república de los sabios" - de la que vimos que muy pocos forman parte- ser algo más que un principado de opereta? Usted dice que la bioética necesita de los ciudadanos del mundo. Gramsci hablaba del optimismo de la voluntad frente al pesimismo de la inteligencia. Usted tiene el pesimismo de la inteligencia, pero ¿tiene el optimismo de la voluntad? En 1984 terminaba su libro, De l'éprouvette au bébé spectacle, con estas palabras: "el género humano va a morir porque nuestro sobreviviente será culturalmente incomparable; ese suicidio no fue decidido, sino que es el resultado de un consenso en el que todos participan porque no hay otra manera de durar sino avanzando. Entonces la regulación ética de nuestro fin se vuelve esencial...". ${ }^{99}$ Kant formulaba esta

28. J. Testart, Des hommes..., ob. cit., p. 152.

29 J. Testart, De l'éprouvette..., ob. cit., pp. 124-125. pregunta: "¿qué nos está permitido esperar?". Me gustaría citar también este pasaje que, por el sentido de la poesia que manifiesta, no deja de hacer pensar en ese viejo maestro un poco olvidado - pero no por usted-, Jean Rostand:

Por profesionalismo actúo, reflexiono, escribo según las evidencias de la razón que razona. Asi redacté este libro. Puedo: hacer como que tengo un carácter fuerte, mofarme de los timidos, confundir a los ignorantes. Avanzo en el mundo según los tiempos que corren y nadie puede buscarme querella. Se defender la ICSI y refutar el DPI como algunos colegas saben hacer la inversa utilizando la misma panoplia de principios irreprochables: prudencia y dignidad, pero también asistencia y eficacia. Somos ineludibles, salvo para nosotros mismos. Y luego, leo una reflexión antropológica acerca de la vida y de la muerte, un artículo sobre la cultura incaica, egipcia o melanesia, un anälisis histórico del poder o de la alienación; incluso discuto acerca de la procreación asistida con mis viejos compinches "humanistas" del Magasin des enfants o sencillamente me despierto tras una noche en que mis sueños me hicieron perder el control o el gusto de los argumentos imbatibles... De pronto ya no sé más nada con certeza pero comprendo casi todo, siento con mucha fuerza que lo sensible es más verdadero que la verdad. En tales sueños del pensamiento competitivo, alguien dentro del técnico se indigna por las recientes concesiones y por las intimidades mediocres, se interroga sobre la inteligencia del mundo y se descubre persuadido de que el circulo de lo que se siente envuelve a aquel de lo que se demuestra. Luego viene la angustia existencial: rápido reprimir a ese doble que sólo conoce la intuición. Actuar para dominar. Entonces, el hom- 
bre sensible vuelve a caer en las necesidades del hombre probable. ${ }^{30}$.

Aqui llegamos a la última pregunta. En esta conclusión de su obra, Des hommes probables, está ese vuelo lírico muy bello, y, al mismo tiempo, el lector tiene la impresión de que usted se encuentra en una especie de estado de fuga respecto de su propio trabajo. El lector siente que usted está tentado por una posición política rigurosa y, a la vez, percibe que es escéptico en cuanto a la "factibili-

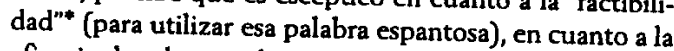
eficacia de tal toma de posición. El lector tiene la sensación de que usted se refugia en una posición que es la del sabio individualista aislado en una sociedad que se acerca a una especie de abismo; se pregunta por último, para retomar esas dos imágenes de sabiduria que la China tradicional nos legó, si no está usted constantemente balanceándose entre el sabio taoista que meditaba solo ante su gruta y el sabio confuciano, que a pesar de todo querria implicarse en los asuntos públicos. Este final es muy humanista y muy literario ( $y$, por otra parte, puede recordarse al respecto que usted escribió dos novelas, cosa que no es totalmente corriente en un investigador). ¿Acaso ese final no es también una manera de decir que las co-
sas ya están perdidas?

J. T.: Me siento efectivamente pesimista porque es la única manera de seguir siendo realista. Creo que el optimismo que algunos derrochan es un modo de ocultar las realidades; además podria decir, siguiendo a Hans Jonas, que hay una "heuristica del miedo"31 con un papel

30 J. Testart, Des hommes..., ob. cit., p. 270.

* La palabra empleada en francés es faisabilité. [N. del T.]

31 La heuristica es el conjunto de los medios de una investigación que permiten desembocar en un descubrimiento. Con que deberá representar en la historia del riesgo y que inquietar puede ser la única forma de evitar ciertos peligros. Una cosa me impactó mucho, y es que no es posible ser técnico y filósofo en el mismo momento. No es posible, le resulta imposible al hombre; yo titulé ese capitulo que usted evoca -y que está bastante desfasado respecto del resto del libro (lo habia escrito aparte, por lo demás)- "Jean en la misa y Pierre en la procesión". Puede pensarse en Jean-Pierre Changeux, quien, como usted sabe, es a la vez el jefe indiscutido de los neurobiólogos, un profesor totalmente eminente en el Colegio de Francia y un notable conocedor de arte. Lo que me impacta en un personaje como él, y hay algunos otros en ese medio, es esa duplicación de las funciones mentales. Durante el dia, puede estar en el laboratorio y hacer una buena investigación, pero creo que no puede, al mismo tiempo, interesarse en las abadias cistercienses, a las que conoce a la perfección; eso es otra cosa. Entonces es otro diferente; por lo tanto, está Jean y está Pierre. Yo traté de vivir eso, y me di cuenta de que también en mí, desde que hago investigación y trato de reflexionar, nunca es simultáneo, de donde acaso proviene un gran peligro para la ética: dejar a los científicos, finalmente, las decisiones y la elección. Hay científicos que poseen el gusto o la capacidad de ser uno y otro, pero yo opino que nunca son al mismo tiempo y que, para la mayoría, son uno u otro; en el momento en que son cientificos, son solamente técnicos, y eso es dramático. Tomemos a los mejores de ellos, entre los cuales se encuentra Jean-Pierre Changeux; están o en la misa o en

"heuristica del miedo", Hans Jonas quería decir que se sabe $l o$ que está amenazado (el ser humano) a partir del momento en que se sabe que está amenazado.

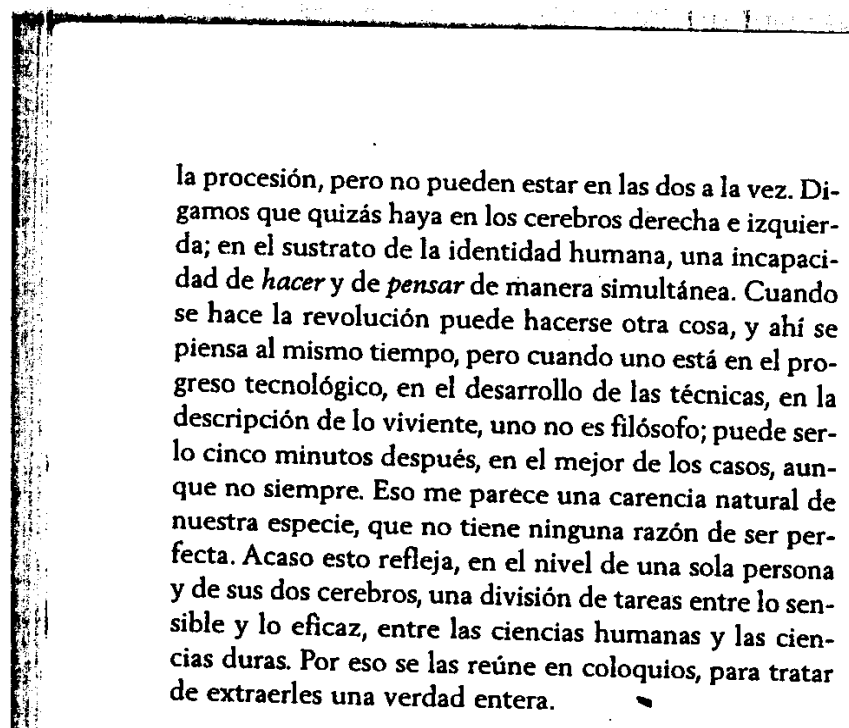

\section{Índice}

Prefacio

1. Introducción

2. Las metamorfosis de la biologia

2 . Lus metamorfosis de la medicina

4. La critica de la razón ética 85 